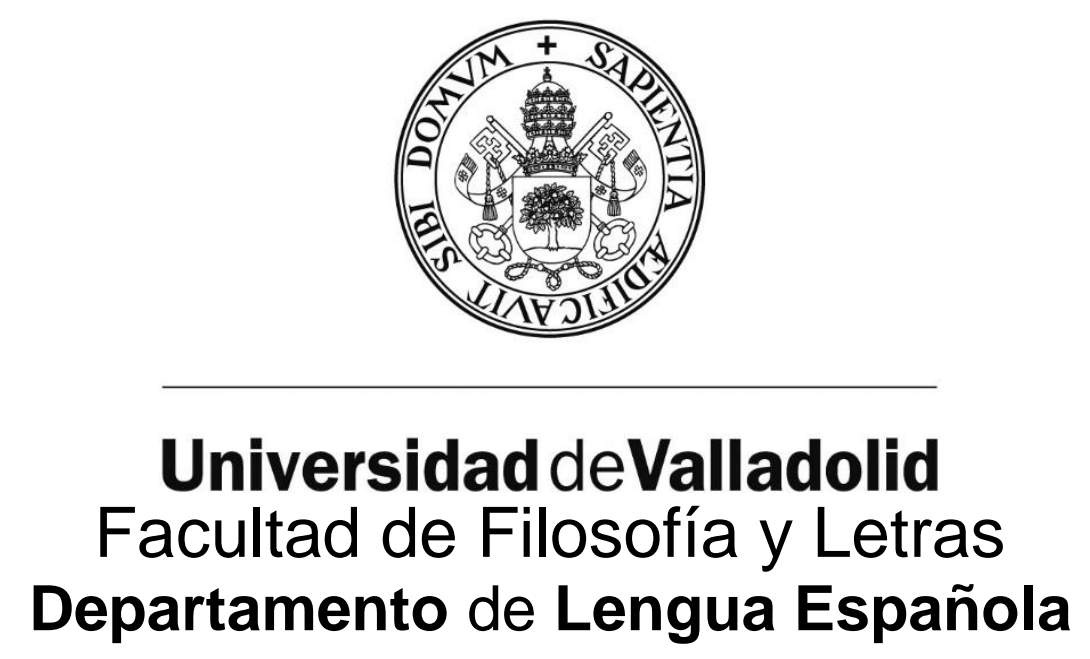

TESIS DOCTORAL

\title{
Análisis pragmalingüístico de los marcadores de coherencia en el discurso de sujetos con esquizofrenia crónica y de primer episodio
}

Presentada por Alicia Figueroa Barra para optar al grado de Doctora por la Universidad de Valladolid 2015

Dirigida por

Dra. Nieves Mendizábal de la Cruz

Dra. Natalia Jimeno Bulnes 
ANÁLISIS PRAGMALINGÜÍSTICO DE LOS MARCADORES DE COHERENCIA EN EL DISCURSO DE SUJETOS CON ESQUIZOFRENIA CRÓNICA Y DE PRIMER EPISODIO 
En el paisaje devastado de la esquizofrenia las ruinas de las cosas familiares y de los símbolos humanos están despiadadamente impregnadas por la luz irreal y amenazadora de un sol extraño: allí donde lo absurdo y lo comprensible, lo atroz y lo patético, la mutación pavorosa y la búsqueda de paz, la transformación suprarreal de los símbolos y la simplicidad de los afectos, se mezclan sin fundirse y se superponen sin unificarse, en una contradicción que no se resuelve, en una tensión que no afloja, allí está la esquizofrenia.

El lenguaje es su cifra misteriosa e inconfundible.

(Sergio Piro, 1968) 
ANÁLISIS PRAGMALINGÜÍSTICO DE LOS MARCADORES DE COHERENCIA EN EL DISCURSO DE SUJETOS CON ESQUIZOFRENIA CRÓNICA Y DE PRIMER EPISODIO 


\section{Dedicatoria}

Para Diego, Alonso, Emilia y Abelardo: por su amor, compañía, paciencia y sobre todo por su fe inquebrantable en mí; gracias por ser como son.

Para mi maestro y amigo Eduardo Durán Lara, por su constante e incondicional apoyo en el vertiginoso recorrido de este laberinto. 
ANÁLISIS PRAGMALINGÜÍSTICO DE LOS MARCADORES DE COHERENCIA EN EL DISCURSO DE SUJETOS CON ESQUIZOFRENIA CRÓNICA Y DE PRIMER EPISODIO 


\section{Agradecimientos}

La realización de este trabajo contó con la imprescindible ayuda y apoyo de personas extraordinarias. En primer lugar, agradezco a mis directoras de tesis, Nieves Mendizábal de la Cruz y Natalia Jimeno Bulnes, por su excepcional dedicación y guía en este proceso, por sus oportunas y agudas observaciones durante el desarrollo del trabajo, además de su permanente y excepcional disposición para ayudarme en la tarea de llevarlo a cabo.

Asimismo, agradezco de todo corazón a mi maestro y amigo, Eduardo Durán Lara, por haber compartido sus conocimientos conmigo y por haber depositado su confianza en mis capacidades en la tarea de abordar una innovadora línea de investigación en el área de Psiquiatría en la Universidad de Chile. Le doy gracias por ser vanguardista, por arriesgarse y más aún, por animarme a abordar este desafío. Espero que este trabajo reivindique sin reservas su interés y entusiasmo en el área de estudio que poco a poco hemos ido desarrollando con tantos desvelos. En definitiva, espero al menos aproximarme a los objetivos científicos que procuró transmitirme con sus permanentes reflexiones.

También quisiera agradecer a mi querida amiga Sonia Oyarzún Sánchez, por compartir sus conocimientos clínicos, por ayudarme a comprender mejor el problema de fondo y en especial, por su constante ánimo, consejo y calidez que me brindaron el impulso para finalizar lo que en más de un momento me pareció inabarcable.

En particular, agradezco a mi esposo Abelardo, por su colaboración en el procesamiento estadístico de los datos de este estudio, así como por sus consejos y observaciones que me permitieron avanzar en el mismo. Y por supuesto a quienes fueron una inspiración en este largo camino, mis queridos hijos: Diego, Alonso y Emilia, quienes a pesar del tiempo robado a su compañía, me animaron paso a paso.

Finalmente, agradezco a las personas afectadas de esquizofrenia que formaron parte de este estudio. Vaya además el agradecimiento a sus familias y a sus cuidadores, pues la sobrecogedora dimensión humana que revela la patología, es sin duda, señal de su profunda resiliencia. 
ANÁLISIS PRAGMALINGÜÍSTICO DE LOS MARCADORES DE COHERENCIA EN EL DISCURSO DE SUJETOS CON ESQUIZOFRENIA CRÓNICA Y DE PRIMER EPISODIO 


\section{Índice}

Índice de figuras $\quad 15$

Índice de tablas $\quad 16$

Índice de gráficos $\quad 21$

1. Introducción 26

1.1. Presentación del tema 27

1.1.1. Objeto de estudio: El desempeño comunicativo en sujetos con 29 diagnóstico de esquizofrenia crónica y de primer episodio

1.1.2. La competencia comunicativa en la esquizofrenia crónica y de 32 primer episodio

1.2. Hipótesis y objetivos del estudio $\quad 39$

1.2.1. Hipótesis general $\quad 39$

1.2.2. Objetivo general 40

1.2.3. Objetivos específicos 40

1.3. Plan de la exposición $\quad 40$

2. Marco conceptual 42

2.1. La esquizofrenia 46

2.2. Esquizofrenia de primer episodio $\quad 59$

2.3. El lenguaje en la esquizofrenia $\quad 64$

2.4. Aspectos pragmáticos discursivos de la esquizofrenia: La competencia $\quad 90$ comunicativa como foco de estudio

2.5. Fenómenos pragmalingüísticos relevantes para el estudio 103

$\begin{array}{ll}\text { 2.5.1. La interacción comunicativa: aspectos generales } & 104\end{array}$

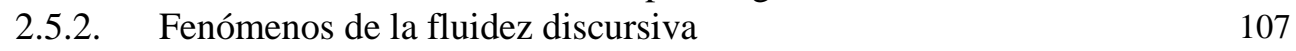

2.5.3. Fenómenos de la productividad verbal $\quad 111$

2.5.4. Fenómenos Índice de participación conversacional 118

2.5.5. Fenómenos de la coherencia temática 119

2.5.6. Fenómenos de la semántica de la coherencia 124

2.5.7. Fenómenos de coherencia interaccional 127

3. Material y método 129

3.1. La muestra 130

3.1.1. Grupo pacientes con esquizofrenia crónica 131

3.1.2. Grupo de pacientes de esquizofrenia de primer episodio 134

3.1.3. Grupo controles 136

3.2. Tipo de estudio y diseño de investigación 144 
3.3. El intrumento utilizado

3.3.1. La entrevista clínica y las tareas comunicativas

3.3.2. Cantidad y condiciones de las entrevistas realizadas a cada participante 148

3. 4. Variables del estudio

3.4.1.1. Estadio de la enfermedad. Personas con diagnóstico de primer episodio. Personas sin patología psiquiátrica

3.4.1.2. Sexo de los participantes

3.4.1.3. Tramo de la enfermedad 152

3.4.1.4. Subtipo de esquizofrenia 152

3.4.2. Variables dependientes y procesamiento de los datos 152

3.4.3. Variables del estudio 153

3.4.3.1. Errores que afectan la fluidez del discurso $\quad 154$

3.4.3.1.1.Titubeos $\quad 155$

3.4.3.1.2. Falsos inicios $\quad 155$

3.4.3.1.3. Pausas extendidas $\quad 156$

3.4.3.1.4. Tartamudeos 156

3.4.3.1.5. Turnos de habla con volumen débil 157

3.4.3.2. Errores que afectan la productividad verbal de los discursos 154

$\begin{array}{ll}3.4 .3 .2 .1 \text {. Total de oraciones } & 157\end{array}$

3.4.3.2.2. Promedio de palabras por oración $\quad 158$

3.4.3.2.3.Palabras diferentes 158

3.4.3.2.4. Neologismos parciales $\quad 158$

$\begin{array}{lr}3.4 .3 .2 .5 . \text { Neologismos totales } & 159\end{array}$

3.4.3.2.6. Referentes $\quad 159$

3.4.3.2.7. Total de vínculos referenciales utilizados $\quad 159$

3.4.3.2.8. Promedio de vínculos referenciales utilizados $\quad 159$

3.4.3.3. Errores que afectan la participación conversacional $\quad 160$

3.4.3.3.1. Índice de participación conversacional $\quad 160$

3.4.3.3.2. Agilidad del turno $\quad 160$

3.4.3.4. Errores que afectan la coherencia temática 161

3.4.3.4.1. Unidad temática nuclear reconocible 161

3.4.3.4.2.Proposiciones con vínculos explícitos respecto al 161 tema central

3.4.3.4.3. Proposiciones con vínculos implícitos respecto al 162 tema central

3.4.3.4.4. Tópico con desarrollo $\quad 162$

3.4.3.4.5. Salto topical 163

3.4.3.4.6. Interacción entre vínculos y referentes 163

3.4.3.5. Errores que afectan la semántica de la coherencia $\quad 164$

3.4.3.5.1.Confusión de mundos posibles 164

3.4.3.6. Errores que afectan la coherencia intraccional 164

$\begin{array}{ll}\text { 3.4.3.6.1.Pares adyacentes } & 165\end{array}$

3.4.3.6.2. Toma de turnos $\quad 165$

3.5. Construcción de la matriz de análisis $\quad 165$

3.6. Descripción de la prueba estadística 167

4. Análisis y presentación de los resultados 169 
4.1. Fluidez verbal 173

4.1.1. Titubeos 174

$\begin{array}{lll}\text { 4.1.1.1. } & \text { Ejemplos } & 174\end{array}$

4.1.1.2. Titubeos y estadio de la enfermedad 177

4.1.1.3. Titubeos y sexo de los individuos $\quad 179$

4.1.1.4. Titubeos y tramo de la enfermedad 181

4.1.1.5. Titubeos y subtipo de la enfermedad 183

4.1.2. Falsos inicios $\quad 185$

$\begin{array}{lll}\text { 4.1.2.1. Ejemplos } & 185\end{array}$

4.1.2.2. Falsos inicios y estadio de la enfermedad 189

4.1.2.3. Falsos inicios y sexo 191

4.1.2.4. Falsos inicios y tramo de la enfermedad 192

4.1.2.5. Falsos inicios y subtipo de la enfermedad 194

4.1.3. Pausas extendidas 196

4.1.3.1. Ejemplos 196

4.1.3.2. Pausas extendidas y estadio de la enfermedad 199

$\begin{array}{ll}\text { 4.1.3.3. Pausas extendidas y sexo } & 201\end{array}$

4.1.3.4. Pausas extendidas y tramo de la enfermedad 203

4.1.3.5. Pausas extendidas y subtipo de la enfermedad 205

4.1.4. Tartamudeos 207

$\begin{array}{lll}\text { 4.1.4.1. Ejemplos } & 207\end{array}$

4.1.4.2. Tartamudeos y estadio de la enfermedad 210

4.1.4.3. Tartamudeos y sexo 211

4.1.4.4. Tartamudeos y tramo de la enfermedad 213

4.1.4.5. Tartamudeos y subtipo de la enfermedad 215

4.1.5. Turnos de habla con volumen débil 218

$\begin{array}{lll}\text { 4.1.5.1. Ejemplos } & 218\end{array}$

4.1.5.2. Turnos de habla con volumen débil y estadio de la 218 enfermedad

4.1.5.3. Turnos de habla con volumen débil y sexo 219

4.1.5.4. Turnos de habla con volumen débil y tramo de la 221 enfermedad

4.1.5.5. Turnos de habla con volumen débil y subtipo de la 223 enfermedad

4.1.6. Conclusiones cluster fluidez verbal 225

4.2. Productividad verbal 228

4.2.1. Ejemplificación global de fenómenos del cluster productividad 228 verbal

4.2.2. Total de oraciones 240

4.2.2.1. Total de oraciones y estadio de la enfermedad 240

4.2.2.2. Total de oraciones y sexo 243

4.2.2.3. Total de oraciones y tramo de la enfermedad 245

4.2.2.4. Total de oraciones y subtipo de la enfermedad 247

4.2.3. Promedio de palabras por oración $\quad 249$

4.2.3.1. Promedio de palabras por oración y estadio de la 250 enfermedad

4.2.3.2. Promedio de palabras por oración y sexo 251

4.2.3.3. Promedio de palabras por oración y tramo de la enfermedad 253 
4.2.3.4. Promedio de palabras por oración y subtipo de la 254 enfermedad

4.2.4. Palabras diferentes 256

4.2.4.1. Palabras diferentes y estadio de la enfermedad 256

4.2.4.2. Palabras diferentes y sexo 258

4.2.4.3. Palabras diferentes y tramo de la enfermedad 260

4.2.4.4. Palabras diferentes y subtipo de la enfermedad 262

4.2.5. Neologismos parciales 264

4.2.5.1. Neologismos parciales y estadio de la enfermedad 266

$\begin{array}{lll}\text { 4.2.5.2. Neologismos parciales y sexo } & 267\end{array}$

4.2.5.3. Neologismos parciales y tramo de la enfermedad 268

4.2.5.4. Neologismos parciales y subtipo de la enfermedad 270

4.2.6. Neologismos totales 269

4.2.6.1. Neologismos totales y estadio de la enfermedad 271

$\begin{array}{ll}\text { 4.2.6.2. Neologismos totales y sexo } & 273\end{array}$

4.2.6.3. Neologismos totales y tramo de la enfermedad 275

4.2.6.4. Neologismos totales y subtipo de la enfermedad 276

$\begin{array}{lll}\text { 4.2.7. Referentes } & 278\end{array}$

$\begin{array}{lll}\text { 4.2.7.1. } & \text { Referentes y estadio de la enfermedad } 278\end{array}$

4.2.7.2. Referentes y sexo 280

4.2.7.3. Referentes y tramo de la enfermedad 281

4.2.7.4. Referentes y subtipo de la enfermedad 283

4.2.8. Total de vínculos referenciales utilizados 284

4.2.8.1. Total de vínculos referenciales utilizados y estadio de la 285 enfermedad

4.2.8.2. Total de vínculos referenciales utilizados y sexo 287

4.2.8.3. Total de vínculos referenciales utilizados y tramo de la 289 enfermedad

4.2.8.4. Total de vínculos referenciales utilizados y subtipo de la 291

enfermedad

4.2.9. Promedio de vínculos referenciales utilizados 293

4.2.9.1. Promedio de vínculos referenciales utilizados y estadio de 294 la enfermedad

4.2.9.2. Promedio de vínculos referenciales utilizados y sexo 296

4.2.9.3. Promedio de vínculos referenciales utilizados y tramo de la 298 enfermedad

4.2.9.4. Promedio de vínculos referenciales utilizados y subtipo de 301 la enfermedad

4.2.10. Conclusiones cluster productividad verbal 304

$\begin{array}{ll}\text { 4.3. Participación conversacional } & 309\end{array}$

4.3.1. Índice de participación conversacional 309

4.3.1.1. Índice de participación conversacional y estadio de la 309 enfermedad

4.3.1.2. Índice de participación conversacional y sexo $\quad 311$

4.3.1.3. Índice de participación conversacional y tramo de la 313 enfermedad

4.3.1.4. Índice de participación conversacional y subtipo de la 315 enfermedad 
4.3.2. Agilidad del turno 317

4.3.2.1. Agilidad del turno y estadio de la enfermedad 320

4.3.2.2. Agilidad del turno y sexo 323

4.3.2.3. Agilidad del turno y tramo de la enfermedad 325

4.3.2.4. Agilidad del turno y subtipo de la enfermedad 327

4.3.3. Conclusiones cluster participación conversacional 330

4.4. Coherencia temática 332

4.4.1. Unidad temática nuclear 333

4.4.1.1. Ejemplos 333

4.4.1.2. Unidad temática nuclear y estadio de la enfermedad 343

4.4.1.3. Unidad temática nuclear y sexo 346

4.4.1.4. Unidad temática nuclear y tramo de la enfermedad $\quad 347$

4.4.1.5. Unidad temática nuclear y subtipo de la enfermedad $\quad 349$

4.4.2. Proposiciones con vínculos explícitos respecto al tema central 351

4.4.2.1. Proposiciones con vínculos explícitos respecto al tema 352 central y estadio de la enfermedad

4.4.2.2. Proposiciones con vínculos explícitos respecto al tema 354 central y sexo

4.4.2.3. Proposiciones con vínculos explícitos respecto al tema 356 central y tramo de la enfermedad

4.4.2.4. Proposiciones con vínculos explícitos respecto al tema 358

central y subtipo de la enfermedad

4.4.3. Proposiciones con vínculos implícitos respecto al tema central 360

4.4.3.1. Proposiciones con vínculos implícitos respecto al tema 360 central y estadio de la enfermedad.

4.4.3.2. Proposiciones con vínculos implícitos respecto al tema 362 central y sexo

4.4.3.3. Proposiciones con vínculos implícitos respecto al tema 364 central y tramo de la enfermedad

4.4.3.4. Proposiciones con vínculos implícitos respecto al tema 366 central y subtipo de la enfermedad

4.4.4. Tópico con desarrollo $\quad 368$

$\begin{array}{lll}\text { 4.4.4.1. Ejemplos } & 368\end{array}$

4.4.4.2. Tópico con desarrollo y estadio de la enfermedad 376

4.4.4.3. Tópico con desarrollo y sexo 377

4.4.4.4. Tópico con desarrollo y tramo de la enfermedad 380

4.4.4.5. Tópico con desarrollo y subtipo de la enfermedad 382

$\begin{array}{lll}\text { 4.4.5. } & \text { Salto topical } & 384\end{array}$

4.4.5.1. Ejemplos $\quad 384$

4.4.5.2. Salto topical y estadio de la enfermedad 389

4.4.5.3. Salto topical y sexo 391

4.4.5.4. Salto topical y tramo de la enfermedad 392

4.4.5.5. Salto topical y subtipo de la enfermedad 395

4.4.6. Interacción entre vínculos y referentes 398

$\begin{array}{lll}\text { 4.4.6.1. Ejemplos } & 398\end{array}$

4.4.6.2. Interacción entre vínculos y referentes y estadio de la 403 enfermedad

4.4.6.3. Interacción entre vínculos y referentes y sexo 405 
4.4.6.4. Interacción entre vínculos y referentes y tramo de la 407 enfermedad

4.4.6.5. Interacción entre vínculos y referentes y subtipo de la 410 enfermedad

4.4.7. Conclusiones del cluster coherencia temática 412

4.5. Semántica de la coherencia 416

4.5.1. Confusión de mundos posibles $\quad 419$

$\begin{array}{lll}\text { 4.5.1.1. Ejemplos } & 419\end{array}$

4.5.1.2. Confusión de mundos posibles y estadio de la enfermedad 421

4.5.1.3. Confusión de mundos posibles y sexo 423

4.5.1.4. Confusión de mundos posibles y tramo de la enfermedad $\quad 425$

4.5.1.5. Confusión de mundos posibles y subtipo de la enfermedad $\quad 428$

4.5.2. Conclusiones cluster semántica de la coherencia 430

4.6. Coherencia intraccional 431

$\begin{array}{lll}\text { 4.6.1. Pares adyacentes } & 431\end{array}$

4.6.1.1. Ejemplos 431

4.6.1.2. Pares adyacentes y estadio de la enfermedad $\quad 434$

4.6.1.3. Pares adyacentes y sexo 436

4.6.1.4. Pares adyacentes y tramo de la enfermedad 438

4.6.1.5. Pares adyacentes y subtipo de la enfermedad 441

4.6.2. Toma de turnos $\quad 443$

4.6.2.1. Ejemplos 443

4.6.2.2. Toma de turnos y estadio de la enfermedad 447

4.6.2.3. Toma de turnos y sexo 449

4.6.2.4. Toma de turnos y tramo de la enfermedad 456

4.6.2.5. Toma de turnos y subtipo de la enfermedad 453

4.6.3. Conclusiones cluster coherencia interaccional 455

5. Conclusiones 457

6. Referencias bibliográficas $\quad 472$

7. Anexos 495 


\section{Índice de figuras}

1. Figura 1: interfaz entre lingüística clínica, esquizofrenia y patologías del lenguaje 46

2. Figura 2: Teorías sobre el lenguaje esquizofrénico 76

3. Figura 3: Competencia Comunicativa 93

4. Figura 4: Tarea de Sally y Ann 96

5. Figura 5: imagen 3 del test de las miradas de Baron Cohen 97

6. Figura 6: cognición social 99

7. Figura 7: interacción comunicativa 105

8. Figura 8:Dimensiones del psicodiagnóstico 146

9. Figura 9: Manejo de personas con primer episodio de psicosis en Chile 150 


\section{Índice de tablas}

1. Tabla 1. Clasificación criterios diagnósticos del DSM-IV y CIE-10. DSM-IV, (1994) 48

2. Tabla 2: Criterios DSM-IV-TR (ESQUIZOFRENIA 50

3. Tabla 3. Clasificación diagnóstica de la esquizofrenia en la CIE-10 52

4. Tabla 4: Subtipos de esquizofrenia $\quad 54$

5. Tabla 5: Tests estandarizados utilizados habitualmente en esquizofrenia en Chile 90

6. Tabla 6: Descripción sociodemográfica de Grupo 1 sujetos con Esquizofrenia Crónica 133 (CRE)

7. Tabla 7 descripción sociodemográfica del Grupo 2: sujetos con esquizofrenia de primer 135 episodio (PEE)

8. Tabla 8: Descripción sociodemográfica de Grupo 3 controles 138

9. Tabla 9 datos sociodemográficos y clínicos grupo de pacientes crónicos 141

10. Tabla 10 datos sociodemográficos y clínicos del grupo de pacientes de esquizofrenia de 142 primer episodio

11. Tabla 11 datos sociodemográficos grupo de controles

12. Tabla 12: Errores en la fluidez que afectan la coherencia 165

13. Tabla 13: Errores en la productividad verbal 166

14. Tabla 14: Índice de participación conversacional 166

15. Tabla 15: Errores en la coherencia temática 177

16. Tabla 16: Semántica de la Coherencia 167

17. Tabla 17: Errores en la coherencia interaccional 167

18. Tabla resumen 18:de los grupos de estudio 171

19. Tabla resumen 19: N del estudio e instrumento aplicado 172

20. Tabla de contingencia 20: titubeos y estadio de la enfermedad 177

21. Tabla valor de chi cuadrado 21: titubeos y estadio de la enfermedad. 179

22. Tabla de contingencia 22: titubeos y sexo 179

23. Tabla valor de chi cuadrado 23: titubeos y sexo $r$

24. Tabla de contingencia 24: titubeos y tramo de la enfermedad. 181

25. Tabla valor de chi cuadrado 25: titubeos y tramo de la enfermedad. 183

26. Tabla de contingencia 26: titubeos y subtipo de la enfermedad. 183

27. Tabla valor de chi cuadrado 27: titubeos y subtipo de la enfermedad. 185

28. Tabla de contingencia 28: falsos inicios y estadio de la enfermedad. 189

29. Tabla valor de chi cuadrado 29: falsos inicios y estadio de la enfermedad. 190

30. Tabla de contingencia 30: falsos inicios y sexo. $\quad 191$

31. Tabla valor de chi cuadrado 31: falsos inicios y sexo. 192

32. Tabla de contingencia 32: falsos inicios y tramo de la enfermedad. 193

33. Tabla valor de chi cuadrado 33: falsos inicios y tramo de la enfermedad. 194

34. Tabla de contingencia 34: falsos inicios y subtipo de la enfermedad 194

35. Tabla valor de chi cuadrado 35: falsos inicios y subtipo de la enfermedad. 196

36. Tabla de contingencia 36: pausas extensas y estadio de la enfermedad. 199

37. Tabla valor de chi cuadrado 37: pausas extensas y estadio de la enfermedad 200

38. Tabla de contingencia 38: pausas extensas y sexo. 201

39. Tabla valor de chi cuadrado 39: pausas extensas y sexo. 203 
40. Tabla de contingencia 40: pausas extensas y tramo de la enfermedad

41. Tabla valor de chi cuadrado 41: pausas extensas y tramo de la enfermedad 204

42. Tabla de contingencia 42: pausas extensas y subtipo de la enfermedad 205

43. Tabla valor de chi cuadrado 43: pausas extensas y subtipo de la enfermedad 206

44. Tabla de contingencia 44: tartamudeos y estadio de la enfermedad 209

45. Tabla valor de chi cuadrado 45: tartamudeos y estadio de la enfermedad 211

46. Tabla de contingencia 46: tartamudeos y sexo 211

47. Tabla valor de chi cuadrado 47: tartamudeos y sexo 213

48. Tabla de contingencia 48: tartamudeos y tramo de la enfermedad 213

49. Tabla valor de chi cuadrado 49: tartamudeos y tramo de la enfermedad 215

50. Tabla de contingencia 50: tartamudeos y subtipo de la enfermedad 215

51. Tabla valor de chi cuadrado 51: tartamudeos y subtipo de la enfermedad 216

52. Tabla de contingencia 52: turnos de habla volumen débil y estadio de la enfermedad 218

53. Tabla valor de chi cuadrado 53: turnos de habla con volumen débil y estadio de la 219 enfermedad

54. Tabla de contingencia 54: turnos de habla volumen débil y sexo 220

55. Tabla valor de chi cuadrado 55: turnos de habla con volumen débil y sexo 221

56. Tabla de contingencia 56: turnos de habla con volumen débil y tramo de la enfermedad

57. Tabla valor de chi cuadrado 57: turnos de habla con volumen débil y tramo de la enfermedad

58. Tabla de contingencia 58: turnos de habla volumen débil y subtipo de la enfermedad

59. Tabla valor de chi cuadrado 59: turnos de habla con volumen débil y subtipo de la enfermedad

60. Tabla de resumen 60: productividad verbal fragmento de entrevista CRE 230

61. Tabla de resumen 61: productividad verbal fragmento de entrevista PEE 234

62. Tabla de resumen 62: productividad verbal fragmento de entrevista CON 239

63. Tabla de contingencia 63: total de oraciones y estadio de la enfermedad

64. Tabla de contingencia 64: total de oraciones y sexo

65. Tabla de contingencia 65: total de oraciones y tramo de la enfermedad

66. Tabla de contingencia 66: total de oraciones y subtipo de la enfermedad

67. Tabla valor de chi cuadrado 67: promedio de palabras por oración y estadio de la enfermedad

68. Tabla valor de chi cuadrado 68: promedio de palabras por oración y sexo 246

69. Tabla valor de chi cuadrado 69: promedio de palabras por oración y tramo de la 248 enfermedad

70. Tabla valor de chi cuadrado 70: promedio de palabras por oración y subtipo de la enfermedad

71. Tabla de contingencia 71: palabras diferentes y estadio de la enfermedad 250

72. Tabla de contingencia 72: palabras diferentes y sexo 252

73. Tabla de contingencia 73: palabras diferentes y tramo de la enfermedad 253

74. Tabla de contingencia 74: palabras diferentes y subtipo de la enfermedad 255

75. Tabla valor de chi cuadrado 75: neologismos parciales y estadio de la enfermedad 256

76. Tabla valor de chi cuadrado 76: neologismos parciales y sexo 258

77. Tabla valor de chi cuadrado 77: neologismos parciales y tramo de la enfermedad 261

78. Tabla valor de chi cuadrado 78: neologismos parciales y subtipo de la enfermedad 267

79. Tabla valor de chi cuadrado 79: neologismos totales y estadio de la enfermedad 269

80. Tabla valor de chi cuadrado 80: neologismos totales y sexo 271

81. Tabla valor de chi cuadrado 81: neologismos totales y tramo de la enfermedad 272

82. Tabla valor de chi cuadrado 82: neologismos totales y subtipo de la enfermedad 274

83. Tabla valor de chi cuadrado 83: referentes y estadio de la enfermedad 276

$\begin{array}{ll}\text { 84. Tabla valor de chi cuadrado 84: referentes y sexo } & 277\end{array}$ 
85. Tabla valor de chi cuadrado 85: referentes y tramo de la enfermedad

279

86. Tabla valor de chi cuadrado 86: referentes y subtipo de la enfermedad

281

87. Tabla de contingencia 87: total de vínculos referenciales y estadio de la enfermedad

284

88. Tabla de contingencia 88: total de vínculos referenciales y sexo

286

288

291

293

295

297

303

305

308

310

97. Tabla de contingencia 97:índice de participación conversacional y sexo

98. Tabla de contingencia 98:índice de participación conversacional y tramo de la enfermedad

99. Tabla de contingencia 99:índice de participación conversacional y subtipo de la enfermedad

100. Tabla resumen 100: promedio de turnos

101. Tabla de contingencia 101:turnos por minuto y estadio de la enfermedad.

102. Tabla de contingencia 102:turnos por minuto y sexo.

103. Tabla de contingencia 103:turnos por minuto y tramo de la enfermedad

104. Tabla de contingencia 104:turnos por minuto y subtipo de la enfermedad.

105. Tabla de contingencia 105: unidad temática nuclear y estadio de la enfermedad.

106. Tabla valor de chi cuadrado 106: unidad temática nuclear y estadio de la enfermedad.

107. Tabla de contingencia 107:unidad temática nuclear y sexo.

108. Tabla valor de chi cuadrado 108:unidad temática nuclear y sexo.

109. Tabla de contingencia 109:unidad temática nuclear y tramo de la enfermedad.

110. Tabla valor de chi cuadrado 110: unidad temática nuclear y tramo de la enfermedad.

111. Tabla de contingencia 111:unidad temática nuclear y subtipo de la enfermedad.

112. Tabla valor de chi cuadrado 112: unidad temática nuclear y subtipo de la enfermedad.

113. Tabla de contingencia 113: Proposiciones con vínculos explícitos y estadio de la enfermedad.

114. Tabla valor de chi cuadrado 114: proposiciones con vínculos explícitos y estadio de la enfermedad.

115. Tabla de contingencia 115: Proposiciones con vínculos explícitos y sexo. 350

116. Tabla valor de chi cuadrado 116: Proposiciones con vínculos explícitos y sexo. 351

117. Tabla de contingencia 117: Proposiciones con vínculos explícitos y tramo de la 352 enfermedad.

118. Tabla valor de chi cuadrado 118: proposiciones con vínculos explícitos y tramo de la enfermedad.

119. Tabla de contingencia 119: Proposiciones con vínculos explícitos y subtipo de la enfermedad.

120. Tabla valor de chi cuadrado 120: Proposiciones con vínculos explícitos y subtipo de la enfermedad.

121. Tabla de contingencia 121: Proposiciones con vínculos implícitos y estadio de la enfermedad.

122. Tabla valor de chi cuadrado 122: Proposiciones con vínculos implícitos y estadio de la enfermedad

123. Tabla de contingencia 123: Proposiciones con vínculos implícitos y sexo.

124. Tabla valor de chi cuadrado 124: Proposiciones con vínculos implícitos y sexo. 
125. Tabla de contingencia 125: Proposiciones con vínculos implícitos y tramo de la enfermedad.

126. Tabla valor de chi cuadrado 126: Proposiciones con vínculos implícitos y tramo de la 362 enfermedad.

127. Tabla de contingencia 127: Proposiciones con vínculos implícitos y subtipo de la enfermedad.

128. Tabla valor de chi cuadrado 128: Proposiciones con vínculos implícitos y subtipo de la enfermedad

129. Tabla de contingencia 129: Tópicos con referentes y estadio de la enfermedad

130. Tabla valor de chi cuadrado 130: Tópicos con referentes y estadio de la enfermedad. 373

131. Tabla de contingencia 131: Tópicos con referentes y sexo. 374

132. Tabla valor de chi cuadrado 132: Tópicos con referentes y sexo. 375

133. Tabla de contingencia 133: Tópicos con referentes y tramo de la enfermedad 377

134. Tabla valor de chi cuadrado 134: Tópicos con referentes y tramo de la enfermedad. 377

135. Tabla de contingencia 135: Tópicos con referentes y subtipo de la enfermedad. 383

136. Tabla valor de chi cuadrado 136: Tópicos con referentes y subtipo de la enfermedad. 384

137. Tabla de contingencia 137: salto topical y estadio de la enfermedad 38

138. Tabla valor de chi cuadrado 138: salto topical y estadio de la enfermedad. 389

139. Tabla de contingencia 139: salto topical y sexo $\quad 391$

140. Tabla valor de chi cuadrado 140: salto topical y sexo. 391

141. Tabla de contingencia 141: salto topical y tramo de la enfermedad. 394

142. Tabla valor de chi cuadrado 142: salto topical y tramo de la enfermedad. 394

143. Tabla de contingencia 143: salto topical y subtipo de la enfermedad. 396

144. Tabla valor de chi cuadrado 144: salto topical y subtipo de la enfermedad. 397

145. Tabla de contingencia 145: interacción entre referentes y vínculos y estadio de la 401 enfermedad.

146. Tabla valor de chi cuadrado 146: interacción entre referentes y vínculos y estadio de la 404 enfermedad.

147. Tabla de contingencia 147: interacción entre referentes y vínculos y sexo. 404

148. Tabla valor de chi cuadrado 148: interacción entre referentes y vínculos y sexo. 406

149. Tabla de contingencia 149: interacción entre referentes y vínculos y tramo de la 406 enfermedad.

150. Tabla valor de chi cuadrado150: interacción entre referentes y vínculos y tramo de la 409 enfermedad.

151. Tabla de contingencia 151: interacción entre referentes y vínculos y subtipo de la 410 enfermedad.

152. Tabla valor de chi cuadrado 152: interacción entre referentes y vínculos y subtipo de la enfermedad.

153. Tabla de contingencia 153: juicio de realidad y estadio de la enfermedad. 421

154. Tabla valor de chi cuadrado 154 juicio de realidad y estadio de la enfermedad. 422

155. Tabla de contingencia 155: juicio de realidad y sexo. 424

156. Tabla valor de chi cuadrado 156: juicio de realidad y sexo. 424

157. Tabla de contingencia 157: juicio de realidad y tramo de la enfermedad. 426

158. Tabla valor de chi cuadrado 158: juicio de realidad y tramo de la enfermedad. 428

159. Tabla de contingencia 159: juicio de realidad y subtipo de la enfermedad. 429

160. Tabla valor de chi cuadrado 160: juicio de realidad y subtipo de la enfermedad. 434

161. Tabla de contingencia 161: pares adyacentes y estadio de la enfermedad. 435

162. Tabla valor de chi cuadrado 162: pares adyacentes y estadio de la enfermedad. 435

163. Tabla de contingencia 163: pares adyacentes y sexo. 437

164. Tabla valor de chi cuadrado 164: pares adyacentes y sexo. 437

165. Tabla de contingencia 165: pares adyacentes y tramo de la enfermedad. 439 
166. Tabla valor de chi cuadrado 166: pares adyacentes y tramo de la enfermedad. 440

167. Tabla de contingencia 167: pares adyacentes y subtipo de la enfermedad. 441

168. Tabla valor de chi cuadrado 168: pares adyacentes y subtipo de la enfermedad. 442

169. Tabla de contingencia 169: toma de turnos y estadio de la enfermedad. 447

170. Tabla valor de chi cuadrado 170: toma de turnos y estadio de la enfermedad. 447

171. Tabla de contingencia 171 toma de turnos y sexo. 448

172. Tabla valor de chi cuadrado 172: toma de turnos y sexo. 449

173. Tabla de contingencia 173: toma de turnos y tramo de la enfermedad. 451

174. Tabla valor de chi cuadrado 174: toma de turnos y tramo de la enfermedad. 452

175. Tabla de contingencia 175: toma de turnos y subtipo de la enfermedad. 453

176. Tabla valor de chi cuadrado 176: toma de turnos y subtipo de la enfermedad. 454 


\section{Índice de gráficos}

1. Gráfico 1. Porcentaje de frecuencia de las variantes: titubeos y estadio de la enfermedad

2. Gráfico 2. Porcentaje de frecuencia de las variantes: titubeos y sexo

180

3. Gráfico 3. Porcentaje de frecuencia de las variantes: titubeos y tramo de la

enfermedad

4. Gráfico 4. Porcentaje de frecuencia de las variantes: titubeos y subtipo de la enfermedad

5. Gráfico 5. Porcentaje de frecuencia de las variantes: falsos inicios y estadio de la enfermedad

6. Gráfico 6. Porcentaje de frecuencia de las variantes: falsos inicios y sexo:

190

7. Gráfico 7. Porcentaje de frecuencia de las variantes: falsos inicios y tramo de la enfermedad

8. Gráfico 8. Porcentaje de frecuencia de las variantes: falsos inicios y subtipo de la enfermedad

9. Gráfico 9. Porcentaje de frecuencia de las variantes: Pausas extensas y estadio de la enfermedad

10. Gráfico 10. Porcentaje de frecuencia de las variantes:Pausas extensas y sexo

11. Gráfico 11. Porcentaje de frecuencia de las variables: pausas extensas y tramo de la enfermedad

12. Gráfico 12. Porcentaje de frecuencia de las variables: pausas extensas y subtipo de la enfermedad

13. Gráfico 13. Porcentaje de frecuencia de las variables: tartamudeos y estadio de la 210 enfermedad

14. Gráfico 14. Porcentaje de frecuencia de las variables: tartamudeos y sexo 211

15. Gráfico 15. Porcentaje de frecuencia de las variables: tartamudeos y tramo de la 214 enfermedad

16. Gráfico 16. Porcentaje de frecuencia de las variables: tartamudeos y subtipo de la 216 enfermedad

17. Gráfico 17. Porcentaje de frecuencia de las variables: turnos de habla con volumen 219 débil y estadio de la enfermedad

18. Gráfico 18. Porcentaje de frecuencia de las variables: turnos de habla con volumen 220 débil y sexo del sujeto

19. Gráfico 19. Porcentaje de frecuencia de las variables: turnos de habla con volumen 222 débil y tramo de la enfermedad

20. Gráfico 20. Porcentaje de frecuencia de las variables: turnos de habla con volumen 224 débil y subtipo de la enfermedad

21. Gráfico 21. Porcentaje de frecuencia de las variables: total de oraciones y estadio 242 de la enfermedad

22. Diagrama de caja y bigotes 1. Porcentaje de las variables: total de oraciones y 243 estadio de la enfermedad

23. Gráfico 23. Porcentaje de frecuencia de las variables: total de oraciones y sexo de 244 los sujetos. 
24. Diagrama de caja y bigotes 2. Porcentaje de las variables: total de oraciones y sexo de los sujetos

25. Gráfico 25. Porcentaje de frecuencia de las variables: total de oraciones y tramo de la enfermedad

26. Diagrama de caja y bigotes 3. Porcentaje de las variables: total de oraciones y tramo de la enfermedad

27. Gráfico 27. Porcentaje de frecuencia de las variables: total de oraciones y subtipo de la enfermedad.

28. Diagrama de caja y bigotes 4. Porcentaje de las variables: total de oraciones y subtipo de la enfermedad

29. Diagrama de caja y bigotes 5. Porcentaje de la variable: estadio de la enfermedad 251

30. Diagrama de caja y bigotes 6. Porcentaje de la variable: sexo de los individuos 252

31. Diagrama de caja y bigotes 7. Porcentaje de la variable: tramo de la enfermedad 254

32. Diagrama de caja y bigotes 8. Porcentaje de la variable: subtipo de la enfermedad 255

33. Gráfico 33. Porcentaje de frecuencia de las variables: palabras diferentes y estadio 257 de la enfermedad

34. Diagrama de caja y bigotes 9. Porcentaje de la variable: estadio de la enfermedad 258

35. Gráfico 35. Porcentaje de frecuencia de las variables: palabras diferentes y sexo 259

36. Diagrama de caja y bigotes 10. Porcentaje de la variable: sexo 260

37. Gráfico 37. Porcentaje de frecuencia de las variables: palabras diferentes y tramo 261 de la enfermedad

38. Diagrama de caja y bigotes 11. Porcentaje de la variable: tramo de la enfermedad. 262

39. Gráfico 39. Porcentaje de frecuencia de las variables: palabras diferentes y subtipo 263 de la enfermedad

40. Diagrama de caja y bigotes 12. Porcentaje de la variable: subtipo de la 264 enfermedad.

41. Diagrama de caja y bigotes 13. Porcentaje de la variable: estadio 267

42. Diagrama de caja y bigotes 14. Porcentaje de la variable: sexo. 268

43. Diagrama de caja y bigotes 15. Porcentaje de la variable: tramo de la enfermedad. 269

44. Diagrama de caja y bigotes 16. Porcentaje de la variable: subtipo de la 271 enfermedad

45. Diagrama de caja y bigotes 17. Porcentaje de la variable: estadio de la enfermedad 273

46. Diagrama de caja y bigotes 18. Porcentaje de la variable: sexo 274

47. Diagrama de caja y bigotes 19. Porcentaje de la variable: tramo de la enfermedad. 276

48. Diagrama de caja y bigotes 20. Porcentaje de la variable: subtipo de la 277 enfermedad

49. Diagrama de caja y bigotes 21. Porcentaje de la variable: estadio de la enfermedad 279

50. Diagrama de caja y bigotes 22. Porcentaje de la variable: sexo 281

51. Diagrama de caja y bigotes 23. Porcentaje de la variable: tramo de la enfermedad 282

52. Diagrama de caja y bigotes 24. Porcentaje de la variable: subtipo de la 284 enfermedad

53. Gráfico 53. Porcentaje de frecuencia de las variables: total de vínculos y estadio 286 de la enfermedad

54. Diagrama de caja y bigotes 25. Porcentaje de la variable: estadio de la enfermedad 287

55. Gráfico 55. Porcentaje de frecuencia de las variables: total de vínculos y sexo de 288 los sujetos

56. Diagrama de caja y bigotes 26. Porcentaje de la variable: sexo. 289

57. Gráfico 57. Porcentaje de frecuencia de las variables: total de vínculos y tramo de 290 la enfermedad

58. Diagrama de caja y bigotes 27. Porcentaje de la variable: tramo 
59. Gráfico 59. Porcentaje de frecuencia de las variables: total de vínculos y tramo de

la enfermedad

60. Diagrama de caja y bigotes 28. Porcentaje de la variable: subtipo de la enfermedad

61. Gráfico 61. Porcentaje de frecuencia de las variables: promedio de vínculos y estadio de la enfermedad.

62. Diagrama de caja y bigotes 29. Porcentaje de la variable: estadio de la enfermedad.

63. Gráfico 63. Porcentaje de frecuencia de las variables: promedio de vínculos y sexo.

64. Diagrama de caja y bigotes 30. Porcentaje de la variable: sexo.

65. Gráfico 65. Porcentaje de frecuencia de las variables: promedio de vínculos y tramo de la enfermedad.

66. Diagrama de caja y bigotes 31. Porcentaje de la variable: tramo de la enfermedad. 300

67. Gráfico 67. Porcentaje de frecuencia de las variables: promedio de vínculos y 302 tramo de la enfermedad

68. Diagrama de caja y bigotes 32. Porcentaje de la variable: subtipo de la enfermedad.

69. Gráfico 69. Porcentaje de frecuencia de las variables: índice de participación conversacional y estadio de la enfermedad

70. Diagrama de caja y bigotes 33. Porcentaje de la variable: estadio de la enfermedad.

71. Gráfico 71. Porcentaje de frecuencia de las variables: índice de participación conversacional y sexo.

72. Diagrama de caja y bigotes 34. Porcentaje de la variable: sexo.

73. Gráfico 73. Porcentaje de frecuencia de las variables: índice de participación conversacional y tramo de la enfermedad

74. Diagrama de caja y bigotes 35. Porcentaje de la variable: tramo de la enfermedad

75. Gráfico 75. Porcentaje de frecuencia de las variables: índice de participación conversacional y subtipo de la enfermedad.

76. Diagrama de caja y bigotes 36. Porcentaje de la variable: subtipo de la enfermedad

77. Gráfico 77. Porcentaje de frecuencia de las variables: número de turnos por minuto y estadio de la enfermedad

78. Diagrama de caja y bigotes 37. Porcentaje de la variable: número de turnos por minuto y estadio de la enfermedad

79. Gráfico 79. Porcentaje de frecuencia de las variables: número de turnos por minuto y sexo

80. Diagrama de caja y bigotes 38. Porcentaje de la variable: número de turnos por minuto y sexo de los sujetos

81. Gráfico 81. Porcentaje de frecuencia de las variables: número de turnos por minuto y tramo de la enfermedad

82. Diagrama de caja y bigotes 39. Porcentaje de la variable: número de turnos por minuto y tramo de la enfermedad

83. Gráfico 83. Porcentaje de frecuencia de las variables: número de turnos por minuto y subtipo de la enfermedad

84. Diagrama de caja y bigotes 40. Porcentaje de la variable: número de turnos por minuto y subtipo de la enfermedad

85. Gráfico 85. Porcentaje de frecuencia de las variables: unidad temática nuclear y estadio de la enfermedad.

86. Gráfico 86. Porcentaje de frecuencia de las variables: unidad temática nuclear y 
sexo

87. Gráfico 87. Porcentaje de frecuencia de las variables: unidad temática nuclear y

tramo de la enfermedad

88. Gráfico 88. Porcentaje de frecuencia de las variables: unidad temática nuclear y subtipo de la enfermedad

89. Gráfico 89. Porcentaje de frecuencia de las variables: proposiciones con vínculos explícitos y estadio de la enfermedad

90. Gráfico 90. Porcentaje de frecuencia de las variables: proposiciones con vínculos explícitos y sexo de los individuos

91. Gráfico 91. Porcentaje de frecuencia de las variables: proposiciones con vínculos explícitos y tramo de la enfermedad

92. Gráfico 92. Porcentaje de frecuencia de las variables: proposiciones con vínculos explícitos y subtipo de la enfermedad

93. Gráfico 93. Porcentaje de frecuencia de las variables: proposiciones con vínculos implícitos y estadio de la enfermedad

94. Gráfico 94. Porcentaje de frecuencia de las variables: proposiciones con vínculos implícitos y sexo de los individuos

95. Gráfico 95. Porcentaje de frecuencia de las variables: proposiciones con vínculos implícitos y tramo de la enfermedad

96. Gráfico 96. Porcentaje de frecuencia de las variables: proposiciones con vínculos implícitos y subtipo de la enfermedad

97. Gráfico 97. Porcentaje de frecuencia de las variables: tópico con desarrollo y estadio de la enfermedad

98. Gráfico 98. Porcentaje de frecuencia de las variables: tópico con desarrollo y sexo de los individuos

99. Gráfico 99. Porcentaje de frecuencia de las variables: tópico con desarrollo y tramo de la enfermedad

100. Gráfico 100. Porcentaje de frecuencia de las variables: tópico con desarrollo y subtipo de la enfermedad

101. Gráfico 101. Porcentaje de frecuencia de las variables: salto topical y estadio de la enfermedad

102. Gráfico 102. Porcentaje de frecuencia de las variables: salto topical y sexo

103. Gráfico 103. Porcentaje de frecuencia de las variables: salto topical y tramo de la enfermedad

104. Gráfico 104. Porcentaje de frecuencia de las variables: salto topical y subtipo

105. Gráfico 105. Porcentaje de frecuencia de las variables: interacción entre referentes y vínculos referenciales y estadio de la enfermedad

106. Gráfico 106. Porcentaje de frecuencia de las variables: interacción entre referentes y vínculos referenciales y sexo

107. Gráfico 107. Porcentaje de frecuencia de las variables: interacción entre

108. Gráfico 108. Porcentaje de frecuencia de las variables: interacción entre referentes y vínculos referenciales y subtipo de la enfermedad

109. Gráfico 109. Porcentaje de frecuencia de las variables: juicio de realidad y estadio de la enfermedad.

110. Gráfico 110. Porcentaje de frecuencia de las variables: juicio de realidad y sexo de los individuos.

111. Gráfico 111. Porcentaje de frecuencia de las variables: juicio de realidad y tramo de la enfermedad.

112. Gráfico 112. Porcentaje de frecuencia de las variables: juicio de realidad y subtipo de la enfermedad 
113. Gráfico 113. Porcentaje de frecuencia de las variables: pares adyacentes y estadio de la enfermedad.

114. Gráfico 114. Porcentaje de frecuencia de las variables: pares adyacentes y sexo.

115. Gráfico 115. Porcentaje de frecuencia de las variables: pares adyacentes y tramo de la enfermedad.

116. Gráfico 116. Porcentaje de frecuencia de las variables: pares adyacentes y 442 subtipo de la enfermedad.

117. Gráfico 117. Porcentaje de frecuencia de las variables: toma de turnos y estadio 448 de la enfermedad.

118. Gráfico 118. Porcentaje de frecuencia de las variables: toma de turnos y sexo. 450

119. Gráfico 119. Porcentaje de frecuencia de las variables: toma de turnos y tramo de 452 la enfermedad.

120. Gráfico 120. Porcentaje de frecuencia de las variables: toma de turnos y subtipo 454 de la enfermedad. 


\section{Capítulo 1}

\section{Introducción}

"El lenguaje es tan valioso para el individuo, tan crítico para el funcionamiento eficiente de las sociedades

humanas y tan asombrosamente intrincado y profundo en su estructura, que no puede dejar de atraer poderosamente la atención [...], esa atención debe producir estudios que tengan importancia práctica (por ejemplo en la terapia del lenguaje, la educación, las técnicas de traducción y otros muchos campos 'aplicados')" (Fowler, 1978) 
Capítulo 1

1.1. Presentación del tema:

La esquizofrenia como paradigma de la locura es, sin duda, una de las enfermedades mentales más graves, complejas e intrigantes. Ha sido objeto de estudio de múltiples disciplinas y continúa presentando muchos aspectos que no han sido dilucidados. Es una afección con alta prevalencia en la población mundial (1\%) sin distinción de clase social, raza o género, conlleva un alto riesgo de suicidio y va en franco detrimento de la vida de la persona afectada.

Clínicamente, esta enfermedad se inicia en etapas precoces del ciclo vital y tiene una evolución prolongada o crónica en alrededor de dos tercios de los casos. Las estadísticas afirman, que hasta en un tercio de los afectados surgirán graves discapacidades psicosociales (Alvarado, R. et al. 2004).

En el momento actual, se cuenta con una amplia gama de tratamientos psicofarmacológicos y métodos de rehabilitación que ofrecen auténticas posibilidades de mejoría. No obstante, ningún tratamiento o intervención psicoterapéutica asegura la remisión absoluta de la enfermedad. Por otra parte, se ha documentado que la baja adherencia a los programas de rehabilitación y tratamiento es sinónimo de inevitable cronicidad, además de, acrecentar el deterioro neurocognitivo tras cada episodio psicótico enfrentado. 
Los altos costos que la enfermedad conlleva para los individuos, la familia y/o cuidadores es un tema que debe considerarse en la toma de decisiones en las políticas públicas de cada país, como señala un estudio sobre los costos de los programas mentales de Cabello y colaboradores (2011):

La Organización Mundial de la Salud estima que el gasto por la atención de los problemas de salud mental en países desarrollados corresponde a 3-4\% del PIB. La Organización para la Cooperación y Desarrollo Económico reporta que, en la Unión Europea, 25\% de los gastos en discapacidad se destinan a las ocasionadas por enfermedad mental. El costo anual total de la esquizofrenia para países de Latinoamérica y el Caribe es de 1.81, para África 0.47, para Europa 1.32 y para el Sur de Asia 0.52 en millones de dólares por millón de personas. En México, en una primera aproximación se concluyó que el costo anual promedio de atención médica de la esquizofrenia es de \$1,230. En este contexto, se desarrolló un análisis de costo-efectividad de las tres alternativas de tratamiento de pacientes con diagnóstico de esquizofrenia (Cabello Rangel, H., Díaz Castro, L., y Arredondo, A. (2011:97).

Uno de sus aspectos más relevantes está dado por su complejidad como patología. En ella desembocan un variado espectro de síntomas clínicos y formas evolutivas, constituye, por tanto, un reto clínico de proporciones. Aún más, debido a la ausencia de marcadores biológicos, el diagnóstico continúa basado en la historia de los síntomas y signos, la entrevista clínica y la observación de las conductas de la persona afectada. Se utilizan como marco de referencia los criterios del DSM-IV y el CIE-10 en los que se configura un conglomerado de síntomas, que para ser etiquetados como esquizofrenia, deben causar deterioro en las condiciones vitales de los afectados por un período de tiempo determinado.

Muchas corrientes de investigación definen a la esquizofrenia como un trastorno neurocognitivo. Cualquier déficit producido en la cognición, afectará a la globalidad de la vida. Un funcionamiento óptimo de la cognición, la puntualiza como un reservorio de los procesos mentales que nos hacen adquirir conocimientos, nos mantienen alerta y nos permiten llegar a conclusiones apropiadas sobre cómo actuar respecto de nuestro entorno (Chattopadhyay, S., 2012). Los estudios neuropsicológicos que investigan la patofisiología de la esquizofrenia muestran déficit en las funciones cognitivas, tales como, la atención, la función ejecutiva y el lenguaje (Kuperberg, G., 2000). 
Se ha establecido que entre los dominios cognitivos, el procesamiento del lenguaje y la memoria verbal son particularmente susceptibles de alteración. Varios investigadores han argumentado que muchos de los déficit en el procesamiento del lenguaje en la esquizofrenia surgen directamente de déficits cognitivos dentro del sistema del lenguaje, e irían acompañados de déficit paralelos en la atención selectiva, la memoria de trabajo, la recuperación de la memoria a corto plazo y otras funciones del lóbulo frontal (Kuperberg, G. 2010).

El lenguaje, una de nuestras funciones cognitivas más relevantes, se encuentra alterado en su función comunicativa durante toda la evolución de la enfermedad. Sin embargo, a pesar de que las primeras descripciones de esta patología ya ofrecían observaciones del lenguaje alterado, desorganizado y desestructurado, se le sigue considerando como un elemento secundario a los signos o síntomas psicopatológicos (Kraepelin, E., 1896; y Bleuler, E., 1911, Crow, T., 1985; Gernsbacher, M.A., 1999).

1.1.1. Objeto de estudio: El desempeño comunicativo en sujetos con diagnóstico de esquizofrenia crónica y de primer episodio:

En el marco de los estudios sobre la patología, las dificultades comunicativas que enfrentan los sujetos con esquizofrenia no han pasado desapercibidas. Las alteraciones del lenguaje manifestadas en las formas crónicas de la esquizofrenia (CRE) se han estudiado ampliamente y desde diferentes enfoques, sin embargo, la comprensión y sistematización de las manifestaciones en el Primer Episodio (PEE), continúa siendo difícil de alcanzar. Desentrañar la desorganización del lenguaje desde el primer episodio, representa uno de los problemas más cruciales y desafiantes para la psiquiatría actual (Mc Gorry, P., 2004, MacKenna, P., 2005)

Tomando en cuenta, la severidad que puede adoptar la enfermedad se ha iniciado una febril búsqueda de elementos que adelanten el diagnóstico. La tarea de anticipar la 
intervención en el primer episodio es una constante en las investigaciones actuales. Se ha reportado que el menor tiempo de psicosis no tratada (Duration Untreated Psychosis, DUP) tiene una incidencia directa en un buen pronóstico para el paciente, mientras más cercano se esté al inicio de la psicosis, aumentarán las posibilidades de éxito del tratamiento (Mc Gorry P., et al., 2008). El primer episodio es visto como una oportunidad crítica para modificar la trayectoria de la enfermedad que está asociada a los trastornos neurocognitivos graves (Marshall, M., Lewis, S., et al., 2005; Perkins, Gu, Boteva, et al., 2005). Factores como la identificación temprana, la derivación a equipos especializados en PEE y el tratamiento psicofarmacológico oportuno, determinan el menor tiempo de DUP, evitando de esta manera el deterioro funcional.

Actualmente en Chile se estima que entre el proceso de la detección, derivación e inicio del tratamiento, transcurren hasta tres años (Alvarado, R: 2012). Es prioritario reducir estos plazos para contribuir a mejorar las políticas de salud pública del país, alineándolas con las propuestas internacionales como la de la OMS, que señala la necesidad de acortar este proceso.

Por desgracia, en Chile la investigación en esta área es aún incipiente. Solo existen unos pocos trabajos que incluyen los aspectos neurocognitivos, genéticos o psicopatológicos transversales en esta etapa de la enfermedad (Orellana, G., 2006, Aboitiz, F., et al 2006). Dada su enorme dificultad, son aún más escasos los trabajos que analizan los déficits en neurofisiología y lenguaje (Brunetti, E., 2013) o aún más, en neurocognición y lenguaje (Durán, E., Figueroa, A., 2011).

Las motivaciones para la realización de este trabajo fueron:

I. La ausencia de estudios interdisciplinarios que sistematicen hallazgos sobre las características del lenguaje en el primer brote de esquizofrenia.

II. La posibilidad de levantar información acerca del contraste en el desempeño comunicativo entre sujetos normales, de PEE y de CRE. 
III. Aproximarse a la identificación de déficits pragmalingüísticos específicos para el PEE y el CRE, con la proyección de que puedan ser utilizados como indicadores de diagnóstico complementario.

En psiquiatría, con escasa frecuencia se incluye el lenguaje en el análisis clínico de los pacientes. Cuando esto sucede, los enfoques a través de los que se observa no tienen una base lingüística.

Si se niega el carácter legítimamente lingüístico de los fenómenos observados, no se establece ningún tipo de evidencia acerca de la conducta comunicativa de los sujetos afectados. Entonces, no se debe pensar el lenguaje como un epifenómeno de la psicosis.

El Desorden Formal del Pensamiento (DFP) (Andreasen, N., 1979) es un ejemplo de definiciones que pueden cuestionarse en la investigación en esquizofrenia. El hecho de que se encuentre vinculada a lo lingüístico, exige que el análisis concierna en stricto sensu, a aspectos lingüísticos que no son explorados por la psicopatología.

Durante años, se ha designado al DFP, como el reflejo de una alteración primaria, fundada biológicamente en la aparición sintomatológica de manifestaciones que solo son observables en el lenguaje, etiquetándolas como un fuerte predictor de mala adaptación y funcionamiento psicosocial, sin aproximarse a la dimensión comunicativa de la alteración. Encima, esta perturbación es heterogénea y no se presenta en todos los pacientes.

Lo que sabemos es que tradicionalmente se ha denominado DFP a la desorganización ininteligible del discurso, por ello, cabe preguntarse en primer término; ¿es una alteración del pensamiento o del lenguaje? En segundo término, asumiendo que las caracterizaciones hechas, conjeturan que es una alteración del lenguaje ¿corresponden a aspectos morfo-sintácticos o semántico-pragmáticos del fenómeno? Finalmente, dos preguntas que no serán materia de estudio de esta tesis, pero que son ineludibles: ¿son manifestaciones (lingüísticas) exclusivas de la esquizofrenia?, ¿se han sistematizado? 
Se han hecho incontables esfuerzos por responder a estas preguntas, tratando de diferenciar entre pensamiento y lenguaje. Sin embargo, numerosos investigadores denuncian la falta de estudios integradores que conduzcan a una descripción de grano fino, indispensable para zanjar estas cuestiones (Belinchón, M., 2002).

Una interpretación plausible sobre el DFP es la propuesta por Chapman y colaboradores (Chapman et al, 1964; Chapman y Chapman, 1973) quienes la describen como la dificultad que tienen estas personas para utilizar el contexto lingüístico. Como principal argumento, su propuesta subraya que los pacientes esquizofrénicos mostraron preferencia por el significado más "fuerte" de una palabra, es decir, su significado literal o el más empleado. Al excluir las acepciones semánticas del término en cuestión no se contempla su contexto de uso. Citan el caso tomado de uno de los pacientes de Bleuler (1911) que enumeró a los miembros de su familia como 'padre', 'hijo', y agregó: 'del Espíritu Santo'. Este sesgo puede incidir en una interpretación errónea de palabras en la conversación, como ejemplifica el otro caso que la autora extracta de Bleuler; un paciente frente a la pregunta "¿hay algo que le pesa?”, responde: “si, el hierro es pesado”, prefiriendo el significado literal a pesar del contexto.

Nos parece que el estudio del lenguaje en la esquizofrenia debe ser integrado en el paradigma de la competencia comunicativa, ya que, como veremos incluye cuestiones esenciales para la psiquiatría y para la lingüística.

\subsubsection{La competencia comunicativa en la esquizofrenia crónica y de primer episodio}

Se ha documentado que en el PEE ya habría un compromiso cognitivo heterogéneo, de tipo global y/o específico (Ditman, T. y Kuperberg, G., 2008, Yung, A., \& Mc Gorry, P., 2007, Levy et al: 2010). Concretamente se verían afectadas la atención, la memoria, el lenguaje y las funciones ejecutivas. La literatura reciente ha procurado caracterizar la prevalencia, el grado y la naturaleza de estos trastornos cognitivos o neuropsicológicos en 
la enfermedad (Heydebrand, G., Weiser M., 2004); (Fioravanti, M., Carlone O,: 2005); (Orellana, G., Slachevsky, A., 2006) pese a ello, persisten múltiples interrogantes sobre estas alteraciones y su impacto en el funcionamiento global de estas personas (Mc Gorry, P., Yung A., 2007).

Dentro de estas alteraciones detectadas pueden documentarse en forma específica, déficit en algunos niveles del procesamiento del lenguaje (Belinchón, M., Castilla del Pino, C., Ruiz Vargas, J., 1991). A la luz de las evidencias que se han descrito en la literatura, estos déficits se complejizarían con la evolución clínica de la enfermedad, convirtiéndose en un factor de creciente desvinculación social del sujeto (Chaika, E., 1974; Piro, S., 1987).

Con el fin de explicarnos el comportamiento comunicativo real de los sujetos con esquizofrenia, asumiremos un enfoque funcional del lenguaje, (Gallardo Páuls, B. y Hernández Sacristán, C., 2013), por ende, nuestro análisis comprenderá la dimensión pragmática (Grice, P., 1975).

El lenguaje es concebido como un sistema interactivo no solo entre diferentes niveles lingüísticos y extralingüísticos, articulado en imbricadas estructuras pragmáticas (Walker, D. and Grosz, B., 1978) y que evidencia complejos procesos de adaptabilidad, intencionalidad y aceptabilidad a los que estamos sometidos como hablantes (Calsamiglia, H., 2007; Saville-Troike, M., 1989).

En la esquizofrenia, estas estructuras y relaciones se ven entorpecidas por los deterioros neurocognitivos que afectan al sujeto. Tareas como la comunicación intersubjetiva, la comprensión de textos o la producción discursiva global, representan dificultades de variada consideración que generan distancia entre el sujeto y su entorno (Rochester, S., 1988; Insúa P., 2004; Cuetos F., 2003; Castilla del Pino, C., 2006). El lenguaje evidencia aspectos deficitarios que tienen como núcleo el deterioro de elementos que conforman la coherencia de los discursos (Kuperberg, G., 2009). Desde un enfoque cognitivo, sabemos que la coherencia es un constructo que va más allá del significado 
explícito de los enunciados o proposiciones del discurso, que incluye las relaciones referenciales de la realidad (hechos) en su dimensión pragmática y la 'lectura' del contexto para que el discurso sea funcional.

Según los axiomas de van Dijk y Kintsch (1983) también la coherencia sería alcanzada por los hablantes cuando son capaces de elaborar modelos mentales sobre los hechos referidos en el discurso, de esta forma, pueden ser interpretados sumando la dimensión semántica al procesamiento. En la utilización de estos modelos mentales se activarían los sistemas de memoria y las redes semánticas de nuestra cognición. La interacción entre ambas dimensiones (pragmática y semántica) se organiza en niveles superiores e inferiores (van Dijk, T., 2006).

Las macroestructuras concuerdan con los procesos superiores, sintetizadas a partir de las macroproposiciones del discurso que establecerían un tema global implícito.

En lo tocante a los niveles inferiores, las representaciones compondrían la llamada microestructura que se sustentaría en las relaciones interproposicionales del discurso. En un modelo mental determinado, las representaciones cognitivas pueden articular relaciones causales, temporales, de comparación y contraste, que atiendan a los requerimientos de la situación comunicativa en la que se participa y, que se apoyen en el conocimiento de mundo, o lo que se conoce como, "parcelas de conocimiento compartido", que es un conocimiento independiente de las características que poseen los hablantes.

La coherencia comporta una estrategia cognitiva multinivel destinada a establecer conexión eficiente con otro hablante, entrañando un complejo proceso de interacción. El control y manejo voluntario de los modelos mentales, activa la selección de los elementos pertinentes y relevantes para la situación comunicativa, redundando en un discurso coherente. 
Será entonces la coherencia, una de las matrices de fondo para la evaluación de la funcionalidad discursiva de los informantes del estudio. Los indicadores de coherencia y cohesión que consideraremos para este estudio, corresponden a lo propuesto por la Lingüística del Texto, dado su enfoque funcional del lenguaje (Beaugrande, R. y Dressler, W., 2003; van Dijk, T., 2003). Es a saber, los siguientes grupos de fenómenos que operacionalizamos como indicadores de déficit:

I. Errores en la fluidez que afectan la coherencia
A. Titubeos
B. Falsos inicios
C. Pausas extensas
D. Tartamudeos
E. Turnos de habla con volumen débil

II. Errores en la productividad verbal
A. Total de oraciones/frases por tarea
B. Promedio de palabras por oración
C. Total de palabras diferentes (no repetidas)
D. Neologismos parciales
E. Neologismos totales
F. Referentes
G. Total vínculos referenciales
H. Promedio de vínculos referenciales

III. Déficit en índice de participación conversacional
A. Índice de participación conversacional
B. Promedio de turnos de habla por minuto

IV. Errores en la coherencia temática
A. Macroestructura
B. Unidad temática nuclear reconocible
C. Proposiciones con vínculos explícitos alusivos al tema central
D. Proposiciones con vínculos implícitos alusivos al tema central 
E. Microestructura

F. Tópico con referente

G. Salto topical

H. Interacción entre referentes y vínculos referenciales

V. Semántica de la Coherencia

A. Confusión en el juicio de realidad (mundos posibles)

VI. Errores en la coherencia interaccional

A. Pares adyacentes

B. Toma de turnos

En el capítulo tres, se explicará de forma extensa en qué consistirá el análisis, aquí nos referimos al procedimiento someramente. Mediante la operacionalización de la coherencia discursiva, se pretende identificar en cuáles de las estructuras lingüístico-comunicativas, se presentan los déficit más significativos en la producción del discurso. Se emplearán tres procedimientos según los diferentes grupos de fenómenos o cluster. El primero de ellos, consiste en analizar el grado de déficit que presentarían algunos de los indicadores lingüísticos conforme a tres criterios de valoración de la eficacia discursiva. El segundo, proporcionará un análisis de medidas estadísticas cuantitativas, con las que se evaluarán algunos indicadores para correlacionarlos con el momento evolutivo de la enfermedad, esto es, esquizofrenia crónica o de primer episodio. El tercero, consiste en verificar con variables dicotómicas la presencia o ausencia del rasgo. Por último, se correlacionarán los déficit intergrupos, para interpretar sus peculiaridades. A la luz de todos los resultados obtenidos, nos interesa identificar algunos indicadores que puedan ser interpretados como marcas tempranas de déficit comunicativo.

En personas con esquizofrenia, los indicadores discursivos a menudo reflejan diferentes repercusiones funcionales en el lenguaje. Las alteraciones son particularmente perjudiciales en las situaciones sociales, pues afectan la capacidad para comunicarse con 
los demás (Docherty et al, 2012). Todos estos déficit están a la base de un mal desempeño de la competencia social y, como sabemos, en muchos programas de rehabilitación se incluyen tareas como el juego de roles para gestionar el autoreporte de vida, que se aprecia disminuido (Bowie y Harvey, 2008; Bowie, Gupta, y Holshausen, 2011). Aún más, estas dificultades afectan a los familiares y/o cuidadores de los pacientes, quienes no siempre consiguen superar la barrera impuesta por las peculiaridades discursivas que implican relacionarse con ellos.

A la luz de este vínculo entre lenguaje y funcionamiento en el mundo, los investigadores han llegado a concluir que el lenguaje es un predictor del funcionamiento mental y de las posibilidades de alcanzar una vida autovalente, requisito central del proceso de rehabilitación (Harrow et al, 1983; Marengo y Harrow, 1987; Racenstein, Penn, Harrow y Schleser, 1999)

Los trastornos del habla en la esquizofrenia se encuentran asociados a rehospitalización, déficits globales en funciones adaptativas, la predicción de altos porcentajes de variaciones del funcionamiento social, sumado a que pueden ser utilizados para estimar la varianza adicional, tanto, de la percepción de las emociones como de la teoría de la mente (Meilijson, S., y Kasher, A., 2004)

Tanto la percepción como la cognición social, se deterioran a menudo en los individuos con esquizofrenia (Corcoran, 2001; Edwards, Jackson, y Pattison, 2002) De este modo, no sólo el trastorno del lenguaje en sí mismo, está asociado a un peor funcionamiento, sino que también, a la prolongación de una mala adaptación en habilidades sociales (Docherty et al., 2012).

Es necesario explicitar el otro parámetro conceptual con el que se trabajarán los datos de esta tesis; nos referimos a la competencia comunicativa, la base de dicha competencia, como ya señalamos, es la coherencia y hemos operacionalizado líneas para evaluarla. Sabemos que la coherencia es para cualquier hablante-oyente, un enunciado, o 
grupo de ellos, que posea sentido como un valor intrínseco. De manera independiente a su estructura lingüística, existen muchas herramientas y recursos para otorgarle sentido al discurso. Visualizando los objetivos comunicativos de la interacción, los participantes colaborarán recíprocamente en la comprensión del significado de las expresiones del otro, mecanismo que a ambos, les permitirá evaluar el sentido del intercambio. La comprensión del significado de un concepto, se emplea para designar la capacidad de una expresión lingüística para representar conocimiento, y el sentido se utiliza cuando dicha transmisión es eficiente. Por tanto, un texto, discurso o manifestación comunicativa, tiene sentido si es que presenta continuidad (Beaugrande, R., y Dressler, W., 2003). La continuidad del sentido es la base de la coherencia. La regulación de los contenidos comunicativos de los hablantes, está dada por una serie de procesos psíquicos, socioculturales y linguiísticos, que al interactuar entre sí, posibilitan la coherencia y con ella la eficacia comunicativa.

Como trabajo adelantado a esta investigación, aunque aún sin publicar, se ha podido comprobar que en la esquizofrenia, tanto CRE y PEE, esta regulación de contenidos presenta alteraciones semántico-pragmáticas, morfoléxicas o sintácticas, tanto en el lenguaje espontáneo (conversación o entrevista semiestructurada) como en la aplicación de tareas comunicativas específicas, como en el caso de algunas subpruebas del test $\mathrm{MEC}^{1}$ :

Discurso espontáneo: a) el carácter intencional, es decir, podemos encontrar discursos/textos con intenciones comunicativas ambiguas, que deben ser re-interpretadas por el interlocutor, b) saltos topicales sin referente explícito, c) ausencia de tópico central, desarrollo subtopical parcial, d) no reconocimiento de expresiones humorísticas (chistes), e) asociaciones semánticas descontextualizadas, f) laxitud en los indicadores de referencia, g) redundancia en la nominación, ausencia de recursos elípticos, h) elaboración inapropiada de superestructuras narrativas y argumentativas.

${ }^{1}$ Protocolo Pragmático para la evaluación de la comunicación de Montreal (MEC) 
Tareas comunicativas específicas MEC (Ferreres, et al 2007)²: a) tareas de elaboración y/o reconocimiento de discurso narrativo, b) discriminación de juicio semántico, c) interpretación de metáforas, d) interpretación de lenguaje figurado, e) interpretación de unidades, f) reconocimiento y/o discriminación de actos de habla indirectos, g) tareas de evocación léxica sin restricción, h) tareas de evocación léxica con restricción fonológica.

\subsection{Hipótesis y Objetivos del estudio:}

En la abundante literatura acerca del lenguaje en la esquizofrenia sobresalen dos perspectivas centrales que procuran caracterizar el discurso de las personas afectadas. La primera, corresponde a la formulación de un marco de tareas discursivas específicas, ya sea con tests estandarizados, checklist, protocolos o la asignación de tareas experimentales de laboratorio (Flekkoy, 1975, Andreasen, 1979, Chaika, E., 1974, Rochester y Martin, 1977, Chapman, 1976, Mckenna y Oh, 2003) Estos métodos permiten entre otras cosas, operacionalizar variables para obtener medidas estadísticas fiables y replicar el estudio en diferentes momentos con resultados similares.

La segunda línea de investigación revela la necesidad de caracterizar las habilidades pragmático-comunicativas en contextos ecológicos, es decir, realizar estudios de discurso espontáneo o semiespontáneo, a fin de obtener resultados representativos de la realidad clínica de los pacientes. Este método se conseguiría al asimilar la estructura tradicional de la entrevista clínica a la de una conversación (Lysaker, et al, 2003). Este es el tipo de estudio que nos interesa exponer aquí, ya que nos parece más informativa de las condiciones comunicativas de los sujetos, y más pertinente con los objetivos propuestos.

\subsubsection{Hipótesis general:}

\footnotetext{
${ }^{2}$ Protocolo pragmático para la evaluación de la comunicación de Montreal (MEC)
} 
Existen diferencias entre los déficits del discurso de la población de esquizofrenia crónica y esquizofrenia de primer episodio.

\subsubsection{Objetivo general:}

Identificar los indicadores de déficit pragmático en los sujetos de esquizofrenia crónica y esquizofrenia de primer episodio.

\subsubsection{Objetivos específicos:}

1. Caracterizar los indicadores de déficit pragmático en los sujetos de esquizofrenia crónica y esquizofrenia de primer episodio.

2. Contrastar indicadores pragmalingüísticos en esquizofrenia crónica y esquizofrenia de primer episodio.

3. Sistematizar indicadores pragmalingüísticos en esquizofrenia crónica y esquizofrenia de primer episodio.

1.3. Plan de la exposición

Para favorecer una mejor comprensión, los contenidos expuestos en esta investigación se ordenan de la manera siguiente:

Marco Conceptual: en este apartado se exponen las bases teóricas que sostienen nuestro estudio. Se expondrán las definiciones conceptuales que son centrales para nuestra investigación. En primer lugar, aquellas que se vinculan a la lingüística clínica. En segundo lugar, aquellas referidas a la esquizofrenia y su perfil etiológico. En tercer lugar, se revisarán los conceptos principales que están en la base de la investigación de esquizofrenia y lenguaje. En cuarto lugar, nos centraremos en los conceptos que nos sirven de marco de referencia, es decir, la competencia comunicativa y su relación con los aspectos semánticos y pragmáticos de la interacción para discutir sus alcances como indicadores relevantes del desempeño comunicativo en estas personas. En lo que sigue, se 
expondrá la relación entre cada indicador y su aporte como componente del perfil lingüístico en personas con esquizofrenia, además de su posible aplicación en tarea de diagnóstico diferencial y como proyección terapéutica.

Método: en esta sección se especificarán los criterios que se utilizaron para la selección, conformación y análisis de las muestras en las que se basa nuestra investigación, así como la naturaleza y características de éstas. Del mismo modo, se expondrán los métodos y matriz de análisis, además de los procedimientos estadísticos que se emplearon en este trabajo.

Presentación y análisis de los resultados: se presentan los principales hallazgos de nuestra indagación de los condicionamientos lingüístico clínicos que inciden en el perfil lingüístico de las personas con esquizofrenia y se reseñan aquellos marcadores que posiblemente sirven como predictores de déficit temprano. Este capítulo se divide en 6 apartados generales que contienen el análisis de la correlación entre las variables I. Estadio de la enfermedad; II. Sexo; III. Tramo de la enfermedad y IV. Subtipo de la enfermedad, con los déficits y características de las variables lingüísticas: I. Fluidez; II. Productividad verbal; III. Índice de participación conversacional; IV. Coherencia temática; V. Semántica de la Coherencia; VI. Coherencia interaccional. Cada apartado contendrá una síntesis de los hallazgos por variable lingüística, de tal manera que, de ser posible podamos reflexionar sobre algunas claves explicativas.

En el capítulo 5 y final, Conclusiones: se sintetizan los resultados más significativos de los distintos aspectos considerados en este estudio. 


\section{Capítulo 2}

\section{Marco Conceptual}

"Para estudiar adecuadamente una ruptura en las comunicaciones, es preciso haber entendido previamente la naturaleza y la estructura del modo particular de comunicación que ha dejado de funcionar. La lingüística tiene como objeto el lenguaje en todos sus aspectos: el lenguaje en acto [el habla], el lenguaje en evolución, el lenguaje en la etapa de su formación y el lenguaje en trance de descomposición"

(Roman Jakobson, 1957) 
El presente trabajo se enmarca en el ámbito de estudio de la lingüística clínica, paradigma de estudio que fue iniciado en la década del 60. David Crystal, considerado uno de sus eximios exponentes, la describe como:

Clinical linguistics is the application of the linguistic sciences to the study of language disability in all its forms. The label 'disability' should not be too narrowly interpreted. It relates to anyone whose ability to use language is sufficiently undeveloped or impaired as to require special treatment or teaching -whether or not they attend a 'clinic' in a surgery or hospital. It is one of several which have been used to characterize the difficulties involved: include disorder, dysfunction, disturbance, disadvantage, deficit, deprivation, and, handicap. These labels differ in their nuances and expectations, and vary in their standing as terms with professional status; some, indeed, are emotionally loaded and politically sensitive. But from a clinical linguistic point of view, what is important is the way they indicate the existence of a domain of abnormal language use which, in its range and complexity, warrants specialist investigation. (Crystal, 2001:673)

En efecto, la lingüística clínica se plantea como la interfaz entre la lingüística y las patologías del lenguaje, en todas sus formas. Pretende describir y comprender todos aquellos aspectos del lenguaje que se encuentren desmedrados por alguna discapacidad, déficit, disfunción, deterioro o trastorno que requieran tratamiento clínico por representar minusvalía para el paciente. Gallardo y Valles (2008:34) la definen sobre todo como la aplicación de la lingüística al campo de las patologías del lenguaje:

La lingüística clínica cubre sobre todo la aplicación de la lingüística al campo de las patologías del lenguaje, y su manifestación profesional más directa es, obviamente, la logopedia, terapia del lenguaje o fonoaudiología (Gallardo y Valles, 2008:34)

En el medio anglosajón, los estudios de lingüística aplicada ostentan una larga tradición de estudios interdisciplinarios, tanto es así que diversas universidades del Reino Unido y Norteamérica poseen departamentos de lingüística aplicada a las patologías del lenguaje o a sus alteraciones, como lo precisa Gallardo Paúls, (2008) realizando un contraste con el medio académico hispánico. En Chile, esta interacción también está lejos de abordarse. Al igual que en otras universidades iberoamericanas, se promueve una clara 
separación marcadamente disciplinar, ofreciendo como núcleos de trabajo académico, departamentos de lingüística, de lengua española, o incluso de castellano, etc. Esta es una de las razones que, sin duda, constituyó un obstáculo difícil de enfrentar para el desarrollo de esta investigación. Aún más, el reducido ámbito de desarrollo que se ha logrado introducir en Chile, únicamente corresponde al medio fonoaudiológico. El trabajo que se extiende en esta área del conocimiento es más cercano a la labor de investigación en trastornos específicos del lenguaje (TEL); patologías cerebrales causadas por accidentes cerebro-vasculares (ACV); envejecimiento (demencias fronto-temporales, alzheimer), todas cuestiones en las que se han hecho notables progresos (Martínez, L., Cabezas, C., et al., 2006; Pavéz, M.M., Coloma, C. y Maggiolo, M., 2008; Donoso, A., Arecheta, P., y González, R., 2009; Araya, C., 2012) Sin embargo, y pese a que estos temas implican un férreo compromiso con el conocimiento, además de ser de una inestimable importancia, excluyen los trastornos del lenguaje que muestran las personas con psicosis. El presente trabajo es una evidencia inicial de que la lingüística puede hacer aportes en el medio clínico psiquiátrico, tal como lo realiza en las patologías de origen neurológico, ya mencionadas.

Dentro de los objetivos de esta interdisciplina, se cuentan:

i. Aclarar mediante una taxonomía terminológica los conceptos referidos a la discapacidad tanto para el área clínica como para la lingüística.

ii. Describir y analizar el comportamiento lingüístico de los pacientes y de las interacciones que se producen entre ellos, sus cuidadores y el personal clínico.

iii. Diagnosticar (diagnóstico diferencial), este es probablemente el objetivo de mayor relevancia, ya que las pesquisas de los fenómenos que caracterizan el comportamiento de los pacientes, es fundamental para descartar o confirmar patologías.

iv. Evaluar el perfil lingüístico de los pacientes, que permite no tan solo realizar precisiones más elaboradas y completas del comportamiento lingüístico del paciente, sino que además, evaluar el grado o nivel de deterioro que éstos presentan. 
v. Intervenir, como el último eslabón de esta cadena, se pretende formular hipótesis que faciliten la rehabilitación de las condiciones lingüístico-comunicativas deficientes que dificultan la vida del paciente.

La ingente tarea de superar la mera observación de fenómenos discursivos, en pacientes con alteraciones comunicativas, es prioritaria para la aplicación de estos objetivos. Si partimos del supuesto de que el lenguaje es una de las herramientas cardinales de la psiquiatría, viene a cobrar profundo sentido nuestro trabajo. La contribución de la lingüística al campo clínico es significativa, siempre y cuando se conserven los debidos límites entre los campos de estudio. En primer lugar, es necesario que existan equipos interdisciplinarios, compuestos por profesionales de las diferentes áreas que puedan tratar al paciente, ya sea para el diagnóstico, tratamiento, evaluación y/o rehabilitación. Un equipo conformado por psiquiatras, neurológos, psicólogos, fonoaudiólogos y lingüistas optimizaría la atención a las personas afectadas de psicosis. En segundo lugar, el trabajo debe estar articulado en función de las competencias de cada perfil profesional, sin pretender realizar tareas que no figuren dentro de dichas competencias, como lo sería el diagnóstico cuya responsabilidad es estrictamente médica, sólo así se contribuirá enormemente al beneficio de la persona afectada.

La siguiente figura que adaptamos de:

[http://liceu.uab.cat/ joaquim/applied_linguistics/speech_pathology/linguistica_patologies/linguisti ca_patologias.html] sirve como ejemplo de cómo se pueden articular dichas áreas en pos de los objetivos clínicos. 
Figura 1: interfaz entre lingüística clínica, esquizofrenia y patologías del lenguaje

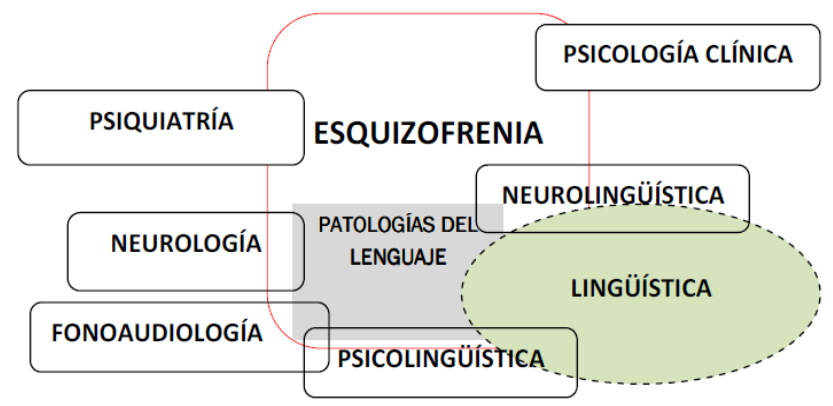

La investigación en esquizofrenia y lenguaje tiene una data de más de ochenta años y está asociada al origen mismo de la descripción nosológica de la enfermedad. Su estudio representa un enorme desafío, con escasa diferencia del trance que propone la enfermedad misma. La heterogeneidad de sus síntomas, signos y posibles causas genera casi la misma enorme variedad de manifestaciones comunicativas; Hoffman (1982) compara la dificultad del análisis del lenguaje en estas personas, con una empresa mítica:

[...] la naturaleza anómala de las emisiones producidas por las personas esquizofrénicas continúa esquivando, al igual que el unicornio, a todos los que tratan de capturarla (Hoffman, 1982, citado por Belinchón, M., 1988:108)

Sabemos que es un campo difícil, que requiere de la contribución colaborativa de disciplinas que tienen ámbitos de aplicación completamente diferentes, pero que pueden realizar un análisis profundo dada su contribución particular.

\subsection{La esquizofrenia}

La esquizofrenia es una afección mental grave y deletérea para el sujeto y su familia. Su alta morbi-mortalidad, multidimensionalidad etiológica y curso deteriorante la 
convierten en un desafío permanente para la salud pública y en un permanente reto para la psiquiatría (Crow, 1980, Castilla del Pino, 1991, Andreasen, 1995 y Mckenna y Oh, 2005).

Es una patología invalidante, ya que su inicio se sitúa en etapas precoces del ciclo vital y se asocia a un deterioro neurocognitivo y psicosocial significativo, que de no contar con tratamiento oportuno y eficaz, tiende a la cronicidad y al deterioro global de la calidad de vida. Representa un alto costo para el sujeto, su familia y/o cuidadores y no existe, hasta ahora, un tratamiento que logre la reversión absoluta de la enfermedad. También se la ha señalado como una de las enfermedades más costosas para los programas de salud pública, según la OMS:

El impacto económico de los trastornos mentales es amplio, duradero y enorme. Estos trastornos imponen una serie de costos en los individuos, familias y comunidades. En los Estados Unidos de América, se ha reportado que el total de los costos anuales relacionados con los trastornos mentales asciende a 147 billones de dólares estadounidenses, más que los costos atribuidos al cáncer, enfermedades respiratorias o SIDA (Instituto de Medicina, 1989). A pesar de que la estimación de los costos directos en los países de bajos ingresos, no alcanzan estos niveles debido a la poca disponibilidad y cobertura de los servicios de atención de salud mental, los costos indirectos que surgen de la pérdida de productividad y representan una proporción mayor de los costos generales [...]Cinco de cada diez de las principales causas de discapacidad a nivel mundial son condiciones psiquiátricas, incluyendo la depresión, consumo de alcohol, esquizofrenia y trastornos compulsivos (Murray \& López, 1996). Las proyecciones estiman que para el año 2020 las condiciones neuropsiquiátricas serán responsables del $15 \%$ de las discapacidades a nivel mundial, y la depresión unipolar por sí sola será responsable del 5.7\% de los DALYs ${ }^{3}$ (OMS, 2001:16).

A continuación, mencionamos, de manera sucinta, los criterios consensuados que se asumen como el perfil representativo de esta patología, presentes en los manuales estandarizados como el DSM-IV TR y CIE-10. Ambas clasificaciones son ampliamente aceptadas y se utilizan de manera complementaria; para este estudio, se comtempló como marco de referencia el DSM-IV TR, si bien, la versión más actualizada, DSM-V, ofrece algunas diferencias que no han podido ser contempladas en este trabajo.

\footnotetext{
${ }^{3}$ Años de Vida Ajustados por Discapacidad
} 
Tabla 1. Criterios diagnósticos del DSM-IV y CIE-10. DSM-IV, (1994):

Guía Clínica 2009 Para el Tratamiento de Personas desde Primer Episodio de Esquizofrenia

\section{ANEXO 4. Criterios diagnósticos seqún CIE-10 y DSM-IV}

\begin{tabular}{|c|c}
\hline CIE-10 & \\
\hline Presencia, como mínimo, de un síntoma muy evidente o & A.
\end{tabular}

dos o más si son menos evidentes, pertenecientes a cualquiera de los grupos (a) a (d), o síntomas de por lo menos dos de los grupos referidos entre el (e) y el (i). Los síntomas deben haber estado claramente presentes por un periodo de un mes o más.

a) Eco, robo, inserción o transmisión del pensamiento.

b) Ideas delirantes de ser controlado, de influencias o de pasividad claramente referidas al cuerpo, a los movimientos de los miembros, o a pensamientos o acciones o sensaciones concretas y percepciones delirantes.

c) Voces alucinatorias que comentan la propia actividad, que discuten entre ellas sobre el enfermo y otros tipos de voces alucinatorias que proceden de alguna parte del cuerpo.

d) Ideas delirantes persistentes de otro tipo que no son adecuadas a la cultura del individuo o que son totalmente imposibles, tales como las de identidad religiosa 0 política, capacidad y poderes sobrehumanos (por ejemplo, de ser capaz de controlar el clima, de estar en comunicación con seres de otros mundos).

e) Alucinaciones persistentes de cualquier modalidad, cuando se acompañan de ideas delirantes no estructuradas y fugaces sin contenido afectivo claro, o ideas sobrevaloradas persistentes, o cuando se presentan a diario durante semanas, meses o permanentemente.

f) Interpolaciones 0 bloqueos en el curso del pensamiento que dan lugar a un lenguaje divagatorio, disgregado, incoherente o lleno de neologismos.

g) Manifestaciones catatónicas, tales como excitación, posturas características, flexibilidad cérea, negativismo, mutismo, estupor.

h) Síntomas "negativos" tales como apatía marcada, empobrecimiento del lenguaje, bloqueo 0 incongruencia de la respuesta emocional (estas últimas habitualmente conducen a retraimiento social y disminución de la competencia social); debe quedar claro que estos síntomas no se deben a depresión o a medicación neuroléptica.

\section{DSM-IV}

A. Síntomas característicos: Dos o más de los siguientes, cada uno de ellos presente durante una parte significativa de un periodo de un mes (o menos si ha sido tratado con éxito): (1) ideas delirantes, (2) alucinaciones, (3) lenguaje desorganizado; por ejemplo, descarrilamientos frecuentes o incoherencia, (4) comportamiento catatónico o gravemente desorganizado, (5) síntomas negativos; por ejemplo, aplanamiento afectivo, alogia o abulia.

*Nota: sólo se requiere un síntoma del criterio A si las ideas delirantes son extrañas, o si las ideas delirantes consisten en una voz que comenta continuamente los pensamientos o el comportamiento del sujeto, o si dos o más voces conversan entre ellas.

B. Disfunción social/ laboral: Durante una parte significativa del tiempo desde el inicio de la alteración, una o más áreas importantes de la actividad, como son el trabajo, las relaciones interpersonales o el cuidado de uno mismo, están claramente por debajo del nivel previo al inicio del trastorno (o, cuando el inicio es en la infancia o la adolescencia, fracaso en cuanto a alcanzar el nivel esperable de rendimiento interpersonal, académico o laboral).

C. Duración: Persisten signos continuos de la alteración durante al menos 6 meses. Este periodo de 6 meses debe incluir al menos un mes de síntomas que cumplan el criterio A (o menos si se ha tratado con éxito) y puede incluir los periodos de síntomas prodrómicos y residuales. Durante estos periodos prodrómicos o residuales, los signos de la alteración pueden manifestarse sólo por síntomas negativos o por dos o más síntomas de la lista del criterio A, presentes en forma atenuada (por ejemplo, creencias raras, experiencias perceptivas no habituales).

D. Exclusión de los trastornos esquizoafectivo y del estado del ánimo: El trastorno esquizoafectivo y el trastorno del estado del ánimo con síntomas psicóticos se han descartado debido a: (1) no ha habido ningún episodio depresivo mayor, maníaco o mixto concurrente con los síntomas de la fase activa; o (2) si los episodios de alteración anímica han aparecido durante los síntomas de la fase activa, su duración total ha sido breve en relación con la duración de los periodos activo y residual.

E. Exclusión de consumo de sustancias y de enfermedad médica: El trastorno no es debido a los efectos fisiológicos directos de alguna sustancia (por ejemplo, una droga de abuso, un medicamento) o de una enfermedad médica.

F. Relación con un trastorno generalizado del desarrollo: Si hay historia de trastorno autista o de otro trastorno generalizado del desarrollo, el diagnóstico adicional de esquizofrenia sólo se hará si las ideas delirantes o las alucinaciones también se mantienen durante al menos 1 mes (o menos si se han tratado con éxito). 
Naturalmente, el modo de conceptualizar teóricamente la esquizofrenia tiene una profunda influencia en todos los aspectos de su comprensión. Como señala Jimeno Bulnes (2002) es requerimiento indefectible la integración de todos los factores que sirvan de evidencia, ya que las manifestaciones son heterogéneas (la negrita es nuestra):

El estudio de las manifestaciones de la esquizofrenia puede ligarse directamente al concepto y diagnóstico de la misma, de tal forma que según los criterios diagnósticos empleados (sean de Kraepelin, o Bleuler, o del grupo de San Luis, o los criterios RDC, o las sucesivas versiones de la CIE o DSM), tal o cual síntoma tendrá un mayor o menor peso específico. En todo caso, en lo que la mayoría — por no decir todoslos autores coinciden es en la heterogeneidad de la enfermedad, que puede expresarse por manifestaciones en las más diversas funciones psicopatológicas. $\mathrm{O}$ dicho con otras palabras, la amplia gama de posibles síntomas de la esquizofrenia supone un estudio en profundidad de la psicopatología misma.

(Jimeno Bulnes, 2002:316)

A través del tiempo, los límites de la esquizofrenia han variado notablemente. Desde las precisiones que introdujo Kraepelin, (1896) hasta la actual conceptualización de los ultra high risk, propuestos por McGorry y sus colaboradores (2002). Sin embargo, existen coincidencias fundamentales para definir su perfil como patología. La literatura científica demuestra que las alteraciones cerebrales se centran en los lóbulos temporal y frontal, provocando alteraciones en los sistemas neuronales y en los neurotransmisores encargados de regular el funcionamiento de estas zonas. Los avances en neuroimagen, han hecho más visible lo que los científicos han caracterizado como una alteración del neurodesarrollo, comprobándose que afecta la percepción, el pensamiento, el lenguaje, la conducta y la voluntad (Orellana, G., 2009)

Se resumen en el apartado siguiente, los criterios diagnósticos para la esquizofrenia, según el modelo que utilizado en los centros psiquiátricos de Chile tomado DSM-IV-TR: 
Tabla 2: Criterios DSM-IV-TR (ESQUIZOFRENIA)

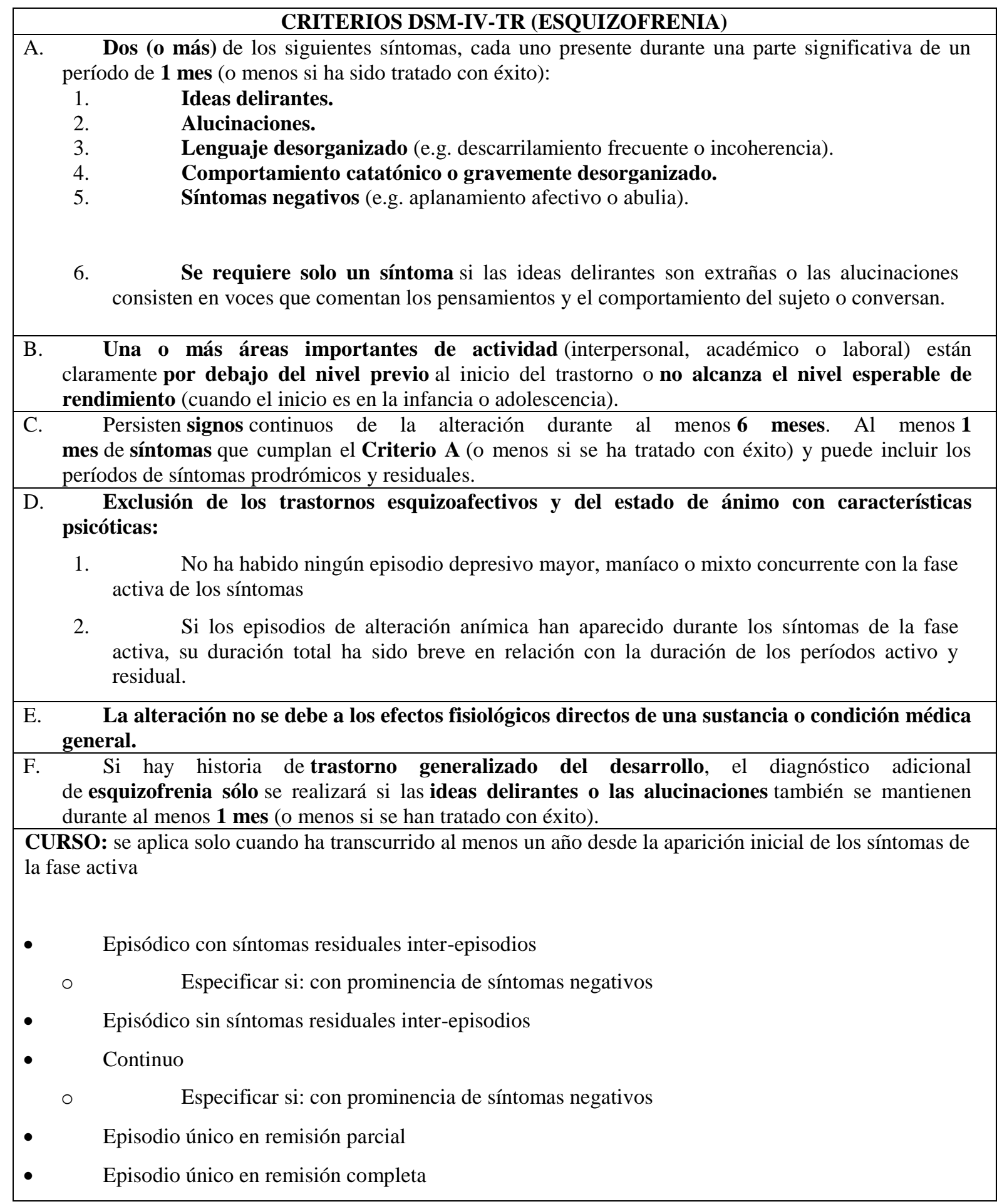


- Otros patrones

\section{TIPO PARANOIDE}

A. Preocupación por una o más ideas delirantes o alucinaciones auditivas frecuentes.

B. No hay lenguaje desorganizado, ni comportamiento catatónico o desorganizado, ni afectividad aplanada o inapropiada.

TIPO DESORGANIZADO

A. Predominan:

1. Lenguaje desorganizado.

2. Comportamiento desorganizado.

3. Afectividad aplanada o inapropiada.

B. No se cumplen los criterios para el tipo catatónico.

TIPO CATATÓNICO

El cuadro clínico está dominado por al menos dos de los siguientes síntomas:

1. Inmovilidad motora manifestada por catalepsia (incluida la flexibilidad cérea) o estupor.

2. Actividad motora excesiva (que aparentemente carece de propósito y no está influida por estímulos externos).

3. Negativismo extremo (resistencia aparentemente inmotivada a todas las órdenes o mantenimiento de una postura rígida en contra de los intentos de ser movido) o mutismo.

4. Peculiaridades del movimiento voluntario manifestadas por la adopción de posturas extrañas, movimientos estereotipados, manierismos marcados o muecas llamativas.

5. Ecolalia o ecopraxia.

TIPO INDIFERENCIADO

Están presentes los síntomas del Criterio A, pero que no cumple los criterios para el tipo paranoide, desorganizado o catatónico.

TIPO RESIDUAL

A. Ausencia de ideas delirantes, alucinaciones, lenguaje desorganizado y comportamiento catatónico o gravemente desorganizado.

B. Hay manifestaciones continuas de la alteración, como lo indica la presencia de síntomas negativos o de dos o más síntomas de los enumerados en el Criterio A para la esquizofrenia, presentes de una forma atenuada.

- $\quad$ Trastorno esquizofreniforme.

- Trastorno esquizoafectivo.

- $\quad$ Trastorno delirante.

- $\quad$ Trastorno psicótico breve. 


$$
\begin{array}{ll}
\text { - } & \text { Trastorno psicótico compartido. } \\
\text { - } & \text { Trastorno psicótico debido a condición médica general } \\
\text { - } & \text { Trastorno psicótico inducido por sustancias. } \\
& \text { Trastorno psicótico no especificado. }
\end{array}
$$

Los criterios del nuevo manual, DSM-V, introducen solo dos cambios;

[...] en el criterio A de esquizofrenia. Primer cambio, en el DSM anterior solo se requería un síntoma si las ideas delirantes son extrañas o existían alucinaciones, en el DSM V se necesitan dos síntomas del criterio A para el diagnóstico de esquizofrenia, en vez de sólo uno, debido a la no especificidad de los síntomas Scheneiderianos y la baja fiabilidad de la distinción entre delirios extraños y no extraños. Segundo cambio, se añade un requisito en el criterio A, que el individuo debe tener al menos uno de estos tres síntomas: delirios, alucinaciones y habla desorganizada. Al menos uno de estos síntomas positivos es necesario para el diagnóstico fiable de esquizofrenia. Subtipos de esquizofrenia Se eliminan los subtipos del DSM IV debido a su limitada estabilidad diagnóstica, baja fiabilidad y poca validez. Estos subtipos tampoco han demostrado tener una respuesta al tratamiento o un curso longitudinal diferenciado. En vez de los subtipos, se incluye en la Sección III una aproximación dimensional para puntuar la severidad de los síntomas y para captar la importante heterogeneidad de los tipos de síntomas y su gravedad presentes en los individuos con trastornos psicóticos. (fuente www.dsmV.org "Highlight of changes from DSM-IV-TR to DSM-V")

Como ya señalamos, la definición de esta nueva versión del DSM, es sustancialmente coincidente con lo descrito en la IV versión:

Los síntomas característicos implican una serie de disfunciones cognitivas, conductuales y emocionales, no hay un solo síntoma que sea patognomónico de la enfermedad. El diagnóstico implica el reconocimiento de una constelación de signos y síntomas asociados con el deterioro de la actividad profesional o social. Los individuos con este trastorno variarán sustancialmente en la mayoría de las características, debido a que la esquizofrenia es un síndrome clínico heterogéneo. (DSM-V, 2013:100).

A continuación se presenta la clasificación diagnóstica de la CIE-10:

Tabla 3. Clasificación diagnóstica de la esquizofrenia en la CIE-10.

\section{CRITERIOS CIE-10 (ESQUIZOFRENIA)}

Caracterizado por distorsiones fundamentales y típicas de la percepción, del pensamiento y de las emociones. En general, se conservan tanto la claridad de la conciencia como la capacidad intelectual, aunque con el paso del tiempo pueden presentarse déficits cognoscitivos.

Son frecuentes las alucinaciones, especialmente las auditivas, que pueden comentar la propia conducta o los pensamientos propios del enfermo. Suelen presentarse además otros trastornos de la percepción. La perplejidad es frecuente ya desde el comienzo, la cual suele acompañarse de la creencia de que las situaciones cotidianas tienen un significado especial, por lo general siniestro y dirigido contra el propio enfermo. En el trastorno del pensamiento 
característico de la esquizofrenia los aspectos periféricos e irrelevantes de un concepto afloran a la superficie y son utilizados en lugar de los elementos pertinentes y adecuados para la situación. Así el pensamiento se vuelve vago, elíptico y oscuro y su expresión verbal es a veces incomprensible. Las características más importantes de la afectividad son la superficialidad, su carácter caprichoso y la incongruencia. La ambivalencia y el trastorno de la voluntad se manifiestan como inercia, negativismo o estupor.

El comienzo puede ser agudo, con trastornos graves del comportamiento o insidioso con un desarrollo gradual de ideas y de una conducta extraña. El curso también presenta una gran variabilidad (no inevitablemente crónico y deteriorante).

Aunque en sentido estricto no se han identificado síntomas patognomónicos, ciertos fenómenos psicopatológicos tienen una significación especial para el diagnóstico de esquizofrenia, los cuales suelen presentarse asociados entre sí. Estos son:

a. $\quad$ Eco, robo, inserción del pensamiento o difusión del mismo.

b. Ideas delirantes de ser controlado, de influencia o de pasividad (referidas al cuerpo, a los movimientos, pensamientos y acciones; sensaciones concretas y percepción).

Voces alucinatorias que comentan la propia actividad, que discuten entre ellas sobre el enfermo o que proceden de otra parte del cuerpo.

d. Ideas delirantes persistentes de otro tipo que no son adecuadas a la cultura del individuo o que son completamente imposibles (identidad religiosa o política, capacidad y poderes sobrehumanos).

e. Alucinaciones persistentes de cualquier modalidad, cuando se acompañan de ideas delirantes no estructuradas y fugaces sin contenido afectivo claro, o ideas sobrevaloradas persistentes, o cuando se presentan a diario durante semanas, meses o permanentemente.

f. Interpolaciones o bloqueos en el curso del pensamiento, que dan lugar a un lenguaje divagatorio, disgregado, incoherente o lleno de neologismos.

Manifestaciones catatónicas, tales como excitación, posturas características o flexibilidad cérea, g. negativismo, mutismo, estupor.

h. Síntomas "negativos" tales como apatía marcada, empobrecimiento del lenguaje, bloqueo o incongruencia de la respuesta emocional (estas últimas habitualmente conducen a retraimiento social y disminución de la competencia social).

i. Un cambio consistente y significativo de la cualidad general de algunos aspectos de la conducta personal, que se manifiestan como pérdida de interés, falta objetivos, ociosidad, estar absorto y aislamiento social.

Pautas para el diagnóstico:

Presencia como mínimo de un síntoma muy evidente o dos o más si son menos evidentes, de cualquiera de los grupos del a) al d), o síntomas de por lo menos dos de los grupos del e) al i), claramente presentes la mayor parte del tiempo durante un período de un mes o más.

El diagnóstico de esquizofrenia no deberá hacerse en presencia de síntomas depresivos o maníacos relevantes, a no ser que los síntomas esquizofrénicos antecedieran claramente al trastorno del humor (afectivo). Tampoco deberá diagnosticarse una esquizofrenia en presencia de una enfermedad cerebral manifiesta o durante una intoxicación por sustancias psicotrópicas o una abstinencia a las mismas.

\section{Formas de evolución}

- $\quad$ Continua

- $\quad$ Episódica con defecto progresivo

- $\quad$ Episódica con defecto estable

- $\quad$ Episódica con remisiones completas 


\begin{tabular}{ll}
\hline$\bullet$ & Remisión incompleta \\
- & Remisión completa \\
- & Otra forma de evolución \\
& Periodo de observación menor de un año
\end{tabular}

Tabla 4: subtipos de esquizofrenia

\section{ESQUIZOFRENIA PARANOIDE}

\section{SUBTIPOS DE ESQUIZOFRENIA}

En el cuadro clínico predominan las ideas delirantes relativamente estables, a menudo paranoides, que suelen acompañarse de alucinaciones, en especial de tipo auditivo y de otros trastornos de la percepción. Sin embargo, los trastornos afectivos, de la voluntad, del lenguaje y los síntomas catatónicos pueden ser poco llamativos.

Ideas delirantes y alucinaciones más frecuentes:

a. Ideas delirantes de persecución, de referencia, de celos, genealógicas, de tener una misión especial o de transformación corporal.

b. Voces alucinatorias que increpan al enfermo dándole órdenes, o alucinaciones auditivas sin contenido verbal

c. Alucinaciones olfatorias, gestatorias, sexuales o de otro tipo de sensaciones corporales.

El curso puede ser episódico, con remisiones parciales o completas, o crónico. En esta última variedad los síntomas floridos persisten durante años y es difícil distinguir episodios aislados. El comienzo tiende a ser más tardío que en las formas hebefrénica y catatónica.

Pautas para el diagnóstico

Deben satisfacerse las pautas generales para el diagnóstico de esquizofrenia y además deben predominar las alucinaciones o las ideas delirantes y ser relativamente poco llamativos los trastornos de la afectividad, de la voluntad y del lenguaje y los síntomas catatónicos.

\section{ESQUIZOFRENIA HEBEFRÉNICA}

Forma de esquizofrenia en la que los trastornos afectivos son importantes, las ideas delirantes y las alucinaciones son transitorias y fragmentarias y es frecuente el comportamiento irresponsable $\mathbf{e}$ imprevisible y los manierismos. La afectividad es superficial es inadecuada. El pensamiento aparece desorganizado y el lenguaje es divagatorio e incoherente. Hay una tendencia a permanecer solitario y el comportamiento carece de propósito y de resonancia afectiva.

Comienza por lo general entre los 15 y los 25 años de edad y tiene un pronóstico malo por la rápida aparición de síntomas negativos, en especial de embotamiento afectivo y de abulia. 
Además de las alteraciones afectivas y de la voluntad, destaca el trastorno del pensamiento. Se pierden la iniciativa y la determinación, se pierde cualquier tipo de finalidad de tal forma que el comportamiento del enfermo parece errático y vacío de contenido. Además, la preocupación superficial y manierística por temas religiosos, filosóficos o abstractos puede hacer difícil al que escucha seguir el hilo del pensamiento.

\section{Pautas para el diagnóstico}

Para un diagnóstico seguro de hebefrenia normalmente es necesario un período de dos o tres meses de observación continua para asegurarse de que persiste el comportamiento característico.

\section{ESQUIZOFRENIA CATATÓNICA}

Presencia de trastornos psicomotores graves, que varían desde la hipercinesia al estupor o de la obediencia automática al negativismo. Durante largos períodos de tiempo pueden mantenerse posturas y actitudes rígidas y encorsetadas. Otra característica llamativa de este trastorno es la excitación intensa.

\section{Pautas para el diagnóstico}

Deben satisfacerse las pautas generales para el diagnóstico de esquizofrenia. Pueden aparecer síntomas catatónicos aislados y transitorios en el contexto de cualquier otro tipo de esquizofrenia. Para el diagnóstico de esquizofrenia catatónica deben predominar en el cuadro clínico uno o más de los siguientes tipos de comportamiento:
i. Estupor o mutismo.
ii. Excitación.
iii. Catalepsia.
iv. Negativismo.
v. Rigidez.
vi. Flexibilidad cérea.
vii. Obediencia automática y perseveración del lenguaje.

\section{ESQUIZOFRENIA INDIFERENCIADA}

Conjunto de trastornos que satisfacen las pautas generales para el diagnóstico de esquizofrenia pero que no se ajustan a ninguno de los tipos o presentan rasgos de más de uno de ellos, sin que haya un claro predominio de uno en particular. Esta categoría deberá utilizarse únicamente para los cuadros psicóticos (excluyendo, pues, a la esquizofrenia residual y a la depresión postesquizofrénica) y sólo después de haber intentado clasificar el cuadro clínico en alguna de las tres categorías precedentes.

\section{Pautas para el diagnóstico}

a. Satisfacen las pautas para el diagnóstico de esquizofrenia.

b. No satisfacen las pautas de los tipos catatónico, hebefrénico o paranoide.

c. $\quad$ No reúnen las pautas para la esquizofrenia residual o la depresión postesquizofrénica. 
Estado crónico del curso de la enfermedad esquizofrénica, en el que se ha producido una clara evolución progresiva desde los estados iniciales (que incluyen uno o más episodios con síntomas psicóticos que han satisfecho las pautas generales de la esquizofrenia) hacia los estadios finales caracterizados por la presencia de síntomas "negativos" y de deterioro persistente, aunque no necesariamente irreversibles.

\section{Pautas para el diagnóstico}

a. $\quad$ Presencia de síntomas esquizofrénicos "negativos" destacados

b. Evidencia de que en el pasado ha habido por lo menos un episodio claro que ha reunido las pautas para el diagnóstico de esquizofrenia.

c. Un período de por lo menos un año durante el cual la intensidad y la frecuencia de la sintomatología florida (ideas delirantes y alucinaciones) han sido mínimas o han estado claramente apagadas, mientras que destacaba la presencia de un síndrome esquizofrénico "negativo".

d. La ausencia de demencia u otra enfermedad o trastorno cerebral orgánico, de depresión crónica o de institucionalización suficiente como para explicar el deterioro.

\section{ESQUIZOFRENIA SIMPLE}

Trastorno no muy frecuente en el cual se presenta un desarrollo insidioso aunque progresivo, de un comportamiento extravagante, de una incapacidad para satisfacer las demandas de la vida social y de una disminución del rendimiento en general. No hay evidencia de alucinaciones y ni de ideas delirantes y el trastorno es no tan claramente psicótico como los tipos hebefrénico, paranoide y catatónico. Los rasgos "negativos" característicos de la esquizofrenia residual aparecen sin haber sido precedidos de síntomas psicóticos claramente manifiestos. El creciente empobrecimiento social puede conducir a un vagabundeo, los enfermos se encierran en sí mismos, se vuelven ociosos y pierden sus objetivos.

\section{Pautas para el diagnóstico}

Desarrollo progresivo durante un período de tiempo superior a un año, de los síntomas "negativos" característicos de la esquizofrenia residual, sinque hayan existido antecedentes de alucinaciones, de ideas delirantes ni de otras manifestaciones de un episodio psicótico pasado, con cambios significativos en la conducta personal manifestados con una marcada pérdida de interés, ociosidad y aislamiento social.

Sintetizando, la esquizofrenia es una enfermedad de enorme complejidad que requiere de equipos de salud mental altamente especializados en su detección y tratamiento, ya que es una patología psiquiátrica muy grave, en opinión de muchos psicopatólogos, la más insidiosa de todas:

La esquizofrenia es una enfermedad heterogénea que cursa con síntomas (como trastornos de la sensopercepción, pensamiento, lenguaje, afectividad, conativo motores, conducta, etc.) y signos (como la disarmonía en los movimientos durante la marcha de los esquizofrénicos, o la pérdida de cadencia, tono y ritmo adecuado de su lenguaje. 
Ha de ser la constelación de síntomas y signos en las diversas funciones psíquicas que presenta un individuo en un momento dado, $-\mathrm{y}$ no la aparición de síntomas aislados, como delirio o alucinaciones, la que nos puede permitir realizar el diagnóstico.

El trastorno fundamental corresponde al llamado defecto de las funciones más humanas y superiores del yo, que se expresa sobre todo por la pérdida de intereses, motivaciones y relaciones sociales, y en definitiva, del proyecto vital. Este concepto ha sido desarrollado por distintos modelos, entre otros el denominado «de los síntomas psicóticos básicos», de Huber y colaboradores, y que seguimos en este trabajo.

Los «síntomas básicos próximos al sustrato» son, según el citado modelo, síntomas psicóticos recogidos en esquizofrénicos como vivencias subjetivas primarias, que constituyen la base de los complejos síntomas psicóticos finales, y que puede suponerse se encuentran más próximos al sustrato neurobiológico que aquéllos.

Los síntomas básicos se evalúan fundamentalmente por medio del «Inventario Psicopatológico de Frankfurt» o FBF, y la «Escala de Bonn para la Evaluación de los Síntomas Básicos» o BSBAS. Estos instrumentos complementan pues la exploración psicopatológica clásica y facilitan la realización de un diagnóstico sindrómico más preciso de la enfermedad. Ofrecen pues una triple utilidad: recogen síntomas más nucleares o básicos, contribuyen a establecer la duración de la enfermedad, y permiten diseñar tratamientos más individualizados. (Jimeno Bulnes, 2002:318)

Por otro lado, la evolución y el pronóstico de la enfermedad dependen de diversos factores, como una organización familiar que ayude a velar por la adherencia a los tratamientos psicofarmacológicos y terapéuticos; la incidencia de factores genéticos predisponentes y/o factores ambientales, entre otros (Gross G., 1989:21-5;37). Estos elementos sumados a un diagnóstico precoz o tardío, definen de forma categórica la impronta que presentará la enfermedad en dichos aspectos (Huber G, Gross G. 1989; 80:646-52).

Las abundantes dimensiones de la enfermedad han despertado un interés común en los científicos, acrecentado por el hecho de que aún se desconocen sus causas. Por tanto, se han cifrado todos los esfuerzos en la pesquisa de la precocidad, así, la búsqueda de elementos que permitan avanzar en el diagnóstico, es una tarea de investigación constante, pues es obvio que el diagnóstico y tratamiento temprano, son algunos de los principales factores que influyen en los costos de evolución a largo plazo. Se ha comprobado que la menor duración de la psicosis no tratada (DUP) tiene un impacto directo en el buen 
pronóstico para el paciente, y el tratamiento temprano, a su vez, favorece una evolución positiva (Mc Gorry, Killackey, Young, 2008).

Para el estudio y una comprensión integrada de esta enfermedad, es imprescindible que se complementen las disciplinas científicas que tengan la capacidad de generar una interfaz significativa para profundizar el conocimiento. Nos parece relevante tomar en cuenta el hecho de que una de las áreas más afectadas es aquella que toca el ámbito de lo social, por ende, de las competencias intersubjetivas. La capacidad para interactuar, comunicarse, ser parte de un medio, participar funcionalmente de un entorno determinado es el tipo de actividades sociales que asumen ribetes casi inabordables para las personas enfermas.

En los relatos de los pacientes, se aprecian frecuentes observaciones acerca de la angustia que les provoca hacerse entender y/o que la expresión de sus opiniones sean tomadas en cuenta por aquellos que les rodean. Estas razones alimentan nuestro profundo interés de dar cuenta del perfil lingüístico que presentan los afectados. Sabemos que, a pesar de que existen abundantes trabajos que han delineado este problema, no contamos con materiales que ilustren qué ocurre con el perfil lingüístico de aquellas personas que inician la patología. Podríamos suponer que el lenguaje es un área que se conserva funcional hasta momentos más avanzados de la enfermedad. O bien, por el contrario, que ya podemos observar algunos fenómenos comunicativos propios de la cronicidad. En la medida en que proliferen los trabajos que comparen, contrasten o describan el comportamiento lingüístico-comunicativo de estas personas, se estará más cerca de una auténtica comprensión del fenómeno. De este modo, lo sugieren autores que desde hace más de diez años han realizado trabajos en el área (Laguna, E. y Turull, N. 2000; Tenyi, T; Herold, R, et al., 2002; Meilijson, S. y Kasher, A. 2004), quienes han llevado a cabo algunas valiosas iniciativas para proponer análisis integrados del problema. Frente a los entresijos sobre su dimensión comunicativa es menester alcanzar una comprensión fenoménica general, describiendo la esquizofrenia de primer episodio, que está delimitada de forma clara en la literatura. 


\subsection{Primer episodio de esquizofrenia:}

La entidad clínica conocida como primer episodio de esquizofrenia (PEE) corresponde a la primera aparición de un episodio psicótico. Es la fase inicial de la enfermedad, que está presente debido a la ocurrencia de los síntomas positivos y/o negativos (Andreasen, 1979:99) Extractamos algunos fragmentos relevantes de la Guía clínica para el tratamiento de la esquizofrenia del MINSAL Chile, versión 2009, sobre las recomendaciones para su manejo:

\section{Sospecha diagnóstica}

- Controlar y evaluar la presencia de otros síntomas que sugieran esquizofrenia, a toda persona que, sin diagnóstico previo de esquizofrenia, presente: cambios de comportamiento como aislamiento, disminución del rendimiento escolar; dificultad para entender sus ideas; uso de explicaciones metafóricas o extrañas; cambios en hábitos higiénicos, vestimenta, adornos.

- Toda persona con episodio psicótico sin diagnóstico previo de esquizofrenia debe ser derivada para evaluación diagnóstica por especialista.

- Los profesionales de salud general, particularmente equipos de salud general, médicos generales, médicos de familia, pediatras y adolescentólogos deben estar capacitados en el reconocimiento de síntomas tempranos de un episodio psicótico.

\section{Confirmación diagnóstica}

- Toda persona derivada a especialidad por sospecha de un episodio psicótico sin diagnóstico previo de esquizofrenia o con sospecha de un primer episodio de esquizofrenia debe ser ingresada a un proceso de evaluación diagnóstica para confirmar o descartar la esquizofrenia.

- El proceso de evaluación diagnóstica debe incluir al menos las siguientes intervenciones: evaluación clínica, examen mental, evaluación psicológica, evaluación social, evaluación de discapacidad y habilidades, exámenes de apoyo según necesidad, diagnóstico de comorbilidad, diagnóstico diferencial y tratamiento de prueba, según esquema recomendado para la etapa aguda de la esquizofrenia.

- Realizar TAC de cerebro a toda persona con sospecha de primer episodio de esquizofrenia que no responde al tratamiento de prueba pasado los 3 meses de iniciado el proceso de evaluación diagnóstica. 


\section{Tratamiento}

- El tratamiento de las personas con esquizofrenia debe ser personalizado en un Plan Individual de Tratamiento Integral, que se elabora en base al diagnóstico integral y en consenso con el usuario y su familia.

- La persona con un primer episodio de esquizofrenia requerirá tratamiento en tanto persista el diagnóstico de esquizofrenia, adecuando la intensidad y énfasis de las intervenciones según se manifiesten las distintas etapas de la enfermedad.

- El tratamiento de una persona con esquizofrenia debe incluir siempre los siguientes 4 componentes: evaluación integral, intervenciones psicosociales, farmacoterapia y servicios de apoyo.

- Las intervenciones psicosociales en la fase aguda de la enfermedad deben considerar acciones que contribuyan a superar la situación de crisis del individuo y su familia.

- Las intervenciones psicosociales en la fase de recuperación de la enfermedad, deben considerar intervenciones específicas adicionales que contribuyan a facilitar la relación entre el individuo afectado y su entorno natural.

- Las intervenciones psicosociales en la fase de compensación de la enfermedad deben considerar intervenciones que contribuyan a la permanencia del individuo en su entorno natural y a mejorar su calidad de vida.

- Incorpore terapia de arte con cualquier modalidad en el tratamiento, tanto en la fase aguda como en la fase de recuperación, particularmente en caso de síntomas negativos marcados.

- Incluya intervenciones familiares en el tratamiento de toda persona con esquizofrenia y en todas las fases de la enfermedad, especialmente en los casos con recaídas recientes o con riesgo de recaída.

- Se recomienda incluir terapia cognitivo-conductual (TCC) en el tratamiento de las personas con esquizofrenia, intervención que puede iniciarse en la fase aguda y debe incluir al menos 16 sesiones consecutivas, desarrolladas según un manual de tratamiento con evidencia de eficacia.

- En la fase aguda de la enfermedad se debe iniciar tratamiento con el antipsicótico más adecuado al perfil sintomático que presenta la persona, en dosis cercanas al límite inferior del rango recomendado

- La elección del antipsicótico debe estar basada en la historia de respuesta del paciente a uno u a otro medicamento y el perfil de efectos colaterales.

- Antes de indicar un determinado antipsicótico, informe al usuario/a acerca de los efectos colaterales de los distintos antipsicóticos (tanto convencionales como atípicos), realizando un análisis en conjunto de las distintas alternativas, de modo que él/ella decida cuál prefiere usar. 
- No es recomendable usar olanzapina o quetiapina si la persona padece de obesidad, diabetes mellitus o dislipidemia. En esos casos es preferible usar un antipsicótico convencional o aripiprazol.

- Si la persona con primer episodio de esquizofrenia presenta riesgo cardiovascular o tiene antecedentes familiares de enfermedad cardiovascular, solicite un ECG antes de iniciar la medicación con un antipsicótico.

- Se recomienda no utilizar combinaciones de antipsicóticos como tratamiento regular, excepto por periodos breves, por ejemplo al cambiar de medicamento.

- Informe al usuario sobre los altos riesgos de recaída si suspenden la medicación dentro de los 2 años siguientes al inicio del tratamiento.

- El retiro de la medicación antipsicótica debe hacerse en forma gradual, controlando en forma regular al usuario para monitorear la posible aparición de signos o síntomas de recaída.

- Después de retirada la medicación antipsicótica, se debe seguir controlando al usuario por un período de al menos 2 años para monitorear la posible aparición de signos o síntomas de recaída.

- En caso de mala respuesta al tratamiento integral revise el diagnóstico, compruebe la adherencia a la medicación, compruebe que el usuario y su familia han recibido las intervenciones psicosociales en la forma y por el tiempo definido en su Plan Individual de Tratamiento Integral (PITI), evalúe otras causas como consumo de alcohol o drogas, uso concomitante de otros medicamentos, enfermedad física, etc.

- Se recomienda tratamiento con clozapina para personas con esquizofrenia, cuya enfermedad no ha respondido adecuadamente al tratamiento después del uso secuencial en dosis adecuadas de por lo menos dos antipsicóticos, uno de los cuales debe ser atípico.

- Para las personas con esquizofrenia, cuya enfermedad no responde adecuadamente al tratamiento con clozapina en dosis óptimas, se recomienda agregar un segundo antipsicótico, previa medición de los niveles plasmáticos. El ensayo de la farmacoterapia combinada puede necesitar hasta 8 a 10 semanas. Se debe elegir un segundo antipsicótico que no aumente los efectos secundarios comunes de la clozapina.

- Se recomienda analizar y discutir estrategias de contracepción de la fertilidad en el caso de mujeres con esquizofrenia en tratamiento con antipsicóticos.

- En caso de embarazo de una mujer con esquizofrenia, se debe evaluar con ella los riesgos y beneficios de suspender o continuar con el antipsicótico durante el primer trimestre de embarazo.

- El uso de antipsicóticos de alta potencia puede ser más seguro (haloperidol) durante el embarazo. La dosis debe ser baja y durante el mínimo tiempo posible.

- La clozapina no debe ser prescrita de rutina en mujeres embarazadas con riesgo (personal y/o antecedentes familiares), para aumento de peso o diabetes.

- Los antipsicóticos de depósito no deben ser utilizados durante el embarazo y la lactancia. 
- Durante el embarazo, la terapia electroconvulsiva es una alternativa eficaz y segura para mujeres con esquizofrenia.

\section{Rehabilitación y seguimiento}

- El tratamiento de las personas con esquizofrenia debe incluir un enfoque rehabilitador durante todo el curso de la enfermedad, iniciando el proceso de rehabilitación desde las primeras fases de la misma.

- El tipo, intensidad y énfasis de las intervenciones de rehabilitación deben ajustarse a las necesidades de cada fase de la enfermedad, según éstas se vayan manifestando.

- Los programas de rehabilitación deben incluir el trabajo con la comunidad para reducir los obstáculos para la plena integración de las personas con esquizofrenia que ocasionan el estigma y la discriminación.

(Ministerio de Salud de Chile. Subsecretaría de Salud Pública Guía Clínica Para el Tratamiento de Personas desde Primer Episodio de Esquizofrenia, 2009: 5-8)

También esta etapa es crucial para modificar la trayectoria asociada a la severidad de los trastornos neurocognitivos, presentes en la esquizofrenia crónica, aparte de representar el período más efectivo para una mejora sostenida (Marshall, et al., 2005; Perkins, Boteva, et al., 2005). Como puede apreciarse en las recomendaciones de la Guía clínica, el diagnóstico se hace evidente sólo después de una evolución clínica que contextualice el cuadro, lo que requiere de un equipo con gran experiencia en salud mental.

Actualmente, en Chile se estima que el proceso de indagación, referencia e inicio del tratamiento, puede tardar hasta tres años (Alvarado, 2012). Es una prioridad reducir ese período para mejorar las políticas de salud pública, y ajustarse a las propuestas internacionales como la OMS, que establecen la necesidad de acortar este proceso. Visualizando dichas necesidades, el Ministerio de la Salud ha definido la esquizofrenia como una de las enfermedades prioritarias y el tratamiento del primer episodio ha sido incorporado en las patologías AUGE. Sin embargo, a pesar de que en Chile se han desarrollado diversas iniciativas destinadas a reducir el tiempo de psicosis no tratada, (DUP) la detección y el diagnóstico siguen siendo tardíos. En consecuencia, una prioridad 
en la investigación es la identificación de los factores que influyen en la temprana detección y el tratamiento, lo que podría conducir a un mejor pronóstico y aumento de la eficacia de los actuales programas (Alvarado, 2004).

Gracias a decenas de años de investigación, hoy sabemos que la cognición es la suma total de procesos mentales que vehiculan el acceso al conocimiento, que además emplea la información decodificada para mantenernos alerta respecto de nuestro entorno y facilitarnos el llegar a conclusiones apropiadas sobre las experiencias vitales (Chattopadhyay, S., 2012). La esquizofrenia desde su inicio presenta un conjunto de alteraciones neurocognitivas, afectando justamente esta capacidad vital para la existencia. Los estudios neuropsicológicos y electrofisiológicos, que investigan desde sus primeras manifestaciones la patofisiología de la esquizofrenia, han descubierto déficits en funciones cognitivas, tales como atención, la función ejecutiva y el lenguaje (Kuperberg, G., 2000; Orellana, G., 2006). Asimismo, se ha podido demostrar que estas funciones cognitivas y ejecutivas son susceptibles de ser evaluadas por baterías de pruebas que abarquen la mayor cantidad de dominios cognitivos. Existe una variada evidencia para sugerir que la disfunción cognitiva es intrínseca a la esquizofrenia, y no el resultado de una enfermedad crónica, de la institucionalización, o de medicamentos. Incluso, se cuenta con antecedentes acerca del carácter de los déficit cognitivos que se presentan en adolescentes en situación de riesgo para la esquizofrenia, siendo coincidentes con los pesquisados entre pacientes esquizofrénicos de primer episodio, sin tratar (Mohamed S, Andreasen NC, et al., 1999).

Todavía son pocos los estudios que analizan la relación entre el lenguaje y funcionamiento ejecutivo en esquizofrenia. En algunos de ellos, se ha informado que, dentro, de los dominios cognitivos deteriorados estarían el procesamiento del lenguaje y el procesamiento de la memoria verbal, como particularmente susceptibles a la alteración. Estos déficit se pesquisan en tareas que incluyen, la atención selectiva, la memoria de trabajo y las otras funciones del lóbulo frontal, que forman parte de los aspectos cognitivos del lenguaje (Kuperberg, 2010) A la detección de estos trastornos en las pruebas ejecutivas, se suma la evidencia de neuroimagen funcional, en la que se ha observado: 
disfunción cortical prefrontal, dorsolateral y orbitofrontal, durante la realización de estas tareas (Egaña et al., 2013).

Con todo, poco se sabe sobre la relación entre el rendimiento neurocognitivo y funcional del paciente, antes de la aparición de los síntomas psicóticos francos. Todavía no se han sistematizado los esfuerzos por llevar a cabo estudios que faciliten la visibilidad de predictores neurocognitivos. Dichos predictores, bien podrían establecerse a partir del estudio de las dificultades funcionales de grupos identificados como de alto riesgo para la psicosis (antecedentes familiares) y, en especial, entre las personas que ya han sido identificadas con síntomas psicóticos. En tal sentido, en esta etapa solo se cuenta (en Chile) con los reportes del entorno o grupo familiar del paciente, en los que en muchas ocasiones, se datan disfunciones que van desde los dos y hasta diez años antes del brote psicótico actual, lo que prueba que los cambios cognitivos son muy precoces.

Debido a la ausencia de marcadores biológicos, el diagnóstico de la esquizofrenia se basa en la historia del desarrollo de los síntomas y signos, la entrevista clínica y la observación de las conductas de la persona afectada, en las que se configura un conglomerado de síntomas que se presentan por un período de tiempo y que generan un deterioro en las condiciones vitales y de adaptación al entorno, como evidencia indesmentible.

\subsection{Lenguaje en la esquizofrenia:}

El lenguaje es el rasgo distintivo más significativo de nuestra especie (Belinchón, Igoa y Rivére, 1992). Todos los estudios sobre el lenguaje han demostrado su complejidad abrumadora. Saussure se refiere a él como:

Tomado en su conjunto, el lenguaje es multiforme y heteróclito; a caballo en diferentes dominios, a la vez físico, fisiológico y psíquico, pertenece además al dominio individual y al dominio social; no se deja clasificar en ninguna de las categorías de los hechos humanos, porque no se sabe cómo desembrollar su unidad (Ferdinand de Saussure, 1968:33) 
Dentro de los hechos del lenguaje, tomamos la lengua como una de sus manifestaciones más relevantes. Se define por su incuestionable pertenencia al dominio social y como conjunto de convenciones, que es adquirida a través de la experiencia de estar vinculado al mundo. $\mathrm{Su}$ génesis es puramente psíquica y su entramado se manifiesta en el habla, que es el segundo de los hechos relevantes del lenguaje. En esta segunda dimensión, cada individuo, miembro de una comunidad de habla determinada, realiza un uso particular de la lengua, a través de actos de inteligencia y voluntad. Ambos constructos son indivisibles, conforman nuestro acervo lingüístico, nuestra herramienta fundamental para manifestarnos en el medio en el que estamos insertos. La función más importante de esta facultad humana es, sin duda, la comunicación. Mediante esta actividad es que solventamos buena parte de las relaciones que establecemos con otros a lo largo de la vida. Es un punto de inflexión crucial, como hecho humano, como acción voluntaria, como manifestación de nuestro self.

La comunicación revela aspectos esenciales de nuestro comportamiento, ya que es en sí misma un comportamiento. ¿Cómo podemos dar cuenta de este aspecto de nuestra conducta?, ¿qué aspectos de ella pueden sernos útiles para revelar una cognición alterada? Únicamente podemos explicarnos el comportamiento comunicativo real, si el lenguajelengua-habla es concebido como un sistema interactivo, no solo entre diferentes niveles lingüísticos, sino que también extralingüísticos (Walker, D., y Grosz, B.J., 1978). La imbricada relación del lenguaje en uso muestra los complejos procesos de adaptabilidad, intencionalidad y aceptabilidad, a los que estamos sometidos como hablantes (Calsamiglia, 2007; Saville-Troike, 1989). En la esquizofrenia, esta relación se ve entorpecida por los deterioros neurocognitivos que afectan al sujeto. Tareas como la comunicación intersubjetiva, la comprensión de textos o la producción discursiva global exhiben dificultades estructurales de diversa consideración, generando distancia entre el sujeto y su entorno (Rochester, 1988; Insúa, P, 2004; Cuetos, 2003; Castilla del Pino, 2006).

Como paradigma, el lenguaje esquizofrénico ha sido estudiado desde enfoques múltiples. Al presente, hay profusas y variadas teorías e interpretaciones en torno al estudio del discurso esquizofrénico. Siguiendo a Piro (1987) en este estudio, sólo serán 
expuestas las más conocidas, con el fin de presentar una visión general que permita conocer el avance que se ha alcanzado en este campo. Estas teorías e interpretaciones pueden ser diferenciadas de la siguiente forma:

\section{A) Teorías descriptivas}

Son aquellas teorías tratadas con frecuencia en los manuales de psiquiatría. No comportan tentativas de interpretación, sino que tienden a clasificar y a definir las anomalías. De esta manera, los autores presentan una parte descriptiva, en relación con el o los grupos de fenómenos lingüísticos, para luego ocuparse del aspecto interpretativo.

\section{B) Teorías correlativas}

Son aquellas teorías que prescinden del aspecto causal, es decir, han situado el problema del lenguaje esquizofrénico, en el ámbito general de la psicopatología de la expresión. Son teorías que presentan una clara tendencia al determinismo, si el esfuerzo del investigador ahonda en el tema. Un ejemplo de este desplazamiento teórico lo hallamos en el modelo de Goldstein (1943): La interpretación de los comportamientos simbólicos, como pérdida de las aptitudes abstractas, que es una teoría correlativa. Sin embargo, dada la actitud del investigador, hay una tendencia más bien, hacia el determinismo organicista.

\section{C) Teorías estructurales}

Son aquellas teorías que presentan el fenómeno lingüístico desde determinado punto de vista, derivado del análisis del lenguaje y cuyo aspecto interpretativo tiene estricta relación con el plano lingüístico, excluyendo las influencias externas. Dentro de este enfoque, se sitúa el trabajo de Piro (1967), que puede ser considerado prevalentemente estructural, en cuanto se vuelve hacia el análisis de una relación estructural semántica. En sentido más general, propone una aspiración fenomenologica objetiva, que va ininterrumpidamente a continuarse más allá de su análisis fenoménico. El autor tiene, además, el gran mérito de haber manejado con una erudición extraordinaria, uno de los temas más complejos de la psicopatología; a nuestro juicio, este trabajo por sí solo, lo convierte en una insigne figura de la psiquiatría italiana. 


\section{D) Teorías fenomenológicas}

Las teorías propiamente fenomenológicas son aquellas que no pueden ser separadas del conjunto de manifestaciones con las cuales un individuo se expresa. Una de estas teorías es la antropoanalítica, que considera el lenguaje como la manifestación más esencial de lo humano.

E) Interpretaciones deterministas

Este es un tipo de interpretación teórica que puede ser organicista, psicologista o del tipo ecléctico. Básicamente, pretenden demostrar una relación directa entre aspectos biológicos y psiquiátrico-lingüísticos, o psicológico y lingüístico, o ambas relaciones a la vez. A continuación, serán brevemente expuestas, en orden de importancia.

a) El pensamiento "arcaico" o "paleológico"

Esta teoría ve en el lenguaje y el pensamiento esquizofrénico, regresiones primitivas y modelos de pensamiento arcaico. Se puede apreciar esta característica en la relación idolátrica que algunos delirantes tienen con el lenguaje, característica que se acercaría al pensamiento paleológico de comunidades primitivas, que veían el lenguaje como una clara manifestación mística.

Fenómenos como el animismo, el antropomorfismo o la logolatría representan esta categorización mística a la que hacemos referencia. Pese a que este tipo de manifestaciones no siempre se aprecia a primera vista, es posible encontrarlo en todas las sociedades, con la forma de supersticiones populares o generalizaciones falsas ("todos los alemanes son nazis") o como adoración de personajes famosos ("si fulano de tal lo dice..."). Estas regresiones arcaicas pesan profundamente en aspectos culturales trascendentes de nuestra sociedad.

La teoría de la regresión primitiva del lenguaje y del pensamiento esquizofrénico tiene sustento desde un punto de vista analógico y no genético. Caracterizado, según White 
(1949), por ser prelógico y rico en procesos imaginativos, en este sentido, es posible compararlo con el pensamiento de los pueblos primitivos o el pensamiento de los niños. Es interesante señalar que el alcance que realiza Piro (1987) con respecto a la teoría de White (1949) no considera la disgregación esquizofrénica como un síntoma de perturbación psíquica, sino como una regresión a un bajo nivel de pensamiento, es decir, a un sub-nivel de la abstracción, que viene siendo análogo a la teoría de la pérdida de las aptitudes abstractas de Goldstein (1943) también explicada por Piro (1987) La regresión lingüística a la que alude White (1949) se presenta en los sujetos esquizofrénicos, a la inversa del proceso que lleva a la construcción de un lenguaje complejo, rico en abstracciones. Por esta razón fue definida por White (1949) como una "psicosis de regresión", sin llegar a definir claramente tal regresión.

También von Domarus (1924), le otorga una gran importancia a la regresión paleológica en la psicopatología de la esquizofrenia. Este investigador, formuló un principio que dice:

Mientras que la persona normal acepta la identidad solamente sobre la base de sujetos idénticos, la paleológica la acepta, basada en predicados idénticos (von Domarus, citado por Piro, 1987:234).

Por ejemplo, un esquizofrénico frente a la proposición "ciertos indios son veloces, los ciervos son veloces", puede finalmente concluir que "ciertos indios son ciervos". Según Domarus, la identidad de los predicados, falsea el pensamiento esquizofrénico y lo induce a una conclusión extraviada.

b) La pérdida de las "aptitudes abstractas"

Según Goldstein (1943) las aptitudes del comportamiento hacia lo abstracto y hacia lo concreto no son hábitos mentales, ni representan aptitudes específicas, como la atención o la memoria. Son más bien "niveles de capacidad" de la personalidad total, formando cada una de ellas, las bases para todas las aptitudes sobre algún plano de referencia. La aptitud concreta está ligada a la experiencia inmediata de una cosa o situación dada, en su particular unicidad. Con las aptitudes abstractas se sobrepasan los aspectos específicos 
inmediatos y la impresión sensorial, abstrayéndose las propiedades particulares. Las actividades mentales están orientadas desde un punto de vista conceptual.

El objeto o la situación singular deviene, en este caso, en un ejemplo accidental o representativo de una categoría. Esta aptitud es definida por Goldstein (1943) como aptitud conceptual o categorial. Goldstein (1943) explica que estas características son semejantes en sujetos con lesiones corticales focales, como es el caso de los afásicos y de los agnósicos, quienes presentan una pérdida neta de las aptitudes abstractas, un abatimiento global de la conducta a nivel concreto: los pensamientos y las ideas surgen, pero sólo pueden realizarse a nivel concreto, es decir, el sujeto no puede tratar un objeto del mundo externo en una trama conceptual de referencias. En efecto, los pacientes neurológicos tratan los pensamientos y las ideas como elementos inherentes al objeto o a la situación dada.

Un menoscabo similar encuentra Goldstein (1943) en los esquizofrénicos, llegando a la conclusión de que "una grandísima concreción es característica en la conducta de los esquizofrénicos, o de la mayoría de ellos" (cit. por Piro, 1987: 271).

El problema de la reacción psicológica a la pérdida de las aptitudes abstractas es visto por Goldstein (1948) como una conducta catastrófica del sujeto, que se caracteriza por su perplejidad y ansiedad.

Por último, es necesario destacar que, en cuanto a la interpretación patogénica, Goldstein (1948) se mantiene organicista y ve en "la pérdida de la aptitudes abstractas" el enlace entre esquizofrenia y enfermedades cerebrales focales.

El cuadro clínico de la esquizofrenia contiene síntomas que pueden sugerir un origen perturbador en una función de algún sitio del cerebro, particularmente de los lóbulos frontales y de los ganglios subcorticales, síntomas que han sido mejor interpretados como reacciones psicológicas.

También Vigotsky llega a la conclusión de que el cambio que él había encontrado en los esquizofrénicos, era similar a la disminución de la aptitud a lo abstracto, que había encontrado en casos de lesión orgánica. 
Sin embargo, algunas críticas a la teoría goldsteiniana están presentes en los trabajos de Rapaport, Grill y Shafer (1945) quienes utilizaron un test de objetos, similar al de Goldstein, y no encontraron que los esquizofrénicos fuesen más concretos que los normales, sino que, solamente, usaban los conceptos de un modo diferente, que definieron como "sincrético". Feldmann y Drasgow (1951), por otro lado, utilizaron un test visual ideado por ellos, mediante el cual descubrieron generalizaciones insólitas que no podrían ser llamadas "concretas". También Cameron (1944) con su teoría de la overinclusion, se opone diametralmente a la teoría de Goldstein (1943).

\section{c) La overinclusion del pensamiento esquizofrénico}

La concepción de Cameron, en torno a la relación entre el lenguaje y el pensamiento esquizofrénico, sostiene que la anormalidad principal del pensamiento esquizofrénico consiste en la incapacidad de mantener los límites conceptuales. En las operaciones mentales en curso y de forma continua, se infiltran componentes parásitos, secundarios, improcedentes, resultando incluidos y aceptados en el pensamiento del sujeto. Estas intervenciones ocurren de este modo overinclusive, es decir, llenas de elementos periféricos, abstractos y vagos. Cuando el esquizofrénico hace uso de un concepto, es completamente incapaz de suprimir la serie de ideas asociadas que acompañan a este concepto, aunque sea lejanamente, operación que un sujeto normal realiza, automáticamente, con el fin de mantener la coherencia general del curso de su pensamiento. Este tipo de inhibición está ausente en los esquizofrénicos.

A nivel global, Cameron (citado por Kasanin, J.S., 1968:50-64) señala que el discurso y el pensamiento esquizofrénicos tienden a volverse:

i. Fragmentarios

ii. Aproximativos

iii. Interpenetrativos

iv. Hiperestésicos

v. Literales (concretos), con respecto a este punto, la posición de Goldstein es aceptada parcialmente. 
Cameron (1944) se valió de problemas lógicos y de un test de elecciones para el estudio de la overinclusion, a su vez, un grupo de investigadores utilizaron test similares. Dentro de este grupo se encuentra Epstein (1953) quien propone un test consistente en una lista encolumnada de 50 palabras. Al lado de cada una de las palabras, fueron agregadas otras seis palabras que el sujeto debía subrayar, si consideraba que tienen una relación indispensable con la palabra estímulo. Los esquizofrénicos tendieron a subrayar más palabras que los sujetos con otras patologías.

Payne, Matussek y George (1961) examinaron un grupo de esquizofrénicos con una batería de test semejantes.

El concepto de la overinclusion es muy importante para el análisis semántico del lenguaje, puesto que permite explicar ciertas contaminaciones esquizofrénicas, ciertos neologismos y paralogismos. Piro (1987) reconoce la utilidad de la overinclusion en el análisis lingüístico de los paralogismos y de los neologismos, obtenidos mediante el psicodiagnóstico de Rorschach.

d) La abstracción formal del pensamiento esquizofrénico

La tendencia a utilizar formas de pensamiento y/o de lenguaje formalmente abstracto y generalizado es bastante característica en los esquizofrénicos, a Barison (1949) debemos la más importante descripción del fenómeno. El autor aclara que su teoría no tiene relación con los procesos formales de abstración o de contenidos abstractos, como lo es el “racionalismo mórbido", descrito por Minkoswki (2000) en relación con la pérdida del sentido de lo real, representado por el desarrollo el pensamiento hacia temas y contenidos filosóficos, científicos, místicos, etc. La abstracción formal del pensamiento es, en cambio, una tendencia característica a expresarse a nivel abstracto, aún cuando el contenido del pensamiento esté constituido por hechos concretos, singulares y materiales. El esquizofrénico tiende a utilizar expresiones abstractas y generalizadas en lugar de hacerlo con expresiones concretas y más adecuadas al contenido del pensamiento. Con frecuencia, intervienen en el curso del pensamiento esquizofrénico frases abstractas para expresar ideas 
concretas. En los sujetos normales, esta conducta verbal obedece a una necesidad de dar ornamento o rebuscamiento al discurso. Una de las razones por las cuales Barison descarta la utilización de estos recursos lingüísticos con motivos ornamentales, es que la encontramos en enfermos que provienen de las capas sociales más bajas de la sociedad y, en general, estos sujetos poseen estudios muy básicos.

La teoría de Barison explica, básicamente, que el pensamiento esquizofrénico tiende a expresarse en un nivel abstracto más elevado y a usar términos más generalizados que los que la situación requiere. La abstracción formal del pensamiento esquizofrénico consiste en que, a causa de ella, el sujeto se expresa a nivel formal, aún cuando debería operar a nivel concreto.

e) El uso lúdico del lenguaje

El uso lúdico del lenguaje es la tendencia esquizofrénica a utilizar el lenguaje en forma de juego verbal, que puede ser total o parcial. La logolatría descrita por Tanzi (1890) así como la interpretación filológica de Pfersdorff (1927) son ejemplos de esta tendencia en la interpretación de la esquizofrenia. El uso lúdico del lenguaje va excluyendo progresivamente la función más esencial del lenguaje, que es la comunicación, llegando a un estadio infantil del uso lingüístico.

Se debe precisar que este uso lúdico del lenguaje no es exclusivo de los niños y de los esquizofrénicos, sino que se presenta en todo hablante. El componente lúdico del lenguaje, en el caso de los esquizofrénicos, puede llegar a ser tan prevalente, que elimina toda función lingüística. El esquizofrénico con esta tendencia "habla por el placer de hablar", sin importar el contexto comunicativo en que se encuentre. Los usos y los elementos que posee este lenguaje lúdico son muy numerosos, sirviendo para incontables ejemplificaciones.

En la psicosis, que es un universo privado y difícilmente franqueable para el sujeto que sufre un deterioro comunicacional, la emergencia del uso lúdico del lenguaje, viene a satisfacer una necesidad. No constituye sólo una regresión infantil o paleológica, sino que 
es una nueva estructuración del lenguaje del individuo. Binswanger (1972) le otorga una gran importancia al uso lúdico, en su análisis del manierismo:

[..]Una existencia, más bien, que se resuelve en el 'desinterés' o, en términos positivos, exactamente en el juego, en lo 'lúdico'. Ciertamente, este elemento lúdico es un rasgo característico de aquello que nosotros llamamos 'autismo' esquizofrénico ([1972] cit. por Piro, 1987: 303 )

f) El lenguaje automático

Las manifestaciones lingüísticas de índole automático estarían relacionadas con una condición de liberación cortical, o bien con una actividad productiva de tipo automático, como ocurre en la catatonía. El lenguaje automático estaría separado del resto de la personalidad: la palabra no es ya usada como símbolo, sino que resulta injertada, incongruentemente, en el comportamiento del sujeto, tal como ocurre con la ecolalia, las impulsiones verbales, etc. Toda relación sígnica está en sí perdida, y su uso ya no es lingüístico. Esta tendencia es análoga al uso lúdico del lenguaje.

El lenguaje automático sería caracterizado por:

i. Unir frases sin sintaxis compleja; las frases están ligadas por "asociaciones", por asonancia, consonancia (aliteración), perseveración de palabras o de fragmentos de palabras compuestas; el sentido ha desaparecido totalmente.

ii. Producciones verbales sin sintaxis compleja; frases ligadas sin nexos asociativos reconocibles y de allí derivando a una inadecuación expresiva e incoherencia gobal del discurso del sujeto.

La cuestión del automatismo del lenguaje esquizofrénico es, en sí, muy discutible. Algunos esquizofrénicos hacen uso de este lenguaje automático, en general los catatónicos, siendo la ecolalia su forma más común. En opinión de Piro (1987) constituye automatismo sólo si se presentan las siguientes condiciones:

i. Pérdida de toda intencionalidad lingüística

ii. Pérdida del uso lingüístico del lenguaje 
iii. Total desinserción del contexto cognoscitivo y emotivo

iv. Tendencia a la repetición idéntica de los fenómenos (en las mismas condiciones del estímulo)

Clasificación teórica

En esta brevísima reseña, hemos privilegiado aquellas teorías que ponen especial acento en lo estrictamente lingüístico. Evidentemente, existen innumerables enfoques acerca del tema que van desde las teorías organicistas hasta las fenomenológicas. Incluiremos, en la página siguiente, un esquema panorámico de las relaciones entre diversas teorías en el campo de investigación acerca del lenguaje psicótico.

Siguiendo a Piro (1987:250-323), presentamos la clasificación técnica en la que están agrupadas las teorías generales acerca de las relaciones entre el lenguaje y el pensamiento esquizofrénico.

\section{PSICOANALÓGICAS:}

i. Tesis del pensamiento paleológico

ii. Tesis del uso lúdico del lenguaje

II. Neuroanalógicas:

i. Tesis de la analogía entre esquizofasia y afasia.

ii. Psicoestructurales:

iii. Psicoanálisis clásico

iv. Psicoanálisis semántico

III. Noético-estructurales:

i. Tesis del abstraccionismo sistematizado

ii. Tesis de la overinclusion 
iii. Tesis del abatimiento del nivel inconsciente

iv. Tesis del deterioro de las aptitudes categoriales

IV.Neuroestructurales:

i. Teorías organicistas no localizadoras

ii. Aspectos organicistas del organodinamismo

iii. Tesis del uso automático del lenguaje

V. Lingüístico estructurales:

i. Tesis acerca de la esquizofasia de Flegel

VI.Semántico estructurales:

i. Tesis de la disociación semántica

Todas estas teorías son complementarias de una u otra forma. Si se tiene en cuenta todas estas vinculaciones, se devana un hilo que pasa a través de las más importantes actitudes de la psicopatología en sus más contrastantes y difluyentes aspectos. Entonces, es posible apreciar dos consideraciones:

i. No hay cortes netos en el campo de la psicopatología entre las diversas impostaciones metodológicas, sino una continuidad que hace evidente el contratse y la inconciliabilidad sólo en los extremos del esquema:

ii. El lenguaje, viene a constituir el nudo crítico de la investigación.

Como es obvio, tomamos del trabajo de Piro (1987:323) el esquema siguiente, aunque no puede mostrar las superposiciones de planos teóricos que se dan en los puntos en que confluyen dichas teorías. 


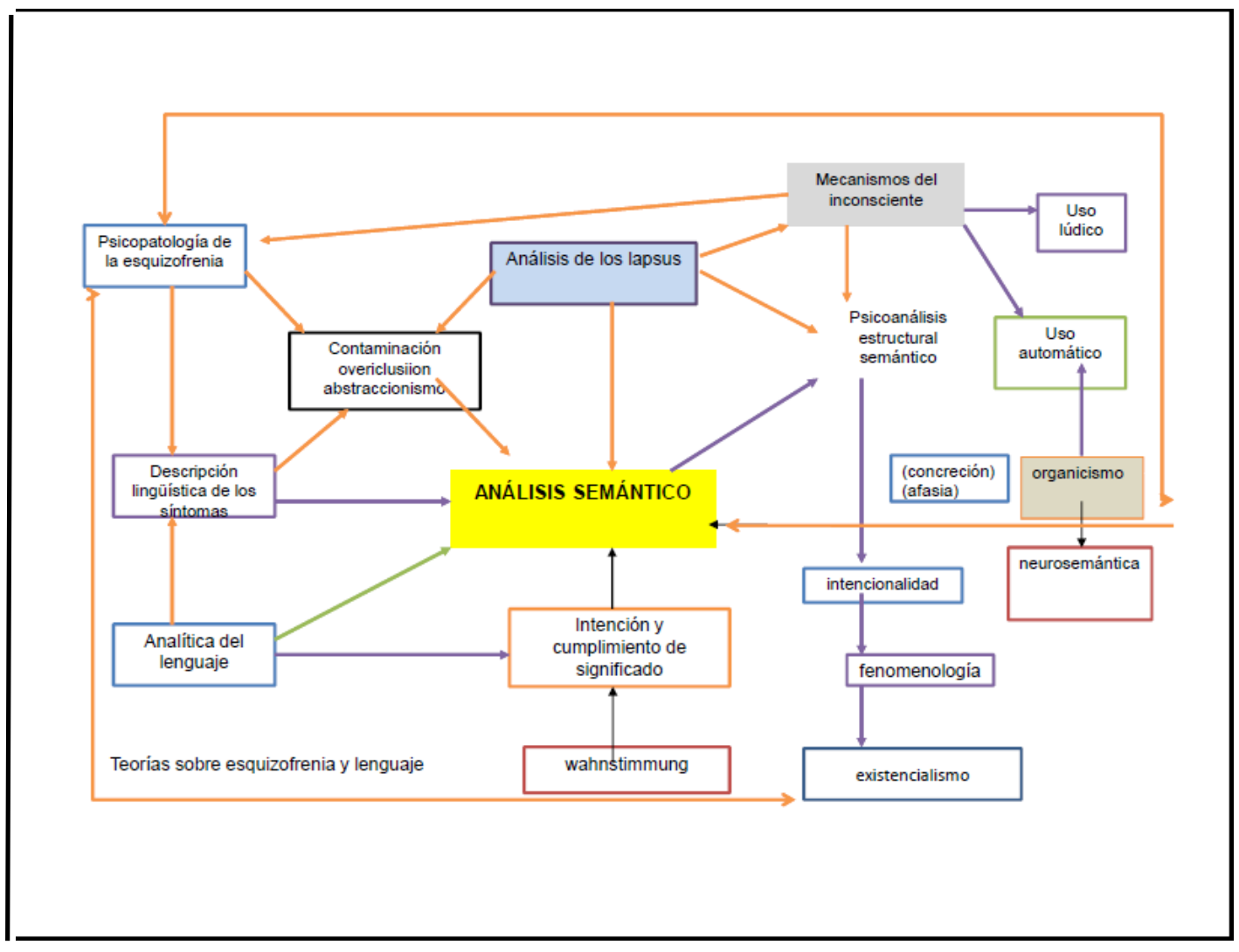

Figura 2: teorías del estudio del lenguaje en la esquizofrenia, adaptadas de Piro (1987:323)

Tras este breve resumen de los enfoques tradicionales en este campo de estudio, observamos que para muchos autores, se advierten deficiencias en los trabajos, no a causa de su falta de rigor, sino a su sesgo. Un ejemplo de estos abordajes denunciados es que, con frecuencia, la investigación se ha centrado casi únicamente en los aspectos morfosintácticos del habla, o bien en el hallazgo de patologías lingüísticas como factor preponderante, descartando la conducta comunicativa como otro factor psicopatológico.

Estas son razones por las que, en la actualidad, se hace necesaria una perspectiva más integrada, que incluya el contexto comunicativo de las intervenciones discursivas acertadas y/o fallidas de los pacientes, ya que solo así puede analizarse, debidamente, el desempeño lingüístico de los sujetos. Sobre todo, tomando en cuenta que para la psiquiatría el lenguaje es un elemento cardinal como herramienta diagnóstica. La información de gran trascendencia que obtiene el terapeuta, se da a partir de esta relación médico-paciente que 
es, evidentemente, comunicativa. Junto con esto, es el medio a través del que se suministran significativos hallazgos acerca de la evolución del cuadro patológico, dando la posibilidad de otorgar un rápido tratamiento terapéutico y farmacológico.

Los problemas del lenguaje, en la esquizofrenia, tienen orígenes diversos. Dependiendo del foco de análisis, se han descrito déficit sintácticos, semánticos, léxicos, etc. La investigación en este campo ha procurado cubrir todos los aspectos del lenguaje en los que se pesquisan disfunciones, algunos de estos aspectos han llamado la atención con más vigor que otros, como es el caso del desempeño de los sujetos frente a tareas comunicativas como la narración (Chapman, L. Chapman, J.P. 1978; Belinchón, M., Insúa, P., 2004) o las asociaciones léxico-semánticas, la elaboración de textos, etc. Algunas de estas dificultades, que se presentan en el procesamiento léxico, como consecuencia de un deterioro del control inhibitorio de elementos ajenos al contexto. En general, básicamente, se han fijado estándares para corroborar el grado o nivel de efectividad discursiva que presentan los pacientes, en un contexto comunicativo acotado. Igualmente, es destacable el hecho de que, pese a las evidencias, no ha logrado explicar de forma categórica cuál es el carácter de los déficit lingüísticos. Inclusive, se postula la existencia tanto de déficit generales como específicos. La hipótesis de Belinchón señala que no se ha descartado que existan disfunciones morfosintácticas, independientes del procesamiento de la información.

Al presente, encontramos diversas orientaciones con las que es posible abordar el concepto de lenguaje esquizofrénico. Las investigaciones hechas por infinidad de expertos a través de los años ha ido generando un enorme acopio de información acerca del problema, que también es descrito como un núcleo crítico para la psiquiatría y la ciencia, en general. La descripción de la conducta humana sigue siendo un reto difícil de enfrentar.

Como ya señalamos, el estudio de las alteraciones del lenguaje en los esquizofrénicos es un tema de larga data, coincidente incluso con la designación misma de esquizofrenia. Ya a comienzos del siglo pasado, ambos autores habían observado que era posible observar en los sujetos que padecían esta enfermedad un "desorden formal del pensamiento" y que algunas de las caracterizaciones clínicas más evidentes eran aquellos 
aspectos fuertemente vinculados con la observación de alteraciones tales como la "incoherencia", la "falta de comprensibilidad del habla" o "el descarrilamiento de las ideas", en el discurso de los pacientes.

Una de las aportaciones que incluiremos en este trabajo, es la que propone Belinchón en "Comunicación y lenguaje en la esquizofrenia" (1991) Este trabajo reviste una gran importancia, ya que incluye muchas de las consideraciones planteadas por la lingüística como requerimiento para analizar el problema.

La autora señala a estudiosos como Rochester y Martin (1979) que al aventurarse a afirmar que el concepto de esquizofrenia fue acuñado por Bleuler, a raíz de las alteraciones del lenguaje observadas en los sujetos estudiados en 1911, concluyendo con esto que el tema del lenguaje en la patología es uno de los problemas identificados en la génesis misma de su estudio. Por lo mismo, comparte la perspectiva de considerar que la ruptura de las funciones psicológicas superiores detectada en el lenguaje incoherente, es la misma que describe la esquizofrenia como patología psiquiátrica.

Rochester y Martin (1979) descubrieron deficiencias y fallas generales en el uso de la cohesión discursiva, utilizando el modelo de Halliday y Hasan (1976) como un marco de referencia para describir el lenguaje en la esquizofrenia. Dentro de los hallazgos más relevantes, está la realización de un análisis de los pronombres anafóricos y de expresiones anafóricas elípticas, a fin de proporcionar medidas de cuán exitosamente el lector-oyente podría resolver referencias en el discurso del sujeto. Los resultados obtenidos indican que estos vínculos serían deficientes, lo que, en parte, podría explicar la percepción de incomprensión que experimentan los oyentes.

Como sabemos, para Halliday (1979) el lenguaje codifica un potencial de conducta en un potencial de significado. La existencia misma de la lengua es justificable en la medida en que puede funcionar como sistema en todas las culturas humanas, bajo algunos supuestos muy importantes: i. El lenguaje como intérprete de la experiencia. Reducción de la complejidad de los fenómenos. ii. El lenguaje como medio para expresar relaciones lógicas básicas. iii. El lenguaje tiene que expresar nuestra participación, es decir, los 
papeles y/o roles que asumimos. iv. El lenguaje tiene que hacer todo esto simultáneamente. Lo que se dice, se debe decir, de acuerdo con un contexto.

Por lo tanto, es necesario conceptualizar el lenguaje, no sólo desde el punto de vista comunicativo, sino como el elemento que nos permite interpretar y categorizar la realidad. Será entonces el estudio de la forma, como del contenido del lenguaje de estos sujetos, la matriz que nos proveerá de la suficiente información como para comprender el déficit cognitivo en que se encuentran los enfermos.

Retomando las observaciones de Belinchón, (1991) tenemos en cuenta las claras condiciones del trabajo de investigación que este tema demanda:

La adopción de una conceptualización precisa y científicamente fundamentada de las funciones y procesos cognitivos (en concreto del propio lenguaje y de sus posibles niveles de abordaje teórico y empírico) y, por otro lado, el que se disponga de una descripción de las alteraciones o síntomas que deben ser explicados que, además de ser objetiva y fiable, sea compatible con la terminología que habitualmente emplea la psicología experimental en la descripción de la actividad cognitiva y/o lingüística normal. (Belinchón, M. 1991:101)

Uno de los problemas centrales que presentan estas investigaciones tiene que ver con la forma en cómo se ha conceptualizado el objeto de estudio mismo, es decir, la discutible connotación que adquiere el concepto de "lenguaje esquizofrénico", que presupone una posible identificación objetiva de un conjunto de rasgos patológicos, referidos a la estructura o a las funciones del lenguaje, que son susceptibles de ser contrapuestos con el lenguaje "normal". O bien, la consideración de que estos rasgos se presentan únicamente en estos pacientes y no en otros enfermos mentales. Esta situación le otorgaría un cierto estatus de estabilidad a estos fenómenos, generando la idea de que hay un común denominador en ellos.

Sin embargo, no existe suficiente evidencia al respecto, por ello es discutible esta noción, además, los sujetos esquizofrénicos no consiguen entender mejor que otros observadores el lenguaje de sus pares. En opinión de Kraepelin (1919) y Bleuler (1911) los fenómenos lingüísticos de los sujetos esquizofrénicos podían ser diferenciados a grandes rasgos como: 
- Los que muestran un lenguaje desorganizado y bizarro.

- Los que muestran un lenguaje empobrecido, lacónico, monocorde y autista.

- Los que nunca muestran alteraciones en su habla. ${ }^{4}$

Belinchón propone el término de "perturbaciones esquizofrénicas del lenguaje", ya que en su opinión, precisa mejor el foco del trabajo que debe abordarse, donde la descripción de los fenómenos es el punto de partida. Ya en un trabajo anterior, (Figueroa, A. 2009) emprendimos esta tarea, estudiando los aspectos generales del comportamiento lingüísticocomunicativo de pacientes con esquizofrenia. En dicho estudio, se inventariaron algunos fenómenos discursivos con el propósito de aproximarnos a un perfil comunicativo. Los materiales utilizados en aquel trabajo, se basaron en entrevistas clínicas realizadas a personas que estaban en la etapa crónica de la enfermedad; varios de ellos, superaban incluso los 20 años de evolución, con múltiples episodios psicóticos y discontinuidad en el tratamiento.

Lo que nos interesa en el presente trabajo es superar la mera descripción de los fenómenos que puedan registrarse. Pretendemos realizar un contraste entre los diferentes estadios de la enfermedad, tema sobre el que no hemos encontrado estudios en español. Nos preguntamos, en primer lugar, si es posible comprobar que los fenómenos descritos tanto en la literatura, como los que pudimos registrar en nuestro primer trabajo, son visibles desde el inicio de la enfermedad. Además, hemos dirigido nuestra atención hacia los aspectos que corresponden al estudio de las competencias comunicativas y las características que presentan las desviaciones del discurso de las personas con esquizofrenia. Sumado a esto, pretendemos acercarnos a precisiones más exactas que en nuestro anterior trabajo, incluyendo la evaluación del uso del concepto "lenguaje esquizofrénico".

Como señalamos, anteriormente, una cuestión no desprovista de aristas controversiales es analizada por Elaine Chaika (1979). Esta lingüista, advierte en torno al

\footnotetext{
${ }^{4}$ En este punto es necesario hacer notar que el esta habla juzgada como "normal" es totalmente coherente.
} 
error de considerar las alteraciones esquizofrénicas del lenguaje y la comunicación, como manifestaciones del desorden formal del pensamiento (DFP). Lo que denuncia Chaika es que, operacionalmente, estas definiciones se refieren solo a alteraciones que tienen que ver con la forma en cómo están estructurados los discursos, y el grado en que parecen ser comprensibles o incomprensibles para quienes los oyen. También critica el hecho de que se le atribuye un rol secundario a las alteraciones, ya que serían producto del DFP mientras que el "debilitamiento de las asociaciones" sería primario. La autora, sostiene que la evidencia del DFP, paradójicamente, se registra a partir de datos orales. Es decir, que incluso se ha sostenido que el DFP se "observa" en el discurso de los pacientes, a la inversa de reconocer que el DFP, en realidad sólo se "infiere" de la observación de las alteraciones del discurso (Chaika, 1977).

Un problema frecuente en las investigaciones acerca de esta área es la visión restrictiva de las perturbaciones en el discurso que tiene la psicopatología, pues al situarlas como una consecuencia de los problemas que presentan los pacientes en las operaciones responsables de la codificación sintáctica de los mensajes, serían interpretados paralelamente como "procesos de pensamiento", o sea, contendrían todas las operaciones relacionadas con la codificación semántica y pragmática de los discursos. Entonces, tanto dichos procesos de pensamiento, como los de producción textual y sus respectivos desórdenes, no han sido tratados con el debido rigor teórico al ser manejados como fenómenos isomórficos del pensamiento.

Lo grave de la confusión entre el DFP y la codificación discursiva, es que se ha llegado a negar que las alteraciones del discurso de los esquizofrénicos, además de reflejar déficit cognitivos o intelectuales, puedan reflejar también una incapacidad específicamente lingüística.

En la actualidad, no debe desconocerse la solidez de los campos de la investigación relacionados con el lenguaje y el pensamiento, como por ejemplo, la psicología del procesamiento de la información, la psicolingüística de inspiración chomskiana o bien, la 
psicología experimental del pensamiento. Hoy existen nuevos modelos teóricos sobre el lenguaje, el pensamiento, entre otros aspectos.

Es lamentable, pero muy evidente, el que los psicopatólogos han negado tanto el carácter legítimamente psicolinguiístico del nivel de codificación y producción textual, por creer que son competencias cognitivas generales, como la posible existencia de déficit o alteraciones en las operaciones responsables de la codificación microestructurales de los mensajes.

A este respecto, Belinchón (1991) propone entonces, que heurísticamente es más eficaz interpretar las alteraciones esquizofrénicas del discurso como alteraciones del lenguaje y/o del procesamiento del lenguaje, que pueden ser descritas e interpretadas desde un punto de vista psicolingüístico y no como lenguaje esquizofrénico.

En el presente, es completamente factible realizar estudios específicos de los perfiles linguiísticos de las personas con la patología, pues, tomando en consideración que se cuenta con modelos psicolingüísticos que despliegan recursos conceptuales útiles, es viable incorporar un nivel específico de descripción macroestructural de la producción verbal. Analizar los aspectos concretos de la actividad lingüística o de la intersección funcional de las competencias lingüísticas, cognitivas y comunicativas, favorece la aproximación a explicaciones sobre dónde se sitúan los déficits esquizofrénicos, responsables de la producción de los discursos desviados.

Según los modelos de psicolingüística de orientación textual, el individuo que aborda la decisión de comunicar lingüísticamente un mensaje a alguien en una situación concreta, atraviesa por diferentes procesos operativos para llevar a cabo esta tarea. Primero, ejecutará el procesamiento de información conceptual y pragmática general (sobre el mundo y la propia experiencia del sujeto en el contexto inmediato o mediato de su discurso, sobre el interlocutor o sobre las reglas que rigen el intercambio de información, etc); segundo, procesará la información específicamente lingüística (de tipo textual, sintáctico, morfoléxico y fonológico) que permite la codificación de la estructura superficial; por 
último, procesará la información y desplegará habilidades relativas a la programación y ejecución motora de la conducta vocal (plano fonoarticulatorio).

La conjugación del procesamiento de todos estos planos informativos redunda, finalmente, en la comunicación de los hablantes, ya que todos estos procesos se ponen a disposición de la construcción discursiva, que tiene lugar en tiempo real y, por ende, es un acto creativo.

La interfaz entre psicopatología y lingüística ha coronado de valiosos resultados que nos acercan un poco más a la comprensión de este problema científico. Ejemplos de estos enlaces abundan, entre los que se destacan, además de los anteriormente mencionados, trabajos de estudiosos como Morice e Ingram (1983), quienes demostraron que la denominada pobreza de habla, descrita por Andreasen en 1979 (TCL), es causada concretamente por la reducción de la complejidad sintáctica en los pacientes crónicos.

La necesidad de alcanzar la comprensión de los mensajes producidos y/o recibidos es una de las funciones lingüísticas fundamentales. La habilidad para entender las relaciones lógicas que se dan entre las diferentes y complejas construcciones gramaticales requiere de un trabajo colaborativo entre los hablantes. (Goodglass y Kaplan, 1983). Los aspectos comunicativos del lenguaje son particularmente relevantes en la esquizofrenia, debido a que se asocia la integridad funcional del lenguaje con porciones del lóbulo temporal y frontal (Benson D. F. 1982; Geschwind, N. 1975). A su vez, ambos circuitos corticales, frontales y temporales, han sido implicados en modelos de neuropatología recientes para esquizofrenia (Cohen, J.D. y Servan-Schreiber, D. 1992; Gray, J. A., Feldon, J., Rawlins, J. N. P., Hemsley, D. R., and Smith, A. D. 1991; Morice, R. 1986; Weinberger, D.R. 1987). Por lo tanto, los desórdenes, las alteraciones o las perturbaciones en el lenguaje pueden representar la presencia de marcadores de vulnerabilidad, que se refieren a características que se apartan de los parámetros normales, Nuecherterlein y Dawson, 1984.

Por otra parte, Morice e Ingram, (1983) observan que hay una relación entre la edad de inicio de la esquizofrenia y la reducción de la complejidad sintáctica en el discurso y sugieren que esa reducción puede reflejar riesgo de esquizofrenia. 
En un trabajo de Coloma (2007), la autora confirma que se han realizado estudios acerca de la adquisición de oraciones subordinadas y coordinadas en español, como una estimación del incremento paulatino de la complejidad sintáctica en niños. Esta secuencia estaría diferenciada en dos períodos fundamentales: en el primero, se adquieren las oraciones coordinadas y con subordinación adjetiva, sustantiva y adverbial, de tipo causal y final. En el segundo, se presentarían oraciones con otro tipo de cláusula, tales como modales, condicionales y temporales. Siendo de adquisición más tardía (6 a 10 años), las oraciones que implican el uso del subjuntivo (Serra, M., Serrat E., Solé R., Bel, A., Aparici, M. 2000) También se han realizado investigaciones longitudinales que han logrado determinar que el desarrollo de la producción sintáctica sigue su evolución hasta, aproximadamente, los 29 años y permanece estable entre los 40 y 49. Además, se estableció que los mejores indicadores de esta adquisición son la longitud de las oraciones y las cláusula relativas (Nippold M., Heskett, L., Duthie J. Y Mansfield 2005).

Algunos investigadores que han extendido el patrón de análisis hacia grupos de familiares, como Condray, Stenhauer y Goldstein (1992), descubrieron indesmentibles evidencias de que los familiares de probandos esquizofrénicos también presentan deterioro en la comprensión del lenguaje, lo que sugiere una vinculación entre disfunciones en el lenguaje y la vulnerabilidad familiar para la esquizofrenia. Estos autores utilizaron el test de Luria-Nebraska (1980) cuya prueba de comprensión del lenguaje ha tenido éxito en la discriminación de factores lingüísticos asociados a la comprensión del lenguaje deteriorado y plantearon que puede existir una relación entre presentar más disfunciones del lenguaje y las alteraciones psiquiátricas del espectro esquizofrénico, mayor que entre los familiares de personas con trastornos psiquiátricos inespecíficos.

De Lisi (2001) reporta que habría una reducción en la incrustación de cláusulas y de la producción verbal general. Además, otros autores como Addington y Addington (2000) descubrieron que si la actuación comunicativa de una persona con esquizofrenia, supera tres o cuatro elementos verbales, empeora drásticamente, lo que apunta a una disfunción en la producción sintáctica. 
Salavera y Puyuelo (2010) realizaron un meta-análisis sobre el lenguaje en la esquizofrenia, centrándose en el perfil pragmático-semántico; en sus conclusiones refutan el concepto propuesto por Belinchón acerca de la denominación lenguaje esquizofrénico (el destacado es nuestro) Aún cuando no es el foco de su investigación, ni se lo proponen, es claro que el concepto puede sostenerse a través de las evidencias teóricas y empíricas que lo validan, y creemos, por tanto, que debe utilizarse como un concepto que esgrime un perfil diferenciador y no aproximado. Entendemos que el conspicuo trabajo de Belinchón (1988) persigue definir fenomenológicamente el problema, por ello, su valor científico es innegable; no obstante, queremos relevar el enfoque que exponen Salavera y Puyuelo que después de la revisión de un gran acervo de trabajos (el destacado es nuestro) concluyen que:

Tras analizar el lenguaje a nivel de semántica y pragmática en personas con esquizofrenia, se puede hablar de distorsiones en la comunicación que son propias de la enfermedad. El deterioro del lenguaje en las personas con esquizofrenia ha quedado demostrado en diferentes estudios (Andreasen, 1979 a, b; Chaika, 1974, 1990; Docherty, De Rosa y Andreasen, 1996; McKenna y Oh, 2005). Asimismo, se puede hablar de una estructura propia del lenguaje en esta enfermedad (Leroy y Beaune, 2008). Por lo visto hasta ahora, se puede afirmar que las personas que padecen esquizofrenia hacen uso de un lenguaje distinto del resto. Se puede hablar de la existencia de un "lenguaje esquizofrénico" (Andreasen, 1979 a, b; Chaika, 1990; Salavera, 2008) Así, hay pautas en el lenguaje de los esquizofrénicos no presentes en el resto de la población. (Salavera y Puyuelo, 2010: 89)

Si bien, no es el tema central que nos ocupa en este trabajo, también estamos de acuerdo en sostener lo planteado por estos autores, en relación con el concepto denominado lenguaje esquizofrénico.

A este respecto, citamos trabajos como los de Gruber y Kring (2008) quienes comprobaron que los pacientes con esquizofrenia son capaces de recordar acontecimientos de su vida que les provocan diferentes emociones, pero se muestran menos concretos con el contexto y menos lineales en la temporalidad, por lo que la explicación de los mismos está llena de dificultades para ellos. Nos parece que este problema se manifiesta por una elaboración o diseño deficiente en los enlaces referenciales o, incluso, por su ausencia. Esta idea es en parte abordada por Docherty (1995), quién alude a un problema pragmático global en el paciente esquizofrénico, manifestado en el desconocimiento de las necesidades 
y/o requerimientos informativos del interlocutor, como la tarea de modelar proposiciones con referentes explícitos, o al menos inferibles, entre otras muchas alteraciones cohesivas.

Es importante recordar que en general los paradigmas cognitivos y experimentales habituales ignoran algunas de las dimensiones fundamentales del lenguaje: la intencionalidad y la intersubjetividad. Vygotski (1934) propone que las bases del lenguaje son sociales e intersubjetivas. Leroy y Beaune (1997) aplicaron esta mirada particular a su trabajo e incluyeron la noción de intención en el campo de la esquizofrenia y el discurso. Utilizan como marco de referencia el modelo neuropsicológico de Frith (1987) cuyo argumento central es que se presenta un déficit en el seguimiento de la intención, que viene a dificultar la propia expresión de intención, como la inferencia de las intenciones ajenas. A partir de aquí, Leroy y Beaune (2008) proponen que los trastornos del lenguaje en la esquizofrenia, podrían ser considerados a la luz de conceptos como la empatía, la conversión de significado, y la división de la intencionalidad en sí. De hecho, el lenguaje y la intencionalidad en la comunicación, según lo conceptualizado por Husserl (1962) no pueden reducirse a la mera transmisión de información.

Se requieren dos componentes: la intención de la significación, y la intención de la comunicación misma. Estas dos dimensiones conducen, en cada acto de habla, a una conversión de un lado a otro, entre pensamiento y lenguaje. En la esquizofrenia, esta división de la intencionalidad y la conversión de significado podría ser muy importante para dar cuenta de los vínculos internos entre el paciente esquizofrénico y su propio discurso [...] (Husserl, E.,1962, citado por Figueroa, G., 2008:231)

Se ha argumentado con frecuencia que los déficits en estas cuestiones, se vinculan con Teoría de la Mente. Definida como la capacidad de inferir y razonar acerca de los estados mentales de otras personas, nos facilita las predicciones y posibles explicaciones de su comportamiento. La literatura apunta a que existe una predisposición al deterioro de esta área cognitiva en la psicosis, particularmente en la esquizofrenia. Los hallazgos establecen que sería un rasgo subyacente durante todo el transcurso de la enfermedad, no restringido a los episodios psicóticos, constituyendo un rasgo específico de la patología, es decir, no atribuible a otros déficits cognitivos. En muchos aspectos, la capacidad para anticiparnos al comportamiento de otros, evaluar sus intenciones o emociones, está en estrecha relación con el concepto de competencia comunicativa de Dell Hymes (1966) Dicha competencia, 
incluye mucho más que un listado de habilidades comunicativas, como señala Habermas (1971), tienen que considerarse las condiciones que facilitan la comunicación. Saettele (1977) concibe la praxis discursiva como una parte de la praxis social, justificando así no solo una visión global del intercambio comunicativo, sino que adjudicándole un componente socio-comunicativo. Hamel (1982) precisa que en la interacción verbal, se debería analizar cómo se constituye la producción e interpretación de significaciones sociales en contextos de interacción. Por lo demás, rechaza la concepción de competencia comunicativa, solo como habilidades aditivas, porque estaría caracterizada por su implicación de que los signos lingüísticos son simplemente aplicados por los hablantes, más adecuada o menos adecuadamente, en contextos socioculturales diversos. Visiblemente, estos alcances son coincidentes con la postura de Goffman (1956) quien describe esta praxis de la forma siguiente:

Cuando un individuo se presenta ante otros, éstos normalmente tratan de obtener información sobre él o sacar a colación información que ya poseen acerca de él. Estarán interesados en su estatus socioeconómico en general, en su concepto de sí mismo, en su actitud hacia ellos, su honradez, etc. Aunque la obtención de parte de esa información puede constituir casi un fin en sí mismo, habitualmente existen razones bastante prácticas para conseguirla. La información sobre el individuo ayuda a definir la situación, permitiendo a los demás saber con anterioridad qué esperará de ellos y qué pueden esperar de él. Con esas informaciones, los otros sabrán mejor cómo actuar para provocar en él una respuesta deseada. (Goffman, 1959:3)

En la emergencia de la praxis comunicativa, se suman factores cognitivos que constituyen marcas de intercambio, evaluadas de forma positiva o negativa por el receptor. Cuando un hablante se desenvuelve, comunicativamente, desempeña un papel, que es valorado como real o falso por el/los interlocutor(es). Como un sobreentendido, el emisor solicita a su interlocutor que lo dicho sea tomado en serio. Para tener éxito en esta tarea, buscará estrategias para facilitar esta impresión de verosimilitud hacia sus propios atributos, por parte del receptor. El hablante presenta su actuación discursiva contemplando en ella las necesidades del interlocutor, rigiéndose por el principio de cooperación griceano (1975)

Entre las personas con la patología, es frecuente observar algunas deficiencias en estas estrategias comunicativas para mantener ligados aspectos cohesivos del discurso. Si el discurso presenta continuidad y armonía, es más probable que las estrategias destinadas a 
mantener la verosimilitud se tornen ineficientes y pobladas de errores. Un buen ejemplo, se aprecia en los frecuentes saltos topicales, en contraste con personas sin patología (Leroy y Beaune, 2008). Como sabemos, desde la perspectiva comunicativa, los cambios de tema en una interacción se encuentran regulados por una serie de recursos lingüísticos, que cumplen la función de orientar al interlocutor en relación con los objetivos discursivos de quien opera como emisor. Entonces, el tópico, el tema y el rema, son estructuras que se encuentran vinculadas semántica y sintácticamente, y su disposición dentro de las intervenciones es estratégica y manifiestamente identificable (Gutiérrez Ordóñez, 1997). Es esencial la utilización de estructuras con función introductoria, que permitan el cambio de tema, de manera tal que sea posible verificar que el interlocutor siga el hilo de lo dicho, algunos ejemplos tomados del corpus de controles de nuestra tesis nos dan una idea de su función discursiva:

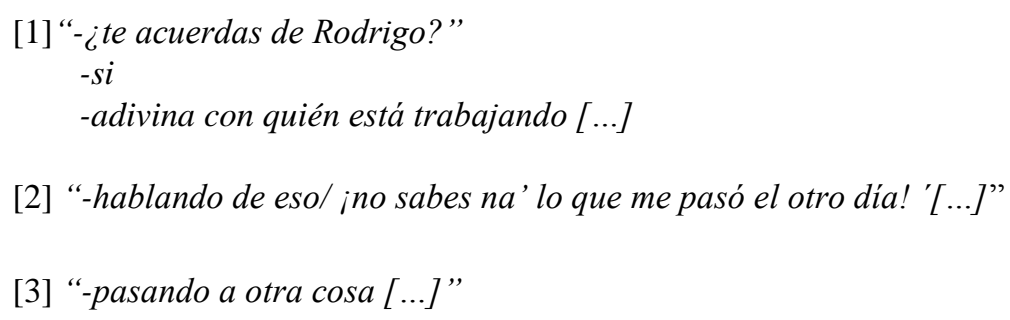

Estructuras como éstas, están ausentes o son muy escasas entre los pacientes.

Allen, Liddle y Frith (1993) y Titone y Levy (1994) sugieren que parte del procesamiento verbal inusual de estas personas es causado por un deterioro en el funcionamiento de las redes semánticas. Los autores lo probaron con tareas de recuperación léxica y priming semántico. Reportaron resultados que apuntan a un bajo control inhibitorio de los enlaces semánticos, lo que redunda en una desorganización en la categorización semántica que debería establecerse frente a tareas de esta clase, lo que se produce probablemente por una desorganización en el almacenamiento de la información, como también en su recuperación.

A medida que inventariamos muchos de los estudios realizados en personas con esquizofrenia, aumentan las evidencias de que una investigación en los aspectos 
pragmáticos del lenguaje se vuelve clínicamente relevante como una línea primaria de análisis.

Las competencias pragmáticas son determinadas por un complejo conjunto de habilidades basadas en la teoría de la mente, como las funciones ejecutivas, que facilitan la selección de significados y la inhibición de los significados inapropiados, además de ser responsables de los procesos de integración interhemisférica. Si dicha integración es débil, se elaboran asociaciones semántico-pragmáticas inusuales (Tavano, A., Sponda, S., Fabbro, F., Perlini, C., Rambaldelli, G., Gero, A., y cols. 2008) Consideraciones sobre esta integración débil, han llevado a plantear una extensión de la teoría del déficit de lateralización hemisférica, a una teoría de insuficiencia en la diferenciación bi-hemisférica en la esquizofrenia (Crow, 2000). En suma, estos alcances contemplarían que ambos déficit, los lingüísticos y los semántico-pragmáticos, provendrían de un trastorno provocado por una asimetría hemisférica funcional.

Una segunda línea debería tomar en cuenta la hipótesis de que gran parte del procesamiento verbal inusual en la esquizofrenia es provocado por la ineficiencia en las redes semánticas. Un ejemplo para ilustrar, cómo se ve afectada la relación entre los elementos de esta red semántica, lo registramos en nuestro corpus de crónicos, donde anotamos esta interesante respuesta a una pregunta del entrevistador:

[4] “E: ¿Qué es el abecedario?/ S: Palabras para la vida”.

Se puede observar una relación semántica bastante remota entre abecedario y palabras, puesto que estamos frente a una superposición de planos semánticos, o de una sobreinclusión, fenómeno descrito por Cameron (1944) que consiste en la incapacidad para mantener un tema dentro de sus límites. Como puede apreciarse, lo que ocurre al amplificar a este extremo la relación semántica entre estos elementos de la realidad [abecedario y palabras-para la vida] es que se vuelve críptica y es evidente la pérdida de significado. Los últimos hallazgos en la literatura indican que los problemas semántico-pragmáticos, como reconocimiento de prosodia emocional, reconocimiento de contextos comunicativos, roles discursivos (Laguna y Turull, 2010) recuperación léxica, inhibición inadecuada, 
desorganización semántica, así como el exceso de enlaces semánticos, pueden contribuir a la descripción del procesamiento del lenguaje específico, en sujetos esquizofrénicos (Himelhoch, et al., 1996).

Como ya señalamos, las distorsiones lingüísticas más relevantes corresponden a la dimensión semántico-pragmática, cuyas manifestaciones serían testimonio de alteraciones en funciones superiores (Kuperberg, 2008). Razón por la cual en el presente trabajo expondremos evidencias que avalan esta afirmación, y que además, nos acerquen a esbozar un perfil en personas que inician con la enfermedad, esto es el primer episodio de esquizofrenia.

2.4. Aspectos pragmáticos discursivos de la esquizofrenia: La competencia comunicativa como foco de estudio:

El estudio de la eficacia comunicativa que conservan los pacientes, es requisito indispensable para determinar en qué condiciones se encuentran muchas de sus funciones cognitivas. En Psiquiatría y Neuropsicología, existe un amplio paradigma en el que los instrumentos estandarizados juegan un rol importante para la evaluación neuropsicológica de las funciones ejecutivas, la memoria, la atención, la capacidad para inhibir impulsos, la capacidad para planificar y clasificar conceptos, entre otras muchas capacidades que se evalúan. A continuación, incluimos una tabla de resumen de algunos test que se aplican en primer episodio de psicosis en Chile:

Tabla 5: Test estandarizados utilizados habitualmente en esquizofrenia en Chile

\begin{tabular}{|l|}
\hline $\begin{array}{l}\text { WAIS-IV Escala Wechsler de Inteligencia para Adultos, cuarta versión, estandarizada } \\
\text { para la población chilena }\end{array}$ \\
\hline TAVEC Test de aprendizaje verbal España-Complutense \\
\hline Test Stroop \\
\hline Trail Making Test Forma A y B \\
\hline $\begin{array}{l}\text { FAB Frontal Assessment Battery at Bedside. Batería de Screening de evaluación } \\
\text { frontal }\end{array}$ \\
\hline Wisconsin Card Sorting Test \\
\hline Dex-Grefex \\
\hline MATRICS
\end{tabular}


La evaluación de todas las áreas que abordan estos test, es una pesquisa ideal, puesto que requiere de un psicólogo experto en evaluación neuropsicológica, además de varias sesiones para evaluar al paciente, sumándole a esto un trabajo coordinado con el psiquiatra tratante. Desgraciadamente, la realidad clínica indica que, la mayoría de las veces, esta evaluación para primer episodio de esquizofrenia, se restringe solo a algunos instrumentos, prioritariamente, el Wais-III o IV y, en ocasiones excepcionales, el test de Wisconsin, ya que en el caso de los pacientes crónicos, a menudo no se activan los protocolos de evaluación. Es importante aclarar que casi todas las baterías mencionadas son de uso restringido al ámbito de investigación. Hoy en Chile, no existen los contextos clínicos en Salud pública para dar cuenta de estas evaluaciones como parte del proceso de atención a las personas enfermas.

En este escenario, es comprensible que en Chile aún no se tome en cuenta el planteamiento de la evaluación del lenguaje o de los aspectos comunicativos generales de los pacientes psicóticos como parte de los criterios de diagnóstico, obviamente, menos aún los que corresponden a rehabilitación. Dejando de lado estas cuestiones y, con el fin de aproximarnos a un camino que contemple la evaluación de estos elementales factores, podemos preguntarnos ¿es posible realizar algún tipo de evaluación del lenguaje en estas personas, contando con los medios actuales? o bien ¿cuáles son las áreas del lenguaje que podemos evaluar en la clínica, en personas con esquizofrenia? Tomando en cuenta estos aspectos, y basados en la evidencia que pudimos documentar para esta investigación, llegamos a la conclusión de que es plenamente posible la evaluación de las personas con esquizofrenia. Si bien es cierto, en algunas escalas psiquiátricas muy difundidas y utilizadas (en Chile) como PANSS ${ }^{5}$, se incorporan acápites sobre lenguaje, el tipo de observaciones que se proponen como marco de evaluación son muy vagas y no centradas de modo alguno en lo comunicativo; extractamos aquí uno de los ítem que corresponde a los síntomas negativos (N1-N7) que incluye la única alusión al lenguaje:

\footnotetext{
${ }^{5}$ Escala de síntomas positives y negativos. Este extracto corresponde a material del Proyecto de apoyo a la evaluación Psicológica Clínica de la Universidad Complutense de Madrid.
} 
N6. FALTA DE ESPONTANEIDAD Y FLUIDEZ DE LA CONVERSACIÓN Reducción de la fluidez normal de conversación asociada con apatía, falta de voluntad, indefensión o déficit cognitivo. Esto se manifiesta por una disminución de fluidez y productividad de la interacción del proceso verbal. Bases de evaluación: Procesos cognitivos verbales observados durante el curso de la entrevista.

1. Ausente: La definición no es aplicable

2. Mínima: Patología cuestionable. Puede estar en el extremo de los límites normales.

3. Leve: La conversación muestra un poco de iniciativa. Las respuestas de los pacientes tiende a ser breve y sin adornos, requiriendo preguntas directas y dirigidas por el investigador.

4. Moderada: Falta de fluidez en la conversación, aparece desigualdad y vacilación. Normalmente se necesitan preguntas dirigidas para dilucidar respuestas adecuadas y proceder con la conversación.

5. Severamente Moderada: El paciente muestra una marcada falta de espontaneidad y apertura, respondiendo a las preguntas del investigador con una o dos breves frases.

6. Severa: Las respuestas del paciente están limitadas principalmente a pocas palabras o frases cortas, intencionadas para evitar o impedir la comunicación (ej: "no sé, no tengo libertad para opinar"). Como consecuencia, la conversación está seriamente dificultada, y la entrevista es altamente insatisfactoria.

7. Extrema: La respuesta verbal se restringe a: lo máximo, murmullos ocasionales, haciendo que la conversación sea imposible.

Como ya lo hemos señalado, nuestro trabajo se centró en la premisa de que lo relevante en la evaluación del lenguaje en pacientes con esquizofrenia corresponde a la situación de intercambio que se da en el marco de la entrevista clínica. Nos interesa, particularmente, relevar la dimensión pragmática de esta interacción clínica, ya que consideramos que es la forma más ecológica de analizar datos lingüísticos. El interés por la pragmática en la clínica surge en la década de los 80, y se aplica, fundamentalmente, a la afasiología. Gallardo-Paúls (2009) menciona lo que se denominó la revolución pragmática, ya que esto permitió la aplicación sostenida de técnicas que facilitaron las tareas de registro, transcripción y etiquetado de los datos. En términos generales, lo que modela el cambio hacia este nuevo paradigma en la lingüística clínica es la integración de la noción de eficacia comunicativa, que se desprende de la competencia comunicativa propuesta por Dell Hymes, en la década del 60:

La competencia comunicativa es el término más general para la capacidad comunicativa de una persona, capacidad que abarca tanto el conocimiento de la lengua como la habilidad para utilizarla. La adquisición de tal competencia está mediada por la experiencia social, las necesidades y motivaciones, y la acción, que es a la vez una fuente renovada de motivaciones, necesidades y experiencias. La competencia comunicativa es el término más general para la capacidad comunicativa de una persona, capacidad que abarca tanto el conocimiento de la lengua como la habilidad para utilizarla. La adquisición de tal competencia está mediada por la experiencia social, 
las necesidades y motivaciones, y la acción, que es a la vez una fuente renovada de motivaciones, necesidades y experiencias (Dell Hymes, 1964:31)

La noción de competencia comunicativa debería constituir la base de cualquier modelo que describa el perfil lingüístico de pacientes con patologías psiquiátricas, dado que es la suma de las demás competencias vinculadas al lenguaje, y como representamos en la siguiente figura, es la más general e inclusiva:

Figura 3: Competencia Comunicativa

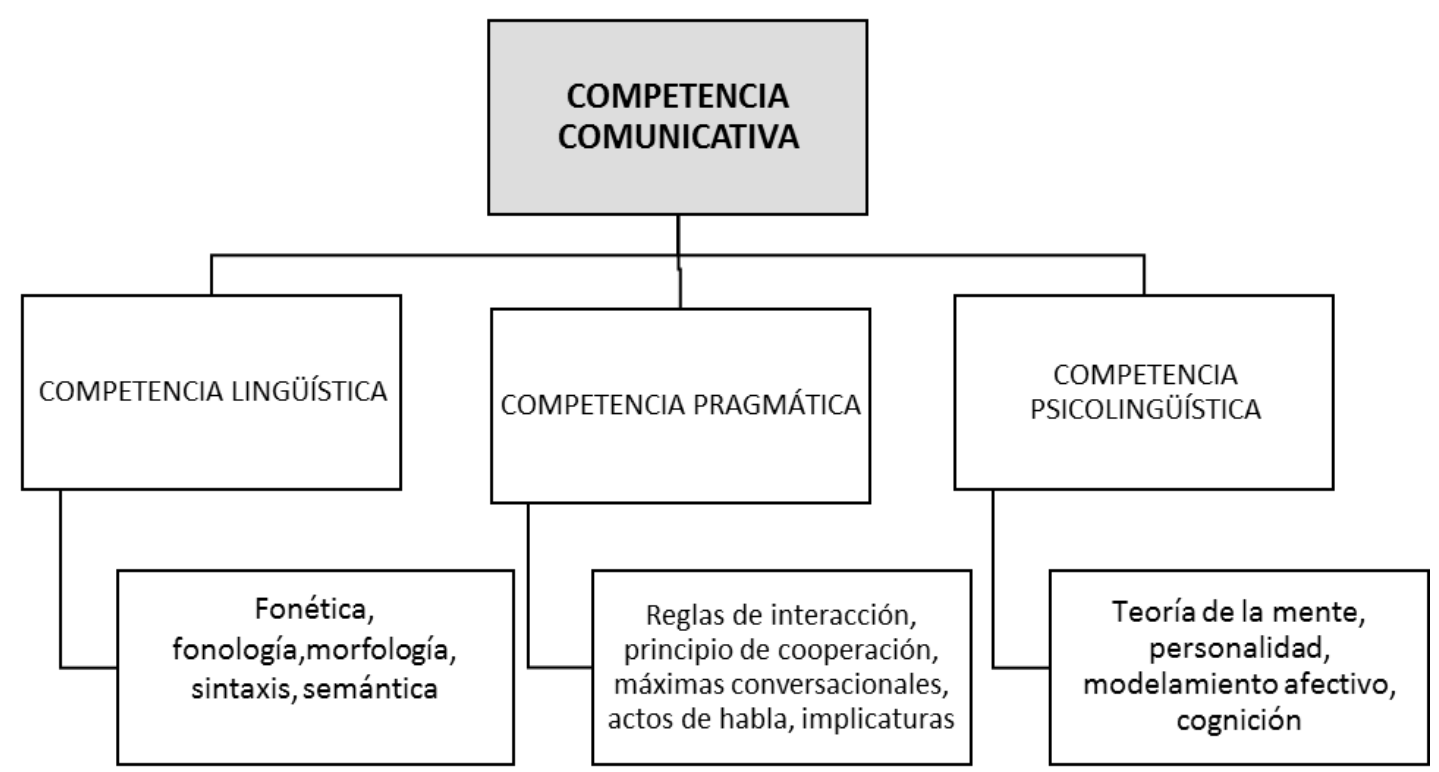

La competencia lingüística incluye el conocimiento formal acerca de la gramática de la lengua, y cómo sus niveles de análisis se modulan en planos diferenciados del lenguaje, es decir, nivel morfológico, sintáctico, fonético-fonológico y semántico.

La competencia pragmática contiene una amplia gama de elementos que funcionan de forma articulada. Una de las cuestiones relevantes para el trabajo con pacientes es la 
consideración de las reglas de interacción. La propuesta de Hymes (1971), que detalla la situación comunicativa con su modelo contenido en el acrónimo SPEAKING ${ }^{6}$, es una interesante guía para verificar el comportamiento de los pacientes en cuanto a algunos aspectos de la interacción, ya que estos elementos responden a las preguntas ¿dónde y cuándo?, ¿quién y a quién?, ¿para qué?, ¿cómo?, ¿de qué modo?, ¿cuáles creencias?, ¿qué tipo de discurso es? En este trabajo, no aplicamos este molde, pero nos sirvió como herramienta orientadora. También es importante contemplar dentro de esta competencia la capacidad del entrevistado para vincularse, por ejemplo, mantener los turnos de habla actualizados, es decir, sin la asistencia del entrevistador.

Gallardo y Hernández Sacristán (2013) expone las características del denominado, índice de participación conversacional, que es un indicador para verificar la gestión de la toma de turnos, la agilidad de los turnos y la gestión de predictibilidad, en las conversaciones de hablantes con déficit lingüístico. Tomado del protocolo de cuantificación de Crockford y Lesser (1994), se utiliza, además, como una huella de intencionalidad participativa del hablante y que la autora utiliza en el corpus PerLa ${ }^{7}$. El IPC es una medida contextual, que se puede relacionar con la fluidez y adecuación de la interacción a nivel individual. La agilidad del turno corresponde, básicamente, a la cantidad de turnos por minuto que se dan en una interacción. Aún cuando esa medida tiene un valor relativo, en este trabajo observaremos si hay diferencias profundas entre controles, pacientes de primer episodio y pacientes de esquizofrenia crónica. La predictibilidad es entendida como la gestión de la construcción concreta de turnos, en virtud de la utilización de actos de habla que presenten vínculos explícitos con el turno siguiente. En este trabajo, abordamos esta evidencia desde la revisión de las proposiciones que podían vincularse explícita o implícitamente respecto del tema central, lo que nos permite evaluar la unidad discursiva de una forma más acotada.

\footnotetext{
${ }^{6}$ SPEAKING: S : setting -P: participants -E : ends-A: acts- K :key- I :instrumentalities-N :norms-G: genre

${ }^{7}$ Corpus PerLa: Percepción, Lenguaje y Afasia, Universidad de Valencia.
} 
También se sitúan dentro de las reglas de interacción, la adecuación pragmática a la situación de entrevista; asimismo, los factores expresivos como la prosodia emocional, entre otros.

En torno a los actos de habla y a las implicaturas, sabemos que su importancia se liga al hecho de que se pueden establecer cuáles son los propósitos comunicativos de un hablante, que en este caso, presenta un déficit. Se ha demostrado que la conversación con pacientes con esquizofrenia es poco fluida e informativa; frecuentemente, es el entrevistador quien debe completar la información, o darle sentido, relacionando elementos dispersos. Las implicaturas obedecen a las presunciones dadas por el contexto comunicativo y que se establecen a partir del Principio de Cooperación de Grice (1975). El autor distingue dos tipos de implicaturas: conversacionales y convencionales, la primera de ellas se deriva de aspectos generales que se darían en la situación comunicativa en cuestión, y la segunda, por la dependencia de significados adicionales al significado convencional de la o las palabras que participan en la implicatura. El llamado Principio de cooperación, se encuentra regido por cuatro máximas conversacionales que se aprehenden en función del uso de la lengua:

i. Cantidad: dé la cantidad necesaria de información, ni más ni menos de lo necesario.

ii. Calidad: dé información verdadera, que no sea falsa ni de la que no esté seguro.

iii. Relación: sea relevante, vaya al grano.

iv. Modo: sea claro, no sea ambiguo, sea breve y ordenado.

En el caso de las presuposiciones, también son definidas como inferencias pragmáticas, pero están relacionadas de forma más directa con la estructura lingüística que se ha elaborado oracionalmente. Pueden servir para evaluar la verosimilitud de la expresión empleada. En este trabajo, no incluimos estas estructuras en la evaluación de la conducta comunicativa. Nos parece que, como indicadores de déficit, son laxos e imprevisibles, ya que en los controles sanos, también encontramos aspectos ambiguos relacionados con este tipo de recursos. Pensamos que para evaluar el comportamiento pragmático a este nivel, habría que haber propuesto algún experimento donde se examinara de forma estricta estos aspectos pragmáticos en todos los sujetos. 
La competencia psicolingüística enlaza la Teoría de la Mente, la personalidad, el modelamiento afectivo y la cognición del hablante. El concepto teoría de la mente (ToM) surge de los trabajos seminales de Premack y Woodruf (1978), quienes demostraron a través del entrenamiento de chimpancés que éstos podían comprender la mente humana. Realizaron una serie de experimentos donde descubrieron que los primates podían interpretar acciones destinadas a conseguir objetivos específicos, como conseguir alimentos. Entonces, la teoría de la mente está definida como la habilidad para comprender y predecir la conducta de otras personas, comprender sus conocimientos, intenciones y/o creencias.

Se cree que la ToM se desarrolla en las primeras etapas de la infancia, período en el que se alcanzan las denominadas, tareas de primer orden, que permiten la comprensión de las "falsas creencias". Baron-Cohen, reconocido estudioso del autismo y el asperger, diseñó junto a Leslie y Frith (1985) una tarea que evalúa este nivel. Se trata de la tarea de Sally y $\mathrm{Ann}^{8}$, que es una variante de la tarea de Maxi de Wimmer et al. (1983), y que reproducimos a continuación con la consigna:

Figura 4: Tarea de Sally y Ann

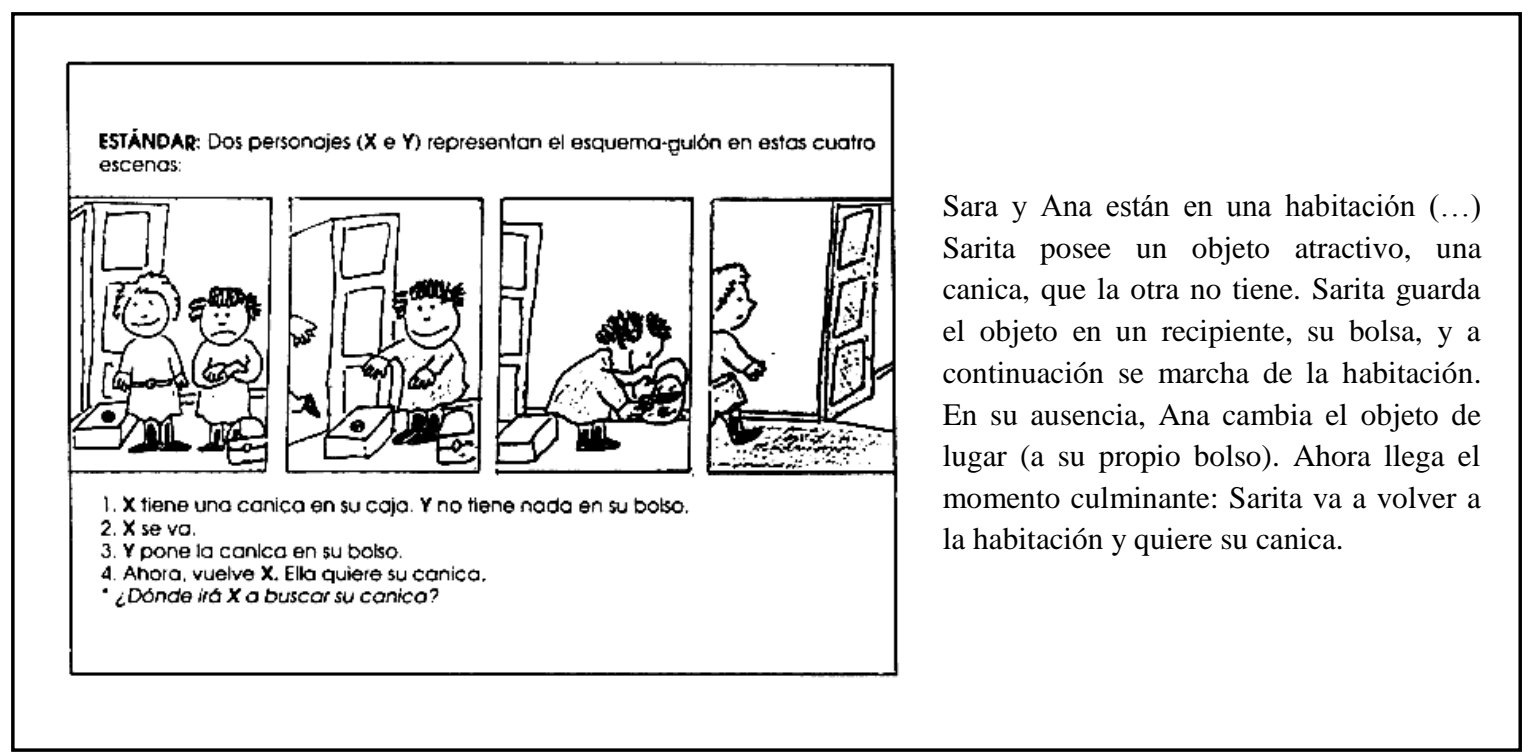

\footnotetext{
${ }^{8}$ La figura estándar fue tomada de Rivière y Castellanos (2003:14)
} 
Al niño entrevistado se le solicita que responda: ¿dónde buscará Sara la canica? La respuesta adecuada sería que el niño pueda distinguir que Sara tiene una falsa creencia acerca de dónde está la canica. Lo que supone un manejo primario de ToM, al tener que considerar el funcionamiento de ToM de Sara. Como es sabido, el lóbulo frontal y, en especial, la corteza prefrontal del HD es crucial para el funcionamiento de la mentalización o autoconciencia, asimismo para la personalidad, la inteligencia y el juicio ético. (Alexander, Benson, Stuss, 1989; Damasio, 1994; Adolphs, 1995) Las lesiones en esta zona cortical producen serias alteraciones pragmáticas, además de la incapacidad para empatizar, comprender el sarcasmo o la ironía y, en general, todas aquellas capacidades que implican inferencias o atribuciones emocionales (Tirapu, et al, 2007) Adolphs (2006) en uno de sus trabajos relaciona la amígdala como parte de una red cortical que incorpora otras regiones cerebrales como el lóbulo temporal y la corteza cingulada. Estos modelos nos permiten comprender la complejidad del concepto ToM que sin dudas no se ha zanjado con respecto a sus límites y funciones. Puede ser evaluado desde diferentes niveles de complejidad, el de las tareas de primer orden es uno de muchos niveles que se pueden abordar en el examen de esta teoría. Como no es materia estricta de este trabajo, solo nos referiremos al reconocimiento de emociones como tarea de ToM, que tiene una aplicación muy frecuente para la esquizofrenia. El reconocimiento de emociones se relaciona más estrechamente con zonas corticales como la amígdala y como tarea es bastante informativa. Con frecuencia se mide a través de la utilización del test de las miradas de Baron Cohen $(2001)^{9}$ :

Figura 5: imagen 3 del test de las miradas de Baron Cohen

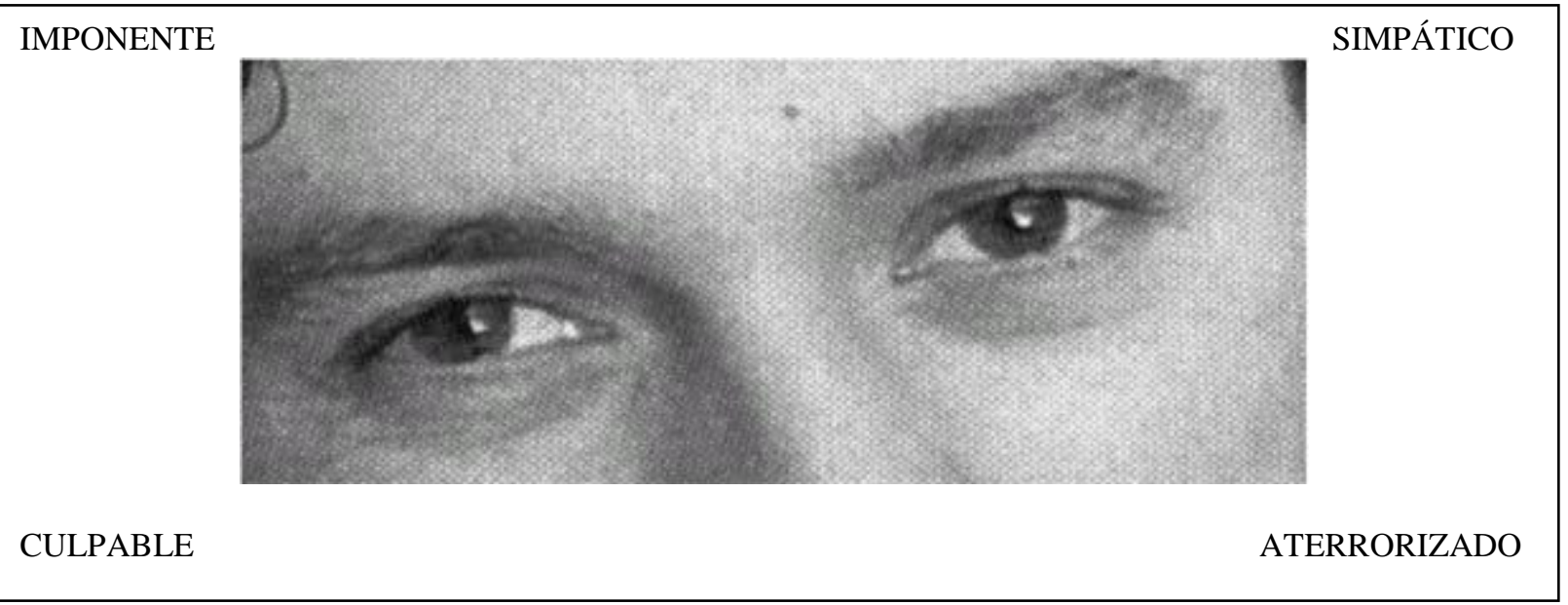


Para cada fotografía de ojos, debe elegir y hacer un círculo en la palabra que mejor describa lo que la persona de la fotografía está pensando o sintiendo. Le puede parecer que pueda ser aplicable más de una palabra, pero elija por favor, aquella que considere la más apropiada. Antes de marcar su opción, asegúrese de que ha leído las cuatro palabras. Debe intentar hacer la tarea lo más rápidamente posible, pero no se va a contabilizar el tiempo. Si no conoce el significado de alguna palabra puede mirarla en el manual de definiciones. (Instrucciones para el test en español, p.2)

Las indicaciones para los participantes es discriminar qué emoción presenta la mirada de la foto. Deben elegir entre cuatro opciones, prestándoles asistencia si no entienden algún concepto. Los resultados de este test en esquizofrenia presentan grandes diferencias con la población de control.

La investigación en neurociencias ha permitido avanzar enormemente en el conocimiento del cerebro, en las últimas décadas. Los estudios de neuroimagen indican que las áreas cerebrales involucradas en la ToM son la zona posterior del surco temporal, regiones del córtex prefrontal medial y polo temporal (Frith, 2007); también en la ejecución específica de tareas se han localizados áreas como la amígdala, que como ya señalamos, permite el reconocimiento de emociones, además de la corteza dorsolateral, en las llamadas tareas de primer y segundo orden. También se han determinado giro frontal medial izquierdo y cingulado posterior, en las tareas de ironía; el frontal dorsolateral y ventromedial en meteduras de patas; el giro frontal medial, amígdala, córtex frontal dorsolateral y lóbulo parietal en tareas de empatía (Tirapu-Ustárroz et al., 2007).

El trabajo de Rizzolatti (1996) y el grupo de investigación que dirigía en Parma, Italia, establecieron que el grupo de monos con el que realizaban experimentos, podían replicar mentalmente el movimiento de sus compañeros. Se constató que se activaban neuronas ubicadas en el córtex ventral promotor y en regiones inferolaterales del lóbulo parietal, que se activaban cuando el animal debía realizar una acción gestual, y que se volvían a activar cuando otro mono las realizaba. El descubrimiento de Rizzolatti (1996) y su grupo de investigación acerca de la existencia de las neuronas que denominaron "espejo", vino a confirmar las evidencias de que los seres humanos tenemos un complejo sistema de mentalización comprendido en parte a través de la ToM. Las neuronas "espejo", les permiten a las personas, comprender las intenciones de otros, ponerse en su lugar, hacer 
lecturas de sus deseos, pensamientos y sentimientos, todo esto es indispensable para la interacción efectiva, ya que funciona como predictor de las conductas de otros.

En pacientes con esquizofrenia, es frecuente encontrar déficit en ToM, y en cognición social en general. Para Adolphs (2001), la cognición social se define como:

La capacidad de construir representaciones de la relación entre uno mismo y los demás y utilizar esas representaciones de manera flexible para guiar el comportamiento social. (Adolphs, R., 2001:232)

Figura 6: cognición social

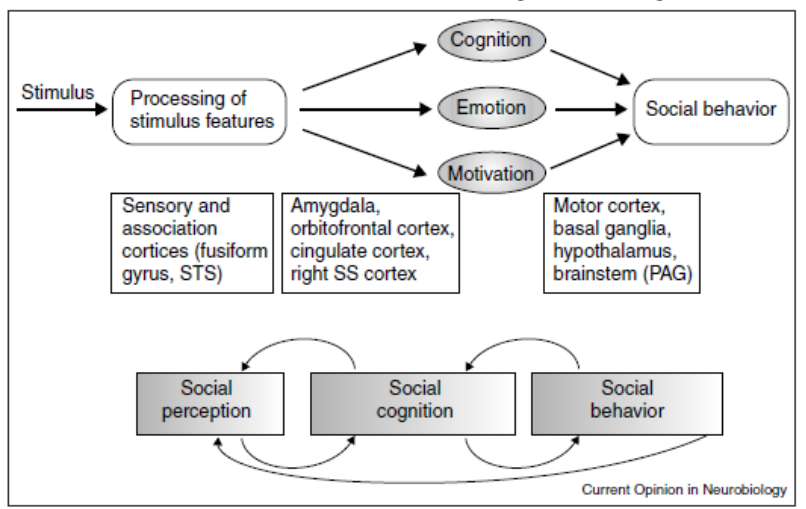

Component processes of social cognition. At the input end, social cognition draws upon neural mechanisms for perceiving, recognizing, and evaluating stimuli, which together provide the information required to construct complex central representations of the social environment. Regions in temporal lobe, such as the fusiform gyrus and the superior temporal sulcus, work together with a network of structures that includes amygdala, orbitofrontal cortex, anterior and posterior cingulate cortices, and right somatosensory-related cortices. Contral processes of social cognition in turn and premotor cortices and hasal gangle motor an such as hypothalamus and periaqueductal gray (PAG) Importantly social periaqueductal gray (PAG). Importantly, social perception and social behavior are causally connected as aspects of social communication, as indicated at the bottom of the figure: an organism's production of social behavior in turn functions as an important source of perceptual input. SS, somatosensory; STS, superior temporal sulcus.

En un trabajo recientemente publicado (Lahera, et al, 2015) se plantea que en la declaración de consenso de $\mathrm{NIMH}^{10}$ se identificaron cuatro dominios básicos que componen la cognición social: procesamiento de las emociones, percepción social, la teoría de la mente y el estilo atribucional, aunque es lamentable que se ha estudiado casi únicamente el dominio que corresponde a ToM.

Social cognition has been defined as 'the set of cognitive processes involved in how people think about themselves, other people, social situations, and interactions'. It is therefore the ability to perceive, process, and interpret social cues, which allows us to infer the mental states of others. The NIMH consensus statement identified four core domains of social cognition - emotion processing, social perception, theory of $\mathrm{mind} / \mathrm{mental}$ state attribution (ToM), and attributional style/ bias. However, research in this field has been disproportionately focused on ToM compared with the other domains. ((Lahera et al., 2015:473)

\footnotetext{
${ }^{10}$ NIMH:National Institute of Mental Health, USA
} 
Para efectos de este estudio, solo nos referiremos de manera general a la cognición social como la base de las competencias sociocognitivas fundamentales para un desempeño eficaz en todas las áreas de la vida. Esto implica una estrecha relación entre la cognición social y el resultado funcional, debido a que la capacidad de procesar rápidamente los estímulos sociales es esencial para la interacción social, y dificultades en esta área pueden impactar en todas las relaciones interpersonales. Además, la cognición social puede afectar el resultado de habilidades de la vida cotidiana, porque se requiere poder evaluar con precisión las señales del entorno para poder desempeñarse socialmente (Couture, 2006). Los estudios realizados han encontrado que el mayor deterioro cognitivo social en las personas con esquizofrenia parece estar en la percepción de la emoción (Roder, 2010). Sin embargo, esta es una capacidad que podemos considerar plástica y entrenable.

Considerando que la percepción, el reconocimiento y el procesamiento emocional son dimensiones fundamentales del constructo cognición social (Couture, 2006), citamos un trabajo clínico de Oyarzún y Figueroa (2013). Se había implementado un trabajo piloto en 2011, con interesantes resultados. En la versión que citamos aquí, se aplicó un programa de rehabilitación experimental en cognición social que fue bautizado como CONECTA-2, en el que se incorporaron módulos de rehabilitación psicolinguística. Con una metodología test-retest, a cargo del equipo Oyarzún-Figueroa, se aplicó el test de las miradas para adultos, (Baron Cohen, 2001) que, como sabemos, representa un procesamiento en tres niveles: una percepción no consciente, automática de una mirada; el otorgamiento de una valencia junto a la detección de la dirección de la mirada que influye en la interpretación del estado mental y el procesamiento consciente para elegir entre las cuatro opciones la que mejor se adapte a la tarea (Burin, D. Drake, M. y Harris P., 2008). Esta experiencia piloto se llevó a cabo en el Instituto de Rehabilitación en Salud Mental RENOVAL de Santiago de Chile y consistió en una primera experiencia clínica en entrenamiento de esta compleja capacidad. Mediante metodologías consistentes en exposiciones, se trabajó durante un programa que constaba de 16 sesiones que abordaron diferentes temáticas tales como: Percepción emocional, reconocimiento de microexpresiones faciales, interpretación y atribución emocional, empatía y adecuación interpersonal. Al finalizar el taller, se procedió 
a verificar si existían cambios que apoyen los resultados clínicos. Los resultados de esta experiencia son prometedores, la mayoría de los participantes incrementó sus puntajes en el test mencionado al final del taller. Subyace a este trabajo inicial, la necesidad de buscar optimizar las intervenciones tendientes a la disminución del estigma y fomentar la inclusión social de las personas con esta patología.

Los demás elementos que conforman la competencia psicolinguiística, como la personalidad y el modelamiento afectivo, están fuertemente relacionadas con la cognición social, pues conforman la identidad de las personas. Se traducen en lo que se ha denominado: modelos mentales, que son representaciones del mundo, elaboradas por nuestra cognición. A menudo estas representaciones son compartidas por una comunidad, en virtud de que es posible establecer redes semánticas y comprender cuestiones tan abstractas como los chistes, las ironías o los conceptos. Los estados anímicos también conforman parte de la comunicación humana, y el modelamiento afectivo puede tener consecuencias diversas sobre este proceso interactivo y se desprende que si hay déficit en la cognición social, los otros factores también se verán afectados.

En suma, la competencia comunicativa conforma en buenas cuentas nuestro perfil individual completo.

La motivación por el análisis de datos que contemple estas consideraciones en la evaluación se hace imprescindible, a partir de trabajos como los protocolos pragmáticos (Prutting y Kirchner 1983; Penn 1985). Es importante recordar que, a medida que se incorpora este eje pragmático en la evaluación de las patologías del lenguaje, disminuye el enfoque estrictamente gramatical de los fenómenos. A menudo las patologías del lenguaje habían estado centradas en los enfoques gramaticales, que se habían entendido como los componentes modulares de la gramática, dejándose de lado su dimensión pragmática, con ella, toda posible descripción de lo funcional en el lenguaje (Sacristán 2006)

Gallardo y Hernández Sacristán (2013) considera que dejando de lado algunas discusiones por los límites disciplinarios, innecesarios para el trabajo clínico, se puede afirmar que las categorías pragmáticas surgen en la intersección que proporcionan las 
funciones del uso verbal orientado a la representación, es decir, en su función cognitiva y en el uso de la interacción, esto es, en su dimensión social.

En efecto, la pragmática, aplicada primero al campo clínico de la afasiología y, posteriormente, al de otras patologías mentales ha permitido distinguir subdominios como los propuestos por Dascal (1983): i. Dominio de los usos mentales, calificada como psicopragmática o pragmática del lenguaje del pensamiento, que contiene actos mentales como juzgar, inferir, recordar, etc. ii. Dominio socio-pragmático, que contiene el estudio de los usos sociales y/o públicos, que confluyen a la vertiente comunicativa. Ambos dominios se complementan y superan su aplicación estricta a enfermedades neurológicas o del neurodesarrollo, como la afasia, la demencia frontotemporal, el asperger, el autismo, entre otras, para servir como marco de referencia a enfermedades psiquiátricas como la esquizofrenia.

El concepto de déficit pragmático puede orientarnos sobre el perfil de trabajo que se persigue. La literatura nos provee de tres criterios para evaluar el habla alterada:

-Habilidades semióticas del hablante, que estarían asociadas a procesos de decodificación de canales comunicativos. Se evalúa el habla, la lectura, la escritura y la repetición oral. El test de Boston (Goodplass y Kaplan, 1983) que es un enfoque muy útil y aplicable al contexto de la esquizofrenia como posible medio investigativo.

-Componentes gramaticales; se evalúan las categorías concretas que muestran déficit, lo que implica asumir que hay modularismo gramatical al igual que en los módulos cognitivos (Ellis y Young, 1988).

-Dimensiones básicas de la organización interna del sistema lingüístico; tomado de Jakobson (1985) manifestaciones diferenciales en los ejes sintagmático y paradigmático. 
Estas dimensiones corroboran un interés marcado por los aspectos expresivos del lenguaje, como precisan Gallardo y Hernández Sacristán (2013), pero no son los únicos que deben evaluarse, ya que en su opinión, se da una relación de interdependencia constitutiva. No sería suficiente la descripción y el análisis de las dimensiones expresivas, sino que debe contarse también con la consideración del déficit como un fenómeno relacional, como lo plantea a continuación:

[...] está claro, por otra parte, que la facultad humana del lenguaje no se identifica con nuestra capacidad de manipular determinados objetos formales, enormemente variables de lengua natural a lengua natural, sino con nuestra capacidad de generarlos, modificarlos o adaptarlos para satisfacer necesidades comunicativas. Las formas lingüísticas no son más que un punto de anclaje, por otra parte necesario, dentro de un complejo relacional donde los sentidos y las funciones comunicativas son realmente lo prioritario para el usuario del lenguaje (Gallardo-Paúls y Hernández Sacristán, 2013:48)

Entonces, los enfoques para evaluar el déficit pueden y deben ser complementarios. En el presente trabajo, hemos tomado en cuenta ambos aspectos, centrándonos en el primero, que nos parece más urgente considerando la escasez de investigaciones en Chile.

En suma, el carácter que asume el déficit en la esquizofrenia, debe contener no solo aspectos expresivos, ligados a cuestiones formales de la lengua, sino que además debe permitir comprender lo mejor posible las habilidades socio-comunicativas que aún retienen los pacientes.

Ahora bien, otro aspecto importante de mencionar con respecto a la complejidad del déficit en la esquizofrenia, es que no tiene un carácter sistemático, es decir, no se presenta del mismo modo en la población afectada. Esto impide realizar precisiones sobre conductas que puedan configurar patrones. Pensamos que, pese a la heterogeneidad de las características del fenómeno, es posible realizar perfiles que contengan marcadores de déficit significativo, incluso, que permitan contrastar las poblaciones de primer episodio y de crónicos en este aspecto.

2.5. Fenómenos pragmalingüísticos relevantes para el estudio:

Para esta investigación, se utilizaron entrevistas clínicas como se describe en la metodología. La finalidad de esta elección corresponde a la búsqueda de información 
relevante sin mediar intervención de instrumentos estandarizados o tareas experimentales de laboratorio. Este es un contexto frecuente al que se ve sometido el paciente, a lo largo de su enfermedad, de modo que, la entrevista resulta ser la instancia más frecuente de contacto con el equipo de salud mental tratante. La interacción médico-paciente resulta ser de gran utilidad, en este sentido, pues se establecen registros de datos y condiciones para determinar la condición de la persona enferma. Durante este intercambio, es factible la evaluación de la competencia comunicativa. Ahora bien, los déficit que, eventualmente, puedan observarse en esta situación comunicativa, no son sistemáticos y ofrecen grados de profundidad que pueden ser diferenciados. Es frecuente que los pacientes presentan dificultades en algunos de los planos de análisis, pero no necesariamente en todos ellos. Hemos graduado los hallazgos en función de los objetivos que exige cada aspecto comunicativo que se estudió; tema que también se explicará en el siguiente capítulo.

Los diversos aspectos, recursos y fenómenos discursivos de las personas con esquizofrenia ofrecen algunos patrones que se han sistematizado en función de lo que representan comunicativamente en el presente trabajo.

\subsubsection{La interacción comunicativa: Aspectos generales}

Diferenciamos aspectos globales y particulares de la unidad discursiva analizada, además de las características que presenta la interacción en sí. En opinión de Mendizábal de la Cruz:

Uno de los aspectos de la psicolingüística que en menor profundidad se ha estudiado, y no por ello deja de tener una gran relevancia en la investigación sobre el funcionamiento del lenguaje, ha sido el análisis de los errores espontáneos que se producen en el habla. Fournié ya había señalado hace muchos años que "el discurso es la única ventana mediante la que un fisiólogo puede observar la vida cerebral" (Mendizábal de la Cruz, 2004:sp )

En efecto, durante la interacción puede observarse una serie de fenómenos que perfilan un funcionamiento diferencial del lenguaje en los sujetos observados. Es en esta 
instancia discursiva donde debe plantearse una diferencia entre los significados explícitos e implícitos, o más bien como lo resume Reyes (1990), entre el querer decir y el decir sin querer. Si bien en la interacción conversacional muchos de los significados no resultan explícitos, esto no es impedimento para que el discurso alcance sentido, pues pasa a convertirse en un constructo elaborado en forma colaborativa por los participantes, como se ilustra en la siguiente figura tomada del trabajo de Escandell (1990:38)

Figura 7: interacción comunicativa

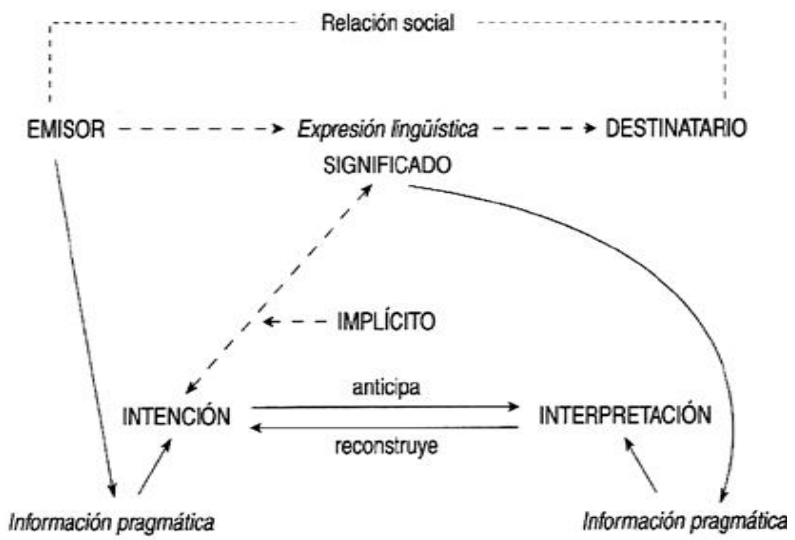

En el caso de la entrevista clínica, también se cumplen algunas premisas discursivas que apuntan al mutuo apoyo de los participantes en el conocimiento compartido. Ahora bien, si nuestra interacción logra ser más o menos exitosa, dependerá del cálculo, a menudo inconsciente, sobre cuáles son las parcelas de conocimiento compartido a las que podemos apelar en el curso de nuestra interacción. En consecuencia, si nuestros cálculos son incorrectos, enfrentaremos la incomprensión o el malentendido.

Basándonos en el concepto de inferencia, encontramos las claves fundamentales de la interacción. Al aludir a los procesos mentales, los mecanismos inferenciales pueden orientar no solo la comprensión del discurso, sino que, también, nuestra comprensión de lo que ha entendido el interlocutor. Otros aspectos como la fluidez, el índice de participación conversacional, la toma de turnos, los énfasis, la prosodia, las pausas, los alargamientos, 
etc, pueden servir como elementos contextualizadores para expresar y comprender significados implícitos. Asimismo, la selección léxica, el cambio de registro, las fórmulas de cortesía, las rutinas de inicio y cierre de una interacción, actúan como marcadores de contexto que equivalen en importancia al significado referencial. Todo este conjunto de elementos claves da cuenta de los procesos mentales implicados en el procesamiento de la información y de la eventual evaluación de su eficacia comunicativa.

Por otro lado, si tomamos en cuenta el concepto de "eficacia comunicativa" como marco de referencia, tenemos que considerar un contexto más amplio que la ejecución de las tareas lingüístico-comunicativas, es decir, es requerimiento indispensable abordar no solo el objetivo general que se plantee en la interacción, sino que además el contexto; de esta forma, evaluaremos la dimensión semántico-pragmática de la interacción.

Configurar un análisis que incluya todos estos aspectos es difícil; sin embargo, la situación discursiva en el marco de la entrevista ofrece una buena cobertura de muchos de ellos, como ya hemos señalado anteriormente. Los pacientes con esquizofrenia son menos sensibles a las violaciones del contexto discursivo que los controles sanos. Su insensibilidad al contexto es una característica de la esquizofrenia especialmente frecuente en el comportamiento discursivo; sus producciones, a menudo, no están adaptadas a los requerimientos informativos del interlocutor. Sumada a esta dificultad, la selección de la información relevante, según el contexto, es un rasgo sine qua non, incluso entre los pacientes que inician la enfermedad (Chapman, Chapman, y Daut, 1976; Chapman, Chapman, y Miller, 1964; - Kuperberg, McGuire, y David, 1998; Titone, Levy, y Holzman, 2000).

Por otro lado, muchas de las disfunciones del lenguaje pueden ser observadas en los familiares directos sanos, lo que es congruente con el juicio de que el lenguaje desviado es un reflejo de vulnerabilidad para la esquizofrenia (Zubin and Spring, 1977).

Otra cuestión de gran relevancia para incluir el contexto en el análisis es el hecho de que los pacientes con esquizofrenia, también incurren en inadecuaciones en la adaptación 
de sus emisiones para hacerlas más informativas, entonces encontramos algunos ejemplos del tipo:

$[5]$

10. E: ¿si yo le pidiera a usted que se definiera/ cómo se definiría?

11. S: ¿уo?/ eh<pausa>/ más que <pausa $>$ yo $<$ pausa extensa $>/$ eh $<$ pausa $>/$ irreprensible<pausa extensa>/

12. E: ¿Qué es irreprensible?

13. S: que tiene la orden para vivir al día/ que sé hasta dónde llegan las metas/ me detengo/ porque o sino no/ se va a rendir en un momento<pausa>/ tiene que rendirse en un momento<pausa>/ es como una voz/ va a decir algo pero tiene que ser por algo// Entonces lo otro ya es cuando tiene que investigar, hacerlo bien<pausa $>/$ conjunto de cosas y las valora todas $<$ pausa $>/$ y siente que posee un conocimiento<pausa>/ y un discernimiento de una cosa y otra/ entonces/ porque/ irreprensible/ es como para que nunca me llamen la atención porque yo he hablado un tontera/¿ah? <pausa>/ ¿está bien o nó? <pausa>/ ¿ah?/ irreprensible<pausa>/ yo pienso eso po' $/<$ pausa $>$ porque yo hablo el ambiente pues hermano/ no me llamen la atención $<$ pausa $>/$ soy irreprensible//Reprender/ ¿está bien o nó? <pausa>/ ¡está bien? <pausa>/ lógico<pausa>/ ¿cierto?// Es como una pareja de mentirosos $<$ pausa $>/$ y la horma tiene la a y la $0<$ pausa $>/$ las que lleva las finales $<$ pausa $>/$ y yo $<$ pausa $>/$ ya por quince $<$ pausa $>/$ amor al revés significa roma <pausa>/¿está bien? <pausa>/ ¿ o no? <pausa>/ ¿quién es el del hilo negro?/ <referencia a uno de los entrevistadores $>/$ simpático el caballero/ iestá buena ah? //Entonces<pausa $>$ / obligado para hacer las cosas en el momento<pausa $>$ ientienden o no? <pausa $>$ / saco la t/ queda cojo<pausa $>/$ icierto? le pongo una t y lo arreglo<pausa $>\mid$ buena esa $<$ riendo $>\mid<$ pausa $>\mid$ a veces digo (CRE-H-04).

Frente a respuestas de este tipo, el entrevistador tiene que componer la información que pueda servir como clave para comprender la respuesta. Esta dificultad en la selección de información relevante se debe probablemente al deterioro de la memoria (Truscott, 1970) o a la dificultad de realizar juicios de credibilidad sobre sus propias emisiones (Anand, Gales, Jackson, y Copolov, 1994; Kuperberg et al., 1998; Tamlyn et al., 1992).

En este trabajo, estudiamos los fenómenos asociados a estos niveles que la literatura asegura que son los de mayor déficit. Agrupamos los fenómenos, en recursos y conductas discursivas en seis núcleos de análisis, que pretenden indagar cuál es el perfil lingüístico que ostentan los pacientes en el marco de la entrevista clínica.

\subsubsection{Fenómenos de la fluidez discursiva:}

Lo referente a la fluidez del discurso en estas personas ha sido tradicionalmente estudiado desde diferentes disciplinas y se ha considerado la fluidez verbal, en general, 
desde un punto de vista eminentemente cuantitativo, y se la pretende evaluar con diversos instrumentos que no dan cuenta de la complejidad de los procesos cognitivos, sociales y no sociales subyacentes a la interacción comunicativa. En el presente trabajo se pretende abordar el concepto de fluidez verbal desde una perspectiva más amplia, que incorpore los elementos intersubjetivos del proceso comunicativo.

La definición tradicional del concepto de fluencia-fluidez reúne en sí misma una multiplicidad de procesos intrapsíquicos e interaccionales. De esta forma, se constituye en un requisito indispensable para el logro de una adecuada eficacia comunicativa. En palabras de Menjura (2007) la fluidez verbal hace referencia, por una parte, a la cantidad de información por unidad de medida que un hablante es capaz de emitir cuando produce un discurso y, por otra, se refiere también a la calidad de la información emitida. Resulta evidente que ya que no basta con producir muchas palabras por minuto, sino que también producir un discurso que progrese, temáticamente, un discurso que muestre un desarrollo y que avance hacia una meta discursiva. Debido a su importancia se ha definido el concepto desde diversas disciplinas, entre las que destacamos las perspectivas que reseñamos a continuación:

La lingüística general la define como la habilidad de llenar el tiempo con habla, b) la habilidad de hablar de forma coherente, razonada y con frases — semánticamente densas, c) la habilidad de decir cosas apropiadas en una amplia gama de contextos y d) la habilidad de algunas personas de ser creativas e imaginativas en el uso del lenguaje. (Traducción Pradas Macías, 2004:106). Más específicamente en la psicolingüística, sobresale el trabajo de Goldman-Eisler, quien plantea como objetivo:

Analizar la posibilidad de aislar del fluir del habla espontánea algunos elementos que sean indicativos de los distintos niveles de la producción de habla y que sean medibles. (Goldman-Eisler, 1964, apud Pradas Macías, 2004:106).

Consistente con esto, destacamos la observación de Belinchón; 
La fluidez es la realización fonoarticulatoria de los discursos, que facilita, en el interlocutor, la automatización de los procesos implicados en las fases iniciales de la percepción y comprensión del habla. (Belinchón, 1998:137)

En la neuropsicología, se ha trabajado tradicionalmente con el concepto de fluidez como la habilidad para generar respuestas verbales con ciertos criterios provistos externamente (Turner, 1999). Se describen dos tipos de fluidez: la fonológica y la semántica. La fluidez fonológica se refiere a la capacidad de generar palabras a partir de una cierta letra determinada (Luteijn y Barelds, 2004). La fluidez semántica determina que las palabras deben ser generadas con base en una categoría semántica (Benton, 1968). Ahora, bien la evaluación de la fluidez desde la perspectiva neurocognitiva se inicia, entre otros, con Thurstone (1938), en cuyos trabajos es posible verificar que la fluencia verbal se evaluaba de manera oral y escrita (Oyarzún, 2014).

La evaluación de esta dimensión se ha incorporado al trabajo neuropsicológico y se recurre, principalmente, a los paradigmas semántico y fonológico (Thurstone, 1931; Newcombe, 1969). Su evaluación tradicional comprende pruebas del tipo fonológico con restricción (por ejemplo, diga todas las palabras que empiecen con la letra $/ \mathrm{p} /$, en un minuto) y semántico nombrado de elementos que pertenezcan a una categoría (por ejemplo, diga nombres animales).

Al presente, se han relacionado áreas corticales con este tipo de tareas, por ejemplo, Martin (1994), quien relacionó la fluidez verbal fonológica con el córtex prefrontal y la fluidez semántica al córtex temporal. En estudios posteriores, sin embargo, se ha encontrado que las fallas en ambas tareas pueden asociarse a daño frontal (Henry, 2004; Baldo y Shimamura, 1998; Schwartz y Baldo, 2001).

Lezak (1995) observa que las palabras generadas se encuentran organizadas en cadenas, que muestran que a la base de la producción verbal se encuentra la generación de estrategias para evocar una mayor cantidad de palabras. De esta forma, al solicitarse por 
ejemplo la categoría animales, se aprecia una tendencia a nombrar animales de la selva, domésticos, aves, etc. Sin duda, la fluidez es un concepto que abarca una gran cantidad de funciones cerebrales; sin embargo, pensamos que su evaluación con este molde tradicional, deja fuera aspectos aclaratorios relevantes de la condición comunicativa del paciente.

En el Análisis del discurso, desde hace algunas décadas, ha desarrollado diversas líneas de investigación para estudiar la comunicación oral, desde una perspectiva que contenga el concepto de competencia comunicativa y, con ella, la fluidez que, a nuestro juicio, debe ser evaluada sin intervención de tareas experimentales:

El análisis de la conversación se propone revelar de qué manera los aspectos técnicos del intercambio verbal se constituyen en los recursos estructurados organizados socialmente por medio de los cuales los participantes realizan y coordinan actividades hablando-en-interacción. Se considera que el habla es un vehículo para la acción social y también uno de los principales medios con que se construye y se mantiene mutuamente la organización social en la interacción entre las personas. De aquí que se vea como un lugar estratégico en el que se puede estudiar de forma empírica y rigurosa de qué manera los agentes sociales, en su interacción, se orientan hacia contextos sociales y evocan esos contextos (Huchtby y Drew, 1995: 183-84)

El discurso oral contiene un sin fín de recursos paraverbales que tienen por objetivo, mantener el vínculo comunicativo con el interlocutor. Las pausas, los silencios, los falsos inicios, los tartamudeos, los titubeos, la tos, las risas, los suspiros, los alargamientos, de una u otra forma, contribuyen a mantener la comunicación abierta, además de proporcionarle un tono emocional cuando sea necesario. Si entre las personas sin patología psiquiátrica se registra esta clase de fenómenos, ¿cómo se interpretan en las personas con esquizofrenia? Nuestros hallazgos indican que este grupo de fenómenos presenta déficits a lo largo de todas las etapas de la enfermedad, ya que incide negativamente en la calidad del discurso, lo hace dificultoso, entrecortado e incomprensible.

Entonces, la evaluación de la fluidez desde un punto de vista lingüístico debe contener, como ya hemos señalado, la posibilidad de que ocurra un eficaz intercambio comunicativo, de manera que la aplicación de este tipo de tareas no intervengan en los resultados. Para este trabajo incluimos la observación de los fenómenos que explicamos en lo que sigue: 
Titubeos: se trata de la producción de uno o más sonidos que no tienen relación estructural con la decisión léxica siguiente, consideramos pausas oralizadas (ej: "mmm", “eeeh"), muletillas (ej: “claro”, “o sea”, “jentiende?”, “¿cierto?”), repeticiones innecesarias de alguna palabra o frase (ej: “es como si”) y alargamientos de sílabas (ej: “aaantes”)

Falsos inicios: es una interrupción inmediata que afecta al primer fonema, morfema, palabra, o frase. A menudo se reformula la expresión, aunque el paciente no siempre logra una versión más informativa. (ej: "por faltar... por falta de... me faltó un remedio").

Pausas extendidas: se considera pausa extendida cuando se produce la interrupción en el flujo de los turnos de habla. Según los parámetros propuestos por Crockford y Lesser (1994), se considera pausa extendida si esta interrupción supera los dos segundos.

Tartamudeos, se trata de la repetición de un fonema, sílaba o parte de una palabra; esta repetición no cumple ninguna función comunicativa y, generalmente, no forma parte de la frase u oración (ej: con...con...co...congé...congenia).

Turnos de habla con volumen débil: se trata de la dificultad que se genera a partir del bajo volumen de voz utilizado por el paciente. Las elocuciones se vuelven apenas audibles, los pacientes parecen musitar sus respuestas, incluso si las condiciones ambientales son óptimas para escuchar, es decir, una sala con buena acústica.

\subsubsection{Fenómenos de la productividad verbal:}

En este cluster se reunieron los fenómenos que apuntan al volumen de la producción verbal de los pacientes. La productividad verbal está entendida como la capacidad para emitir y comprender enunciados nuevos, ajustándose a la situación comunicativa que los genera, de acuerdo con Aitchison (1988). Este ajuste debe seguir reglas lingüísticas, además de semántico-pragmáticas. La concepción de calidad en el discurso no se refiere 
aquí a una cuestión meramente estilística, sino de efectividad comunicativa. Los hablantes que integran este corpus no fueron filtrados por su nivel educativo como criterio central (se seleccionó la enseñanza primaria completa como el mínimo educacional, ya que hay pacientes muy jóvenes que todavía están cursando estudios secundarios) Por otro lado, es importante aclarar que muchos pacientes crónicos se encuentran en una situación de menoscabo económico, ya sea porque proceden de estratos socioeconómicos bajos o porque la enfermedad les ha impedido un desarrollo laboral, educativo y social, en general; esta situación puede dificultar el acceso al código escrito y, por ende, a un nivel culto formal, pero de ninguna forma es un impedimento para el desarrollo de la competencia comunicativa.

En este grupo de fenómenos se incluyeron algunos de los aspectos estructurales, es decir, del material lingüístico con el que los entrevistados elaboraron sus intervenciones. La evaluación de los volúmenes de la producción discursiva, es un indicador de cómo y de qué se componen las estructuras empleadas por los hablantes. Sabemos que la elaboración de la información es una actividad sometida a reglas y que por tanto, debe presentar aspectos regulares.

Total de oraciones y promedio de palabras por oración: dentro de este grupo de fenómenos, nos interesa observar el comportamiento de las oraciones, esto es, el total de oraciones y el promedio de palabras por oración. Las relaciones lógicas que se establecen a nivel de oración o frase están en estrecha relación con la intención del emisor. Por tanto, si las oraciones tienen una extensión superior a 30 elementos o inferior a dos o tres, generarían discontinuidad si se presentan seguidas o si predominan en la intervención. Según Moreno (2010), el promedio de palabras por oración en personas sin patología psiquiátrica o neurológica es de 12,4 palabras por oración. La literatura ha señalado que cuando los elementos sintácticos superan los tres o cuatro, la elaboración oracional en los pacientes se vuelve dificultosa (Addington y Addington, 2000; Chaika y Lambe, 1989). También se ha señalado que el número de nexos oracionales es menor que el que presentan los controles, esta característica le restaría foricidad al discurso y en consecuencia de 
sentido (Leroy y Beaune, 2008). Además entre los turnos de habla, pueden observarse exceso de monólogos que evidencian un grado de autismo en estos pacientes (Salavera y Puyuelo, 2010).

Entre pacientes crónicos puede darse que, a pesar de su deterioro cognitivo, pueden hacer uso de conectores de forma inadecuada, ya que al sumar elementos gramaticales en sus oraciones, pierden el hilo con frecuencia. La estructura de los conectores, más no su función discursiva parecen quedar en la red semántica de algunos pacientes, que entonces los aplican cuando surgen en su memoria. Probablemente, el hecho de que sean unidades lingüísticas invariables ya que:

[...] no ejercen una función sintáctica en el marco de la predicación oracional — son, pues, elementos marginales - y poseen un cometido coincidente en el discurso: el de guiar, de acuerdo con sus distintas propiedades morfosintácticas, semánticas y pragmáticas, las inferencias que se realizan en la comunicación (Zorraquino y Portolés en Ignacio Bosque y Violeta Demonte, Gramática descriptiva, 1999:4057)

Se cristalizan en la memoria, pero sin funcionalidad discursiva, no sirven para unir de forma explícita segmentos textuales, por tanto, las relaciones semántico-pragmáticas se ven debilitadas en el enunciado. Ya no aportan sentido para comprender el significado de la unidad discursiva o de sus segmentos. A pesar de estas graves deficiencias, la mayoría de las veces, las oraciones son gramaticalmente correctas. Si bien la mayoría de los pacientes presentan una sintaxis empobrecida (Chaika, 1978) ésta sigue siendo funcional, en la mayoría de los casos. Un hecho que nos llamó la atención es que en el corpus de pacientes de esta tesis, encontramos algunas paradojas al respecto. Observamos que existe una correlación entre las reservas cognitivas previas a la enfermedad y el uso de una sintaxis más elaborada; aquellos pacientes que alcanzaron niveles de estudio más avanzados, presentaron este rasgo gramatical. A pesar de este hallazgo, no nos aventuramos a asegurar que sea un rasgo lingüístico, ya que habría que estudiar un corpus compuesto por más individuos y que contemple el criterio de estudios superiores como variable.

Número total de palabras diferentes (no repetidas), número total de neologismos parciales y número total de neologismos totales: en la literatura científica se destaca el 
componente léxico, tanto por su singularidad como por su volumen en la esquizofrenia. Lo que genera atención sobre estos elementos linguiísticos es la utilización de ítemes léxicos poco frecuentes. El léxico rebuscado y manierista pareciera ser más común que entre los controles. La utilización de acepciones léxicas en contextos semánticos que pueden relacionarse, pero no son directamente significativos, es una prueba de que puede servir de marcador por sí mismo (Baskak, Tugba, Cem y Baskak, 2008; Cechirini-Nelly y Crow, 2003; Holzman, Shenton y Solovay, 1986) Lamentablemente, no existen trabajos que avalen esta observación y podría ser materia de un futuro estudio.

En lo tocante a esta tesis, nos interesa corroborar si el volumen léxico presenta diferencias en comparación con los controles. Incluiremos todas las palabras empleadas por el entrevistado descontando las que se repiten. Esto significa, dejar dentro del conteo los marcadores del discurso, conectores y enlaces, que aunque no aportan significado por sí solas, son parte de los recursos de los participantes. Como se trata de comparar volúmenes, solo discriminaremos cuántas de estas palabras no se repiten. Asumimos que, dado el deterioro en las funciones ejecutivas, es probable que el volumen de palabras de los pacientes se vea desmedrado. Asimismo, tras observar el comportamiento comunicativo reticente en pacientes de primer episodio, nos parece que este factor también puede vincularse a un volumen léxico restringido.

En torno a los neologismos, su singularidad, es un tema que ha fascinado a muchos estudiosos, tal como citan Álvarez y de la Peña (2008)

De esa singularidad se hizo también eco Enrico Morselli cuando, al final de sus comentarios, observó que las creaciones neológicas de los alienados no se comparten entre ellos, aunque vivan durante muchos años en el mismo manicomio. Cosa bien distinta es la que se advierte en las prisiones, donde los nuevos términos inventados por los criminales acaban incorporándose al vocabulario general de la jerga con la que se comunican. Para el neologismo del alienado vale aquella máxima de Suetonio: "Tú, César, puedes darle la ciudadanía a un hombre, pero no a una palabra" (Álvarez y de la Peña, 2008:361). 
Enrico Morselli Módena, fue el primer director del manicomio de Macareta y más tarde de las clínicas psiquiátricas de las Universidades de Turín y Génova. Fundó revistas especializadas como Antropologia generale (1888) y Manuale di semiotica delle malattie mentali (1896). Tanzi, aporta una sistematización y una visión general sobre el fenómeno, destacando el papel preponderante que adquiere el neologismo en los delirios crónicos, "flor y nata de la ideación delirante". Por otra parte, Seglás distingue entre pasivos y activos; los primeros serían resultado de procesos automáticos, en cambio los segundos, corresponden a procesos voluntarios, estarían creados conscientemente. Sobre éstos últimos, Séglas (1892) señala que pueden ser palabras completamente nuevas, o palabras existentes utilizadas en otro medio semántico, pero que no poseen sentido más que para el paciente.

Con posterioridad, es Lacan (1981) quien le dedica especial importancia a la presencia de neologismos en el discurso de los psicóticos. Realza el hecho de que su carácter críptico le confiere una separación radical del discurso de los sujetos sanos.

Frente a la emergencia de nuevas realidades que deben nominarse, el lenguaje humano establece soluciones léxicas muchas veces novedosas, entonces, ¿cuál es la diferencia entre estos términos y el neologismo surgido en la psicosis? La cultura proporciona contornos definidos acerca de los límites posibles para un nuevo término. La lengua es convencional, sistemática y social y la adquirimos por estar inmersos en ella, de la misma forma en que compartimos visiones de mundo al interior de la comunidad de habla que integramos. La diferencia que se instaura es la aceptabilidad por el consenso que concede el hecho de compartir un significado. Si un hablante es capaz de reconocer y comprender la morfología de un término, sumando este conocimiento al contexto en que se utiliza se mantiene la funcionalidad semántica, incluso si el término es "nuevo".

Entre las personas con esquizofrenia, los neologismos, en cuanto a originalidad, superan ampliamente las expectativas lexicográficas y morfológicas. No solo pueden ser 
completamente nuevos, sino que, además, su significado permanece oculto para el receptor, inclusive si el entrevistado logra explicar lo que significa el término:

[6] 35. E: ¿Y cómo le hicieron le tuvieron que hacer una operación o/ cómo le hicieron eso?

36. S: Es que ellos son eleotósticos

37. E: ¿Cómo?

38. S: Ellos son eleotósticos.

39. E: Disculpe/ no le entiendo.

40. S: Ellos son eleotósticos /<repite pronunciando mejor $>/$

41. E: ¿Eleotósticos?/ ¿Y qué significa eso?

42. S: son los que hablan mentalmente con las personas/ <pausa>/ ¿me entiende?

43. E: Ya.

44. S: hay un libro sobre eso.

(PEE-H02)

Una cuestión relevante en la evaluación de los neologismos, es que no representan un fenómeno ni frecuente ni abundante. Por peculiares que éstos sean, su aparición no es regular. En el corpus de pacientes de este trabajo, su aparición fue restringida a cinco pacientes, por lo que no fue un rasgo importante en comparación con otros fenómenos lingüísticos.

\section{Total de referentes; total de vínculos referenciales $y$ promedio de vínculos} referenciales: como ya hemos precisado, nuestro objetivo es evaluar el perfil lingüístico de los pacientes en virtud de su eficacia discursiva. La incorporación de estas medidas tiene el propósito de visualizar si se puede comprobar que, a pesar de que el discurso esquizofrénico demuestra que el lenguaje puede contener muchos enlaces cohesivos, aún así dejar de ser coherente. La coherencia del discurso, como ya hemos señalado, es ese atributo de los textos (hablados y/o escritos) que captura lo bien que las partes componentes pueden tener unidad temática. El lector/oyente le asigna un grado de 'calidad' que es una medida que representa el nivel o grado en que el texto se mantiene unido (Hoey 1991:265266). Mientras que los oyentes y lectores a menudo pueden identificar con facilidad cuando un texto es incoherente, es en general más difícil decir qué característica o características lingüísticas contribuyen a una impresión subjetiva de la incoherencia. 
La RAE (2005) define referente como:

Entidad (persona, animal o cosa) a la que se refiere un signo lingüístico. Así, el referente del sustantivo 'mesa' en 'La mesa de mi despacho mide dos metros' es la mesa concreta a la que se refiere el que habla, distinta de cualquier otra $[\ldots]$

Fuente:http://www.rae.es/diccionario-panhispanico-dedudas/terminoslinguisticos\#sthash.3aATcGfK.dpuf

Los referentes muestran nudos informativos a los que el receptor dirigirá su atención, por tanto, el emisor deberá explicitar lo mejor posible las relaciones causales, temporales y espaciales que los unen para dar cuenta de los objetivos comunicativos. No olvidemos que cada elemento discursivo contribuye, en menor o mayor cuantía, al proceso de gestión temática del discurso. Si se presenta gran cantidad de referentes, éstos deberían ir acompañados de enlaces y elementos conectivos que los vinculen entre sí o que permitan inferir esas relaciones. Ahora bien, si esos referentes no van vinculados, es decir, si se presentan con un carácter nominativo, generan una impresión de discurso abigarrado, por ende, no informativo.

Si la cantidad de referentes y su relación con los vínculos referenciales es desproporcionada, estas características lingüísticas y discursivas contribuirán a esta impresión de incoherencia. Hemos encontrado que la reiteración de referentes es constante, ya que no se emplean estrategias correferenciales que eviten la redundancia. Además, encontramos frases verbales y sintagmas nominales repetidos con exactitud, en varias ocasiones. El efecto de esta repetición es que el oyente no logra la sensación de que el hablante está haciendo algún progreso en su exposición discursiva. El entrevistado sigue revisando los mismos puntos, a pesar de haber incorporado más referentes.

Otro asunto que puede pesquisarse es la ausencia de correferencialidad registrada en la inadecuada utilización de los deícticos, los pronombres personales u otras estructuras con función anafórica, ya que no cumplen con la función orientadora-actualizadora necesaria para la progresión temática, en especial, si la cantidad de referentes discursivos es insuficiente o excesiva. Otra cuestión que observamos tiene que ver con la cantidad y frecuencia de estas estructuras, esto es la presencia de varias anomalías sintácticas 
incluyendo la omisión de referentes (de persona) en cláusulas incrustadas y/o construcciones oracionales incompletas. El efecto combinado de estas diversas características lingüísticas y discursivas que genera en el oyente se quede con muchas preguntas sin respuesta y mucha confusión, de hecho, una sensación de que el entrevistado no ha tenido éxito en la presentación de una explicación coherente. Estas dificultades en el diseño de los referentes y sus vínculos contribuyen a la impresión de que es difícil seguir al entrevistado.

\subsubsection{Fenómenos del Índice de participación conversacional (IPC)}

Este indicador tomado del protocolo de cuantificación de conductas conversacionales de (Crockford y Lesser, 1994), y se relaciona con la tradición psicolingüística de medida de la longitud media de un enunciado (MLU) ${ }^{11}$. Desde una perspectiva pragmática, de eficacia comunicativa, el IPC sería una manera de valorar la intencionalidad participativa del hablante. Este indicador permite tomar en cuenta las habilidades para tomar el turno de habla y mantener un ritmo de interacción que posee parámetros regulares.

Braun, et al. (2004), citados por Gallardo y Hernández Sacristán (2013), quienes se refieren a la densidad de la conversación. Clasifican la producción de los hablantes con déficit verbal; en un extremo estaría el completo silencio, al que denominan mutismo acinético, que se daría por la renuencia a hablar por estar sometido a una extrema presión psicológica derivada de procesos mentales o emocionales, este mutismo estaría activado por el hemisferio derecho, especialmente por el lóbulo frontal. El contraste se daría cuando se presenta logorrea o hyperlalia, conducta que estaría activada por el hemisferio izquierdo, y por el lóbulo frontal en específico, y que se traduce en una auténtica incontinencia verbal, un parloteo sin pausa.

\footnotetext{
${ }^{11}$ MLU: Mean Length of Uterance, trabajo de Brown en la década del 70, citado por Gallardo-Páuls, 2013
} 
Esta es una construcción que puede operacionalizarse con facilidad, dado el conteo del número de palabras expresadas por unidad, en este caso tomamos en cuenta, el volumen producido en los turnos del segmento de entrevista que seleccionamos.

Total de palabras utilizadas: Gallardo y Hernández Sacristán (2013) indican que puede estar definido en términos locutivos, como el número total de las palabras utilizadas por el sujeto estudiado. También puede ser medido en términos comunicativos, en cuanto al número de actos de habla empleados por el hablante. En este estudio utilizaremos la primera medida sugerida por los autores.

La agilidad del turno: se contará el promedio de turnos de habla por minuto. Es una medida relativa, pero puede ser funcional al compararla con los promedios de turnos empleados por hablantes de un corpus como el ESECH, del español de hablantes de Santiago de Chile, que arrojó un promedio de 6 turnos por minuto.

Ambos indicadores se complementan con las medidas de fluidez verbal que ya describimos.

\subsubsection{Fenómenos de la Coherencia temática:}

Al mirar la unidad discursiva completa, puede inferirse que los pacientes comprenden lo que se les pregunta; no obstante, a pesar de su comprensión, la elaboración de las respuestas es poco informativa y a menudo enrevesada o saturada de elementos secundarios al tema que se discute. Esta característica se enmarca dentro de las dificultades macroestructurales del discurso esquizofrénico. El que no se contemplen principios inherentes a la situación comunicativa como lo propone la teoría de la relevancia, finalmente representa un alto costo de procesamiento para el entrevistador:

Siendo las demás cosas iguales, la más relevante de dos proposiciones en un contexto dado es aquella que requiere menor procesamiento. [...]Nuestra afirmación es que la interpretación que el hablante intenta que se haga y la que el oyente debe elegir, es aquella que satisface un principio de relevancia máxima (Sperber y Wilson, 1991:585)

Tomados en su conjunto, estos aspectos aparentemente no configuran barreras infranqueables para que la interacción en personas con esquizofrenia. Sin embargo, es sabido por todos que la singularidad de los fenómenos discursivos en las personas con 
esquizofrenia es por completo inusual, Covington (2005), en una revisión crítica, incluye estudios que datan del siglo XIX, que investigaron lo que habitualmente se examina, el lenguaje esquizofrénico por niveles, es decir, fonético, morfológico, sintáctico, semántico y pragmático. A contar de esta revisión, habría dos tipos de deterioro registrados en la literatura. El primero de ellos corresponde a diversas dificultades de carácter disfásico, como expresiones ininteligibles, prosodia aplanada o monocorde, etc. Un segundo grupo de fenómenos estaría relacionado con la planificación de los mensajes, como la dificultad de explicitar un tema central, o presentar frecuentes saltos topicales. Evidencias que suman fuerza a la interpretación de que el lenguaje en la esquizofrenia se ve afectado, prioritariamente, en su nivel semántico y pragmático, además de los otros niveles mencionados.

Siguiendo la taxonomía de van Dijk (1996) incluimos el concepto de macroestructura, para dar cuenta de la configuración general del discurso de los pacientes, en ella, incluimos la coherencia temática, contenida en recursos como la elaboración de: i. Unidad temática nuclear reconocible; ii. Proposiciones con vínculos explícitos respecto del tema central; iii. Proposiciones con vínculos implícitos respecto del tema central. Los criterios que utilizamos para considerar coherente la macroestructura son los que propone, van Dijk (1996). Como sabemos, la llamada macroestructura corresponde al contenido semántico global que representa sentido en un texto/discurso. En términos de análisis del discurso, ha de contener un núcleo informativo fundamental, que es el asunto o tema del que se trata, a fin de constituirse en unidad discursiva. Las proposiciones con vínculos explícitos o implícitos respecto del tema serán otras de las evidencias que buscaremos para establecer el grado de coherencia interna que presenta la intervención del entrevistado. Valiéndonos del principio de cooperación de Grice, podemos observar la relación semántico-pragmática que puede darse en estas estructuras lingüísticas, ya que darán cuenta de cómo el entrevistado organiza, jerarquiza y relaciona la información propuesta, para hacerla accesible para su intelocutor y si este proceso es exitoso o no.

Sabemos que la comunicación involucra no solo estructuras lingüísticas, sino que fundamentalmente procesos, que puedan proporcionar un significado general que posea 
sentido en sí mismo. La interacción involucra, además, la intención y la actitud de los participantes en torno a los enunciados. Por tanto, la macroestructura será el nivel profundo que debería alcanzar un hablante.

La microestructura corresponde a la estructura superficial, es decir, la coherencia local, que da cuenta de cómo se dispone la información. De qué forma los elementos lingüísticos están relacionados entre sí, cómo las microproposiciones contribuyen o no a la comprensión global de la unidad discursiva. Renkena (1999) la ha definido como "la trabazón morfosintáctica del texto", aludiendo a sus propiedades estructurales, que descansan sobre recursos gramaticales. Petöfi (1978) la considera como un conjunto de mecanismos lingüísticos que sostienen la congruencia lingüístico-comunicativa del texto/discurso. Algunos de los recursos que mantienen esta congruencia son, por ejemplo, la repetición, la elipsis, la sustitución, etc. En este trabajo, incluimos principalmente las siguientes estructuras para su análisis: i. Tópico con referente; ii. Salto topical y iii. Referentes y vínculos referenciales.

Los tópicos, serán entendidos discursivamente como el marco al que se ha de atener de forma acotada el hablante, es decir, como señala Gutiérrez Ordóñez (2000):

Se trata de señalar el universo de discurso a cuyas fronteras se han de atener los que ostenten la palabra en sus referencias y denotaciones. Es asimismo la palestra delimitada donde se desarrollan los procesos significados por el verbo y el campo de validez veritativa del enunciado (Gutiérrez Ordóñez, 2000, p.40).

O presentan los rasgos que propone Escribano (1991):

Los tópicos son constituyentes prosódicamente desgajados, recubiertos de curvas de entonación que finalizan en semianticadencia, que concretan la capacidad referencial de ciertos elementos integrados, por lo general clíticos, y que a veces van introducidos por expresiones especializadas como en cuanto a, por lo que respecta $a$, etc. (Escribano, 1991:362)

En el proceso comunicativo, se establecen marcos referenciales que acotados como son permiten una comprensión óptima del segmento en cuestión. Hemos observado que entre las personas con esquizofrenia este recurso presenta déficit en su delimitación como estructura. Incluso, pudimos corroborar la existencia de palabras o conceptos tipo eslogan, 
que no guardan relación con las estructuras discursivas contiguas, que se trazan como una introducción topical que queda vacía. Es decir, se bosquejan como un referente del cual se espera un desarrollo topical, esto es, un microtema delimitado. Entonces puede ocurrir una de las situaciones siguientes: mediar la intervención del entrevistador, para inquirir en forma explícita sobre el particular, en ocasiones es posible que el entrevistado consiga completar los límites que él mismo ha propuesto. O bien, como observamos en otras muchas ocasiones, dejan pendiente lo enunciado, a pesar del modelamiento del entrevistador, generando una sensación de perplejidad en el receptor.

Ligado a este concepto, encontramos los saltos topicales, es decir, los cambios de tópicos sin mediar algún tipo de enlace lingüístico, como conectores. Para este trabajo tomamos este rasgo como una alteración de la progresión temática, requerimiento lógico para el desarrollo de un tema global. Si el hablante ha propuesto un tópico, precisará los límites, y al requerir inclusión de información nueva, empleará estrategias discursivas para dirigir la atención del interlocutor a la nueva información, minimizando sus posibilidades de incomprensión. Algunos de estos recursos corresponden a reformulaciones, paráfrasis, repeticiones y sustituciones, entre otros. Entonces, para esta tesis doctoral, los saltos topicales han sido considerados como alteraciones o déficit de la coherencia local, ya que de la forma en que se presentan no contribuyen a aumentar el seguimiento del tema, desorientando al receptor.

Por otro lado, la relación que se da entre los referentes y las partículas gramaticales que los vinculan presenta el mismo tratamiento lingüístico deficiente entre las personas con esquizofrenia crónica. Si contamos la cantidad de referentes que se dan en una determinada porción discursiva, los pacientes crónicos presentarán una desproporción en cuanto a la cantidad de referentes y el promedio de vínculos que amplían la información referencial, en comparación con los controles. Como ya sabemos, esta estructura está íntimamente ligada al fenómeno de la progresión temática, lo mismo que ocurre con los tópicos y los posibles saltos topicales. Las deficiencias en la elaboración de estas estructuras suele estar encadenada, ya que conceptualmente es improbable una progresión sin ampliar los 
referentes, que se vinculan por medio de unidades lingüísticas, o bien, cambiar de tópico para ahondar en alguna cuestión más peculiar.

También nos parece importante precisar que, para este trabajo, también nos apoyamos en el concepto de coherencia de Beaugrande y Dressler (2003) que se basa en la estabilidad de un texto o discurso como unidad completa. Ambos autores señalan que si el concepto significado se emplea para designar la capacidad de una expresión lingüística para representar y/o transmitir conocimientos, entonces el término sentido se referirá al conocimiento transmitido de forma efectiva. Si dicho sentido intencionado, que ha sido incorporado por uno de los interlocutores se mantiene inaccesible de forma sostenida en el tiempo para el receptor, se convierte en ambigüedad (si no era este el propósito del emisor) o polivalencia si la intención del emisor es transmitir varios sentidos. La selección de unos $\mathrm{u}$ otros sentidos es una cuestión que descansa en complejos procesos mentales. En consecuencia, un texto/discurso tiene sentido cuando dicho sentido representa o se compone de una continuidad. La detección de ausencia o problemas de continuidad da como resultado la percepción de un discurso incoherente, en virtud de una serie de desajustes entre las relaciones de los elementos expresados y/o su arquitectura global. Entonces, la continuidad de sentido es la base de la coherencia, es decir, que la propiedad de los conceptos y las relaciones que se expresan inferencialmente, permanezcan accesibles e interactúen de forma relevante entre sí. Para que un texto/discurso sea considerado como una unidad discursiva, y no como un mero conjunto de oraciones, debe cumplir aunque sea en forma parcial con siete estándares: cohesión, coherencia, intencionalidad, aceptabilidad, situacionalidad, intertextualidad e informatividad. Para que puedan verificarse dichos estándares, se aplican tres principios comunicativos, es a saber, i. Eficacia; ii. Efectividad y iii. Adecuación.

i. La eficacia, depende de que quienes intervengan en la interacción optimicen los resultados o productos comunicativos empleando un bajo costo de procesamiento.

ii. La efectividad, tiene relación con las consecuencias en cuanto a impacto comunicativo que alcanza lo planteado en el receptor. 
iii. La adecuación, es la estabilización entre la satisfacción de las demandas informativas del receptor y la accesibilidad al o los sentidos del texto/discurso.

De no cumplirse estas demandas, un texto/discurso, no puede ser considerado comunicativo. Una precisión que nos plantea Petöfi, (1978), es que la condición fundamental para que un texto/discurso sea adecuado es que sea funcional, comunicativamente. Las posibles dificultades que tenga un texto/ discurso pueden ser compensadas por los participantes de la interacción, de esta forma, no sería necesario que se cumplan todos los requisitos.

2.5.6. Fenómenos de la semántica de la coherencia:

La semántica de la coherencia es un concepto que hemos tomado del modelo de Van Dijk, y que se refiere a las relaciones semánticas que nos sirven para entender los límites ficcionales de un texto/discurso. Aristóteles aborda la ficción (literaria) como un ejemplo para representar de forma verosímil la realidad, que denomina: "mímesis". La semántica modal, por su parte ha proporcionado la noción de mundo posible, (Van Dijk, 1988):

Obsérvese que la noción de mundo posible no debe identificarse con nuestras ideas intuitivas de (nuestro) "mundo", "realidad", etc., sino como un constructo abstracto de teoría semántica (teoría de modelos). Un mundo posible, como el término posible sugiere, es también un estado de cosas que no es verdadero, pero que podría haber sido verdadero. Esta posibilidad puede ser de varios tipos: podemos imaginar una situación donde los hechos son diferentes de los hechos reales o verdaderos, pero compatibles con los postulados (leyes, principios, etc.) del mundo real (van Dijk, 1988:61)

La clave de interpretación es evaluar no si lo referido es verdadero o falso, sino que si tienen compatibilidad o no con el mundo real. Si imaginamos mundos con leyes diferentes al nuestro, también estos mundos deberían satisfacer la misma serie de postulados.

El juicio de realidad es un concepto utilizado en psicopatología que se compone, entre otras cosas, de la semántica de la coherencia, ya que el paciente enjuicia su proceso mórbido, muchas veces como una experiencia impuesta y la referencia a sus vivencias no dan cuenta de una conciencia sobre la enfermedad. ¿Qué tipo de construcciones discursivas emplean para dar cuenta de este proceso mórbido? ¿La narración de sus 
vivencias puede ser representativa de sus juicios de realidad? Los alcances del concepto en psicopatología son más abarcantes que lo contemplado, en este estudio. El concepto ha sido discutido desde las diferentes escuelas de psiquiatría contemporáneas, y no existe consenso absoluto respecto a sus límites:

i. En el medio de Salud Mental chileno, se utilizan las tres etapas propuestas por Gomberoff (1999). Presencia/ausencia de alucinaciones o ideas delirantes: circunstancia en que se alude a si el paciente percibe o no el significado de estas manifestaciones, ya sea las tenga en el momento de la entrevista, o las haya tenido en otra ocasión. Se considera perdido el juicio de realidad si es que no le causan extrañeza. Sobre este punto en particular, no propusimos una evaluación lingüísitca, ya que nos parece muy complejo de sistematizar un haz de indicadores para etiquetar presencia o ausencia de alucinaciones o ideas delirantes.

ii. Mantención de criterios sociales: se confronta al paciente con algún aspecto bizarro que ha llamado la atención del clínico, en especial, si el paciente nunca ha tenido alucinaciones ni ideas delirantes, con preguntas del tipo: "veo que usted estaba cree/hace/piensa esto o reacciona de tal forma y esto me pareció raro ¿usted entiende que a mí me haya parecido extraño o es un problema mío?" El juicio de realidad conservado se daría si el paciente, en dicha confrontación explica la situación mejorando su entendimiento, o relativizando su planteamiento como posible o imaginado. Por el contrario, el juicio de realidad se denota perdido si el paciente no puede ver por qué a otra persona le resulte extraño cierto comportamiento.

iii. Identificar, en la interacción, mecanismos de defensa primitivos e interpretarlos: Se debe tener una visión global del paciente, tomar en cuenta su comportamiento y como responde a las preguntas del entrevistador. Las reacciones defensivas primitivas comienzan a aparecer en las estructuras limítrofes y psicóticas al pedirle al paciente que se describa y continúan apareciendo en el transcurso de la entrevista estructural. Ante las defensas del paciente, interpretar en el presente y ver la 
reacción de este. Los pacientes limítrofes mejoran con esta intervención, los psicóticos empeoran (Kernberg, 1987; Gomberoff, 1999).

De ellas únicamente consideramos la segunda etapa: mantención de criterios sociales, ya que por su perfil como fenómeno, nos parece que es factible hacer un análisis lingüístico para verificar la presencia o la ausencia del rasgo. Es posible dar cuenta de marcas textuales que evidencian aspectos semánticos de los juicios de realidad emprendidos por los pacientes. La autoasignación de roles y/o poderes fantásticos, experiencias imposibles o interpretaciones inverosímiles de la realidad para explicar su proceso mórbido será la base de nuestro registro. Nos basaremos en marcas semánticogramaticales como la utilización de construcciones del tipo:

[7] E: Sra. C/ me puede explicar ¿cómo es eso de la virgen María/ y lo de la reencarnación?

S: es que <pausa $>/$ la reencarna<pausa $>/$ reencarnación, porque que he resucitado varias veces y soy<pausa $>/$ y <pausa $>/$ yo soy María<pausa $>/$ yo para mí es mejor ser C B que la virgen María/ porque es menos la responsabilidad.

E: ya

(CRE-M03)

En suma, son atribuidas a instancias inverosímiles las razones, causas o las explicaciones con que los hablantes expresan su condición de estar padeciendo una enfermedad psiquiátrica como la esquizofrenia, o el hecho de estar hospitalizados. Para van Dijk (1988), un mundo posible es un conjunto de hechos particulares. Si bien al haber diversos mundos posibles, la coherencia puede convertirse en un concepto inestable, sigue operando a nivel inferencial, gracias a los modelos mentales con los que procesamos la información (Kinstch y van Dijk, 1983). Los usuarios de la lengua también construyen modelos de la situación comunicativa en la que participan. Se despliegan características de nuestro self, y éstas deben regirse por una coherencia interaccional. Suponemos que la interpretación de los hechos del mundo obedece a reglas que pueden ser aceptadas y/o procesadas por la comunidad a la que pertenecemos. Por tanto, son estos parámetros los que pueden evaluarse. 


\subsubsection{Fenómenos de coherencia interaccional}

La interacción es una de las evidencias base de la eficacia comunicativa, el intercambio es la representación del guión del principio de cooperación griceano.

En este contexto, es factible plantear que, comunicativamente, la interacción debiera considerarse como la capacidad de establecer un adecuado contacto con un interlocutor, involucrando la capacidad de mentalizar y, por ende, los procesos de cognición social, las habilidades pragmáticas y obviamente los procesos cognitivos subyacentes. Desde una perspectiva neurocognitiva, debido a la estrecha interrelación entre los diferentes subsistemas implicados en el lenguaje, se hace necesario considerar que un amplio espectro de procesos y mecanismos específicos del lenguaje son los que están incidiendo en la interacción comunicativa (Oyarzún, 2014).

Pares adyacentes: son enunciados mutuamente correspondientes, la presencia de la primera parte hace obligatoria la segunda parte del intercambio. La interacción nos provee de información lingüística, la que produce propiamente, y la que se infiere. En la esquizofrenia el deterioro puede impactar ambos tipos de expresiones. Los pares adyacentes son actos de habla que se presentan anclados uno al otro. Según la clasificación de Schegloff y Sack (1974) pueden ser:

1. saludo-saludo: como en el ejemplo de la definición;

2. pregunta-respuesta: A: [¿Has visto a Juan?]; B: [No, no lo he visto.]

3. ofrecimiento-aceptación/rechazo: A: [¿Quieres un café?]; B: [Sí, gracias]

4. agradecimiento-minimización: A: [Te agradezco la ayuda]; B: [No hay de qué]

5. petición-aceptación/rechazo: A: [¿Tienes un momento?]; B: [Dime]

6. llamada-respuesta: A: [iMaría!]; B: [¿Qué?]

7. disculpa-aceptación/rechazo: A: [Lo siento]; B: [No pasa nada]

8. aserción-acuerdo/desacuerdo: A: [Estoy segura de que ya lo sabe]; B: [Por supuesto]

9. cumplido-aceptación/rechazo: A: [iQué blusa más bonita llevas hoy!]; B: [Pues a mí no me acaba de gustar]

Toma de turnos: una característica interesante de las interacciones es que los cambios de turnos se producen, intuitivamente, de forma coordinada. Los cambios son organizados y 
pocas veces se dan fenómenos como superposiciones o interrupciones de turnos. Sacks, Schegloff y Jefferson (1974) señalan que los participantes de una interacción tienden a minimizar los solapamientos, las pausas y la toma de turnos, en sí misma. En el marco de una entrevista, la toma de turnos sufre aún menos alteraciones, al ser una estructura comunicativa basada en preguntas y respuestas, se modelan los tiempos de interacción y sus límites, generando un ritmo regular difícil de impactar. La construcción de turnos se apoya a demás en marcas como las pausas y las curvas entonacionales de las preguntas o declaraciones.

Las personas con esquizofrenia presentan dificultades en la toma de turnos, ya sea por los bloqueos que les impiden tomar el turno o, por el contrario, porque no lo ceden. En ambos casos, se presenta una conducta poco comunicativa, ya que el sentido del intercambio es colaborativo, rasgo del que carecen muchas emisiones de los pacientes con esquizofrenia.

Pensamos que la mayoría de los déficits lingüísticos principales que se presentan en esta patología, pueden ser observados y más relevante aún, evaluados sin mediar instrumentos ni pruebas, únicamente contando con la participación en entrevistas o interacciones espontáneas, ya que los niveles más afectados son el semántico y el pragmático, porque estos niveles son los que requieren mayor de un procesamiento atencional (Tényi, Herold, Szili y Trixler, 2002). Sin duda, este es un campo de investigación de enormes dimensiones, en el que este trabajo se propone contribuir a una determinada parcela. 


\section{Capítulo 3}

\section{Método}

«Una de las maneras más sencillas de entender el

funcionamiento de un sistema, es observar lo que

pasa cuando el sistema falla».

(Parkin, 1999) 
Capítulo 3

\subsection{La muestra}

Con el propósito de proporcionar una mayor representatividad de la enfermedad, la presente investigación fue realizada con una muestra no probabilística intencional. De una muestra inicial de 160 personas diagnosticadas con esquizofrenia, fueron seleccionados 50 sujetos de ambos sexos según los criterios que se describen en 3.3. La muestra final está compuesta por 25 pacientes con esquizofrenia crónica (CRE) y 25 pacientes diagnosticados con esquizofrenia de inicio (EI). Dichos pacientes fueron ingresados en tres diferentes servicios de Salud Mental de Santiago de Chile entre los años 2007 al 2013:

-De la red de Salud Mental Pública de Santiago de Chile:

A) Instituto Psiquiátrico del Hospital Sanatorio El Peral.

B) Departamento de Hospitalización Psiquiátrica de Corta Estadía del Complejo Asistencial Dr. Ramón Barros Luco Trudeau.

-De la red de Salud Mental Privada de Santiago de Chile:

C) Hospital de día del Instituto de Rehabilitación en Salud Mental, RENOVAL.

Para todos los pacientes incluidos en este estudio se confirmaron los diagnósticos por un equipo de psiquiatras senior, quienes utilizaron la estructura de la entrevista clínica para el DSM-IV (SCID-P; Primera et al, 1997a, b) y la escala de síndromes positivos y negativos PANSS Kay y cols ${ }^{12}$.

\footnotetext{
${ }^{12}$ Ver anexo
} 
Todos los pacientes esquizofrénicos que fueron incluidos en el estudio estaban en la fase de estabilidad clínica. Estaban recibiendo dosis orales estables de antipsicóticos atípicos por espacio mínimo de un mes y se encontraban en tratamiento y rehabilitación psicosocial en el caso de los CRE y al menos por tres semanas en el caso de los EI, quienes además estaban insertos en el programa AUGE (Acceso Universal de Garantías Explícitas en salud).

La participación en este estudio contó con un consentimiento informado escrito firmado por los pacientes o sus cuidadores ${ }^{13}$.

\subsubsection{Grupo 1 pacientes con esquizofrenia crónica $(\mathrm{CRE})=\mathrm{N} 25$ :}

\subsubsection{Instituciones:}

Los sujetos de esta muestra corresponden a 25 pacientes afectados por esquizofrenia crónica. Fueron reclutados de la red de Salud Mental Pública de Santiago de Chile: A) Instituto Psiquiátrico del Hospital Sanatorio El Peral; B) del Departamento de Hospitalización Psiquiátrica de Corta Estadía del Complejo Asistencial Dr. Ramón Barros Luco Trudeau. Fueron entrevistados por un equipo de Salud Mental compuesto por psiquiatras, becados de psiquiatría y una lingüista.

\subsubsection{Género}

Este grupo está compuesto por 13 hombres y 12 mujeres. En ambos corpus de pacientes, decidimos incluir más sujetos de sexo masculino, a pesar de que tradicionalmente no se ha considerado la incidencia y prevalencia del género en esquizofrenia, algunos estudios indican una mayor incidencia en los hombres (Ninullain, O`Hare y Walsh, 1987) encontraron una relación de 1.5:1 y Nicole, Ledage y Lalonde (1992) encontraron una relación de 2.5:1. Por su parte, Iacono y Breiser (1992) confirman esta mayor incidencia incluso al utilizar distintos criterios diagnósticos (Jiménez García-Bóveda y Vázquez Morejón, 2006)

\footnotetext{
${ }^{13}$ Ver anexo
} 


\subsubsection{Edad de los sujetos:}

El rango de edad es de 25-50 años y el promedio de edad es de 37 años.

\subsubsection{Subtipos:}

En este grupo se encuentra un predominio del subtipo paranoide $(68 \%)^{14}$. Otros tipos son: indiferenciado (16\%), desorganizado o hebefrenia (12\%) y catatónico (4\%). Por la baja proporción de catatónicos, se excluyeron de la muestra final. Es necesario hacer notar que en, la versión del DSM-V, esta consideración de los subtipos ha desaparecido. En el capítulo del espectro de la esquizofrenia y otros trastornos psicóticos, se señala que los subtipos de esquizofrenia del DSM-IV-TR (paranoide, desorganizada, catatónica, indiferenciada y residual) no han mostrado una estabilidad diagnóstica limitada, además de no haber respondido diferencialmente al tratamiento (McGorry, 2010) ${ }^{15}$.

Con respecto a los factores parentales, se verificó que un $44 \%$ de los sujetos presentaba a lo menos un familiar de primer grado (padres, hermanos) con esquizofrenia o alguna patología psiquiátrica severa.

\subsubsection{Actividad laboral:}

Los pacientes con algún tipo de actividad laboral alcanzan el 12\%, mientras los desempleados o sin actividad laboral corresponden a un $80 \%$ de la muestra, en tanto el $8 \%$ corresponde a amas de casa.

\subsubsection{Estado civil:}

El $68 \%$ de los sujetos de la muestra son solteros, el 20\% está casado/a y el 12\% señala tener una relación de pareja al momento del estudio.

\footnotetext{
${ }^{14}$ Factor coincidente con la descripción del DSM-IV y el CIE-10: p118

${ }^{15}$ Echeburúa, Salaberría y Cruz-Sáez: 2014
} 


\subsubsection{Nivel de estudios:}

En cuanto al nivel de estudios, todos los sujetos tienen una escolaridad básica completa, 52\% alcanzó a completar estudios secundarios, en cambio $48 \%$ presenta estudios secundarios incompletos, el $8 \%$ completó estudios superiores técnico profesionales, el $12 \%$ presenta estudios técnico profesionales incompletos, el $4 \%$ completó estudios universitarios correspondientes a 8 o más semestres, en cambio el $16 \%$ presenta estudios universitarios incompletos.

Tabla 6: Descripción sociodemográfica de Grupo 1 sujetos con Esquizofrenia Crónica (CRE):

\begin{tabular}{|c|c|c|c|}
\hline CORPUS 1 CRE $=25$ & ENTREVISTA CLÍNICA & \multicolumn{2}{|c|}{ ESQUIZOFRENIA } \\
\hline EDAD & Rango (25- 50a ) $X: 35,56$ & $\mathrm{~N}$ & $\%$ \\
\hline \multirow[t]{2}{*}{ SEXO } & Mujeres $X: 40,4$ & 12 & $(48 \%)$ \\
\hline & Hombres $X: 35$ & 13 & $(52 \%)$ \\
\hline \multirow[t]{4}{*}{ SITUACIÓN LABORAL } & Trabajador dependiente/independiente & 3 & $(12 \%)$ \\
\hline & Cesante/sin actividad laboral & 20 & $(80 \%)$ \\
\hline & Dueña de casa & 2 & $(8 \%)$ \\
\hline & Estudiante & 0 & $(0 \%)$ \\
\hline \multirow[t]{8}{*}{ NIVEL EDUCATIVO } & Ens. Básica completa $\left(1^{\circ}-8^{\circ}\right.$ básico $)$ & 25 & $100 \%$ \\
\hline & Ens. Básica incompleta & 0 & $0 \%$ \\
\hline & Ens. Media completa (I-IV medio) & 13 & $(52 \%)$ \\
\hline & Ens. Media incompleta & 12 & $(48 \%)$ \\
\hline & $\begin{array}{l}\text { Carrera Técnico profesional completa } \\
(2-3 \text { años) }\end{array}$ & 2 & $(8 \%)$ \\
\hline & $\begin{array}{l}\text { Carrera Técnico profesional } \\
\text { incompleta }\end{array}$ & 3 & $(12 \%)$ \\
\hline & $\begin{array}{l}\text { Carrera Universitaria completa ( } 8 \text { o } \\
\text { más semestres) }\end{array}$ & 1 & $(4 \%)$ \\
\hline & Carrera Universitaria incompleta & 4 & $(16 \%)$ \\
\hline \multirow[t]{3}{*}{ ESTADO CIVIL } & Soltero & 17 & $(68 \%)$ \\
\hline & Casado & 5 & $(20 \%)$ \\
\hline & Con pareja & 3 & $(12 \%)$ \\
\hline \multirow[t]{3}{*}{ DIAGNÓSTICO } & Esquizofrenia paranoide & 17 & $(68 \%)$ \\
\hline & Esquizofrenia desorganizada & 3 & $(12 \%)$ \\
\hline & Esquizofrenia indiferenciada & 5 & $(20 \%)$ \\
\hline
\end{tabular}




\begin{tabular}{|l|l|c|c|}
\hline $\begin{array}{l}\text { TRATAMIENTO } \\
\text { FARMACOLÓGICO }\end{array}$ & $\begin{array}{l}\text { Permanente y/o seguimiento } \\
\text { hospitalario completo }\end{array}$ & 21 & $(84 \%)$ \\
\cline { 2 - 4 } & Esporádico & 4 & $(16 \%)$ \\
\hline $\begin{array}{l}\text { MEDIA INGRESOS } \\
\text { HOSPITALARIOS }\end{array}$ & Días & & $\begin{array}{c}109 \mathrm{~d}=3,6 \\
\text { meses }\end{array}$ \\
\cline { 2 - 4 } & Meses & $\begin{array}{c}630 \mathrm{~d}=21 \\
\text { meses }\end{array}$ \\
\cline { 2 - 4 } & Años & $\begin{array}{c}1825 \mathrm{~d}=60,8 \\
\text { meses }\end{array}$ \\
\hline $\begin{array}{l}\text { ANTECEDENTES PSIQUIÁTRICOS FAMILIARES (directos: padre, } \\
\text { madre, hermano) }\end{array}$ & 11 & $44 \%$ \\
\hline
\end{tabular}

3.1.2. Grupo 2 de pacientes de esquizofrenia de primer episodio (PEE) $\mathrm{N}=25$ :

\subsubsection{Instituciones:}

Los sujetos de esta muestra corresponden a 25 pacientes afectados por esquizofrenia de inicio. Fueron reclutados de la red de Salud Mental Pública de Santiago de Chile: A) Instituto Psiquiátrico del Hospital Sanatorio El Peral; B) del Departamento de Hospitalización Psiquiátrica de Corta Estadía del Complejo Asistencial Dr. Ramón Barros Luco Trudeau y de la red de Salud Mental Privada de Santiago de Chile: C) Hospital de día del Instituto de Rehabilitación en Salud Mental, RENOVAL. Fueron entrevistados por un equipo de Salud Mental compuesto por psiquiatras, becados de psiquiatría y una lingüista.

\subsubsection{Género y Edad:}

Este grupo está compuesto por 14 hombres y 11 mujeres. El rango de edad es de 14-24 años y el promedio de edad es de 18,2 años.

\subsubsection{Subtipos:}

En este grupo encontramos un predominio del 56\% del subtipo paranoide, un $4 \%$ del subtipo desorganizado (hebefrenia) y $40 \%$ del subtipo indiferenciado. El $40 \%$ de los sujetos presenta a lo menos un familiar directo (padres, hermanos) con esquizofrenia o alguna patología psiquiátrica severa. 


\subsubsection{Actividad laboral/estudiantil:}

Los pacientes con algún tipo de actividad laboral alcanzan el 30\%, mientras los desempleados o sin actividad laboral corresponden a un $60 \%$ de la muestra, en tanto el $10 \%$ corresponde a amas de casa.

\subsubsection{Estado civil:}

El 100\% de los sujetos de la muestra son solteros y el $8 \%$ señala tener una relación de pareja al momento del estudio.

\subsubsection{Nivel de estudios:}

En cuanto al nivel de estudios, todos los sujetos tienen una escolaridad básica completa, 65\% alcanzó a completar estudios secundarios, en cambio 35\% presenta estudios secundarios incompletos, el $10 \%$ completó estudios superiores técnico profesionales, el $5 \%$ presenta estudios técnico profesionales incompletos, el $20 \%$ presenta estudios universitarios incompletos.

Tabla 7 descripción sociodemográfica del Grupo 2: sujetos con esquizofrenia de primer episodio (PEE):

\begin{tabular}{|c|c|c|c|}
\hline CORPUS 2 EI=25 & Entrevista clínica & \multicolumn{2}{|c|}{ Esquizofrenia $(\mathrm{n}=25)$} \\
\hline EDAD & Rango (14-24a ) $\bar{X}: 18,2$ & $\mathrm{~N}$ & $\%$ \\
\hline \multirow[t]{2}{*}{ SEXO } & Mujeres $X: 18,4$ & 11 & $44 \%$ \\
\hline & Hombres $\bar{X}: 18$ & 14 & $56 \%$ \\
\hline \multirow[t]{4}{*}{ SITUACIÓN LABORAL } & Trabajador dependiente/independiente & & $20 \%$ \\
\hline & Cesante & & $30 \%$ \\
\hline & Dueña de casa & 0 & $0 \%$ \\
\hline & Estudiante & & $50 \%$ \\
\hline \multirow[t]{6}{*}{ NIVEL EDUCACIONAL } & Ens. Básica completa: & & $100 \%$ \\
\hline & Ens. Básica incompleta: & & $0 \%$ \\
\hline & Ens. Media completa: & & $65 \%$ \\
\hline & Ens. Media incompleta & & $35 \%$ \\
\hline & Carrera Técnico profesional completa: & & $10 \%$ \\
\hline & Carrera Técnico profesional incompleta & & $5 \%$ \\
\hline
\end{tabular}




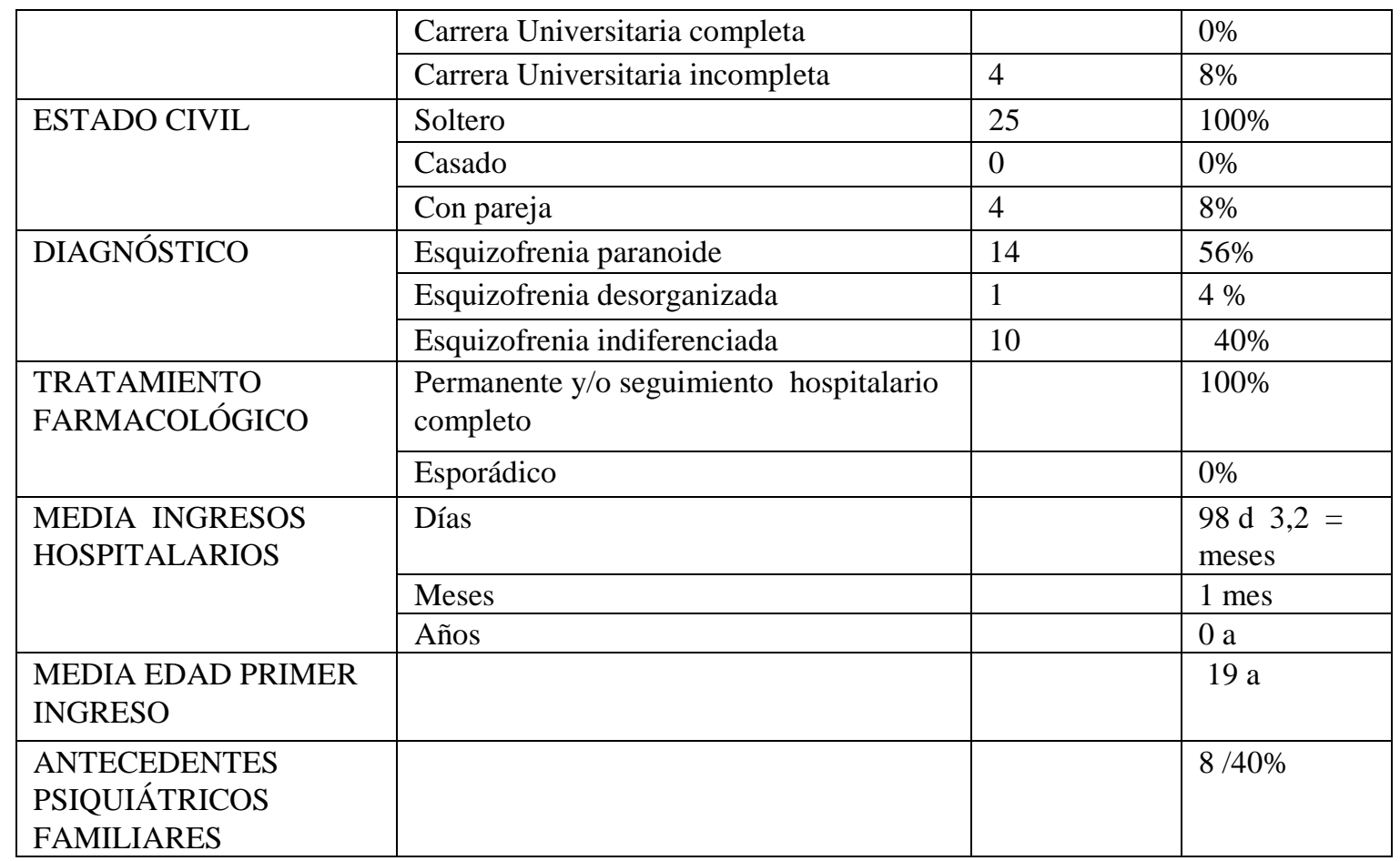

\subsubsection{Grupo 3: Controles}

El grupo control corresponde a 12 personas sin diagnóstico psiquiátrico. Seis hombres y seis mujeres, pareados por edad y características sociodemográficas congruentes con los sujetos del grupo 1 y 2. Este grupo control fue extraído del CORPUS ESECH ${ }^{16}$ (Estratificación Sociolingüística del español de Chile) proyecto del área de Sociolingüística de la Universidad de Chile. Está compuesto por un número aproximado de más de 300 entrevistas realizadas a hablantes de ambos sexos, de diferentes edades y grupos sociales, todos nativos de español de Santiago de Chile. Las entrevistas de este proyecto se enmarcan en la metodología variacionista propuesta por el sociolingüista William Labov, que consiste en superar la paradoja del observador ${ }^{17}$, para conseguir muestras de habla que sean

${ }^{16}$ Corpus ESECH, proyecto a cargo del Académico del Departamento de Lingüística de la Facultad de Filosofía \& Humanidades de la Universidad de Chile, profesor Abelardo San Martín, a quien agradecemos la gentileza de facilitarnos las entrevistas para esta sección de la investigación.

${ }^{17} \mathrm{~W}$. Labov plantea que con el fin de acceder a las muestras de habla representativas de una determinada comunidad de hablantes, es necesario romper con la llamada paradoja del observador, fenómeno que se daría en circunstancias en que los hablantes pueden ser conscientes de la observación del entrevistador. La 
representativas del estilo vernacular de los hablantes. Las entrevistas fueron grabadas en formato digital y transcritas íntegramente por los estudiantes de la cátedra de Sociolingüística, pertenecientes a las carreras de Licenciatura en Lengua y Literatura Hispánicas y Lengua y Literatura Inglesas de la Universidad de Chile, entre los años 2007 2011, es necesario hacer notar que cada año se agrega un número estimado de 50 entrevistas nuevas a este proyecto. La duración de estas entrevistas tiene un promedio de 45-50 minutos, y se abordan diferentes temas y secciones dentro de los que constan entre otras, una que procura la elicitación de narraciones personales. Este contenido surge dentro de los primeros 20 minutos de entrevista, razón por la cual fueron considerados los primeros 15 minutos.

Este Corpus cuenta con una codificación propia a la que nos remitiremos a continuación.

\subsubsection{ESECH: TABLA DE ADSCRIPCIÓN DE STATUS SOCIAL ${ }^{\mathbf{1 8}}$}

a) Estrato socioeconómico

b) Nivel educacional

c) Profesión u ocupación

d) Comuna de residencia

e) Ingreso familiar mensual

f) Grupo de edad:

g) 20 a 34 años

h) 35 a 54 años

i) 55 años y más

j) Sexo: Hombres / Mujeres

k) Criterios de asignación de hablante nativo de Santiago de Chile:

1) Haber nacido y residido en forma ininterrumpida en Santiago.

m) Haber residido en forma ininterrumpida en Santiago desde los cinco años de edad.

n) Haber nacido en Santiago y haber residido en Santiago la mayor parte de sus vidas, salvo por periodos que sumados no superen los cuatro años en el tramo de 50 años y más y los tres años en el tramo de 35 a 49 años.

superación de este inconveniente se daría por ejemplo, con la incorporación de temas informales relacionados con relatos anecdóticos, etc.

${ }^{18}$ Basado en Prieto 1995-1996: 402-409 e ICCOM 2007, actualizado por San Martín, 2013 
Tabla 8: Descripción sociodemográfica de Grupo 3 controles

\begin{tabular}{|c|c|c|}
\hline $\begin{array}{l}\text { CORPUS } 3= \\
\text { CONTROLES }\end{array}$ & ENTREVISTA SOCIOLINGÜÍSTICA & $\mathrm{N}=12$ \\
\hline EDAD & Rango (20-54) & $X: 36,1$ \\
\hline \multirow[t]{2}{*}{ SEXO } & \multirow{2}{*}{$\begin{array}{l}\text { MUJERES: } 6 \\
\text { HOMBRES: } 6\end{array}$} & $50 \%$ \\
\hline & & $50 \%$ \\
\hline \multirow{2}{*}{$\begin{array}{l}\text { ESTRATO } \\
\text { SOCIOECONÓMICO }\end{array}$} & \multirow{2}{*}{$\begin{array}{l}\text { MEDIO BAJO=6 } \\
\text { MEDIO MEDIO=6 }\end{array}$} & $50 \%$ \\
\hline & & $50 \%$ \\
\hline \multirow[t]{7}{*}{ NIVEL EDUCACIONAL } & Hasta 8 BÁSICO & $8.3 \%$ \\
\hline & Hasta III EM & $25 \%$ \\
\hline & TÉC PROFESIONAL & $25 \%$ \\
\hline & UNIV COMPLETO & $8,3 \%$ \\
\hline & EST UNIV & $16,6 \%$ \\
\hline & UNIVE INCOMP & $8.3 \%$ \\
\hline & EST TÉC PROF & $8,3 \%$ \\
\hline \multirow{4}{*}{$\begin{array}{l}\text { PROFESIÓN U } \\
\text { OCUPACIÓN } \\
\text { (SITUACIÓN } \\
\text { LABORAL) }\end{array}$} & Trabajador dependiente/independiente & $6=50 \%$ \\
\hline & Cesante & $1=8.3 \%$ \\
\hline & Dueña de casa & $2=16,6 \%$ \\
\hline & Estudiante & $3=25 \%$ \\
\hline \multirow{8}{*}{$\begin{array}{l}\text { COMUNA DE } \\
\text { RESIDENCIA }\end{array}$} & Conchalí & $1=8.3 \%$ \\
\hline & Recoleta & $1=8.3 \%$ \\
\hline & Santiago & $2=16,6 \%$ \\
\hline & Ñuñoa & $216,6 \%$ \\
\hline & Macul & $1=8.3 \%$ \\
\hline & San Miguel & $2=16,6 \%$ \\
\hline & Maipú & $2=16,6 \%$ \\
\hline & San Bernardo & $1=8.3 \%$ \\
\hline \multirow[t]{3}{*}{ GRUPO DE EDAD: } & 20 a 34 años & $6=50 \%$ \\
\hline & 35 a 54 años & $6=50 \%$ \\
\hline & 55 años y más & $0=0 \%$ \\
\hline
\end{tabular}

3.1.4. Criterios de inclusión de los grupos 1,2 y 3 :

3.1.4.1. Los criterios generales de inclusión para CRE fueron:

a. Diagnóstico de la esquizofrenia de acuerdo a los criterios (DSM -IV )

b. Edad entre 25 a 50 años con CI normal $(>0=80)$

c. De ambos sexos.

d. Nivel educativo mayor o igual a $8^{\circ}$ básico.

e. No existe una terapia electro convulsiva actual. 
f. Consentimiento informado escrito para la participación en el estudio ${ }^{19}$.

g. Duración mínima de la enfermedad de $>5$ y $<$ de 20 años.

\subsubsection{Los criterios generales de inclusión para PEE fueron:}

a. Diagnóstico de la esquizofrenia de inicio de acuerdo a los criterios (DSM-IV), realizado por un equipo de psiquiatras en junta médica

b. $\quad$ Edad entre 14 y 24 años con un CI normal $(>0=80)$

c. De ambos sexos.

d. Historia de un episodio psicótico previo o actual, tratado con antipsicóticos atípicos con o sin hospitalización.

e. $\quad$ El nivel educativo igual o mayor que el primero medio.

f. El nivel educativo de los padres a nivel de 8 básico.

g. Duración de la enfermedad desde el primer episodio menos de tres años ${ }^{20}$.

h. Por lo menos seis meses sin consumo de sustancias neurotóxicas.

i. $\quad$ No existe una terapia electroconvulsiva anterior o actual.

j. $\quad$ Consentimiento informado para la participación en el estudio.

3.1.4.3. Los criterios generales para la inclusión de los controles son:

a. Características sociodemográficas congruentes con los sujetos de los corpus 1 y 2 .

b. Pareados por sexo y edad con los sujetos de los corpus 1 y 2 .

c. La ausencia de trastornos psiquiátricos actuales o enfermedades neurológicas.

d. La ausencia de abuso de drogas y alcohol.

e. La ausencia de uso actual de drogas psicotrópicas.

3.1.4.4. Los criterios generales de exclusión para los sujetos de CRE y EI son:

a. Historia de las enfermedades médicas o neurológicas graves.

b. Presencia de genopatías.

c. Consumo activo de sustancias neurotóxicas

d. $\quad$ IQ total $>\mathrm{o}=\mathrm{a} 79$

e. Descompensación o psicopatológica.

${ }^{19}$ A cada participante del estudio se les informó previamente, y se les solicitó dar su consentimiento para la utilización de las muestras de habla resultantes de las entrevistas. Este procedimiento fue realizado por los entrevistadores, quedando un registro para el comité de bioética de la Facultad de Medicina de la Universidad de Chile.

${ }^{20}$ Según los protocolos de Salud Pública del MINSAL, se considera esquizofrenia de inicio o de primer episodio aquella cuya duración desde las primeras pesquisas corresponda a ser: $>0 \mathrm{y}<2$ o incluso de $>2 \mathrm{y}<$ 3 años. Tomando en cuenta que a nivel general las consultas psiquiátricas recién se presentan alrededor de los 18 meses de sus primeros síntomas, el diagnóstico con frecuencia se realiza sobre los 18 o 24 meses. 
ANÁLISIS PRAGMALINGÜÍSTICO DE LOS MARCADORES DE COHERENCIA EN EL DISCURSO DE SUJETOS CON ESQUIZOFRENIA CRÓNICA Y DE PRIMER EPISODIO

A continuación se resumen las características sociodemográficas y clínicas de los corpus 1,2 y 3 : 
Tabla 9 datos sociodemográficos y clínicos grupo de pacientes crónicos

\begin{tabular}{|c|c|c|c|c|c|c|c|c|c|}
\hline G 2 CóDIGO & EDAD & SEXO & EST. ENFERM & TR. ENFERM & SUBTIPO & AÑO NAC & N. EDUCATIVO & AÑO ENTR & DUR ENTR \\
\hline CRE-M01 & 50 & $\mathrm{M}$ & CRÓNICA & 5 Y MÁS & DESORGAN & 1957 & IIEM & 2007 & $19: 49$ \\
\hline CRE-M02 & "43 & $\bar{M}$ & CRÓNICA & 5 Y MÁS & PARANOIDE & 1965 & IV EM & 2008 & $47: 46: 00$ \\
\hline CRE-M03 & 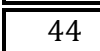 & $\overline{\mathrm{M}}$ & CRÓNICA & 5 Y MÁS & PARANOIDE & $\overline{\overline{1964}}$ & TEC.PROF & 2008 & $=37: 54: 00$ \\
\hline CRE-M04 & 50 & $\mathrm{M}$ & CRÓNICA & 5 Y MÁS & INDIFERENC & 1958 & IEM & 2008 & $23: 24$ \\
\hline CRE-M05 & 34 & $\mathrm{M}$ & CRÓNICA & 5 Y MÁS & PARANOIDE & 1975 & IIIEM & 2009 & $23: 11$ \\
\hline CRE-M06 & 50 & $\mathrm{M}$ & CRÓNICA & 5 Y MÁS & PARANOIDE & 1959 & $3^{\circ} \mathrm{QUIIM}-\mathrm{FAR}$ & 2009 & $18: 00$ \\
\hline CRE-M07 & 34 & $\mathrm{M}$ & CRÓNICA & 5 Y MÁS & DESORGAN & 1975 & IEM & 2009 & 36:09:00 \\
\hline CRE-M08 & 26 & $\overline{\mathrm{M}}$ & CRÓNICA & HASTA 5 & PARANOIDE & 1983 & $2^{\circ}$ ING COMERC & 2009 & 1H:10 \\
\hline CRE-M09 & 28 & $\overline{\mathrm{M}}$ & CRÓNICA & HASTA 5 & DESORGAN & 1981 & IEM & 2009 & $18: 18$ \\
\hline CRE-M10 & 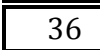 & $\overline{\mathrm{M}}$ & CRÓNICA & 5 Y MÁS & INDIFERENC & 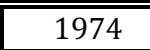 & IIIEM & 2010 & $22: 52$ \\
\hline CRE-M11 & 28 & $\overline{\mathrm{M}}$ & CRÓNICA & HASTA 5 & PARANOIDE & 1985 & $1^{\circ}$ IDIOMAS & 2013 & $6: 45$ \\
\hline CRE-M12 & 29 & $\mathrm{M}$ & CRÓNICA & HASTA 5 & PARANOIDE & 1984 & IIEM & 2013 & $28: 03: 00$ \\
\hline CRE-H01 & 43 & $\mathrm{H}$ & CRÓNICA & 5 Y MÁS & PARANOIDE & 1964 & IIIM IND & 2007 & $32: 55: 00$ \\
\hline CRE-H02 & 42 & $\mathrm{H}$ & CRÓNICA & 5 Y MÁS & PARANOIDE & 1965 & IVEM & 2007 & $24: 12: 00$ \\
\hline CRE-H04 & 43 & $\overline{\mathrm{H}}$ & CRÓNICA & 5 Y MÁS & PARANOIDE & 1965 & $3^{\circ}$ ING INFORM & 2008 & $33: 10: 00$ \\
\hline CRE-H05 & 28 & $\overline{\mathrm{H}}$ & CRÓNICA & " HASTA 5 & PARANOIDE & $\overline{1980}$ & IV M IND & 2008 & 41:32:00 \\
\hline CRE-H06 & ב37 & $\overline{\mathrm{H}}$ & CRÓNICA & 5 Y MÁS & PARANOIDE & 1971 & $3^{\circ \circ}$ PED. HIST & 2008 & 37:10:00 \\
\hline CRE-H07 & 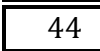 & $\overline{\mathrm{H}}$ & CRÓNICA & 5 Y MÁS & INDIFERENC & 1964 & I EM & 2008 & 48:13:00 \\
\hline CRE-H08 & 37 & $\mathrm{H}$ & CRÓNICA & 5 Y MÁS & INDIFERENC & 1972 & ING EJEC & 2009 & $43: 02: 00$ \\
\hline CRE-H09 & 25 & $\mathrm{H}$ & CRÓNICA & HASTA 5 & INDIFERENC & 1984 & II EM & 2009 & $43: 15: 00$ \\
\hline CRE-H10 & 34 & $\overline{\mathrm{H}}$ & CRÓNICA & 5 Y MÁS & DESORGAN & 1976 & IEM & 2010 & $53: 11: 00$ \\
\hline CRE-H11 & 30 & $\overline{\mathrm{H}}$ & CRÓNICA & HASTA 5 & PARANOIDE & 1980 & III EM & 2010 & $42: 33: 00$ \\
\hline CRE-H12 & 41 & $\overline{\mathrm{H}}$ & CRÓNICA & 5 Y MÁS & PARANOIDE & 1971 & $4^{\circ}$ ING INFORM & 2012 & $45: 30: 00$ \\
\hline
\end{tabular}


Tabla 10 datos sociodemográficos y clínicos del grupo de pacientes de esquizofrenia de primer episodio.

\begin{tabular}{|c|c|c|c|c|c|c|c|c|c|}
\hline $\begin{array}{c}\text { G2 CóDIGO } \\
\text { CóDIGO }\end{array}$ & EDAD & SEXO & GRUPO DE & TRAMO DE LA ENFERMEDAD & SUBTIPO & A NAC & NIVEL EDUCATIVO & AÑO ENTR & DUR ENTR \\
\hline PEE-M01 & 19 & $\mathrm{M}$ & EQZ. PRIMER EPISODIO & 0 A 2 & PARANOIDE & 1988 & IIEM & 2007 & $42: 35: 00$ \\
\hline PEE-M02 & 23 & $\mathrm{M}$ & EQZ. PRIMER EPISODIO & 2 A 3 & PARANOIDE & 1985 & IVEM & 2008 & $34: 54: 00$ \\
\hline PEE-M03 & 22 & M & EQZ. PRIMER EPISODIO & 2 A 3 & INDIFERENC & 1986 & $1^{\circ}$ CONTABILID & 2008 & 1H:08 \\
\hline PEE-M04 & 22 & M & EQZ. PRIMER EPISODIO & 2 A 3 & PARANOIDE & 1987 & $1^{\circ} \mathrm{LIC}$ MÚSICA & 2009 & 24:06:00 \\
\hline PEE-M05 & 15 & $\mathrm{M}$ & EQZ. PRIMER EPISODIO & $0 \mathrm{~A} 2$ & PARANOIDE & 1995 & II EM & 2010 & 33:53:00 \\
\hline PEE-M06 & 18 & $\mathrm{M}$ & EQZ. PRIMER EPISODIO & 0 A 2 & INDIFERENC & 1992 & IV EM & 2010 & $18: 53$ \\
\hline PEE-M07 & 19 & $\mathrm{M}$ & EQZ. PRIMER EPISODIO & $2 \mathrm{A3}$ & DESORGAN & 1993 & IIEM & 2012 & $26: 45: 00$ \\
\hline PEE-M08 & 14 & $\mathrm{M}$ & EQZ. PRIMER EPISODIO & $0 \mathrm{~A} 2$ & PARANOIDE & 1998 & IEM & 2012 & $38: 18: 00$ \\
\hline PEE-M09 & 17 & $\mathrm{M}$ & EQZ. PRIMER EPISODIO & $0 \mathrm{~A} 2$ & PARANOIDE & 1990 & IIEM & 2012 & $13: 23$ \\
\hline PEE-M10 & 20 & $\mathrm{M}$ & EQZ. PRIMER EPISODIO & $2 \mathrm{A3}$ & PARANOIDE & 1993 & IIIEM & 2013 & $16: 23$ \\
\hline PEE-M11 & 14 & $\mathrm{M}$ & EQZ. PRIMER EPISODIO & $0 \mathrm{A2}$ & INDIFERENC & 1999 & IEM & 2013 & $15: 58$ \\
\hline PEE-H01 & 22 & $\mathrm{H}$ & EQZ. PRIMER EPISODIO & $2 \mathrm{A3}$ & PARANOIDE & 1986 & $2^{\circ}$ ING COM & 2008 & 53:00:00 \\
\hline PEE-H02 & 19 & $\mathrm{H}$ & EQZ. PRIMER EPISODIO & $2 \mathrm{A3}$ & DESORGAN & 1989 & IIEM & 2008 & $38: 30: 00$ \\
\hline PEE-H03 & 17 & $\overline{\mathrm{H}}$ & EQZ. PRIMER EPISODIO & $0 \mathrm{A2} 2$ & PARANOIDE & 1992 & IIEM & 2009 & $41: 30: 00$ \\
\hline PEE-H04 & 17 & $\overline{\mathrm{H}}$ & EQZ. PRIMER EPISODIO & 0 A 2 & PARANOIDE & 1992 & IVEM & 2009 & 49:00:00 \\
\hline PEE-H05 & 18 & $\mathrm{H}$ & EQZ. PRIMER EPISODIO & 0 A 2 & PARANOIDE & 1992 & IIIEM & 2010 & 26:00:00 \\
\hline PEE-H06 & 19 & $\mathrm{H}$ & EQZ. PRIMER EPISODIO & $2 \mathrm{A3}$ & PARANOIDE & 1991 & $1^{\circ}$ & 2010 & $17: 34$ \\
\hline PEE-H07 & 16 & $\mathrm{H}$ & EQZ. PRIMER EPISODIO & $0 \mathrm{~A} 2$ & PARANOIDE & 1994 & IIEM & 2010 & $40: 12: 00$ \\
\hline PEE-H08 & 18 & $\mathrm{H}$ & EQZ. PRIMER EPISODIO & $0 \mathrm{A2}$ & PARANOIDE & 1992 & IIIEM & 2010 & $16: 00$ \\
\hline PEE-H09 & 14 & $\overline{\mathrm{H}}$ & EQZ. PRIMER EPISODIO & $0 \mathrm{A2}$ & PARANOIDE & 1998 & IEM & 2012 & $12: 00$ \\
\hline PEE-H10 & 16 & $\overline{\mathrm{H}}$ & EQZ. PRIMER EPISODIO & $0 \mathrm{A2} 2$ & PARANOIDE & 1996 & IIEM & 2012 & 26:00:00 \\
\hline PEE-H11 & 18 & $\overline{\mathrm{H}}$ & EQZ. PRIMER EPISODIO & $2 \mathrm{A3}$ & PARANOIDE & 1997 & IIIEM & 2013 & $8: 34$ \\
\hline PEE-H12 & 15 & $\overline{\mathrm{H}}$ & EQZ. PRIMER EPISODIO & $0 \mathrm{A2} 2$ & PARANOIDE & 1998 & IIEM & 2013 & 45:12:00 \\
\hline PEE-H13 & 22 & $\mathrm{H}$ & EQZ. PRIMER EPISODIO & $2 \mathrm{A3}$ & PARANOIDE & 1991 & $2^{\circ}$ DISEÑO & 2013 & $19: 52$ \\
\hline PEE-H14 & 17 & $\overline{\mathrm{H}}$ & EQZ. PRIMER EPISODIO & $0 \mathrm{~A} 2$ & PARANOIDE & 1996 & IIEM & 2013 & $30: 17: 00$ \\
\hline
\end{tabular}


Tabla 11 datos sociodemográficos grupo de controles

\begin{tabular}{|c|c|c|c|c|c|c|c|c|c|}
\hline G 3CÓDIGo & SEXO & EDAD & AÑO NAC & $\begin{array}{c}\text { AÑ̃O } \\
\text { ENTREVISTA } \\
\end{array}$ & NIVEL ED & $\begin{array}{c}\text { NIVEL } \\
\text { SOC-EC }\end{array}$ & PROF/OCUPACIÓN & ORIGEN & $\begin{array}{l}\text { DURACIÓN } \\
\text { ENTR }\end{array}$ \\
\hline CON-M01 & $\mathrm{M}$ & 49 & 1959 & 2008 & IEM & $\mathrm{MB}$ & AUXILIAR DE ASEO & SANTIAGO & \begin{tabular}{|l|}
$57: 56: 00$ \\
\end{tabular} \\
\hline CON-M02 & $\mathrm{M}$ & 46 & 1961 & 2007 & $8 \mathrm{~B}$ & $\mathrm{MB}$ & COMERCIANTE & SANTIAGO & 60:03:00 \\
\hline CON-M03 & $\mathrm{M}$ & 25 & 1984 & 2009 & TÉC PROF. & $\mathrm{MM}$ & LABORATORISTA DENTAL & SANTIAGO & 50:42:00 \\
\hline CON-M04 & $\mathrm{M}$ & 54 & 1954 & 2008 & UNIV COMP & MB & TRADUCTORA & SANTIAGO & 51:03:00 \\
\hline CON-M05 & $\mathrm{M}$ & 28 & 1981 & 2009 & TÉC PROF. & $\mathrm{MB}$ & SECRETARIA & SANTIAGO & 55:03:00 \\
\hline CON-M06 & $\mathrm{M}$ & 22 & 1989 & 2011 & EST UNIV & MM & EST PSICOLOGÍA & SANTIAGO & 60:45:00 \\
\hline CON-H01 & $\mathrm{H}$ & 42 & 1968 & 2010 & III EM & MB & CUIDADOR CABALLOS DE CARRERA & SANTIAGO & 55:47:00 \\
\hline CON-H02 & $\mathrm{H}$ & 20 & 1989 & 2009 & \begin{tabular}{|l|} 
EST \\
UNIVERSITARIO
\end{tabular} & $\overline{\mathrm{MM}}$ & $\begin{array}{l}\text { EST LICENCIATURA EN LENGUA } \\
\text { INGLESA }\end{array}$ & SANTIAGO & 57:04:00 \\
\hline CON-H03 & $\mathrm{H}$ & 34 & 1974 & 2008 & TÉC PROF. & $\mathrm{MB}$ & CHOFER & SANTIAGO & 79:00:00 \\
\hline CON-H04 & $\mathrm{H}$ & 23 & 1985 & 2008 & EST UNIV & $\mathrm{MM}$ & EST INGENIERÍA & SANTIAGO & 55:31:00 \\
\hline CON-H05 & $\mathrm{H}$ & 51 & 1958 & 2009 & V AÑO ING & $\mathrm{MM}$ & \begin{tabular}{|l} 
CONSULTOR \\
\end{tabular} & SANTIAGO & 50:07:00 \\
\hline CON-H06 & $\mathrm{H}$ & 40 & 1968 & 2008 & III EM & MM & OPERARIO DE BODEGA & SANTIAGO & 70:67 \\
\hline
\end{tabular}




\subsection{Tipo de estudio y diseño de investigación:}

Desde las primeras descripciones de la patología, se han registrado observaciones clínicas en torno a la presencia de trastornos del lenguaje en las personas afectadas. Dichos trastornos han sido considerados como parte de los indicadores de diagnóstico (American Psychiatric Association, 1994; Bleuler, 1911; Kraepelin, 1919). Asimismo, a través de múltiples estudios se ha tratado de describir y especificar cuáles son los aspectos del lenguaje que se encuentran perturbados de la esquizofrenia (Maher, 1972; Frith, 1993; Frith y Allen, 1988; Schwartz, 1978). En un intento por encontrar explicaciones sobre las causas de las alteraciones, no pocos estudios han sugerido que no se deben a factores lingǘsticos, sino a anormalidades en el pensamiento (Brown , 1973; Fromkin , 1975) o a déficit en el procesamiento de la información, debido, entre otras causa al déficit atencional que se ha documentado en estos pacientes (RuizVargas, 2004) Sin duda, aunque existe hasta el presente una gran controversia sobre las causas de las alteraciones, también hay un acuerdo general de que el lenguaje de las personas con esquizofrenia posee características generales tales como los problemas de coherencia y cohesión discursivas. Son conocidos los trabajos de Rochester y Martin, 1979, quienes aplicaron el modelo de Halliday para comprobar este tipo de dificultades (Chaika, 1978) También el trabajo de Morice e Ingram, 1983, quienes demostraron que la reducción de la complejidad sintáctica en estos pacientes era la causa de la llamada "pobreza del habla"21. De Lisi, 2001, también aportó información relevante en torno a la reducción de la incrustación de cláusulas y a la producción verbal general.

Tomando en consideración que todos estos trabajos han arrojado valiosa información sobre el fenómeno del que interesa dar cuenta en este estudio, hemos escogido concentrarnos en la descripción y posible sistematización cuantitativa de algunos de los indicadores de coherencia discursiva ya descritos en la literatura. Con ese propósito, hemos elegido la realización de un estudio de carácter cuantitativo y

${ }^{21}$ Escala de Nancy Andreasen TLC: 1979 
descriptivo. Por otro lado, también nos interesa delinear el perfil lingüístico de los pacientes jóvenes, recién diagnosticados, para establecer un contraste con los crónicos y comprobar, posiblemente, si existe la posibilidad de detectar indicadores tempranos del déficit en la coherencia de los discursos.

El diseño de este estudio es transversal, comparativo y no experimental. Responde al interés por analizar el comportamiento comunicativo de pacientes de esquizofrenia crónica y precoz, en una situación de habla similar al discurso espontáneo. Sabemos que, a pesar de la gran cantidad de estudios sobre el lenguaje en la esquizofrenia, no hay registro de investigaciones que aborden un contraste entre el desempeño comunicativo en diferentes momentos evolutivos de la enfermedad. Cabe recordar que hasta la fecha no se conocen marcadores biológicos y el diagnóstico se realiza en base a múltiples factores neuropsicosociales, por lo tanto, uno de los aspectos aún en desarrollo en la investigación de la esquizofrenia de inicio es el referido a los marcadores que permitan adelantar el diagnóstico y por ende, su tratamiento. El uso de indicadores de déficit en el lenguaje puede ser considerado como una estrategia emergente en la pesquisa de marcadores precoces de la enfermedad.

\subsection{El Instrumento utilizado:}

\subsubsection{La entrevista clínica:}

La entrevista clínica es una herramienta básica utilizada en medicina y en el área de salud mental, provee de información sumamente valiosa acerca del sujeto y su padecimiento. Según el DSM-IV la entrevista psiquiátrica semi-estructurada se utiliza con fines diagnósticos y terapéuticos, posee una estructura tradicional que comprende una etapa de contacto, de desarrollo y de despedida a través de las que se pretende realizar tanto un psicodiagnóstico como el abordaje de aspectos y/o etapas de la enfermedad. 
Existen parámetros flexibles en torno a los contenidos que se incluyen, ya que estos son modificados en función de la etapa de evolución en la que se encuentra el paciente. Si se trata de las primeras entrevistas, es probable que incorporen aspectos diversos relacionados con la vida privada, ocupación, intereses, trayectoria de la enfermedad, la infancia, los estudios, los hábitos personales, etc. El perfil diagnóstico que persigue un profesional de salud mental comprende las siguientes dimensiones como reseñamos en la siguiente figura:

Figura 8: Dimensiones del psicodiagnóstico

\section{DIAGNÓSTICO DIMENSIONES}

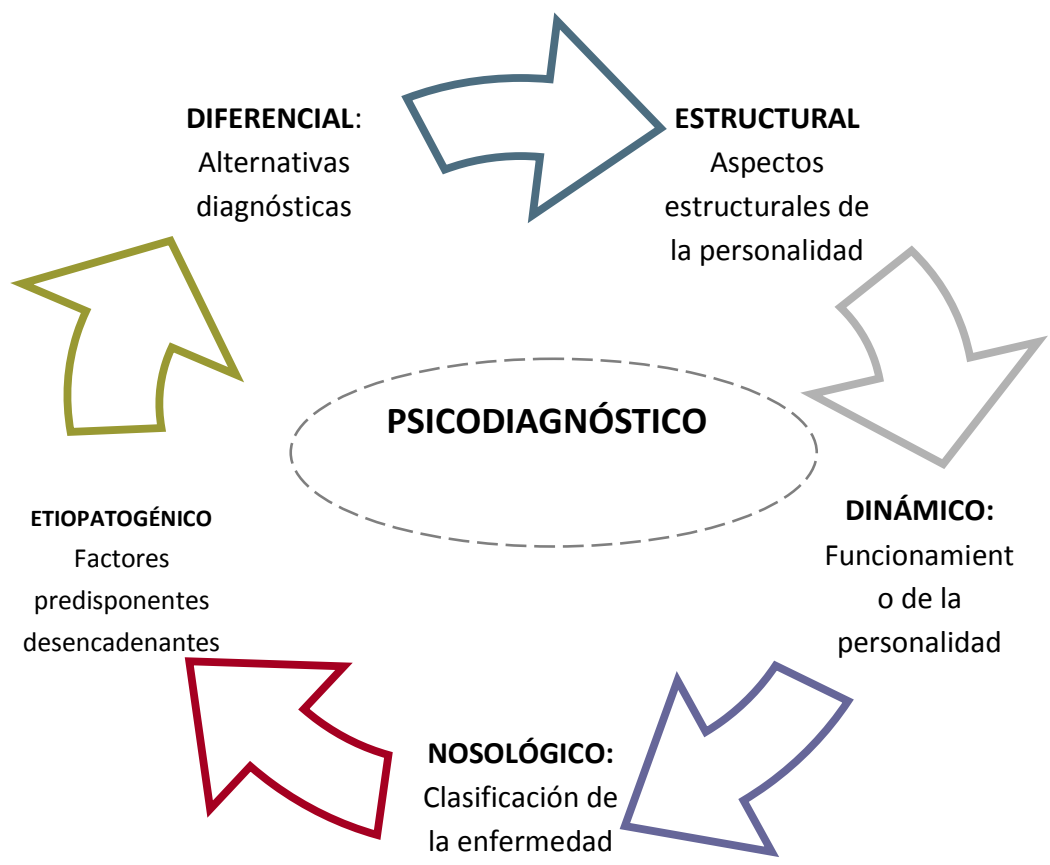

3.3.1.1.Áreas y contenidos explorados en la entrevista:

Las áreas exploradas en la entrevista utilizada en este estudio fueron las siguientes:

1) Datos demográficos

2) Historia académica

3) Historia ocupacional 
4) Tratamiento actual

5) Motivo de consulta y descripción del problema

6) Inicio del mismo

7) Aparición o recurrencia de síntomas

8) Contexto ambiental y posibles precipitantes de la enfermedad/problema

9) Curso del problema

10) Historia de tratamientos

11) Otros problemas actuales

12) Funcionamiento social

Es muy importante señalar que los contenidos estresantes, como el curso de la enfermedad, problemas familiares y el motivo de la consulta, se hipotetiza que pueden ser más informativos respecto de la productividad de los fenómenos discursivos que los contenidos neutros, por ejemplo información del entorno.

Además, con el fin de proporcionar información que contraste el desempeño comunicativo en pacientes de inicio, crónicos y grupo control, comparamos las entrevistas de los tres grupos en función de la tarea comunicativa asignada para este fin, que fue incorporada en el punto 5: Motivo de consulta y descripción del problema. La tarea comunicativa consistió en lo siguiente:

\subsubsection{Narración de su historia personal:}

Se les solicitó que realizaran un relato biográfico sin restricciones. Los sujetos debían estructurar su relato en función de los elementos que les pareciesen interesantes de comentar. El relato autobiográfico se utiliza con frecuencia en el ámbito de la psiquiatría, pues este tipo de tareas presupone una compleja elaboración diacrónica por parte del sujeto entrevistado, y su carácter depende de sus condiciones emocionales, sociales y cognitivas. Es a través de esta aproximación narrativa que se formula una identidad (Gallagher, 2003). 


\subsubsection{Cantidad y condiciones de las entrevistas realizadas a cada participante:}

Estas entrevistas fueron realizadas en el marco de la cátedra de psicopatología clínica para los becados de psiquiatría sede sur, de la Facultad de Medicina de la Universidad de Chile, dictada por el Psiquiatra Eduardo Durán Lara.

Todos los pacientes del estudio fueron sometidos a más de una entrevista psiquiátrica, una de inicio durante el ingreso y otras de control semanal por espacio de un mes con consentimiento informado escrito. Los pacientes crónicos que tenían un período de ingreso superior al mes de hospitalización, también fueron sometidos a dos o más entrevistas. La metodología utilizada en la realización de las entrevistas se ajustó a los siguientes criterios:

1) Las entrevistas se realizaron bajo las mismas condiciones, una sala sin ruidos externos y buena iluminación.

2) De cada uno de los participantes se tomó aquella que fue considerada más representativa de la enfermedad, según el juicio crítico de un grupo de profesionales de salud mental.

3) Se descartaron aquellas que correspondían al ingreso ya que en algunos casos los informantes se encontraban en psicosis aguda, agitados y/o agresivos. Se optó por la segunda o tercera entrevista, o por aquella en la que el paciente se encontraba en estabilidad clínica.

4) Los participantes escogidos dieron su consentimiento para participar en el estudio.

5) Calidad del sonido y/o video de la entrevista.

6) La entrevista en la que el informante fue más cooperativo con el entrevistador.

\subsubsection{Registro técnico:}


Las entrevistas semiestructuradas fueron registradas con grabadora digital y/o con video grabación (gradabora Olympus Voice Trek V-41 y/o cámara de video profesional Sony HXR-MC2000N). La duración fluctuó entre 30 y 80 minutos. Posteriormente a la selección del corpus, se optó por realizar un corte temporal de 15 minutos a cada entrevista, con el fin de homogeneizar los datos.

El conjunto de antecedentes antes proporcionado nos permitió seleccionar, de entre cerca de 160 entrevistas, las 50 correspondientes a este estudio.

3. 4. Variables del estudio:

\subsubsection{Variables independientes:}

3.4.1.1. Estadio de la enfermedad: se consideró la clasificación psiquiátrica tradicional en la que se define el inicio de la enfermedad teniendo en cuenta criterios temporales. Según el MINSAL de Chile, los pacientes con esta patología psiquiátrica son pesquisados a través de las redes de salud pública y/o privadas y son integrados al programa AUGE en el caso de que se trate del inicio de la enfermedad, pero, como ya señalamos en la introducción, en Chile se estima que entre el proceso de la detección, derivación e inicio del tratamiento, transcurren hasta tres años (Alvarado, R: 2012). En general el protocolo que se sigue en caso de la detección precoz, se resume como sigue: 
Figura 9: Manejo de personas con primer episodio de psicosis en Chile

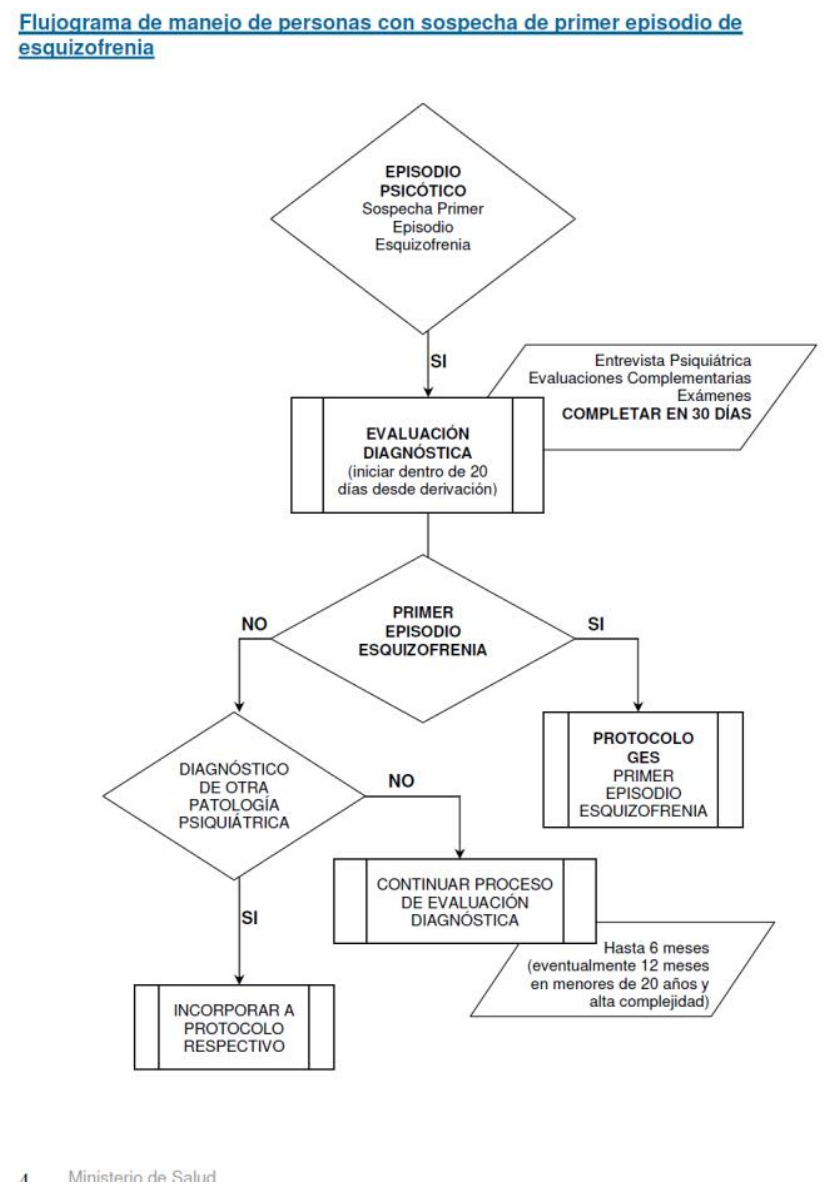

Fuente: MINSAL, 2009

En el caso de los pacientes crónicos, son aquellos que superan los 5 años de tratamiento, terapia y/o rehabilitación, con o sin internaciones hospitalarias. Se resume a continuación: 


\subsection{Grupo 1: pacientes con esquizofrenia crónica:}

Según las descripciones y protocolos psiquiátricos, se consideraron para este grupo 25 pacientes que superaban los 3 años de enfermedad, muchos de ellos con varias hospitalizaciones por frecuentes episodios psicóticos y deterioro cognitivo.

\subsection{Grupo 2: pacientes con esquizofrenia de primer episodio}

Según los criterios psiquiátricos de rigor, se consideraron 25 pacientes con esquizofrenia precoz, de inicio o también llamada de primer episodio, a aquellos sujetos que presentaban la enfermedad con una duración inferior a 3 años, que habían iniciado el tratamiento o que se encontraban cursando una primera hospitalización.

\subsection{Grupo 3: sujetos controles:}

En este grupo se consideraron 12 personas sanas, sin diagnóstico psiquiátrico, pareadas por sexo y características sociodemográficas de los pacientes.

\subsubsection{Sexo de los participantes:}

Grupo 1: pacientes con esquizofrenia precoz

11 mujeres y 14 hombres

Grupo 2: pacientes crónicos de esquizofrenia

12 mujeres y 13 hombres

Grupo 3: controles

6 hombres y 6 mujeres 
3.4.1.3. Tramo de la enfermedad:

Esquizofrenia de primer episodio:

Tramo 1: de 0 a 2 años de enfermedad

Tramo 2: de 2 a 3 años de enfermedad

Esquizofrenia crónica:

Tramo 3: hasta 5 años de enfermedad

Tramo 4: 5 años y más de enfermedad

\subsubsection{Subtipo de esquizofrenia ${ }^{22}$ :}

Subtipo 1: esquizofrenia paranoide

Subtipo 2: esquizofrenia indiferenciada

Subtipo 3: esquizofrenia desorganizada

\subsubsection{Variables dependientes y procesamiento de los datos:}

Durante la entrevista, los informantes, pacientes y controles construyeron relatos sobre sus vivencias personales, asociadas fundamentalmente al motivo de la consulta psiquiátrica, en el caso de los pacientes; y de carácter anecdótica, en el caso de los controles.

De las entrevistas hechas a los pacientes, se seleccionó la mejor de dos o tres así como en el caso de los controles y primeros episodios. Para los controles, se conservaron los filtros propuestos por el proyecto ESECH, ya descritos anteriormente. Se transcribieron las 50 entrevistas de los Grupos 1 y 2, con ortografía convencional, con anotaciones sobre la pronunciación cuando correspondió, como en el caso de las

${ }^{22}$ Se excluyeron los pacientes del subtipo catatónico por no existir coincidencias absolutas en el equipo de evaluación psiquiátrica. 
elisiones, acortamientos, aspiraciones, alargamientos, chasquidos, muletillas, etc. Como ya mencionamos, en esta investigación nos proponemos analizar y comparar, desde una perspectiva pragmalingüística (cuantitativa) la coherencia de los discursos de personas con diagnóstico de esquizofrenia de inicio y crónica.

Creemos que el criterio de selección que hemos empleado para conformar el corpus resulta pertinente, tomando en cuenta que al tratarse de personas afectadas por una enfermedad psiquiátrica, hay que tener un mayor control sobre variables intervinientes tales como el cansancio, la falta de atención, presencia de síndromes estuporosos, descompensaciones psicóticas provocadas por su situación particular o bien, por la entrevista misma, etc. En este sentido, se cauteló el hecho de realizar entrevistas en pequeños equipos que siempre incluyeran a un psiquiatra senior.

\subsubsection{Variables del estudio:}

Basados en la observación de fenómenos clínicos ya descritos en la psiquiatría, se han modelado seis cluster de fenómenos discursivos, que pretenden establecer el nivel de eficacia discursiva que ostentan los sujetos estudiados. Basados en el principio griceano, se han operativizado una serie de indicadores de coherencia y cohesión discursiva considerados la base de una interacción eficiente. Por la misma razón, se tomó desde el modelo de Beaugrande y Dressler (2003), el mismo núcleo de análisis con el que en este trabajo se pretende dar cuenta no solo del perfil comunicativo de los pacientes crónicos y de primer episodio, sino también de los indicadores de deterioro considerados tempranos por su aparición en el comportamiento discursivo de los pacientes de primer episodio.

Dentro de estos elementos que se incluyeron, tomamos como cluster de análisis los siguientes núcleos: 


\subsubsection{Errores que afectan la fluidez del discurso:}

La fluidez verbal se refiere a la cantidad de información por unidad de medida, que un hablante es capaz de emitir cuando produce un discurso. Se refiere también a la calidad de la información emitida ya que no es suficiente producir muchas palabras por minuto sino también producir un discurso que progrese temáticamente, un discurso que muestre un desarrollo y que avance hacia una meta discursiva (Menjura, 2007:8).

La fluidez verbal también se ha tipificado como una tarea de producción lingüística que requiere la utilización de los mecanismos de acceso al léxico. Sin embargo, esta tarea también incluye otras áreas cognitivas como las funciones ejecutivas, como atención sostenida, velocidad, memoria de trabajo, inhibición de respuestas, entre otras. Por esta versatilidad, se la utiliza con frecuencia para la evaluación de las funciones ejecutivas (Huff, 1990). En diferentes protocolos se mide la fluidez, a partir de criterios que pueden ser fonológicos o semánticos. (MEC, subprueba de restricción léxica, generar todas las palabras posibles, que inicien con el fonema /p/, durante 120 segundos).

Se ha observado que el modo en que se aborda la evaluación suele ser contrario a la producción lingüística normal de un hablante ya que las situaciones son experimentales y no constituyen un comportamiento comunicativo estándar. A los sujetos estudiados se les pide que produzcan una serie de palabras durante un tiempo acotado, por ejemplo 60 segundos, tomando en cuenta algunas restricciones que pueden particular de los PEE, dicho tipo de tareas les genera una ansiedad intensa dado el humor paranoide que presentan en esta etapa. A menudo los pacientes preguntan cómo salieron evaluados, o si es significativo su desempeño para los parámetros esperados. En este punto, nos parece importante destacar que existen parámetros que ofrecen un marco de referencia para los fenómenos, como señala Mendizábal de la Cruz (2004: sp):

En la producción del lenguaje se estudia el proceso por el que un hablante transforma un concepto mental en un enunciado oral, basándose en los datos que nos aportan los errores espontáneos del habla. Precisamente conocer una lengua es saber cómo se produce y comprende un conjunto ilimitado de enunciados. Cualquier hablante nativo realiza esta tarea sin esfuerzo alguno, sin consciencia de cómo lo hace y a una velocidad de 150 palabras por minuto. Estas tres características, facilidad, inconsciencia y velocidad son relevantes a la hora de entender los errores espontáneos del habla. 
Tomando en cuenta este inconveniente incluimos aquellas conductas comunicativas que aparecen en la conversación normal, considerando la observación de Belinchón:

La fluidez es la realización fonoarticulatoria de los discursos, que facilita, en el interlocutor, la automatización de los procesos implicados en las fases iniciales de la percepción y comprensión del habla (Belinchón, 1988:137)

Evaluaremos si existe presencia o ausencia de estos rasgos en las intervenciones seleccionadas. Dentro de este cluster incluimos:

3.4.3.1.1. Titubeos: se trata de la producción de uno o más sonidos que no tienen relación estructural con la decisión léxica siguiente, consideramos pausas oralizadas, (ej: “mmm”, “eeeh”) muletillas (ej: “claro”, “o sea”, “entiende?”), repeticiones innecesarias de alguna palabra o frase (ej: “es como si”). Según Gallardo-Páuls y Hernández Sacristán (2013) durante la interacción pueden presentarse los llamados actos activadores de inferencias, como las vocalizaciones, interjecciones o titubeos, sin embargo, cumplen con un fin compensatorio desde la perspectiva comunicativa. En el caso de los pacientes con esquizofrenia, a menudo estas estrategias se utilizan, pero no siempre aportan información, por tanto no contribuirían al proceso comunicativo. Se incluirán aquellas que no tengan ninguna relación con el contexto léxico semántico posterior.

3.4.3.1.2. Falsos inicios: inicio e interrupción inmediata que afecta al primer fonema, morfema, palabra, o frase. A menudo se reformula la palabra o frase, aunque el paciente no siempre logra una versión más informativa. (ej: "por faltar... por faltando de... me faltó un remedio"). Los falsos inicios podemos documentarlos en el discurso de personas sanas, sin embargo, la reformulación de algún elemento constituye un recurso que suma información, funcionando como un movimiento discursivo de carácter retroactivo que reorienta la línea argumentativa del discurso y reinterpreta un miembro discursivo previo desde una nueva perspectiva enunciativa 
(Roulet, 1987). Es decir, cumple una función semántico-pragmática dentro de las interacciones, pero cuando es constante y no aporta más información, ni son enunciados clarificadores, no se cumple el propósito discursivo de este recurso, estos casos serán contados como falsos inicios.

3.4.3.1.3. Pausas extensas: Se considera pausa extendida cuando se produce la interrupción en el flujo de los turnos de habla. Las pausas son parte de la estructura comunicativa de la interacción, nos permiten descansar y respirar, además marcan la pauta de cambio de turno del interlocutor. Cuando ocupan un espacio natural dentro de la conversación, añadimos matices semánticos, énfasis y ritmo. En este fenómeno nos interesa ver si las pausas resultan funcionales o no. A menudo los pacientes presentan silencios extensos tanto al cambiar el turno o durante éste. Según los parámetros propuestos por Crockford y Lesser, (1994), se considera pausa extendida si esta interrupción supera los dos segundos.

3.4.3.1.4. Tartamudeos: se trata de la repetición de un fonema, sílaba o parte de una palabra. esta repetición no cumple ninguna función comunicativa y generalmente no forma parte de la frase u oración. (ej: con...con...co...congé...congenia). Verificaremos la presencia o ausencia de este rasgo, tomando en cuenta como parámetro si se presenta en el $25 \%$ o más, en los turnos de habla del paciente. Esto quiere decir que si se contabilizan 65 turnos en 15 minutos, el tartamudeo debería ser $\tan$ frecuente, que se aprecie en alrededor de 16 turnos de habla. En las personas sin patología psiquiátrica, a veces es posible observar un pseudo-tartamudeo ocasional, también llamado disfacundia, que según la literatura se produciría por cansancio o por otras razones como falta de atención o monitoreo cognitivo. Esta manifestación en la población normal, sería escasa, en ningún caso podría elevarse a un $25 \%$ de las intervenciones. descartaremos a aquellos pacientes que por estar estuporosos presentan problemas articulatorios constantes. 
3.4.3.1.5. Turnos de habla con volumen débil: se trata de la dificultad que se genera a partir del bajo volumen de voz utilizado por el paciente. Las elocuciones se vuelven apenas audibles, los pacientes parecen musitar sus respuestas, incluso si las condiciones ambientales son óptimas para escuchar, es decir, una sala con buena acústica. Con frecuencia es necesario preguntarle reiteradamente qué dijo. (ej: " $S:$ que todos esos recuerdos son de años pasados, cuando estaba con mi ex/ E: ¿con...?/S: mi ex /E: ¿miedo?/S: mi ex/E: ¿qué lo que es miets?/S: mi ex novia/ E: ¡ah!, “mi ex novia", ya, perfecto")

\subsubsection{Errores que afectan la productividad verbal de los discursos:}

En este cluster se reunieron los fenómenos que apuntan al volumen de la producción verbal de los pacientes. La productividad verbal, también está entendida como la capacidad para emitir y comprender enunciados nuevos, ajustándose a la situación comunicativa que los genera (Aitchison, 1988). En este grupo de fenómenos se privilegiaron las medidas que daban cuenta de esta capacidad para responder a las necesidades informativas del entrevistador. Una propiedad estructural en la productividad, es que la conducta verbal está sometida a reglas en la elaboración de la información. Se revisan las producciones discursivas de los sujetos estudiados, se contabilizarán, tomando en cuenta aquellos elementos que inciden en la calidad de las emisiones:

3.4.3.2.1. Total de oraciones: aquí se tomará en cuenta la cantidad de enunciados producidos por cada participante del estudio, en una extensión de 15 minutos. Suponemos que los hallazgos apuntarán a una mayor homogeneidad entre controles y crónicos, por tanto, también esperamos encontrar diferencias con el grupo de esquizofrénicos de primer episodio, quienes suponemos presentarían una tendencia a estar más reticente en el curso de la conversación, incluso mostrando más conductas monosilábicas que los crónicos y controles. Las abundantes descripciones encontradas en la literatura indican que hay un menor control inhibitorio y un menor monitoreo cognitivo en los pacientes crónicos, de manera que creemos en resultados 
posiblemente similares entre crónicos y controles, aunque, subrayamos sólo en lo referido a la estimación de cantidad de oraciones.

3.4.3.2.2. Promedio de palabras por oración: Se contará el promedio de palabras que utilizaron los sujetos en los 15 minutos de participación. Según Moreno (2010), el promedio de palabras por oración en personas sin patología es de 12,4 palabras por oración. Se comprobará esta cifra con el parametrizador de textos: PARAMTEXT TIP 23 en una muestra piloto, y se llegó a coincidencias sobre el $70 \%$.

3.4.3.2.3. Total de palabras diferentes (no repetidas): Se contará el número de palabras diferentes, es decir, que no se repiten en el transcurso de 15 minutos. Sabemos que la densidad léxica en el discurso oral es inferior a la del discurso escrito, pero nos parece importante realizar una comparación en el plano léxico, con el fin de apreciar si se observan diferencias entre los grupos. Para evitar discordancias, también se comprobó una muestra piloto con el parametrizador de textos: PARAMTEXT TIP, llegando a coincidencias sobre el $80 \%$ en las muestras piloto.

3.4.3.2.4. Total de neologismos parciales: Se consideran neologismos parciales aquellas palabras que son utilizadas en un contexto semántico diferente al que pertenecen, sin embargo, son reconocibles dentro de una familia semántica. También se contaron aquí aquellos ítemes léxicos que fueron utilizados en un contexto semántico aproximado, pero que conservan una estructura aún identificable en cuanto a los procedimientos de formación de palabras del español. (ej: CRE_M03: "a mi mamá le gusta soberanearse con los demás"* de soberanía, por ser autoritaria). Nos parece llamativa la presencia de este rasgo incluso en personas sin patología psiquiátrica como el conocido caso del jugador de fútbol chileno, Gary Medel, quien

${ }^{23}$ Disponible en http://tip.dis.ulpgc.es/paramtext/ Es aplicación web destinada a la parametrización morfológica de textos. Los resultados se representan mediante tablas y gráficas que permiten analizar la estructura del documento desde el punto de vista morfológico y facilitan la comparación entre diferentes textos 
en una entrevista durante el Mundial de Fútbol 2014, refirió que había que jugar con chispeza, en referencia al desempeño desplegado en el campo de juego.

3.4.3.2.5. Total de neologismos totales: se consideran neologismos totales todas aquellas palabras que no presentan un referente semántico identificable, son ítemes léxicos desconocidos, que incluso no siguen por completo las reglas de formación de palabras en el español (ej: "tomitometole", "perjunjula", “eleotósticos”)

3.4.3.2.6. Total de referentes utilizados en el segmento escogido: Se consideraron aquellos nombres y sintagmas nominales que se formularon en adyacencia a un verbo. Sobre estos nombres se dispone un volumen específico de información que permite comprender no solo el contexto en el que se enmarca, sino que también el referente mismo. (Ej: "el dr. X me dijo que me iban a hacer unos exámenes")

3.4.3.2.7. Total de vínculos referenciales: Se contarán aquí la cantidad de palabras que amplifican el referente. (ej [el dr. Pérez] ] $\rightarrow$ REFERENTE [me dijo que me iban a hacer una resonancia] ] $\rightarrow$ VÍNCULOS REFERENCIALES). Esta medida permitirá verificar si existen o no mecanismos cohesivos funcionales o si éstos están deteriorados; además, se espera verificar cómo es el desempeño de los esquizofrénicos de primer episodio, medida que suponemos puede arrojar información acerca del manejo y conservación de las estructuras cohesivas.

3.4.3.2.8. Promedio de vínculos referenciales: Se contarán en este punto, el promedio de vínculos referenciales utilizados. Lo que se pretende estimar es si aparecen distancias anómalas entre los grupos estudiados.

3.4.3.3. Errores que afectan el índice de participación conversacional:

El cluster de participación conversacional se incluyó como una medida para evaluar la capacidad de interactuar comunicativamente con el entrevistador. Está 
tomado del protocolo de cuantificación de conductas conversacionales de Crockford y Lesser, 1994, que se relaciona con la medida de longitud media de un enunciado $(M L U)^{24}$. Desde una perspectiva pragmática de eficacia comunicativa, el IPC sería una manera de valorar la intencionalidad participativa del hablante. Se tomarán en cuenta las habilidades para tomar el turno de habla y mantener un ritmo de interacción que posee parámetros regulares. Al contrastar estas medidas con lo que la literatura expresa sobre el estudio de la afasiología, pensamos que pueden ser significativas.

3.4.3.3.1. Índice de participación conversacional (IPC): El IPC, puede estar definido en términos locutivos, como el número total de las palabras utilizadas por el sujeto estudiado. También puede ser medido en términos comunicativos, en cuanto al número de actos de habla empleados por el hablante. En este estudio utilizaremos la primera medida.

3.4.3.3.2. Agilidad del turno: se contará el promedio de turnos de habla por minuto. Es una medida relativa, pero puede ser funcional al compararla con los promedios de turnos empleados por hablantes de un corpus como el ESECH, del Español de Santiago de Chile, que arrojó un promedio de 6 turnos por minuto. Es importante hacer notar que, el grupo de investigación del corpus PERLA ${ }^{25}$ estableció medidas comparativas con el corpus Valesco, del español coloquial peninsular, proyecto de la Universidad de Valencia, llegando a un promedio de 17,4 turnos por minuto. Las causas de la diferencia, que no son motivo de estudio de este trabajo, se deben probablemente al tipo de entrevista ${ }^{26}$ o a un estilo discursivo diferente entre hablantes españoles y chilenos.

\footnotetext{
${ }^{24}$ MLU: Mean Length of Uterance, trabajo de Brown en la década del 70, citado por Gallardo-Páuls, 2013

${ }^{25}$ PERLA: Percepción, Lenguaje y Afasia, Universidad de Valencia, a cargo de Beatriz Gallardo-Paúls

${ }^{26}$ Ver anexo con ejemplo tomado del ESECH
} 


\subsubsection{Errores que afectan la coherencia temática:}

En el cluster de coherencia temática encontramos aspectos que apuntan a la evaluación de la estructura profunda de los discursos de los sujetos estudiados. Se replican algunos fenómenos que fueron contabilizados en el nivel anterior, pero en este nivel se pretendió evaluar la eficacia comunicativa medida en tres niveles de significación, es a saber, si es que el sujeto lo realiza adecuadamente (3), si es que requiere ayuda del entrevistador para esclarecer el significado (2), o bien si es deficiente a pesar de contar con el modelamiento del entrevistador (1)

\section{Macroestructura:}

Para comprender qué tipo de estructura lingüística se ve afectada o interferida en los pacientes, siguiendo a van Dijk (1983) en el discurso de los sujetos diferenciaremos dos niveles; la estructura semántica global que le proporciona unidad al discurso, tomada como una representación abstracta del significado que se pretende transmitir. Es la proposición profunda que representa el tema de un texto y que en buenas cuentas constituye la síntesis del contenido. Se identifica reconstruyendo el texto. Usando la semántica, se organiza en predicado y argumentos. Y la estructura semántica lineal, que permite la mantención de la meta con la utilización de recursos cohesivos.

Para el modelamiento de la macroestructura se incluye:

3.4.3.4.1. Presencia de Unidad temática nuclear reconocible: la unidad temática nuclear, entendida como la macroproposición o macroacto de habla, se aplicará en la tarea comunicativa inserta en los primeros minutos de entrevista.

3.4.3.4.2. Presencia de proposiciones con vínculos explícitos alusivos al tema central: Tomaremos en cuenta aquellas frases u oraciones que contribuyan a 
desarrollar el tema central, que cuenten con una estructura semántica reconocible en términos de relaciones lógicas, incluso si presentan algunos errores cohesivos. Se enuncian de manera explícita y clara, constituyen ideas principales en el texto/discurso. La red de dependencia entre los enunciados es una forma de actividad mental, en tanto modelo de procesamiento de la información proveniente de la realidad, se le atribuye en doble faz, tanto el conocimiento del mundo como el conocimiento presentado en el texto o discurso. De esta forma se espera acceder a la intencionalidad del discurso de los sujetos entrevistados. Se evaluará si estas conexiones con el tema central se realizaron de forma autónoma, con ayuda o fueron deficientes.

3.4.3.4.3. Presencia de proposiciones con vínculos implícitos alusivos al tema central: Dentro de las estructura generales que aluden al tema central, también se encuentran frases u oraciones que plantean información relacionada de una forma menos directa o cuya organización textual es menos económica, sin embargo, pueden vincularse al tema central, evaluaremos la presencia de éstas y si son realizadas con o sin ayuda del entrevistador o son deficientes.

\section{Microestructura:}

Se entiende por el nivel discursivo que conecta proposiciones textuales explícitas que se establecen mediante relaciones entre conexiones conceptuales o argumentos como temporalidad o causalidad. Tales conexiones locales se establecen, además, mediante distinto tipo de relaciones funcionales como contraste, comparación, ejemplificación, explicación, etc. La microestructura corresponde a la estructura gramatical, a las relaciones léxicas, referenciales y las que permiten mantener la continuidad temática. Además está relacionada con los aspectos prosódicos y/o fonéticos, como pausas y entonación, asimismo, con cuestiones semánticas, en el sentido de lo que se expresa.

3.4.3.4.4. Presencia de Tópico con referente (desarrollo): Se evaluarán las secuencias de oraciones en torno a un referente que presente uno o varios tópicos 
desarrollados. Estas estructuras pueden aparecer contiguas a las ideas del tema central. Para este fin se utilizan una serie de recursos tales como la referencia endofórica, ya sea anáfora o catáfora, o bien exofórica, extratextual. Los tópicos introducen nueva información en el discurso. Según Escribano:

Son constituyentes prosódicamente desgajados, recubiertos de curvas de entonación que finalizan en semianticadencia, que concretan la capacidad referencial de ciertos elementos integrados, por lo general clíticos, y que a veces van introducidos por expresiones especializadas como en cuanto a, por lo que respecta a, etc. (Escribano, (1991:362)

También nos interesa hacer notar las observaciones de Shibatani, quien denomina tópico a aquel:

Elemento que limita la aplicabilidad de la predicación principal a un dominio restringido. (Citado por Gutiérrez Ordóñez, 1997:42)

Frecuentemente, las personas con esquizofrenia solo enuncian referentes, sin que estos sean desarrollados en el hilo discursivo. Verificaremos la presencia de frases u oraciones que respondan a esta función dentro del discurso, y si los informantes las realizan de forma autónoma o no, o es deficiente.

3.4.3.4.5. Presencia de salto topical: La función de los tópicos es mantener actualizados los mecanismos referenciales, es decir, conseguir un movimiento constante y progresivo del discurso. Sin embargo, la introducción de un tópico no es informativa por sí sola es necesario que esa incorporación posea el contexto necesario para su comprensión. Nos parece claro que la presencia de este fenómeno es señal de un deterioro notorio en las funciones ejecutivas. Por lo tanto, si también se halla en los informantes de primer episodio sería una marca significativa de déficit inicial.

3.4.3.4.6. Interacción entre referentes y vínculos referenciales: la relación que se da entre ambos, implicaría una serie de mecanismos desplegados con el fin de mantener el referente. Se establecerían relaciones semánticas de base léxica y 
gramatical, así como recursos de progresión para ir ligando los vínculos y los referentes. Si la distancia que se da entre los vínculos referenciales es muy extensa, el interlocutor debe realizar un mayor esfuerzo para relacionarlos. Ya que en el cluster de Fluidez, evaluamos el promedio de vínculos que ostentan los participantes, nos interesa ahora comprobar si la relación entre estas estructuras es adecuada o no lo es, o bien, se realiza con ayuda del entrevistador.

\subsubsection{Errores que afectan la semántica de la coherencia:}

Este índice fue medido como presencia o ausencia de la conducta, (1) ausencia, (2) presencia. Se operacionalizó el concepto a partir de la utilización de verbos de certeza como ser o estar y de probabilidad o duda como imaginar. (ej: "me gustaría ser mago para tener lo que quiera", "me imagino que podría" en oposición a enunciados como, "soy la virgen María", "soy Cleopatra").

3.4.3.5.1. Confusión en el juicio de realidad (mundos posibles): Presencia o ausencia de verbos ser o estar en enunciados referidos a sí mismo o a una situación vivenciada, en oposición a verbos de percepción como creer, imaginar, sentir, etc. Ser o estar, expresan cualidades del sujeto y hacen referencia a aspectos propios de su naturaleza. El verbo ser, presenta cualidades permanentes, el verbo estar, cualidades circunstanciales. Nos interesa comprobar si se presentan estructuras del tipo: soy Cleopatra, en oposición a me imagino que soy como Cleopatra. Que darían cuenta de un juicio de la realidad adecuado o alterado.

3.4.3.6. Errores que afectan la coherencia interaccional: Con el fin de indagar la naturaleza de la interacción, se valorará el desempeño de los informantes en función de dos índices: los turnos de habla y los pares adyacentes. Ambos índices aportan 
información sobre la participación comunicativa de los informantes. Se valorarán en términos de desempeño adecuado, o no, o si se realizó con ayuda del entrevistador.

3.4.3.6.1. Pares adyacentes: Los pares adyacentes están construidos por dos turnos de habla sucesivos, y responden a necesidades informativas específicas, tales como pregunta-respuesta; saludo-despedida; ofrecimiento-aceptación o rechazo; agradecimiento-minimización, etc. En los pacientes crónicos es frecuente que respondan adecuadamente a algunos pares adyacentes, generalmente situados en el inicio de la entrevista.

3.4.3.6.2. Toma de turnos: La toma de turnos sin ayuda del entrevistador, da cuenta del grado de atención de los sujetos, así como del grado de involucramiento en la situación comunicativa. También los valoraremos como adecuados o no, o con ayuda del entrevistador.

\subsection{Construcción de la matriz de análisis}

Se operacionalizaron los índices ya descritos y de acuerdo con la información proporcionada en 3.4, la matriz analítica quedó constituida como sigue:

3.5.1. Operacionalización de los cluster como indicadores de déficits

\subsubsection{Matrices de análisis}

Tabla 12: Errores en la fluidez que afectan la coherencia

\begin{tabular}{|l|l|l|}
\hline INDICADORES & $\begin{array}{l}\text { AUSENCIA } \\
(\mathbf{2})\end{array}$ & $\begin{array}{l}\text { PRESENCIA } \\
(\mathbf{1})\end{array}$ \\
\hline Titubeos & & \\
\hline Falsos inicios & & \\
\hline Pausas extensas & & \\
\hline Tartamudeos & & \\
\hline
\end{tabular}


Turnos de habla con volumen muy débil

Tabla 13: Errores en la productividad verbal

\begin{tabular}{|l|l|}
\hline INDICADORES & $\mathbf{N}^{\circ}$ \\
\hline Total de oraciones/frases por tarea & \\
\hline Promedio de palabras por oración & \\
\hline Total de palabras diferentes (no repetidas) & \\
\hline Neologismos parciales & \\
\hline Neologismos totales & \\
\hline Referentes & \\
\hline Total vínculos referenciales & \\
\hline Promedio de vínculos referenciales & \\
\hline
\end{tabular}

Tabla 14: Índice de participación conversacional

\begin{tabular}{|l|l|}
\hline INDICADORES & NÚMERO \\
\hline Índice de participación conversacional & \\
\hline Promedio de turnos de habla por minuto & \\
\hline
\end{tabular}

Tabla 15: Errores en la coherencia temática

\begin{tabular}{|l|l|l|l|}
\hline INDICADORES & $\begin{array}{l}\text { REALIZADO } \\
\text { ADECUADAMENTE } \\
(\mathbf{3})\end{array}$ & $\begin{array}{l}\text { CON AYUDA DEL } \\
\text { ENTREVISTADOR } \\
\text { (2) }\end{array}$ & $\begin{array}{l}\text { FALLA } \\
\text { COMPLETA } \\
\text { (1) }\end{array}$ \\
\hline Macroestructura & & & \\
\hline Unidad temática nuclear & & & \\
\hline Proposiciones con vínculos & & & \\
\hline Proposiciones con vínculos & & & \\
\hline Microestructura & & & \\
\hline Tópico con referente & & & \\
\hline Salto topical & & & \\
\hline $\begin{array}{l}\text { Interacción entre referentes y } \\
\text { vínculos }\end{array}$ & & & \\
\hline
\end{tabular}

Tabla 16: Semántica de la Coherencia

\begin{tabular}{|l|l|l|}
\hline INDICADORES & AUSENCIA (2) & PRESENCIA (1) \\
\hline $\begin{array}{l}\text { Confusión en el juicio de realidad } \\
\text { (mundos posibles) }\end{array}$ & & \\
\hline
\end{tabular}


Tabla 17: Errores en la coherencia interaccional

\begin{tabular}{|l|l|l|l|}
\hline CRITERIOS & $\begin{array}{l}\text { REALIZADO } \\
\text { ADECUADAMENTE }\end{array}$ & $\begin{array}{l}\text { CON AYUDA DEL } \\
\text { ENTREVISTADOR }\end{array}$ & $\begin{array}{l}\text { FALLA } \\
\text { COMPLETA }\end{array}$ \\
\hline INDICADORES & $\mathbf{( 3 )}$ & $\mathbf{( 2 )}$ & $\mathbf{( 1 )}$ \\
\hline Pares adyacentes & & & \\
\hline Toma de turnos & & & \\
\hline
\end{tabular}

3.6. Descripción de la prueba estadística:

En lo que se refiere a la descripción de los procedimientos estadísticos utilizados, al tratarse de un estudio con variables cuantitativas múltiples, lo que haremos en primer lugar es comprobar si se produce una distribución normal de los datos conseguidos. El resultado nos permitirá determinar si las pruebas estadísticas que se emplearán, serán de tipo paramétricas, (por ejemplo, un ANOVA), o se complementarán con un ANOVA de Kruskar Wallis; y si son de tipo no paramétricas (por ejemplo, una prueba de ji cuadrado) que correlacione la presencia o ausencia de algunas variables con factores como el estadio de la enfermedad, el subtipo y el tramo de tiempo que llevan cursando la patología.

En todos los casos, el grado de significación estadística se definirá en el 5\%, según el cual $\mathrm{p}=<0.05$ será estadísticamente significativo. El paquete estadístico utilizado es el SPSS (Statistical Package for the Social Sciences), versión 21 para Windows

Para propósitos de análisis los datos están organizados en dos niveles diferentes de observación: a) en términos descriptivos, según frecuencias absolutas y porcentajes de frecuencia de algunas variables; b) en términos inferenciales, basados en la comparación de las tendencias centrales de los datos de las otras variables.

Es importante señalar que para la aplicación de las pruebas estadísticas, se trabajará sobre la base de las siguientes preguntas: 1) ¿existe algún efecto del estadio o 
grupo de la enfermedad en que se encuentran los pacientes sobre las variables dependientes? 2) ¿existe algún efecto del sexo sobre las variables dependientes? 3) ¿existe algún efecto entre el tramo de tiempo de la enfermedad sobre las variables dependientes? 4) ¿existe algún efecto sobre el subtipo de esquizofrenia sobre las variables dependientes?

Para cada una de las preguntas, se aplicará la prueba estadística correspondiente en función de los datos. En caso de identificarse diferencias estadísticamente significativas, se aplicará la prueba post-hoc que corresponda para localizar las diferencias.

Finalmente, en aquellos casos en que se estime necesario, bastará con un análisis porcentual de los datos. 


\section{Capítulo 4 Resultados}

"El habla de un sujeto esquizofrénico tiene algo diferente, nuevo, una neo organización del lenguaje, que difiere sin dependencia de las formas habituales del uso del lenguaje. Enfrentamos algo nuevo y dramático, a tal punto que el acto de habla se torna vacío".

(Eduardo Durán, 2011) 
Resultados

4. Análisis y presentación de los resultados

Cuando hablamos de comprender el discurso, nos referimos no solo a la transformación de unidades lingüísticas en representaciones proposicionales. El procesamiento de la información no consiste únicamente en una conversión de la estructura formal a la abstracción semántica. Las complejas tareas que conforman dicho proceso comprensivo, incluyen depuración, abstracción, interpretación y reelaboración del significado. Esta evidencia nos aclara que, por un lado debemos analizar por separado cada una de las fases de este proceso y, por otra, tomarlo en su globalidad, en especial cuando hemos alcanzado la comprensión del significado.

Con el fin de diferenciar los factores de análisis y los aspectos más particulares del mismo, es necesario tomar en cuenta algunos supuestos de base que nos expliquen hipotéticamente la configuración del discurso en este procesamiento de la información. Si partimos de los supuestos en torno a la organización discursiva: 1) los textos y/o discursos se elaboran a partir de una intención comunicativa independiente de su estructura formal. 2) la consideración de que la comprensión del discurso estaría completa si estos significados centrales son descubiertos por los hablantes.

En la esquizofrenia, la capacidad para visualizar tanto la intención comunicativa de un interlocutor como su desempeño para manifestar la propia, se ve entorpecida por el deterioro en la ToM que afecta a la comprensión de las claves sociocomunicativas de la intersubjetividad. En general, la capacidad para hacer inferencias sobre los estados mentales de otros, con el propósito de predecir su conducta, o sus conocimientos, creencias e intenciones. Un ejemplo de esto es el bajo desempeño que obtienen los sujetos enfermos en los test de atribución emocional, como es el caso del test de las miradas (TdlM) de Baron Cohen (2001). Dicho test es 
uno de los instrumentos más usados en la práctica clínica para determinar las competencias en ToM en pacientes con diversas patologías psiquiátricas, entre ellas, la esquizofrenia. (Román, et al, 2012)

Como ya señalamos, a la hora de expresar sus intenciones comunicativas, elaboran y componen segmentos discursivos poco económicos y a menudo crípticos, que convierten la comprensión en una ardua tarea de interpretación y reconstrucción del significado a partir de lo que el interlocutor puede inferir o desprender del mensaje. A menudo, en la clínica, hemos observado que los pacientes parecen comprender los alcances semánticos de alguna pregunta o expresión, sin embargo, al expresar sus contribuciones, éstas se vuelven enrevesadas y poco comunicativas.

A continuación, se presentan los resultados de esta investigación. Para dar cuenta de ellos, los presentamos por fenómenos y variables independientes. Los tres grupos que componen este estudio se dividieron como sigue:

Tabla resumen 18: de los grupos de estudio

\begin{tabular}{cccc}
\hline GRUPO & N & Hombres & Mujeres \\
\hline Controles & 12 & 6 & 6 \\
\hline Primer episodio & 25 & 14 & 11 \\
\hline Crónicos & 25 & 13 & 12 \\
Total & 62 & 33 & 29 \\
\hline
\end{tabular}

Como señalamos anteriormente en el capítulo 3, la muestra global fue dividida en 3 grupos; un grupo de 25 sujetos con diagnóstico de esquizofrenia de inicio, 25 sujetos con diagnóstico de esquizofrenia crónica y 12 sujetos control, sin diagnóstico psiquiátrico. Los tres grupos están descritos in extenso en el capítulo anterior: 
Tabla resumen 19: $\mathrm{N}$ del estudio e instrumento aplicado

\begin{tabular}{|c|c|}
\hline \multicolumn{2}{|c|}{ GRUPO 1 DE CRE N=25 } \\
\hline CRE 1: N=25 & Entrevista clínica semiestructurada \\
\hline Instrumento & GRUPO 2 DE PEE N=25 \\
\hline PEE 1: N=25 & Entrevista clínica semiestructurada \\
\hline Instrumento & \\
\hline 12 Controles sin \\
patología psiquiátrica
\end{tabular}

A continuación, presentaremos las secciones en que se analizan los datos obtenidos de las 62 entrevistas que conforman nuestra muestra de estudio. Se organizará un análisis de los factores independientes en el orden siguiente; estadio de la enfermedad ${ }^{27}$, sexo, tramo de la enfermedad ${ }^{28}$ y subtipo de la enfermedad, ${ }^{29}$ y por otra, con los factores dependientes, agrupados en seis cluster de análisis pragmalingüístico, dispuestos como sigue: fluidez verbal, productividad verbal, participación conversacional, coherencia temática, semántica de la coherencia y coherencia interaccional. Para desarrollar lo recién planteado, en primer lugar, presentaremos en el análisis los datos de los cluster pragmáticos en relación con los efectos que encontramos sobre los factores independientes mencionados arriba ${ }^{30}$, dispuestos en el orden previamente descrito.

${ }^{27}$ Crónicos o con esquizofrenia de inicio

${ }^{28}$ De $0<2$ años, $2-3$ años, $3-<5$ años, $>/ 5$ años

${ }^{29}$ Paranoide, indiferenciada, desorganizada

${ }^{30}$ Estadio de la enfermedad, sexo, tramo de la enfermedad y subtipo de la enfermedad 
En cada caso se realizarán pruebas estadísticaspertinentes para los grupos de fenómenos en estudio; para fluidez verbal, coherencia temática, semántica de la coherencia y coherencia interaccional, se usará chi cuadrado de Pearson, ya sea para presencia o ausencia de los fenómenos o bien, para la evaluación de datos ordinales. Las variables categóricas, a las que pertenecen los fenómenos de productividad verbal y participación conversacional se emplearán pruebas paramétricas, un ANOVA para datos de intervalo o razón, y si la distribución de los datos es anormal, se empleará Kruskar Wallis; a fin de determinar su correlación con los factores externos. Junto con esto, se incluirán bloxsplot para estos dos cluster, con el fin de representar visualmente los datos de estos cluster, así como su dispersión y simetría.

Con respecto al análisis de interacción de las variables, se expondrá cada fenómeno con sus respectivas frecuencias absolutas y sus datos porcentuales equivalentes, ilustrándolos con ejemplos tomados de la muestra y destacando al final de cada capítulo, aquellos casos que puedan ser un aporte diferente a lo señalado. Se agregará el análisis estadístico correspondiente, que pretende dar cuenta de la existencia de correlación entre las variables lingüísticas en estudio y los mencionados factores externos. Este último análisis nos permitirá comprobar nuestra hipótesis de investigación.

\section{1. Fluidez verbal:}

Este grupo de fenómenos se refieren, por una parte, a la cantidad de información por unidad de medida que un hablante es capaz de emitir cuando produce un discurso. Por otro lado, también apuntan a la calidad de la información emitida, ya que la producción de muchas palabras por minuto no asegura la progresión temática ni alcanzar un propósito discursivo. La información emitida por los hablantes en el transcurso de una interacción, está dada por las necesidades informativas específicas de la situación comunicativa. Según Goldman-Eisler, (1964), la fluidez, además, puede interpretarse como la eventual caracterización y medición de algunos elementos 
que sean indicativos de los distintos niveles de la producción de habla, que sean susceptibles de ser aislados del habla espontánea de los sujetos.

Ahora bien, la producción del discurso dependerá invariablemente de la finalidad que el hablante se plantee. Dado este carácter intencional, se presume que hay un complejo despliegue de funciones cognitivas, las que comprenden un sistema tripartito: ejecutivo, semántico y atencional, para abordar la tarea (Henry y Crawford, 2004). Los déficit presentes en la fluidez verbal pueden estar relacionados con diversos compromisos; ejecutivo, al efectuar búsquedas estratégicas de palabras, evocación de unidades léxicas o la iniciación de alguna tarea. Semántico, que funcionaría como reservorio léxico, asociativo, facilitando la elección adecuada (Collins y Loftus, 1975) y, finalmente, ejecutivo, al afectar al sistema atencional que es el que permite la focalización, sostén y ejecución de la tarea comunicativa.

En este cluster de análisis se consideró la alternancia, presencia o ausencia de los rasgos. Está compuesto por el siguiente grupo de fenómenos: titubeos, falsos inicios, pausas extendidas, tartamudeos y turnos de habla con volumen débil. Nuestros hallazgos fueron los siguientes:

4.1.1. Titubeos: se trata de la producción de uno o más sonidos que no tienen relación estructural con la decisión léxica siguiente; consideramos pausas oralizadas, (ej: “mmm”, “eeeh”) muletillas o estereotipias verbales (ej: "claro", "o sea”, “ientiende?”, “icierto?”) repeticiones innecesarias de alguna palabra o frase (ej: "es como si”), alargamientos de sílabas (ej: “aaantes”)

\subsubsection{Ejemplos de titubeos del grupo de crónicos:}

1) Sonidos sin conexión estructural con la decisión siguiente; muletillas:

E: pero/ cuénteme cómo es eso/.

S: S $<$ pausa $>\mid t a<$ pausa $>\mid$ taf $<$ pausa $>\mid$ es $<$ pausa $>/$ te $<$ pausa $>/$ est $<$ pausa $>/$ está $<$ pausa $>$ está saliendo/ bien/ (al entrevistador) op $<$ pausa $>/$ un $<$ pausa $>/ /$ oye/ eso es muy importante.

E: ¿qué cosa? 
S: loq<pausa>/lo que anda<pausa>/ andando se ve el asunto/ ¿cierto?

E: $\mathrm{mmm}$

(CRE-H04)

2) Sonidos sin conexión estructural con la decisión siguiente; repeticiones innecesarias de palabras, muletillas:

E: ¿y cuál es/ su misión en este mundo don M...?

S: $s$...se $r . . . r a i \ldots j \ldots$ veinticuatro nueve ${ }^{31}$, por eso se rebelan hijos a los padres/ y los padres a los hijos// cada/ cada/ cada vez que está el tiempo/ dejando su voto/ nada se va a afectar// buscar una solución/ y aprendimos a vivir mejor/ a vivir mejor/me alegra el alma/ recupero entero en un momento determinado// ¿cierto?

(CRE-H01)

3) Pausas oralizadas, alargamientos, repeticiones innecesarias de frases:

E: ¿Qué edad usted tiene/ señora M?/

$S:$ Tengo<pausa or $>$ voy a $t<$ pausa $>\mid$ no $s e<$ alargamiento $>\mid$ me dijeron<pausa $>\mid$ co $<$ pausa $>\mid$ como $<$ pausa $>/$ como cincuenta años no máh/.

E: ¿Por quél, en qué año nació?!

S: No me acuerdo/ no me acuerdo/ no me acuerdo/.

E: ya/ no importa.

(CRE-M01)

4) Pausas oralizadas, alargamientos, sonidos sin conexión estructural con la decisión siguiente, muletillas:

E: ¿nos podría contar/ por qué está aquí en el servicio?

S: por una <alargamiento/> s/<pausa>/ una ca <pausa>/ una <pausa>/surmenage/<pausa ext >/

E: ya/ ¿qué es un surmenage?

S: ca<pausa $>/ s\langle$ pausa $>/$ te $\langle$ pausa $\rangle /$ par $\langle$ pausa $\rangle /$ cansancio mental //

E: ¿qué es/ el cansancio mental?

S: el distinguir <pausa ext $>/$ las co <pausa $>/ s<$ pausa $>/$ coo<pausa $>/$ cosah tal como son $<$ pausa $>/$ como son/ ¿no cierto?/ ¿me entiende?// claro <alargamiento/> eehh... logré establecer <pausa ext $>/$ el equilibrio <pausa ext $>/$ mental <pausa ext $>$ el equilibrio mental/ ¿me entiende, cierto?/

(CRE-H10)

Ejemplos de titubeos del grupo de primer episodio:

1) Pausas oralizadas, repeticiones innecesarias, muletillas:

${ }^{31}$ Referencia a la cita bíblica del libro de Lucas 12:54 
E: hola hola/ ¿cómo estás?/ ¿por qué vienes J P?/

$\mathrm{S}$ : vengo/ <pausa> porque/ <pausa> estoy tratando que/ <pausa>para que/ <pausa> viera que no estaría mal/ pero igual/ mi mamá dice que nunca fue así y yo <pausa $>/$ ehmmm <alargamiento/> me gustaría saber/ si/ <pausa ext> eh / <pausa ext> no sé/ <pausa ext>si creerle o no/, creerle, creerle/ porque Gerardo/ también, mi primo/ me dijo algo como raro/, como que en un momento si, y después como que no...

E: a ver JP/ no te entiendo mucho/ quiero que tú me expliques/ ¿qué es lo que a ti te pasa?/

$\mathrm{S}$ : <pausa> que igual <alargamiento/> me siento mal/ además mi mamá lo niega/ y yo no sé// estoy/ creo creer que fue así/ que no hay/ no, no estoy seguro/ pero yo creo que tal vez fue así/

$\mathrm{E}: \mathrm{mmm}$

(PEE-H12)

2) Pausas oralizadas, repeticiones innecesarias, muletillas:

E: ¿qué dificultad tienes/ para pensar?

S: cuando se me vienen los pensamientos/....negativa.

E: ya/ ¿ejemplos?

S: se me olvida ahoral...eh...eh ...eh ... eh...(p or)

E: piensa

S: eh...eh... /por ejemplo, por ejemplo/ que algunas cosas/...las tengo/...eh...eh...eh...(p or $>$ ¿qué puedo nombrar? Pensamiento, tras otro pensamiento/, pensamiento/, pensamiento/ $<$ musita $>$... es que no me acuerdo ahora// me vienen pensamientos/ así como/...como/...como cruzados así/ ¿me entiende?

(PEE-M02)

Ejemplo de titubeos del grupo de controles:

1) alargamientos, repeticiones innecesarias:

E: ya, cuéntame <alargamiento/> la más reciente.

S: $l<$ pausa $>/$ la más reciente <alargamiento/> fue <alargamiento/> que iba de vuelta de <alargamiento/> un carrete con mih amigoh/con mih amigos/ y nos siguieron tres tipos // y con mih amigos no alcanzamos a arrancar/arrancar / y un flaite ${ }^{32}$ agarró a <vacilación/> a mi amigo y <alargamiento/> lo encañonó / y a mí también / con pistola // y <alargamiento/> noh decía $\mathrm{q}$ entregáramos el bolso / y mi amigo llevaba unos cuadernos en unas bolsas así como de Ripley ${ }^{33}$ entonces yo cacho que se pasó rollos ${ }^{34}$, como que llevaba algo importante//; cachai?

(CON-M03)

\footnotetext{
${ }^{32}$ Flaite $=$ en la jerga juvenil se refiere a gente generalmente de bajo nivel económico, educacional y que por lo general es delincuente.

${ }^{33}$ Ripley= es una tienda departamental.

${ }^{34}$ Rollo= en la jerga juvenil se refiere a que se imaginó cosas que no eran verdad.
} 
Se identificaron 16 casos de presencia de titubeos, correspondientes a un $25,8 \%$ de la muestra total, en ninguno de los cruces de variables arrojaron resultados significativos. A continuación presentamos el análisis por variable independiente:

\subsubsection{Titubeos y Estadio de la enfermedad}

Se identificaron 3 casos de presencia en los de primer episodio y 3 casos de presencia en los controles, correspondientes al $(18,8 \%)$ respectivamente. En los crónicos, se detectaron 10 casos de presencia en, $(62,5 \%)$, reflejado en la tabla y gráfico siguiente:

Tabla de contingencia 20: titubeos y estadio de la enfermedad.

\begin{tabular}{|l|l|l|l|}
\hline \multirow{2}{*}{$\begin{array}{l}\text { ESTADIO DE LA } \\
\text { ENFERMEDAD }\end{array}$} & \multicolumn{2}{|c|}{ TITUBEOS } & \multirow{2}{*}{ TOTAL } \\
\cline { 2 - 3 } & Presencia & Ausencia & \\
\hline Controles & 3 & 9 & 12 \\
\cline { 2 - 4 } & $18,8 \%$ & $19,6 \%$ & $19,4 \%$ \\
\hline \multirow{2}{*}{ Primer episodio } & 3 & 22 & 25 \\
\cline { 2 - 4 } & $18,8 \%$ & $47,8 \%$ & $40,3 \%$ \\
\hline Crónicos & 10 & 15 & 25 \\
\cline { 2 - 4 } & $62,5 \%$ & $32,6 \%$ & $40,3 \%$ \\
\hline \multirow{2}{*}{ Total } & 16 & 46 & 62 \\
\cline { 2 - 4 } & $100,0 \%$ & $100,0 \%$ & $100,0 \%$ \\
\hline
\end{tabular}


Gráfico 1. Porcentaje de frecuencia de las variantes: titubeos y estadio de la enfermedad:

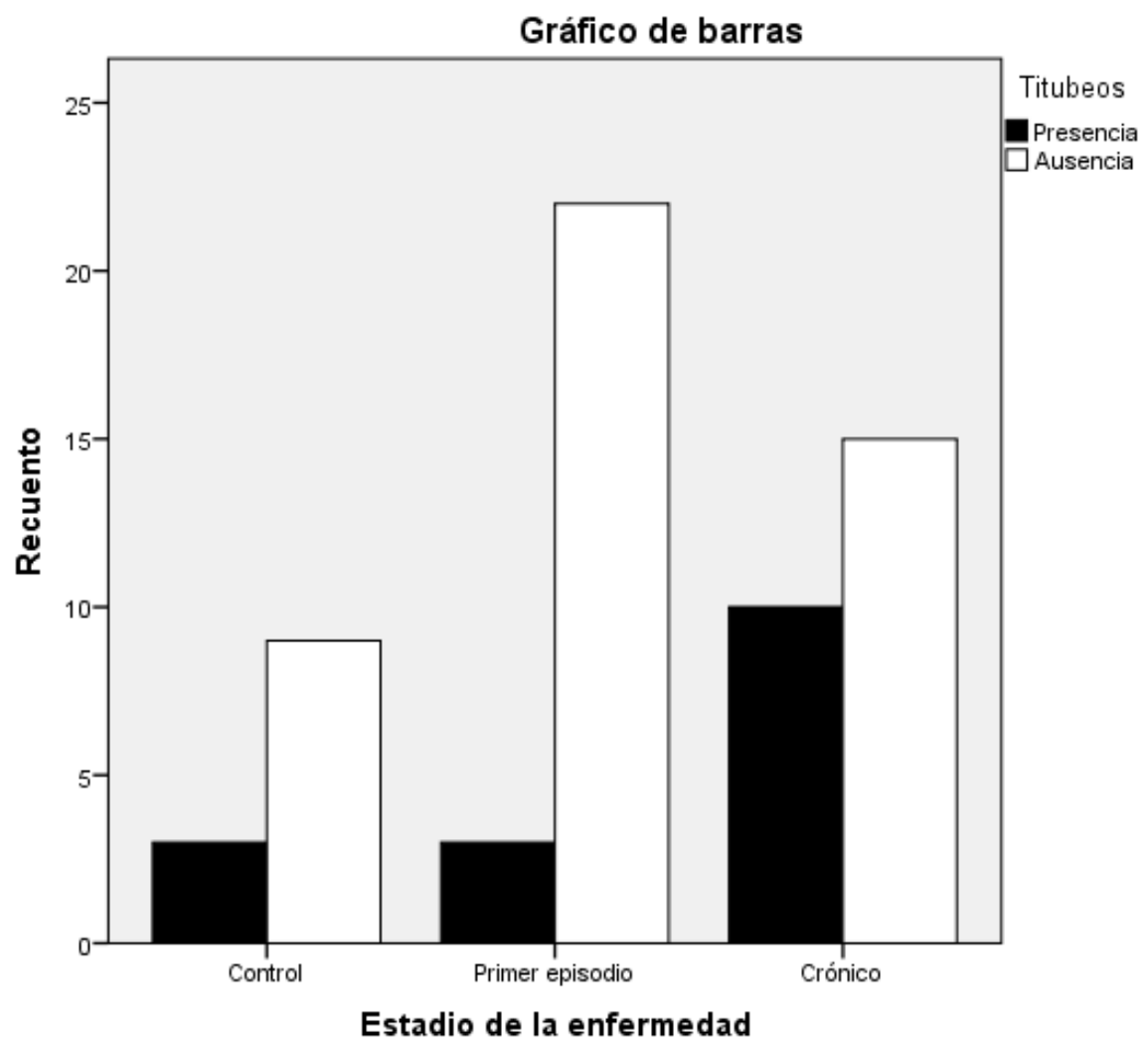

El valor de chi cuadrado fue de 5,123 a dio como resultado ( $\mathrm{p}<0,77>$ ), no significativo estadísticamente. Este fenómeno presentó un comportamiento transversal en el corpus, con una mayor recurrencia en los crónicos. Además de esta mayor recurrencia, se presentó en momentos diferentes en el grupo de los crónicos, como vemos en los casos 1-4 tomados de este grupo. 
Tabla 21: valor de chi cuadrado; titubeos y estadio de la enfermedad.

\begin{tabular}{||l|c|c|cr||}
\hline \multicolumn{5}{|c||}{ Pruebas de chi-cuadrado } \\
\hline & Valor & gl & Sig. asintótica (bilateral) & \\
\hline Chi-cuadrado de Pearson & $5,123^{\mathrm{a}}$ & 2 & &, 077 \\
\hline
\end{tabular}

\subsubsection{Titubeos y sexo}

De las 29 mujeres de la muestra, encontramos 8 casos de presencia, equivalentes al (50\%) y de los 33 hombres del corpus, también encontramos 8 casos, es decir, (50\%), como se resume en la tabla y en el gráfico:

Tabla de contingencia 22: titubeos y sexo.

\begin{tabular}{||l|l|l|l||}
\hline \multirow{2}{*}{ SEXO DEL SUJETO } & \multicolumn{2}{|l||}{ TITUBEOS } & \multirow{2}{*}{ TOTAL } \\
\cline { 2 - 3 } & Presencia & Ausencia & \\
\hline \multirow{2}{*}{ Mujer } & 8 & 21 & 29 \\
\cline { 2 - 4 } & $50,0 \%$ & $45,7 \%$ & $46,8 \%$ \\
\hline \multirow{3}{*}{ Hombre } & 8 & 25 & 33 \\
\cline { 2 - 4 } & $50,0 \%$ & $54,3 \%$ & $53,2 \%$ \\
\hline \multirow{2}{*}{ Total } & 16 & 46 & 62 \\
\cline { 2 - 4 } & $100,0 \%$ & $100,0 \%$ & $100,0 \%$ \\
\hline
\end{tabular}


Gráfico 2. Porcentaje de frecuencia de las variantes: titubeos y sexo:

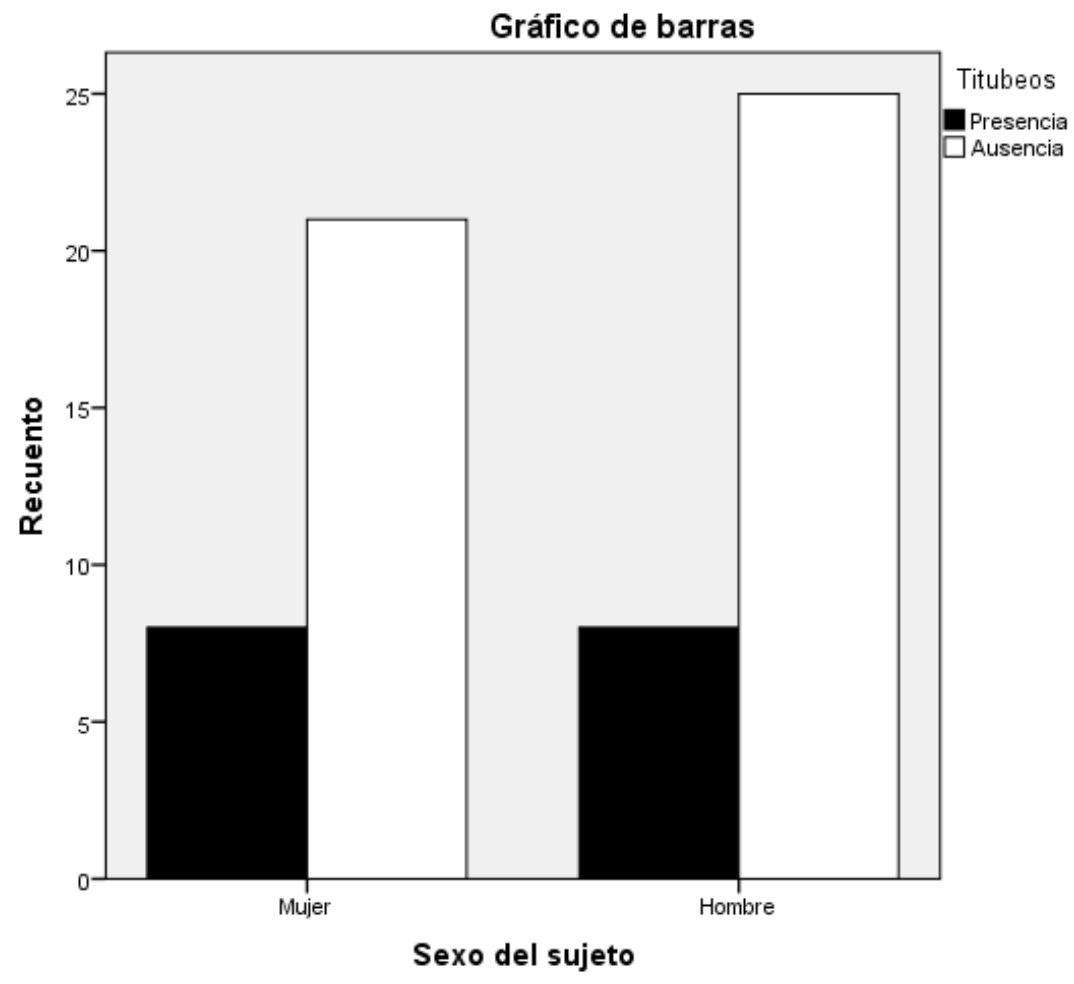

El valor de chi cuadrado fue de $090^{\mathrm{a}}$ y dio como resultado $(\mathrm{p}<0,764>$ ), la variable sexo, no ofreció diferencias significativas, como podemos observar en los ejemplos, tuvo un comportamiento similar entre hombres y mujeres.

Tabla valor de chi cuadrado 23: titubeos y sexo

\begin{tabular}{||l|c|c|c|c|c||}
\hline \hline \multicolumn{7}{|c||}{ Pruebas de chi-cuadrado } \\
\hline & $\begin{array}{c}\text { Val } \\
\text { or }\end{array}$ & gl & $\begin{array}{c}\text { Sig. } \\
\text { asintótica } \\
\text { (bilateral) }\end{array}$ & $\begin{array}{c}\text { Sig. exacta } \\
\text { (bilateral) }\end{array}$ & $\begin{array}{c}\text { Sig. exacta } \\
\text { (unilateral) }\end{array}$ \\
\hline $\begin{array}{l}\text { Chi-cuadrado de } \\
\text { Pearson }\end{array}$ & $\begin{array}{r}090 \\
\text { a }\end{array}$ & 1 &, 764 & & \\
\hline
\end{tabular}


4.1.1.4. Titubeos y tramo de la enfermedad: Como ya fue descrito en la metodología, el tiempo de la enfermedad que han cursado los pacientes lo dividimos en cuatro tramos de acuerdo con la duración a partir del diagnóstico: 1-2: corresponden a primer episodio (1: 0-<2 años; y 2: >2-<3 años) 3-4: a los pacientes crónicos, (3: >3->5años; y 4: >5 y más años). Encontramos 3 presencias en los controles (18.8\%); 2 presencias en el tramo 1 de primer episodio (12,5\%); 1 presencia en el tramo 2 de primer episodio, (6,3\%), 1 presencia en el tramo 3 de crónicos, $(6,3 \%)$ y 9 presencias en el tramo 4 de crónicos $(56,3 \%)$, se resume información en la tabla y en el gráfico siguiente:

Tabla de contingencia 24: titubeos y tramo de la enfermedad.

\begin{tabular}{||l|c|c|c||}
\hline \multirow{2}{*}{ Tramo de la enfermedad } & \multicolumn{2}{|c|}{ Titubeos } & \multirow{2}{*}{ Total } \\
\cline { 2 - 4 } & Presencia & Ausencia & \\
\hline \multirow{2}{*}{ Control } & 3 & 9 & 12 \\
\cline { 2 - 4 } & $18,8 \%$ & $19,6 \%$ & $19,4 \%$ \\
\hline \multirow{2}{*}{ Primer episodio 0 a 2 años } & 2 & 12 & 14 \\
\cline { 2 - 4 } & $12,5 \%$ & $26,1 \%$ & $22,6 \%$ \\
\hline Primer episodio 2 a 3 años & 1 & 10 & 11 \\
\cline { 2 - 4 } & $6,3 \%$ & $21,7 \%$ & $17,7 \%$ \\
\hline Crónico hasta 5 años & 1 & 9 & 10 \\
\cline { 2 - 4 } & $6,3 \%$ & $19,6 \%$ & $16,1 \%$ \\
\hline Crónico 5 y más años & 9 & 6 & 15 \\
\cline { 2 - 4 } & $56,3 \%$ & $13,0 \%$ & $24,2 \%$ \\
\hline Total & 16 & 46 & 62 \\
\cline { 2 - 4 } & $100,0 \%$ & $100,0 \%$ & $100,0 \%$ \\
\hline \hline
\end{tabular}


Gráfico 3. Porcentaje de frecuencia de las variantes: titubeos y tramo de la enfermedad:

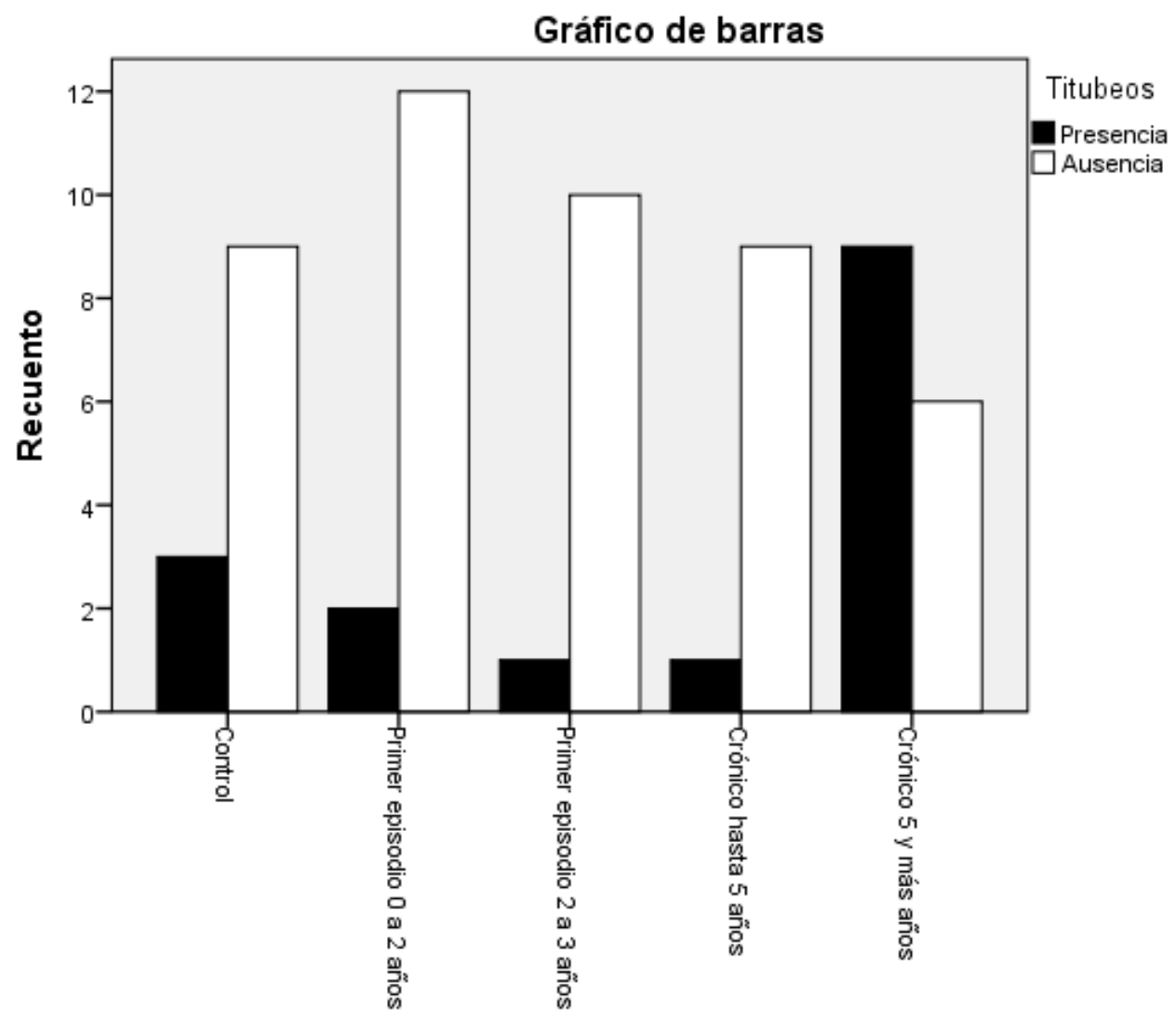

Tramo de la enfermedad

El valor de chi cuadrado fue de $13,044^{\mathrm{a}}$ y dio como resultado ( $\mathrm{p}<0,11>$ ), este fenómeno se presentó con una dispersión transversal en el corpus, y no tuvo valores significativos. Se observó una restricción en el grupo de primer episodio de entre 2 y 3 años y también entre los crónicos de hasta 5 años. 
Tabla valor de chi cuadrado 25: titubeos y tramo de la enfermedad.

\begin{tabular}{||c|c|c|c||}
\hline \multicolumn{4}{|c||}{ Pruebas de chi-cuadrado } \\
\hline & Valor & $\mathrm{gl}$ & Sig. asintótica (bilateral) \\
\hline $\begin{array}{c}\text { Chi-cuadrado de } \\
\text { Pearson }\end{array}$ & $13,044^{\mathrm{a}}$ & 4 &, 011 \\
\hline
\end{tabular}

\subsubsection{Titubeos y subtipo de la enfermedad}

En la relación entre titubeos y subtipo de la enfermedad encontramos 3 presencias en los controles, (18,8\%), 6 presencias en los paranoides, $(37,5 \%), 3$ presencias en los indiferenciados, (18,8\%), 4 presencia en los desorganizados, $(25 \%)$, ejemplificado en la tabla y el siguiente gráfico:

Tabla de contingencia 26: titubeos y subtipo de la enfermedad.

\begin{tabular}{||c|c|c|c||}
\hline \multirow{2}{*}{$\begin{array}{c}\text { Subtipo de la } \\
\text { esquizofrenia }\end{array}$} & \multicolumn{2}{|c|}{ Titubeos } & \multirow{2}{*}{ Total } \\
\cline { 2 - 4 } & Presencia & Ausencia & \\
\hline \multirow{2}{*}{ Control } & 3 & 9 & 12 \\
\cline { 2 - 4 } & $18,8 \%$ & $19,6 \%$ & $19,4 \%$ \\
\hline \multirow{2}{*}{ Paranoide } & 6 & 27 & 33 \\
\cline { 2 - 4 } & $37,5 \%$ & $58,7 \%$ & $53,2 \%$ \\
\hline \multirow{2}{*}{ Indiferenciado } & 3 & 6 & 9 \\
\cline { 2 - 4 } & $18,8 \%$ & $13,0 \%$ & $14,5 \%$ \\
\hline \multirow{2}{*}{ Desorganizada } & 4 & 4 & $12,9 \%$ \\
\cline { 2 - 4 } & $25,0 \%$ & $8,7 \%$ & 62 \\
\hline \multirow{2}{*}{ Total } & 16 & 46 & $100,0 \%$ \\
\cline { 2 - 4 } & $100,0 \%$ & $100,0 \%$ & \multicolumn{2}{|c||}{} \\
\hline \hline
\end{tabular}


Gráfico 4. Porcentaje de frecuencia de las variantes: titubeos y subtipo de la enfermedad:

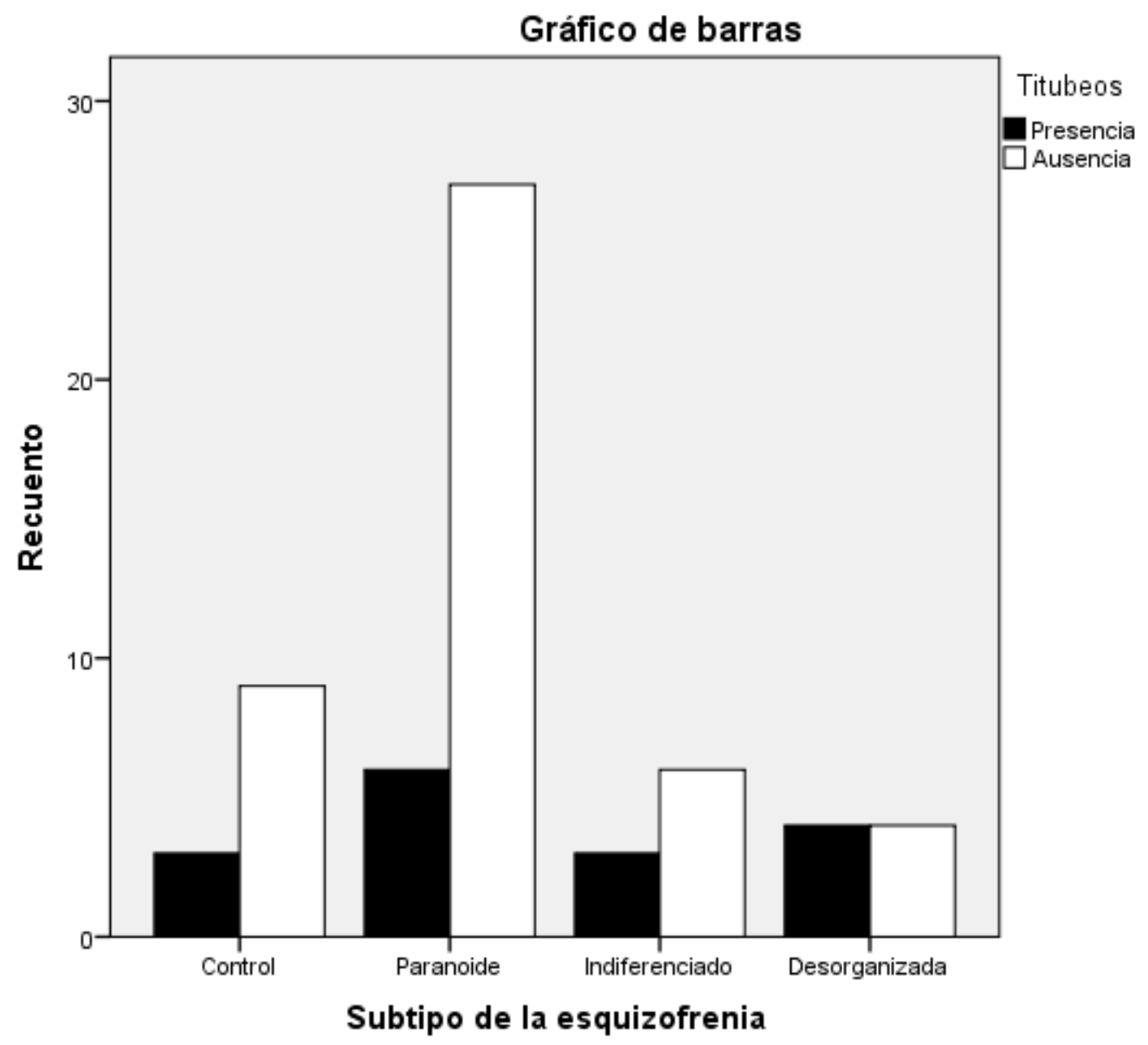

El valor de chi cuadrado fue de 3,718 a dio como resultado (p < 0, 294>), observamos una mayor presencia del fenómeno entre los informantes del subtipo paranoideo. 
Tabla valor de chi cuadrado 27: titubeos y subtipo de la enfermedad.

\begin{tabular}{||l|l|l|l||}
\hline \multicolumn{4}{|c||}{ Pruebas de chi-cuadrado } \\
\hline & Valor & Gl & $\begin{array}{l}\text { Sig. asintótica } \\
\text { (bilateral) }\end{array}$ \\
\hline Chi-cuadrado de Pearson & $3,718^{\mathrm{a}}$ & 3 &, 294 \\
\hline
\end{tabular}

4.1.2. Falsos inicios: inicio e interrupción inmediata que afecta al primer fonema, morfema, palabra, o frase. A menudo, se reformula la expresión aunque el paciente no siempre logra una versión más informativa. (ej: "por faltar... por falta de... me faltó un remedio"). Encontramos 11 casos de falsos inicios, predominando el fenómeno en el grupo de crónicos, con un 72,7\% del fenómeno.

\subsubsection{Ejemplos del grupo de crónicos}

1) Reformulación de una palabra o expresión:

E: cuéntenos/ ¿por qué está aquí?

S: bueno/<pausa $>$ yo estoy/<pausa $>/$ o sea vine $<$ pausa $>$ / me traj/ yo estoy aquí por unos problemas/ digamos/ $<$ pausa $>$ /eh $<$ pausa $>$ eh $<$ pausa $>$ /estoy enfermo ahora $<$ pausa $>/$ esto caducó/<pausa $>/ \mathrm{mis}$ viejos se fueron de la casa/ $/$ pausa $>/$ mi papá se fue de la casa/ $<$ pausa $>/$ yo me fui a otra pieza/ con la rubia// estaba entre la rubia y la morena/ y resulta que perdí a la rubia/ poh' ¿cachai?/ y ahí sentí pena/ mucha pena.

E: a ver/¿tuvo un problema con<pausa $>/$ ?/ ¿la eligió<pausa $>/$ ?/ ¿Cómo pareja<pausa $>/$ ?

(CRE-H09)

\section{2) Reformulación de una palabra o expresión:}

E: ¿Quiénes son los personajes?/ ¿tus papás<pausa>/? /¿tu papá o tu hermano/? <pausa>/¿o alguien en especial para ti?

$\mathrm{S}$ : Eeh<pausa or $>/$ haber<alargamiento $>/$ en especial<pausa $>/$ podrían $\mathrm{ser}<$ pausa $>/ \mathrm{o}$ sea/ yo creo que<pausa or $>$ /podrían ser mis hermanas/ pero no/ nada en especial/ es que nos llevábamos mal no más/siempre/ desde chicas.

(CRE-M-12)

3) Reformulación de una palabra o expresión:

E: Ya/ volviste a la casa/ ¿y qué pasó<pausa $>/$ ? 
$\mathrm{S}$ : Eeh<pausa or $>/$ hay<alargamiento $>/$ mmm<alargamiento $>/$ creo que fue $<$ pausa $>/$ es que $<$ pausa ext $>/$ el Jonathan escribió/ hizo un escrito/ que yo tenía ideas delirantes/ poco menos que alucinaciones/ y cuestiones// $\mathrm{y}<$ pausa ext $>/$ me vieron $<$ pausa ext $>/$ se pusieron en contacto con gente de acá del Peral/ para hacer mi< pausa $>/$ para traerme para acá $<$ pausa $>/$ fueron un día $<$ pausa $>/$ en una ambulancia dos tipos me trajeron.

(CRE-M-12)

\section{4) Reformulación de una palabra o expresión:}

E: O sea/ ¿hay alguien que te quería hacer daño?

S: Mucha gente.

E: ¿En tu casa <pausa $>$ ?/

$\mathrm{S}$ : es que<pausa ext $>/$ no<pausa ext $>/$ no sé<pausa $>/$ bueno igual $/<$ pausa $>/$ puede que $\mathrm{si}<$ pausa ext $>/$ bueno de la casa/ porque la vieja de mi hermana ha hecho cosas muy feas// el Jorge también se crió conmigo/ aunque no seamos hermanos de sangre/<pausa $>/$ pero<pausa ext $>/$ nos criamos juntos y no tiene por qué haber $<$ pausa ext $>/$ hacer esas cosas/ yo nunca le haría algo/ diciendo que él se cree<pausa ext>/ no sé/ cualquier cuestión /inventando cosas/ para que lo encierren/ entonces/ eso no tiene perdón de Dios//

(CRE-M10)

\section{5) Reformulación de una palabra o expresión:}

E: ¿Y quién más te quería hacer daño/ M?

S: No sé poh/ no soy <pausa>/ no sé <pausa>/ no soy adivina<pausa>/ tampoco soy detective <pausa>/

E: ¿Usted/ dio motivos?

$\mathrm{S}$ : Mmm<pausa or $>/$ no<pausa or $>/$ no creo <pausa $>/$ ¿motivaciones <pausa<?/ ¿motivos por qué? $<$ pausa ext $>$ / porque si no más poh<pausa ext>/ porque la gente no tiene <pausa ext>/ no sé<pausa ext $>$ / en vez de estar haciendo otras cosas/ haciendo el bien/ hay gente que le gusta hacer eso/ nada más poh <pausa $>/$

(CRE-M11)

\section{6) Reformulación de una palabra o expresión:}

$\mathrm{S}$ : es que/ una parte de mí/ quiere estar enferma.

E: ya.

S: entonces $<$ pausa $>/$ hago cosas para estar enferma.

E: ¿Como qué cosas?

$\mathrm{S}$ : como querer/ empiezo a inventar/ como que/ <pausa>/como si <pausa>/como que estoy enferma/ como <pausa $>/$ quiero estar enferma/ qué cosas puedo hacer para que/<pausa $>/$ para comportarme como enferma $<$ pausa ext $>$ /entonces empiezo a $<$ pausa ext $>/$ a romper cosas/ tratar de matar a la gente.

E: ¿Cómo/ perdón?

$\mathrm{S}$ : romper cosas/ lo he hecho/ pero matar a la gente/ <pausa $>/$ pero < pausa ext $>/$ no lo he hecho/ pero podría ser.

(CRE-M08) 


\section{7) Reformulación de una palabra o expresión:}

E: ¿Cuéntame S/ eh <pausa</ por qué estás acá?/

S: Eh $<$ pausa $</$ eh $<$ pausa $</$ es que $<$ pausa $</$ no sé $<$ pausa $</$ puede que $<$ pausa $</$ es que $<$ pausa $</$ a veces $<$ pausa $</$ es que me pasaron unas cosas raras/ así como que siento una $<$ pausa ext $<$ / por mis/ por mis ganas de salir adelante/ yo solo/ eh<pausa $<$ / como que adquirí una cierta iluminación/ como digamos/ filosofía budista se refiere/ como que adquirí una especie de iluminación/ pero de Buda/ que me dijo/ como una luz/ me dijo/: "tú has despertado así iluminado"/ así diferente a las demás personas/ pero aún así/ yo digo no me interesa ser un dios/ ni nada/ porque si fuera un dios/ andaría gobernando el mundo/ y eso no sería justo/ yo digo yo/ para el resto de los mortales/ entonces soy un cabro chico/ como tengo 25 años/ como me dicen/ un cabro chico.

(CRE-H11)

8) Reformulación de una palabra o expresión:

E: Qué/ qué síntom<pausa>/ ¿qué molestias tuviste/ que estás aquí ahora?/

S: ah <pausa $>$ ya/ yo te cuento/ <pausa $>/$ me parece que/ <pausa $>/$ en una de esas/ hasta que/ $<$ pausa $>/$ bueno voy a $<$ pausa $>/$ voy hacerte como un resumen rápido/ bueno/<pausa $>/$ resulta que $<$ pausa ext $>/$ eeh<pausa or $>/$ haber/ haciendo un resumen de todo lo que pasó en la casa/ no/ es que yo sentía como voces/ como que/ de Pavarotti/ no cacho mucho.

(CRE-H11)

\section{9) Reformulación de una palabra o expresión:}

E: ¿usted está en controles?

S. si/ me eeeh <pausa or >/ es decir/ <pausa $>$ me/ <pausa>/constantemente trato de asistir// Yo al principio necesitaba la ayuda de <pausa ext $>/$ del control/ asi que<pausa ext $>/$ pedí ayuda a psiquiatría/ y cosas así.

E: y/ ¿por qué pidió ayuda?

S: porque no tuve otro escape/ otra opción<pausa ext>/ a la enfermedad/ es decir/ me precipité tanto/ que no tuve opción.

(CRE-H07)

10) Reformulación de una palabra o expresión:

E: ¿usted veía edificios/ en el patio de su casa?

S: $\mathrm{mmm}<$ pausa or $>/$ era como ver imag <pausa ext $>$ era como ver sorpresivamente <pausaext $>/$ creer ver/ porque no los podía ver/ porque era como<pausa $>/$ cosas que se/ $<$ pausa $>/$ era como cosas que sonaban del cielo/ cosas así// Mmm pausa or>/ cosas así.

(CRE-H11) 
Ejemplos del grupo de primer episodio:

\section{1) Reformulación de una palabra o expresión:}

E: ¿y qué tiene que ver la cantante con el supermercado?/no entiendo//

$\mathrm{S}$ : eso mismo dicen todos/

E: ¿qué te imaginas tú?

S: es extra/ ni pe<pausa>/ puede que<pausa $>$ que no puedo comprar cosas para comer/ porque o si no me voy a convertir en/ <pausa ext> como ella/ así<pausa> como que/ me tinca/ no pa/ que voy a tener los mismos ojos de ella.

(PEE-M01)

\section{2) Reformulación de una palabra o expresión:}

E: Es que me llamaba la atención <pausa>/ que esté tocando saxofón/ y además esté yendo a la escuela de música de la Universidad de Chile/ mucho ruido.

S: si.

E: ¿cómo lo hace <pausa>/ como lo hace ahí para lidiar con<pausa>/ con todo eso del miedo al sonido?

S: trato de lograr/ eeh <pausa or $>/$ al principio era<alargamiento $>/$ eeh<pausa or $>/$ en un comie<pausa>/ al principio era bastante incómodo/ pero<pausa>/ ahora como que ya me acostumbré/ y no sé/ trato de conversar con mi pololo/ o de hacer otra cosa/ tocar cualquier cosa para/ para que yo<pausa $>$ / olvidarme de eso.

(PEE-M04)

\section{Ejemplos en el grupo de sujetos controles:}

E: ¿cuá<alargamiento/>1 <vacilación/> ha si[d]o el susto más grande que te ha toca[d]o pasar?

I: <silencio/> sa[b]í que <vacilación/> cuando pasé susto eh cuando we[v]a[da]h eeh<alargamiento/> <vacilación/>

E: malah

I: no no malah sino que<alargamiento/> irrehponsableh

E: ya

I: y<alargamiento/> hace un tiempo atráh ehtaba pensando así como esah we[v]a[da]s que de verda[d] me habían da[d]o suhto/ que me había puehto nervioso y <ininteligible/> <silencio/> la $<$ alargamiento/> <vacilación/ $>$ ha $<$ palabra_cortada/ $>$ habían si[d]o treh cosah que una fue cuando ehtaba perforando a una mina a $<$ alargamiento/ $>$ de hecho a la I

E: <simultáneo> ¿en la oreja? </simultáneo>

I: <simultáneo > le ehtaba haciendo un aro </simultáneo > en la nariz

$\mathrm{E}: \mathrm{ah} /$ en la nariz

I: ya/ esa we[v]a[da] me dio mucho suhto porque la <vacilación/> ¿cómo se llama?/la ag <pausa>/

la aguja se me pasó de largo / y yo we[v]ón te juro que <vacilación/> del miedo que le fuera a 
pinchar el ojo / tiré la aguja pa[ra] afuera / y se me salió del <vacilación/> de la narih [en]tonceh fue como we[v]ón [es]toy puro cagándola <risas = "E"/> ya y de ahí we[v]ón no volví a perforar a $<$ vacilación/> a nadie más

E: uhum

(CON-H05)

\subsubsection{Falsos inicios y estadio de la enfermedad}

Encontramos presencia de 2 casos en los controles, (18,2\%), de 1 caso en los primer episodio $(9,1 \%)$ y 8 casos en los crónicos, $(72,7 \%)$ :

Tabla de contingencia 28: falsos inicios y estadio de la enfermedad.

\begin{tabular}{||l|l|l|l||}
\hline \multirow{2}{*}{$\begin{array}{l}\text { Estadio de la } \\
\text { enfermedad }\end{array}$} & \multicolumn{2}{|c|}{ Falsos inicios } & \multirow{2}{*}{ Total } \\
\cline { 2 - 3 } & Presencia & Ausencia & \\
\hline \multirow{2}{*}{ Control } & 2 & 10 & 12 \\
\cline { 2 - 4 } & $18,2 \%$ & $19,6 \%$ & $19,4 \%$ \\
\hline \multirow{2}{*}{ Primer episodio } & 1 & 24 & 25 \\
\cline { 2 - 4 } & $9,1 \%$ & $47,1 \%$ & $40,3 \%$ \\
\hline \multirow{2}{*}{ Crónico } & 8 & 17 & 25 \\
\cline { 2 - 4 } & $72,7 \%$ & $33,3 \%$ & $40,3 \%$ \\
\hline \multirow{2}{*}{ Total } & 11 & 51 & 62 \\
\cline { 2 - 4 } & $100,0 \%$ & $100,0 \%$ & $100,0 \%$ \\
\hline \hline
\end{tabular}


Gráfico 5. Porcentaje de frecuencia de las variantes: falsos inicios y estadio de la enfermedad:

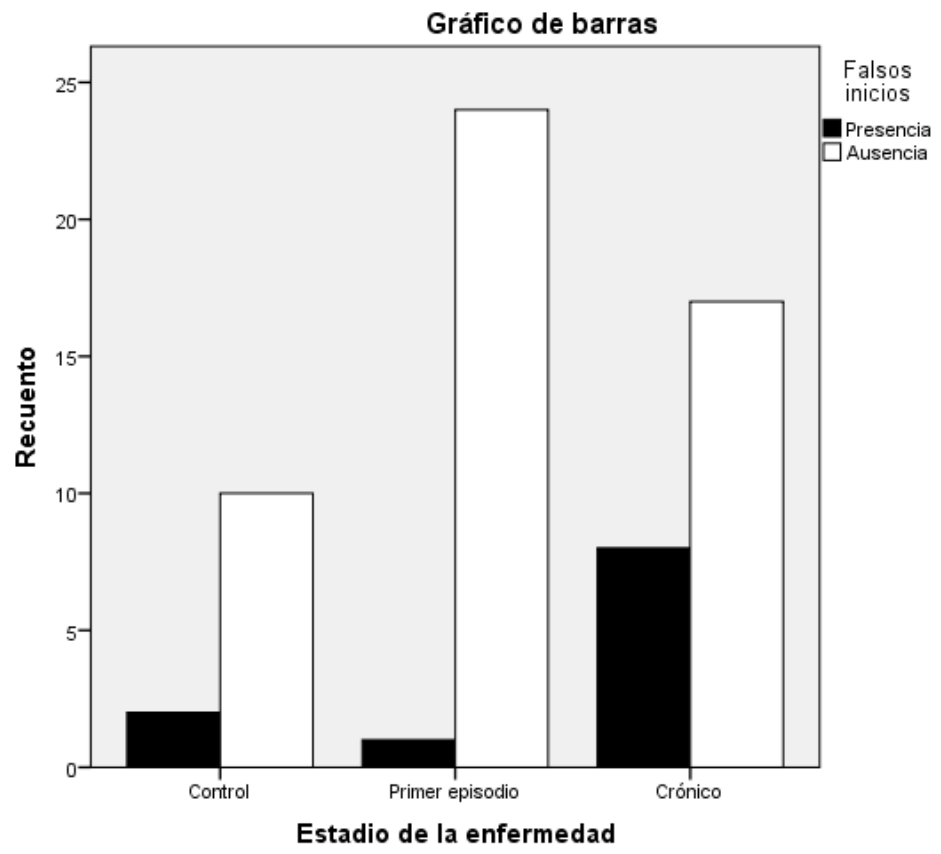

El valor de chi cuadrado fue de $6,727^{\mathrm{a}}$ y dio como resultado $(\mathrm{p}<, 035>$ ), entre los crónicos observamos mayor presencia del fenómeno, aunque la medida resultante, no es significativa.

Tabla valor de chi cuadrado 29: falsos inicios y estadio de la enfermedad.

Resumen del procesamiento de los casos

\begin{tabular}{||l|l|l|l||}
\hline \multicolumn{4}{|c||}{ Pruebas de chi-cuadrado } \\
\hline & Valor & Gl & Sig. asintótica (bilateral) \\
\hline Chi-cuadrado de Pearson & $6,727^{\text {a }}$ & 2 &, 035 \\
\hline \hline
\end{tabular}




\subsubsection{Falsos inicios y sexo}

En el recuento total de casos, las mujeres presentaron 2 casos $(18,2 \%)$ y los hombres alcanzaron un $(81,8 \%)$ con 9 casos:

Tabla de contingencia 30: falsos inicios y sexo.

\begin{tabular}{|c|c|c|c|c|}
\hline \multirow{2}{*}{\multicolumn{2}{|c|}{ Sexo del sujeto }} & \multicolumn{2}{|c|}{ Falsos inicios } & \multirow{3}{*}{$\begin{array}{l}\text { Total } \\
29 \\
\end{array}$} \\
\hline & & \multirow{2}{*}{$\begin{array}{r}\text { Presencia } \\
2 \\
\end{array}$} & \multirow{2}{*}{$\begin{array}{r}\text { Ausencia } \\
27 \\
\end{array}$} & \\
\hline \multirow{4}{*}{$\begin{array}{l}\text { Sexo del } \\
\text { sujeto }\end{array}$} & \multirow[t]{2}{*}{ Mujer } & & & \\
\hline & & $18,2 \%$ & $52,9 \%$ & $46,8 \%$ \\
\hline & \multirow[t]{2}{*}{ Hombre } & 9 & 24 & 33 \\
\hline & & $81,8 \%$ & $47,1 \%$ & $53,2 \%$ \\
\hline \multirow{2}{*}{\multicolumn{2}{|c|}{ Total }} & 11 & 51 & 62 \\
\hline & & $100,0 \%$ & $100,0 \%$ & $100,0 \%$ \\
\hline
\end{tabular}

Gráfico 6. Porcentaje de frecuencia de las variantes: falsos inicios y sexo:

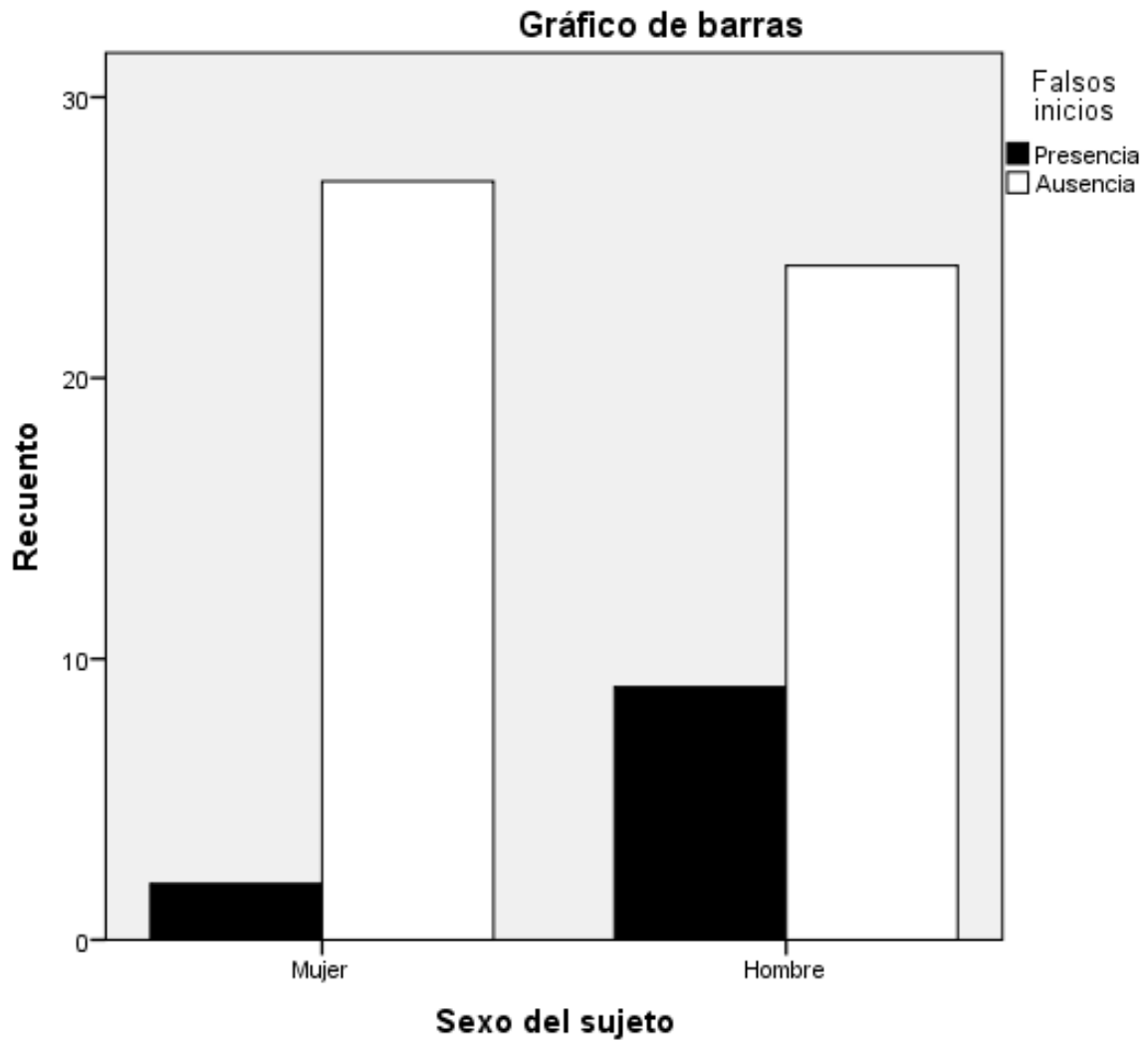


El valor de chi cuadrado es, 4,391 ${ }^{\mathrm{a}}$ y dio como resultado ( $\mathrm{p}<, 036>$ ), se observaron muchos más casos entre los sujetos de sexo masculino, ya que de las 11 ocurrencias, 9 corresponden a hombres. La medida resultante, no es significativa.

Tabla valor de chi cuadrado 31: falsos inicios y sexo.

\begin{tabular}{||l|c|r|r|r|c||}
\hline \multicolumn{7}{|c||}{ Pruebas de chi-cuadrado } \\
\hline & Valor & $\mathrm{gl}$ & $\begin{array}{c}\text { Sig. asintótica } \\
\text { (bilateral) }\end{array}$ & $\begin{array}{c}\text { Sig. exacta } \\
\text { (bilateral) }\end{array}$ & $\begin{array}{c}\text { Sig. exacta } \\
\text { (unilateral) }\end{array}$ \\
\hline Chi-cuadrado de Pearson & $4,391^{\mathrm{a}}$ & 1 &, 036 & & \\
\hline
\end{tabular}

4.1.2.4. Falsos inicios y tramo de la enfermedad

Encontramos 2 casos de presencia en los controles, (18,2\%), 0 presencias en el tramo 1 de primer episodio (0\%); 1 presencia en el tramo 2 de primer episodio, $(9,1 \%), 1$ presencia en el tramo 3 de crónicos, $(27,3 \%)$ y 5 presencias en el tramo 4 de crónicos (45,5\%); se resume información en la tabla y en el gráfico siguiente: 
Tabla de contingencia 32: falsos inicios y tramo de la enfermedad

\begin{tabular}{||l|l|l|l||}
\hline \multirow{2}{*}{ Falsos inicios } & \multicolumn{2}{|c||}{ Falsos inicios } & \multirow{2}{*}{ Total } \\
\cline { 2 - 4 } & Presencia & Ausencia & \multicolumn{1}{||}{} \\
\hline \multirow{3}{*}{ Control } & 2 & 10 & 12 \\
\cline { 2 - 4 } & $18,2 \%$ & $19,6 \%$ & $19,4 \%$ \\
\hline \multirow{3}{*}{ Primer episodio 0 a 2 años } & 0 & 14 & 14 \\
\cline { 2 - 4 } & $0,0 \%$ & $27,5 \%$ & $22,6 \%$ \\
\hline \multirow{3}{*}{ Primer episodio 2 a 3 años } & 1 & 10 & 11 \\
\cline { 2 - 4 } & $9,1 \%$ & $19,6 \%$ & $17,7 \%$ \\
\hline \multirow{3}{*}{ Crónico hasta 5 años } & 3 & 7 & 10 \\
\cline { 2 - 4 } & $27,3 \%$ & $13,7 \%$ & $16,1 \%$ \\
\hline \multirow{2}{*}{ Crónico 5 y más años } & 5 & 10 & $24,2 \%$ \\
\cline { 2 - 4 } & $45,5 \%$ & $19,6 \%$ & 62 \\
\hline Total & 11 & 51 & $100,0 \%$ \\
\cline { 2 - 4 } & $100,0 \%$ & $100,0 \%$ & 15 \\
\hline
\end{tabular}

Gráfico 7. Porcentaje de frecuencia de las variantes: falsos inicios y tramo de la enfermedad

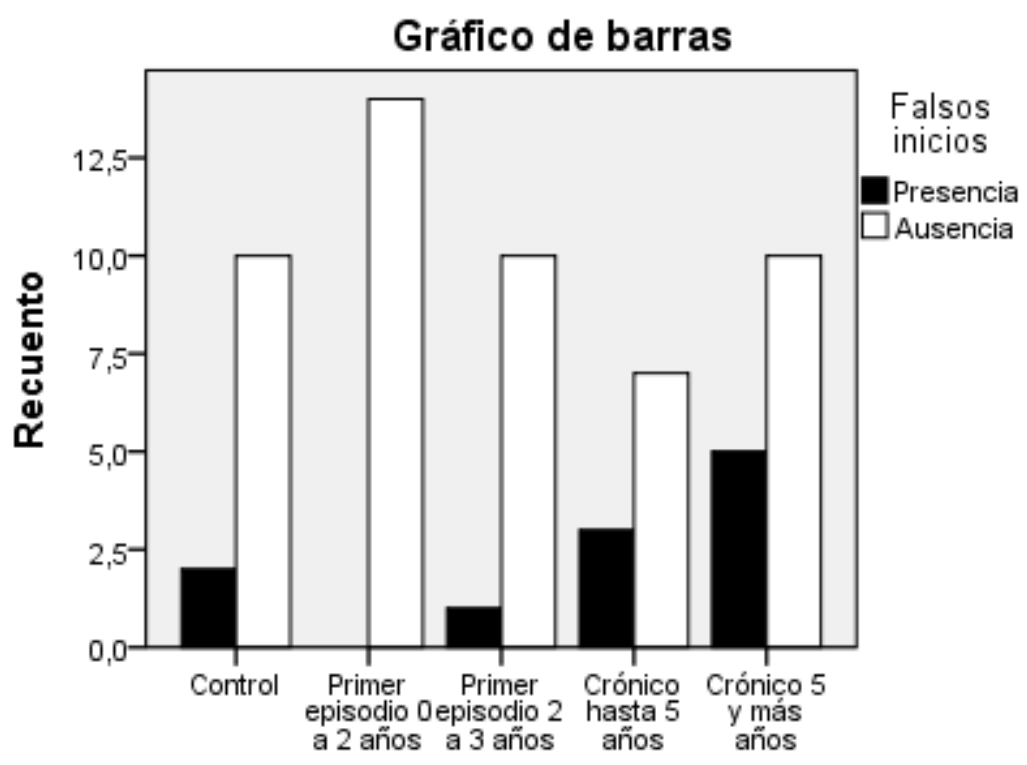

Tramo de la enfermedad 
El valor de chi cuadrado es 7,121 y dio como resultado ( $<\mathrm{p} 0,130>)$, entre los pacientes crónicos de 5 años y más, se presentó la mayoría de los casos.

Tabla valor de chi cuadrado 33: falsos inicios y tramo de la enfermedad.

\begin{tabular}{||l|c|c|c||}
\hline \multicolumn{5}{|c||}{ Pruebas de chi-cuadrado } \\
\hline & Valor & gl & $\begin{array}{c}\text { Sig. asintótica } \\
\text { (bilateral) }\end{array}$ \\
\hline Chi-cuadrado de Pearson & $7,121^{\mathrm{a}}$ & &, 130 \\
\hline
\end{tabular}

4.1.2.5. Falsos inicios y subtipo de la enfermedad

Se encontraron 2 presencias en los controles, (18,2\%), en los paranoides 3 casos, $(27,3 \%), 3$ casos en los indiferenciados, (27,3\%), 3 casos en los desorganizados, $(27,3 \%)$

Tabla de contingencia 34: falsos inicios y subtipo de la enfermedad.

\begin{tabular}{|l|l|l|l|}
\hline \multirow{2}{*}{ Subtipo de la esquizofrenia } & \multicolumn{2}{|c|}{ Falsos inicios } & \multirow{2}{*}{ Total } \\
\cline { 2 - 4 } & Presencia & Ausencia & \\
\hline \multirow{2}{*}{ Control } & 2 & 10 & 12 \\
\cline { 2 - 4 } & $18,2 \%$ & $19,6 \%$ & $19,4 \%$ \\
\hline \multirow{2}{*}{ Paranoide } & 3 & 30 & 33 \\
\cline { 2 - 4 } & $27,3 \%$ & $58,8 \%$ & $53,2 \%$ \\
\hline Indiferenciado & 3 & 6 & 9 \\
\cline { 2 - 4 } & $27,3 \%$ & $11,8 \%$ & $14,5 \%$ \\
\hline
\end{tabular}




\begin{tabular}{|l|l|l|l|}
\hline \multirow{2}{*}{ Desorganizada } & 3 & 5 & 8 \\
\cline { 2 - 4 } & $27,3 \%$ & $9,8 \%$ & $12,9 \%$ \\
\hline \multirow{2}{*}{ Total } & 11 & 51 & 62 \\
\cline { 2 - 4 } & $100,0 \%$ & $100,0 \%$ & $100,0 \%$ \\
\hline
\end{tabular}

Gráfico 8. Porcentaje de frecuencia de las variantes: falsos inicios y subtipo de la enfermedad

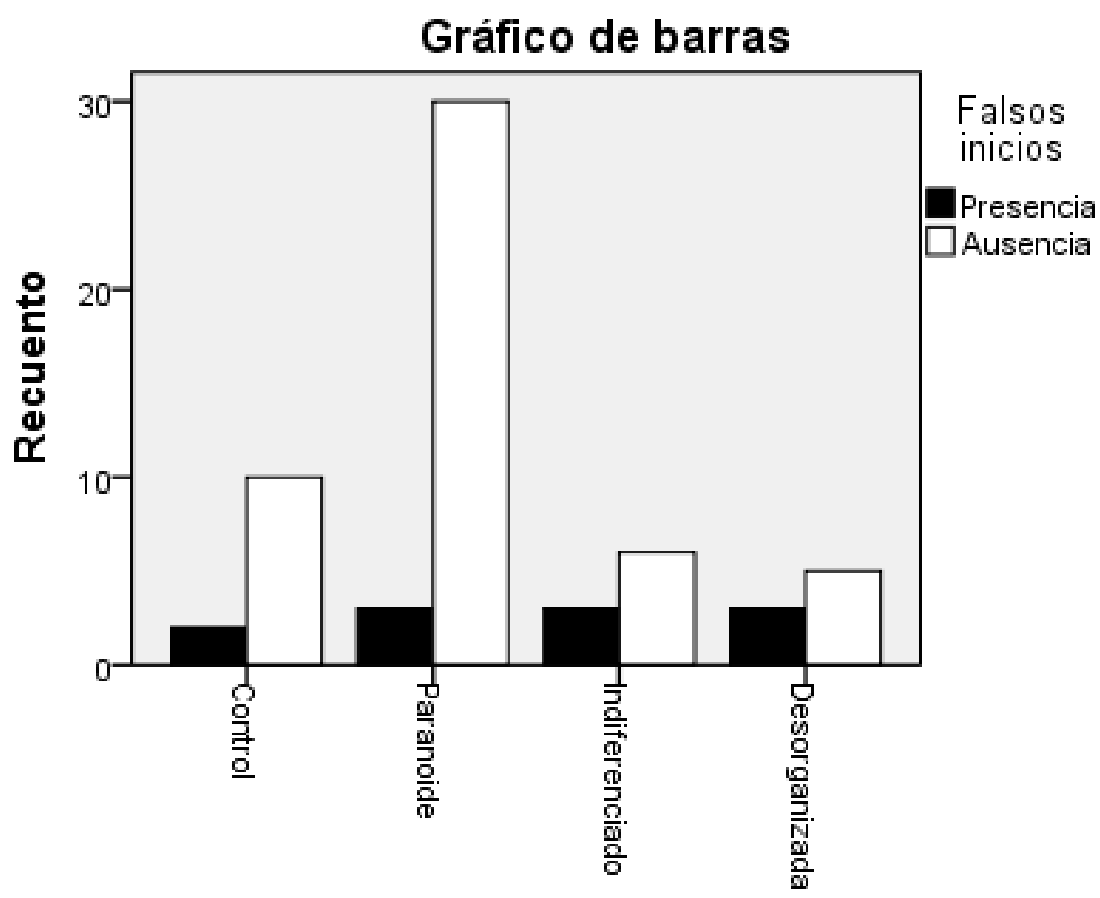

Subtipo de la esquizofrenia

El valor de chi cuadrado es 5,341 y dio como resultado $(<\mathrm{p} 0,148>)$, entre los pacientes crónicos de 5 años y más, se presentó la mayoría de los casos, sin significación estadística. 
Tabla valor de chi cuadrado 35: falsos inicios y subtipo de la enfermedad.

\begin{tabular}{||c|c|c|c||}
\hline \multicolumn{4}{|c||}{ Pruebas de chi-cuadrado } \\
\hline & Valor & $\mathrm{gl}$ & $\begin{array}{c}\text { Sig. asintótica } \\
\text { (bilateral) }\end{array}$ \\
\hline Chi-cuadrado de Pearson & $5,341^{\mathrm{a}}$ & 3 &, 148 \\
\hline
\end{tabular}

\subsubsection{Pausas extendidas}

Se encontraron 25 casos de pausas extendidas, es importante señalar que este rasgo no fue pesquisado en los controles.

\subsubsection{Ejemplos del grupo de crónicos:}

\section{1) Pausas extendidas:}

E: y/ ¿por qué está hospitalizada?

S: porque tengo esquizofrenia/ <pausa ext> paranoide/

E: ya <alargamiento $>/$ ¿nos puede contar un poquito más qué es lo que siente usted?

S: <pausa ext $>$ /siento que andan espíritus/ ahora mismo andan <pausa ext $>$ / espíritus

E: ¿ahora mismo andan espíritus<pausa $>$ ?

S: me andan <pausa ext>/rodeando/ en estos momentos me andan rodeando/ me quieren $<$ pausa ext $>/$ matar.

E: ¿hace cuánto que siente esos espíritus que la andan rodeando?

S: <pausa ext $>/$ hace tiempo.

(CRE-M03)

\section{2) Pausas extendidas:}

E: [...]para que entiendan la función/ así está $<$ pausa ext $>/$ la función/ porque si se pone lo que dice ahí<pausa ext $>/ y$ ver<pausa ext $>/ q u e$ es factible<pausa ext $>/$ el justo juicio<pausa ext $>/$ como un<pausa ext $>/$ sentir humano/ como un sentir humano.

(CRE-H04)

\section{3) Pausas extendidas:}

E: [...] Aquello <pausa ext $>/$ explicado para que tú te desenvuelvas <pausa ext $>/$ lo importante es que todos tenemos una retórica $<$ pausa ext $>/$ de donde vengamos $<$ pausa ext $>/$ donde 
vayamos $<$ pausa ext $>/$ lo ideal/ están las virtudes y los valores/ y<pausa ext $>/$ y $\langle$ pausa ext $>/$ $\mathrm{y}<$ pausa ext $>/ \mathrm{y} /$ dan un curso de eso. [...]

(CRE-H05)

\section{4) Pausas extendidas:}

E: ¿Se acuerda qué <pausa>/que es lo que gatilló que la trajeran para acá?

S: Eh <pausa ext $>$ /

E: ¿Alguna pelea $<$ pausa $>/$ ?

$\mathrm{S}:\langle$ pausa ext $>/ \mathrm{Si}<$ pausa $>/$ una discusión $<$ pausa ext $>/$ es que $<$ pausa ext $>/$

E: ¿Con su mamá?

$\mathrm{S}$ : Si con mi madre<pausa $>/$ es que ella me<pausa ext $>/$ eh $<$ pausa ext $>/$ ¿cómo puedo decirlo<pausa ext $>/$ ? ¡Ah!/ por la pieza/ porque estaba en la pieza $<$ pausa ext $>/$ porque estaba mucho en la pieza y no salía a hacer cosas/ ¿entiende? $\langle$ pausa $>/$ y me $\langle$ pausa $>/$ me dio patadas.

(CRE-M02)

\section{5) Pausas extendidas:}

E: ¿hace cuánto tiempo que está casada?

S: eeh <pausa or $>/$ mmm<pausa or $>/ ¿$ a ver? $<$ pausa ext $>/$ con él llevo más<pausa ext $>/$ menos unos once $<$ pausa $>/$ doce años $<$ pausa $>/$ como mujer de vichún<pausa $>/$ enábar<pausa $>$ /espérate<pausa $>$ ¿cómo se llama? <pausa ext $>/$ José<pausa ext $>/$ me cuesta el nombre.

E: no se preocupe<pausa>/ ¿José se llama?

S: no<pausa ext $>/$ si<pausa ext $>/$ José se llama.

E: ¿recuerda el nombre de su esposo?

S: lo tengo borrado/ no es que no sepa cómo se llamaba<pausa $>/$ lo que pasa es que no ha hecho mucho por mí<pausa $>/$ no ha hecho nada<pausa $>/$ mi amorcito<pausa ext $>/$ (súbitamente grita) ¡Jaime Arrieta!/ ahí está.

(CRE-M10)

\section{6) Pausas extendidas:}

E: ¿Y esto le ha pasado últimamente/ o siempre ha sido así?

S: No siempre/ eso es natural en el ser humano<pausa ext $>/$ de que piense más de lo que se puede hacer $\langle$ pausa $>/$ que se imagine cosas $\langle$ pausa $>/$ porque está haciendo cosas $\langle$ pausa $>/$ por ejemplo<pausa $>/$ y quiere hacer cosas y no puede<pausa ext $>\mid$ eso lo reprime a uno $<$ pausa $>\mid$ lo reprime $<$ pausa $>/$ como que a uno lo frena/ en seco// de repente/ estás caminando /ya $<$ pausa $>/$ de vuelta esperando que <pausa ext $>/$ de repente <pausa ext $>/$ instantáneo / como que el cuerpo te pidió hacer algo así/ no sé/ salir de ese movimiento<pausa ext $>/$ de ese movimiento tan transitorio y hacer otra cosa<pausa ext $>/$ moverte pa algún lado/ no pudiste no más y eso te perjudica/ te <pausa ext $>/$ hacia ti mismo/ el hecho de haber estado insultando tanto y me pregunto<pausa ext $>/$ y me pregunto <pausa ext $>/$ pero estoy aquí poh.

$\mathrm{E}: \iota \mathrm{M} / \mathrm{y}$ qué quiere usted para el futuro/ en qué se proyecta?

S: No tengo nada planeado hacer.

(CRE-H13) 
Ejemplos del grupo de primer episodio:

1) Pausas extendidas:

E: ¿cómo te llamas tú?

$\mathrm{S}:$ <pausa ext $>/ \mathrm{V}$

E:¿tu apellido?

$\mathrm{S}:$ <pausa ext $>/ \mathrm{V}$

E: ¿cómo es?

S: V

E: V V

$\mathrm{S}:$ <pausa ext >/ si

E: ¿qué edad tienes?

S: <pausa ext >/ 19

E: ¿y con quién vives/ V?

$\mathrm{S}$ : <pausa ext >/ con mi mamá<pausa ext >/ mi mamá y mi hermano

E: ¿y qué edad tiene tu hermano?

S: como <pausa ext >/ $21<$ pausa ext >/ algo por ahí

E: ah/ ¿no sabes bien la edad?

S: <pausa ext >/ no

(PEE-M07)

\section{2) Pausas extendidas:}

E: y ¿a qué juegas en el computador?

S: <pausa ext >/ música

E: ya, ¿qué más?

S: eh<pausa or-pausa ext $>/$

E: ¿a qué más?

$\mathrm{S}$ : <pausa ext >/ ¿jugar?

E: mmmm (confirmatorio)

S: a<pausa ext >/ las cartas

E: y tú y tus amigas/ ¿conversan?

$\mathrm{S}$ : si

(PEE-M08) 


\subsubsection{Pausas extendidas y estadio de la enfermedad}

No se encontró presencia de este fenómeno en los controles, en el grupo de primer episodio, se contaron 12 casos, (48\%) y en los crónicos alcanzó un (52\%) con 13 casos:

Tabla de contingencia 36: pausas extensas y estadio de la enfermedad.

\begin{tabular}{||l|l|l|l||}
\hline \hline \multirow{2}{*}{$\begin{array}{l}\text { Estadio de la } \\
\text { enfermedad }\end{array}$} & \multicolumn{2}{|l||}{ Pausas extensas } & \multirow{2}{*}{ Total } \\
\cline { 2 - 4 } & Presencia & Ausencia & \\
\hline \multirow{2}{*}{ Control } & 0 & 12 & 12 \\
\cline { 2 - 4 } & $0,0 \%$ & $32,4 \%$ & $19,4 \%$ \\
\hline \multirow{2}{*}{ Primer episodio } & 12 & 13 & 25 \\
\cline { 2 - 4 } & $48,0 \%$ & $35,1 \%$ & $40,3 \%$ \\
\hline \multirow{2}{*}{ Crónico } & 13 & 12 & 25 \\
\cline { 2 - 4 } & $52,0 \%$ & $32,4 \%$ & $40,3 \%$ \\
\hline \multirow{2}{*}{ Total } & 25 & 37 & 62 \\
\cline { 2 - 4 } & $100,0 \%$ & $100,0 \%$ & $100,0 \%$ \\
\hline
\end{tabular}


Gráfico 9. Porcentaje de frecuencia de las variantes: Pausas extensas y estadio de la enfermedad:

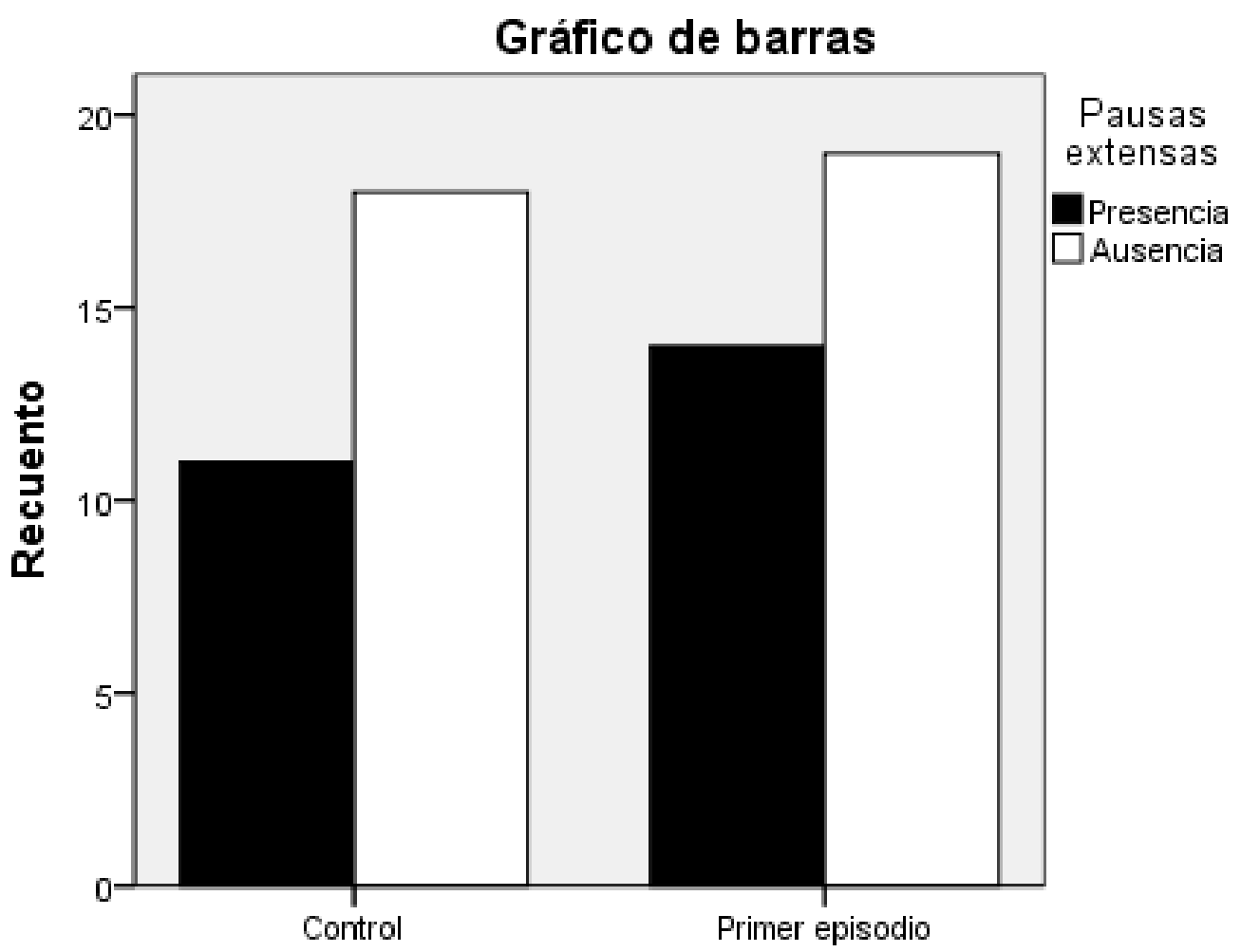

Estadio de la enfermedad

El valor de chi cuadrado es 10,137 y dio un resultado estadísticamente significativo $(<p$ 0,006), este fenómeno resultó ser informativo, se presentó únicamente en los grupo de pacientes, con una alta recurrencia.

Tabla valor de chi cuadrado 37: pausas extensas y estadio de la enfermedad.

\begin{tabular}{||c|c|c|c||}
\hline \multicolumn{4}{|c||}{ Pruebas de chi-cuadrado } \\
\hline & Valor & $\mathrm{gl}$ & $\begin{array}{c}\text { Sig. asintótica } \\
\text { (bilateral) }\end{array}$ \\
\hline
\end{tabular}




\begin{tabular}{||l|r|r|r||}
\hline \hline Chi-cuadrado de Pearson & $10,137^{\mathrm{a}}$ & 2 &, 006 \\
\hline \hline
\end{tabular}

\subsubsection{Pausas extensas y sexo}

Se encontraron 25 casos, distribuidos en 11 casos de presencia entre las mujeres (44\%) y 14 casos de presencia entre los hombres de la muestra (56\%) como podemos ver en la tabla de contingencia y el gráfico respectivo:

Tabla de contingencia 38: pausas extensas y sexo.

\begin{tabular}{||l|l|l|l||}
\hline \multirow{2}{*}{ Sexo del sujeto } & \multicolumn{2}{|l||}{ Pausas extensas } & \multirow{2}{*}{ Total } \\
\cline { 2 - 3 } & Presencia & Ausencia & \\
\hline \multirow{3}{*}{ Mujer } & 11 & 18 & 29 \\
\cline { 2 - 4 } & $44,0 \%$ & $48,6 \%$ & $46,8 \%$ \\
\hline \multirow{2}{*}{ Hombre } & 14 & 19 & 33 \\
\cline { 2 - 4 } & $56,0 \%$ & $51,4 \%$ & $53,2 \%$ \\
\hline \multirow{2}{*}{ Total } & 25 & 37 & 62 \\
\cline { 2 - 4 } & $100,0 \%$ & $100,0 \%$ & $100,0 \%$ \\
\hline
\end{tabular}


Gráfico 10. Porcentaje de frecuencia de las variantes:Pausas extensas y sexo

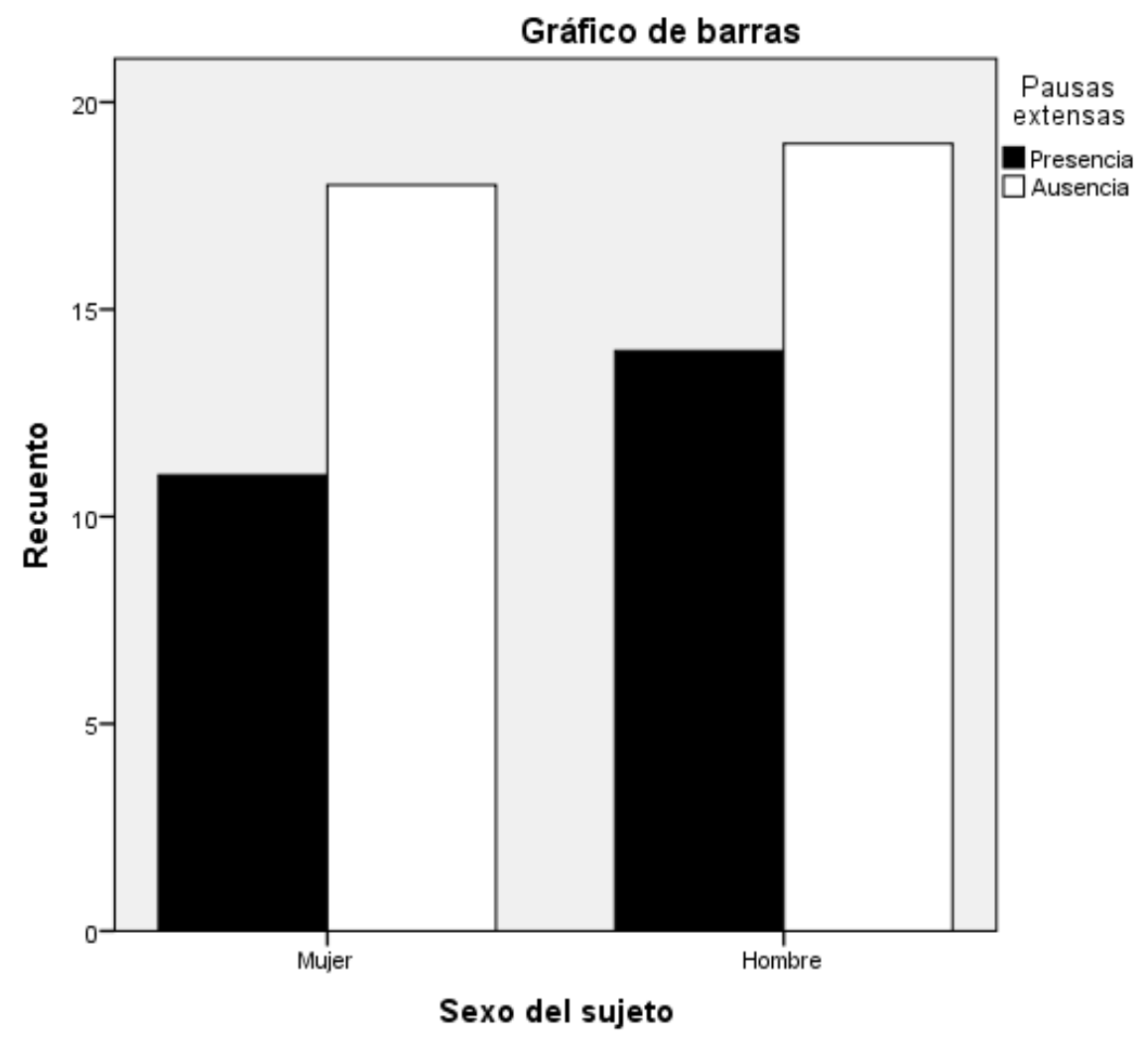

Los valores de chi cuadrado son ,130 ${ }^{\mathrm{a}}$ y dieron como resultado (<p 0,719>), nuevamente vemos que la variable sexo, no ofrece diferencias relevantes como fenómeno lingüístico. 
Tabla valor de chi cuadrado 39: pausas extensas y sexo.

\begin{tabular}{||l|c|c|c|c|c||}
\hline \multicolumn{7}{|c||}{ Pruebas de chi-cuadrado } \\
\hline & Valor & Gl & $\begin{array}{c}\text { Sig. asintótica } \\
\text { (bilateral) }\end{array}$ & $\begin{array}{c}\text { Sig. exacta } \\
\text { (bilateral) }\end{array}$ & $\begin{array}{c}\text { Sig. exacta } \\
\text { (unilateral) }\end{array}$ \\
\hline $\begin{array}{l}\text { Chi-cuadrado de } \\
\text { Pearson }\end{array}$ &, $130^{\mathrm{a}}$ & 1 &, 719 & & \\
\hline \hline
\end{tabular}

\subsubsection{Pausas extendidas y tramo de la enfermedad}

Encontramos presencia de 6 casos en primer episodio tramo 1, (24\%), 6 presencia en el tramo 2 de primer episodio, (24\%), 3 casos en el tramo 3 de crónicos, (24\%) y 9 casos en el tramo 4 de crónicos (36\%):

Tabla de contingencia 40: pausas extensas y tramo de la enfermedad.

\begin{tabular}{||l|l|l|l||}
\hline \hline \multirow{2}{*}{$\begin{array}{l}\text { Tramo de la } \\
\text { enfermedad }\end{array}$} & \multicolumn{2}{|c||}{ Pausas extensas } & \multirow{2}{*}{ Total } \\
\cline { 2 - 3 } & Presencia & Ausencia & \\
\hline \multirow{2}{*}{ Control } & 0 & 12 & 12 \\
\cline { 2 - 4 } & $0,0 \%$ & $32,4 \%$ & $19,4 \%$ \\
\hline \multirow{2}{*}{$\begin{array}{l}\text { Primer episodio 0 a } \\
\text { 2 años }\end{array}$} & 6 & 8 & 14 \\
\cline { 2 - 4 } & $24,0 \%$ & $21,6 \%$ & $22,6 \%$ \\
\hline \multirow{2}{*}{$\begin{array}{l}\text { Primer episodio 2 a } \\
\text { años }\end{array}$} & 6 & 5 & 11 \\
\cline { 2 - 4 } & $24,0 \%$ & $13,5 \%$ & $17,7 \%$ \\
\hline \multirow{2}{*}{$\begin{array}{l}\text { Crónico hasta 5 } \\
\text { años }\end{array}$} & 4 & 6 & 10 \\
\hline \multirow{2}{*}{$\begin{array}{l}\text { Crónico 5 y más } \\
\text { años }\end{array}$} & $16,0 \%$ & $16,2 \%$ & $16,1 \%$ \\
\hline \multirow{2}{*}{ Total } & 9 & 6 & 15 \\
\cline { 2 - 4 } & $25,0 \%$ & $16,2 \%$ & $24,2 \%$ \\
\cline { 2 - 4 } & $100,0 \%$ & $100,0 \%$ & $100,0 \%$ \\
\hline \hline
\end{tabular}


Gráfico 11. Porcentaje de frecuencia de las variables: pausas extensas y tramo de la enfermedad

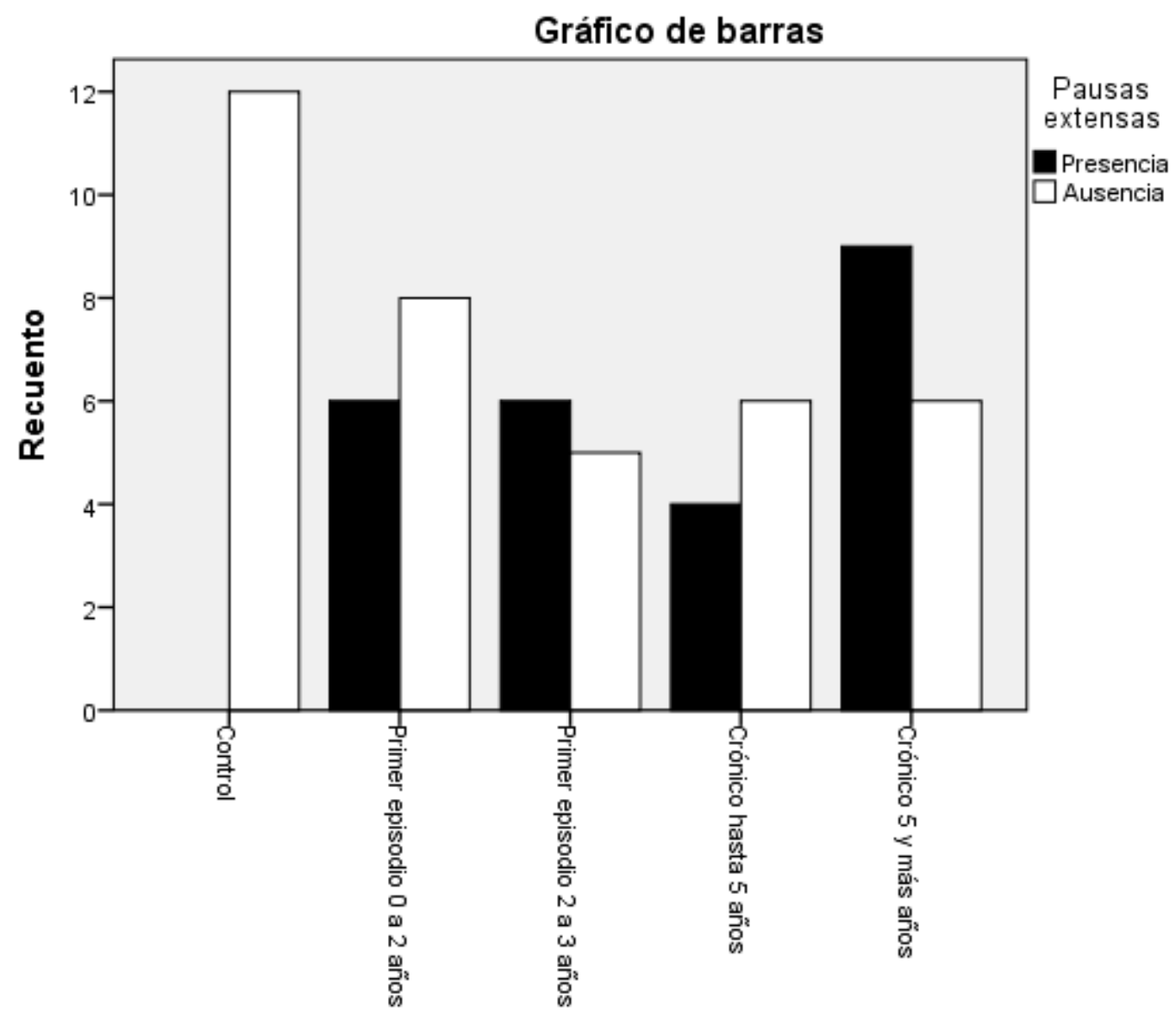

\section{Tramo de la enfermedad}

Los valores de chi cuadrado son $11,484^{\mathrm{a}}$ y dieron como resultado $(<\mathrm{p}, 022>)$, no significativo estadísticamente.

Tabla valor de chi cuadrado 41: pausas extensas y tramo de la enfermedad.

\begin{tabular}{||c|c|r|c||}
\hline \multicolumn{5}{|c||}{ Pruebas de chi-cuadrado } \\
\hline & Valor & gl & $\begin{array}{c}\text { Sig. asintótica } \\
\text { (bilateral) }\end{array}$ \\
\hline Chi-cuadrado de Pearson & $11,484^{\mathrm{a}}$ & & 4 \\
\hline
\end{tabular}




\subsubsection{Pausas extendidas y subtipo de la enfermedad}

Encontramos 15 presencias en los paranoides, (60\%), 4 en los indiferenciados, (16\%), y 6 presencias en los desorganizados, $(24 \%)$ :

Tabla de contingencia 42: pausas extensas y subtipo de la enfermedad

\begin{tabular}{||l|l|l|l||}
\hline \hline \multirow{3}{*}{$\begin{array}{l}\text { Subtipo de la } \\
\text { esquizofrenia }\end{array}$} & \multicolumn{2}{|c|}{ Pausas extensas } & \multirow{2}{*}{ Total } \\
\cline { 2 - 4 } & Presencia & Ausencia & \\
\hline \multirow{3}{*}{ Control } & 0 & 12 & 12 \\
\cline { 2 - 5 } Paranoide & $0,0 \%$ & $32,4 \%$ & $19,4 \%$ \\
\hline \multirow{3}{*}{ Indiferenciado } & 15 & 18 & 33 \\
\cline { 2 - 5 } & $60,0 \%$ & $48,6 \%$ & $53,2 \%$ \\
\hline \multirow{2}{*}{ Desorganizada } & 4 & 5 & 9 \\
\cline { 2 - 5 } & $16,0 \%$ & $13,5 \%$ & $14,5 \%$ \\
\hline \multirow{2}{*}{ Total } & 6 & 2 & $12,9 \%$ \\
\cline { 2 - 5 } & $24,0 \%$ & $5,4 \%$ & 62 \\
\hline
\end{tabular}


Gráfico 12. Porcentaje de frecuencia de las variables: pausas extensas y subtipo de la enfermedad

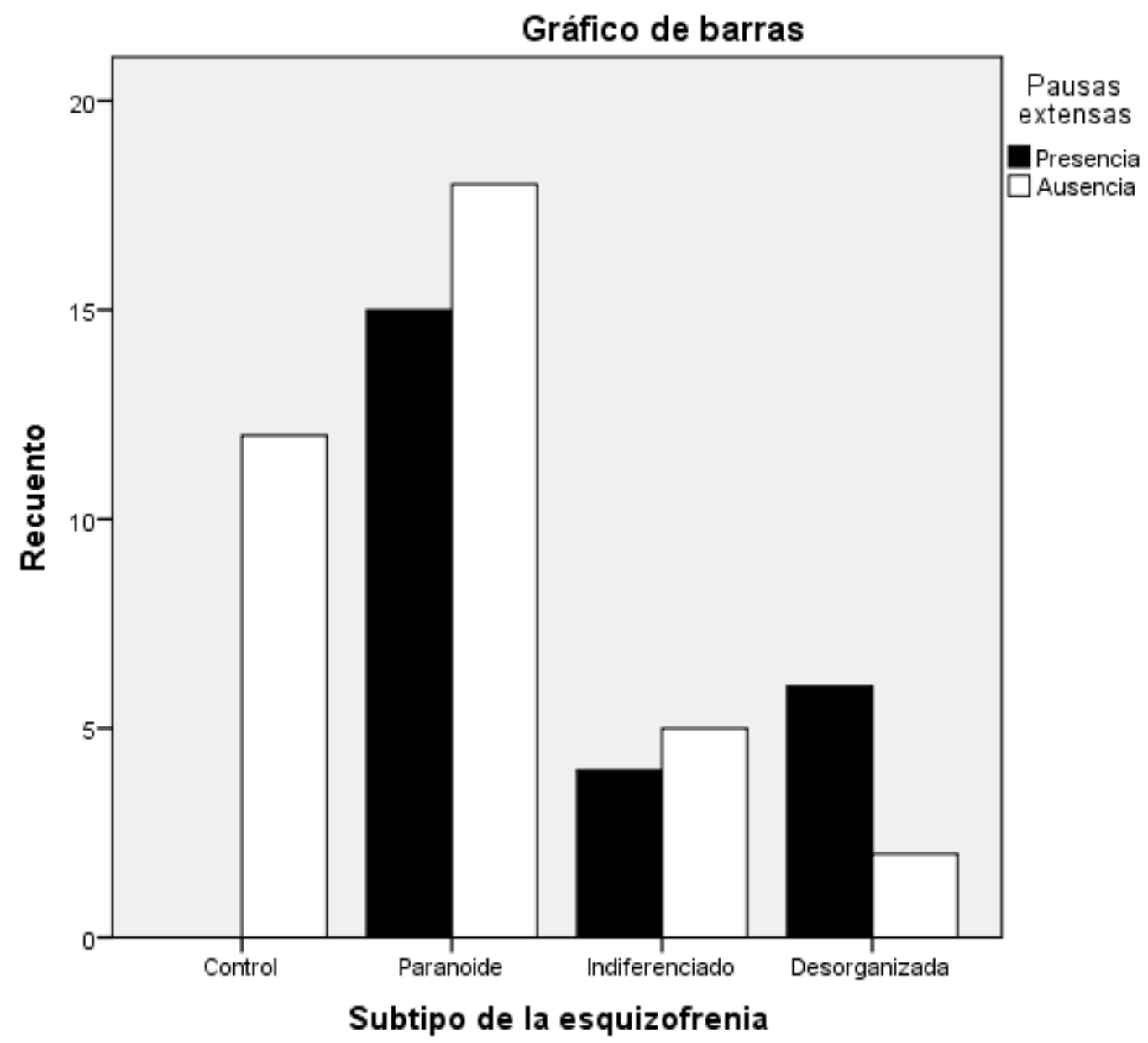

El valor de chi cuadrado es $12,531^{\mathrm{a}}$ y dio un resultado significativo de $(<\mathrm{p} 0,006>)$

Tabla valor de chi cuadrado 43: pausas extensas y subtipo de la enfermedad.

\begin{tabular}{||l|c|r|r||}
\hline \multicolumn{4}{|c||}{ Pruebas de chi-cuadrado } \\
\hline & Valor & $\mathrm{gl}$ & $\begin{array}{c}\text { Sig. asintótica } \\
\text { (bilateral) }\end{array}$ \\
\hline Chi-cuadrado de Pearson & $12,531^{\mathrm{a}}$ & 3 &, 006 \\
\hline
\end{tabular}




\subsubsection{Tartamudeos}

Se contaron 26 casos de presencia de tartamudeo, un porcentaje de $41,9 \%$ del total. Este fenómeno se dio en forma transversal, con prevalencia entre los crónicos. También presentaron tartamudeos los grupos de primer episodio y controles, sin embargo, no tienen las mismas características, como se aprecia en los ejemplos

\subsubsection{Ejemplos de tartamudeos en el grupo crónicos:}

1)

E: ¿Qué hizo con su mamá?

S: pero <pausa $>$ / no fue solo por eso<pausa $>/$ si no que fue porque $<$ pausa $>/$ porque $<$ pausa ext $>/$ fue también porque yo<pausa $>$ / por lo de las voces $<$ pausa $>$ / que dije/ que/ que/ que/ que/ que pierdo mas el control que antes $<$ pausa $>/$ entonces por eso.

E: ¿Qué le hizo a su mamá?

S: le dije que<pausa ext $>$ / que/ que/ que/ que de repente no<pausa ext $>$ / que de repente me caía mal.

E: ¿y cómo anda la relación con sus padres/? Entonces/ ¿más o menos?/ o ¿más o menos mal?

$\mathrm{S}$ : bueno<pausa $>$ / ahora nos llevamos bien<pausa ext $>$ / es que es de repente <pausa ext $>/$ lo que pasa es que es muy <pausa $>/$ es muy $<$ pausa $>/$ es muy $<$ pausa $>/$ de repente $<$ pausa $>/$ es muy enojoncita $<$ pausa $>/$ pero<pausa>/pero<pausa>/pero nos llevamos bien igual/ por lo general nos llevamos bien/ si es de repente que yo me pongo media atrevida/ como que me altero pero<pausa ext $>/$

(CRE-M09)

E: ¿nos podría contar por qué está aquí?

S: por unaaa<pausa ext $>/$ surmenage $<$ pausa ext $>/$

E: ya/ ¿qué es un surmenage?

S: cansancio mental/

E: ¿qué es el cansancio mental?

S: el distinguir <pausa ext $>/$ las co $<$ pausa ext $>/$ co $<$ pausa $>/$ co $<$ pausa $>/$ cosas tal como son $<$ pausa ext $>$ /

E: mmm <pausa or $>/$

S:eeh <alargamiento $>/$ logré establecer < pausa $>$ /el equilibrio <pausa $>/$ mental $<$ pausa ext $>/$ hasta saber <pausa ext $>/$ existe el cambio <pausa $>$ de actitud <pausa $>$ para enfrentar <pausa ext $>/<$ carraspea $>/$ mmm $<$ pausa or $>/$ para enfren $<$ pausa ext $>/$ tar prole $<$ pausa ext $>/$ enfrentar prol $<$ pausa ext $>/$ problema es $<$ pausa ext $>/$ y como no tenía ningún vicio so $<$ pausa ext $>/$ soy re/ re/ re/ renovando el camino<pausa ext $>/$ y como si/ si si<pausa $>/$ si<pausa $>/$ siemp<pausa ext $>/$ siempre he estado/ si p amistades y cu 
$<$ pausa $>$ / de mi integridad personal pude seguir adelante/ con toda la $<$ pausa ext $>/ \operatorname{logros} / \mathrm{mmm}<$ pausa or $>/ y$ creo que siempre estuv<pausa>/ estuve bien/ porque <alargamiento $>/$ sabía las cosas exis $<$ pausa $>/$ existen y se cumplen/ cuando tienen control en sí mismo.

(CRE-H04)

3)

S: Aquello explicado para que tú te desenvuelvas/ lo importante es que todos tenemos una retórica/ de donde vengamos/ donde vayamos/ lo ideal/ están las virtudes y los valores/y/y/y/y/y/dan un curso de eso/ mira/ <al entrevistador> ésta es buena/ me van a entender más todavía lo que quiero decir/ porque es muy importante.

(CRE-H04)

4)

E: Bueno/ estábamos hablando de su problema <pausa>/

S: es/ est/ est/ estábamos hablando de mi problema.

E: Cuéntenos un poco.

$\mathrm{S}$ : $\mathrm{Y}<$ pausa ext $>/$ bueno yo<pausa ext $>/$ yo /yo / yo/ yo a todo esto conozco todo Chile/ he caminado por todo Chile <pausa $>$ y ese día <pausa ext $>/$ que me gusta a mí/ me gusta fuera de Santiago/ porque no me gusta aquí<pausa ext>/ aquí en Santiago nunca eh querido vivir/ también estuve hospitalizado en Putaendo <pausa ext>/ y mi vida quiero hacerla para allá porque es bonito para allá/ es un pueblito que está ahí en San Felipe/ quiero ir a vivir pa/ pa/ pa/ allá cuando salga de aquí del hospital/ a salir a trabajar todas esas cosas y/ tener una casa allá porque me gustó pa allá/ yo lo digo sinceramente/ me gustó pa allá/ yo estuve hospitalizado dos años allá.

(CRE-H07)

\section{Ejemplos de tartamudeos en el grupo de primer episodio:}

\section{1)}

E: ya/ ¿qué significa esto de este señor y la cábala?/ no te entiendo lo que me quieres decir.

S: que esa canción/ algunas partes<pausa ext $>/$ las palabras/ las tengo como una cábala/ como un amuleto/ como una moneda/ que/ que/que/que/que/que ahí/ahí me/ahí me da los pensamientos/ esos pensam <pausa ext>/ eso es cábala/ como que lo uso como una moneda/ un amuleto/ esas/ para que me dé más suerte.

$\mathrm{E}$ : ya/¿cuéntame $\mathrm{P} /$ ¿qué estás haciendo/ a qué estás dedicada?

S: nada/ en la casa/ hago el aseo<pausa ext>/ pero apenas hago el aseo<pausa>/ ahora mi mamá me mandó a hacer una copia porque tengo muy mala letra/ muy mala ortografía/ se me está colocando fea la letra/ tengo mala ortografía y <pausa ext $>/$

(PEE-M08) 
2)

E: y esto ha sido como qué cosa/ diálogos/ conversaciones/ ruidos/ voces/ ¿qué es exactamente lo que le pasa.

S: sssss $<$ pausa ext $>/$ so<pausa ext $>/$ so<pausa $>/$ so $<$ pausa $>/$ so $<$ pausa $>/$ son voces.

$\mathrm{E}:$ ¿voces como las nuestras?, ¿o distintas?

$\mathrm{S}$ : como las nuestras.

(PEE-H13)

\subsubsection{Tartamudeos y estadio de la enfermedad}

Se contaron 3 casos entre los controles, $(11,5 \%), 5$ casos entre los de primer episodio, $(19,2 \%)$ y 18 casos entre los crónicos, $(69,2 \%)$ como se resume en la tabla y en el gráfico:

Tabla de contingencia 44: tartamudeos y estadio de la enfermedad

\begin{tabular}{||l|l|l|l||}
\hline \multirow{2}{*}{ Estadio de la enfermedad } & \multicolumn{2}{|l||}{ Tartamudeos } & \multirow{2}{*}{ Total } \\
\cline { 2 - 4 } & Presencia & Ausencia & \\
\hline \multirow{2}{*}{ Control } & 3 & 9 & 12 \\
\cline { 2 - 4 } & $11,5 \%$ & $25,0 \%$ & $19,4 \%$ \\
\hline \multirow{2}{*}{ Primer episodio } & 5 & 20 & 25 \\
\cline { 2 - 4 } & $19,2 \%$ & $55,6 \%$ & $40,3 \%$ \\
\hline \multirow{2}{*}{ Crónico } & 18 & 7 & 25 \\
\cline { 2 - 5 } & $69,2 \%$ & $19,4 \%$ & $40,3 \%$ \\
\hline \multirow{2}{*}{ Total } & 26 & 36 & 62 \\
\cline { 2 - 4 } & $100,0 \%$ & $100,0 \%$ & $100,0 \%$ \\
\hline
\end{tabular}


Gráfico 13. Porcentaje de frecuencia de las variables: tartamudeos y estadio de la enfermedad

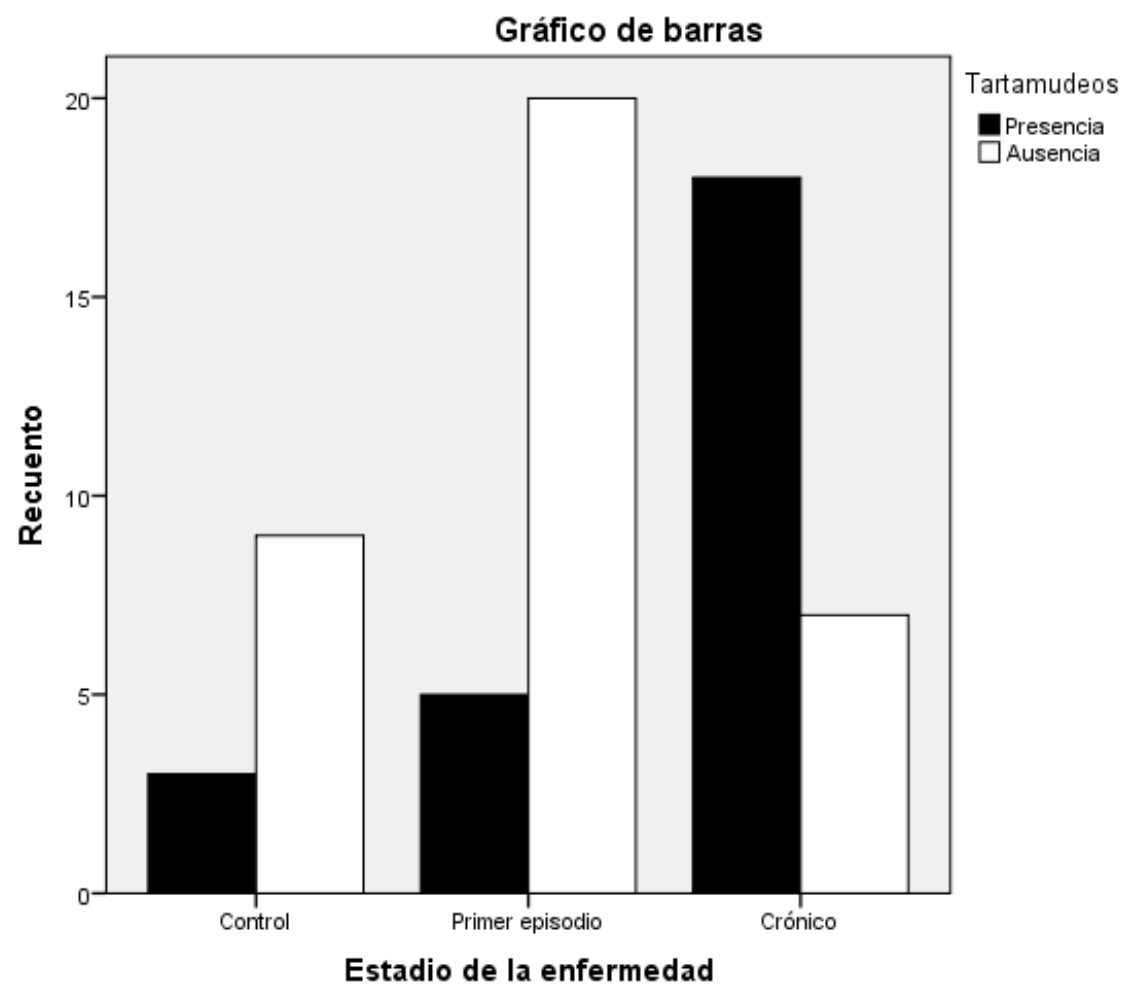

El valor de chi cuadrado es de $15,634^{\mathrm{a}}$ y dio como resultado $(<\mathrm{p}, 000>)$ significativo como variable. 
Tabla valor de chi cuadrado 45: tartamudeos y estadio de la enfermedad.

\begin{tabular}{|c|c|c|c|}
\hline \multicolumn{4}{|c|}{ Pruebas de chi-cuadrado } \\
\hline & Valor & $\mathrm{gl}$ & $\begin{array}{l}\text { Sig. asintótica } \\
\text { (bilateral) }\end{array}$ \\
\hline Chi-cuadrado de Pearson & $15,634^{\mathrm{a}}$ & 2 &, 000 \\
\hline
\end{tabular}

\subsubsection{Tartamudeos y sexo}

Los resultados que encontramos en este fenómeno, son los siguientes: en las mujeres del corpus alcanzó una presencia de 42,3\%, con 11 ocurrencias y un $57.7 \%$ en hombres con 15 ocurrencias:

Tabla de contingencia 46: tartamudeos y sexo

\begin{tabular}{||l|l|l|l||}
\hline Sexo del sujeto & \multicolumn{2}{|l|}{ Tartamudeos } & \multirow{2}{*}{ Total } \\
\cline { 2 - 4 } & Presencia & Ausencia & \\
\hline \multirow{3}{*}{ Mujer } & 11 & 18 & 29 \\
\cline { 2 - 4 } & $42,3 \%$ & $50,0 \%$ & $46,8 \%$ \\
\hline \multirow{2}{*}{ Hombre } & 15 & 18 & 33 \\
\cline { 2 - 4 } & $57,7 \%$ & $50,0 \%$ & $53,2 \%$ \\
\hline \multirow{2}{*}{ Total } & 26 & 36 & 62 \\
\cline { 2 - 4 } & $100,0 \%$ & $100,0 \%$ & $100,0 \%$ \\
\hline
\end{tabular}


Gráfico 14. Porcentaje de frecuencia de las variables: tartamudeos y sexo

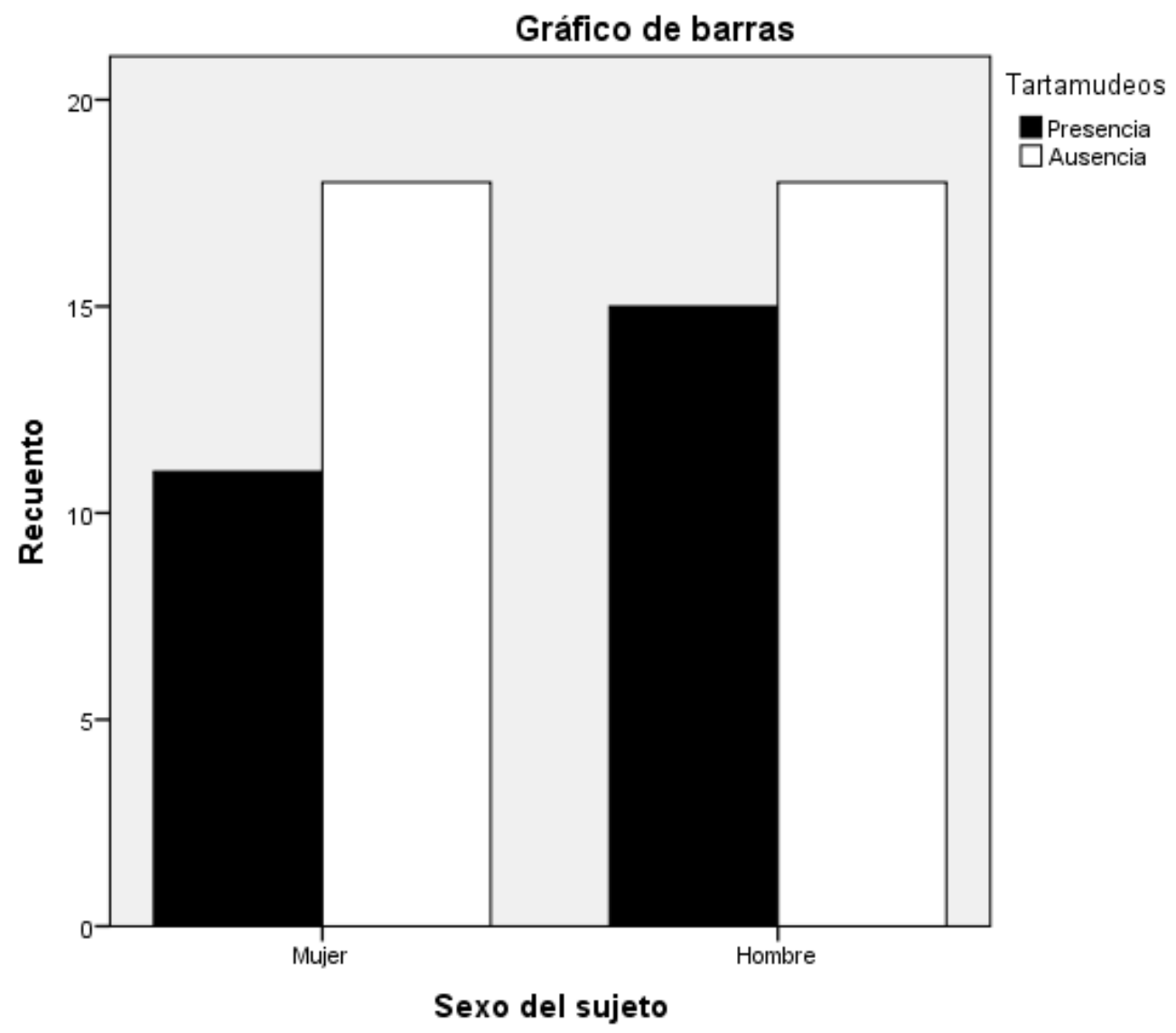

El valor de chi cuadrado es de, $359^{\mathrm{a}}$ y dio como resultado $(<\mathrm{p}, 549>)$, que no es significativo estadísticamente. 
Tabla valor de chi cuadrado 47: tartamudeos y sexo.

\begin{tabular}{|c|c|c|c|c|c|}
\hline \multicolumn{6}{|c|}{ Pruebas de chi-cuadrado } \\
\hline & Valor & $\mathrm{gl}$ & $\begin{array}{l}\text { Sig. asintótica } \\
\text { (bilateral) }\end{array}$ & $\begin{array}{c}\text { Sig. exacta } \\
\text { (bilateral) }\end{array}$ & $\begin{array}{l}\text { Sig. exacta } \\
\text { (unilateral) }\end{array}$ \\
\hline $\begin{array}{l}\text { Chi-cuadrado de } \\
\text { Pearson }\end{array}$ &, $359^{\mathrm{a}}$ & 1 &, 549 & & \\
\hline
\end{tabular}

\subsubsection{Tartamudeos y tramo de la enfermedad}

Se encontraron 3 presencias en los controles, (11,5\%), 2 casos en el tramo 1 de primer episodio, (7,7\%), 3 presencias en el tramo 2 de primer episodio $(11,5), 6$ presencias en el tramo 3 de crónicos, $(23,1 \%)$ y 12 presencias en el tramo 4 correspondiente a crónicos $(46,2 \%)$ :

Tabla de contingencia 48: tartamudeos y tramo de la enfermedad.

\begin{tabular}{||l|l|l|l||}
\hline \hline \multirow{2}{*}{ Tramo de la enfermedad } & \multicolumn{2}{|l||}{ Tartamudeos } & \multirow{2}{*}{ Total } \\
\cline { 2 - 4 } & Presencia & Ausencia & \\
\hline \multirow{2}{*}{ Control } & 3 & 9 & \multirow{2}{*}{12} \\
\cline { 2 - 4 } & $11,5 \%$ & $25,0 \%$ & $19,4 \%$ \\
\hline \multirow{2}{*}{ Primer episodio 0 a 2 años } & 2 & 12 & 14 \\
\cline { 2 - 4 } & $7,7 \%$ & $33,3 \%$ & $22,6 \%$ \\
\hline \multirow{2}{*}{ Primer episodio 2 a 3 años } & 3 & 8 & 11 \\
\cline { 2 - 4 } & $11,5 \%$ & $22,2 \%$ & $17,7 \%$ \\
\hline \multirow{2}{*}{ Crónico hasta 5 años } & 6 & 4 & 10 \\
\cline { 2 - 4 } & $23,1 \%$ & $11,1 \%$ & $16,1 \%$ \\
\hline \multirow{2}{*}{ Crónico 5 y más años } & 12 & 3 & 15 \\
\cline { 2 - 4 } & $46,2 \%$ & $8,3 \%$ & $24,2 \%$ \\
\hline \multirow{2}{*}{ Total } & 26 & 36 & $100,0 \%$ \\
\cline { 2 - 4 } & $100,0 \%$ & $100,0 \%$ & \\
\hline \hline
\end{tabular}


Gráfico 15. Porcentaje de frecuencia de las variables: tartamudeos y tramo de la enfermedad

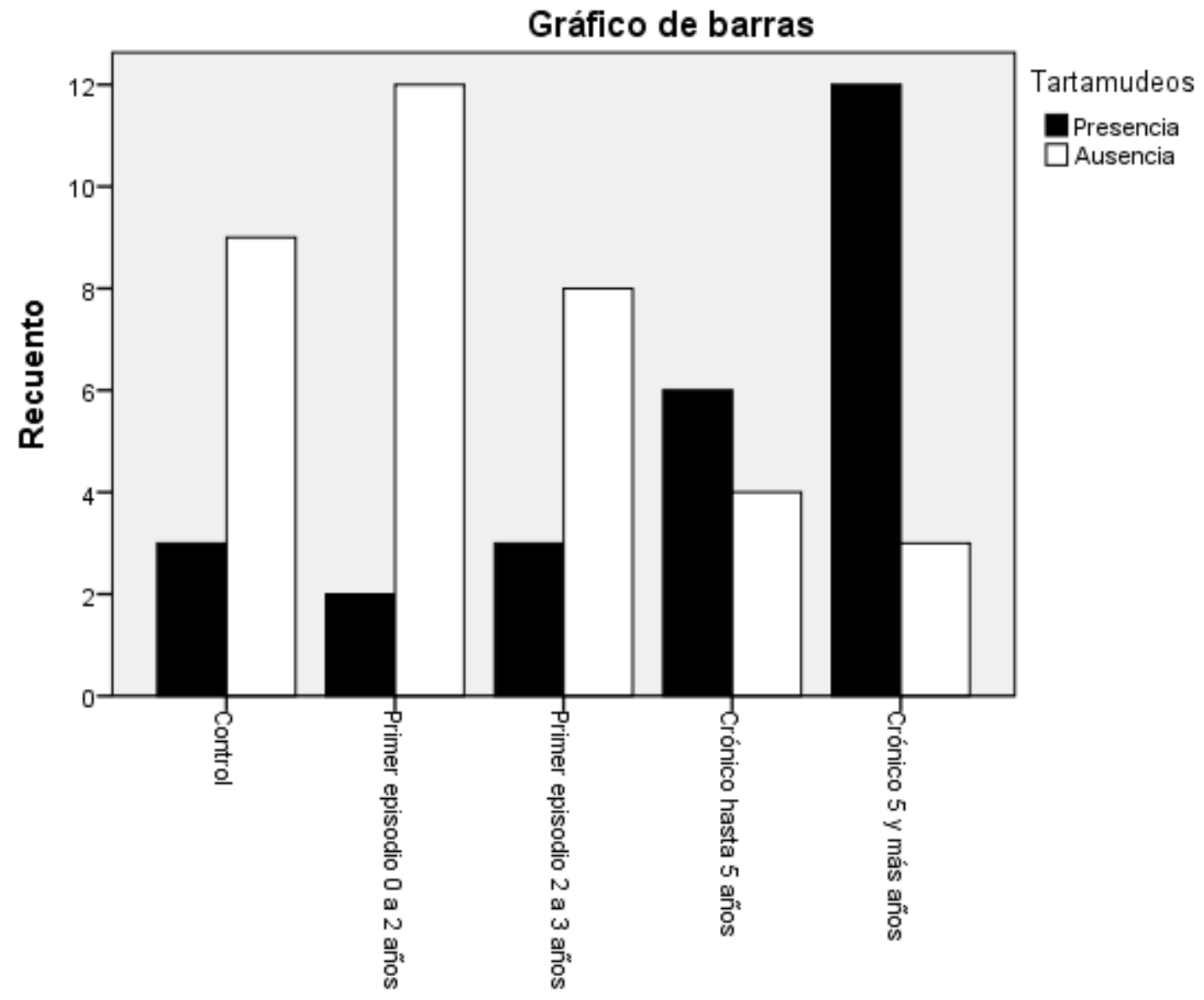

Tramo de la enfermedad

El valor de chi cuadrado es $17,046^{\mathrm{a}}$, que dio como resultado, $(<\mathrm{p}, 002>)$ que presenta una significación estadística relevante. 
Tabla valor de chi cuadrado 49: tartamudeos y tramo de la enfermedad.

\begin{tabular}{||l|c|c|c||}
\hline \multicolumn{4}{|c||}{ Pruebas de chi-cuadrado } \\
\hline & Valor & gl & $\begin{array}{c}\text { Sig. asintótica } \\
\text { (bilateral) }\end{array}$ \\
\hline Chi-cuadrado de Pearson & $17,046^{\mathrm{a}}$ & & 4 \\
\hline
\end{tabular}

\subsubsection{Tartamudeos y subtipo de la enfermedad}

Se encontraron 3 presencias entre los controles, (11,5\%), 13 ocurrencias entre los paranoides, (50\%), 4 ocurrencias entre los indiferenciados $(15,4 \%)$ y por último 6 ocurrencias entre el grupo que presenta esquizofrenia desorganizada, $(23,1 \%)$ :

Tabla de contingencia 50: tartamudeos y subtipo de la enfermedad.

\begin{tabular}{||l|l|l|l||}
\hline \hline \multirow{2}{*}{ Subtipo de la esquizofrenia } & \multicolumn{2}{|l||}{ Total } \\
\cline { 2 - 4 } & Presencia & Ausencia & \\
\hline \multirow{2}{*}{ Control } & 3 & 9 & 12 \\
\cline { 2 - 4 } & $11,5 \%$ & $25,0 \%$ & $19,4 \%$ \\
\hline \multirow{2}{*}{ Paranoide } & 13 & 20 & 33 \\
\cline { 2 - 4 } & $50,0 \%$ & $55,6 \%$ & $53,2 \%$ \\
\hline \multirow{2}{*}{ Indiferenciado } & 4 & 5 & 9 \\
\cline { 2 - 5 } & $15,4 \%$ & $13,9 \%$ & $14,5 \%$ \\
\hline \multirow{2}{*}{ Total } & 6 & 2 & 8 \\
\cline { 2 - 5 } & $23,1 \%$ & $5,6 \%$ & $12,9 \%$ \\
\hline
\end{tabular}


Gráfico 16. Porcentaje de frecuencia de las variables: tartamudeos y subtipo de la enfermedad

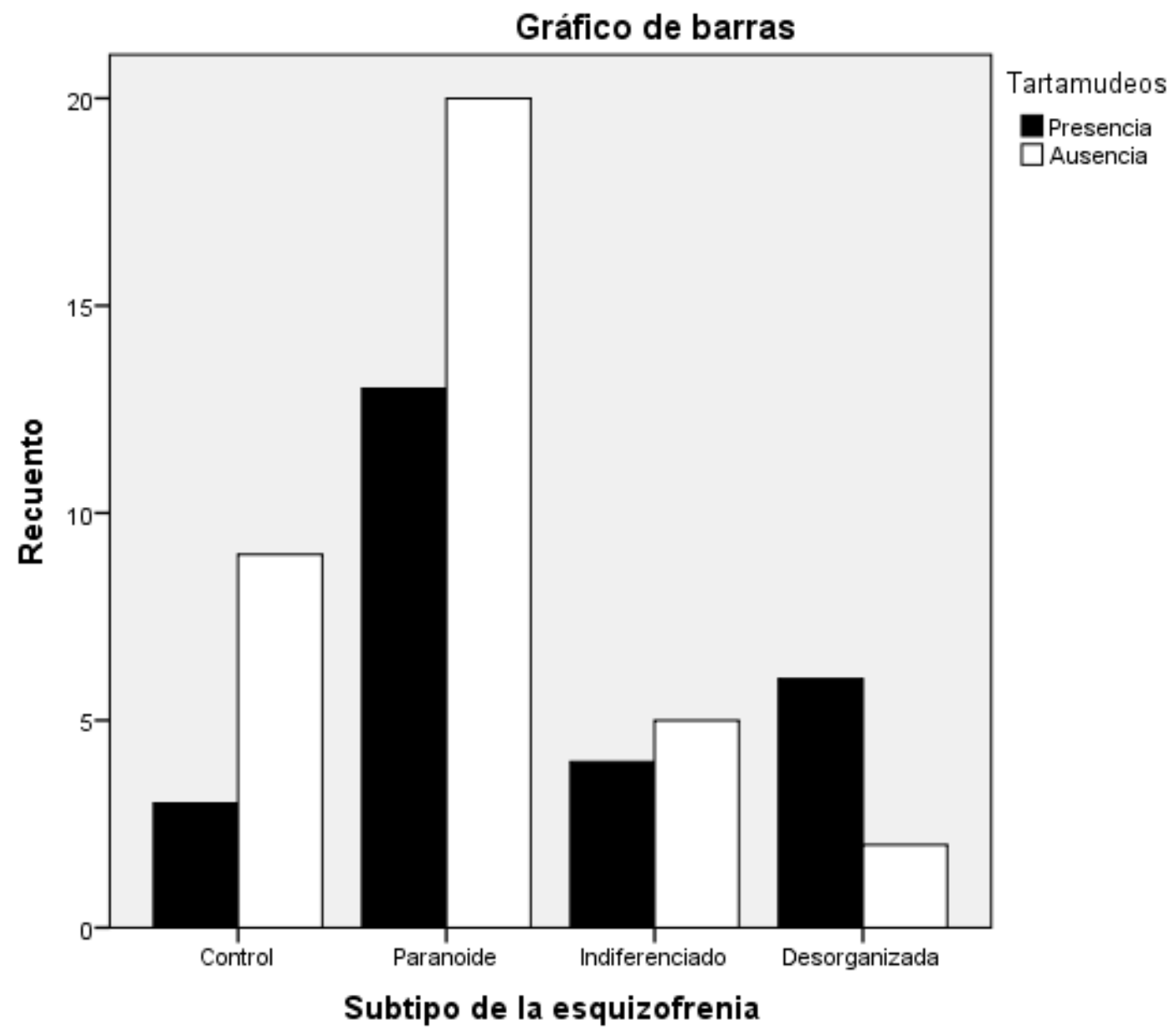

El valor de chi cuadrado es de 5,116 a dio como resultado (<p, 163>), no significativo estadísticamente.

Tabla valor de chi cuadrado 51: tartamudeos y subtipo de la enfermedad.

\begin{tabular}{||c|c|c|c||}
\hline \multicolumn{4}{|c||}{ Pruebas de chi-cuadrado } \\
\hline & Valor & $\mathrm{gl}$ & $\begin{array}{c}\text { Sig. asintótica } \\
\text { (bilateral) }\end{array}$ \\
\hline
\end{tabular}




\begin{tabular}{||l|l|l|l||}
\hline \hline Chi-cuadrado de Pearson & $5,116^{\mathrm{a}}$ & 3 &, 163 \\
\hline
\end{tabular}

\subsubsection{Turnos de habla con volumen débil}

Se contaron 23 casos totales, correspondientes al 37\% del corpus total. Resultó ser un indicador muy informativo; las variables en las que da significativo es el estadio y el tramo, además, el sexo

\subsubsection{Ejemplos en grupo de crónicos:}

1)

E: don $\mathrm{J} /$ ¿cómo está usted?

S: bien <apenas audible>

E: cuénteme/ ¿por qué estamos acá?

S: por tristeza <apenas audible> tristeza <aumento de volumen><entrevistador se acerca más al sujeto>

E: ya/ ¿Cómo es eso?/explíqueme

S: eeh <pausa or $>$ me siento triste $<$ alargamiento $>/$ sin ganas $<$ pausa $>$ de nada $<$ pausa ext $>$ triste $\langle$ pausa ext $\rangle\langle$ musita para sí, inaudible $>/$ pero $\langle$ pausa $>/$ quiero recuperarme/salir adelante.

E: ¿cuándo empezó esto? <paciente suspira superp>

S: ha $<$ pausa or $>/$ hace días $<$ pausa $>/$ hace poco<pausa $>/$ tenía esa idea fantástica que no puedo recuperar

E: ¿cómo?

S: al <ininteligible por volumen débil>

E: ¿cómo?

S: <ininteligible por volumen débil>

(CRE-H10)

Ejemplos de turnos de habla con volumen débil en primer episodio:

1)

E: como por ejemplo/ que sueñes cosas bonitas o desagradables

$\mathrm{S}:$ no/ sueño cosas bonitas <vol débil>

E: ¿cómo/? habla un poquito más fuerte

S: soñar cosas bonitas <volumen normal>/

(PEE-M08) 
4.1.5.2. Turnos de habla con volumen débil y estadio de la enfermedad

No se encontraron ocurrencias de este fenómeno en los controles. En el primer episodio, se encontraron 11 casos, $(47,8 \%)$ y en los crónicos 12 casos, con $52,2 \%$ :

Tabla de contingencia 52: turnos de habla volumen débil y estadio de la enfermedad.

\begin{tabular}{||l|l|l|l||}
\hline \multirow{2}{*}{ Estadio de la enfermedad } & \multicolumn{2}{|l||}{ Turnos de habla volumen débil } & \multirow{2}{*}{ Total } \\
\cline { 2 - 4 } & Presencia & Ausencia & \\
\hline \multirow{2}{*}{ Control } & 0 & 12 & 12 \\
\cline { 2 - 4 } & $0,0 \%$ & $30,8 \%$ & $19,4 \%$ \\
\hline \multirow{2}{*}{ Primer episodio } & 11 & 14 & 25 \\
\cline { 2 - 4 } & $47,8 \%$ & $35,9 \%$ & $40,3 \%$ \\
\hline \multirow{2}{*}{ Crónico } & 12 & 13 & 25 \\
\cline { 2 - 5 } & $52,2 \%$ & $33,3 \%$ & $40,3 \%$ \\
\hline \multirow{2}{*}{ Total } & 23 & 39 & 62 \\
\cline { 2 - 5 } & $100,0 \%$ & $100,0 \%$ & $100,0 \%$ \\
\hline
\end{tabular}


Gráfico 17. Porcentaje de frecuencia de las variables: turnos de habla con volumen débil y estadio de la enfermedad

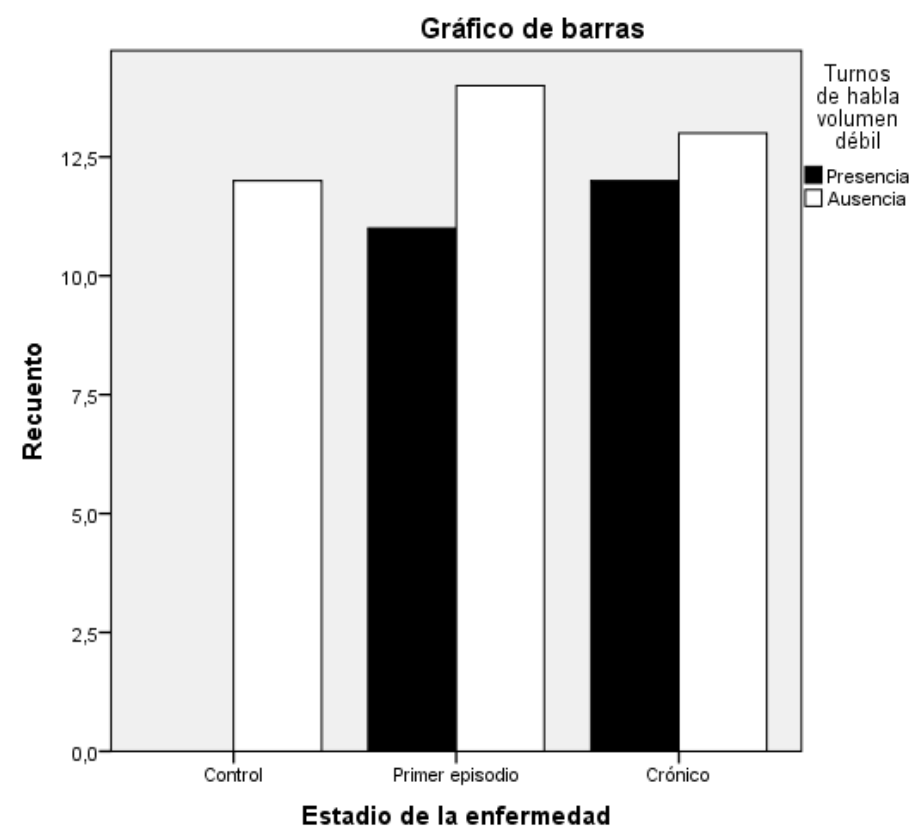

El valor de chi cuadrado es de $17,046^{\mathrm{a}}$ y dio como resultado ( $\left.<\mathrm{p}, 002\right)$, muy significativo como variable. Como podemos observar en el ejemplo.

Tabla valor de chi cuadrado 53: turnos de habla con volumen débil y estadio de la enfermedad

\begin{tabular}{||l|c|r|c||}
\hline \multicolumn{4}{|c||}{ Pruebas de chi-cuadrado } \\
\hline & Valor & $\mathrm{gl}$ & $\begin{array}{c}\text { Sig. asintótica } \\
\text { (bilateral) }\end{array}$ \\
\hline Chi-cuadrado de Pearson & $17,046^{\mathrm{a}}$ & 4 &, 002 \\
\hline
\end{tabular}

\subsubsection{Turnos de habla con volumen débil y sexo}

Se encontraron 9 ocurrencias en las mujeres, $(39,1 \%)$ y 14 ocurrencias entre los hombres $(60,9 \%)$ 
Tabla de contingencia 54: turnos de habla volumen débil y sexo.

\begin{tabular}{||l|l|l|l||}
\hline \hline \multirow{2}{*}{ Sexo del sujeto } & \multicolumn{2}{|l||}{ Turnos de habla volumen débil } & \multirow{2}{*}{ Total } \\
\cline { 2 - 3 } & Presencia & Ausencia & \\
\hline \multirow{2}{*}{ Mujer } & 9 & 20 & 29 \\
\cline { 2 - 4 } & $39,1 \%$ & $51,3 \%$ & $46,8 \%$ \\
\hline \multirow{2}{*}{ Hombre } & 14 & 19 & 33 \\
\cline { 2 - 4 } & $60,9 \%$ & $48,7 \%$ & $53,2 \%$ \\
\hline \multirow{2}{*}{ Total } & 23 & 39 & 62 \\
\cline { 2 - 4 } & $100,0 \%$ & $100,0 \%$ & $100,0 \%$ \\
\hline
\end{tabular}

Gráfico 18. Porcentaje de frecuencia de las variables: turnos de habla con volumen débil y sexo del sujeto

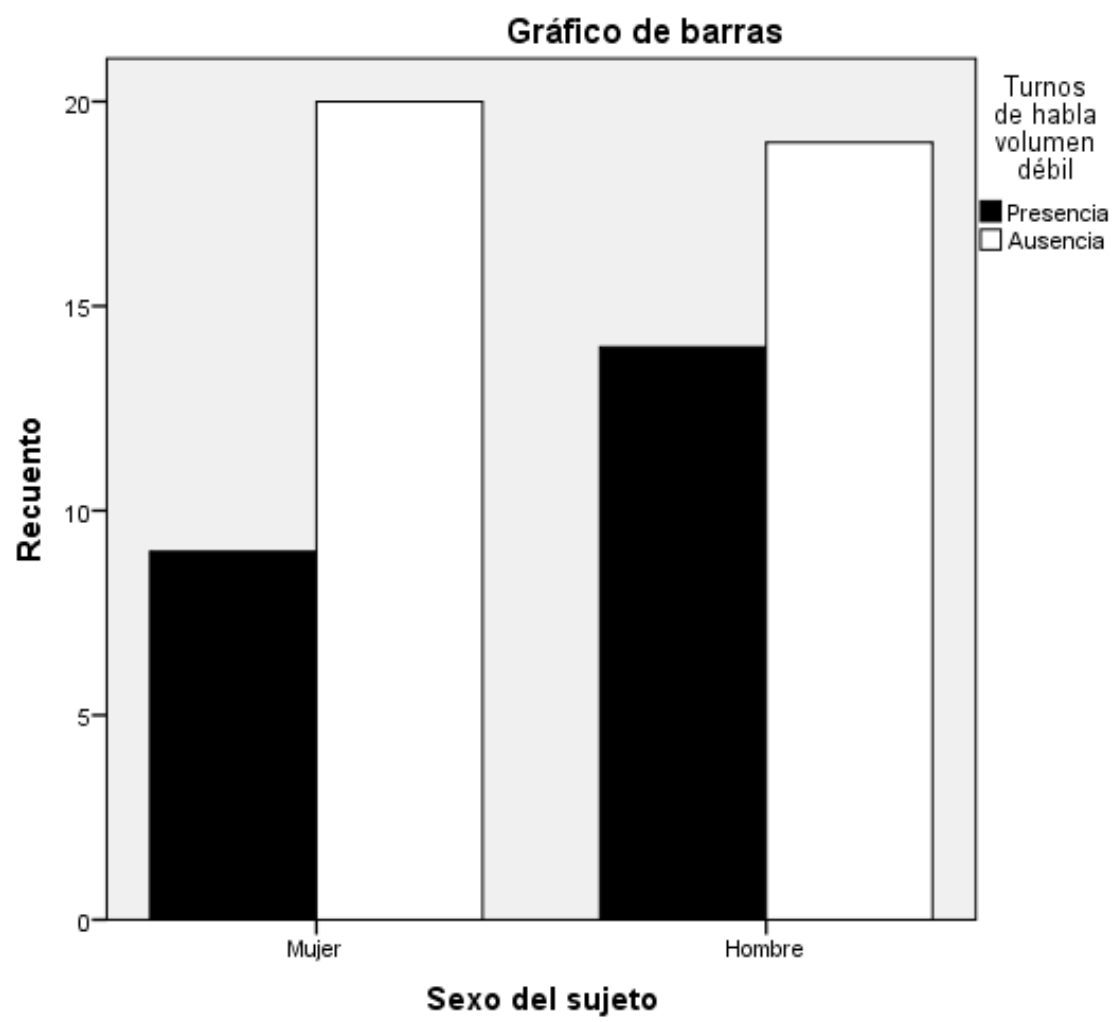

El valor de chi cuadrado es de , 858, y dio como resultado ( $<\mathrm{p}, 354>)$ no significativo estadísticamente: 
Tabla valor de chi cuadrado 55: turnos de habla con volumen débil y sexo.

\begin{tabular}{||l|c|r|c|c|c||}
\hline \multicolumn{7}{|c||}{ Pruebas de chi-cuadrado } \\
\hline & Valor & Gl & $\begin{array}{c}\text { Sig. asintótica } \\
\text { (bilateral) }\end{array}$ & $\begin{array}{c}\text { Sig. exacta } \\
\text { (bilateral) }\end{array}$ & $\begin{array}{c}\text { Sig. exacta } \\
\text { (unilateral) }\end{array}$ \\
\hline $\begin{array}{l}\text { Chi-cuadrado } \\
\text { de Pearson }\end{array}$ &, $858^{\mathrm{a}}$ & 1 &, 354 & & \\
\hline \hline
\end{tabular}

4.1.5.4. Turnos de habla con volumen débil y tramo de la enfermedad

No encontramos ocurrencias en los controles, en el tramo 1 de primer episodio, encontramos 6 presencias, $(26,1 \%), 5$ presencias en el tramo 2 de primer episodio, $(21,7 \%), 4$ en el tramo 3 de crónicos, $(17,4 \%)$ y 8 presencias en los crónicos tramo $4(34,8 \%)$ :

Tabla de contingencia 56: turnos de habla volumen débil y tramo de la enfermedad.

\begin{tabular}{||l|l|l|l||}
\hline \hline \multirow{2}{*}{ Tramo de la enfermedad } & \multicolumn{2}{|l||}{ Turnos de habla volumen débil } & \multirow{2}{*}{ Total } \\
\cline { 2 - 4 } & Presencia & Ausencia & \multicolumn{1}{||}{} \\
\hline \multirow{3}{*}{ Control } & 0 & 12 & 12 \\
\cline { 2 - 4 } & $0,0 \%$ & $30,8 \%$ & $19,4 \%$ \\
\hline Primer episodio 0 a 2 años & 6 & 8 & 14 \\
\cline { 2 - 4 } & $26,1 \%$ & $20,5 \%$ & $22,6 \%$ \\
\hline \multirow{2}{*}{ Primer episodio 2 a 3 años } & 5 & 6 & 11 \\
\cline { 2 - 4 } & $21,7 \%$ & $15,4 \%$ & $17,7 \%$ \\
\hline \multirow{2}{*}{ Crónico hasta 5 años } & 4 & 6 & 10 \\
\cline { 2 - 4 } & $17,4 \%$ & $15,4 \%$ & $16,1 \%$ \\
\hline Crónico 5 y más años & 8 & 7 & 15 \\
\cline { 2 - 4 } & $34,8 \%$ & $17,9 \%$ & $24,2 \%$ \\
\hline Total & 23 & 39 & 62 \\
\cline { 2 - 4 } & $100,0 \%$ & $100,0 \%$ & $100,0 \%$ \\
\hline \hline
\end{tabular}


Gráfico 19. Porcentaje de frecuencia de las variables: turnos de habla con volumen débil y tramo de la enfermedad

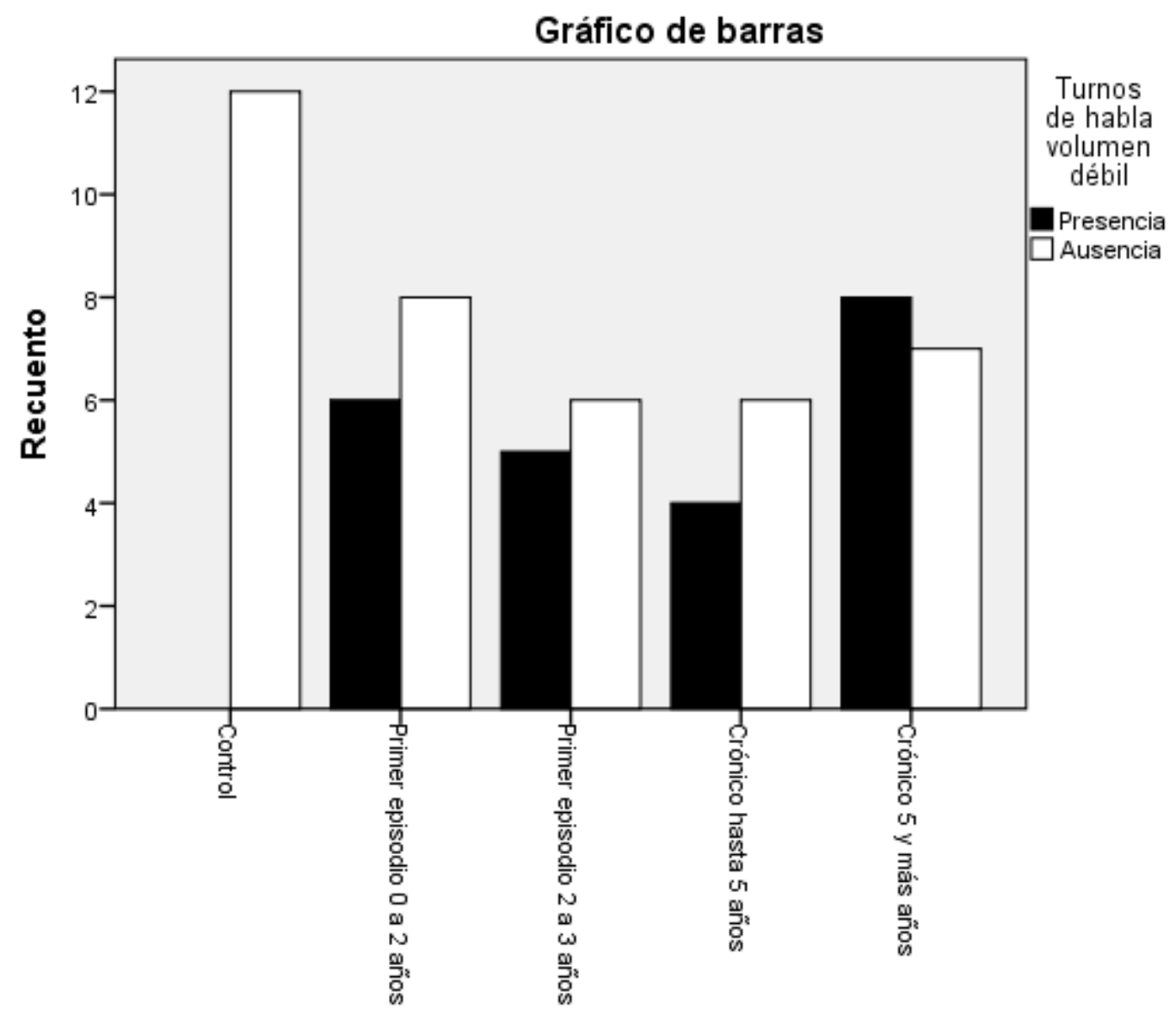

Tramo de la enfermedad

El valor de chi cuadrado es e $9,336^{\mathrm{a}}$ y el resultado es de $(\langle\mathrm{p} 0,53>)$, resultando no significativo:

Tabla valor de chi cuadrado 57: turnos de habla con volumen débil y tramo de la enfermedad.

\begin{tabular}{||c|c|c|c||}
\hline \multicolumn{5}{|c||}{ Pruebas de chi-cuadrado } \\
\hline & Valor & $\mathrm{gl}$ & $\begin{array}{c}\text { Sig. asintótica } \\
\text { (bilateral) }\end{array}$ \\
\hline
\end{tabular}




\begin{tabular}{||l|l|l|r|}
\hline \hline Chi-cuadrado de Pearson & $9,336^{\mathrm{a}}$ & 4 &, 053 \\
\hline
\end{tabular}

4.1.5.5. Turnos de habla con volumen débil y subtipo de la enfermedad: los controles no reportan ocurrencia. En los paranoides, encontramos 16 ocurrencias, (69,9\%), 3 presencias en el grupo de indiferenciados (13\%) y 4 ocurrencias en los desorganizados, $(17,4 \%)$ :

Tabla de contingencia 58: turnos de habla volumen débil y subtipo de la enfermedad.

\begin{tabular}{||l|l|l|l||}
\hline \multicolumn{4}{||}{ Tabla de contingencia Subtipo de la esquizofrenia * Turnos de habla volumen débil } \\
\hline \multirow{4}{*}{} & \multicolumn{2}{|l||}{$\begin{array}{l}\text { Turnos de habla volumen } \\
\text { débil }\end{array}$} & \multirow{2}{*||}{ Total } \\
\cline { 2 - 4 } & Presencia & Ausencia & \\
\hline \multirow{2}{*}{ Control } & 0 & 12 & 12 \\
\cline { 2 - 5 } & $0,0 \%$ & $30,8 \%$ & $19,4 \%$ \\
\hline \multirow{2}{*}{ Paranoide } & 16 & 17 & 33 \\
\hline \multirow{2}{*}{ Indiferenciado } & $69,6 \%$ & $43,6 \%$ & $53,2 \%$ \\
\hline \multirow{2}{*}{ Desorganizada } & 3 & 6 & 9 \\
\cline { 2 - 5 } & $13,0 \%$ & $15,4 \%$ & $14,5 \%$ \\
\hline Total & 4 & 4 & 8 \\
\cline { 2 - 5 } & $17,4 \%$ & $10,3 \%$ & $12,9 \%$ \\
\hline
\end{tabular}


Gráfico 20. Porcentaje de frecuencia de las variables: turnos de habla con volumen débil y subtipo de la enfermedad

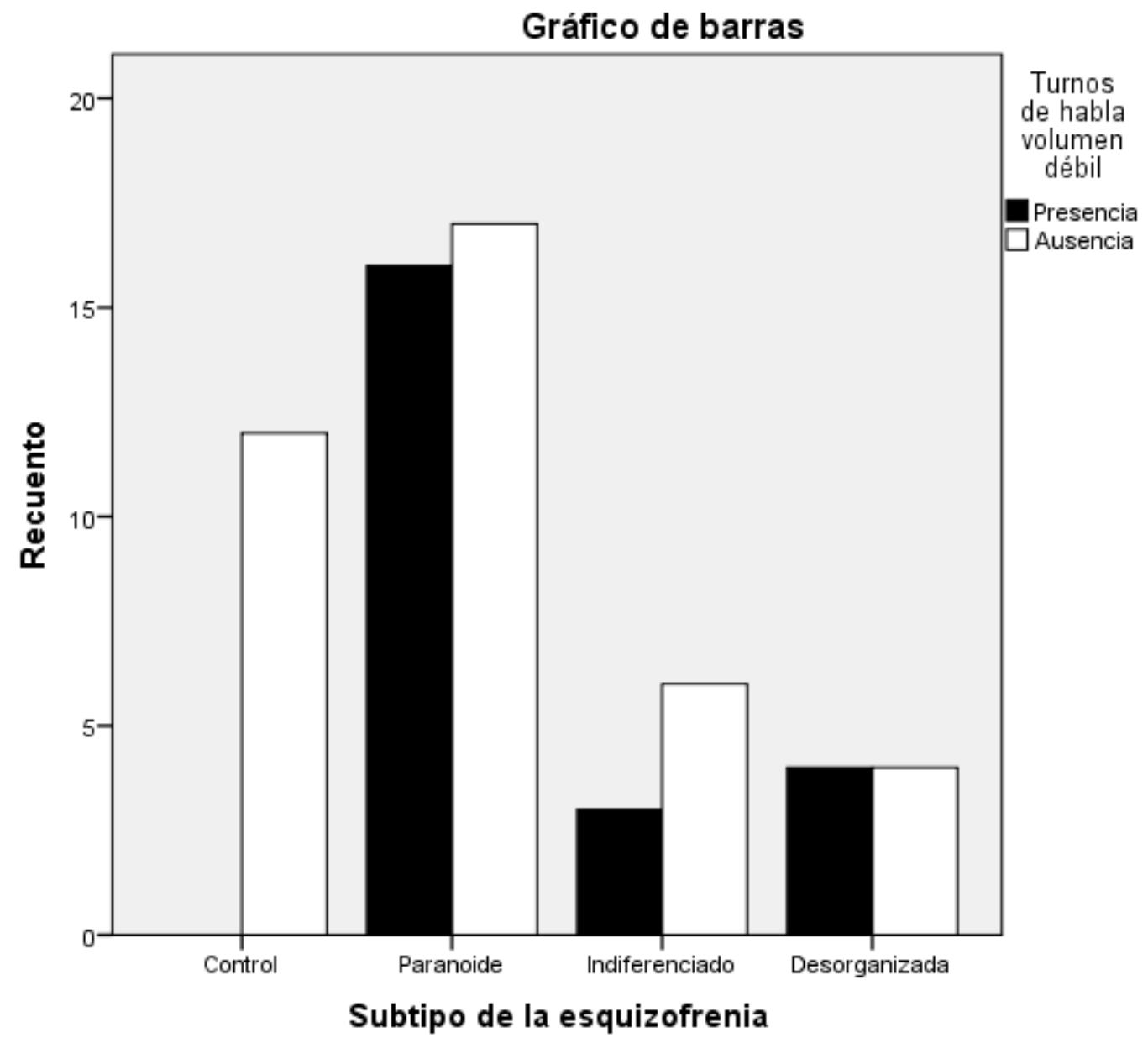

El valor de chi cuadrado es de $9,536^{\mathrm{a}}$ y dio como resultado $(<\mathrm{p}, 023>)$, no significativo

Tabla valor de chi cuadrado 59: turnos de habla con volumen débil y subtipo de la enfermedad.

\begin{tabular}{||l|c|c|c||}
\hline \multicolumn{4}{|c||}{ Pruebas de chi-cuadrado } \\
\hline & Valor & gl & $\begin{array}{c}\text { Sig. asintótica } \\
\text { (bilateral) }\end{array}$ \\
\hline Chi-cuadrado de Pearson & $9,536^{\mathrm{a}}$ & 3 &, 023 \\
\hline
\end{tabular}




\subsubsection{Conclusiones cluster fluidez}

La fluidez opera como un catalizador de una multiplicidad de procesos intrapsíquicos e interaccionales. Según la literatura, las técnicas de evaluación de la fluidez son consideradas eficientes para dar cuenta de aspectos claves de distintas áreas neuropsicológicas. Dichas técnicas, por el hecho de ser simples, presentar una gran sensibilidad y estar clínicamente probadas, están difundidas ampliamente a nivel mundial. Sin embargo, el punto de partida desde el que se delimita el concepto de fluidez es restringido y, a nuestro juicio, no representa una descripción del desempeño comunicativo a cabalidad, que es indispensable para dar cuenta de estos aspectos que se pretenden evaluar.

La fluidez desde la neuropsicología se define básicamente como la producción de palabras en un tiempo delimitado por el evaluador de la tarea, quien le plantea a la persona ciertos requisitos como la restricción fonológica para la búsqueda verbal. Se les solicita la evocación de palabras durante uno o dos minutos (usualmente el tiempo requerido) para luego repetir la tarea cambiando la consigna de búsqueda verbal. Estas tareas pretenden abarcar aspectos ya sean semánticos o fonológicos. (MEC, tarea de evocación léxica con o sin restricción fonológica) Los datos son registrados por el examinador, quien los contabiliza, restando las repeticiones, categorías supraordinales, etc.

Los paradigmas principales por medio de los cuales se evalúa la fluidez, son el semántico y el fonológico, los estudios iniciados por Newcombe (1969) y sistematizados por Benton (1980) elaborador del COWAT (Controlled Oral Word Association Test), han contribuido de forma vital a vincular la aplicación de pruebas como las descritas, al uso de la región prefrontal y temporal del cerebro, y a demostrar entre otras cosas que, se incrementa el metabolismo de la región frontal y temporal. Asimismo, los procesos de memoria semántica y episódica también se encuentran involucrados, ya que los mecanismos de acceso al léxico se almacenan en nodos o redes neuronales, conformando sistemas de memorias explícitas. 
No obstante, en este trabajo, nos interesa estudiar la fluidez en el marco de la situación comunicativa, y con este objetivo en mente, hemos operacionalizado algunos indicadores de fluidez que ya fueron descritos en este capítulo. Únicamente a través de un análisis que considere no solo la cantidad de información, sino también la calidad de la información emitida (Menjura, 2007). Resulta evidente que no basta con producir muchas palabras por minuto sino también producir un discurso que progrese temáticamente, un discurso que muestre un desarrollo y que avance hacia una meta discursiva. Citando aquí la perspectiva que nos interesa como lingüistas, la fluidez se ha definido como: La habilidad de llenar el tiempo con habla, b) la habilidad de hablar de forma coherente, razonada y en frases semánticamente densas, c) la habilidad de decir cosas apropiadas en una amplia gama de contextos, d) la habilidad de algunas personas de ser creativas e imaginativas en el uso del lenguaje. (Traducción Pradas Macías, 2004, p. 106). Y más específicamente en la psicolingüística: sobresale el planteamiento de Goldman-Eisler, (1964) quien plantea que el objetivo de la fluidez discursiva es:

Analizar la posibilidad de aislar del fluir del habla espontánea algunos elementos que sean indicativos de los distintos niveles de la producción de habla y que sean medibles\| (Goldman-Eisler, 1964, p. 118, apud Pradas Macías, 2004, p. 110).

Consistente con esto, destacamos la observación de Belinchón (1988)

La fluidez es la realización fonoarticulatoria de los discursos, que facilita, en el interlocutor, la automatización de los procesos implicados en las fases iniciales de la percepción y comprensión del habla (Belinchón, 1988:137)

Tras el análisis de los indicadores de fluidez, podemos concluir que fenómenos discursivos como: titubeos, falsos inicios y tartamudeos se encuentran presentes en todos los entrevistados, no obstante, la frecuencia y características que presentan en los tres grupos analizados, genera claras diferencias en la calidad de la eficacia comunicativa de los tres grupos.

En el grupo de los controles, los titubeos, falsos inicios y tartamudeos, en primer lugar, se presentan en una baja frecuencia, y, a pesar de que se interrumpe el 
flujo de información, no se ve afectada la comprensión de lo expresado por el entrevistado. En segundo lugar, se presentan generalmente en el inicio del turno, como una estrategia de precisión o reformulación de la idea que se está planteando, son predecibles ya que coinciden con aspectos sintácticos.

En el caso de los crónicos, las ocurrencias de estos fenómenos son más abundantes y variables, ya que se presentan no solo en el inicio del turno, sino a lo largo de este. Con frecuencia, afectan a la comprensión de lo dicho, evidencia que se aprecia en la constante vuelta atrás de los entrevistadores, pidiendo precisiones o realizando una y otra vez preguntas para esclarecer el asunto que ha planteado el entrevistado. Como pudimos apreciar en los ejemplos, las interrupciones no solo afectan al flujo de la interacción, al ser frecuentes e imposibles de escamotear por el entrevistador, sino que, incluso cuando aparentan ser una estrategia de reparación o reformulación, es importante señalar que difieren de las pausas predecibles, lo que apunta a una posible falla en la planificación discursiva.

Encontramos una situación similar en el grupo de primer episodio. Frente a preguntas directas, como: ¿desde cuándo te ocurre esto...? respondidas a menudo con información inespecífica, ambigua o críptica, que apuntarían a diversas dificultades en la planificación de los mensajes, al igual que en el grupo de crónicos.

Ahora bien, los turnos de habla con volumen débil y las pausas extendidas no fueron registrados en los controles. De los fenómenos estudiados en este cluster, estos últimos generan mayor interferencia en la comprensión de las emisiones de los grupos de pacientes. Podemos considerarlos como indicadores de déficit en la fluidez. 


\subsection{Productividad verbal}

En este cluster se reunieron los fenómenos que apuntan al volumen de la producción verbal de los pacientes. La productividad verbal, está entendida como la capacidad para emitir y comprender enunciados nuevos, ajustándose a la situación comunicativa que los genera (Aitchison, 1988). En este grupo de fenómenos se privilegiaron las medidas que daban cuenta de esta capacidad para responder a las necesidades informativas del entrevistador. Una propiedad estructural en la productividad, es que la conducta verbal está sometida a reglas en la elaboración de la información. Se revisan las producciones discursivas de los sujetos estudiados tomando en cuenta aquellos elementos que inciden en la calidad de las emisiones.

4.2.1. Ejemplificación global de fenómenos del cluster: con el propósito de ilustrar de qué forma se realizó el análisis en este grupo de fenómenos, incluiremos un segmento extenso de una entrevista de un sujeto del grupo crónico y otra correspondiente al grupo de los controles. En este análisis se incluirán marcas para ejemplificar el resto de los fenómenos que integran este núcleo. Es a saber:

1. Total de oraciones

2. Promedio de palabras por oración

3. Número total de palabras diferentes (no repetidas)

4. Número total de neologismos parciales

5. Número total de neologismos totales

6. Total de referentes

7. Total de vínculos referenciales

8. Promedio de vínculos referenciales

Posteriomente, presentaremos los resultados estadísticos que corresponden a estos fenómenos y a su combinación con las variables independientes: 
1) Fragmento de entrevista del grupo crónico: hombre, 43 años, esquizofrenia paranoide, hospitalizado en el Instituto de Psiquiatría del Hospital Sanatorio El Peral

S: ¡hola doctor!/ ¿cómo le va?/ buscando <alargamiento>/un diario vivir<pausa> mejor/ en el hospital $<$ pausa $>/$ bien/ bien/ $i$ ah? $<$ pausa $>/<$ risas del paciente $>/$

E: bien/ bien

S: bien/ ¿ah?/ ¿cierto?/ sí// bueno yo me llamo o/ espero que nos llevemos bien hoy día/ para que tengamos un día feliz<pausa ext $>/$ eh $<$ pausa ext $>$ yo quiero decirles mi<pausa ext $>/$ parte de mi vida $<$ pausa $>/$ es que puedo darme cuenta de toda la realidad concreta/ que nos hace mejores $<$ pausa $>/$ cuando nace un hijo <pausa $>/$ de una pareja<pausa $>/$ innato/ conciencia innato/ o sea conciencia<pausa $>$ / y lo otro/ género humano <pausa $>/$ de la parte congenia/ congenia<pausa $>/$ congénito/ ¿cierto? <pausa $>/$ viene más allá de innato/ congénito $<$ pausa $>/$ eh $<$ pausa or ext $>/$ viene del verbo mental como proceso/ la verdad<pausa $>/ /$ va por hecho/ lo congénito $<$ pausa $>/$ somos capaces de discernir el bien del mal/ para después tener conciencia de saber una<pausa $>/$ una esencia del bien<pausa>/ lo <pausa>/ para manejar <pausa>/ el comportarse con influencias definitivas del mundo<pausa $>/$ lograr como somos capaces de que uno y los demás<pausa $>$ y tener para sí<pausa $>/$ un don $\langle$ pausa $>/$ vivo y capaz $<$ pausa $>/$ capaz de creer en el amor $\langle$ pausa $>/$ y más sobre todas las cosas <pausa>/ el perdón <pausa>/ la amistad<pausa> ¿ya? <pausa $>/ /$ me quedó completa la introducción<pausa $>$ / me costó un poquito<pausa>/ pero tenía que hablar así po <pausa>/ para logr/ lograr diferentes punto de vista/ hay palabras que son ne/nemotécnicos <pausa $>$ y en computación

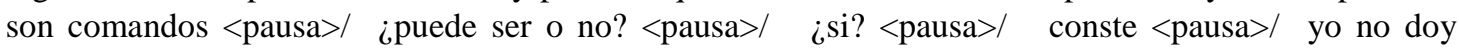
entonces yo inint. Así cree en su método/ dr $\langle$ pausa $>$ ¿cierto?/ en el próximo vamos a esperar mucho <pausa>/ y esto de estar para mí <pausa>/ un <pausa>/ un asilo/ un <pausa>/ con capacidad al momento <pausa $>$ así son las cosas que hablo yo <pausa $>/$ entonces mira $<$ pausa $>/ /$ errar tiene la a ¿cierto? <pausa>/ errar tiene la a ¿cierto? <pausa>/ error la o ¿sí? <pausa>/ ya <pausa>/ ahí entonces $\langle$ pausa $>/$ el proceso de sinapsis $\langle$ pausa $>/$ las neuronas cómo piensan $<$ pausa $>/$ y como van dando ajuste <pausa $>/$ a los procesos mentales $\langle$ pausa $>/$ como procede el cerebro $\langle$ pausa $>/$ como fun/ fun $\langle$ pausa $>/$ a través de un funcionamiento $\langle$ pausa $>/$ entra en un proceso mental que tiene <pausa $>/$ entre nosotros interactivos <pausa $>/$ ya $<$ pausa $>/$ entonces <pausa ext $>/$ también está la parte/ esto yo lo inventé ¿ah? <pausa>/ pero/ está bien/ está bien/ accesar información <pausa>/ es accesar información al revés parece ¿a ver?/ claro <pausa>/ es al revés <pausa>/ accesar información es star <pausa >/ porque uno actúa <pausa ext>/ porq hab <ininteligible> después viene el seguimiento <pausa>//el poder <pausa>/ lógico de tu lado <ríe compulsivamente> ¿está bien o no?/ ¿usted lo vio?

E: don o/ buenos días

S: ¿ah?/ ¿qué pasó?

E: soy el doctor $r$.

S: ah <pausa>/ un gusto haberlo visto/ <le extiende la mano y lo saluda> con mayor caballerosidad $<$ pausa $>/$

[03:42] 
(CRE-H04)

Tabla resumen 60: de productividad verbal fragmento de entrevista en CRE-H04

\begin{tabular}{||l|l||}
\hline TOTAL ORACIONES & 45 \\
\hline Promedio palabras por oración & 7,7 \\
\hline Palabras diferentes & $154 / 346$ \\
\hline Neologismos parciales & 0 \\
\hline Neologismos totales & 0 \\
\hline Referentes & 38 \\
\hline Total de vínculos & 249 \\
\hline Promedio de vínculos & 6,6 \\
\hline
\end{tabular}

Se efectuó este análisis tomando en cuenta la participación de cada entrevistado, se contaron todos los fenómenos de productividad verbal a mano y posteriormente se sometió cada fragmento de las entrevistas al programa PARAMTEXT TIP, $\underline{\text { http://tip.dis.ulpgc.es/paramtext/ }}^{35}$ con el propósito de evitar posibles fugas de información. Hubo coincidencia en muchos de los indicadores y en los casos contrarios, se analizó nuevamente a mano:

\section{CRE-H12}

1. ¡hola doctor!/ ¿cómo le va?/ anáfora $<12>$

2. ( elipsis de estoy) buscando <alargamiento>/un diario vivir<pausa> mejor/ en el hospital $<8>$ catáfora

3. Bueno yo me llamo $\mathrm{O}<5>$ catáfora

4. espero que nos llevemos bien hoy día/ para que tengamos (elipsis de nosotros) un día feliz $\langle$ pausa ext $>/\langle 13\rangle$ catáfora

5. yo quiero decirles mi<pausa ext $>/$ parte de mi vida $<$ pausa $>/<8>$ anáfora

6. (parte de mi vida) es que puedo darme cuenta de toda la realidad concreta/ que nos hace mejores $<$ pausa ext $>/<14>$ anáfora

7. cuando nace un hijo $\langle$ pausa $>/$ de una pareja $\langle$ pausa $>/<7\rangle$ anáfora

8. y lo otro/ (el) género humano <pausa $>$ de la parte congenia/ congenia $<$ pausa $>/$ congénito/ ¿cierto? <pausa>/ viene más allá de innato (elipsis de género humano)/ congénito<pausa $>$ / $<18>$ anáfora

${ }^{35}$ Vínculo activo en marzo 2015 


\begin{tabular}{|c|}
\hline (elipsis de el género humano) viene del verbo mental como proceso/ $\langle 6\rangle c$ \\
\hline 10. la verdad $\langle$ pausa $>/ /$ va por hecho/ lo congénito $\langle$ pausa $\rangle /\langle 7\rangle$ catáfora \\
\hline 11. (elipsis de nosotros) somos capaces de discernir el bien del mal/ $\langle 8\rangle$ catáfora \\
\hline $\begin{array}{l}\text { 12. para después tener conciencia (elipsis de nosotros) de saber una }<\text { pausa }>/ \text { una esencia del } \\
\text { bien }<\text { pausa }>/<11>\text { anáfora }\end{array}$ \\
\hline $\begin{array}{l}\text { 13. lo <pausa }>/ \text { para manejar (elipsis de nosotros) }<\text { pausa }>/ \text { el comportarse con influencias } \\
\text { definitivas del mundo }<\text { pausa }>/<10>\text { anáfora }\end{array}$ \\
\hline $\begin{array}{l}\text { 14. lograr como (elipsis de nosotros) somos capaces de que uno y los demás }<\text { pausa }>/<10> \\
\text { anáfora }\end{array}$ \\
\hline $\begin{array}{l}\text { 15. y tener para sí (elipsis de nosotros) }<\text { pausa }>/ \text { un don }\langle\text { pausa }>/ \text { vivo y capaz }\langle\text { pausa }>/<9> \\
\text { anáfora }\end{array}$ \\
\hline $\begin{array}{l}\text { 16. (elipsis de ser) capaz de creer en el amor }<\text { pausa }>/ \text { y más sobre todas las cosas (elipsis de } \\
\text { ser capaz de creer) <pausa }>/ \text { el perdón }\langle\text { pausa }>/ \text { la amistad }\langle\text { pausa }\rangle\langle 16\rangle \text { catáfora }\end{array}$ \\
\hline 17. me quedó completa la introducción $\langle$ pausa $>/<5>$ catáfora \\
\hline 18. me costó un poquito (elipsis de la introducción) $\langle$ pausa $>/\langle 4\rangle$ anáfora \\
\hline 19. pero (elipsis de yo) tenía que hablar así po $\langle$ pausa $>/<6>$ anáfora \\
\hline 20. para logr/ lograr diferentes punto de vista(elipsis de yo) / <5> anáfora \\
\hline $\begin{array}{l}\text { 21. hay palabras que son ne/nemotécnicos }<\text { pausa }>/ \text { y en computación son comandos } \\
\text { <pausa }\rangle|<10\rangle \text { catáfora }\end{array}$ \\
\hline 22. ¿puede ser o no? (elipsis de hay palabras que son $[. .$.$] ) \langle$ pausa $>/\langle 4>* * *$ \\
\hline $\begin{array}{l}\text { 23. conste <pausa }>/ \text { yo no doy entonces yo inint. así cree en su método/ doctor }<\text { pausa }>/ \\
<12>\text { catáfora }\end{array}$ \\
\hline 24. en el próximo (elipsis de referente $\mathrm{x}$ ) vamos a esperar mucho $\langle$ pausa $\rangle /\langle 7\rangle$ catáfora \\
\hline $\begin{array}{l}\text { 25. y esto de estar para mí <pausa>/ (elipsis de en un asilo) un <pausa>/ un asilo/ un } \\
\text { <pausa>/ con capacidad (elipsis de para ¿realizar algo mejor?) al momento <pausa }>/<14> \\
\text { catáfora }\end{array}$ \\
\hline 26. así son las cosas que hablo yo <pausa $>$ / $<7>$ catáfora \\
\hline 27. entonces mira $\langle$ pausa $>/ /$ errar tiene la a ¿cierto? $\langle$ pausa $\rangle /\langle 7\rangle$ catáfora \\
\hline 28. errar tiene la a ¿cierto? $\langle$ pausa $>/<5>$ anáfora \\
\hline 29. error (elipsis de tiene) la o ¿sí? <pausa $>/<4>$ catáfora \\
\hline $\begin{array}{l}\text { 30. ahí entonces <pausa }>\text { ( (elipsis de en) el proceso de sinapsis <pausa>/ las neuronas (elipsis } \\
\text { de sabemos) cómo piensan <pausa }><10>\text { catáfora }\end{array}$ \\
\hline $\begin{array}{l}\text { 31. y como (elipsis de las neuronas) van dando ajuste <pausa }>\text { a los procesos mentales } \\
\text { <pausa }>/\langle 9\rangle\end{array}$ \\
\hline $\begin{array}{l}\text { 32. como procede el cerebro <pausa }>/ \text { como fun/ fun <pausa }>/ \text { a través de un funcionamiento } \\
<11><\text { pausa }>\text { catáfora }\end{array}$ \\
\hline $\begin{array}{l}\text { 33. (elipsis de el cerebro) entra en un proceso mental que tiene }\langle\text { pausa }\rangle / \text { entre nosotros } \\
\text { interactivos }\langle\text { pausa }\rangle /\langle 10\rangle \text { anáfora }\end{array}$ \\
\hline $\begin{array}{l}\text { 34. ya <pausa }>/ \text { entonces <pausa ext>/ también está la parte (elipsis de el cerebro)/ <6> } 63 \\
\text { anáfora }\end{array}$ \\
\hline 35. / esto yo lo inventé ¿ah? <pausa $>$ / $\langle 5\rangle$ anáfora \\
\hline $\begin{array}{l}\text { 36. pero/ está bien/ está bien/ accesar información (elipsis de en el cerebro)/ }\langle\text { pausa }><7\rangle \\
\text { anáfora }\end{array}$ \\
\hline 37. es accesar información al revés (elipsis de en el cerebro)/ parece ¿a ver?/<8> anáfora \\
\hline 38. claro $\langle$ pausa $>/$ es al revés $\langle$ pausa $>/<4>$ anáfora \\
\hline 39. accesar información (elipsis de en el cerebro)/ es star $\langle$ pausa $\rangle /\langle 4\rangle$ anáfora \\
\hline 40. porque uno actúa $\langle 3\rangle$ \\
\hline $\begin{array}{l}\text { 41. porq hab <ininteligible> después viene el seguimiento <pausa>/el poder }<\text { pausa }>\text { lógico } \\
\text { de tu lado }\langle 12>\end{array}$ \\
\hline 42. ¿está bien o no?/<4> \\
\hline
\end{tabular}


43. ¿usted lo vio?<3>

44. ¿qué pasó?<2>

45. un gusto haberlo visto (elipsis de $a$ usted) anáfora/ <le extiende la mano y lo saluda> con mayor caballerosidad $\langle$ pausa $\rangle \mid\langle 7\rangle$

2) Fragmento de entrevista del grupo de primer episodio: Hombre, 15 años, esquizofrenia paranoide, atendido en el Hospital de día del Instituto de Rehabilitación en Salud Mental, RENOVAL

1. E: hola/ hola/ ¿cómo estás?/ ¿por qué vienes j p?

2. S: vengo porque $<$ pausa $>/$ estoy tratando que $<$ pausa $>/$ para que $<$ pausa $>/$ viera que no estaría mal, pero igual, mi mamá dice que nunca fue así y yo<pausa ext $>/$ ehmmm<pausa or-ext $>/$ me gustaría saber si<pausa ext $>/$ eh $<$ pausa ext $>/$ no sé<pausa ext $>/$ si creerle o no porque gerardo $<$ pausa $>/$ también<pausa $>/$ mi primo me dijo algo como raro<pausa $>/$ como que en un momento si<pausa $>/$ y después como que no<pausa ext $>/$

3. E: a ver jp<pausa $>/$ no te entiendo mucho<pausa $>/$ quiero que me expliques<pausa $>/$ ¿qué es lo que a tí te pasa?

4. S: <pausa $>/$ que igual <alargamiento $>/$ me siento mal<pausa $>/$ además mi mamá lo niega y yo no sé<pausa $>/$ estoy<pausa $>/$ creo creer que fue así<pausa $>/$ que no hay $<$ pausa $>/$ no $<$ pausa $>/$ no estoy seguro<pausa $>/$ pero yo creo que tal vez fue así<pausa $>/$

5. E: ¿fue así qué? <pausa>/ ¿qué es lo que pasó?/

6. S: eso le digo que no está<pausa $>/$ que mi primo dice que no<pausa $>/$ pero mi ame<pausa ext $>/$ pero parece que si<pausa $>/$ mi mamá está pagando pa' que estuviera en santiago $<$ pausa $>$ / en la casa de mi primo que <pausa $>/ \mathrm{no} / \mathrm{no} /$ estaría mal/ porque yo me estaría quedando<pausa $>/$ pero yo $<$ pausa $>$ yo $<$ pausa $>/$ no estoy seguro// ella dice que no/ pero yo he escuchado y parece que si<pausa ext $>/$ mi primo decía como que<pausa $>/$ decía algo asíl

7. E: no/ te entiendo/ ¿decía que sí a qué? <pausa>/ ¿qué es lo que pasa? <pausa>/ es que hablas mucho y no te logro entender<pausa>/ ¿qué es lo que te pasa?

8. S: que parece que pagaron $<$ pausa $>/$ mire $<$ pausa $>/$ yo no estoy seguro/ pero/ mi mamá dice que no pagaron por mí<pausa $>/$ para que yo estuviera en santiago $\mathrm{y}<$ pausa $>/ \mathrm{v}<$ pausa $>/ \mathrm{y}<$ pausa $>/$ pppp $<$ pausa $>/$ dicen que sí<pausa $>/$ que yo he escuchado que parece que si<pausa $>/$

9. E: a ver $<$ pausa $>/$ tú escuchaste que tus padres habrían pagado a tus primos $<$ pausa $>/$ ¿para que te tengan en la casa?

10. S: si

11. E:¿eso es? 


\section{S:si}

13. E: ¿eso es lo que me quieres decir<superpuesto>

14. S:si

15. E: ¿o no?

16. $\mathrm{S}: \mathrm{si}$

17. E:ya/ ¿y por qué/ tendrían que pagar para que te tengan en la casa?

18. S: no sé porque<superpuesto>

19. E: entre var<superpuesto $>/\langle$ pausa $>/$

20. S: porque yo genero gastos/

21. E: ¿y tú?/ <pausa>/ ¿para que te tengan?/ ¿para que vengas de vacaciones<alargamiento>?/ ¿dónde viniste <alargamiento $>/$ de $<$ alargamiento $>/$ ?

22. S:venía a entrenar en tenis/

23. E: ya <alargamiento>/

24. S:yo juego tenis/ juego de chico/ para mejorar no más/ si yo/ igual después volvía al colegio<pausa $>/$ porque quiero esttt<vacilación or $>/$ una carrera universitaria/ pero vine a una academia por diversión en verano/

25. E: ya<pausa $>$ entonces/ en la casa de tus primos/ tus padres habrían pagado los gastos que tú generas $/ /<$ pausa $>/$ la comida $<$ pausa $>/$ ¿está bien?/ ¿pues o no?

26. $\mathrm{S}: \mathrm{si}$

27. E: ¿y/ cuál es el problema?/

28. S:si, ese es uno/ ese el el primero/ y después yo como que<pausa $>/$ había otro que $<$ alargamiento $>/$ problema que yo<pausa or >/que no sé qué<pausa or $>/$ escuché que<pausa or $>/$ mi nana/ escuché como que <pausa or>/yo una vez fue/ fue/ fue una vez iba a una fiesta<pausa or $>/$ y como que<pausa or $>/$ que<pausa or $>$ que mi mamá había como pagado para que yo fuera $<$ pausa $>$ /eso no $<$ pausa $>/$ lo de mi primo no está mal porque $<$ pausa ext $>/$ eso $<$ pausa $>/$ pero lo de la fiesta<pausa $>/$ no sé que yo<pausa or $>$ que yo<alargamiento $>/$ he escuchado/ yo he escuché eso en mi<pausa >/en la bernardita algo así/ porque ella/ ella quería como un dinero extra/ porque yo he escuchado que a mi mamá parece que le gusta como ayudar a la gente/ económicamente/ parece algo así<pausa ext>/entonces/ eso no me gustaría porque yo no voy a ir a/ a una cosa así<pausa >/ a una fiesta así<pausa >/pero yo no sé / si eso es verdad/ puedo haber escuchado mal/ porque a ellos qué les importa eso/ pero yo no sé<pausa >/ese es el problema/ pero todo empezó como lo de gerardo/ la cosa rara/ con mi primo/ 
29. E: ¿qué/ es lo raro?

30. S: eso/ como que no es así/ como que no<pausa >/de que mi madre dijera así/ como que no ha hecho nada y ha hecho cosas/ no sél

(pee-h12)

Tabla resumen 61: de productividad verbal fragmento de entrevista en PEE-H12

\begin{tabular}{||l|l||}
\hline TOTAL ORACIONES & 45 \\
\hline Promedio palabras por oración & 9,9 \\
\hline Palabras diferentes & $123 / 448$ \\
\hline Neologismos parciales & 0 \\
\hline Neologismos totales & 0 \\
\hline Referentes & 45 \\
\hline Total de vínculos & 402 \\
\hline Promedio de vínculos & 8,9 \\
\hline
\end{tabular}

Al igual que en el caso anterior, se efectuó este análisis tomando en cuenta la participación del entrevistado, contando todos los fenómenos de productividad verbal a mano y posteriormente se sometió al mismo análisis con el PARAMTEXT TIP, como ya señalamos evitar discordancias significativas de información.

\begin{tabular}{|c|}
\hline PEE-H12 \\
\hline $\begin{array}{l}\text { 1. S: vengo porque<pausa }>/ \text { estoy tratando que<pausa }>/ \text { para que<pausa }>/ \text { viera que no estaría } \\
\text { mal/ (elipsis de para que yo vea que) catáfora }\end{array}$ \\
\hline $\begin{array}{l}\text { 2. pero igual<pausa }>/ \text { mi mamá dice que nunca fue así y yo<pausa ext }>/ \text { ehmmm<pausa or }> \\
\text { catáfora }\end{array}$ \\
\hline $\begin{array}{l}\text { 3. me gustaría saber si<pausa ext }>/ \text { eh<pausa ext }>/ \text { no sé<pausa ext }>/ \text { si creerle o no (elipsis } a m i \\
\text { mamá) anáfora }\end{array}$ \\
\hline $\begin{array}{l}\text { 4. porque Gerardo<pausa }>/ \text { también<pausa }>/ \text { mi primo me dijo algo como raro<pausa }>/ \text { como } \\
\text { que en un momento } \mathrm{si}<\text { pausa }>/ \text { y después como que no<pausa }>/ \text { catáfora }\end{array}$ \\
\hline$\langle$ pausa $>/$ que igual <alargamiento $>/$ me siento mal <pausa $>/$ catáfora \\
\hline 5. además mi mamá lo niega/ y yo no sé<pausa>/ anáfora \\
\hline 6. (elipsis de yo) estoy<pausa $>/$ creo creer que fue así<pausa $>/$ que no hay<pausa $>/$ anáfora \\
\hline 7. (elipsis de yo) no<pausa $>/$ no estoy seguro<pausa $>/$ anáfora \\
\hline 8. pero yo creo que tal vez fue así/ anáfora \\
\hline
\end{tabular}




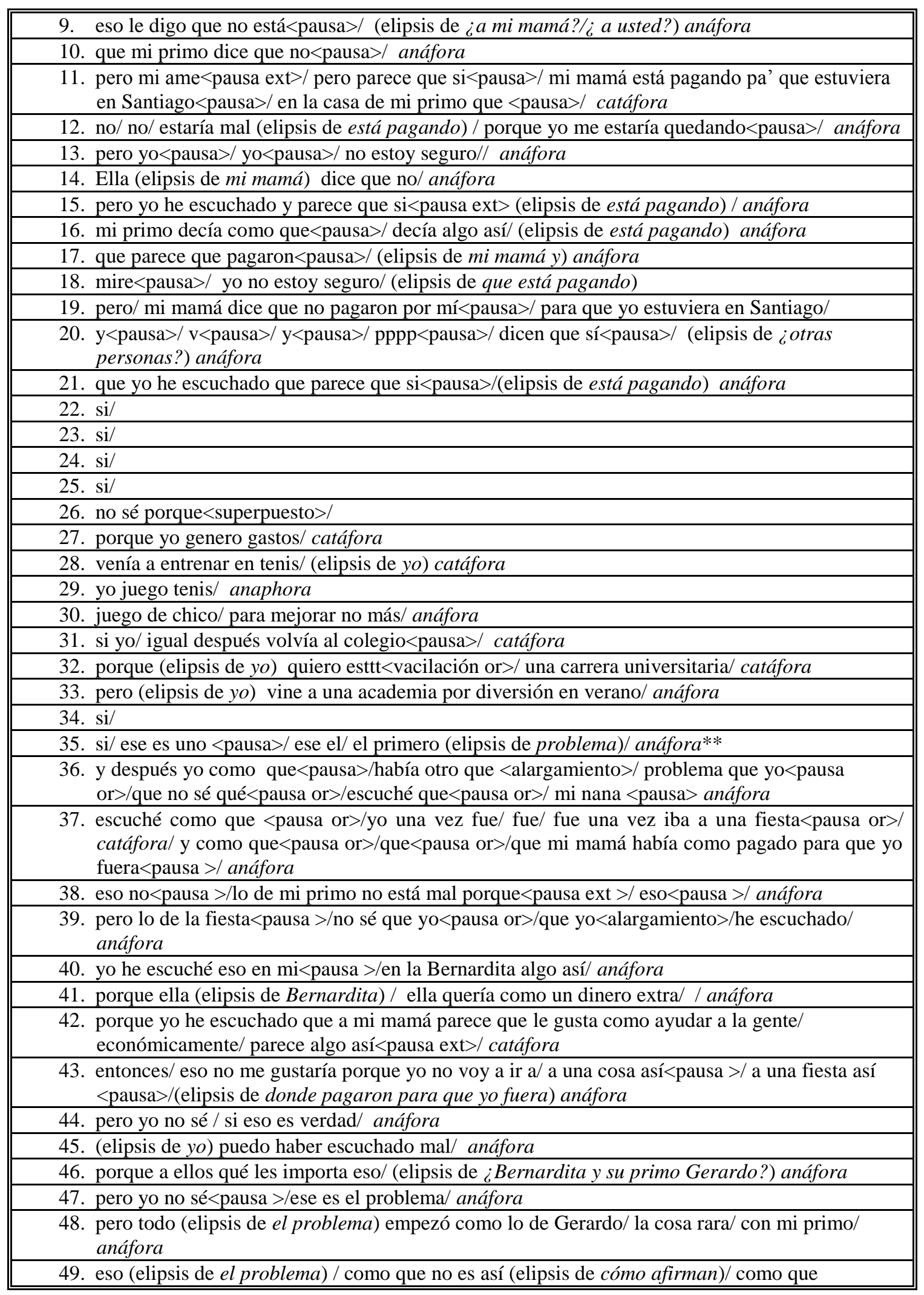


3) Fragmento de entrevista del grupo control: hombre, 20 años, estudiante de Licenciatura en Lengua y Literatura Inglesas, Universidad de Chile, pertenece al grupo socioeconómico medio medio.

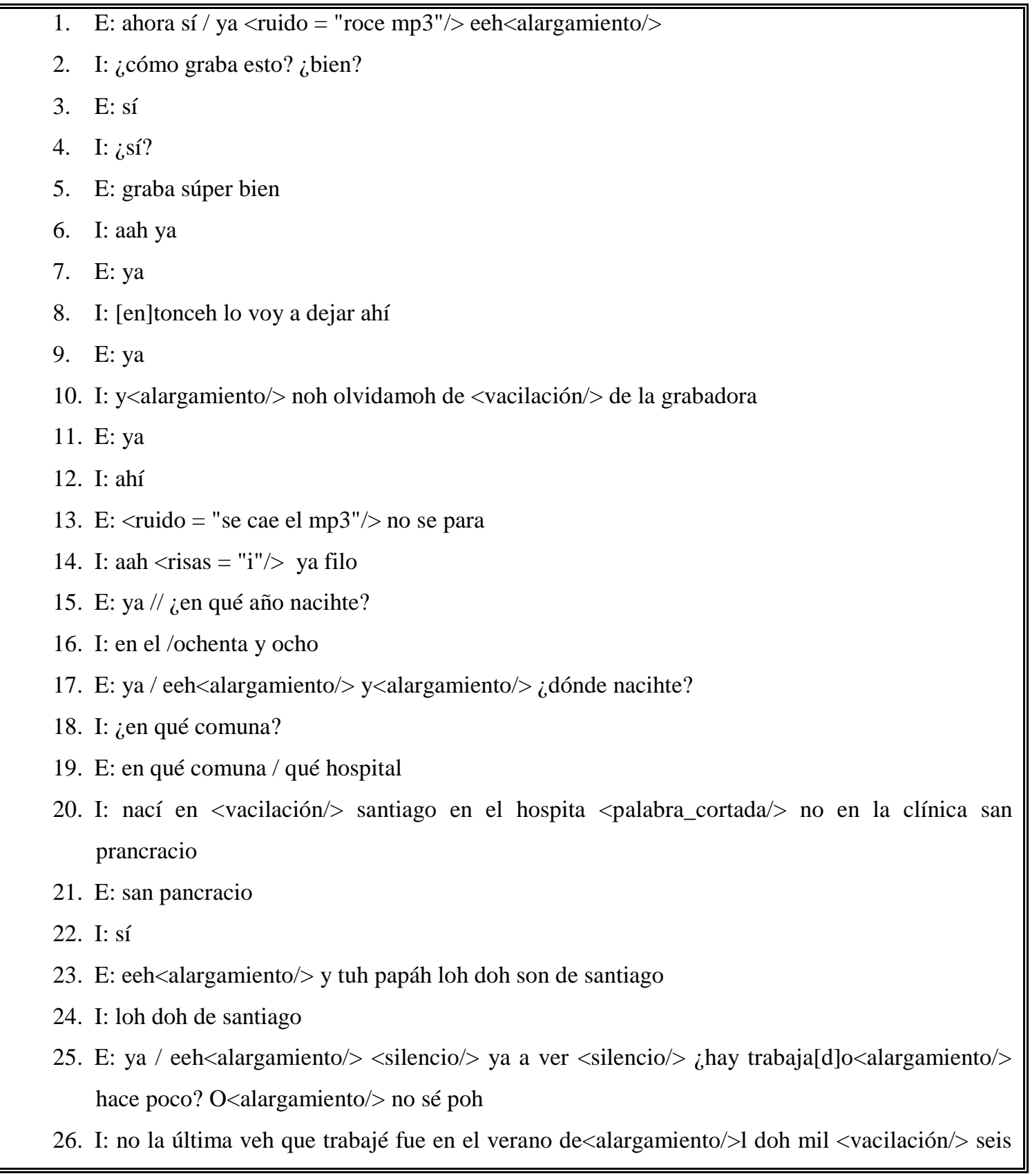


<vacilación/> doh mil siete / ese <simultáneo> verano </simultáneo>

27. E: <simultáneo> ya </simultáneo> ya / y<alargamiento/> ¿en qué trabajahte?

28. I: eeh<alargamiento/> trabajé en una tienda de $s<$ palabra_cortada/> vendiendo zapatillah // en el mall plaza tobalaba

29. E: ya / eem<alargamiento/> ¿recordai alguna anécdota graciosa / jocosa / o<alargamiento/> no sé poh de la enseñanza básica media o de cuando entramoh a la u? <observación_complementaria = "u en la jerga juvenil se refiere a la universidad"/>

30. I: de acá en la u / ¿una anécdota?/ yo soy terrible malo pa[ra] acordarme de esah we[v]a[da]h $<$ risas $=$ "e"/>

31. E: no importa

32. I: eeh<alargamiento/>

33. E: cualquier cosa // no te pregunto si noh mechonearon porque no noh mechonearon

34. I: no poh

35. E: por eso / <simultáneo> no sé poh </simultáneo>

36. I: 〈simultáneo> ¿aquí en la u? </simultáneo> me acuerdo que en <vacilación/> a [v]er ya podría ser como ya chihtoso así como que no no no <vacilación/> no correhponde a la u // con rosita rodrígueh <observación_complementaria = "profesora de lengua y cultura inglesa de la universidad de chile"/><simultáneo> cuando </simultáneo > teníamos clase con ella

37. E: <simultáneo > ya<alargamiento/></simultáneo >

38. I: teníamos clase con ella de práctica<alargamiento/> hacíamoh purah we[v]a[da]h / y un día la profe / ya era típico que < vacilación/> todah lah claseh llegaba / se sentaba / y decía <cita> voy no sé dónde y vuelvo al tiro </cita> y se demora[b]a veinte minutoh y perdíamoh cualquier clase // entonceh un día la profe dijo <cita> ya voy a no sé dónde y vuelvo al tiro </cita> la wea eh que pehcamoh to[d]ah lah weah ¿cachai? <observación_complementaria = "cachai en la jerga jvenil chilena significa entiendes"/> lah $\mathrm{m}<$ palabra_cortada/> lah <vacilación/> pehcamoh lah cosah de [e]lla / lah mochilah / to[d]ah lah weah y noh cambiamoh de sala y noh ehcondimoh <risas = "e"/> / y rosita rodrígueh dehpueh llegó y miraba y noh buhcaba así como que andaba por to[d]oh la[d]oh tratando de cachar dónde noh habíamoh meti[d]o <risas $=$ "e"/> y<alargamiento/><vacilación/ $>$ hahta que en una me asomé ¿cachai? Y me vió y dijo <cita> ¡ah! Tú / yo sabía que erai tú </cita> <risas = "e"/> así <cita> sabí que era tu culpa $</ c i t a>$ y to[d]a la we[v]a[da] / y de ahí no <vacilación/> no se volvió a atrasar máh po / igual por lo menoh sivió la <vacilación/> la we[v]a[da]

39. E: ya

40. I: eso poh / no era muy entreteni[d]o pero

41. E: pero igual eh divertí[d]o nosotroh nunca hicimoh na[da] <risas = "i"/> / ya $/$ 


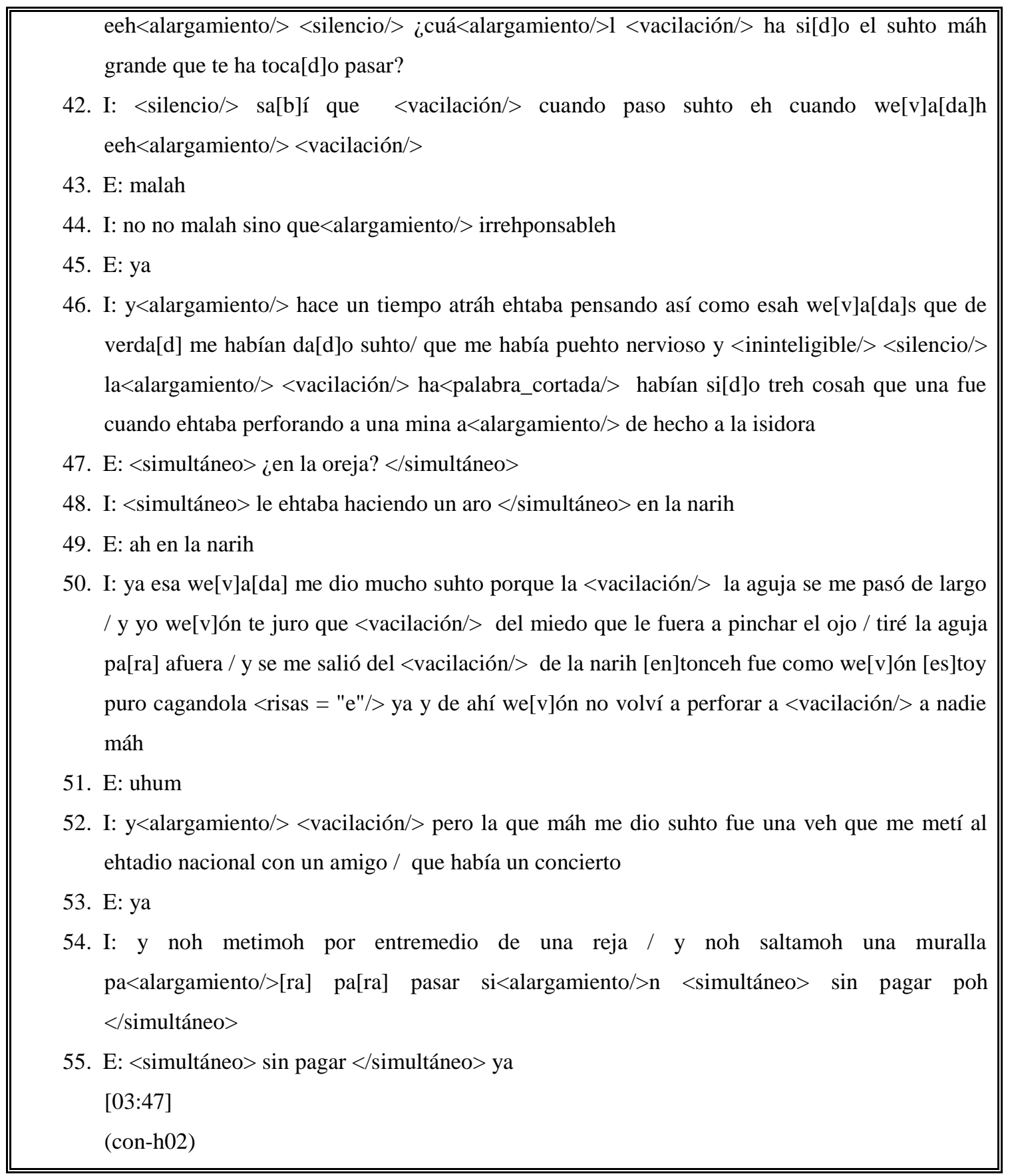

Al igual que en el caso anterior, se efectuó este análisis tomando en cuenta la participación del entrevistado, contando todos los fenómenos de productividad verbal a mano y posteriormente se sometió al mismo análisis con el PARAMTEXT TIP, con el propósito de cotejar los resultados. 
Tabla resumen 62: de productividad verbal fragmento de entrevista en CON-H07

\begin{tabular}{||l|l||}
\hline TOTAL ORACIONES & 39 \\
\hline Promedio palabras por oración & 9,7 \\
\hline Palabras diferentes & $166 / 380$ \\
\hline Neologismos parciales & 0 \\
\hline Neologismos totales & 0 \\
\hline Referentes & 32 \\
\hline Total de vínculos & 365 \\
\hline Promedio de vínculos & 11,4 \\
\hline \hline
\end{tabular}

\begin{tabular}{|c|}
\hline CON-H07 \\
\hline 1. ¿cómo graba esto? ¿bien? \\
\hline 2. ¿sí? \\
\hline 3. Ah, ya \\
\hline 4. [en]tonceh lo voy a dejar ahí \\
\hline 5. Y<alargamiento/> noh olvidamoh de < vacilación/> de la grabadora \\
\hline 6. $\quad$ Ahí [se cae la grabadora ] \\
\hline 7. $\quad$ Aah <risas $=$ "i"/> ya filo \\
\hline 8. (elipsis de $n a c \hat{\imath})$ en el /ochenta y ocho \\
\hline 9. (elipsis de $n a c \hat{\imath})$ ¿en qué comuna? \\
\hline $\begin{array}{l}\text { 10. Nací en <vacilación/> santiago en el hospita <palabra_cortada/> no en la clínica san } \\
\text { prancracio }\end{array}$ \\
\hline 11. Sí \\
\hline 12. Loh doh de Santiago \\
\hline $\begin{array}{l}\text { 13. No la última veh que trabajé fue en el verano de<alargamiento/>1 doh mil <vacilación/> seis } \\
<\text { vacilación/> doh mil siete / ese <simultáneo > verano }</ \text { simultáneo }>\end{array}$ \\
\hline $\begin{array}{l}\text { 14. Eeh<alargamiento/> trabajé en una tienda de } s<\text { palabra_cortada/> vendiendo zapatillah // en } \\
\text { el mall plaza tobalaba }\end{array}$ \\
\hline $\begin{array}{l}\text { 15. De acá en la u / ¿una anécdota?/ yo soy terrible malo pa[ra] acordarme de esah we[v]a[da]h } \\
\text { <risas > }\end{array}$ \\
\hline 16. Eeh<alargamiento/> \\
\hline 17. No poh \\
\hline $\begin{array}{l}\text { 18. <simultáneo> ¿aquí en la u? </simultáneo> me acuerdo que en <vacilación/> a [v]er ya } \\
\text { podría ser como ya chihtoso }\end{array}$ \\
\hline $\begin{array}{l}\text { 19. Así como que no no no <vacilación/> no correhponde a la u // con rosita rodrígueh } \\
36<\text { simultáneo> cuando </simultáneo> teníamos clase con ella }\end{array}$ \\
\hline
\end{tabular}

36 <observación_complementaria = "Profesora de Lengua y Cultura Inglesa de la Universidad de Chile"/> 
20. Teníamos clase con ella de práctica<alargamiento/>

21. Hacíamoh purah we[v]a[da]h /

22. Y un día la profe / ya era típico que <vacilación/> todah lah claseh llegaba / se sentaba / y decía <cita> voy no sé dónde y vuelvo al tiro </cita> y se demora[b]a veinte minutoh y perdíamoh cualquier clase //

23. Entonceh un día la profe dijo <cita> ya voy a no sé dónde y vuelvo al tiro </cita>

24. La wea eh que pehcamoh to[d]ah lah weah icachai? ${ }^{37}$ lah $\mathrm{m}<$ palabra_cortada/ $>$ lah <vacilación/> pehcamoh lah cosah de [e]lla / lah mochilah / to[d]ah lah weah y noh cambiamoh de sala y noh ehcondimoh <risas >

25. / y rosita rodrígueh dehpueh llegó y miraba y noh buhcaba así como que andaba por to[d]oh la[d]oh tratando de cachar dónde noh habíamoh meti[d]o <risas >

26. Y<alargamiento/><vacilación/> hahta que en una me asomé ¿cachai? Y me vió y dijo <cita> ¡ah! Tú / yo sabía que erai tú </cita > <risas = "e"/> así <cita > sabí que era tu culpa </cita > y to[d]a la we[v]a[da]

27. / y de ahí no <vacilación/> no se volvió a atrasar máh po /

28. Igual por lo menoh sirvió la <vacilación/> la we[v]a[da]

29. Eso poh / no era muy entreteni[d]o pero

30. <silencio/> sa[b]í que <vacilación/> cuando paso suhto eh cuando we[v]a[da]h eeh<alargamiento/><vacilación/>

31. No no malah sino que $<$ alargamiento/ $>$ irrehponsableh

32. Y<alargamiento/> hace un tiempo atráh ehtaba pensando así como esah we[v]a[da]s que de verda[d] me habían da[d]o suhto/ que me había puehto nervioso y <ininteligible/> <silencio/> la $<$ alargamiento/> <vacilación/> ha<palabra_cortada/>

33. Habían si[d]o treh cosah que una fue cuando ehtaba perforando a una mina a<alargamiento/> de hecho a la Isidora

34. <simultáneo > le ehtaba haciendo un aro </simultáneo > en la narih

35. Ya esa we[v]a[da] me dio mucho suhto porque la <vacilación/> la aguja se me pasó de largo I

36. Y yo we[v]ón te juro que <vacilación/> del miedo que le fuera a pinchar el ojo /

37. Tiré la aguja pa[ra] afuera / y se me salió del <vacilación/> de la narih [en]tonceh fue como we[v]ón [es]toy puro cagándola 〈risas >

38. Ya y de ahí we[v]ón no volví a perforar a <vacilación/> a nadie máh

39. Y<alargamiento/> <vacilación/> pero la que máh me dio suhto fue una veh que me metí al ehtadio nacional con un amigo / que había un concierto

40. Y noh metimoh por entremedio de una reja /

41. Y noh saltamoh una muralla pa<alargamiento/>[ra] $p a[r a]$ pasar si<alargamiento/ $>n$ $<$ simultáneo> sin pagar poh $</$ simultáneo $>$

\subsubsection{Total de oraciones}

Como ya se señaló en la metodología, se contaron las oraciones producidas por los informantes en 15 minutos.

37 <observación_complementaria = "cachai en la jerga jvenil chilena significa entiendes"/> 


\subsubsection{Total de oraciones y estadio de la enfermedad}

Con respecto al análisis de las medias correspondientes a la cantidad total de oraciones según el factor estadio de la enfermedad de los sujetos, a continuación se muestras los resultados del análisis paramétrico ANOVA, según el cual la media para los controles es 429,167, los de primer episodio, 172, 720, mientras que la de los crónicos alcanza 228,200. Por lo tanto, se trata de medias muy disímiles, se muestra una mayor tendencia hacia una mayor número de oraciones totales por parte de los hablantes controles. Los resultados son significativos estadísticamente.

Tabla de contingencia 63: total de oraciones y estadio de la enfermedad.

\begin{tabular}{||l|c|c|c|c|c||}
\hline \multicolumn{5}{|c||}{ Pruebas de los efectos inter-sujetos } \\
\hline Variable dependiente: & Total de oraciones & Sig. \\
\hline Origen & $\begin{array}{c}\text { Suma de } \\
\text { cuadrados tipo } \\
\text { III }\end{array}$ & $\mathrm{gl}$ & $\begin{array}{c}\text { Media } \\
\text { cuadrática }\end{array}$ & $\mathrm{F}$ & \\
\hline Modelo corregido & $544669,632^{\mathrm{a}}$ & $\mathrm{2}$ & 272334,816 & 48,758 &, 000 \\
\hline
\end{tabular}


Gráfico 21. Porcentaje de frecuencia de las variables: total de oraciones y estadio de la enfermedad

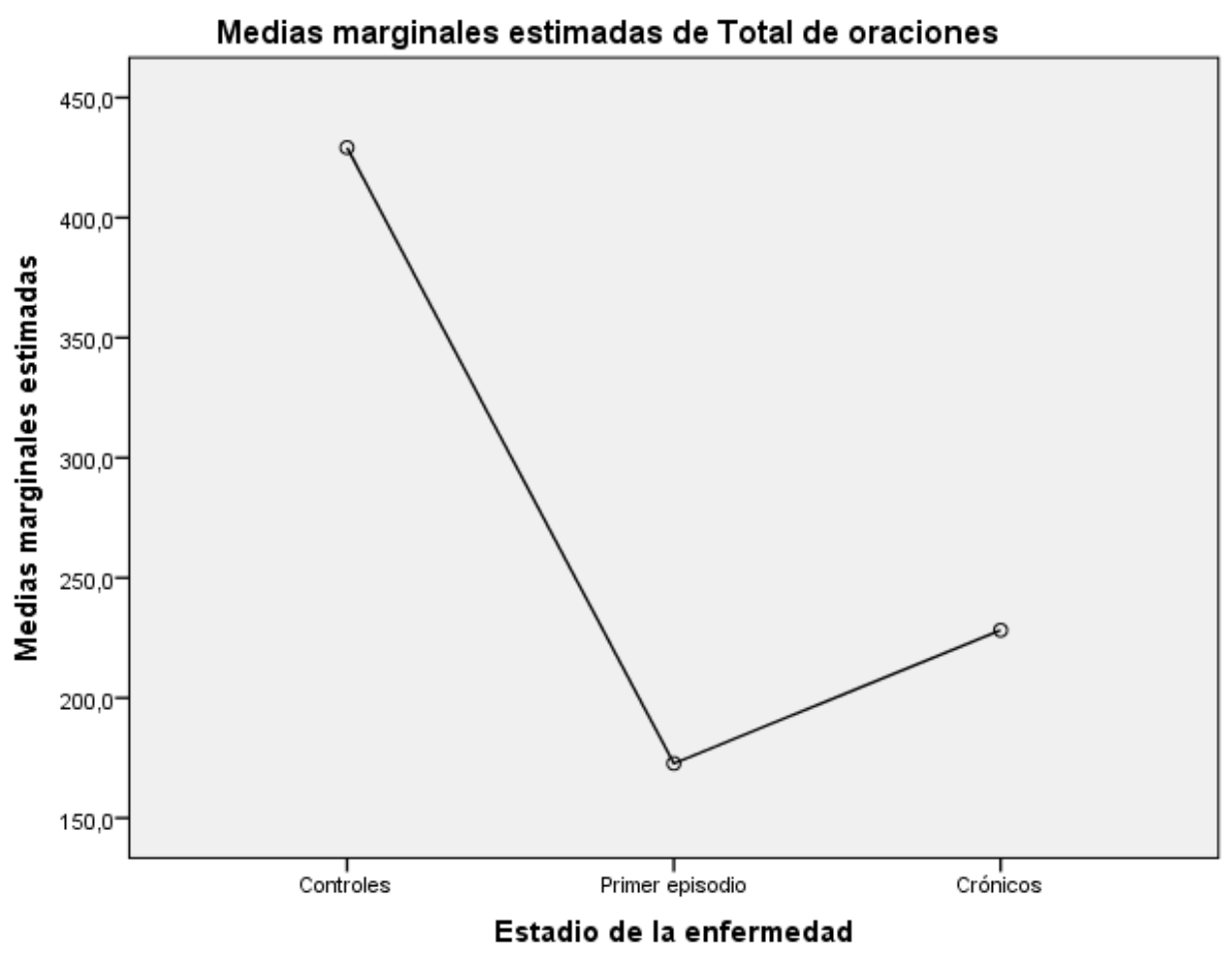

Cotejamos este análisis paramétrico con un diagrama de caja y bigotes, en el que se aprecia una diferencia significativa para el grupo de controles que se distancia de los grupos 1 y 2. 
22. Diagrama de caja y bigotes 1. Porcentaje de las variables: total de oraciones y estadio de la enfermedad

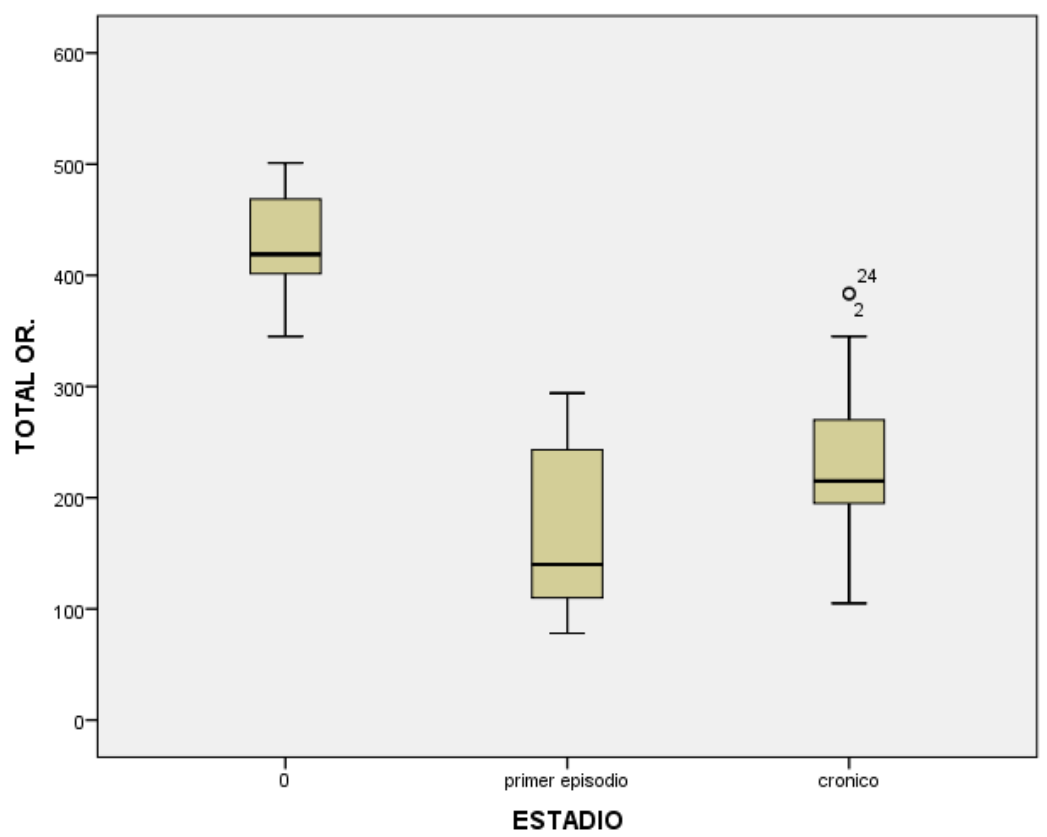

4.2.2.2. Total de oraciones y sexo

Con respecto al análisis de las medias correspondientes a la cantidad total de oraciones según el factor sexo de los sujetos, a continuación se muestras los resultados del análisis paramétrico ANOVA, según el cual la media para los hombres es 250,667, mientras que la de las mujeres alcanza 237,966. Los resultados no son significativos estadísticamente. 
Tabla de contingencia 64: total de oraciones y sexo.

\begin{tabular}{|c|c|c|c|c|c|}
\hline \multicolumn{6}{|c|}{ Pruebas de los efectos inter-sujetos } \\
\hline Variable dependiente: & Total de oraciones & & & & \\
\hline Origen & $\begin{array}{c}\text { Suma de } \\
\text { cuadrados tipo } \\
\text { III }\end{array}$ & Gl & $\begin{array}{c}\text { Media } \\
\text { cuadrática }\end{array}$ & $\mathrm{F}$ & Sig. \\
\hline Modelo corregido & $2490,040^{\mathrm{a}}$ & 1 & 2490,040 &, 171 & 680 \\
\hline
\end{tabular}

Gráfico 23. Porcentaje de frecuencia de las variables: total de oraciones y sexo de los sujetos.

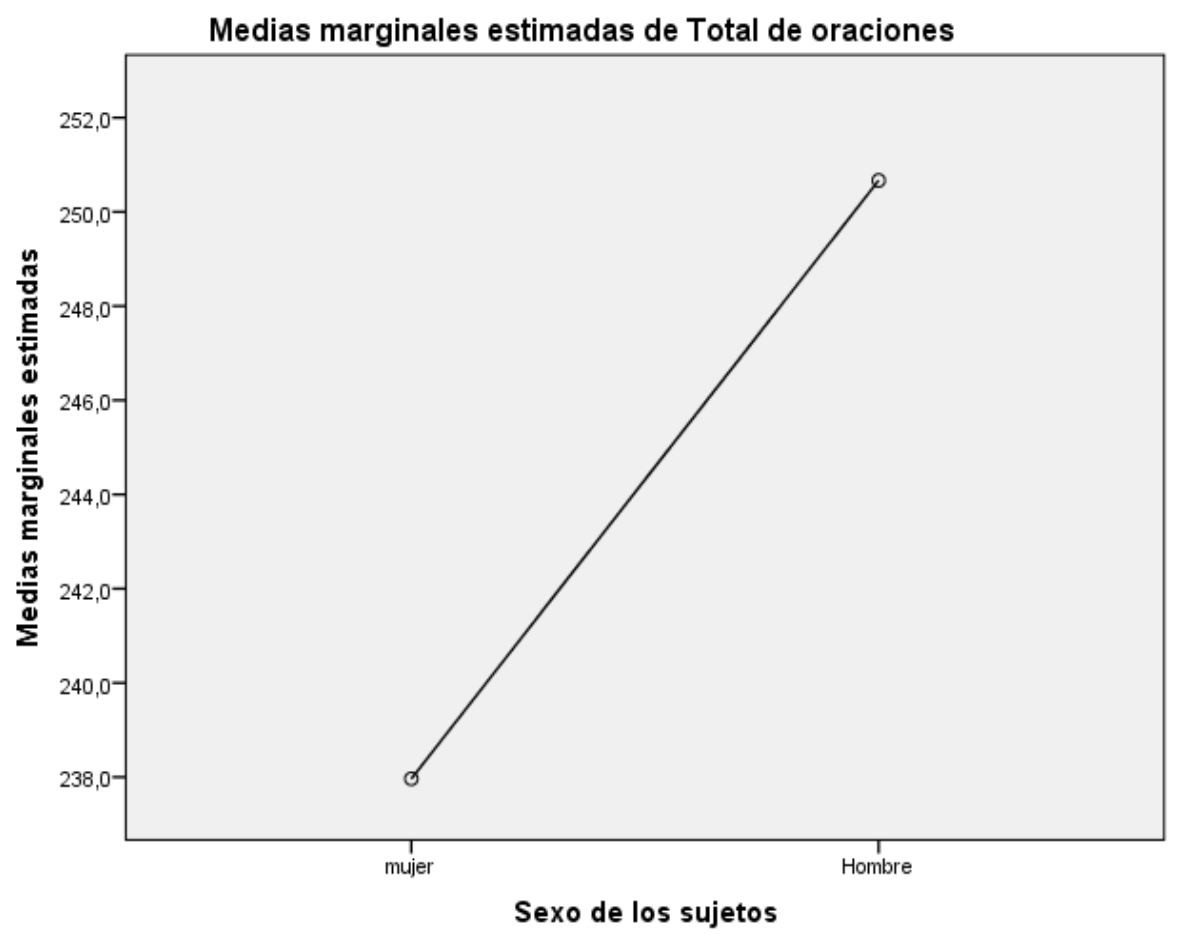

Cotejamos este análisis paramétrico con un diagrama de caja y bigotes, en el que no se aprecia una diferencia significativa entre el grupo de hombres y mujeres. 
24. Diagrama de caja y bigotes 2. Porcentaje de las variables: total de oraciones y sexo de los sujetos

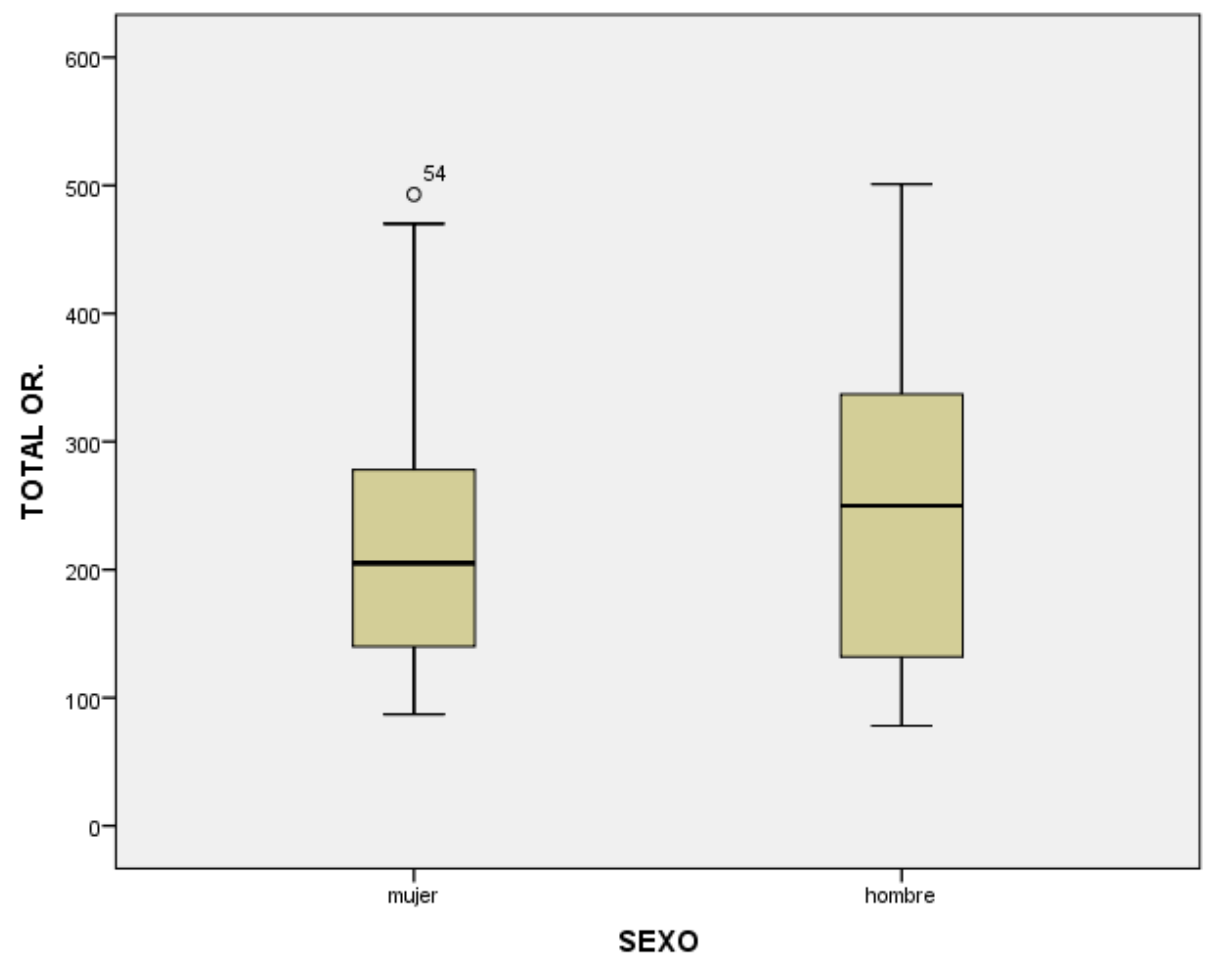

4.2.2.3. Total de oraciones y tramo de la enfermedad

Con respecto al análisis de las medias correspondientes a la cantidad total de oraciones según el factor tramo de la enfermedad de los sujetos, a continuación se muestras los resultados del análisis paramétrico ANOVA, según el cual la media para los controles es de 429,167, en tanto, para los de primer episodio de $0-<2$ años es 159,071 , para los de primer episodio de $>2-<3$ es de 190,091, mientras que para los crónicos de hasta 5 años es de 211,800 y para los crónicos de 5 y más años es de 239,133. Los resultados son significativos estadísticamente. 
Tabla de contingencia 65: total de oraciones y tramo de la enfermedad.

\begin{tabular}{|c|c|c|c|c|c|}
\hline \multicolumn{6}{|c|}{ Pruebas de los efectos inter-sujetos } \\
\hline Variable dependiente: & Total de oraciones & & & & \\
\hline Origen & $\begin{array}{c}\text { Suma de } \\
\text { cuadrados tipo } \\
\text { III }\end{array}$ & gl & $\begin{array}{c}\text { Media } \\
\text { cuadrática }\end{array}$ & $\mathrm{F}$ & Sig. \\
\hline Modelo corregido & $555079,501^{\mathrm{a}}$ & 4 & 138769,875 & 24,786 & 000 \\
\hline
\end{tabular}

Gráfico 25. Porcentaje de frecuencia de las variables: total de oraciones y tramo de la enfermedad

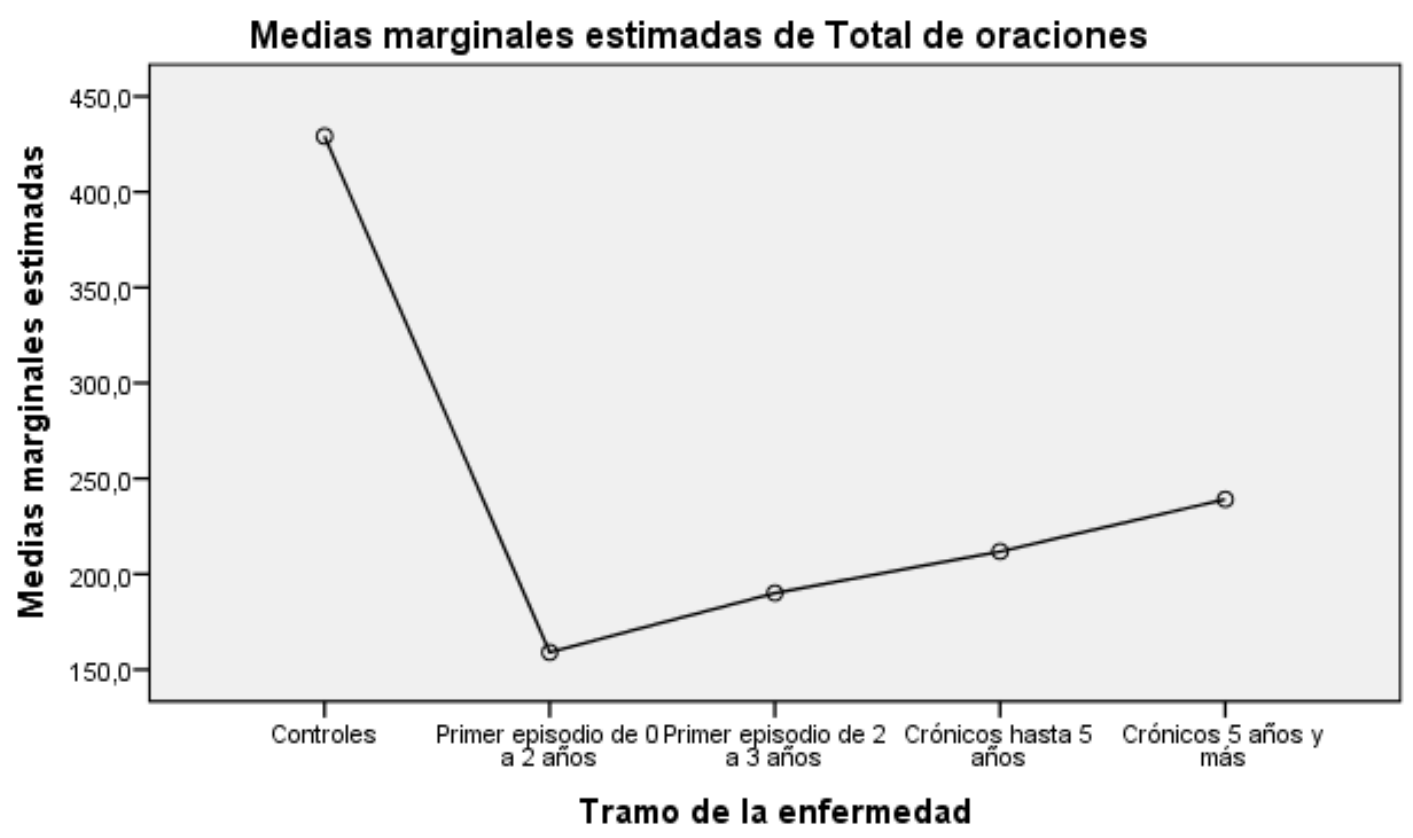


Cotejamos este análisis paramétrico con un diagrama de caja y bigotes, en el que se aprecia una diferencia significativa entre los grupos de pacientes y los controles.

26. Diagrama de caja y bigotes 3. Porcentaje de las variables: total de oraciones y tramo de la enfermedad

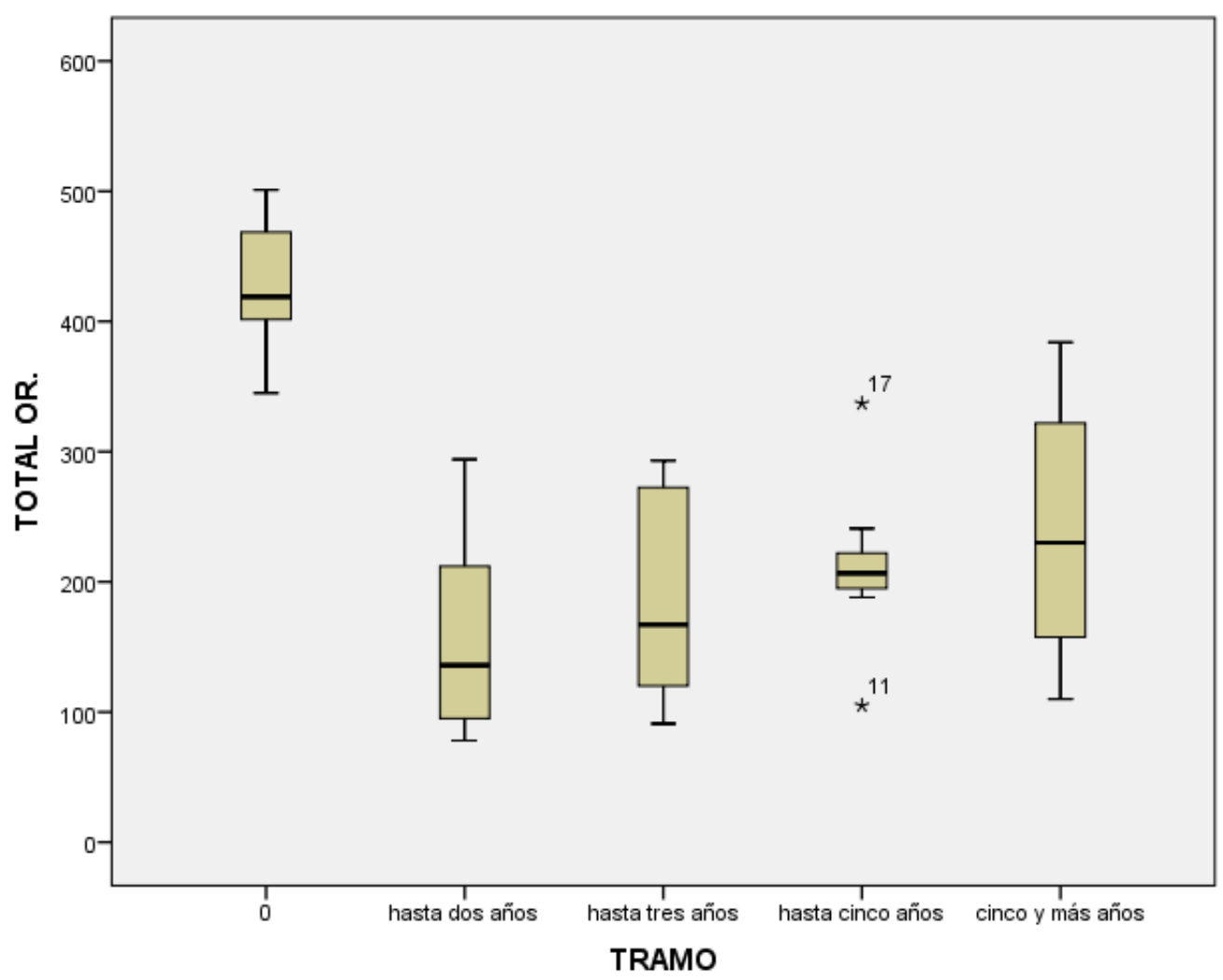

4.2.2.4. Total de oraciones y subtipo de la enfermedad

Con respecto al análisis de las medias correspondientes a la cantidad total de oraciones según el factor tramo de la enfermedad de los sujetos, a continuación se 
muestran los resultados del análisis paramétrico ANOVA, según el cual la media para los controles es de 429,167, en tanto, para los paranoide es 193,242, para los del subtipo indiferenciado es de 230,667, mientras que para los de esquizofrenia del subtipo desorganizada es de 196,250 Los resultados son significativos estadísticamente.

Tabla de contingencia 66: total de oraciones y subtipo de la enfermedad.

\begin{tabular}{|c|c|c|c|c|c|}
\hline \multicolumn{6}{|c|}{ Pruebas de los efectos inter-sujetos } \\
\hline Variable dependiente: & Total de oraciones & & & & \\
\hline Origen & $\begin{array}{c}\text { Suma de } \\
\text { cuadrados tipo } \\
\text { III }\end{array}$ & $\mathrm{gl}$ & $\begin{array}{c}\text { Media } \\
\text { cuadrática }\end{array}$ & $\mathrm{F}$ & Sig. \\
\hline Modelo corregido & $516267,111^{\mathrm{a}}$ & 3 & 172089,037 & 27,885 &, 000 \\
\hline
\end{tabular}

Gráfico 27. Porcentaje de frecuencia de las variables: total de oraciones y subtipo de la enfermedad.

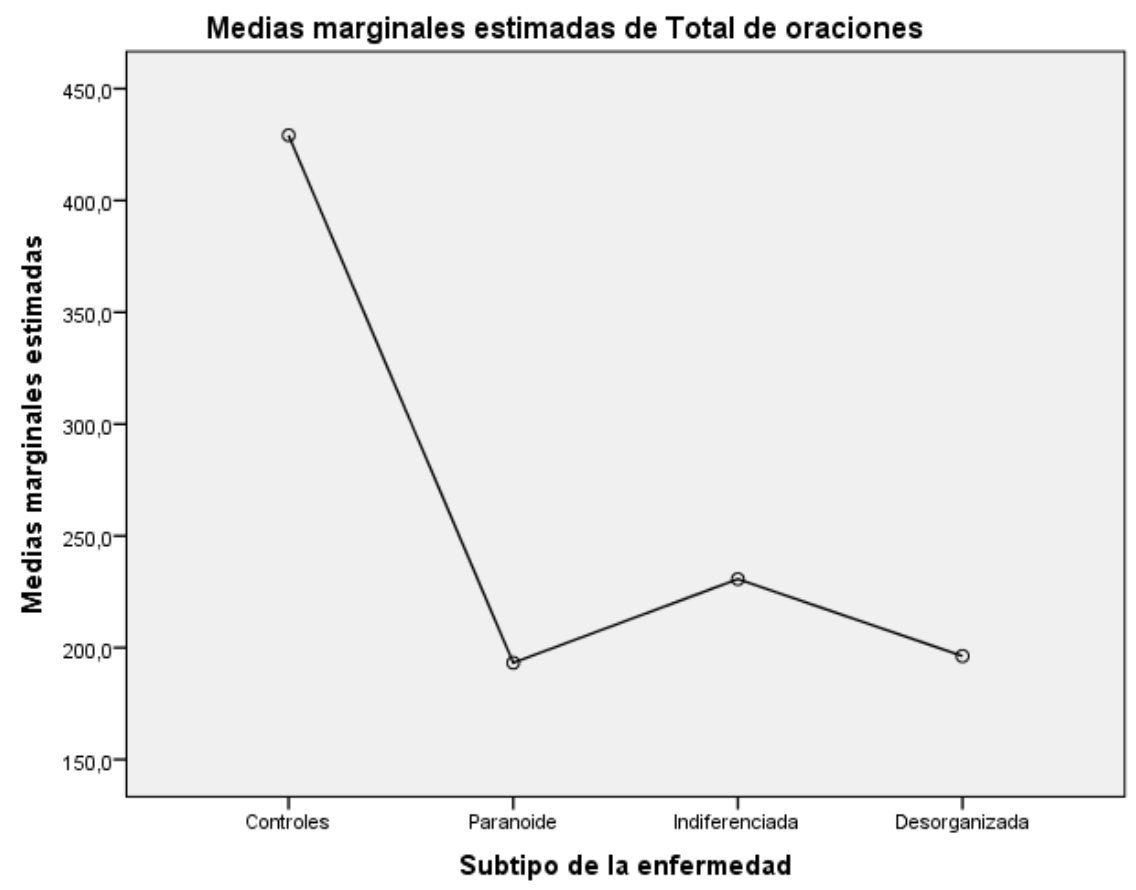


Cotejamos este análisis paramétrico con un diagrama de caja y bigotes, en el que no se aprecia una diferencia significativa entre los diferentes subtipos de la enfermedad, coincidiendo notoriamente el resultado significativo.

28. Diagrama de caja y bigotes 4. Porcentaje de las variables: total de oraciones y subtipode la enfermedad

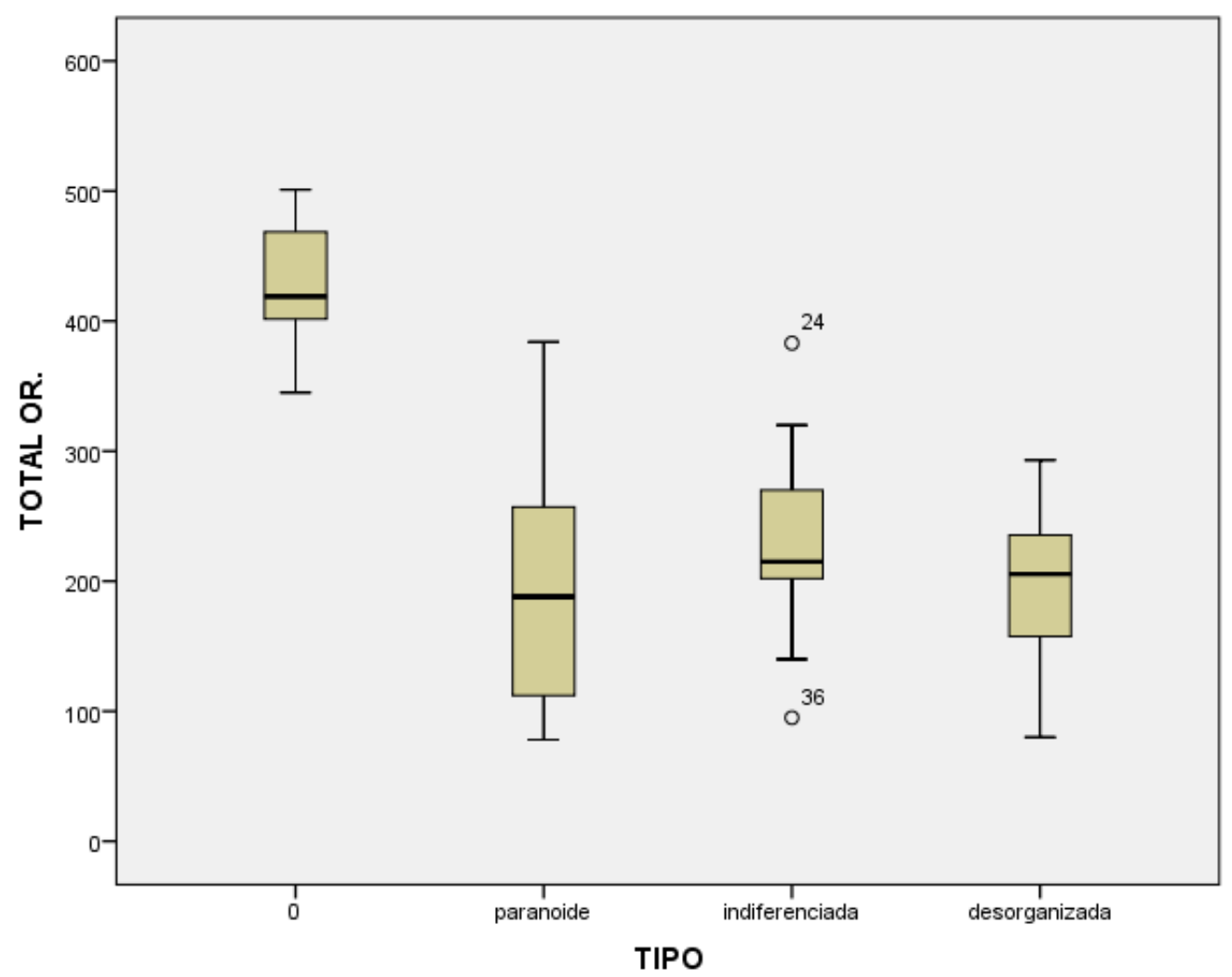

\subsubsection{Promedio de palabras por oración}

La longitud de las oraciones nos parece un indicador interesante de comparar entre estos tres grupos, dado que suponemos que pueden existir diferencias que apunten a una mejor o peor conservación de habilidades de producción oral. Los estudios realizados por Nippold, (2006), indican que en el lenguaje oral existe una 
progresión en la longitud de las oraciones que alcanza una estabilidad alrededor de los 29 años. La complejidad sintáctica, respecto al tipo de estructura clausular que contendrían las oraciones, también sería progresiva y descendería alrededor de los 50 años. La autora señala que sería una pauta para seguir en el lenguaje escrito. No encontramos estudios sobre la longitud promedio de las oraciones para hablantes de español, algunas referencias indirectas las hallamos en Loprete, (1984), quien señala un volumen aproximado de 120 palabras por minuto en una conversación.

\subsubsection{Promedio de palabras por oración y estadio de la enfermedad}

La aplicación de la prueba no paramétrica Anova de Kruskal-Wallis, por su parte, arroja como rangos promedio 1,21. En el promedio de palabras por oración en los crónicos, se observa un rango promedio de 31,04 y en los de primer episodio de 19,96. El resultado de Chi cuadrado fue de 7,305, que da como resultado ( $<\mathrm{p}, 007\rangle)$ no significativo estadísticamente.

Tabla valor de chi cuadrado 67: promedio de palabras por oración y estadio de la enfermedad.

\begin{tabular}{||l|r||}
\hline \hline \multicolumn{2}{||l||}{ Estadísticos de contraste } \\
\hline & \multicolumn{2}{|c|}{ Promedio de palabras por oración $^{\mathbf{b}}$} \\
\hline Chi-cuadrado & 7,305 \\
\hline Gl & 1 \\
\hline Sig. asintót. &, 007 \\
\hline
\end{tabular}

Con el fin de verificar si la dispersión de los datos presentaba alguna anomalía, se incluye también el diagrama de caja y bigotes correspondiente. 
29.Diagrama de caja y bigotes 5. Porcentaje de la variable: estadio de la enfermedad

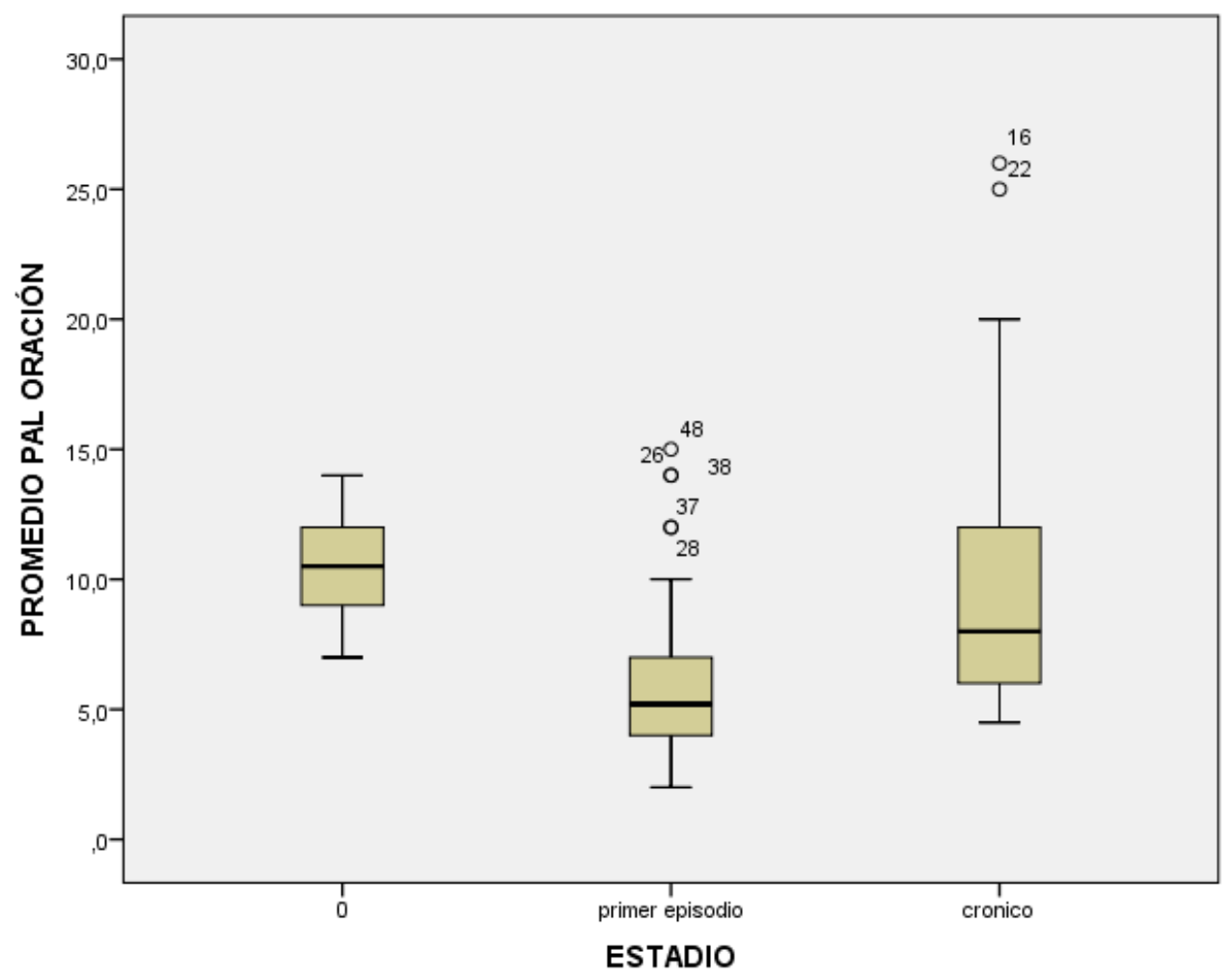

4.2.3.2. Promedio de palabras por oración y sexo

La aplicación de la prueba no paramétrica Anova de Kruskal-Wallis, por su parte, arroja como rangos promedio 1,53. En el promedio de palabras por oración en los hombres es de 34,44 y el de las mujeres, es de, 28,16. El valor de chi cuadrado es de $1,889$, dando como resultado ( $<\mathrm{p}, 169>)$, no significativo estadísticamente. 
Tabla valor de chi cuadrado 68: promedio de palabras por oración y sexo.

\begin{tabular}{||l|r||}
\hline \multicolumn{2}{|c||}{ Estadísticos de contraste } \\
\hline & \multicolumn{2}{|c|}{ Promedio de palabras por oración } \\
\hline Chi-cuadrado & 1,889 \\
\hline Gl & 1 \\
\hline Sig. asintót. &, 169 \\
\hline
\end{tabular}

Con el fin de verificar si la dispersión de los datos presentaba alguna anomalía, se incluye también el diagrama de caja y bigotes correspondiente.

30.Diagrama de caja y bigotes 6. Porcentaje de la variable: sexo de los individuos

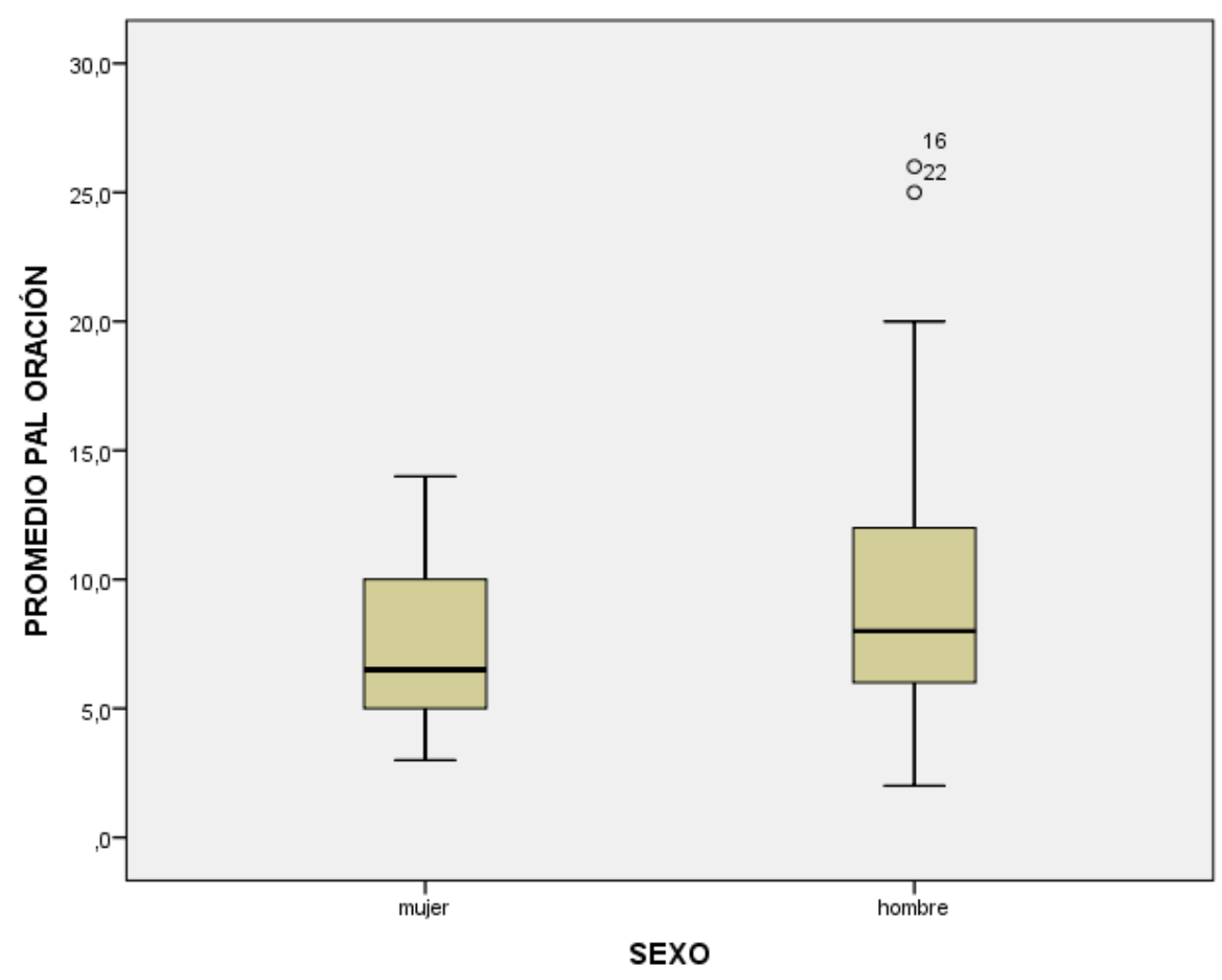


4.2.3.3. Promedio de palabras por oración y tramo de la enfermedad

La aplicación de la prueba no paramétrica Anova de Kruskal-Wallis, por su parte, arroja como rangos promedio 2,03. La media para los de primer episodio de $0-<2$ años es 15,96, para los de primer episodio de $>2-<3$ es de 25,05, mientras que para los crónicos de hasta 5 años es de 30,70 y para los crónicos de 5 y más años es de 31,27. El valor de chi cuadrado es de 9,732, Los resultados, dieron $(<\mathrm{p} 0,21>)$, no son significativos estadísticamente.

Tabla valor de chi cuadrado 69: promedio de palabras por oración y tramo de la enfermedad.

\begin{tabular}{||l|r||}
\hline \multicolumn{2}{|c||}{ Estadísticos de contraste } \\
\hline & \multicolumn{1}{|c|}{ Promedio de palabras por oración } \\
\hline Chi-cuadrado & 9,732 \\
\hline Gl & 3 \\
\hline Sig. asintót. &, 021 \\
\hline
\end{tabular}

Con el fin de verificar si la dispersión de los datos presentaba alguna anomalía, se incluye también el diagrama de caja y bigotes correspondiente. 
31. Diagrama de caja y bigotes 7. Porcentaje de la variable: tramo de la enfermedad

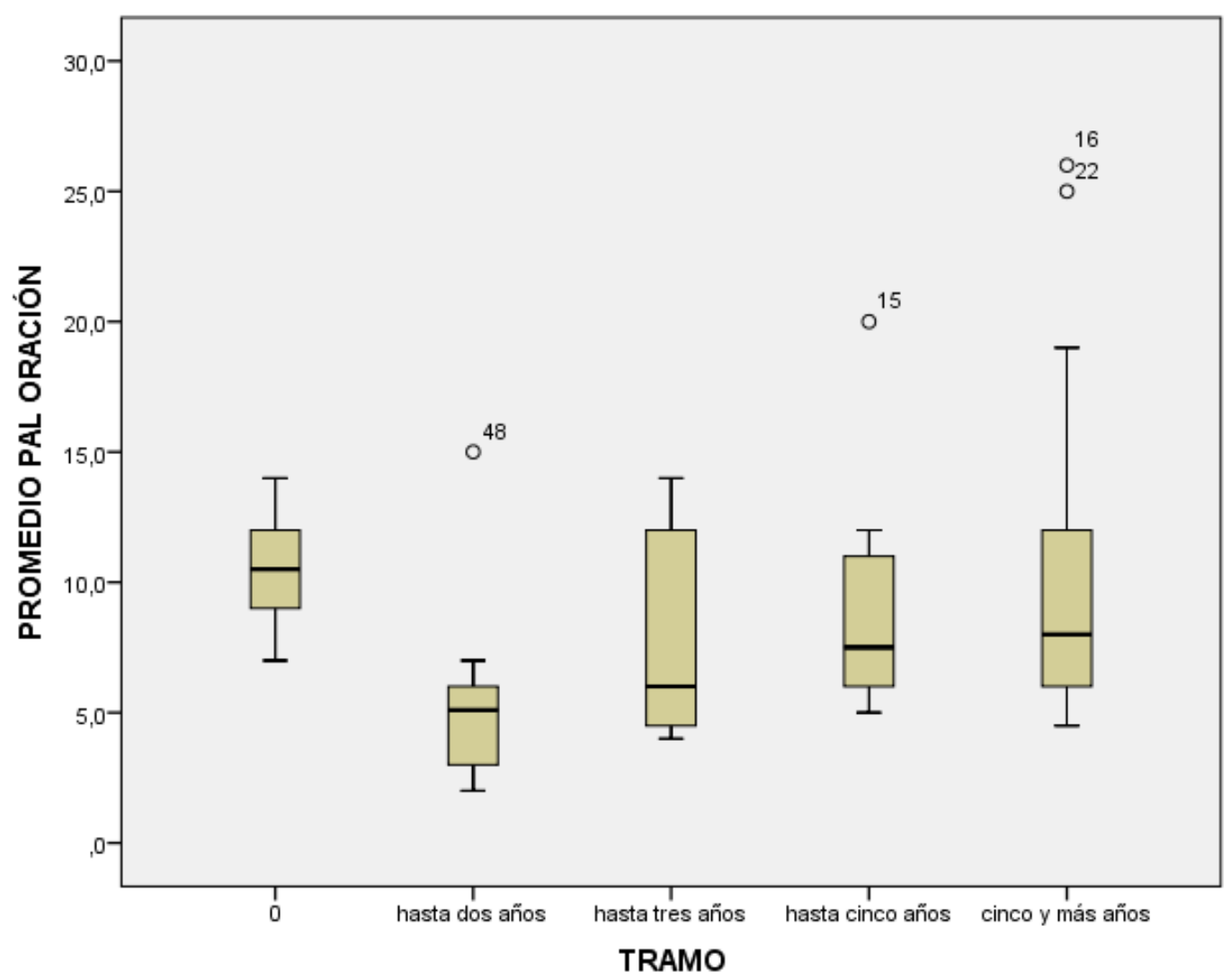

4.2.3.4. Promedio de palabras por oración y subtipo de la enfermedad

La aplicación de la prueba no paramétrica Anova de Kruskal-Wallis, por su parte, arroja como rangos promedio 1,21. La media para los paranoide es 24,50, para los del subtipo indiferenciado es de 29,83, mientras que para los de esquizofrenia del subtipo desorganizada es de 24,75. El valor de chi cuadrado es de , 983. Los resultados, dieron $(<\mathrm{p}, 612>)$, no son significativos estadísticamente. 
Tabla valor de chi cuadrado 70: promedio de palabras por oración y subtipo de la enfermedad.

\begin{tabular}{||l|r||}
\hline \multicolumn{2}{|c||}{ Estadísticos de contraste } \\
\hline & \multicolumn{2}{|c|}{ Promedio de palabras por oración } \\
\hline Chi-cuadrado &, 983 \\
\hline Gl & 2 \\
\hline Sig. asintót. &, 612 \\
\hline
\end{tabular}

Con el fin de verificar si la dispersión de los datos presentaba alguna anomalía, se incluye también el diagrama de caja y bigotes correspondiente.

32.Diagrama de caja y bigotes 8. Porcentaje de la variable: subtipo de la enfermedad

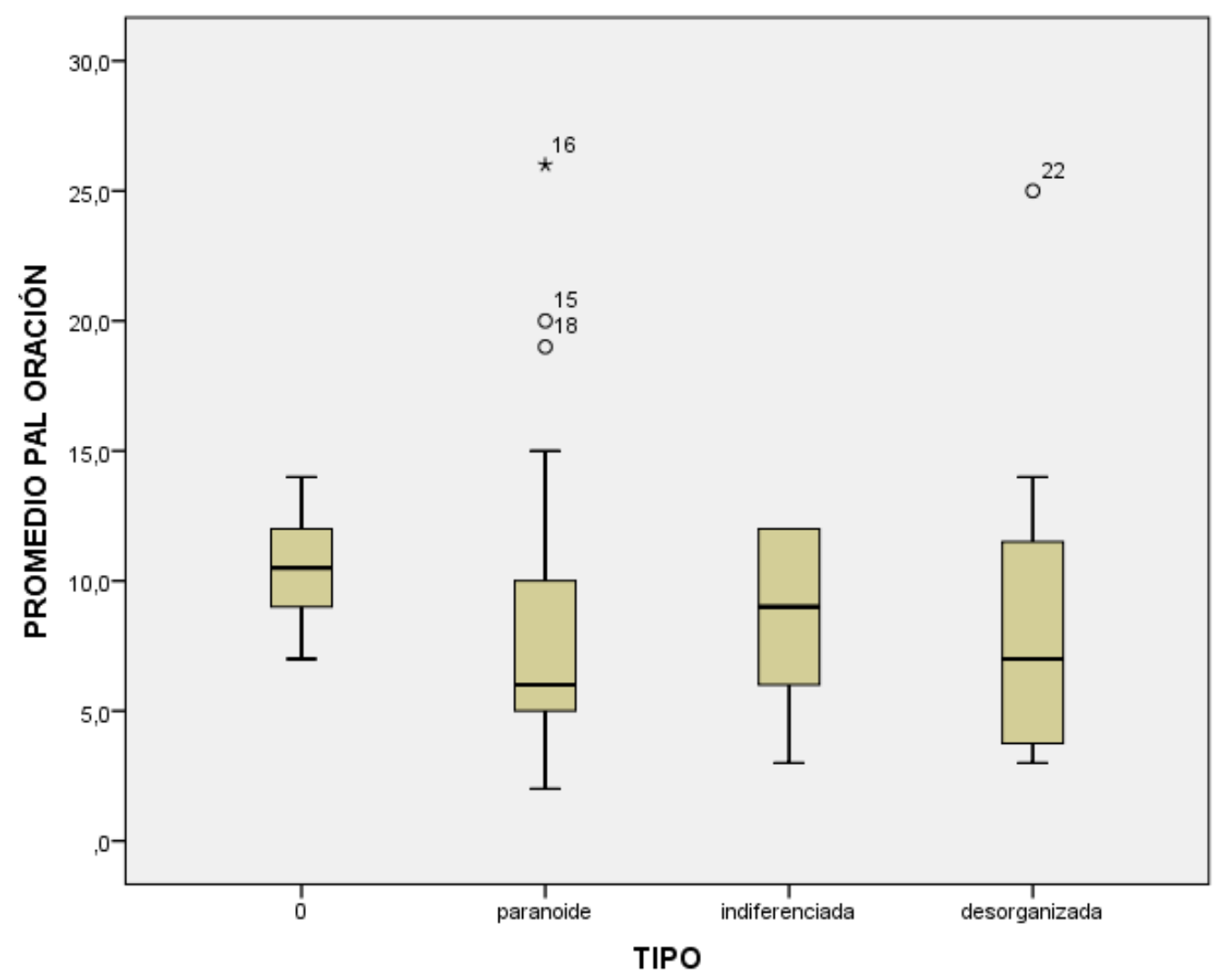




\subsubsection{Palabras diferentes}

Como una medida de comparación respecto de la flexibilidad léxica que presentan los grupos, se tomó el número total de palabras empleadas, restándoles todas aquellas palabras repetidas. En general, pudimos comprobar que el grupo de de primer episodio de primer episodio repite más palabras que los otros grupos, aunque en el grupo de los crónicos, también encontramos una gran cantidad de palabras que funcionaban como muletillas. Y las medidas que se registraron en los controles, son muy superiores a las de los grupos de sujetos con la enfermedad.

\subsubsection{Palabras diferentes y estadio de la enfermedad}

Con respecto al análisis de las medias correspondientes a las palabras diferentes según el factor estadio de la enfermedad de los sujetos, a continuación se muestran los resultados del análisis paramétrico ANOVA, según el cual la media para los controles es de 530,000 en tanto, para los de primer episodio, es de 285, 120, para los crónicos es de 412, 200. Los resultados son significativos estadísticamente.

Tabla de contingencia 71: palabras diferentes y estadio de la enfermedad.

\begin{tabular}{||l|c|c|c|c|c||}
\hline \multicolumn{6}{|c||}{ Pruebas de los efectos inter-sujetos } \\
\hline Variable dependiente: & Palabras diferentes & Sig. \\
\hline Origen & $\begin{array}{c}\text { Suma de } \\
\text { cuadrados tipo } \\
\text { III }\end{array}$ & gl & $\begin{array}{c}\text { Media } \\
\text { cuadrática }\end{array}$ & F & \\
\hline Modelo corregido & $520100,731^{\text {a }}$ & 2 & 260050,365 & 18,231 &, 000 \\
\hline a. R cuadrado $=, 382$ (R cuadrado corregida =,361) \\
\hline
\end{tabular}


Gráfico 33. Porcentaje de frecuencia de las variables: palabras diferentes y estadio de la enfermedad

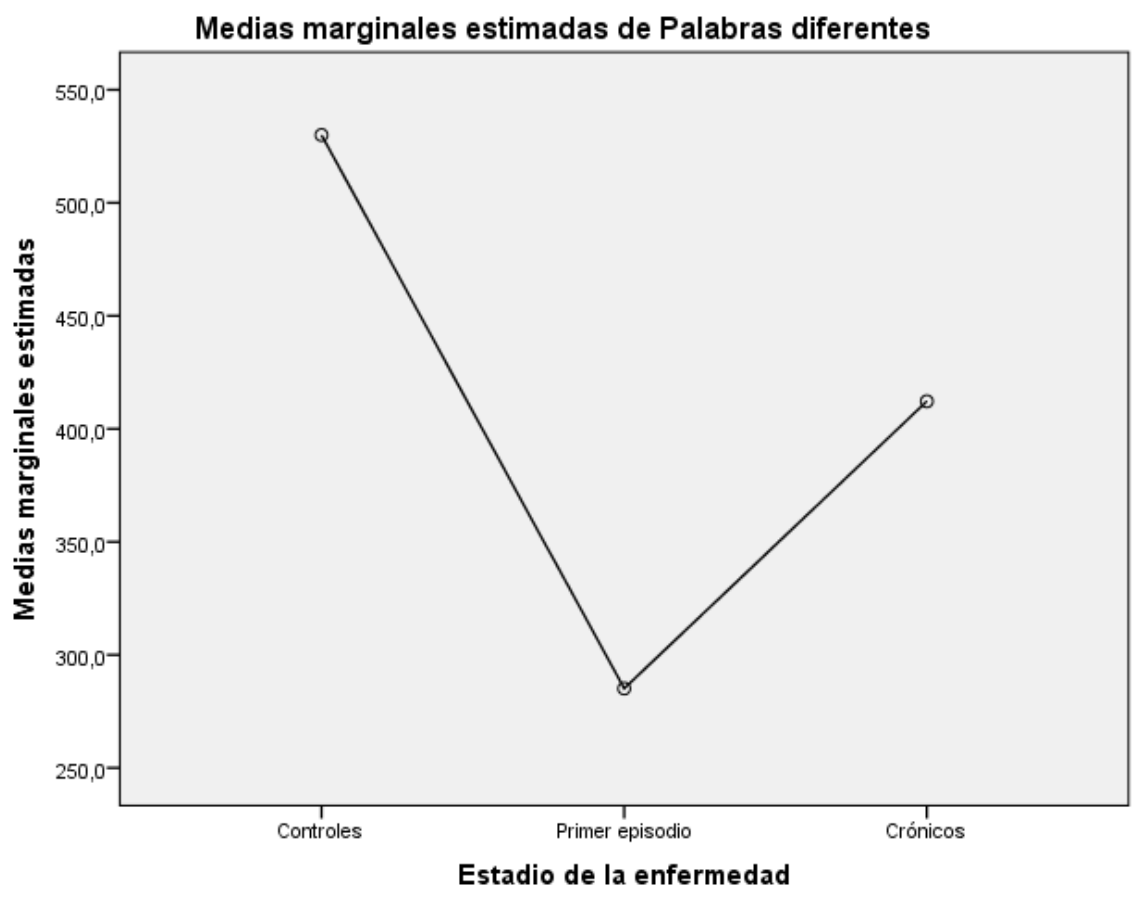

Con el fin de verificar si la dispersión de los datos presentaba alguna anomalía, se incluye también el diagrama de caja y bigotes correspondiente. 
34.Diagrama de caja y bigotes 9. Porcentaje de la variable: estadio de la enfermedad

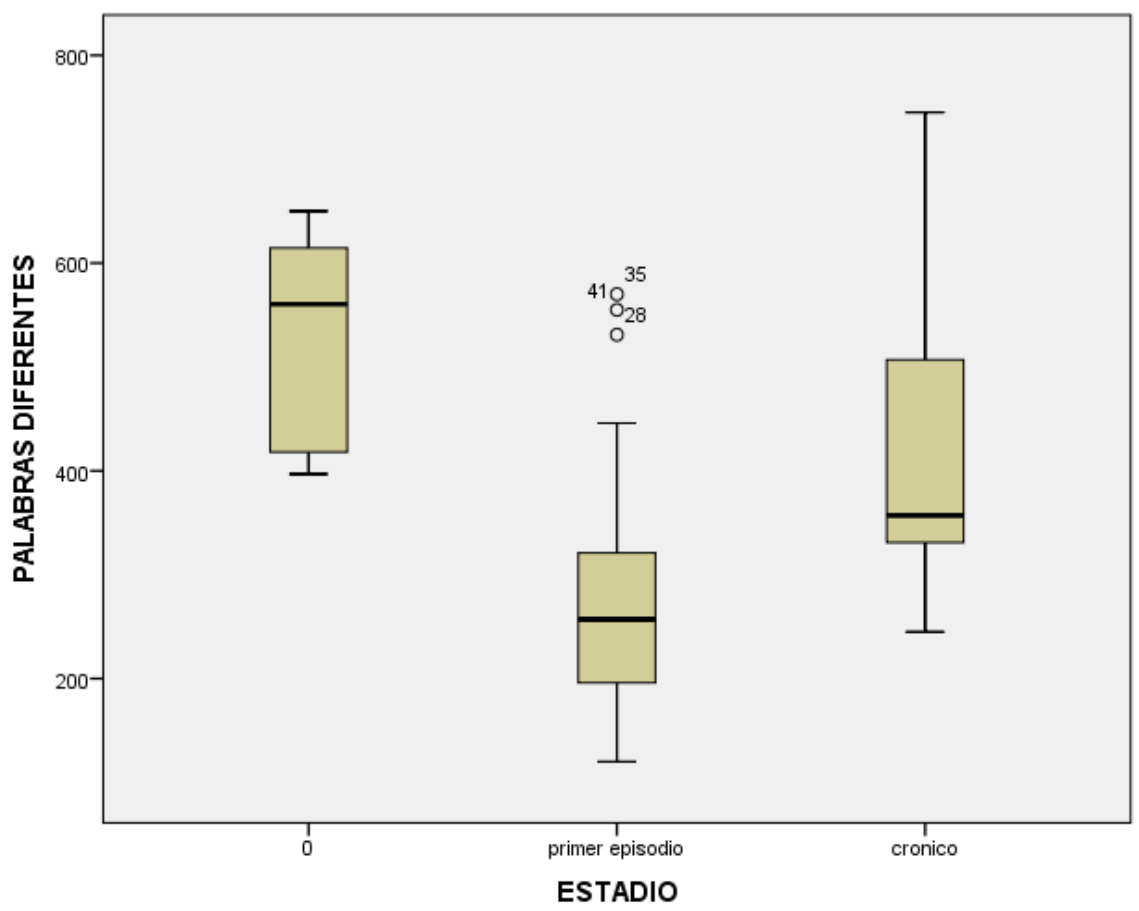

4.2.4.2. Palabras diferentes y sexo

Con respecto al análisis de las medias correspondientes a las palabras diferentes según el factor sexo de los sujetos, a continuación se muestran los resultados del análisis paramétrico ANOVA, según el cual la media para los hombres es de 362, 788 en tanto, para las mujeres, es de 407, 621. Los resultados no son significativos estadísticamente.

Tabla de contingencia 72: palabras diferentes y sexo.

\begin{tabular}{||l|c|c|c|c|c||}
\hline \multicolumn{5}{|c||}{ Pruebas de los efectos inter-sujetos } \\
\hline Variable dependiente: & Palabras diferentes & Sig. \\
\hline Origen & $\begin{array}{c}\text { Suma de } \\
\text { cuadrados tipo } \\
\text { III }\end{array}$ & gl & $\begin{array}{c}\text { Media } \\
\text { cuadrática }\end{array}$ & F & \\
\hline Modelo corregido & $31025,028^{\text {a }}$ & 1 & 31025,028 & 1,399 &, 242 \\
\hline
\end{tabular}


a. $\mathrm{R}$ cuadrado $=, 023(\mathrm{R}$ cuadrado corregida $=, 006)$

Gráfico 35. Porcentaje de frecuencia de las variables: palabras diferentes y sexo

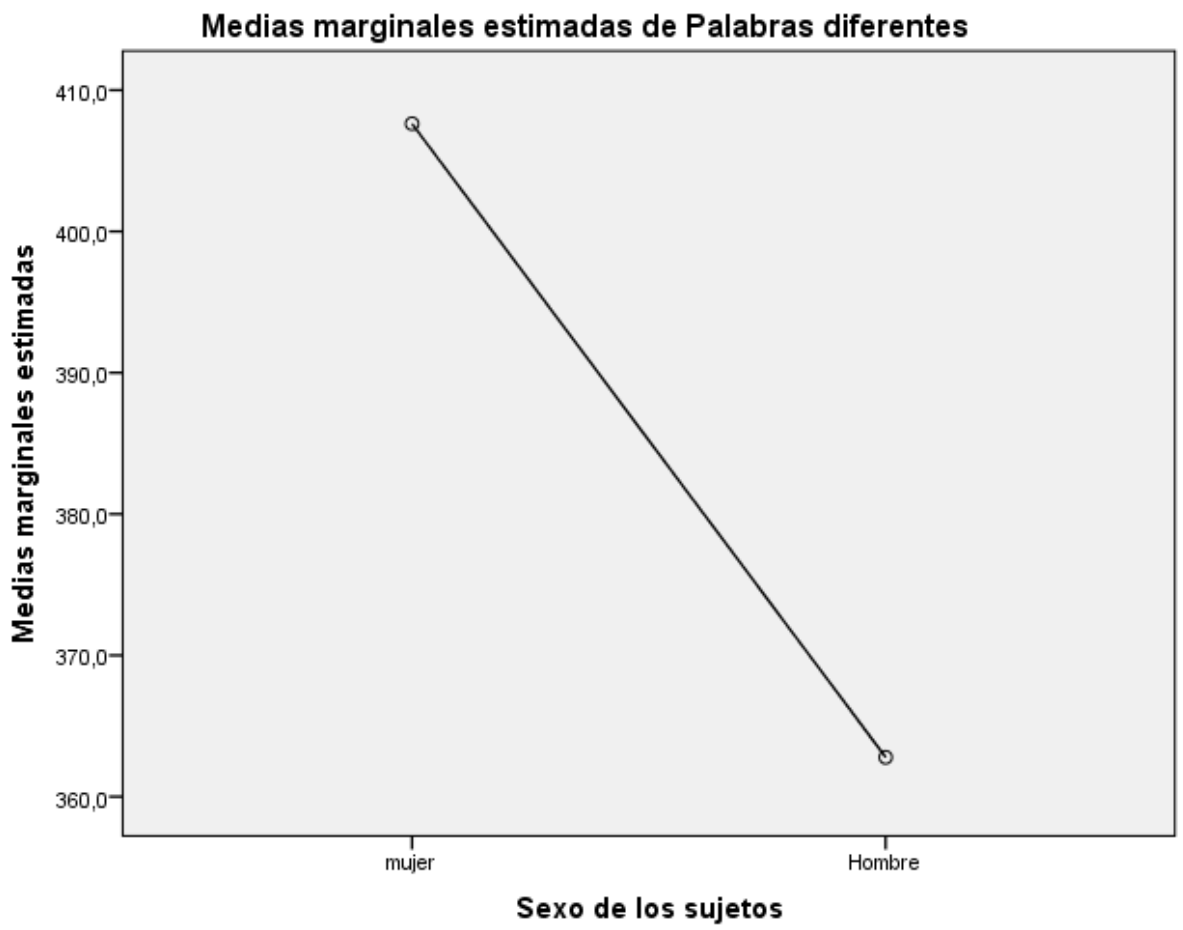

Con el fin de verificar si la dispersión de los datos presentaba alguna anomalía, se incluye el diagrama de caja y bigotes correspondiente. 
36. Diagrama de caja y bigotes 10. Porcentaje de la variable: sexo

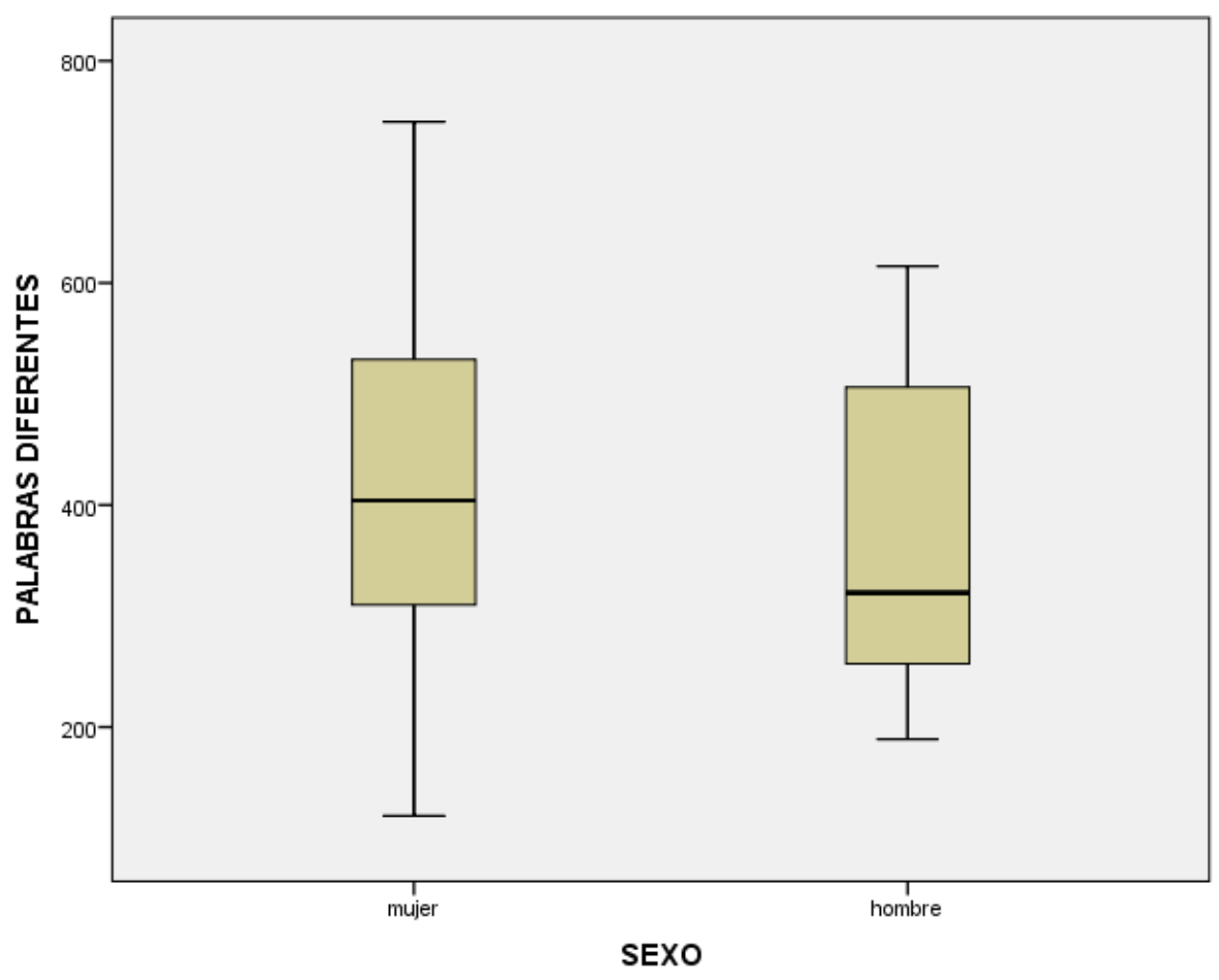

4.2.4.3. Palabras diferentes y tramo de la enfermedad

Con respecto al análisis de las medias correspondientes a las palabras diferentes según el factor sexo de los sujetos, a continuación se muestran los resultados del análisis paramétrico ANOVA, según el cual, la media para los controles es de 530,000; para el grupo de primer episodio $>0$ a $<2$ años es de 268,929; para los de primer episodio de >2 a <3 años, es de 305,727, Crónicos hasta 5 años es de 409,600 y para los crónicos de 5 años y más 413,933. Los resultados son significativos estadísticamente. 
Tabla de contingencia 73: palabras diferentes y tramo de la enfermedad.

\begin{tabular}{||l|c|c|c|c|c||}
\hline \multicolumn{6}{|c||}{ Pruebas de los efectos inter-sujetos } \\
\hline Variable dependiente: & Palabras diferentes & F & Sig. \\
\hline Origen & $\begin{array}{c}\text { Suma de } \\
\text { cuadrados tipo } \\
\text { III }\end{array}$ & Gl & $\begin{array}{c}\text { Media } \\
\text { cuadrática }\end{array}$ & & \\
\hline Modelo corregido & 528554,927 & 4 & 132138,732 & 9,040 &, 000 \\
\hline
\end{tabular}

Gráfico 37. Porcentaje de frecuencia de las variables: palabras diferentes y tramo de la enfermedad.

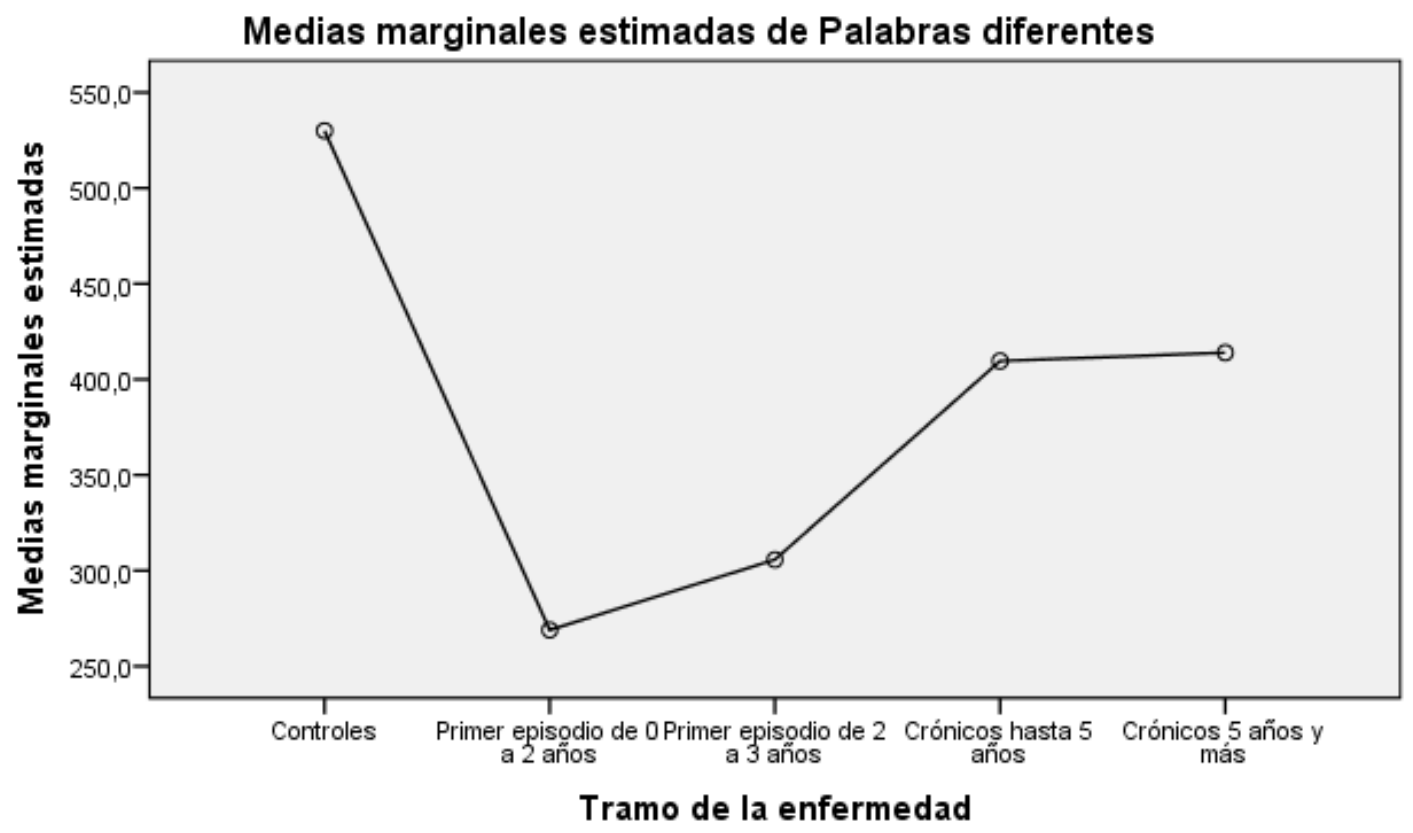


Con el fin de verificar si la dispersión de los datos presentaba alguna anomalía, se incluye el diagrama de caja y bigotes correspondiente.

38. Diagrama de caja y bigotes 11. Porcentaje de la variable: tramo de la enfermedad.

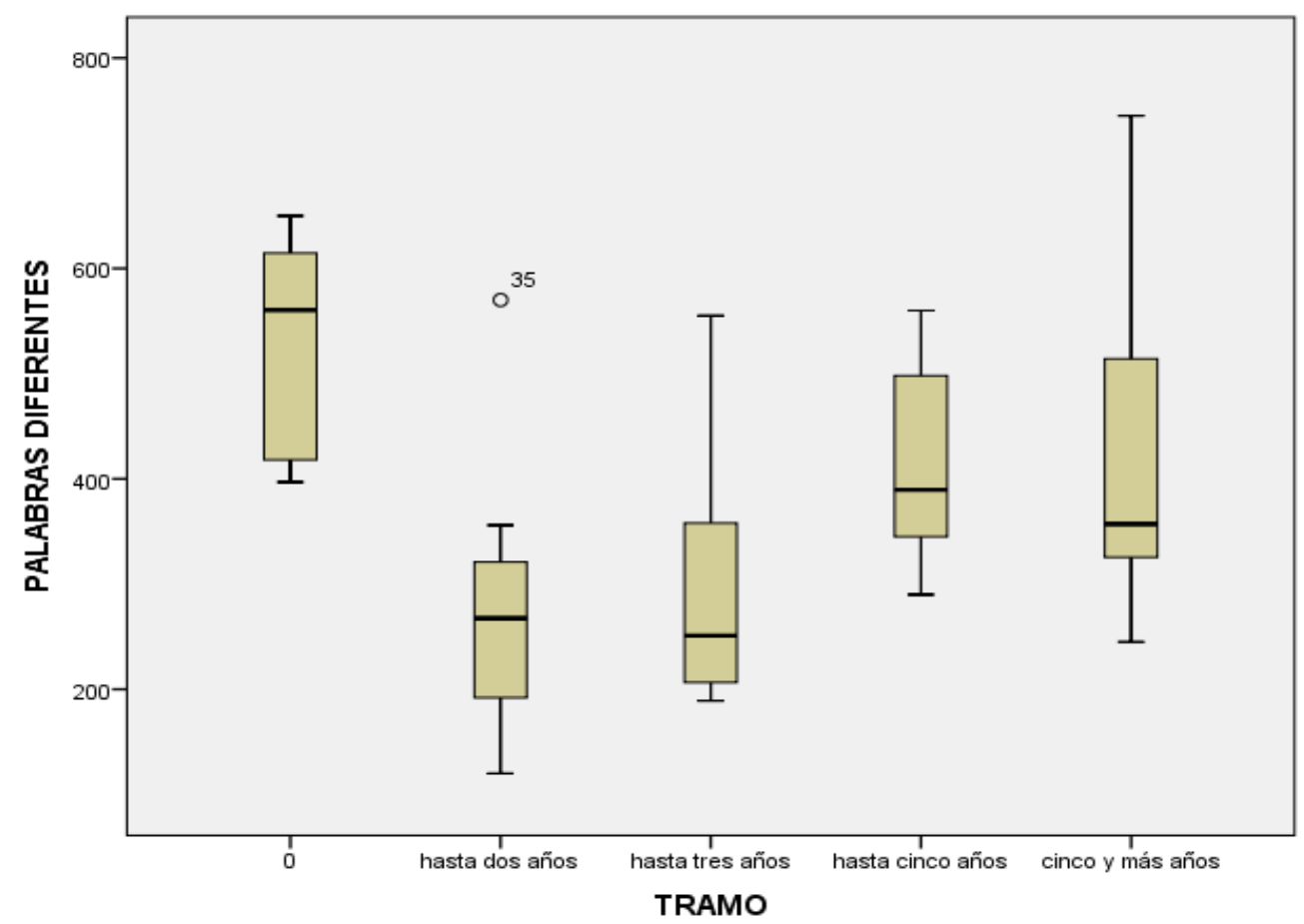

\subsubsection{Palabras diferentes y subtipo de la enfermedad}

Con respecto al análisis de las medias correspondientes a las palabras diferentes según el factor sexo de los sujetos, a continuación se muestran los resultados del análisis paramétrico ANOVA, según el cual la media para los controles es de 429, 167; para los paranoide de 193, 242; para los indiferenciada, 230,667 y para los de esquizofrenia desorganizada, de 196, 250. Los resultados son significativos estadísticamente. 
Tabla de contingencia 74: palabras diferentes y subtipo de la enfermedad.

\begin{tabular}{||l|c|c|c|c|c||}
\hline \multicolumn{7}{|c||}{ Pruebas de los efectos inter-sujetos } \\
\hline Variable dependiente: & Total de oraciones & Sig. \\
\hline Origen & $\begin{array}{c}\text { Suma de } \\
\text { cuadrados tipo } \\
\text { III }\end{array}$ & Gl & $\begin{array}{c}\text { Media } \\
\text { cuadrática }\end{array}$ & F & \\
\hline Modelo corregido & $516267,111^{\mathrm{a}}$ & 3 & 172089,037 & 27,885 &, 000 \\
\hline
\end{tabular}

Gráfico 39. Porcentaje de frecuencia de las variables: palabras diferentes y subtipo de la enfermedad.

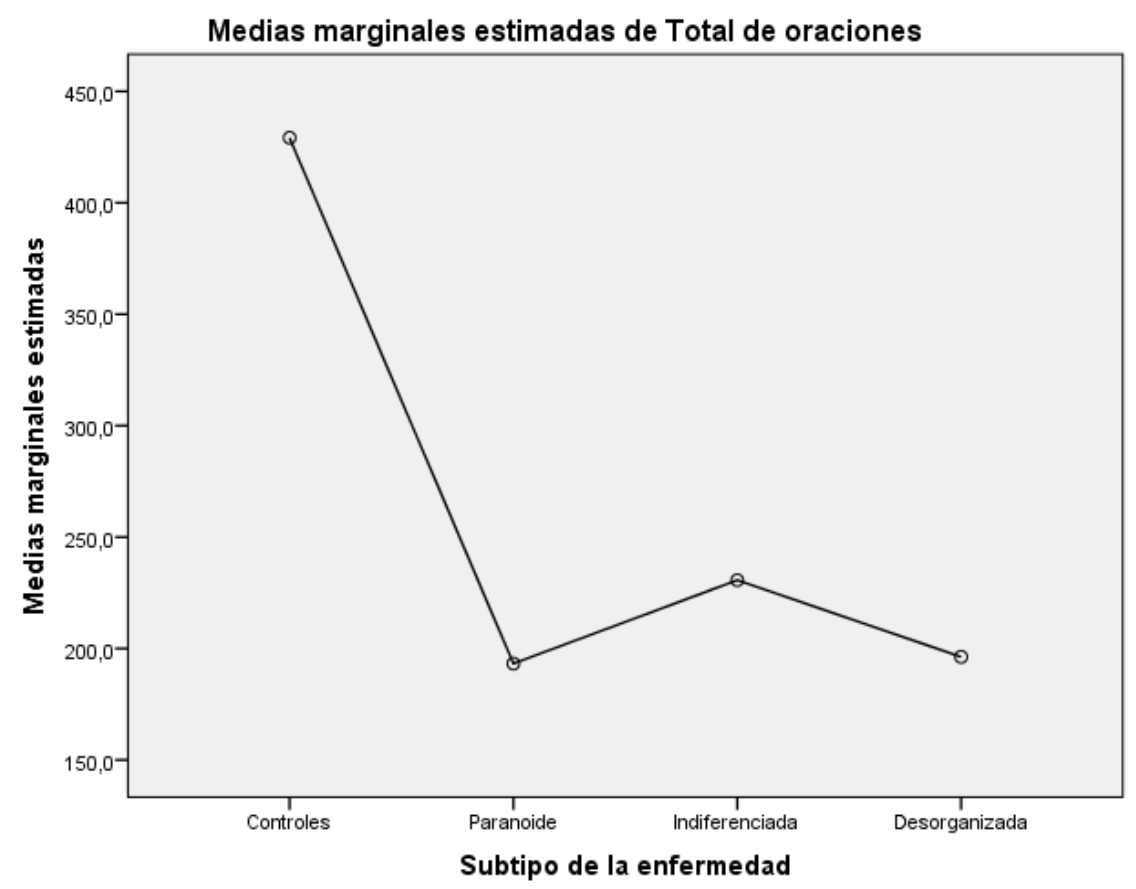

Con el fin de verificar si la dispersión de los datos presentaba alguna anomalía, se incluye el diagrama de caja y bigotes correspondiente. 
40. Diagrama de caja y bigotes 12. Porcentaje de la variable: subtipo de la enfermedad.

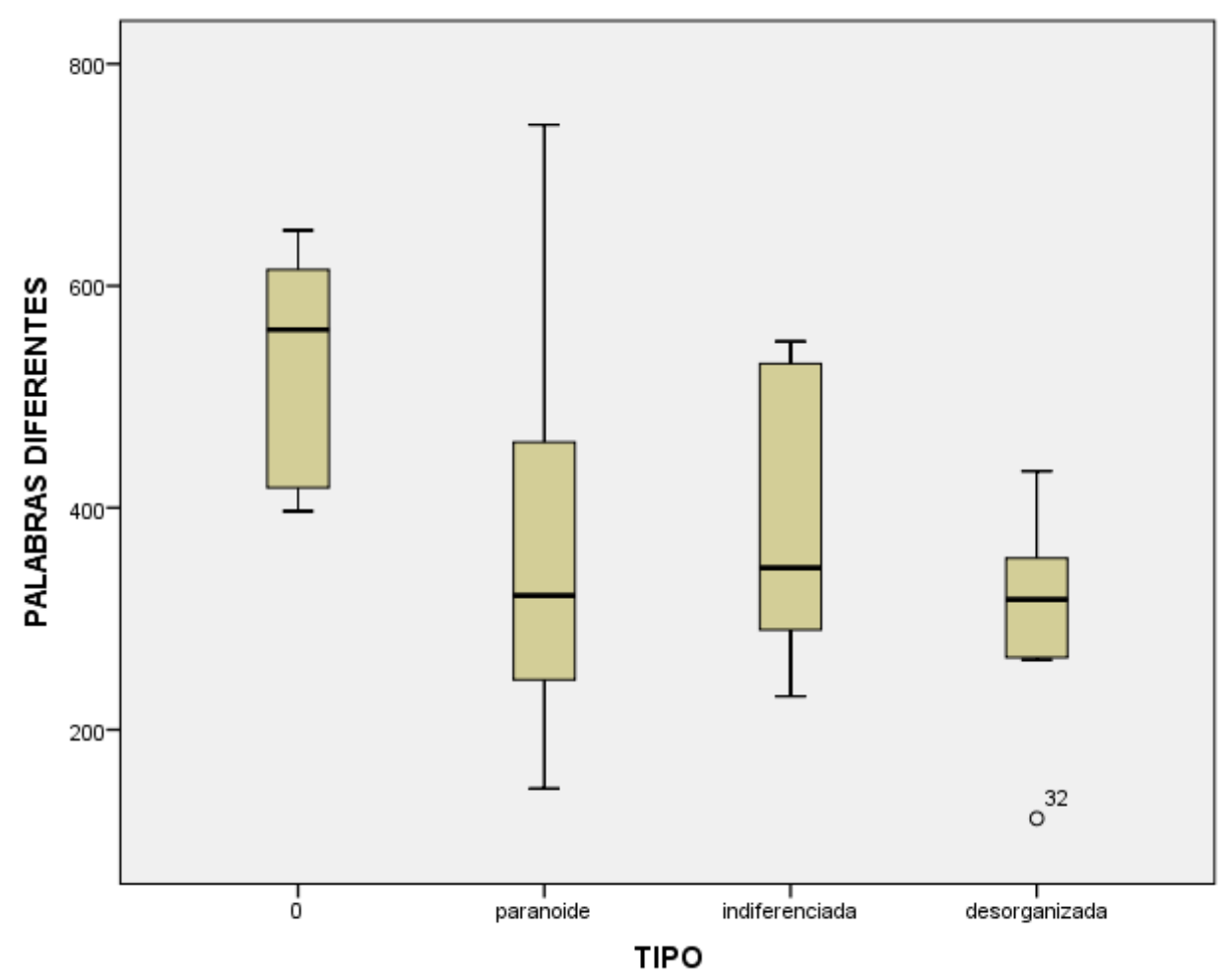

\subsubsection{Neologismos parciales}

Se trata de palabras que presentan algún vínculo semántico con el contexto debido a un desplazamiento ya sea en su morfología o en su significado, sin embargo, aún pueden cumplir propósitos comunicativo-discursivos, como podemos apreciar en los siguientes ejemplos, a los que le hemos añadido una definición aproximada en el contexto en que fueron empleados por los informantes:

1) Bajeza: evento o situación o cosa de escasa importancia: ej: "digo/ ya no tengo que preocuparmel preocuparme tanto de esto si<pausa>/ es una es una bajezal es algo que <pausa>/ no tiene sentido" (PEE-M04) 
2) Catratonia: por catatonía, ej: "Que quedo mirando hacia arriba como una catra, catratonia"(PEE-M02)

3) Denergisa: perder vigor, ej: "porque sé, porque el cuerpo se denergisa" (CRE-M02)

4) Desgasto: cansancio o desinterés, ej: “No/ tenía un desgasto para conversar"(CRE-H01)

5) Emprendimiento: una lección aprendida, ej: "o sea no secuelas, si no que un emprendimiento<pausa>/ de nunca levantar la mano a nadie"38 (CRE-M02)

6) Enigrama: por crucigrama, fusión de enigma y crucigrama, ej: "tras otro pensamiento/ tengo que resolver como un enigramal un enigrama que tengo que resolver con los pensamientos que me $d a "$ (PEE-M02)

7) Enlace: por pelea " $y$ uno no sale de ese enlace y si está en un en una pieza hay que salir de ahí para salvarse, ¿entiende? y no seguir el mismo juego" (CRE-M02)

8) Fortificada: por sentirse fortalecido, ej: "Este año no/ no estuve más fortificada $\langle$ pausa > no más fortificada si" (CRE-M11)

9) Insoldable: por insondables, ej: “No, no son solucionables para el problema de la psiquis, así que algo más insoldable más $\langle$ pausa > más<pausa > como le dijera es como un velo, un velo mágico que hay que saber llegar a la psiquis". (CRE-H01)

10) Reconciliador: Por reparador "Pero dormíamos súper bien con mi hijo reconciliador el sueño, con mi hijo yo le ponía el bracito<pausa >/ en su <pausa>/ en su cabecita y él se dormía pero al tiro/ al tiro" (CRE-M-02)

11) Respingué: por enderezarse, ej: "me respingué [...] así y me vi el cuerpo y dije: ‘¡oh que hermoso!'/ 'soy delgada'/ "iqué linda que soy!'/"

12) Ropaje: por ropa, ej: "Eh<pausa $>/$ el niño dejó de faltar a la escuela por eh<pausa $>/$ falta de ropaje" (CRE-M08)

${ }^{38}$ Para más contexto S: No es que si a uno la golpean, uno golpeall/ E: Ya.//I S: ¿Entiende? <pausa>/ y uno no sale de ese enlace y si está en un/ en una pieza/ hay que salir de ahí para salvarse/ ¿entiende?/ y no seguir el mismo juego/// E: Ok. [...] E: Con los golpes/ usted dice que le causaron golpes <pausa>II/ S: Ah si/ no/ eso no más/ eso no más/ eh y pena/ penal pena de víctima<pausa>/ sentirme víctima,/¿entiende?/II E: Si<pausa>/ ¿Cuándo fue eso?III S: En<pausa>/ ahí por el<pausa>/ mire la fecha que más me golpearon fue el 2007/ ahilll E: Hace pocol/IS: Hace poco sil el otro añol//E: ¿Y le dejó alguna secuela esto a usted?/I/S: Secuelas no///E: ¿Qué le pasaba?///S: O sea no secuelas/ si no que un emprendimiento<pausa>/ de nunca levantar la mano a nadiel/IE: ¿A qué se refiere con emprendimiento?/I/S: De<pausa>/ no de<pausa>/ de<pausa>/ de no querer por ejemplo si<pausa>/ si te dan una $<$ pausa $>/$ como te dice una $<$ pausa $>/$ que no sé cómo decirlo/ una premisa [...]" 
13) Salomones: asociado a una persona santa, ej: "S: En todas/ en varias partes hay dioses/ en todas partes hay salomones//E: ¿Cómo son esos dioses y esos salomones?//S: Son personas buenas<pausa ext>/ personas buenas <pausa>/que muchas veces abusan de ellos por ser tan buenos" (CRE-03)

14) Soberanearse: hacerse dueño de una cosa y dominarla, ej: "eso yo creo que es $\langle$ pausa $\rangle$ / ella le gusta ella soberanearse sobre los demás". (CRE-M08)

15) Soberanía: autoridad, ej: "Porque<pausa>/ porque mi mamá cuando discute no le gusta que la pasen a llevar en su/ en su soberanía/ ¿me entiende?/ mental”. (CRE-M08)

4.2.5.1. Neologismos parciales y estadio de la enfermedad

La aplicación de la prueba no paramétrica Anova de Kruskal-Wallis, por su parte, arroja como rangos promedio 1,516y en el estadio de la enfermedad 1,21. En el promedio de neologismos parciales en los crónicos, se observa un rango promedio de 22, 22 y en los de primer episodio de 28, 78. El resultado de Chi cuadrado fue de 3,178 , que da como resultado $(<\mathrm{p}, 075>)$ no significativo estadísticamente.

Tabla valor de chi cuadrado 75: neologismos parciales y estadio de la enfermedad.

\begin{tabular}{||l|r||}
\hline \multicolumn{2}{|c|}{ Estadísticos de contraste ${ }^{\mathbf{a}, \mathbf{b}}$} \\
\hline & \multicolumn{1}{|c|}{ Neologismos parciales } \\
\hline Chi-cuadrado & 3,178 \\
\hline Gl & 1 \\
\hline Sig. asintót. &, 075 \\
\hline
\end{tabular}

Con el fin de verificar si la dispersión de los datos presentaba alguna anomalía, se incluye el diagrama de caja y bigotes correspondiente. 
41.Diagrama de caja y bigotes 13. Porcentaje de la variable: estadio.

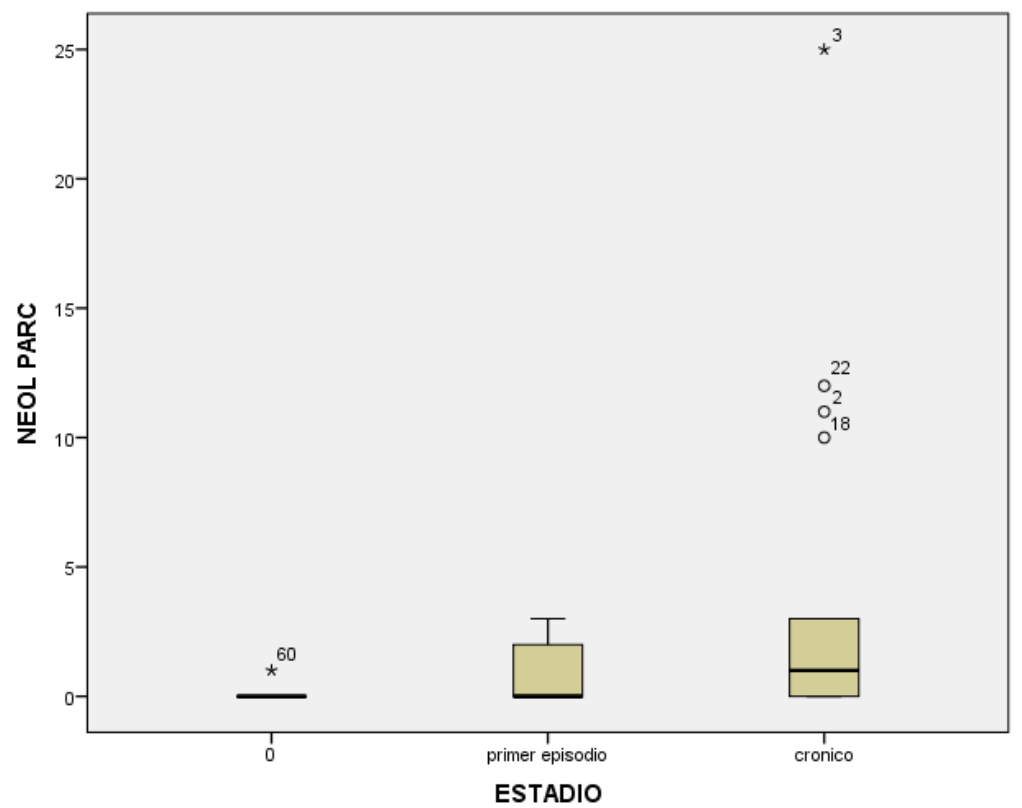

\subsubsection{Neologismos parciales y sexo}

La aplicación de la prueba no paramétrica Anova de Kruskal-Wallis, por su parte, arroja como rangos promedio 1,516 y sexo de los individuos 1,53. En el promedio de neologismos parciales en los hombres se observa un promedio de 34, 53 y en las mujeres, de 28,05. El valor de chi cuadrado es de 2,738, (<p, 098>)

Tabla valor de chi cuadrado 76: neologismos parciales y sexo.

\begin{tabular}{|c|c|}
\hline \multicolumn{2}{|c|}{ Estadísticos de contraste $^{\mathrm{a}, \mathrm{b}}$} \\
\hline & Neologismos parciales \\
\hline Chi-cuadrado & 2,738 \\
\hline
\end{tabular}


Con el fin de verificar si la dispersión de los datos presentaba alguna anomalía, se incluye el diagrama de caja y bigotes correspondiente.

42.Diagrama de caja y bigotes 14. Porcentaje de la variable: sexo.

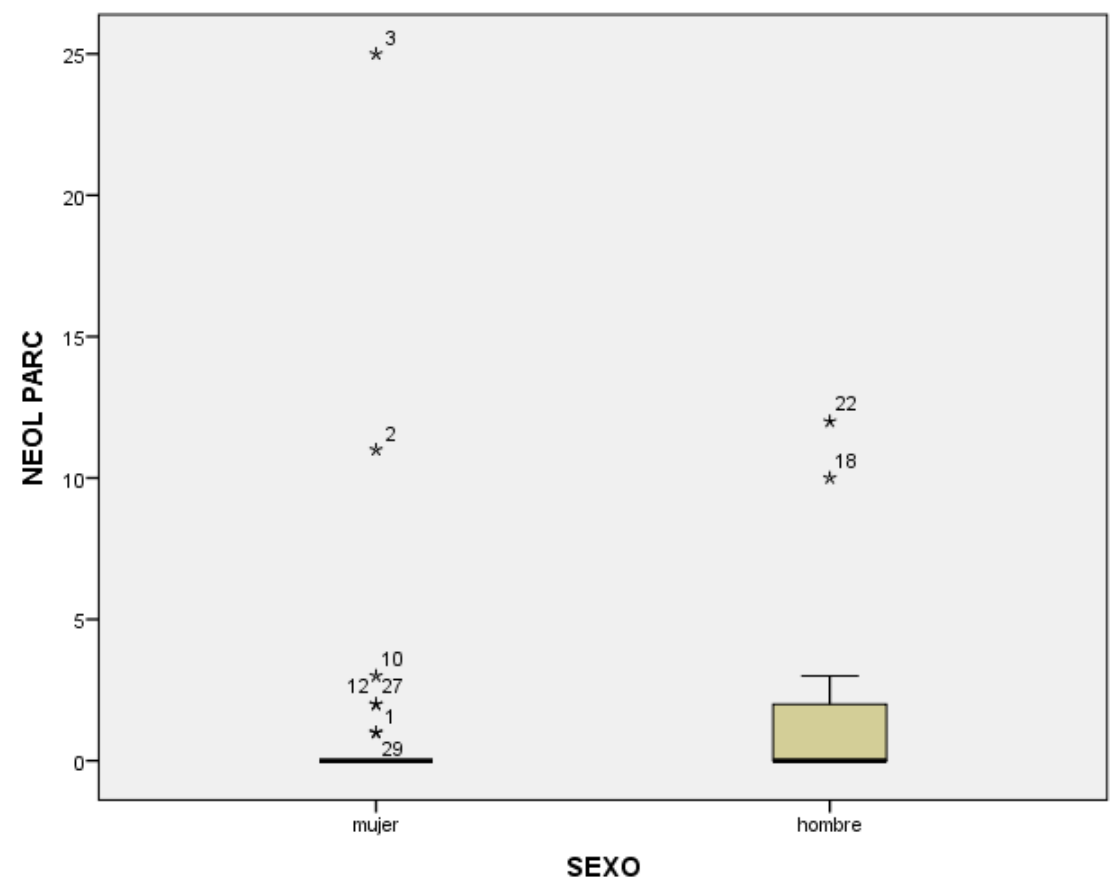

4.2.5.3. Neologismos parciales y tramo de la enfermedad

La aplicación de la prueba no paramétrica Anova de Kruskal-Wallis, por su parte, arroja como rangos promedio 1,516 y tramo de la enfermedad de 2,03. En el promedio de neologismos parciales en los primer episodio de $>0$ a $<2$ años es de 19,82, primer episodio de <2 a >3 años es de 25,27; en los crónicos de hasta cinco años, es de 27,65 y en los crónicos de cinco años y más, es de 29, 53. El valor de chi cuadrado es de 4,386, dio como resultado ( $\langle\mathrm{p}, 223\rangle)$, no siendo significativo estadísticamente. 
Tabla valor de chi cuadrado 77: neologismos parciales y tramo de la enfermedad.

\begin{tabular}{||l|r||}
\hline \multicolumn{2}{|c|}{ Estadísticos de contraste $^{\mathbf{a}, \mathbf{b}}$} \\
\hline & $\begin{array}{c}\text { Neologismos } \\
\text { parciales }\end{array}$ \\
\hline Chi-cuadrado & 4,386 \\
\hline Gl & 3 \\
\hline Sig. asintót. &, 223 \\
\hline
\end{tabular}

Con el fin de verificar si la dispersión de los datos presentaba alguna anomalía, se incluye el diagrama de caja y bigotes correspondiente.

43. Diagrama de caja y bigotes 15. Porcentaje de la variable: tramo de la enfermedad.

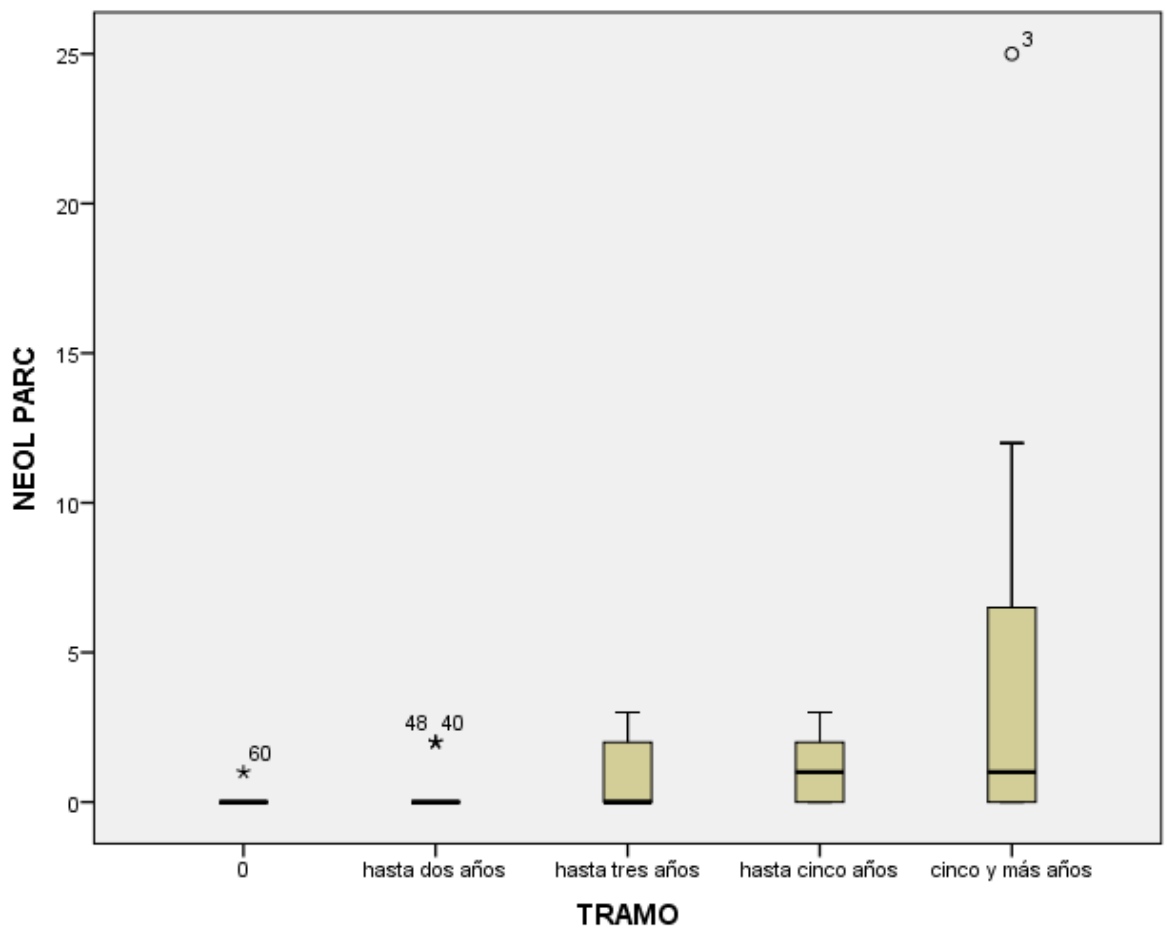




\subsubsection{Neologismos parciales y subtipo de la enfermedad}

La aplicación de la prueba no paramétrica Anova de Kruskal-Wallis, por su parte, arroja como rangos promedio 1,516 y subtipo de la enfermedad de 1,21. En el promedio de neologismos parciales en los paranoide es de 27, 14, en los indiferenciada es de 17, 50 y en los desorganizada, es de 27, 75. El valor de chi cuadrado es de 4,165, que dio como resultado $(<\mathrm{p}, 125>)$, no significativo estadísticamente.

Tabla valor de chi cuadrado 78: neologismos parciales y subtipo de la enfermedad.

\begin{tabular}{||l|r||}
\hline \multicolumn{2}{|c||}{${\text { Estadísticos de } \text { contraste }^{\mathbf{a}, \mathbf{b}}}^{-2}$} \\
\hline & \multicolumn{2}{|c||}{ Neologismos parciales } \\
\hline Chi-cuadrado & 4,165 \\
\hline Gl & 2 \\
\hline Sig. asintót. &, 125 \\
\hline
\end{tabular}

Con el fin de verificar si la dispersión de los datos presentaba alguna anomalía, se incluye el diagrama de caja y bigotes correspondiente. 


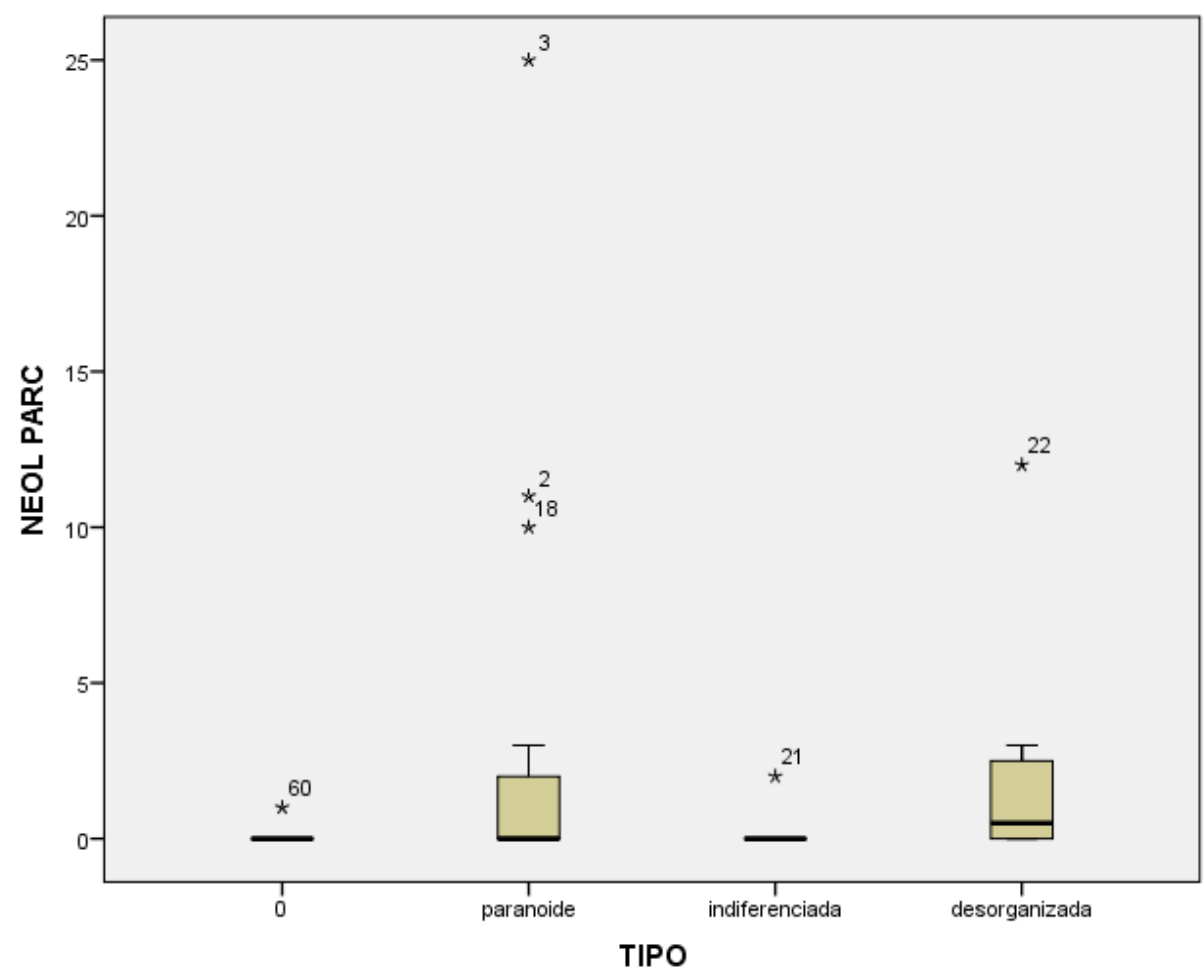

\subsubsection{Neologismos totales}

Son palabras a las que no pueden asignársele significado, están desprovistas de sentido para contribuir a una mejor comprensión de los enunciados en que se utilizan:

1. Eleotósticos: “[...] S: Ellos son eleotósticos///E: ¿Eleotósticos? ¿Y qué significa eso?///S: son los que hablan mentalmente con las personas/ ¿me entiende?” (PEE-H02)

2. Gutaporio/gubatorio: "[...] E: ¿Sabe dónde está ahora?//S: Aquí ta gubatorio, en el gutaporio"

3. Home/verba: E: ¿Pertenece a la inteligencia naval?/ ¿Cómo adquirió esa capacidad?///S: por homel mi new home y por verba/ en mi forma de ser siempre he sido asíl prolijo/ esa forma de ser prolija/ de excelencia/ se contrapone a la forma en que yo estaba siempre<pausa >/ con la gentel relacionándome” (CRE-H06) 
4. Soberbonante/chiconaniqueante/insistentene/ desgrobosoba/ pasteliban/ gie espet: " $S$ : consiste en ir insistentenel porque yo no veo televisión y nunca he visto la televisión/ ahora estoy viendo programas regrabados y el cable no se desgraval no se desgravabal ni se se desgrobosobal se pasteliban y mi robot la aplastó pa' que se haga la luz y la electricidad <pausa>/ tengo dos robos ahoral que tengo que alimentar entonces vinieron unas familias del cementeriol primero vinieron unos a pedir préstamos/ préstamos que querían/ después vinieron otros del cementerio a vender flores/ ahí y anteriormente ahí/ vendían cadina un neoprén//Más allál en San Bernardo había una ferretería de gie espet / y aqui en bonanza <pausa>/ había una ferretería mil pren [...] no existe la espada del augurio/ esos son perros los tengo que alimentar/<pausa ext>/ lo que dije significa tengo que solventarme/ ya que nadie me solventa y tengo que solventar a mis mascotas/mis mascotas no me van a protegerme nuncal entonces acabo de alimentar a mis mascotas y ahora tengo que congelarlas a todas". (CRE-H10) $)^{39}$

5. Under: "under es como una manera minoritaria de pararme frente a la vidal o seal no estoy buscando otros naturales que son tradicionales/ ¿cómo se podría decir?/ gente común/ diferenciado que es común/ de común de cualquier otro mi forma de vestir/ los lugares donde voy/ la manera de confrontar la vida y siento que la cultura chilena tipo/ no es parte de mi cultura, pero sí es mi país". (CRE-H06)

4.2.6.1. Neologismos totales y estadio de la enfermedad

La aplicación de la prueba no paramétrica Anova de Kruskal-Wallis, por su parte, arroja como rangos promedio 1, 048 y estadio de la enfermedad de 1,21. En el promedio de neologismos totales en los crónicos es de 26, 96, en los de primer episodio, es de 24, 04. El valor de chi cuadrado es de 1,851, que dio como resultado $(<p, 174>)$, no significativo estadísticamente.

Tabla valor de chi cuadrado 79: neologismos totales y estadio de la enfermedad.

\begin{tabular}{|c|c|}
\hline \multicolumn{2}{|c|}{ Estadísticos de contraste ${ }^{a, b}$} \\
\hline & Neologismos totales \\
\hline Chi-cuadrado & 1,851 \\
\hline Gl & 1 \\
\hline Sig. asintót. &, 174 \\
\hline
\end{tabular}

\footnotetext{
${ }^{39}$ El sujeto CRE-H10, presenta un registro de más de 60 neologismos totales con una alta ocurrencia en la mayoría de los turnos de habla, aquí exponemos solo algunos de ellos.
} 
Con el fin de verificar si la dispersión de los datos presentaba alguna anomalía, se incluye el diagrama de caja y bigotes correspondiente.

45. .Diagrama de caja y bigotes 17. Porcentaje de la variable: estadio de la enfermedad

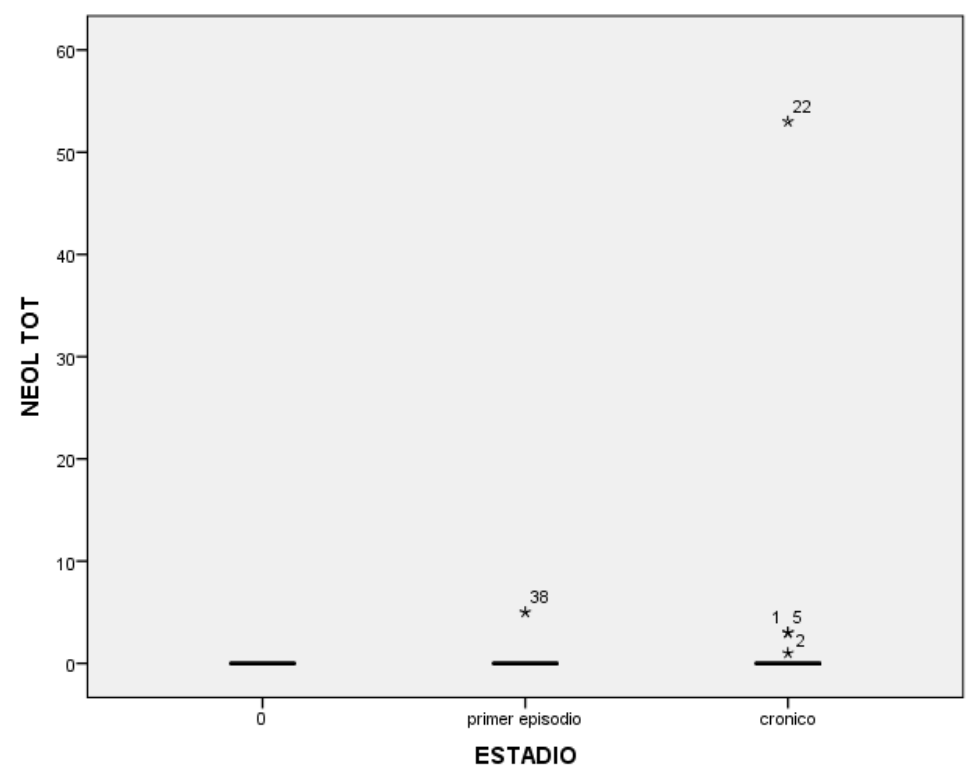

\subsubsection{Neologismos totales y sexo}

La aplicación de la prueba no paramétrica Anova de Kruskal-Wallis, por su parte, arroja como rangos promedio 1, 048 y sexo de los sujetos de 1,53. En el promedio de neologismos totales en los hombres es de 30, 97, en cambio en las mujeres, es de 32,10. El valor de chi cuadrado es de ,273 que dio como resultado $(<\mathrm{p}$, 601>), no significativo estadísticamente. 
Tabla valor de chi cuadrado 80: neologismos totales y sexo.

\begin{tabular}{|c|c|}
\hline & Neologismos totales \\
\hline Chi-cuadrado &, 273 \\
\hline Gl & 1 \\
\hline Sig. asintót. &, 601 \\
\hline
\end{tabular}

Con el fin de verificar si la dispersión de los datos presentaba alguna anomalía, se incluye el diagrama de caja y bigotes correspondiente.

46. .Diagrama de caja y bigotes 18. Porcentaje de la variable: sexo

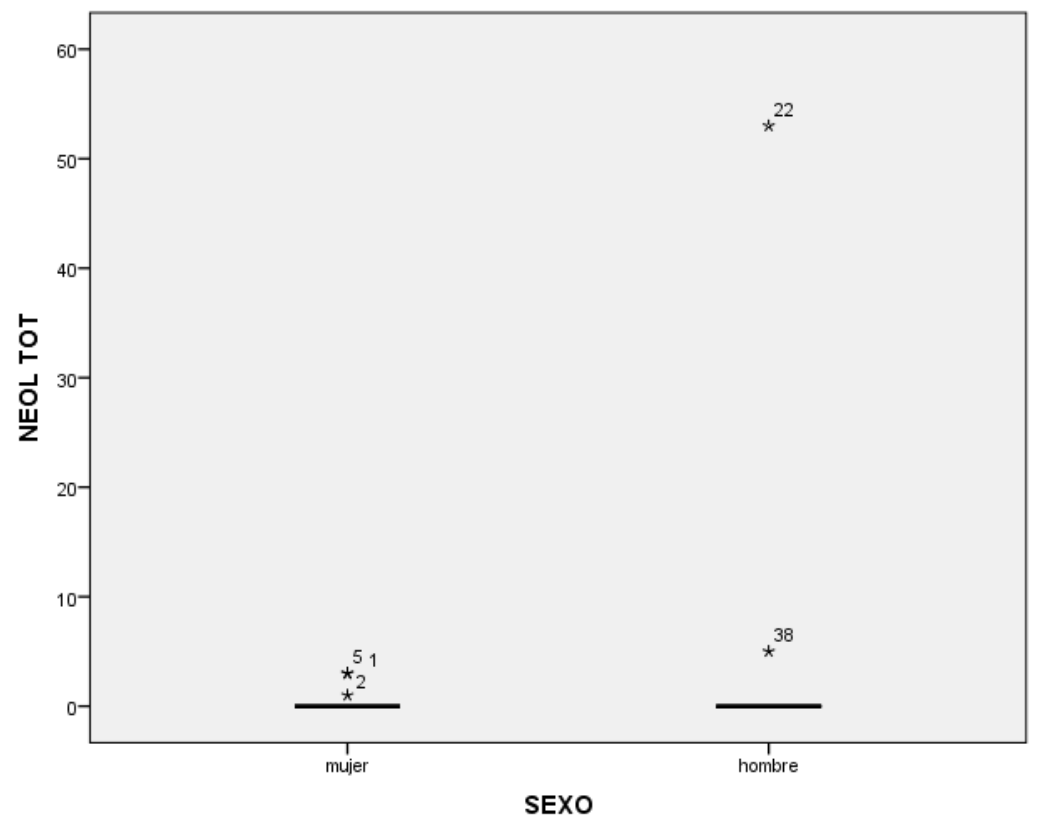




\subsubsection{Neologismos totales y tramo de la enfermedad}

La aplicación de la prueba no paramétrica Anova de Kruskal-Wallis, por su parte, arroja como rangos promedio 1, 048 y tramo de la enfermedad de 2,03. En el promedio de neologismos totales en los primer episodio de $>0$ a $<2$ años es de 23,00, primer episodio de <2 a >3 años es de 25,36; en los crónicos de hasta cinco años, es de 23,00 y en los crónicos de cinco años y más, es de 29, 60. El valor de chi cuadrado es de 6,986, dio como resultado $(<\mathrm{p}, 072)$, no siendo significativo estadísticamente.

Tabla valor de chi cuadrado 81: neologismos totales y tramo de la enfermedad.

\begin{tabular}{||l|r||}
\hline \multicolumn{2}{|c|}{ Estadísticos de contraste } \\
\hline & Neologismos totales \\
\hline Chi-cuadrado & 6,986 \\
\hline Gl & 3 \\
\hline Sig. asintót. &, 072 \\
\hline
\end{tabular}

Con el fin de verificar si la dispersión de los datos presentaba alguna anomalía, se incluye el diagrama de caja y bigotes correspondiente. 
47. .Diagrama de caja y bigotes 19. Porcentaje de la variable: tramo de la enfermedad.

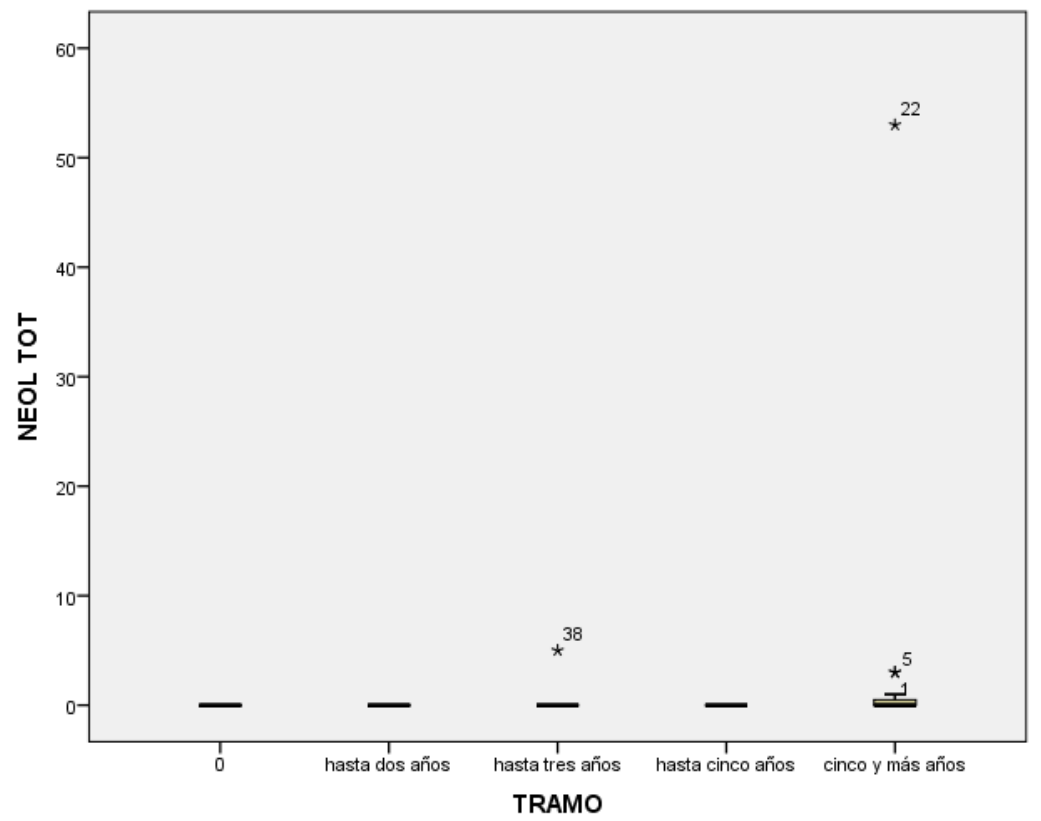

4.2.6.4. Neologismos totales y subtipo de la enfermedad

La aplicación de la prueba no paramétrica Anova de Kruskal-Wallis, por su parte, arroja como rangos promedio 1,048 y subtipo de la enfermedad de 1,21. En el promedio de neologismos totales en los paranoide es de 24,44 , en los de esquizofrenia indiferenciada es de 23,00 y en los de desorganizada, es de 32,69. El valor de chi cuadrado es de 8,797, que dio como resultado ( $<\mathrm{p}, 012\rangle)$, no significativo estadísticamente. 
Tabla valor de chi cuadrado 82: neologismos totales y subtipo de la enfermedad.

\begin{tabular}{||l|r||}
\hline \multicolumn{2}{|c|}{ Estadísticos de contraste } \\
\hline & $\begin{array}{c}\text { Neologismos } \\
\text { totales }\end{array}$ \\
\hline Chi-cuadrado & 8,797 \\
\hline Gl & 2 \\
\hline Sig. asintót. &, 012 \\
\hline
\end{tabular}

Con el fin de verificar si la dispersión de los datos presentaba alguna anomalía, se incluye el diagrama de caja y bigotes correspondiente.

48. Diagrama de caja y bigotes 20. Porcentaje de la variable: subtipo de la enfermedad

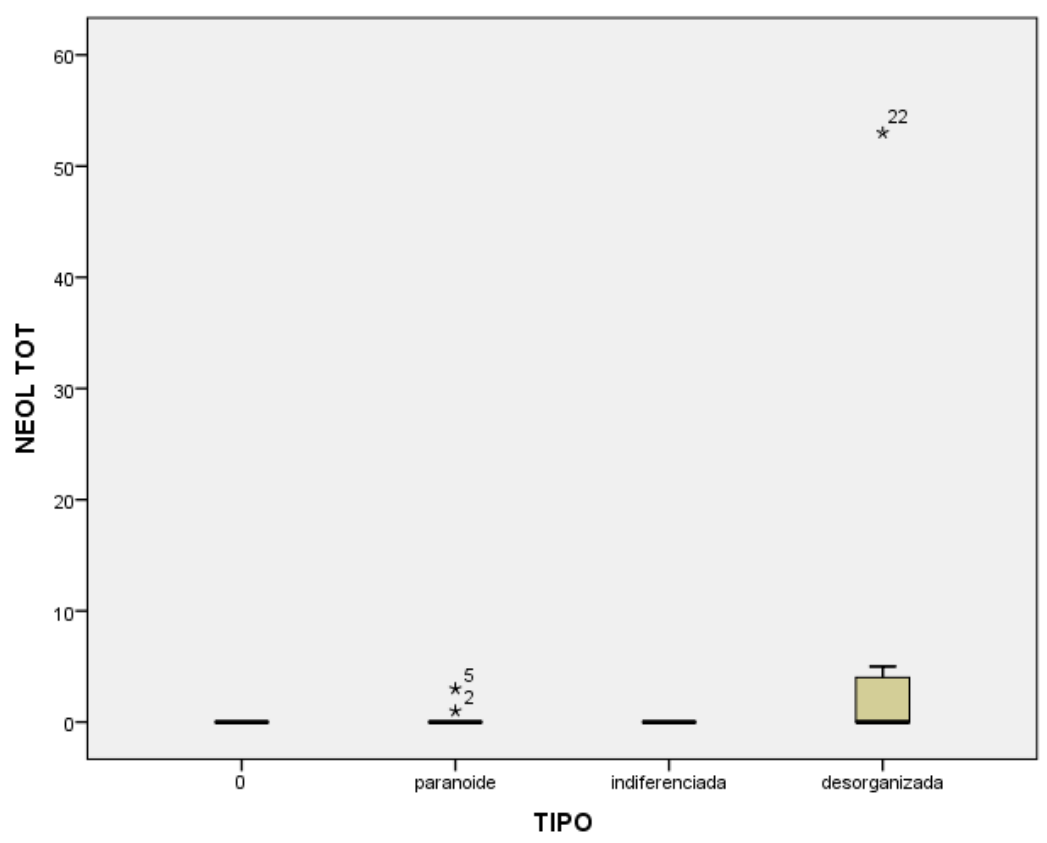




\subsubsection{Referentes}

Los referentes son figuras denotativas que se expresan como modelos de lo representado, que muestran una relación con una entidad del mundo o del universo creado en el discurso, ya sea mental, física o extralingüística. Jakobson señala que, para poder comunicar el referente, se requiere de un contexto, aprehendido por el hablante. Además, dicho contexto debe estar compartido con el oyente para que exista una interacción comunicativa eficiente. Nos interesa saber si hay diferencias entre la cantidad de referentes enunciados y además, verificar cuál es el tratamiento que reciben en el discurso, si es que hay o no diferencias en la calidad de las elaboraciones discursivas donde estos se sitúan y, por último, comprobar si son desarrollados a través de la vinculación de elementos, o solo se enuncian sin desarrollo del contexto requerido. Vimos que respecto a los aspectos cuantitativos, existen diferencias entre los tres grupos. En el grupo de los controles observamos un promedio de referentes de 120, todos con desarrollo contextual, comprendidos por el entrevistador. Entre los crónicos se registró una disminución que llega a 95 referentes en promedio, aproximadamente. La formulación de los referentes es singular, ya que se observa que muchos de ellos solo se enuncian como elementos sueltos o fragmentarios. Finalmente en el grupo de los de primer episodio, la disminución alcanza a 60 referentes en promedio, pese a que presentan alrededor de un 50\% menos que los controles, tenemos que señalar que no se elicitan referentes desprovistos de contexto.

\subsubsection{Referentes y estadio de la enfermedad}

La aplicación de la prueba no paramétrica Anova de Kruskal-Wallis, por su parte, arroja como rangos promedio 42, 194 y estadio de la enfermedad de 1,21. En el promedio de referentes en los crónicos es de 33, 22, en los de primer episodio, es de 
17,78. El valor de chi cuadrado es de 14,046 , que dio como resultado $(<p, 000\rangle)$, significativo estadísticamente.

Tabla valor de chi cuadrado 83: referentes y estadio de la enfermedad.

\begin{tabular}{||l|r||}
\hline \multicolumn{2}{|c||}{ Estadísticos de contraste } \\
\hline & \multicolumn{2}{|c|}{ Referentes } \\
\hline Chi-cuadrado & 14,046 \\
\hline Gl & 1 \\
\hline Sig. asintót. &, 000 \\
\hline
\end{tabular}

Con el fin de verificar si la dispersión de los datos presentaba alguna anomalía, se incluye el diagrama de caja y bigotes correspondiente.

49.Diagrama de caja y bigotes 21. Porcentaje de la variable: estadio de la enfermedad

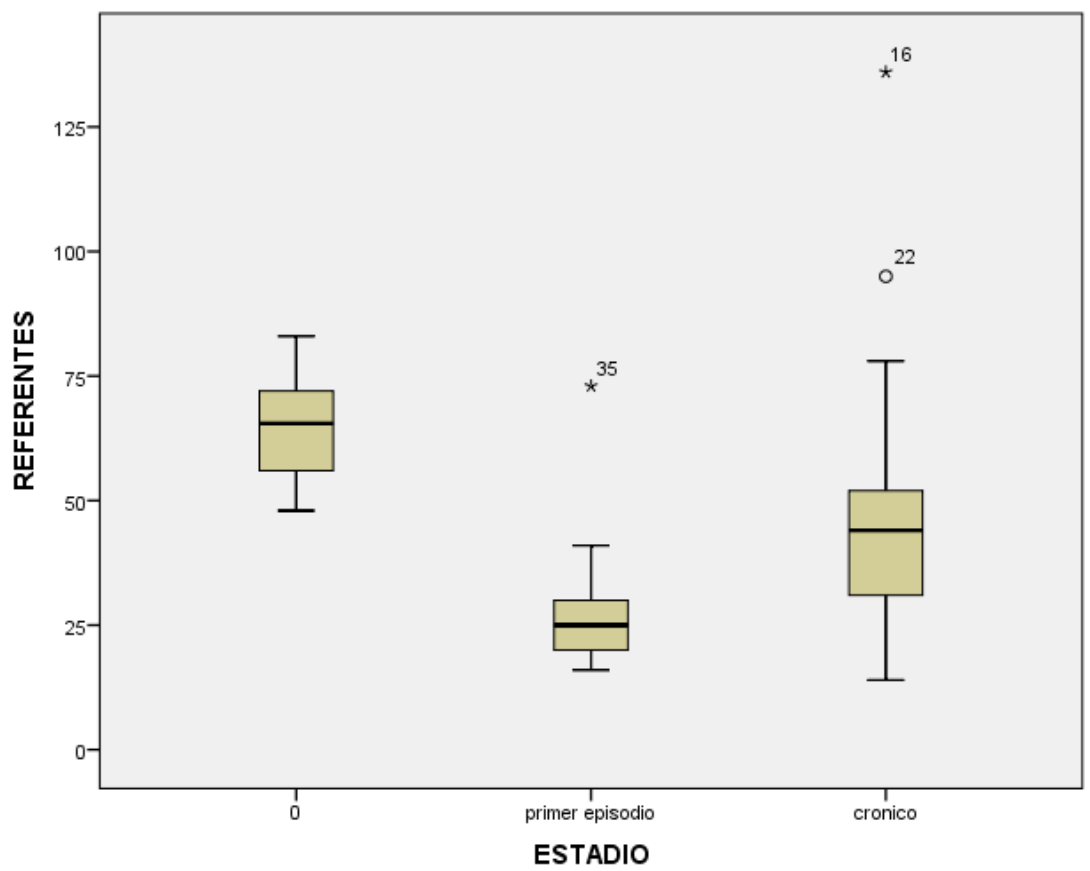




\subsubsection{Referentes y sexo}

La aplicación de la prueba no paramétrica Anova de Kruskal-Wallis, por su parte, arroja como rangos promedio 42, 194 y sexo de los sujetos de 1,53. En el promedio de referentes en los hombres es de 33,42, en cambio en las mujeres, es de 29,31. El valor de chi cuadrado es de ,803 que dio como resultado ( $<\mathrm{p}, 370>$ ), no significativo estadísticamente.

Tabla valor de chi cuadrado 84: referentes y sexo.

\begin{tabular}{||l|r||}
\hline \multicolumn{2}{||c||}{ Estadísticos de contraste $^{\mathbf{a}, \mathbf{b}}$} \\
\hline & \multicolumn{2}{|c|}{ Referentes } \\
\hline Chi-cuadrado &, 803 \\
\hline Gl & \\
\hline Sig. asintót. & \\
\hline
\end{tabular}

Con el fin de verificar si la dispersión de los datos presentaba alguna anomalía, se incluye el diagrama de caja y bigotes correspondiente. 
50.Diagrama de caja y bigotes 22. Porcentaje de la variable: sexo

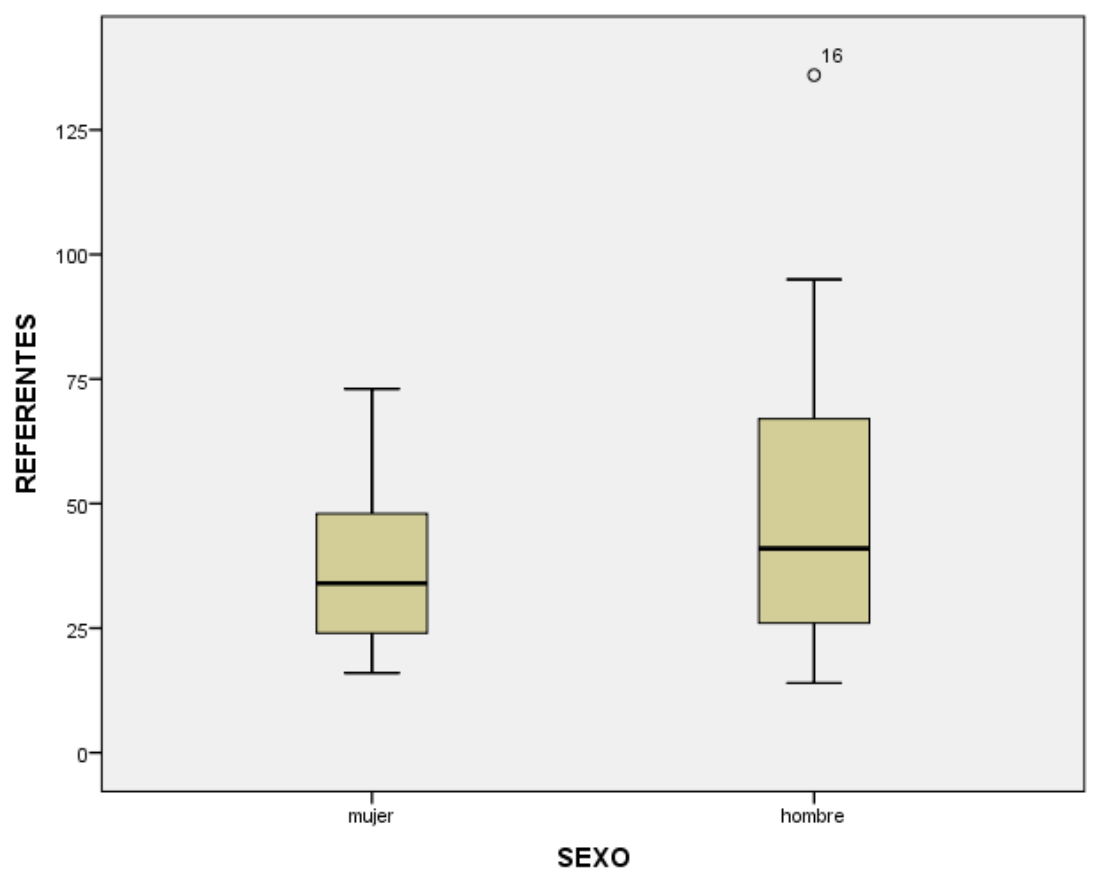

4.2.7.3. Referentes y tramo de la enfermedad

La aplicación de la prueba no paramétrica Anova de Kruskal-Wallis, por su parte, arroja como rangos promedio 42, 194 y tramo de la enfermedad de 2,03. En el promedio de neologismos totales en los de primer episodio de $>0$ a $<2$ años es de 17,79, primer episodio de <2 a >3 años es de 17,77; en los crónicos de hasta cinco años, es de 29,70 y en los crónicos de cinco años y más, es de 35,57. El valor de chi cuadrado es de 15,019, dio como resultado ( $<\mathrm{p}, 002)$, siendo significativo estadísticamente. 
Tabla valor de chi cuadrado 85: referentes y tramo de la enfermedad.

\begin{tabular}{||l|r||}
\hline \multicolumn{2}{|c||}{ Estadísticos de contraste $^{\mathbf{a}, \mathbf{b}}$} \\
\hline & \multicolumn{2}{|c|}{ Referentes } \\
\hline Chi-cuadrado & 15,019 \\
\hline Gl & 3 \\
\hline Sig. asintót. &, 002 \\
\hline
\end{tabular}

Con el fin de verificar si la dispersión de los datos presentaba alguna anomalía, se incluye el diagrama de caja y bigotes correspondiente.

51.Diagrama de caja y bigotes 23. Porcentaje de la variable: tramo de la enfermedad

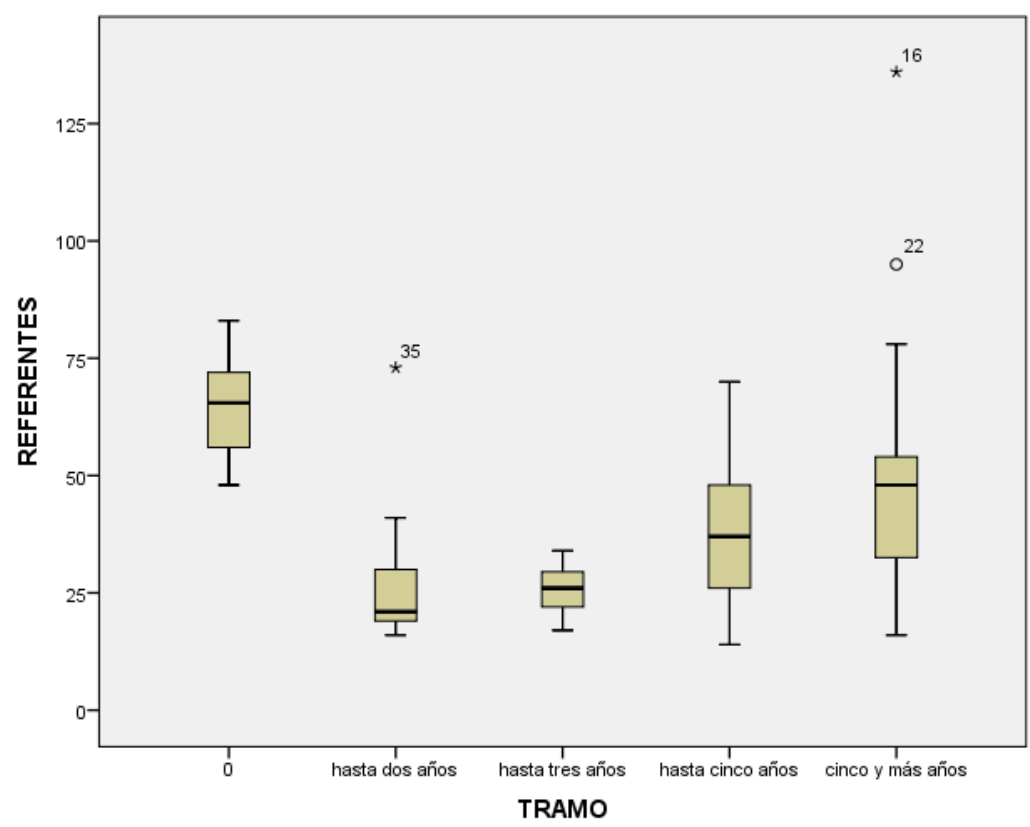




\subsubsection{Referentes y subtipo de la enfermedad}

La aplicación de la prueba no paramétrica Anova de Kruskal-Wallis, por su parte, arroja como rangos promedio 42, 194 y subtipo de la enfermedad de 1,21. En el promedio de neologismos totales en los paranoide es de 24,61 , en los de esquizofrenia indiferenciada es de 27,39 y en los de desorganizada, es de 27,06. El valor de chi cuadrado es de ,368 que dio como resultado ( $<\mathrm{p}, 832\rangle)$, no significativo estadísticamente.

Tabla valor de chi cuadrado 86: referentes y subtipo de la enfermedad.

\begin{tabular}{||l|r||}
\hline \multicolumn{2}{|c||}{ Estadísticos de contraste ${ }^{\mathrm{a}, \mathrm{b}}$} \\
\hline & \multicolumn{1}{|c||}{ Referentes } \\
\hline $\begin{array}{l}\text { Chi- } \\
\text { cuadrado }\end{array}$ &, 368 \\
\hline Gl & 2 \\
\hline Sig. asintót. &, 832 \\
\hline
\end{tabular}

Con el fin de verificar si la dispersión de los datos presentaba alguna anomalía, se incluye el diagrama de caja y bigotes correspondiente. 
52.Diagrama de caja y bigotes 24. Porcentaje de la variable: subtipo de la enfermedad

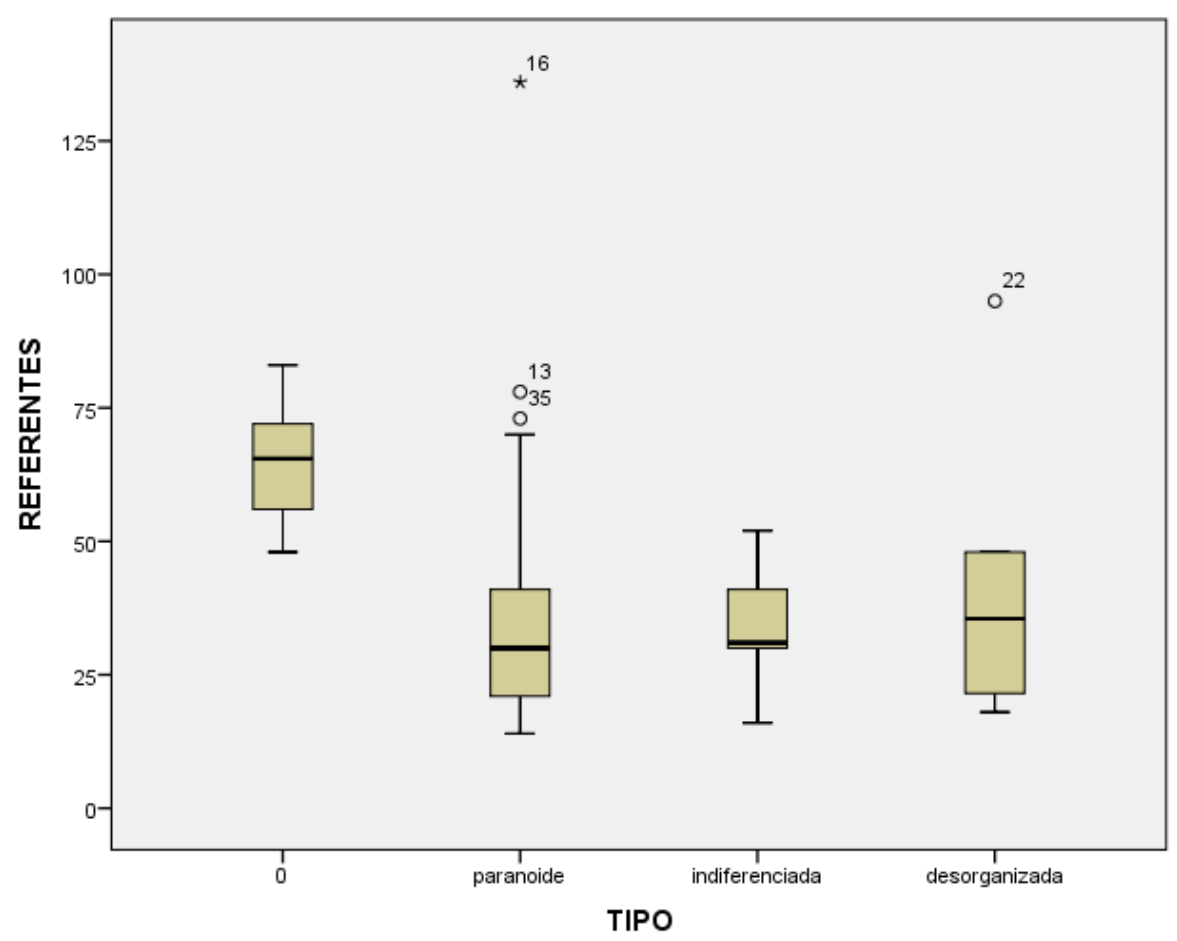

4.2.8. Total de vínculos referenciales utilizados

Como suponemos, la totalidad de los vínculos con que se ligan los referentes debería ser muy superior a los referentes enunciados. Las proporciones que registramos nos dan la impresión de que los del grupo control presentan un equilibrio entre la cantidad de referentes y la cantidad de vínculos dada, entonces, encontramos un promedio total de vínculos empleados entre los controles de aproximadamente 1950/120, entre los crónicos alcanza a 1086/95 y entre los de primer episodio. Por sí 
solas estas medidas no nos ofrecen mucha información, sin embargo, al relacionarlas con la cantidad de referentes, se torna más claro que los controles señalan más referentes y también disponen de más vínculos para relacionarlos, con una relación aproximada de 16,25 vínculos por referente. Esta medida es más equivalente a la de los de primer episodio que presentan un promedio de vínculos de 14,1 vínculos por referente, quedando en evidencia que la relación entre la cantidad de referentes y la cantidad de vínculos es más distanciada en el grupo de los crónicos que solo alcanzan a 11, 4 vínculos por referente. Frente a la interrogante de si esta relación impacta la composición semántica del discurso, no tenemos plena claridad de si es un factor determinante, aunque, al parecer, la tendencia de incluir más elementos permite una mejor comprensión por parte del entrevistador.

4.2.8.1. Total de vínculos referenciales utilizados y estadio de la enfermedad

Con respecto al análisis de las medias correspondientes a vínculos referenciales según el factor estadio de la enfermedad de los sujetos, a continuación se muestran los resultados del análisis paramétrico ANOVA, según el cual la media para los controles es de 1049,667 en tanto, para los de primer episodio, es de 699,080, para los crónicos es de 1153,400. Los resultados son significativos estadísticamente (<p, 000>).

Tabla de contingencia 87: total de vínculos referenciales y estadio de la enfermedad

\begin{tabular}{||l|c|c|c|c|c||}
\hline \multicolumn{6}{|c||}{ Pruebas de los efectos inter-sujetos } \\
\hline Variable dependiente: & Total de vínculos & Sig. \\
\hline Origen & $\begin{array}{c}\text { Suma de } \\
\text { cuadrados tipo } \\
\text { III }\end{array}$ & Gl & $\begin{array}{c}\text { Media } \\
\text { cuadrática }\end{array}$ & F & \\
\hline Modelo corregido & $2727510,461^{\text {a }}$ & 2 & 1363755,231 & 18,143 &, 000 \\
\hline
\end{tabular}


Gráfico 53. Porcentaje de frecuencia de las variables: total de vínculos y estadio de la enfermedad

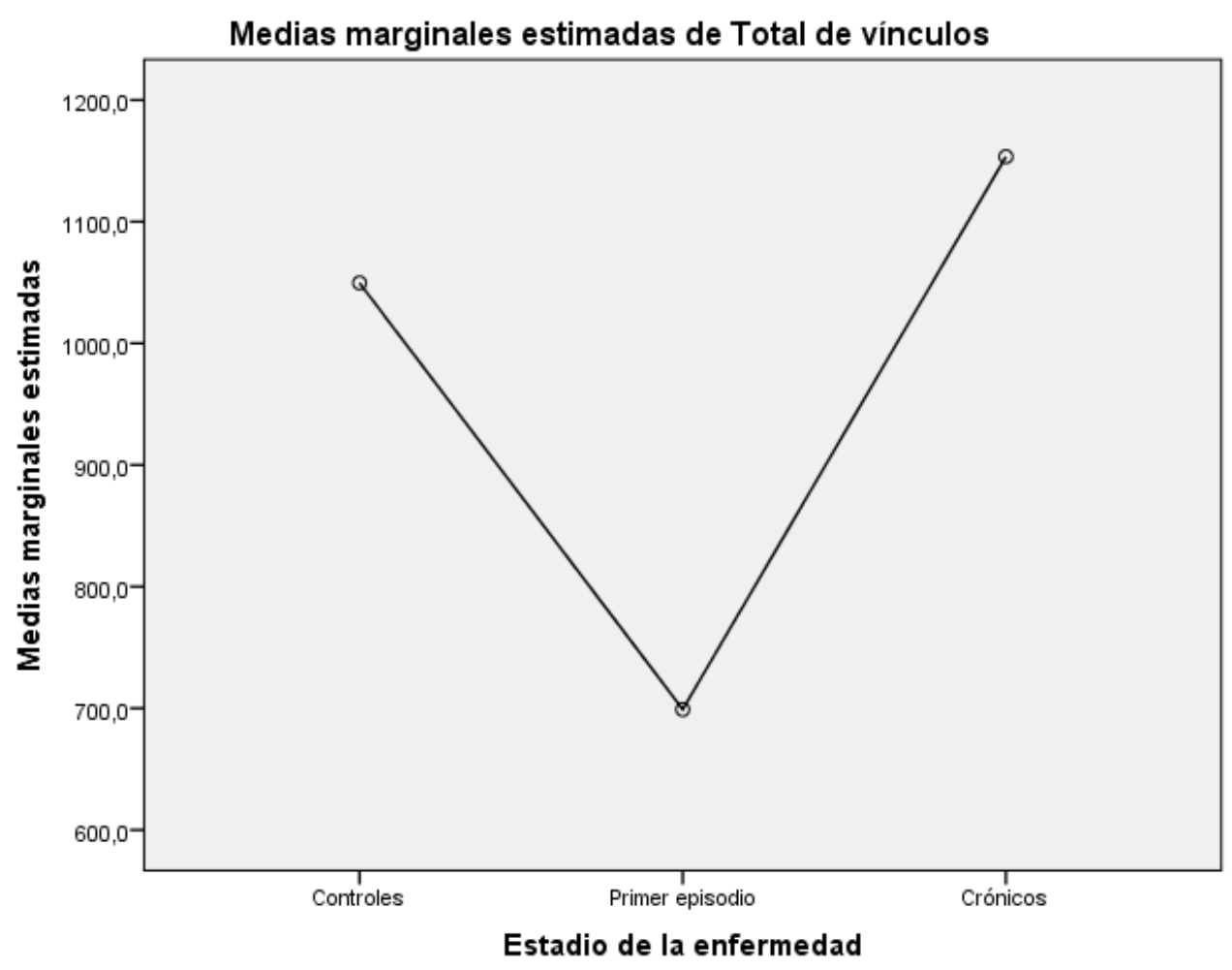

Con el fin de verificar si la dispersión de los datos presentaba alguna anomalía, se incluye el diagrama de caja y bigotes correspondiente. 
54..Diagrama de caja y bigotes 25. Porcentaje de la variable: estadio de la enfermedad

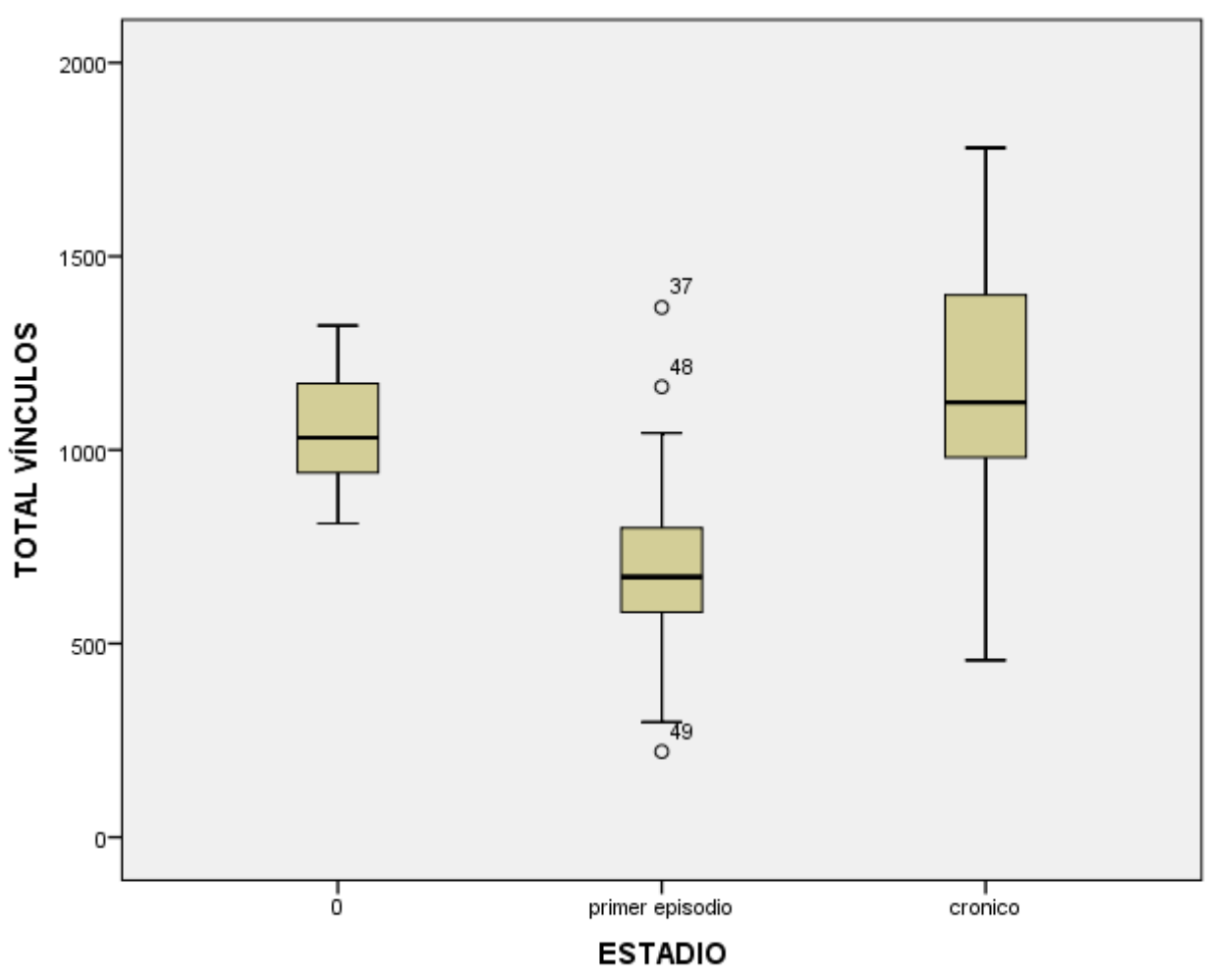

4.2.8.2. Total de vínculos referenciales utilizados y sexo

Con respecto al análisis de las medias correspondientes a las palabras diferentes según el factor sexo de los sujetos, a continuación se muestran los resultados del análisis paramétrico ANOVA, según el cual la media para los hombres es de 1047,515 en tanto, para las mujeres, es de 839,310. Los resultados no son significativos estadísticamente. 
Tabla de contingencia 88: total de vínculos referenciales y sexo.

\begin{tabular}{||l|c|c|c|c|c||}
\hline \multicolumn{5}{|c||}{ Pruebas de los efectos inter-sujetos } \\
\hline Variable dependiente: & Total de vínculos & Sig. \\
\hline Origen & $\begin{array}{c}\text { Suma de } \\
\text { cuadrados tipo } \\
\text { III }\end{array}$ & Gl & $\begin{array}{c}\text { Media } \\
\text { cuadrática }\end{array}$ & F & \\
\hline Modelo corregido & $669116,518^{\text {a }}$ & 1 & 669116,518 & 6,183 &, 016 \\
\hline
\end{tabular}

Gráfico 55. Porcentaje de frecuencia de las variables: total de vínculos y sexo de los sujetos

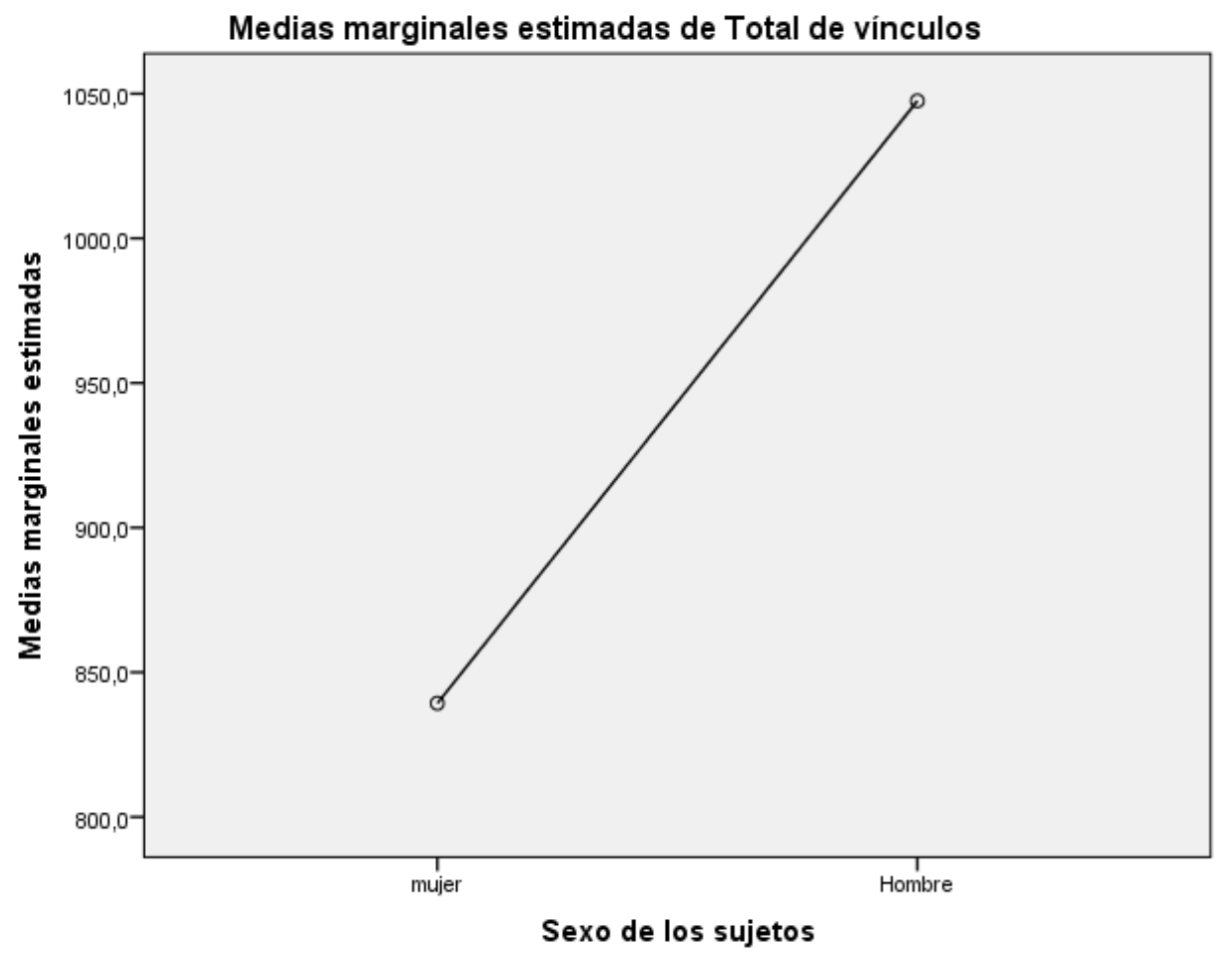

Con el fin de verificar si la dispersión de los datos presentaba alguna anomalía, se incluye el diagrama de caja y bigotes correspondiente 
56. Diagrama de caja y bigotes 26. Porcentaje de la variable: sexo.

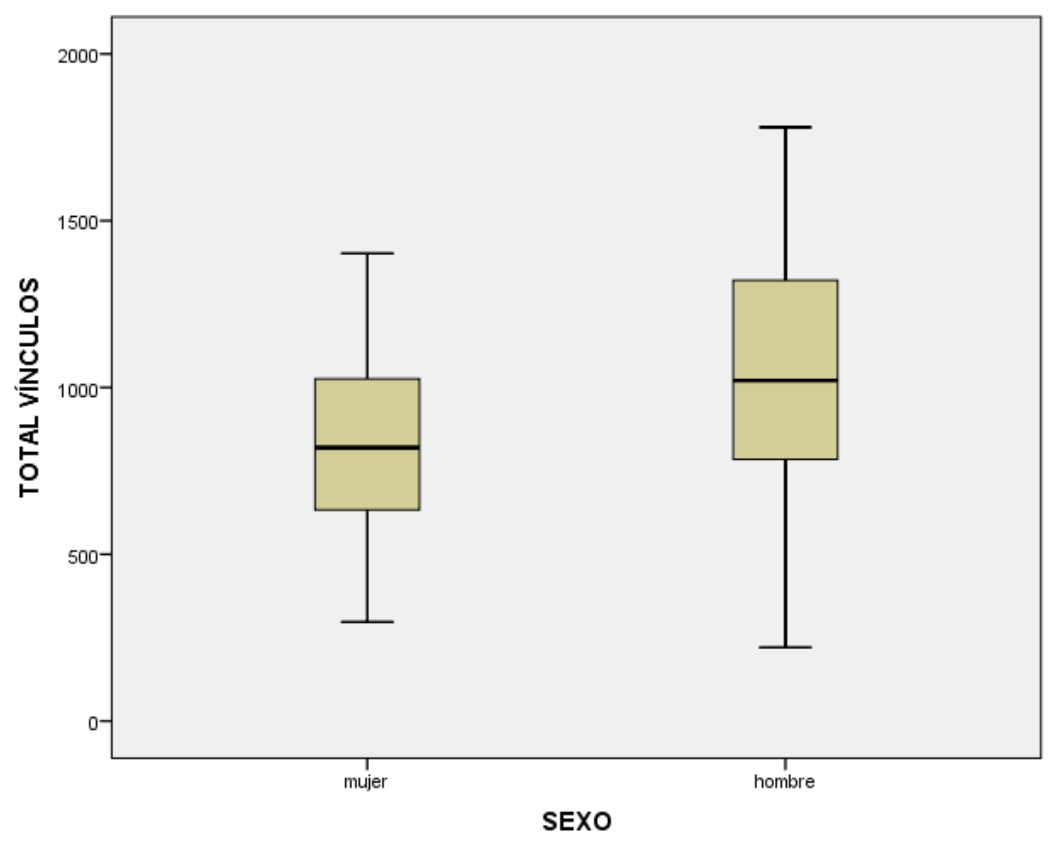

4.2.8.3. Total de vínculos referenciales utilizados y tramo de la enfermedad

Con respecto al análisis de las medias correspondientes a las palabras diferentes según el factor sexo de los sujetos, a continuación se muestran los resultados del análisis paramétrico ANOVA, según el cual la media para los controles es de 1049,667; para el grupo de primer episodio >0 a $<2$ años es de 630,929; para los de primer episodio de $>2$ a $<3$ años, es de 785,818, Crónicos hasta 5 años es de 1231,000 y para los crónicos de 5 años y más 1101,667. Los resultados son significativos estadísticamente. 
Tabla de contingencia 89: total de vínculos referenciales y tramo de la enfermedad.

\begin{tabular}{|c|c|c|c|c|c|}
\hline \multicolumn{6}{|c|}{ Pruebas de los efectos inter-sujetos } \\
\hline Variable dependiente: & Total de vínculos & & & & \\
\hline Origen & $\begin{array}{c}\text { Suma de } \\
\text { cuadrados tipo } \\
\text { III }\end{array}$ & $\mathrm{gl}$ & $\begin{array}{c}\text { Media } \\
\text { cuadrática }\end{array}$ & $\mathrm{F}$ & Sig. \\
\hline Modelo corregido & $2975656,403^{\mathrm{a}}$ & 4 & 743914,101 & 10,128 &, 000 \\
\hline
\end{tabular}

Gráfico 57. Porcentaje de frecuencia de las variables: total de vínculos y tramo de la enfermedad

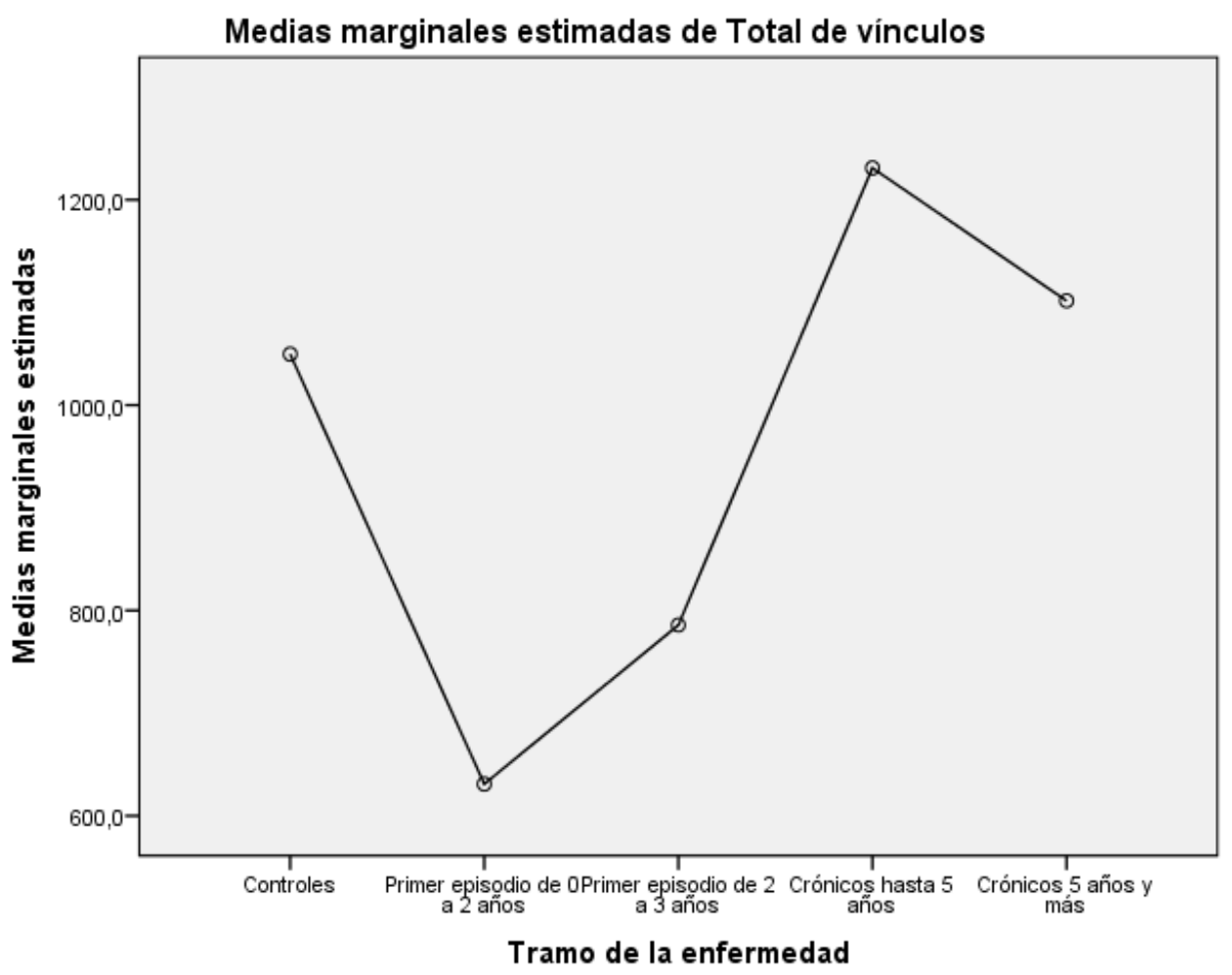

Con el fin de verificar si la dispersión de los datos presentaba alguna anomalía, se incluye el diagrama de caja y bigotes correspondiente. 
58. Diagrama de caja y bigotes 27. Porcentaje de la variable: tramo

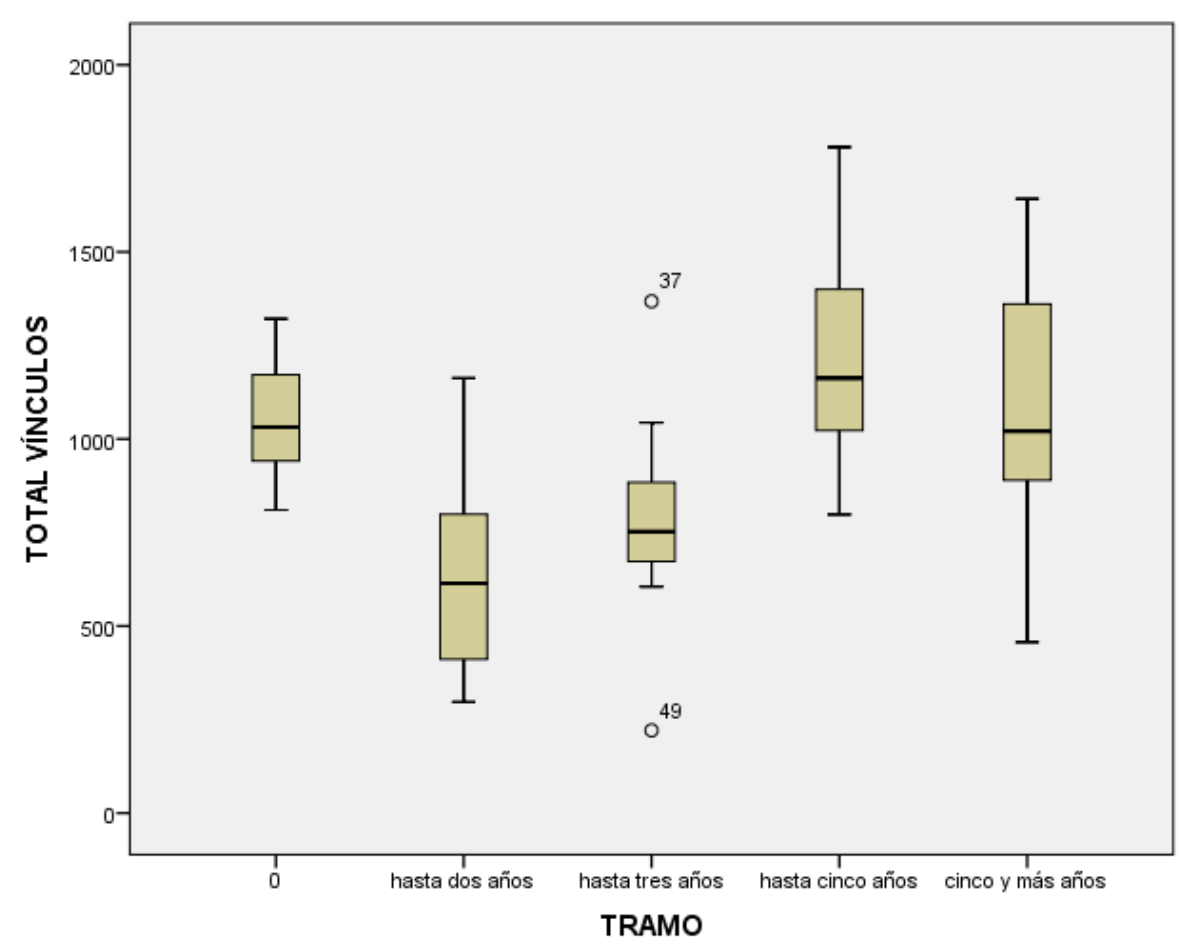

4.2.8.4. Total de vínculos referenciales utilizados y subtipo de la enfermedad

Con respecto al análisis de las medias correspondientes a las palabras diferentes según el factor sexo de los sujetos, a continuación se muestran los resultados del análisis paramétrico ANOVA, según el cual la media para los controles es de 1049,667; para los paranoide de 877,333; para los indiferenciada, 1159,778 y para los de esquizofrenia desorganizada, de 865,250. Los resultados no son significativos estadísticamente. 
Tabla de contingencia 90: total de vínculos referenciales y subtipo de la enfermedad.

\begin{tabular}{||l|c|c|c|c|c||}
\hline \multicolumn{5}{|c||}{ Pruebas de los efectos inter-sujetos } \\
\hline Variable dependiente: & Total de vínculos \\
\hline Origen & $\begin{array}{c}\text { Suma de } \\
\text { cuadrados tipo } \\
\text { III }\end{array}$ & gl & $\begin{array}{c}\text { Media } \\
\text { cuadrática }\end{array}$ & F & Sig. \\
\hline Modelo corregido & $746975,912^{\text {a }}$ & 3 & 248991,971 & 2,251 &, 092 \\
\hline
\end{tabular}

Gráfico 59. Porcentaje de frecuencia de las variables: total de vínculos y tramo de la enfermedad

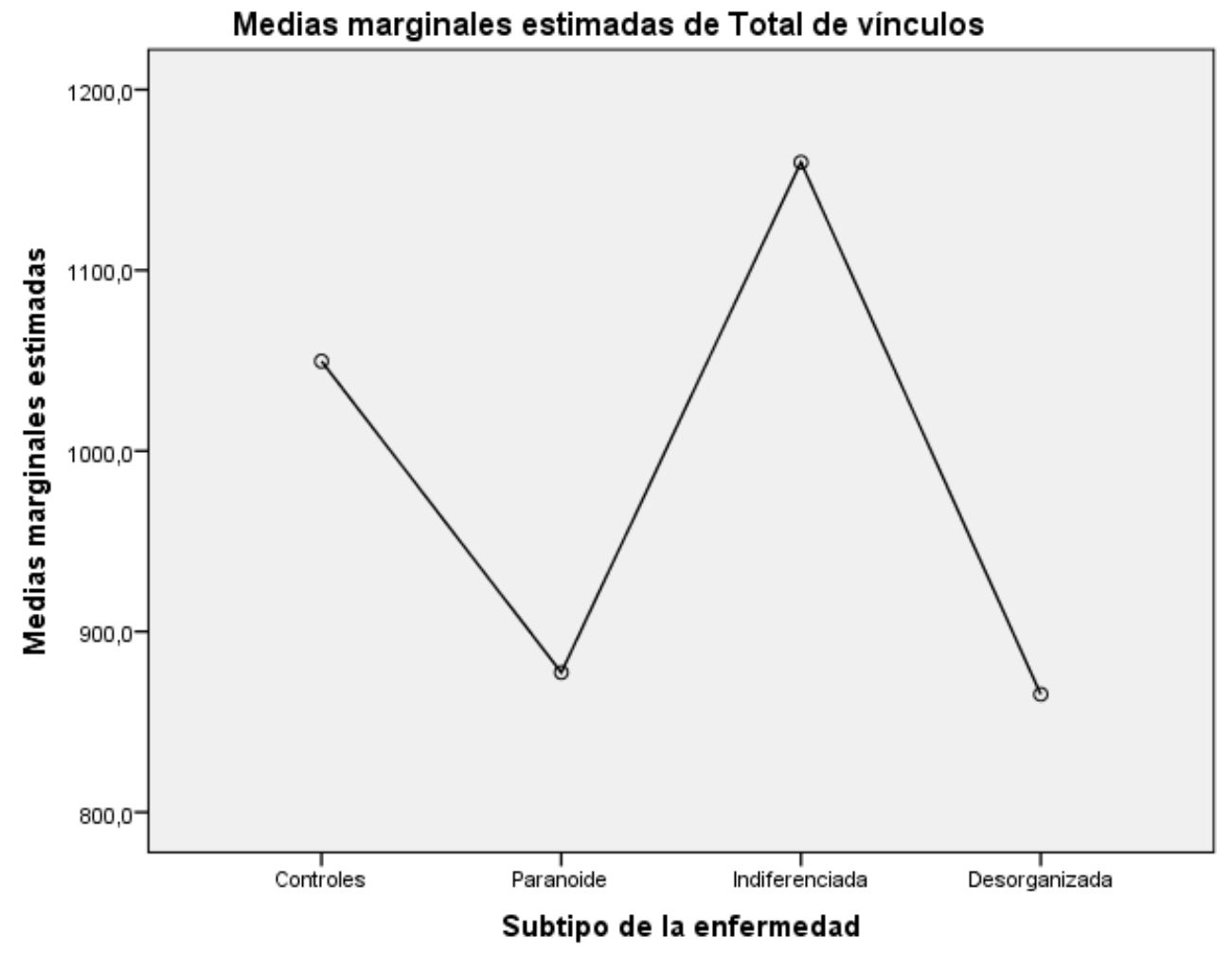

Con el fin de verificar si la dispersión de los datos presentaba alguna anomalía, se incluye el diagrama de caja y bigotes correspondiente. 


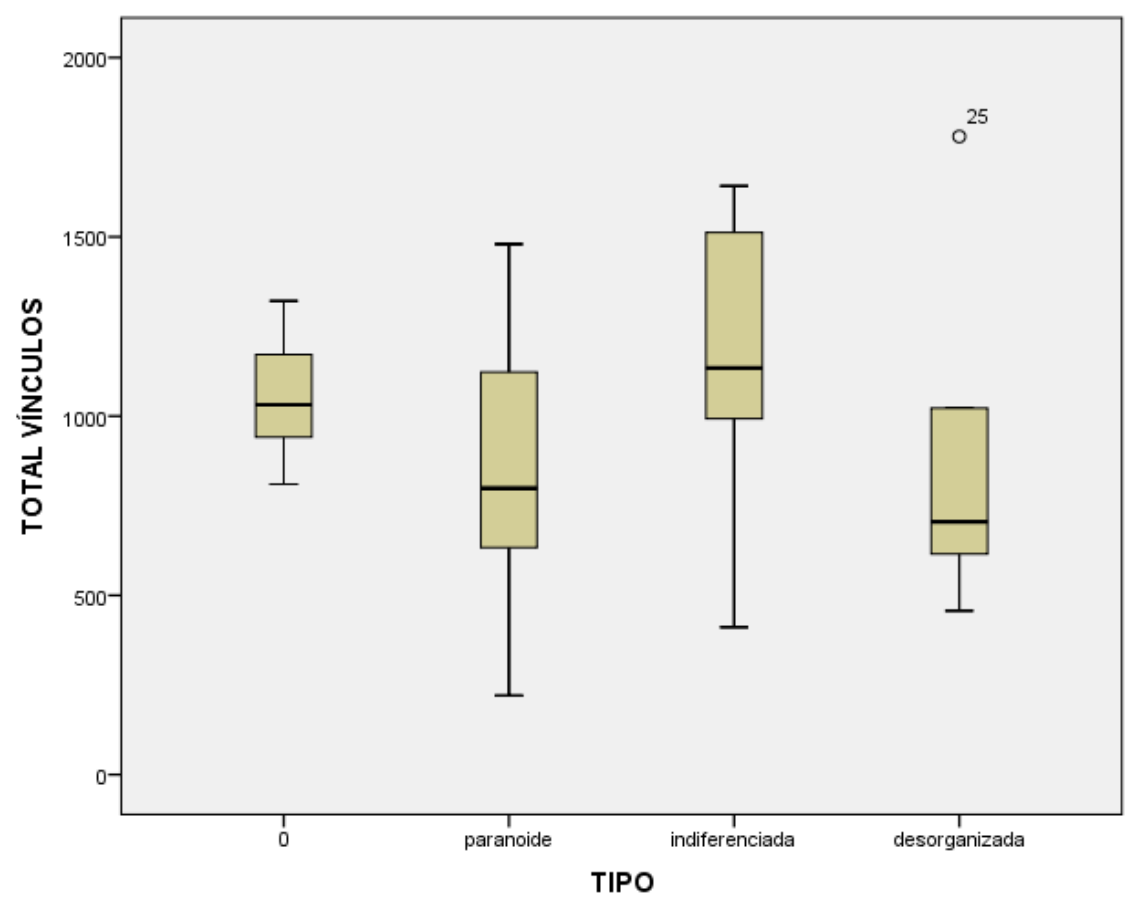

4.2.9. Promedio de vínculos referenciales utilizados

Siguiendo con los indicadores arriba descritos, este promedio nos permitirá verificar si existen diferencias respecto a la densidad de los núcleos semánticos que se agrupan a partir de la mención de referentes en el discurso. Como ya señalamos anteriormente, al ser mayor el total de vínculos entre los controles, el promedio también es más elevado, lo siguen los del grupo de primer episodio y finalmente los crónicos, que ostentan un promedio reducido. 
4.2.9.1. Promedio de vínculos referenciales utilizados y estadio de la enfermedad

Con respecto al análisis de las medias correspondientes a las palabras diferentes según el factor estadio de la enfermedad de los sujetos, a continuación se muestran los resultados del análisis paramétrico ANOVA, según el cual la media para lcontroles es de 16,358 en tanto, para los de primer episodio, es de 27,848, para los crónicos es de 29,920. Los resultados no son significativos estadísticamente.

Tabla de contingencia 91: promedio de vínculos y estadio de la enfermedad.

\begin{tabular}{||l|c|c|c|c|c|c||}
\hline \multicolumn{7}{|c||}{ Pruebas de los efectos inter-sujetos } \\
\hline Variable dependiente: & Promedio de vínculos & $\begin{array}{c}\text { Media } \\
\text { Suma de } \\
\text { tipo III }\end{array}$ & gl & $\begin{array}{c}\text { F } \\
\text { cuadrática }\end{array}$ & Sig. & $\begin{array}{c}\text { Eta al } \\
\text { cuadrad } \\
\text { o } \\
\text { parcial }\end{array}$ \\
\hline $\begin{array}{l}\text { Modelo } \\
\text { corregido }\end{array}$ & $1571,978^{\mathrm{a}}$ & 2 & 785,989 & 4,266 &, 019 &, 126 \\
\hline
\end{tabular}


Gráfico 61. Porcentaje de frecuencia de las variables: promedio de vínculos y estadio de la enfermedad.

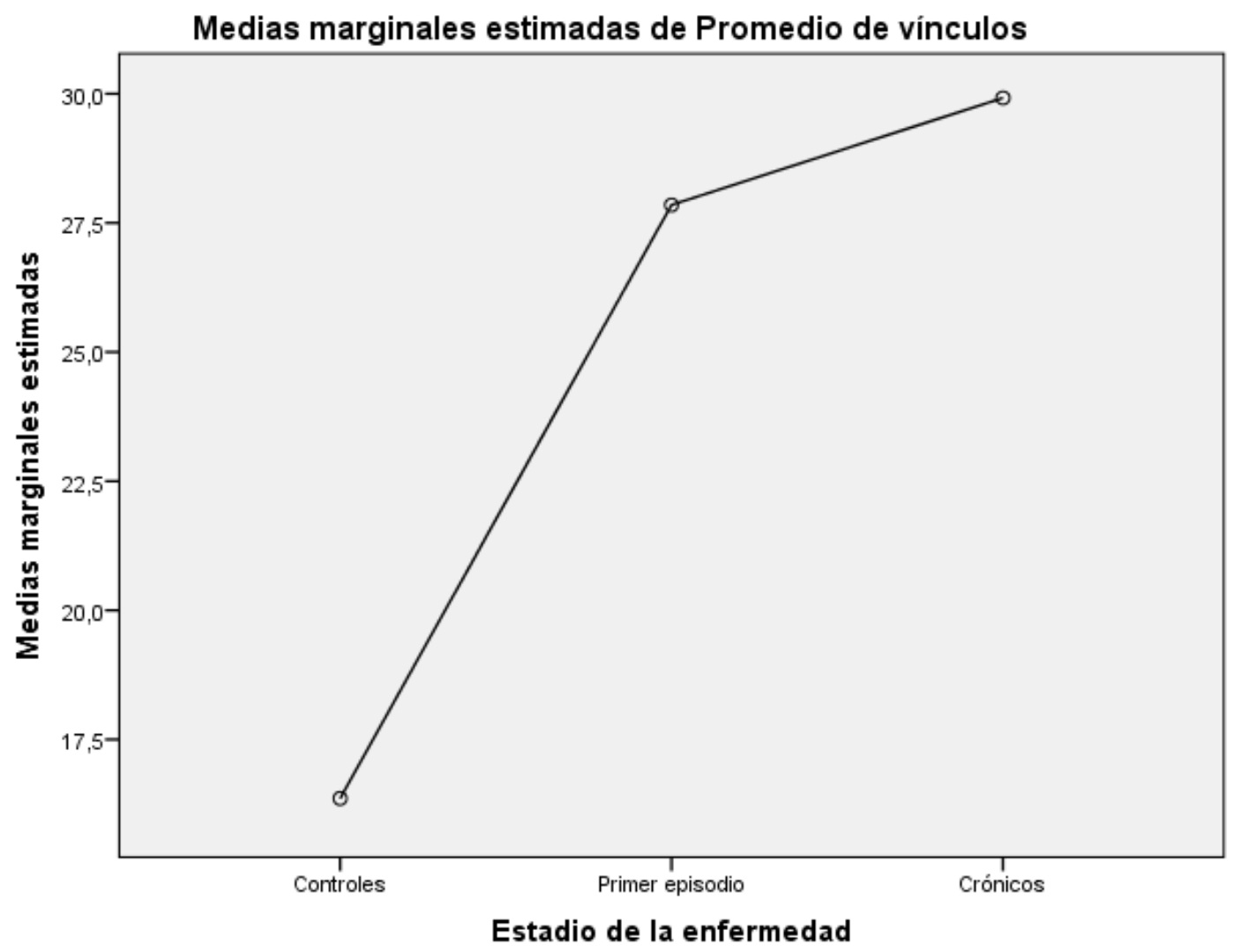

Con el fin de verificar si la dispersión de los datos presentaba alguna anomalía, se incluye el diagrama de caja y bigotes correspondiente. 
62.Diagrama de caja y bigotes 29. Porcentaje de la variable: estadio de la enfermedad.

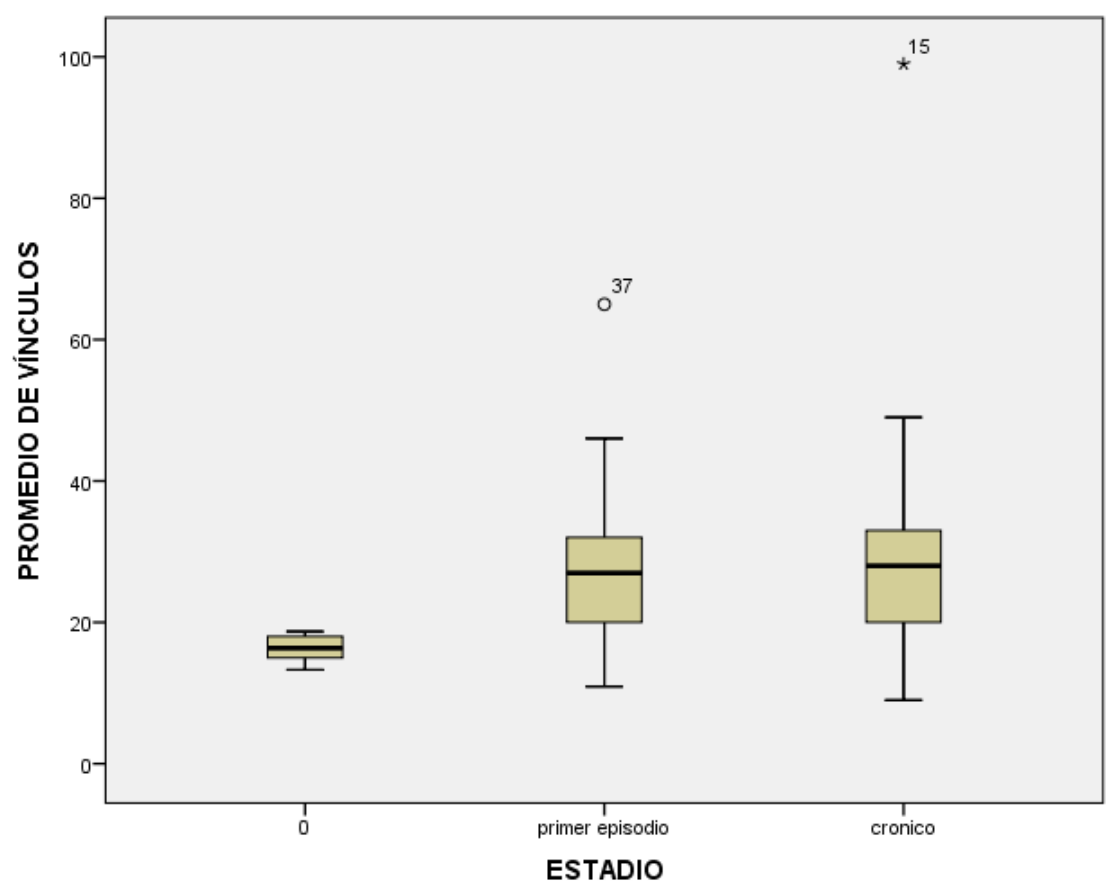

4.2.9.2. Promedio de vínculos referenciales utilizados y sexo

Con respecto al análisis de las medias correspondientes al promedio de vínculos según el factor sexo de los sujetos, a continuación se muestran los resultados del análisis paramétrico ANOVA, según el cual la media para los hombres es de 28,385 en tanto, para las mujeres, es de 24,269. Los resultados no son significativos estadísticamente. 
Tabla de contingencia 92: promedio de vínculos y sexo.

\begin{tabular}{||l|c|c|c|c|c|c||}
\hline \multicolumn{7}{|c||}{ Pruebas de los efectos inter-sujetos } \\
\hline Variable dependiente: & $\begin{array}{c}\text { Promedio de vínculos } \\
\text { cuadrados } \\
\text { tipo III }\end{array}$ & gl & $\begin{array}{c}\text { Media } \\
\text { cuadrática }\end{array}$ & F & Sig. & $\begin{array}{c}\text { Eta al } \\
\text { cuadrado } \\
\text { parcial }\end{array}$ \\
\hline Origen & $261,485^{\text {a }}$ & 1 & 261,485 & 1,288 &, 261 &, 021 \\
\hline Modelo \\
corregido
\end{tabular}

Gráfico 63. Porcentaje de frecuencia de las variables: promedio de vínculos y sexo.

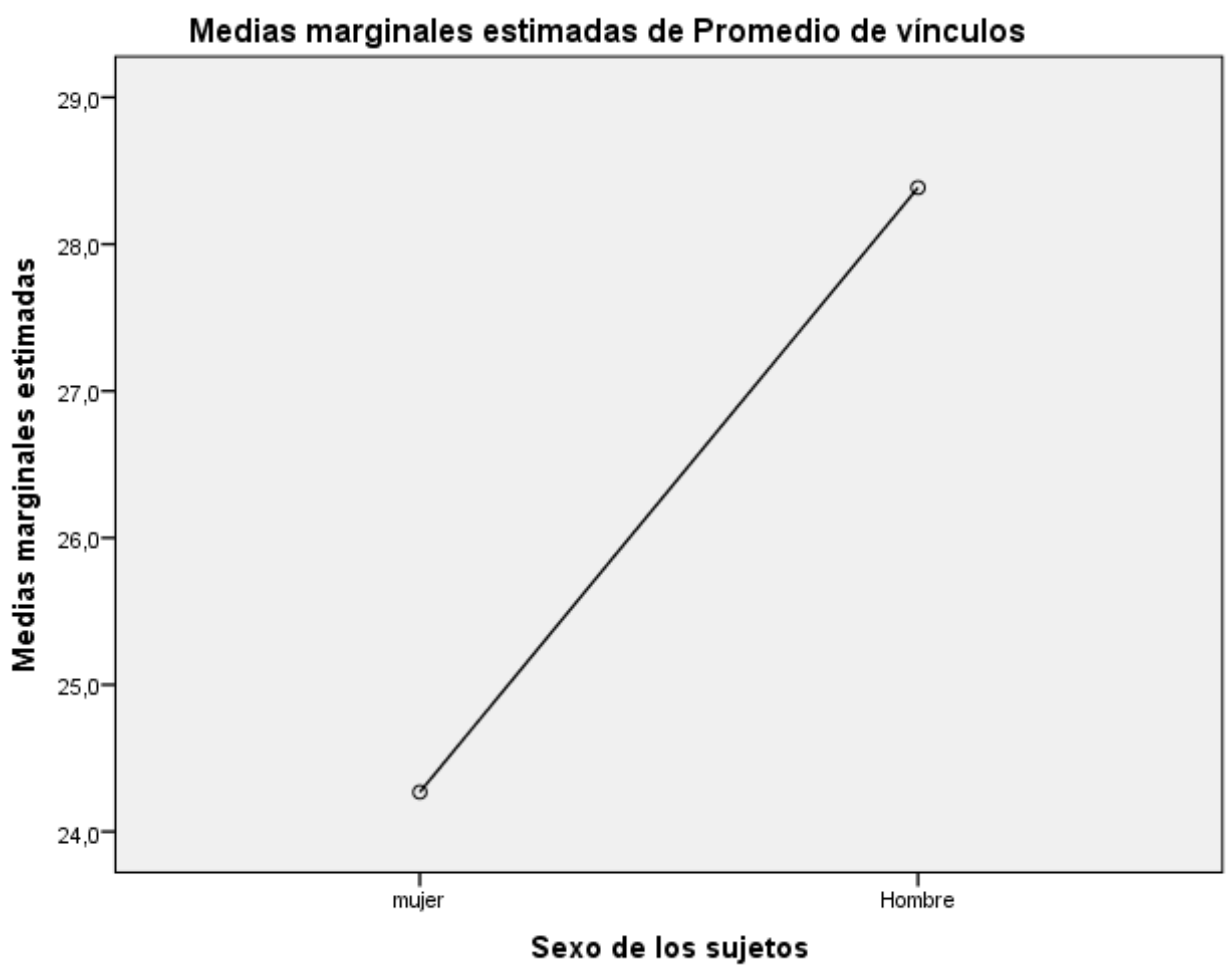


Con el fin de verificar si la dispersión de los datos presentaba alguna anomalía, se incluye el diagrama de caja y bigotes correspondiente.

64. Diagrama de caja y bigotes 30. Porcentaje de la variable: sexo.

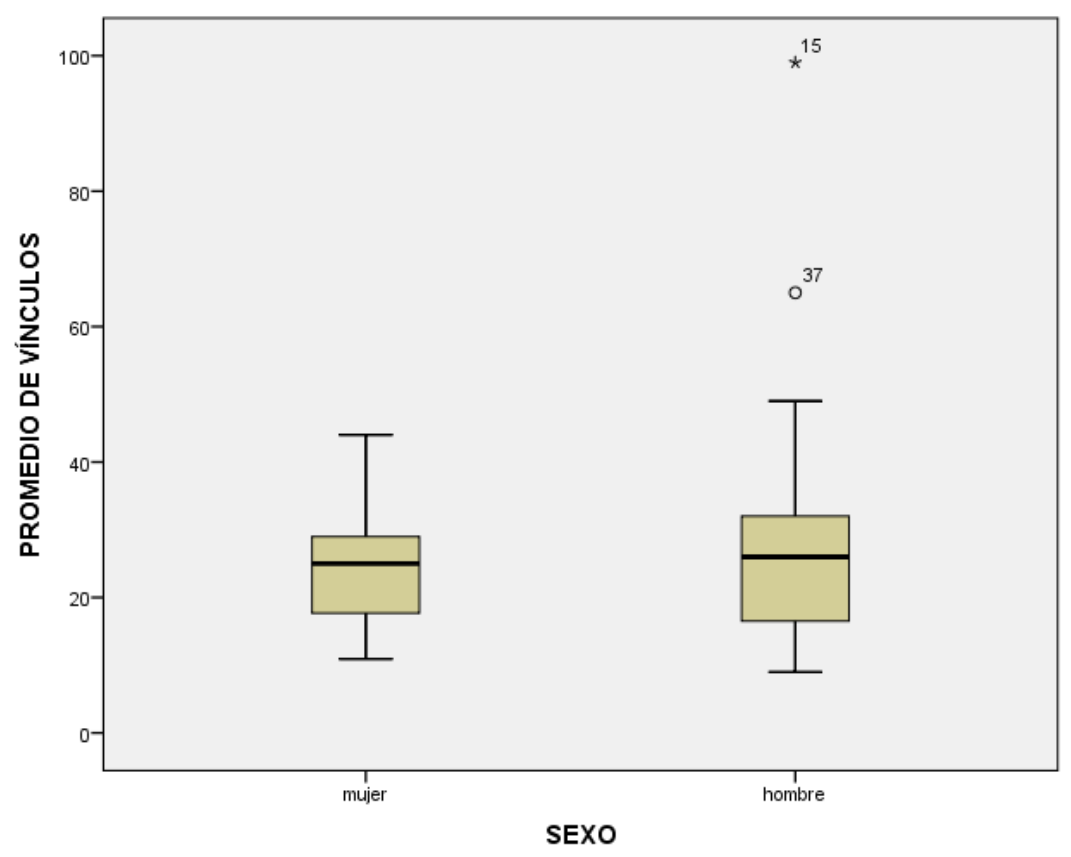

4.2.9.3. Promedio de vínculos referenciales utilizados y tramo de la enfermedad

Con respecto al análisis de las medias correspondientes a las palabras diferentes según el factor tramo de la enfermedad de los sujetos, a continuación se muestran los resultados del análisis paramétrico ANOVA, según el cual la media para los controles es de 16,358; para el grupo de primer episodio $>0$ a $<2$ años es de 24,664; para los de primer episodio de $>2$ a $<3$ años, es de 31,900, Crónicos hasta 5 años es de 37,000 y para los crónicos de 5 años y más 25,200. Los resultados son significativos estadísticamente. 
Tabla de contingencia 93:promedio de vínculos y tramo de la enfermedad.

\begin{tabular}{||l|c|c|c|c|c|c||}
\hline \multicolumn{7}{||c||}{ Pruebas de los efectos inter-sujetos } \\
\hline Variable dependiente: & Promedio de vínculos \\
\hline Origen & $\begin{array}{c}\text { Suma de } \\
\text { cuadrados } \\
\text { tipo III }\end{array}$ & gl & $\begin{array}{c}\text { Media } \\
\text { cuadrática }\end{array}$ & F & Sig. & $\begin{array}{c}\text { Eta al } \\
\text { cuadrado } \\
\text { parcial }\end{array}$ \\
\hline $\begin{array}{l}\text { Modelo } \\
\text { corregido }\end{array}$ & $2729,928^{a}$ & 4 & 682,482 & 4,005 &, 006 &, 219 \\
\hline \hline
\end{tabular}

Gráfico 65. Porcentaje de frecuencia de las variables: promedio de vínculos y tramo de la enfermedad

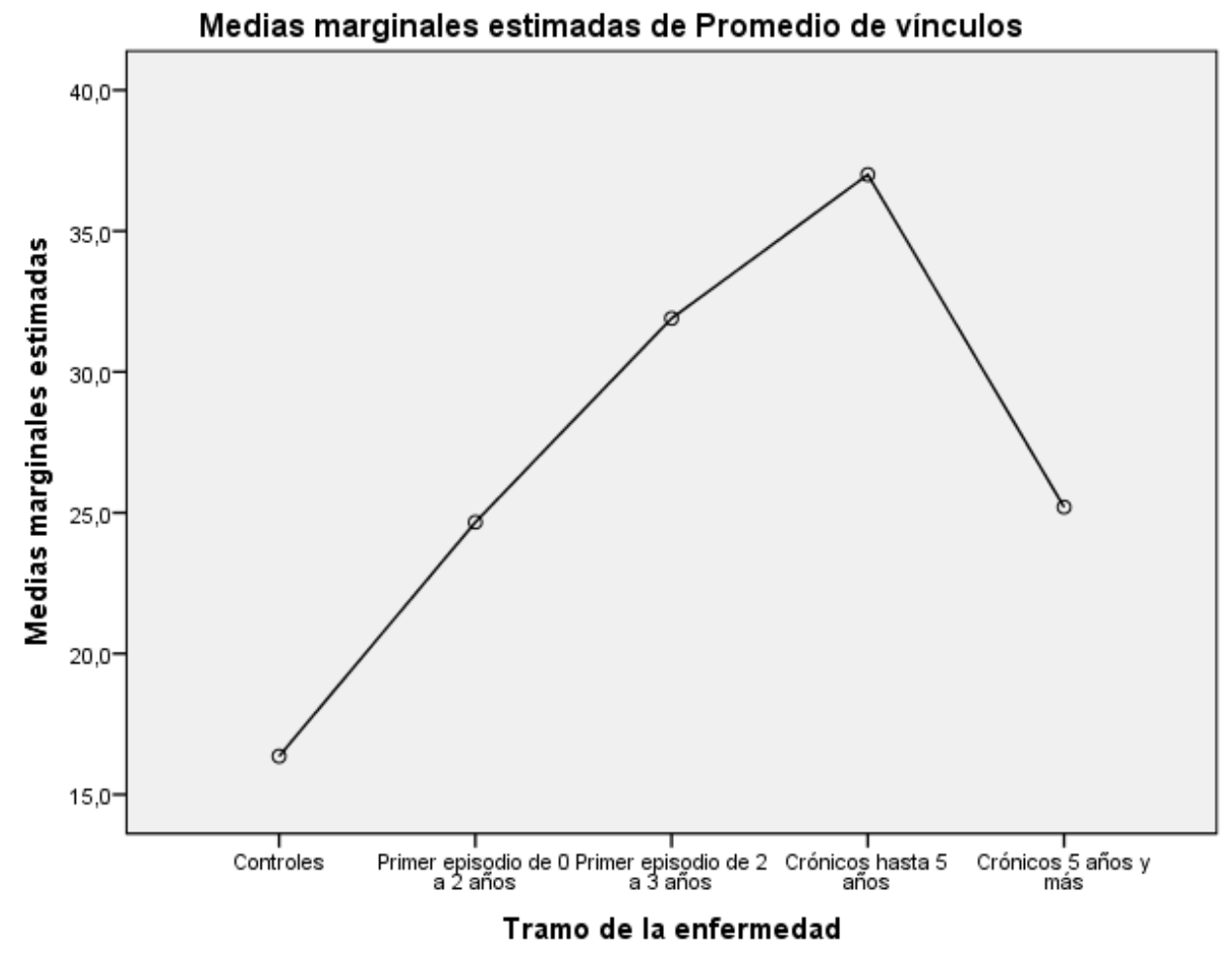


Con el fin de verificar si la dispersión de los datos presentaba alguna anomalía, se incluye el diagrama de caja y bigotes correspondiente

66. Diagrama de caja y bigotes 31. Porcentaje de la variable: tramo de la enfermedad.

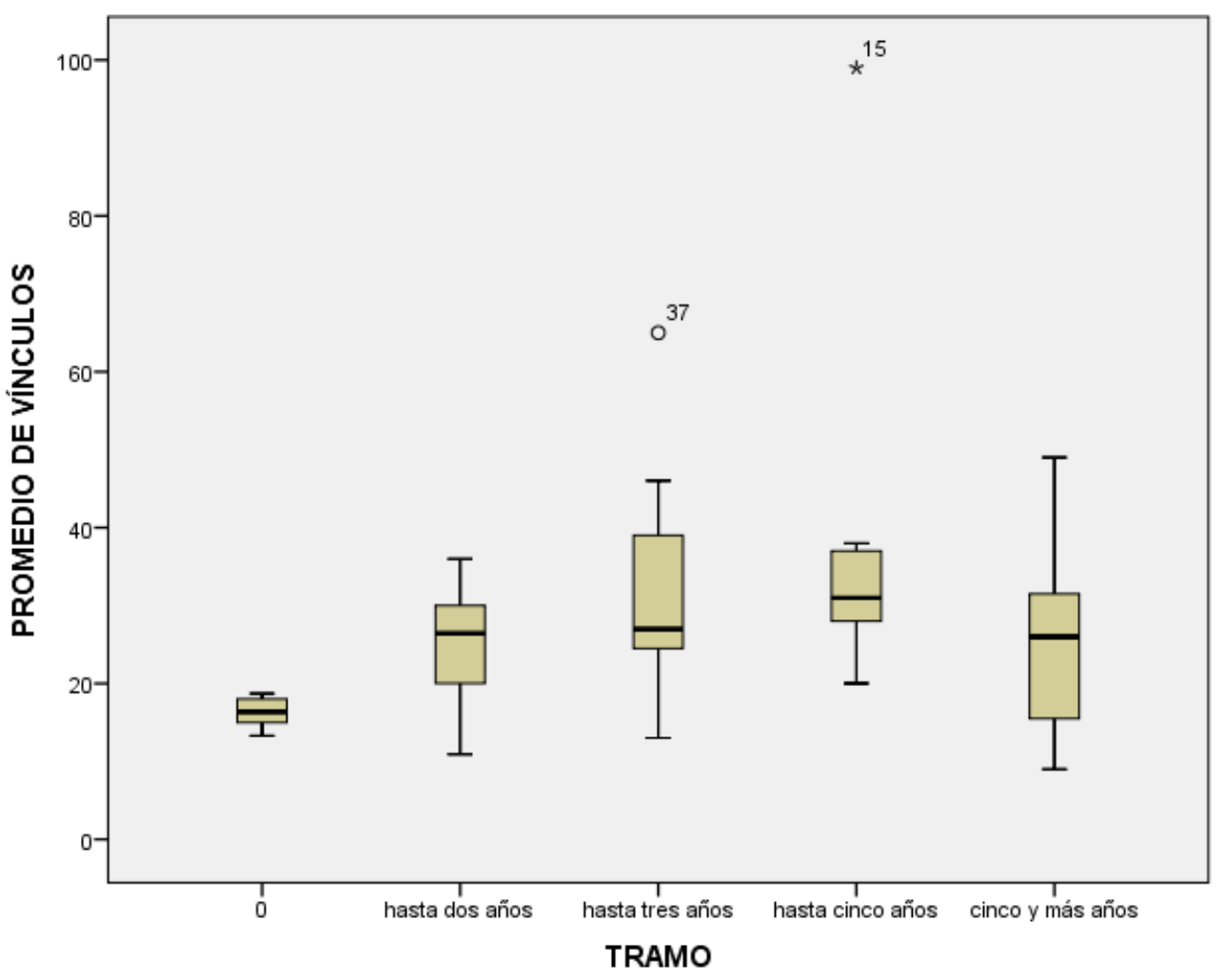


4.2.9.4. Promedio de vínculos referenciales utilizados y subtipo de la enfermedad

Con respecto al análisis de las medias correspondientes a las palabras diferentes según el factor sexo de los sujetos, a continuación se muestran los resultados del análisis paramétrico ANOVA, según el cual la media para los controles es de 16,358; para los paranoide de 28,788; para los indiferenciada, 33,100 y para los de esquizofrenia desorganizada, de 24,538. Los resultados no son significativos estadísticamente.

Tabla de contingencia 94 :promedio de vínculos y subtipo de la enfermedad.

\begin{tabular}{|c|c|c|c|c|c|c|}
\hline \multicolumn{7}{|c|}{ Pruebas de los efectos inter-sujetos } \\
\hline \multicolumn{7}{|c|}{ Variable dependiente: Promedio de vínculos } \\
\hline Origen & $\begin{array}{c}\text { Suma de } \\
\text { cuadrados tipo III }\end{array}$ & $\mathrm{gl}$ & $\begin{array}{c}\text { Media } \\
\text { cuadrática }\end{array}$ & $\mathrm{F}$ & Sig. & $\begin{array}{c}\text { Eta al } \\
\text { cuadra } \\
\text { do } \\
\text { parcial }\end{array}$ \\
\hline $\begin{array}{l}\text { Modelo } \\
\text { corregido }\end{array}$ & $1829,726^{\mathrm{a}}$ & 3 & 609,909 & 3,333 & 026 &, 147 \\
\hline
\end{tabular}


Gráfico 67. Porcentaje de frecuencia de las variables: promedio de vínculos y tramo de la enfermedad

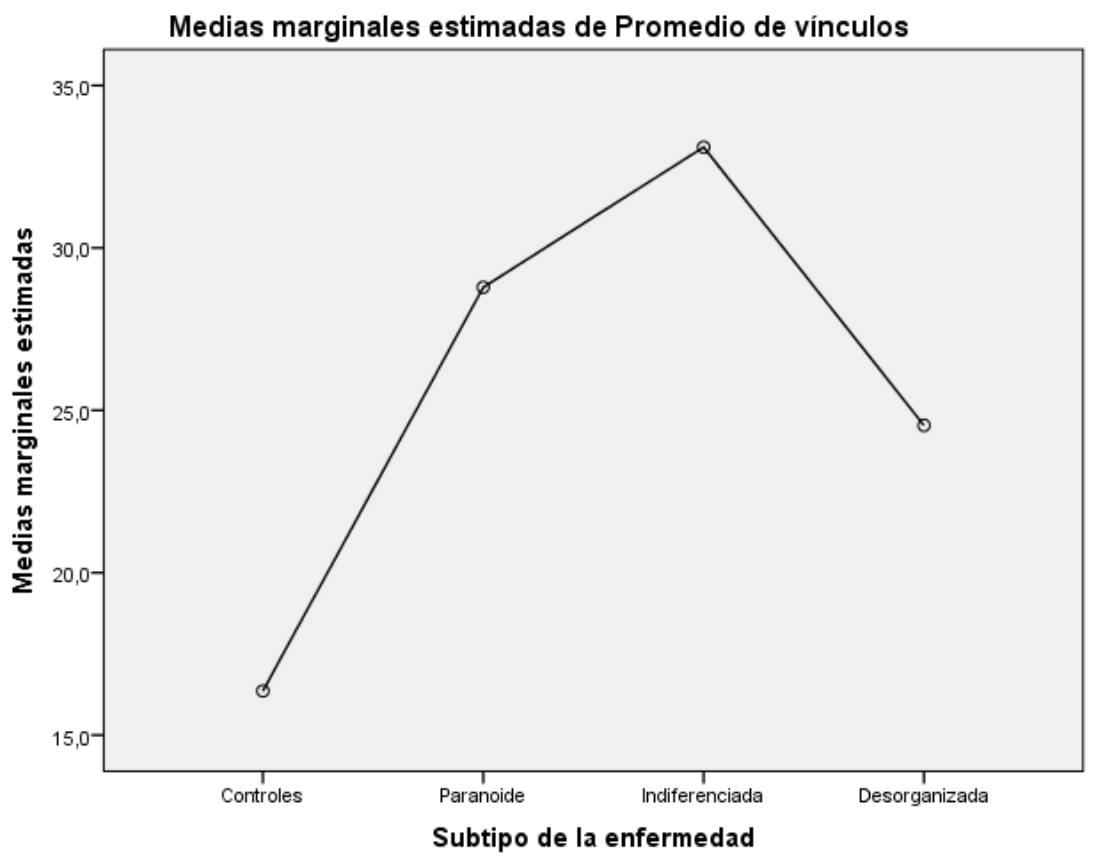

Con el fin de verificar si la dispersión de los datos presentaba alguna anomalía, se incluye el diagrama de caja y bigotes correspondiente. 
68. Diagrama de caja y bigotes 32. Porcentaje de la variable: subtipo de la enfermedad.

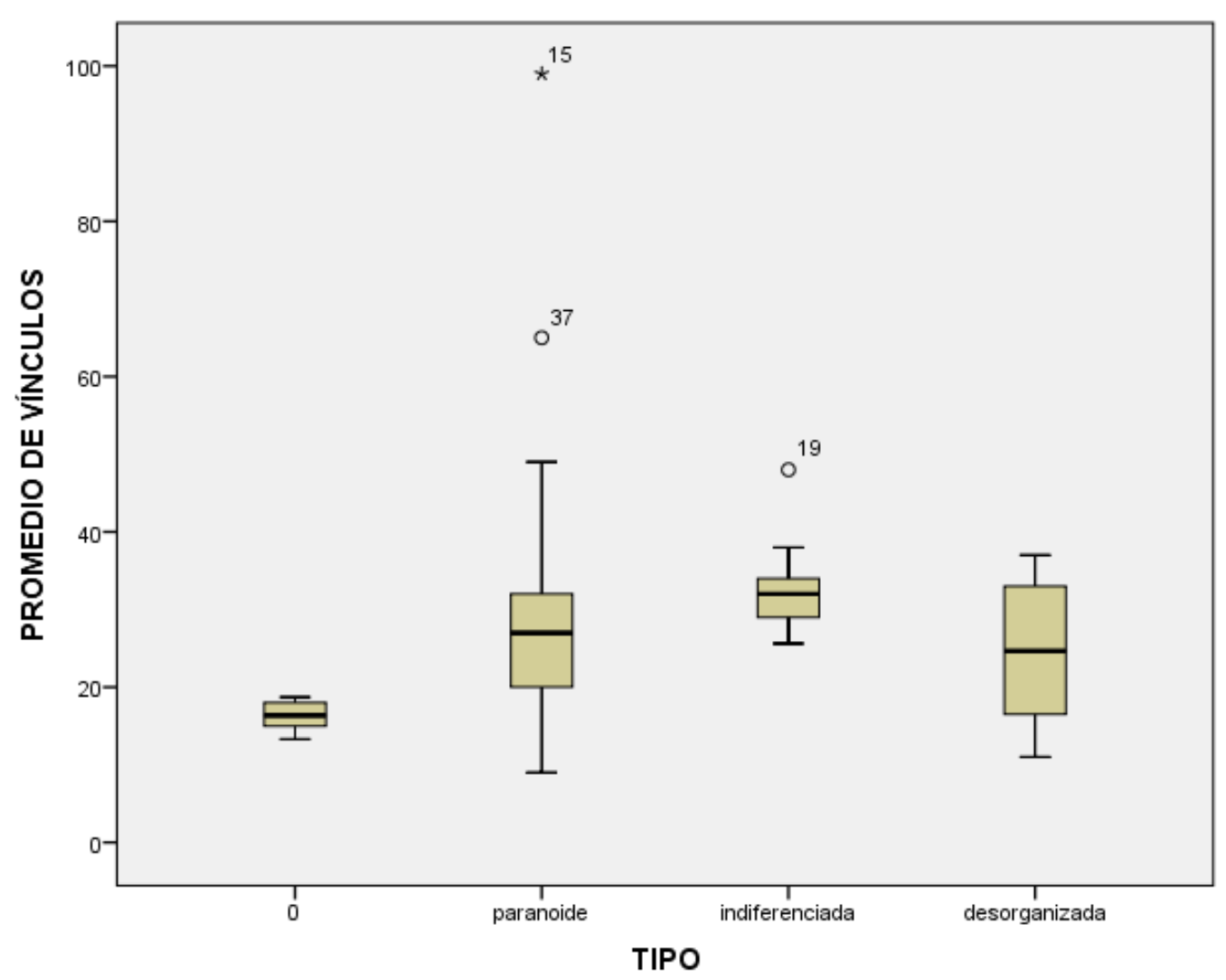


4.2.10. Conclusiones cluster de productividad verbal

Nuestras principales conclusiones para el cluster de productividad verbal corresponden a los hallazgos siguientes: se encuentran evidencias de déficit significativo en la comparación y contraste del comportamiento comunicativo de los corpus 1 y 2 de este estudio.

En primer lugar, en el indicador total de oraciones, el grupo de los controles presenta una diferencia considerable en el volumen de oraciones producidas, asimismo, observamos que en el indicador promedio de palabras por oración, también es más elevado que en los grupos 1 y 2. Este dato no tendría mayor importancia si no se tomara en cuenta que, en general, casi la totalidad de las emisiones del grupo 3 son productivas en términos sintácticos, diferencia significativa a la hora de contrastar con el grupo de crónicos en los que se observa diversas intervenciones no oracionales, etc. Además, observamos un manejo adecuado de estructuras oracionales complejas, lo que redundó en construcciones más elaboradas. (Serra et al., 2000). La capacidad para producir oraciones complejas se adquiere tempranamente, se ha reportado el hallazgo y utilización de estas construcciones en niños de tres y cuatro años (Paul, 2001) que se afianzarían con la escolarización, la lectura de textos y la producción escrita. Pavéz, (1999), señala que junto con el manejo de estas estructuras, se registraría un incremento en el número de unidades por oración, asi como una mayor variedad en los tipos de oraciones empleadas. En un trabajo de Coloma, et al., (2007), se señala que entre los 6 y 18 años se aprecia una mayor longitud oracional, junto con una tendencia a la utilización de cláusulas sustantivas, estructuras subordinadas, etc. La literatura abunda en descripciones acerca de la llamada "sintaxis empobrecida" en el discurso de los crónicos, (Chaika, 1982, Salavera, 2012), sin embargo, este rasgo también fue pesquisado en los del grupo de 
primer episodio, lo que nos hace pensar que constituye un rasgo distintivo relevante. Ahora bien, las causas de una sintaxis empobrecida pueden deberse a diferentes fenómenos cognitivos. Las evaluaciones neuropsicológicas que se realizan en adolescentes, apuntan a que existe una estructura cognitiva de alto rendimiento en la mayoría de los casos, (Oyarzún, 2014). Por lo tanto, se infiere que rasgos como el humor paranoide y los síntomas negativos son las causas más probables de una sintaxis pobre, que un deterioro cognitivo.

Se conocen algunos estudios transversales como el de Nippold (2005), quien estudió el contraste entre la conversación y el discurso expositivo de 120 personas con desarrollo típico, niños, adolescentes y adultos entre 7 y 49 años. Encontró medidas significativas de estabilidad en la complejidad sintáctica entre los 40-49 años, en ambos géneros, asi como una complejidad sintáctica que evolucionaría hasta alrededor de los 30 años.

Respecto del empleo de palabras diferentes, también se presentaron diferencias importantes entre los grupos 1 y 2, respecto del grupo control. Existen innumerables repeticiones de palabras, en particular de sustantivos y conectores o marcadores discursivos entre los pacientes. En promedio simple, los controles presentan más de 200 palabras diferentes que los crónicos, y estos, a su vez, alrededor de 240 palabras diferentes más que el grupo de primer episodio. Una forma de comprender este rasgo que muestran los grupos es analizar el comportamiento comunicativo de los entrevistados, las soluciones más pertinentes, precisas y, por tanto, adecuadas al contexto semántico, las encontramos en los controles. Entre los crónicos, es interesante hacer notar que existió una tendencia a la repetición de ítemes léxicos, como ya señalamos arriba. Sin embargo, también se inventarió un gran contingente de palabras inusuales, que por su particularidad a menudo sorprenden al entrevistador. 
En el caso del grupo de primer episodio, las soluciones simples y comunicativas fueron la tendencia general. Esta circunstancia puede deberse a la edad de los sujetos, quienes por su juventud y por estar en proceso de formación educativa, probablemente posean menos recursos estilísticos que el grupo de crónicos.

La utilización de menor variedad de recursos lingüísticos hace menos flexibles y eficientes las emisiones de los grupos de pacientes en estos tres indicadores de productividad verbal.

Respecto de los indicadores neologismos parciales y neologismos totales, no se reportaron en el caso de los controles, y su ocurrencia en los grupos 1 y 2 , fue muy baja. Tradicionalmente a los neologismos se les ha considerado como un rasgo psicopatológico por excelencia, Tanzi, (1890) lo declaró "la flor y nata de la ideación delirante". Séglas (1968) distinguió entre dos tipos de neologismo: los pasivos, que serían producto de procesos automáticos y los activos, que reportarían una ideación voluntaria. Nuestro enfoque, siempre comunicativo, nos llevó a la conclusión de que la presencia de neologismos constituye un rasgo evidente de un grave deterioro comunicativo. Los hallazgos de neologismos parciales fueron escasos, y los de neologismos totales, más exiguos aún. Se concentraron en dos o tres pacientes crónicos y en uno solo de primer episodio. Nos damos cuenta de que el papel de la nominación es un elemento resistente al deterioro cognitivo que afecta a los pacientes con esquizofrenia, es decir, a pesar de las dificultades comunicativas que enfrentan, esta función está conservada en la mayoría de los casos. Los desplazamientos semánticos, o lo que para este trabajo llamamos neologismos parciales, fueron más frecuentes, algunos de ellos ingeniosamente aplicados, como el ejemplo citado de CRE-M02 "soberanearse", como referencia al autoritarismo que la madre de la paciente ejercía sobre ella. Dentro de la entrevista, este término no representó un obstáculo para la comprensión. En cambio, los múltiples ejemplos tomados de CREH10, sí constituyeron un problema en la comprensión. 
Finalmente, los indicadores: Total de referentes, Total de vínculos referenciales y Promedio de vínculos referenciales, ofrecen un interesante perfil de las emisiones de los entrevistados, pues si analizamos en términos de promedio, estos indicadores delinean diferencias significativas. Los controles presentaron un promedio general de 120 referentes utilizados en el transcurso de la entrevista, en cambio, los crónicos sólo alcanzaron 85 referentes en promedio, y los sujetos de primer episodio, solo 62. Hay que hacer notar que, únicamente entre los controles, los referentes enunciados se acompañaron de desarrollo contextual, se explicitaron las relaciones semánticas y fueron plenamente comprendidas por el entrevistador quien no debió realizar preguntas para precisar a qué se estaba apuntando con X o Y referente. Muy distinto es el caso del grupo de crónicos, pese a que se registran en promedio 85 referentes, muchos de estos no son desarrollados en el contexto de las emisiones realizadas, algunos se mencionan como palabras sueltas, no se apoyan o anclan a estructuras semánticas o se presentan dentro de una frase suelta, sin contexto alguno. Los del grupo de primer episodio ciertamente emiten menos referentes, pero casi la totalidad de estos ofrece un contexto que seguir o a través del cuál es posible seguir una ruta semántica.

En tanto, la cantidad de vínculos referenciales de los tres grupos, muestran aspectos consistentes. Se inventariaron aproximadamente 1940 vínculos referenciales en los controles, lo que arroja en promedio construcciones que no superan los 16,4 elementos. En cambio, los crónicos presentan 2218 promedio de vínculos totales, que arrojan construcciones de poco o más o menos 26 elementos, que evidencian una mayor distancia entre vínculos, por tanto, una mayor dificultad en la comprensión y seguimiento del asunto tratado. A su vez, los del grupo de primer episodio, muestran en promedio total, 1343 vínculos referenciales, lo que da como resultado, la elaboración de construcciones de 21,6. Estos hallazgos respaldan las descripciones hechas por Belinchón (1988) en torno a la particularidad de los enunciados de 
personas con esquizofrenia, en los que la autora encontró distancias anómalas entre los indicadores referenciales y en el promedio de vínculos que utilizaban estos hablantes. 


\subsection{Participación conversacional}

La evaluación de estos indicadores corresponde a la dimensión pragmática de la interacción, más adelante en el cluster seis, se analizará si esta dimensión interactiva es coherente o no. Para este cluster hemos considerado si la participación de los entrevistados es fluida o no, y si manifiestan interés y conexión por los intercambios.

\subsection{1. Índice de participación conversacional}

En esta dimensión del análisis se tomó en cuenta, en primer lugar, la cantidad de palabras totales utilizadas en el segmento. Aunque este conteo no arrojó diferencias llamativas entre los tres grupos, notamos un número levemente mayor en la cantidad de palabras utilizadas en los controles sobre los crónicos y los de primer episodio:

Tabla resumen 95: promedio de palabras totales.

\begin{tabular}{||c|c|c||}
\hline CONTROLES & CRÓNICOS & PRIMER EPISODIO \\
\hline 1433 & 1343,6 & 931,6 \\
\hline
\end{tabular}

A continuación, presentamos los resultados de este indicador y su relación con las variables independientes:

\subsubsection{1. Índice de participación conversacional y estadio de la enfermedad}

Con respecto al análisis de las medias correspondientes a las palabras diferentes, según el factor estadio de la enfermedad de los sujetos, a continuación se muestran los resultados del análisis paramétrico ANOVA, según el cual la media para los controles 
es de 1467.42 en tanto, para los de primer episodio, es de 931.36, para los crónicos es de 1343.60. Los resultados no son significativos estadísticamente.

Tabla de contingencia 96: índice de participación conversacional y estadio de la enfermedad.

\begin{tabular}{||l|c|c|c|c|c|c||}
\hline \multicolumn{7}{|c||}{ Pruebas de efectos inter-sujetos } \\
\hline Variable dependiente: Índice de participación \\
\hline Origen & $\begin{array}{c}\text { Tipo III de } \\
\text { suma de } \\
\text { cuadrados }\end{array}$ & gl & $\begin{array}{c}\text { Cuadrático } \\
\text { promedio }\end{array}$ & F & Sig. & $\begin{array}{c}\text { Eta parcial } \\
\text { al cuadrado }\end{array}$ \\
\hline $\begin{array}{l}\text { Modelo } \\
\text { corregido }\end{array}$ & $\begin{array}{r}3177739.210 \\
\text { a }\end{array}$ & 2 & 1588869.605 & 22.233 & .000 & .430 \\
\hline
\end{tabular}

Gráfico 69. Porcentaje de frecuencia de las variables: índice de participación conversacional y estadio de la enfermedad

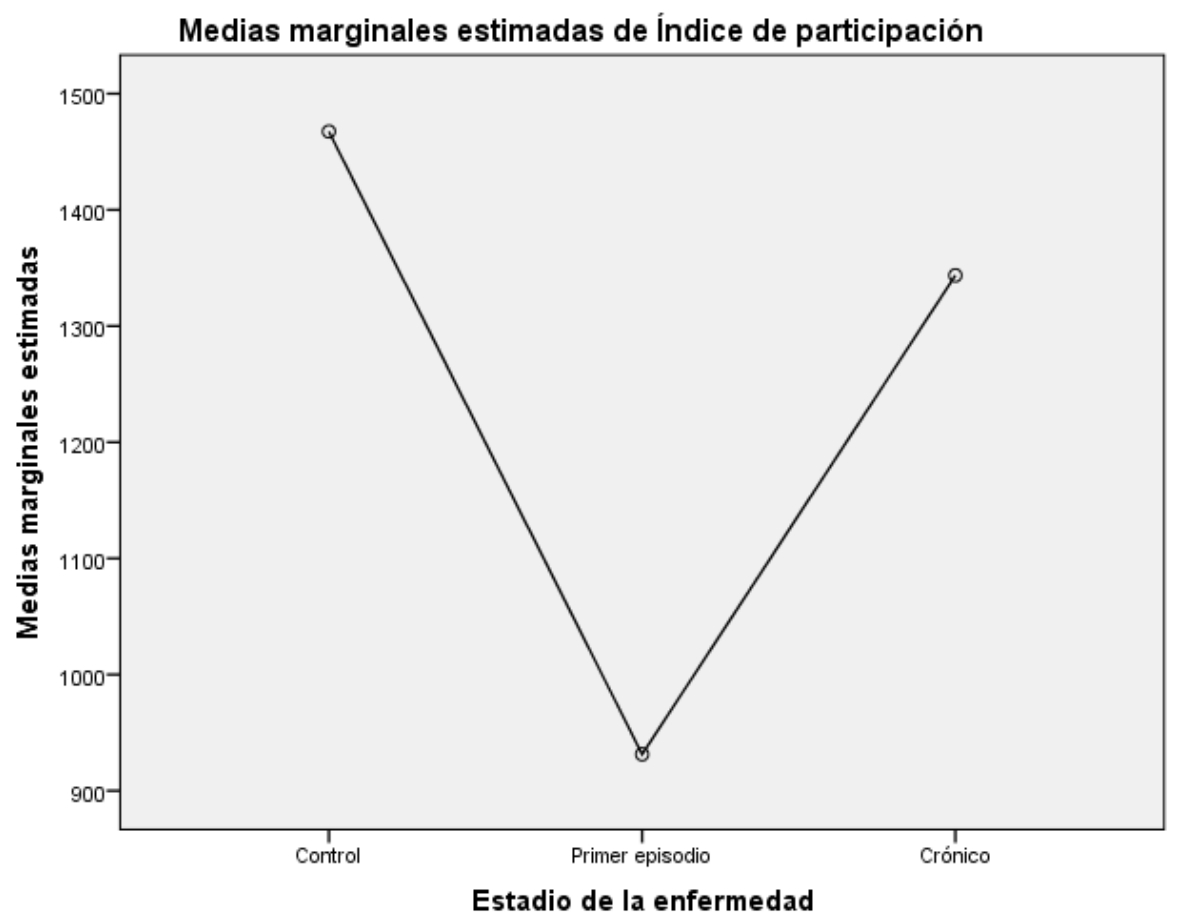


Con el fin de verificar si la dispersión de los datos presentaba alguna anomalía, se incluye el diagrama de caja y bigotes correspondiente.

70. Diagrama de caja y bigotes 33. Porcentaje de la variable: estadio de la enfermedad.

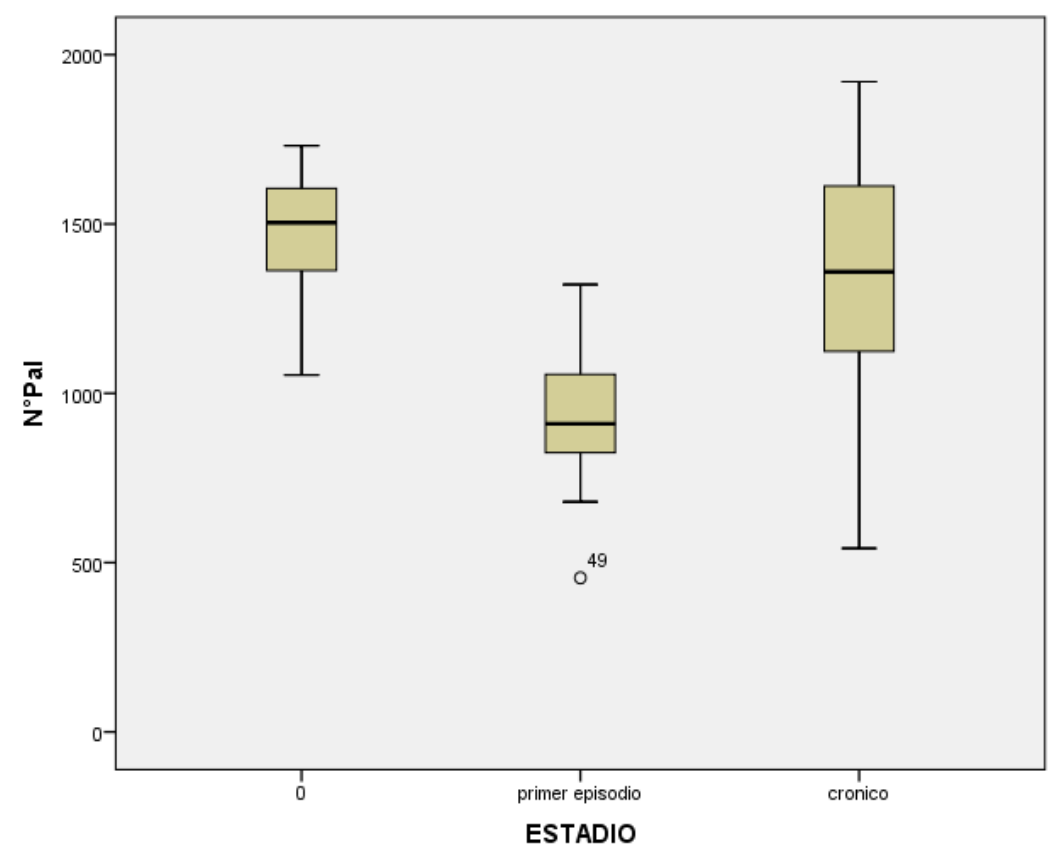

4.3.1.2. Índice de participación conversacional y sexo

Con respecto al análisis de las medias correspondientes a las palabras diferentes según el factor sexo de los sujetos, a continuación se muestran los resultados del análisis paramétrico ANOVA, según el cual la media para los hombres es de 1269.06, en tanto, para las mujeres, es de 1124.28. Los resultados no son significativos estadísticamente. 
Tabla de contingencia 97:índice de participación conversacional y sexo.

\begin{tabular}{||l|c|c|c|c|c|c||}
\hline \multicolumn{7}{||c||}{ Pruebas de efectos inter-sujetos } \\
\hline Variable dependiente: Índice de participación \\
\hline Origen & $\begin{array}{c}\text { Tipo III de } \\
\text { suma de } \\
\text { cuadrados }\end{array}$ & gl & $\begin{array}{c}\text { Cuadrático } \\
\text { promedio }\end{array}$ & F & Sig. & $\begin{array}{c}\text { Eta parcial al } \\
\text { cuadrado }\end{array}$ \\
\hline $\begin{array}{l}\text { Modelo } \\
\text { corregido }\end{array}$ & $323568.215^{\mathrm{a}}$ & 1 & 323568.215 & 2.746 & .10 & .044 \\
\hline
\end{tabular}

Gráfico 71. Porcentaje de frecuencia de las variables: índice de participación conversacional y sexo

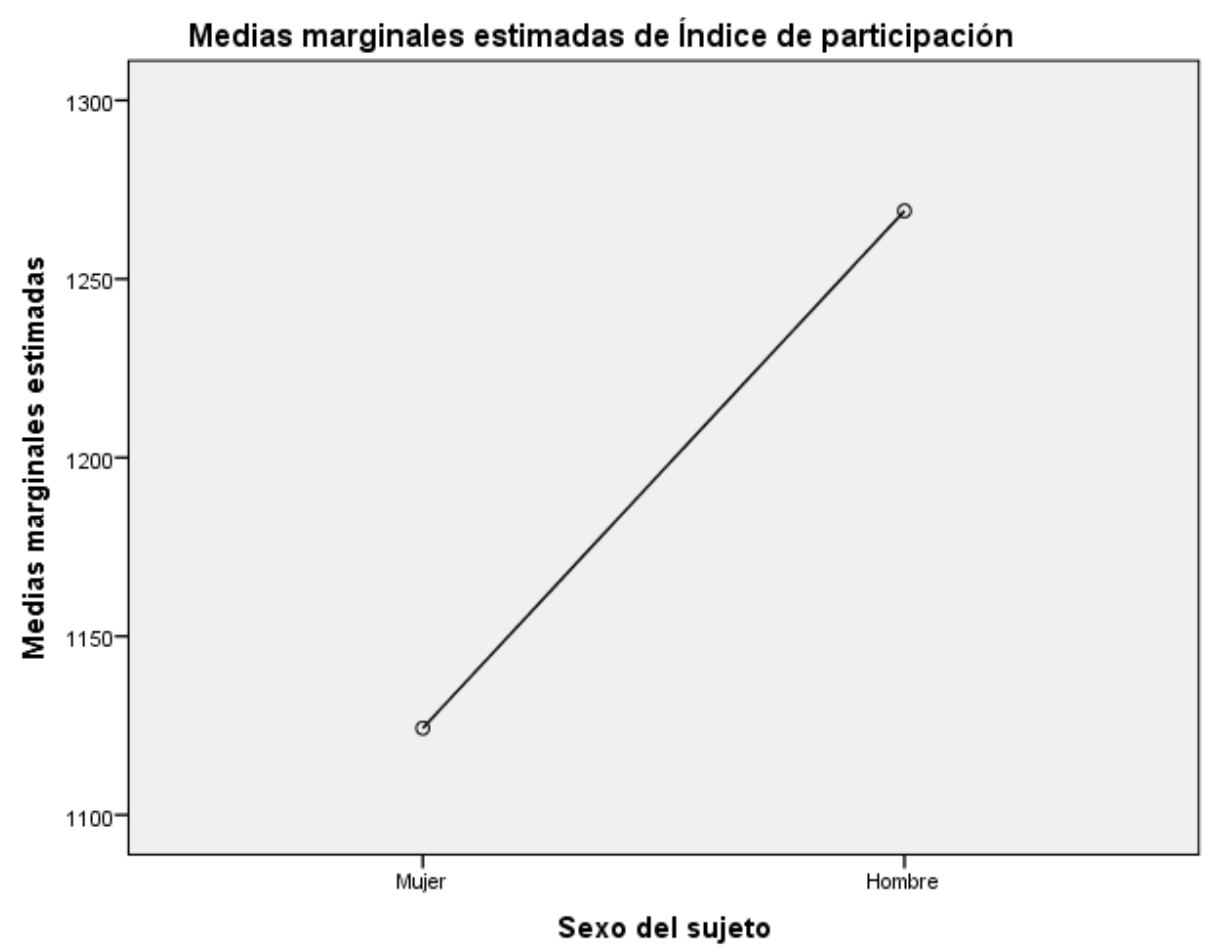


Con el fin de verificar si la dispersión de los datos presentaba alguna anomalía, se incluye el diagrama de caja y bigotes correspondiente.

72..Diagrama de caja y bigotes 34 . Porcentaje de la variable: sexo.

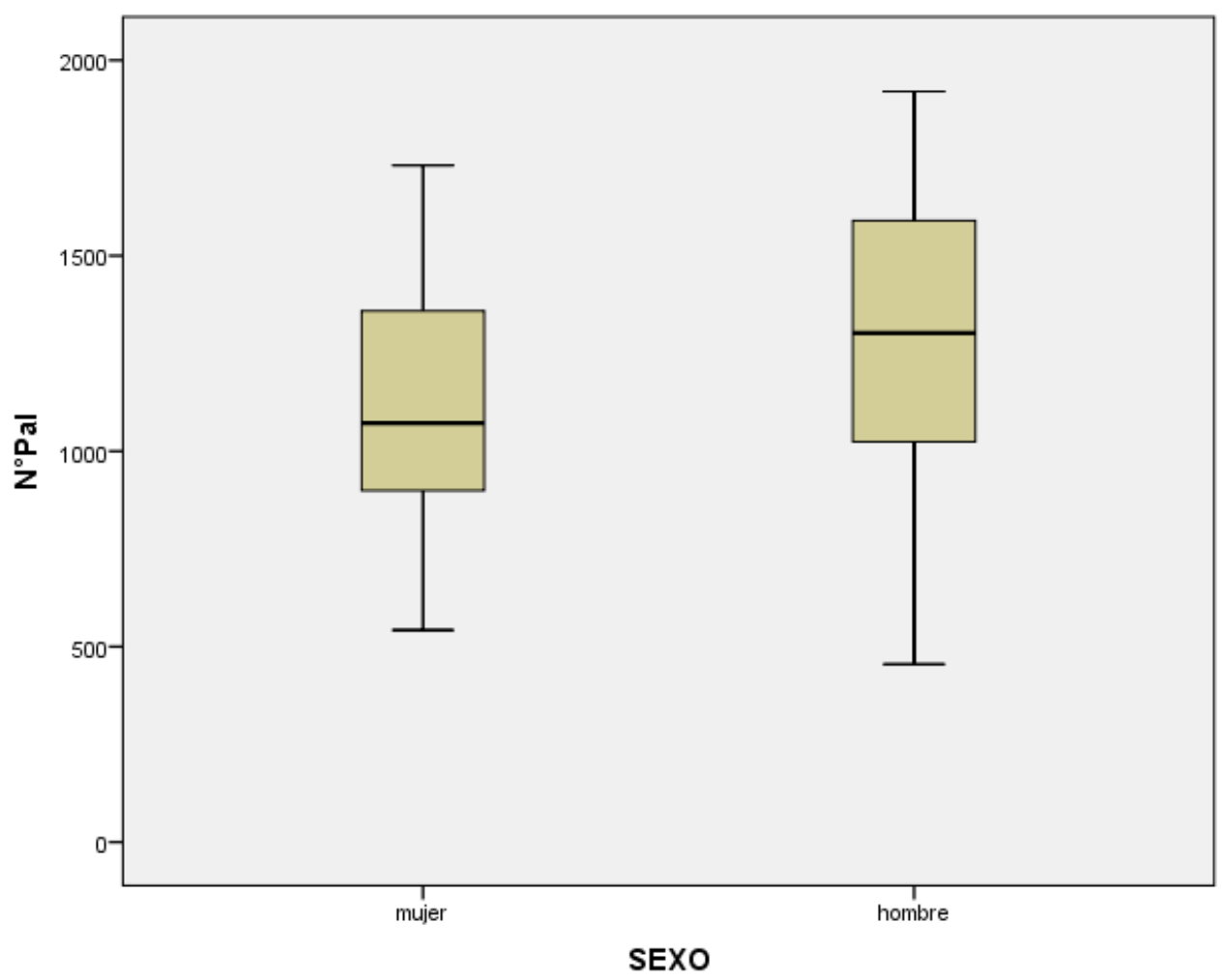

4.3.1.3. Índice de participación conversacional y tramo de la enfermedad

Con respecto al análisis de las medias correspondientes a las palabras diferentes según el factor sexo de los sujetos, a continuación se muestran los resultados del análisis paramétrico ANOVA, según el cual la media para los controles es de 1467.42; para el grupo de primer episodio $>0$ a $<2$ años es de 927.00; para los de primer 
episodio de $>2$ a $<3$ años, es de 936.91, Crónicos hasta 5 años es de 1429.40 y para los crónicos de 5 años y más 1286.40. Los resultados no son significativos estadísticamente.

Tabla de contingencia 98:índice de participación conversacional y tramo de la enfermedad.

\begin{tabular}{||l|c|c|c|c|c|c||}
\hline \hline \multicolumn{7}{||c||}{ Pruebas de efectos inter-sujetos } \\
\hline Variable dependiente: Índice de participación \\
\hline Origen & $\begin{array}{c}\text { Tipo III de } \\
\text { suma de } \\
\text { cuadrados }\end{array}$ & $\mathrm{gl}$ & $\begin{array}{c}\text { Cuadrático } \\
\text { promedio }\end{array}$ & $\mathrm{F}$ & Sig. & $\begin{array}{c}\text { Eta parcial } \\
\text { al cuadrado }\end{array}$ \\
\hline $\begin{array}{l}\text { Modelo } \\
\text { corregido }\end{array}$ & $\begin{array}{c}3301038.06 \\
1^{\mathrm{a}}\end{array}$ & 4 & 825259.515 & 11.492 & .000 & .446 \\
\hline
\end{tabular}

Gráfico 73. Porcentaje de frecuencia de las variables: índice de participación conversacional y tramo de la enfermedad

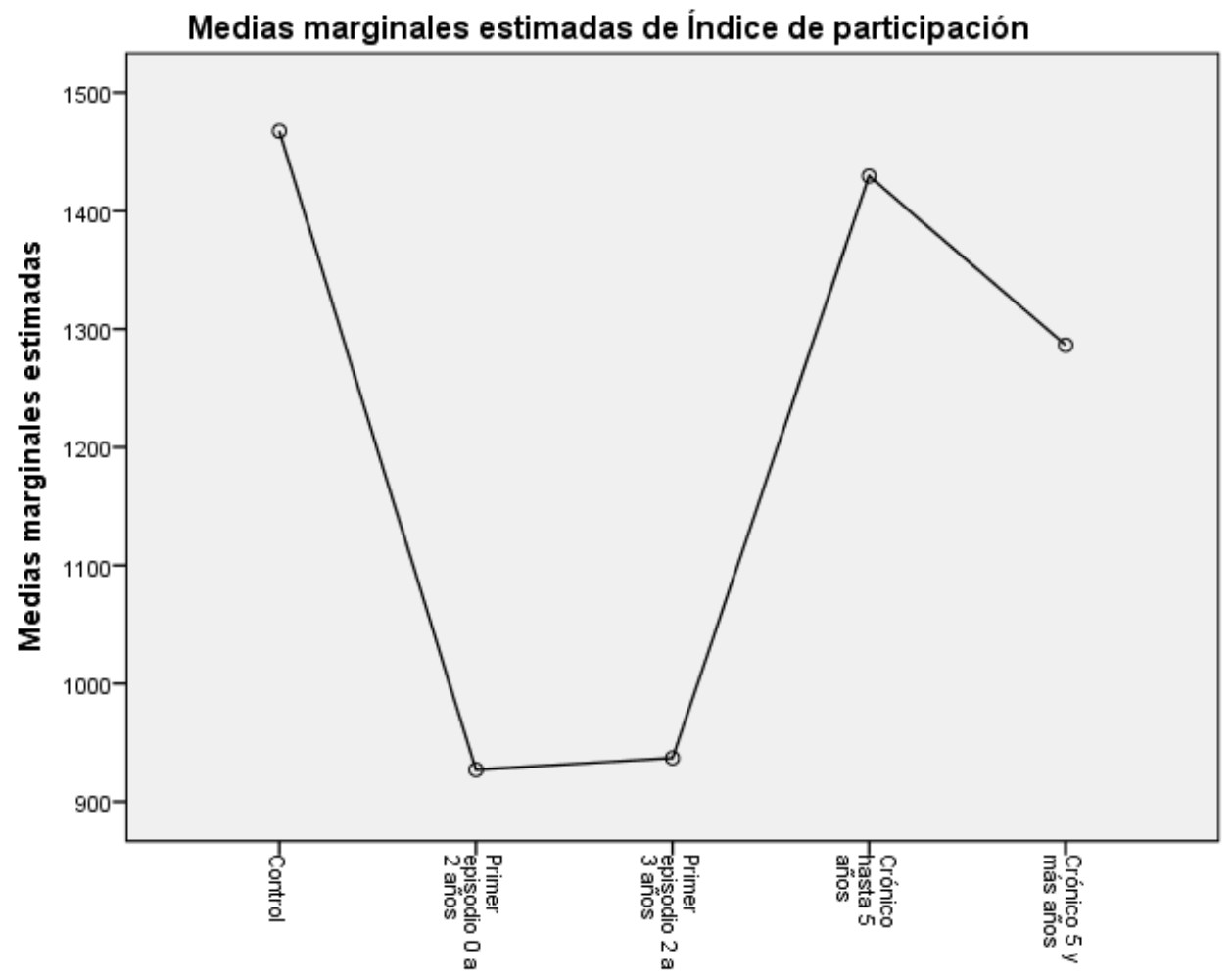


Con el fin de verificar si la dispersión de los datos presentaba alguna anomalía, se incluye el diagrama de caja y bigotes correspondiente.

74. Diagrama de caja y bigotes 35. Porcentaje de la variable: tramo de la enfermedad

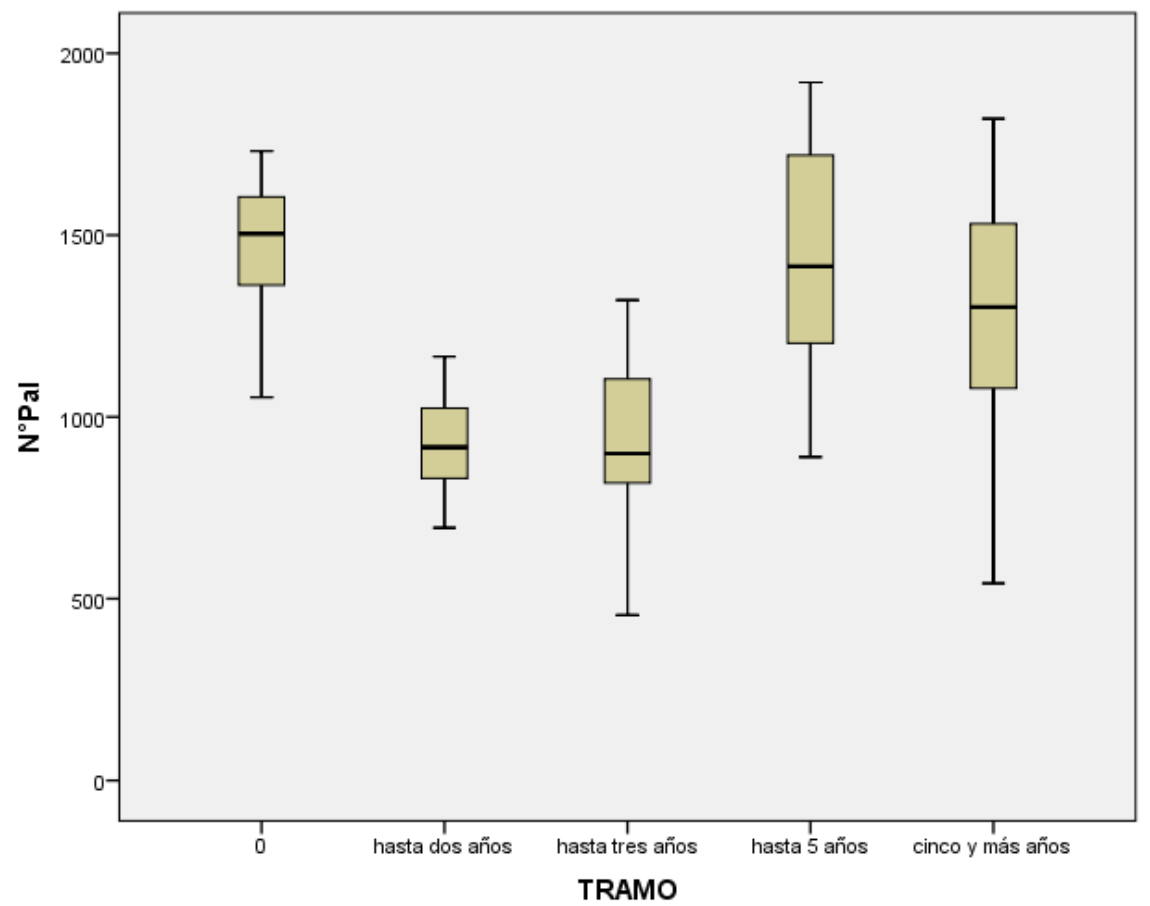

4.3.1.4. Índice de participación conversacional y subtipo de la enfermedad

Con respecto al análisis de las medias correspondientes a las palabras diferentes según el factor sexo de los sujetos, a continuación se muestran los resultados del análisis paramétrico ANOVA, según el cual la media para los controles es de 1467,417; para los paranoide de 1093,939; para los indiferenciada, 1320,111 y para los 
de esquizofrenia desorganizada, de 1111,625. Los resultados no son significativos estadísticamente.

Tabla de contingencia 99:índice de participación conversacional y subtipo de la enfermedad.

\begin{tabular}{||l|c|c|c|c|c|c||}
\hline \multicolumn{7}{|c||}{ Pruebas de los efectos inter-sujetos } \\
\hline Variable dependiente: Índice de participación \\
\hline Origen & $\begin{array}{c}\text { Suma de } \\
\text { cuadrados tipo } \\
\text { III }\end{array}$ & gl & $\begin{array}{c}\text { Media } \\
\text { cuadrátic } \\
\text { a }\end{array}$ & F & Sig. & $\begin{array}{c}\text { Eta al } \\
\text { cuadrado } \\
\text { parcial }\end{array}$ \\
\hline $\begin{array}{l}\text { Modelo } \\
\text { corregido }\end{array}$ & $1421562,328^{\text {a }}$ & 3 & $\begin{array}{r}473854,1 \\
09\end{array}$ & 4,602 &, 006 &, 192 \\
\hline \hline
\end{tabular}

Gráfico 75. Porcentaje de frecuencia de las variables: índice de participación conversacional y subtipo de la enfermedad.

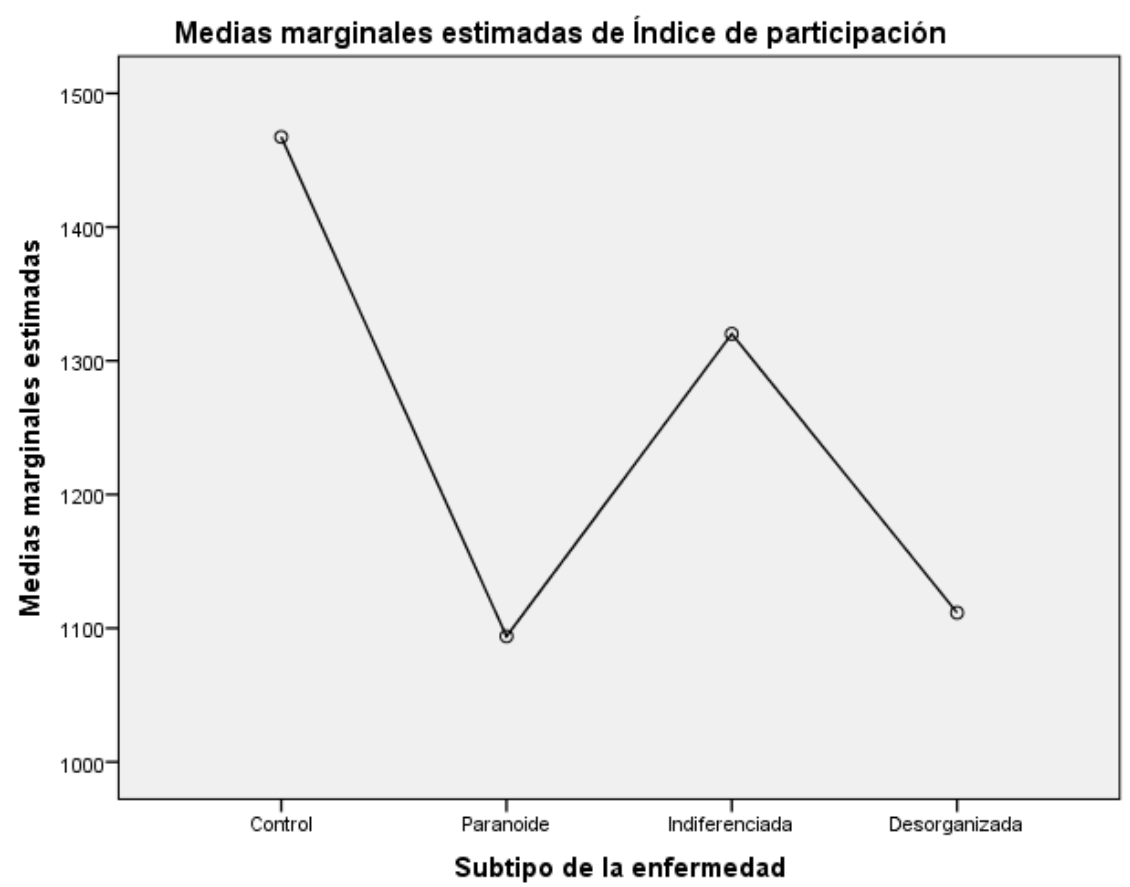


Con el fin de verificar si la dispersión de los datos presentaba alguna anomalía, se incluye el diagrama de caja y bigotes correspondiente.

76. Diagrama de caja y bigotes 36. Porcentaje de la variable: subtipo de la enfermedad

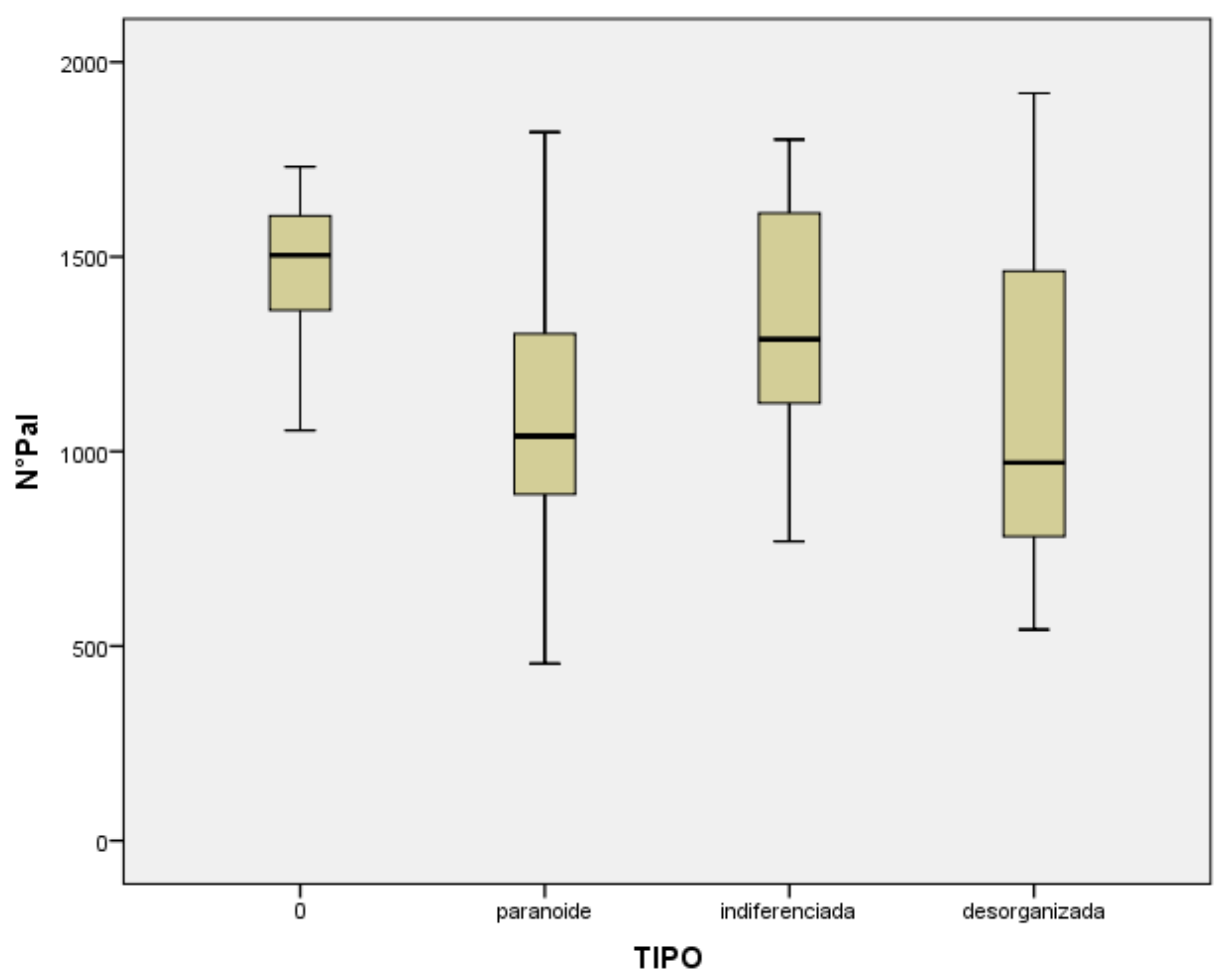

\subsubsection{Agilidad del turno}

En segundo lugar, analizamos la agilidad del turno de habla durante las interacciones. Esta medida consiste en contar los promedios de turnos por minuto, durante la conversación estudiada. Es importante señalar que en este grupo de fenómenos no identificamos elementos que puedan ser considerados relevantes como marcadores lingüísticos. Al realizar una comparación de las medidas obtenidas de los 
grupos, no existen diferencias significativas. Sin embargo, es evidente un mayor enlentecimiento en la toma de turnos en los pacientes crónicos. También fue posible verificar que en el grupo de los pacientes jóvenes hay una aparente agilidad en la toma de turnos, pero en muchos casos se debe al recurso de respuestas monosilábicas.

Tabla resumen 100: promedio de turnos.

\begin{tabular}{|l|l|l||}
\hline CONTROLES & CRÓNICOS & PRIMER EPISODIO \\
\hline 4,5 & 4,4 & 5,3 \\
\hline
\end{tabular}

A continuación exponemos tres fragmentos de entrevista de cada uno de los grupos analizados.

1) Fragmento del grupo crónico: hombre, 42 años, esquizofrenia paranoide, hospitalizado en el Instituto de Psiquiatría del Hospital Sanatorio El Peral.

1. Pero el hecho es que a mí/ mi papá me susurró al ojo al oído: "hace el servicio 40 ” y yo lo hice.

2. $\mathrm{E}: \mathrm{Ya} /$

3. S: Mi madre como yo le digo/<pausa ext $>/<$ al entrevistador $>/$ hazlo los puros fines de semana/ es teniente pero no es activo/ pero ahí ya es distinta la justificación/ ¿no sé si ustedes han hablado de eso?

4. E: Si/ algo he escuchado.

5. $\mathrm{S}: \mathrm{Ah} / \mathrm{ya}$.

6. E: ¿Cómo es esto de los pensamientos don D?/ ¿usted puede leerle la mente a alguien? $<$ pausa $>/$ ¿a las personas?

7. S: Eso lo hacen <enfático, dirigiéndose a la investigadora>/ aquellas.

8. E: ¿Quiénes son aquellas?

9. S: Las damas/ < ríe compulsivamente> <en volumen bajo pero audible> ¡la cara que pone! <aludiendo a la investigadora>

10. E: ¿Las damas podrían leerle la mente a usted?

11. S: Creo que es secreto/ no sé cómo es eso/ no he leído nada<pausa $>/$ pero<pausa ext $>/$

12. E: $¿$ Y usted le puede leer la mente a las personas?

13. S: no/ no se puede/ soy hombre

14.E: O sea/ eso de leer la mente/ ¿solamente es una característica de las mujeres?

${ }^{40}$ Referencia al Servicio Militar Obligatorio de Chile 
15. S: Como no soy mujer/ no sé qué es lo que hacen/ pero manejan a la mente.

(CRE-H02)

Dur: 01:02 Total: 8 turnos

2) Fragmento del grupo de primer episodio: hombre, 14 años, esquizofrenia desorganizada, compensado después de un grave brote psicótico, entrevista posterior a hospitalización:

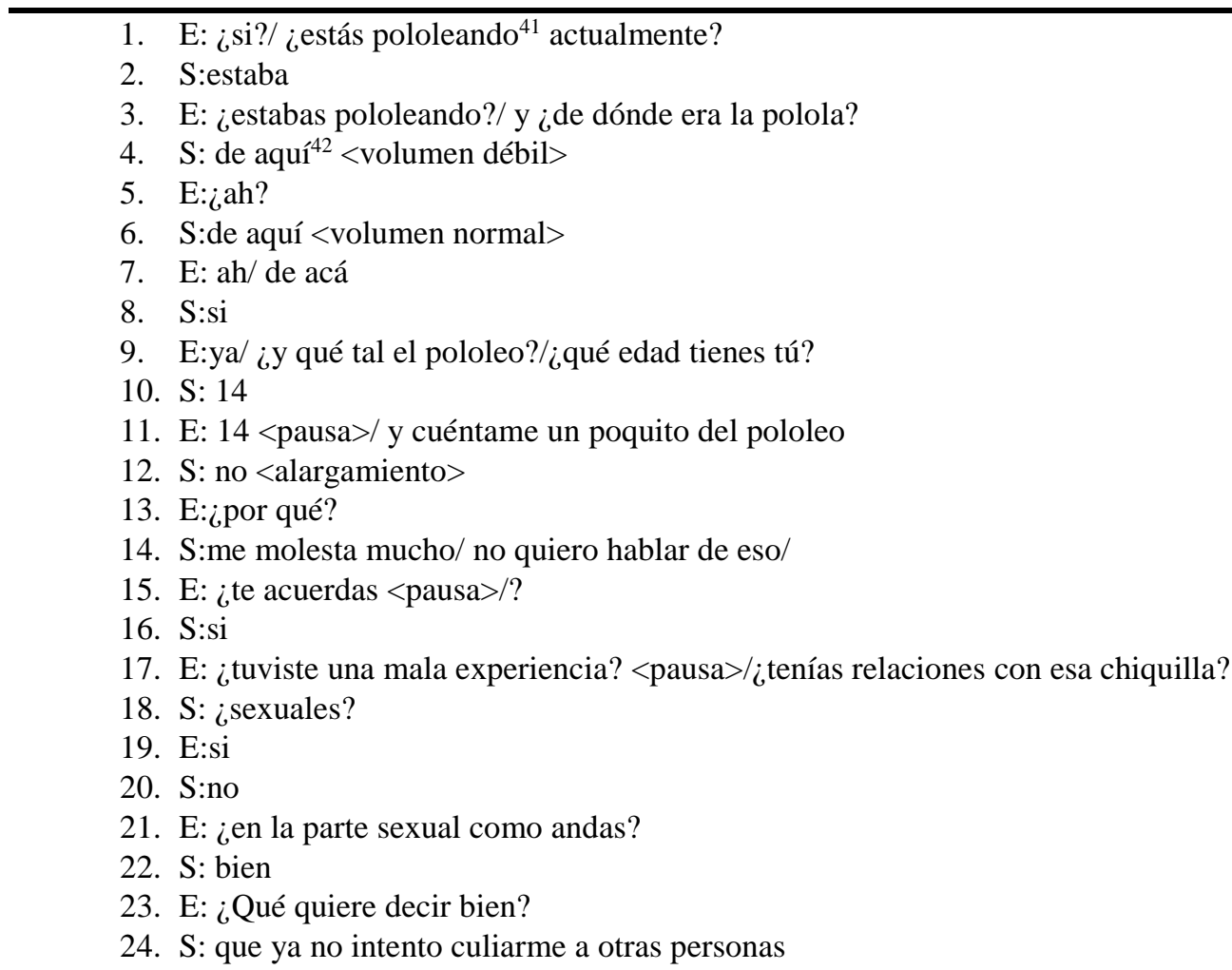

(PEE-H09)

Dur:01:02 Total: 12 turnos

${ }^{41}$ Pololear=noviazgo informal

${ }^{42}$ Referencia al centro de Rehabilitación en Salud Mental, RENOVAL 
3) Fragmento del grupo de control: mujer, 28 años, Secretaria administrativa, no ejerce, dueña de casa, pertenece al grupo socioeconómico medio bajo.

1. E: $\mathrm{mmm} /$ ¿hahta que curso ehtudiahte?

2. I : eh<alargamiento/> hasta técnico / secretaria<alargamiento/> adminihtrativa

3. E: eh<alargamiento/> eh ¿cuál eh tu ocupación actualmente?

4. I: dueña de casa

5. E: ¿y cuanto tiempo llevah en ehta actividad?

6. I: eh unos<alargamiento/> cinco/ seih añoh /

7. E: ¿hace cuanto tiempo<alargamiento/> viveh en tu comuna?

8. I : $\mathrm{mmm} /$ quince años

9. E: ya / vamoh a otra parte / narración de experienciah personaleh / eh re<palabra_cortada/> ¿recuerdah alguna anécdota graciosa de tu época de ehtudiante ya sea eh / de enseñanza básica o media?

10. I: $\mathrm{mmm}\langle$ silencio/> cuando ehtábamoh en enseñanza media / me acuerdo que era <énfasis> súper </énfasis> peliadora / y que me decían Martín Vargas ${ }^{43}$ y que <alargamiento/> siempre andábamoh rompiendo lah cosah que hacían en arteh pláhticah ${ }^{44}$ / eso siempre me acuerdo

11. E: $¿ y$ te agarrabai a comboh ${ }^{45}$ o no?

12. I : <énfasis> sí po / si me agarraba a comboh </énfasis> pero por que era mujer no me pegaban loh hombreh po

13. E: ah obvio

14. I: pero con lah mujereh me agarraba // <risas = "E"/>

15. $\mathrm{E}: \mathrm{ja} / \mathrm{ja} / \mathrm{ja}$

16. I: muy chihtoso

(CONT-M05)

Dur: 01:01 Total: 8 turnos

\subsubsection{Agilidad del turno y estadio de la enfermedad:}

Con respecto al análisis de las medias correspondientes al número de turnos por minuto según el factor estadio de la enfermedad de los sujetos, a continuación se muestran los resultados del análisis paramétrico ANOVA, según el cual la media para

${ }^{43}$ Martín Vargas = boxeador chileno retirado

${ }^{44}$ Artes Plásticas = asignatura de la enseñanza media y básica en Chile

${ }^{45}$ Agarrarse a combos = vulgarmente, empezar o participar en una pelea 
los controles es de 4,442 en tanto, para los de primer episodio, es de 5,312, para los crónicos es de 4,672. Los resultados no son significativos estadísticamente.

Tabla de contingencia 101:turnos por minuto y estadio de la enfermedad.

\begin{tabular}{||l|c|c|c|c|c|c||}
\hline \multicolumn{7}{||c||}{ Pruebas de los efectos inter-sujetos } \\
\hline Variable dependiente: Turnos por minuto \\
\hline Origen & $\begin{array}{c}\text { Suma de } \\
\text { cuadrados } \\
\text { tipo III }\end{array}$ & $\mathrm{gl}$ & $\begin{array}{c}\text { Media } \\
\text { cuadrática }\end{array}$ & $\mathrm{F}$ & Sig. & $\begin{array}{c}\text { Eta al } \\
\text { cuadrado } \\
\text { parcial }\end{array}$ \\
\hline $\begin{array}{l}\text { Modelo } \\
\text { corregido }\end{array}$ & $8,051^{\mathrm{a}}$ & 2 & 4,025 & 1,071 &, 349 &, 035 \\
\hline
\end{tabular}

Gráfico 77. Porcentaje de frecuencia de las variables: número de turnos por minuto y estadio de la enfermedad

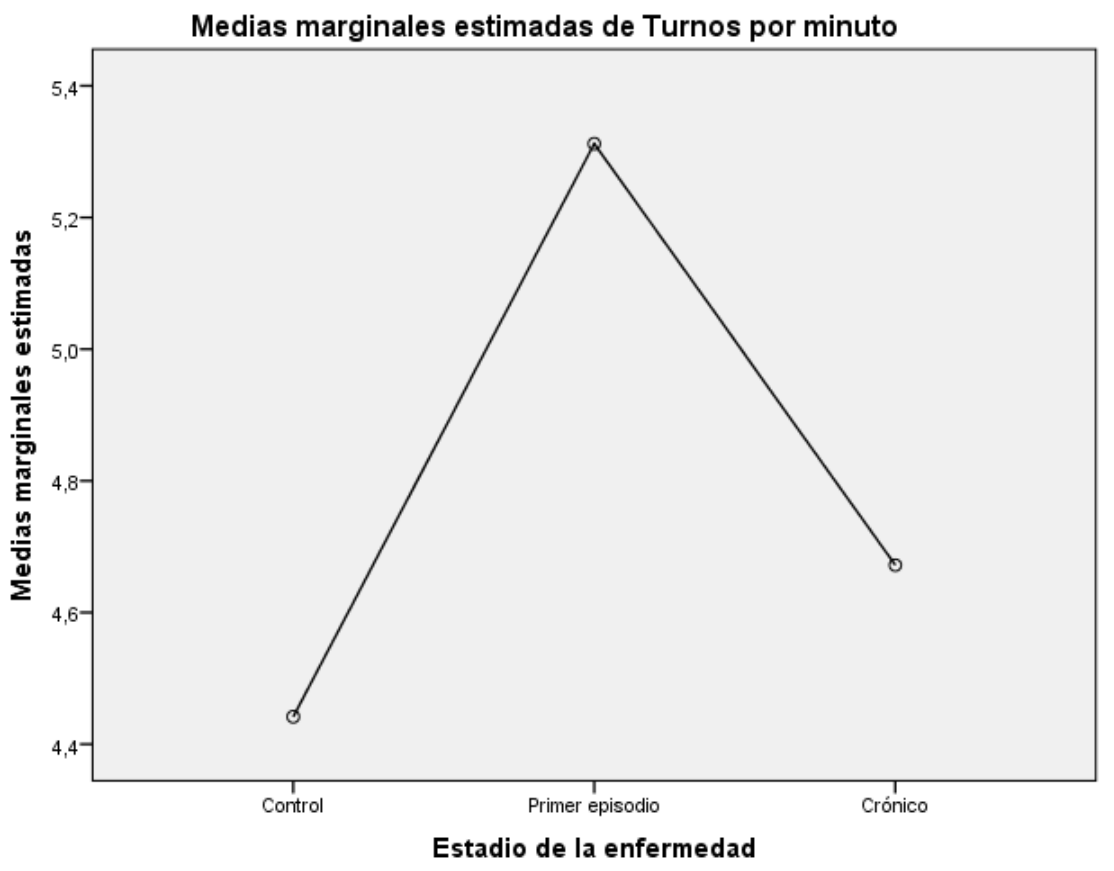


Con el fin de verificar si la dispersión de los datos presentaba alguna anomalía, se incluye el diagrama de caja y bigotes correspondiente.

78.Diagrama de caja y bigotes 37. Porcentaje de la variable: número de turnos por minuto y estadio de la enfermedad

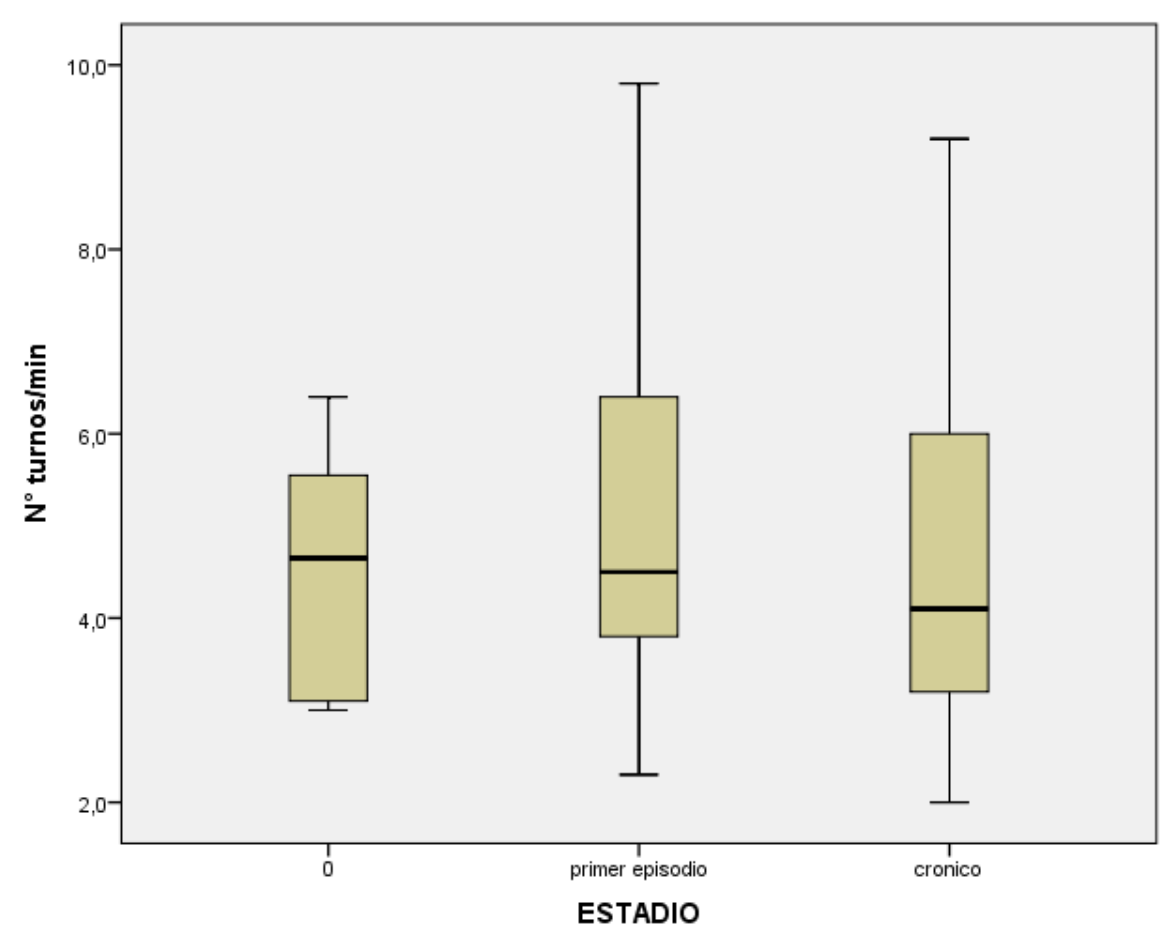




\subsubsection{Agilidad del turno y sexo}

Con respecto al análisis de las medias correspondientes a las palabras diferentes según el factor sexo de los sujetos, a continuación se muestran los resultados del análisis paramétrico ANOVA, según el cual la media para los hombres es de 4,403 en tanto, para las mujeres, es de 5,434. Los resultados no son significativos estadísticamente.

Tabla de contingencia 102:turnos por minuto y sexo.

\begin{tabular}{||l|c|c|c|c|c|c||}
\hline \hline \multicolumn{1}{||c||}{ Pruebas de los efectos inter-sujetos } \\
\hline Variable dependiente: & Turnos por minuto \\
\hline Origen & $\begin{array}{c}\text { Suma de } \\
\text { cuadrados } \\
\text { tipo III }\end{array}$ & Gl & $\begin{array}{c}\text { Media } \\
\text { cuadrática }\end{array}$ & F & Sig. & $\begin{array}{c}\text { Eta al } \\
\text { cuadrad } \\
\text { o } \\
\text { parcial }\end{array}$ \\
\hline Modelo \\
corregido
\end{tabular}


Gráfico79. Porcentaje de frecuencia de las variables: número de turnos por minuto y sexo

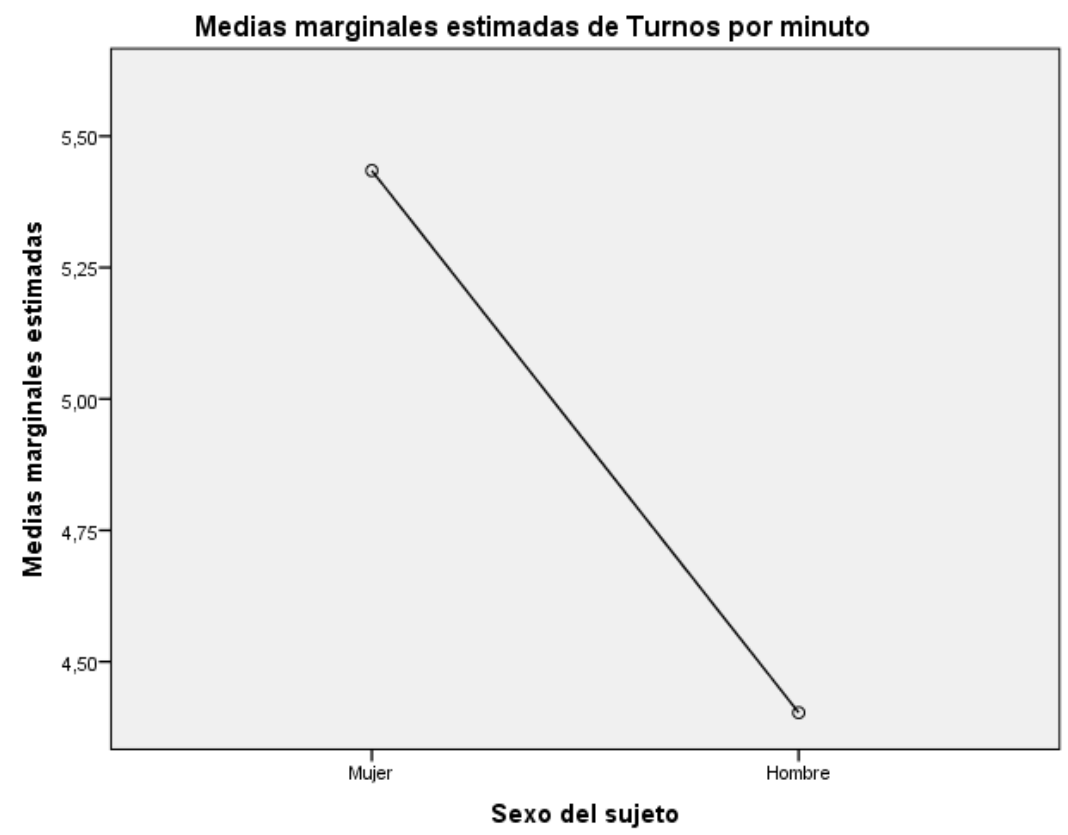

Con el fin de verificar si la dispersión de los datos presentaba alguna anomalía, se incluye el diagrama de caja y bigotes correspondiente. 
80.Diagrama de caja y bigotes 38. Porcentaje de la variable: número de turnos por minuto y sexo de los sujetos

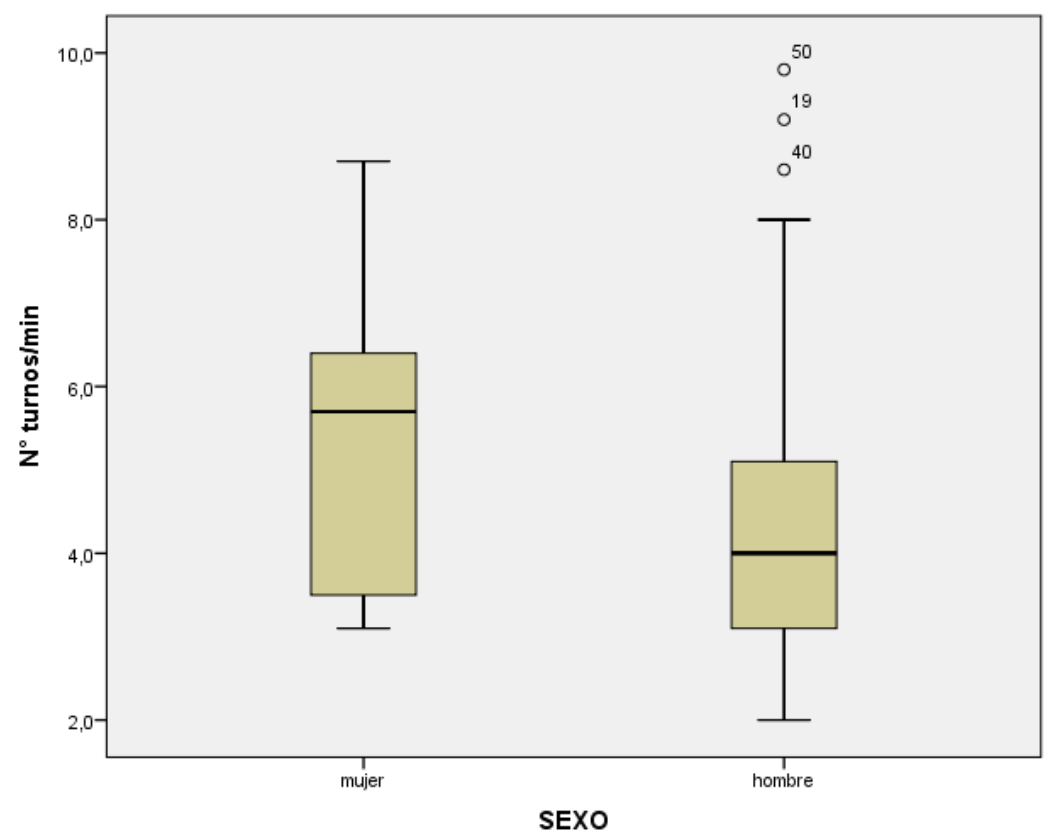

\subsubsection{Agilidad del turno y tramo de la enfermedad}

Con respecto al análisis de las medias correspondientes a las palabras diferentes según el factor sexo de los sujetos, a continuación se muestran los resultados del análisis paramétrico ANOVA, según el cual la media para los controles es de 4,442; para el grupo de primer episodio $>0$ a $<2$ años es de 6,264; para los de primer episodio de $>2$ a $<3$ años, es de 4,100, Crónicos hasta 5 años es de 4,210 y para los crónicos de 5 años y más 4,980. Los resultados no son significativos estadísticamente. 
Tabla de contingencia 103:turnos por minuto y tramo de la enfermedad.

\begin{tabular}{||l|c|c|c|c|c|c||}
\hline \hline \multicolumn{7}{||c||}{ Pruebas de los efectos inter-sujetos } \\
\hline Variable dependiente: Turnos por minuto \\
\hline Origen & $\begin{array}{c}\text { Suma de } \\
\text { cuadrados } \\
\text { tipo III }\end{array}$ & gl & $\begin{array}{c}\text { Media } \\
\text { cuadrática }\end{array}$ & F & Sig. & $\begin{array}{c}\text { Eta al } \\
\text { cuadrado } \\
\text { parcial }\end{array}$ \\
\hline $\begin{array}{l}\text { Modelo } \\
\text { corregido }\end{array}$ & $40,463^{\text {a }}$ & 4 & 10,116 & 3,046 &, 024 &, 176 \\
\hline \hline
\end{tabular}

Gráfico 81. Porcentaje de frecuencia de las variables: número de turnos por minuto y tramo de la enfermedad

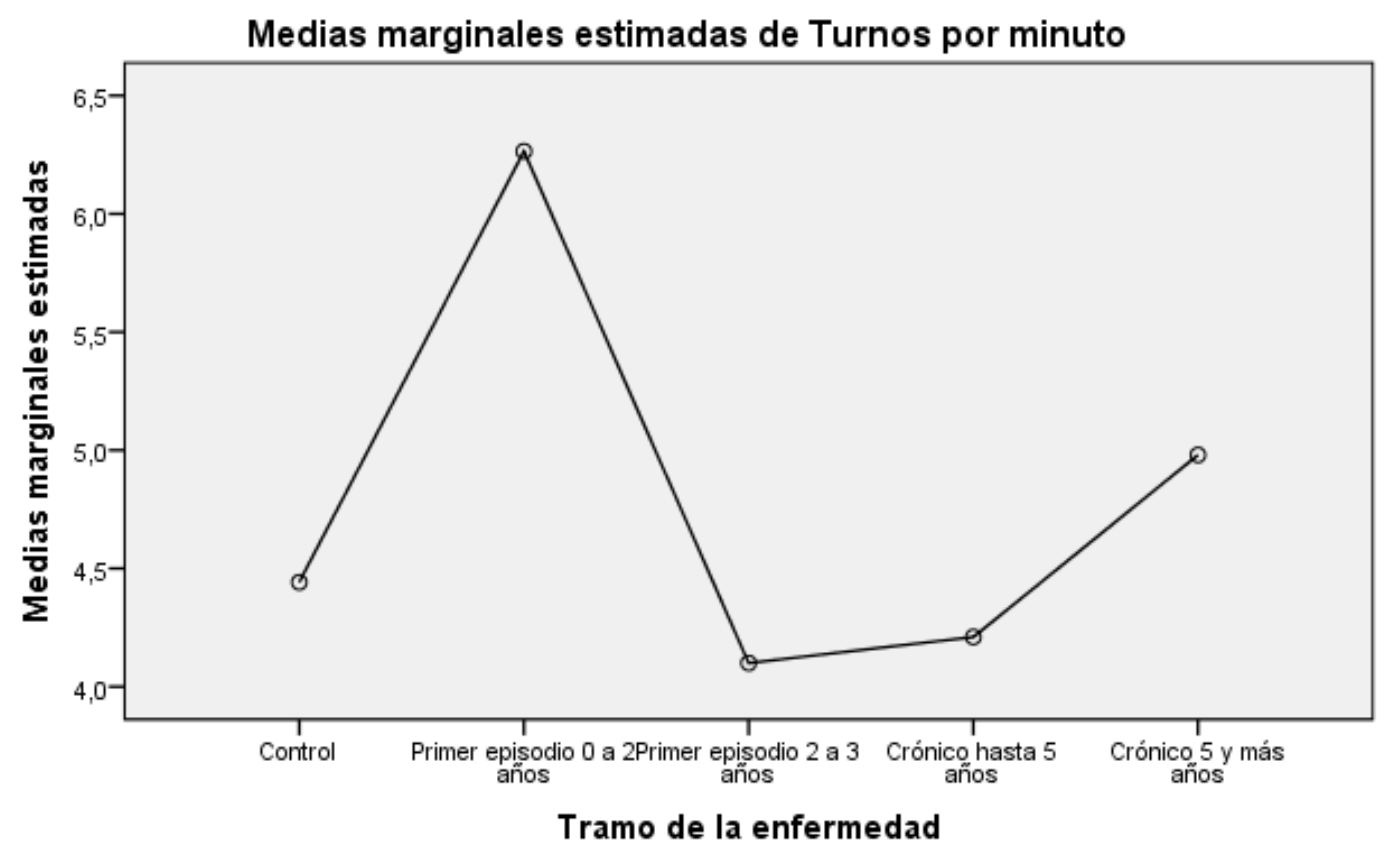


Con el fin de verificar si la dispersión de los datos presentaba alguna anomalía, se incluye el diagrama de caja y bigotes correspondiente.

82.Diagrama de caja y bigotes 39. Porcentaje de la variable: número de turnos por minuto y tramo de la enfermedad

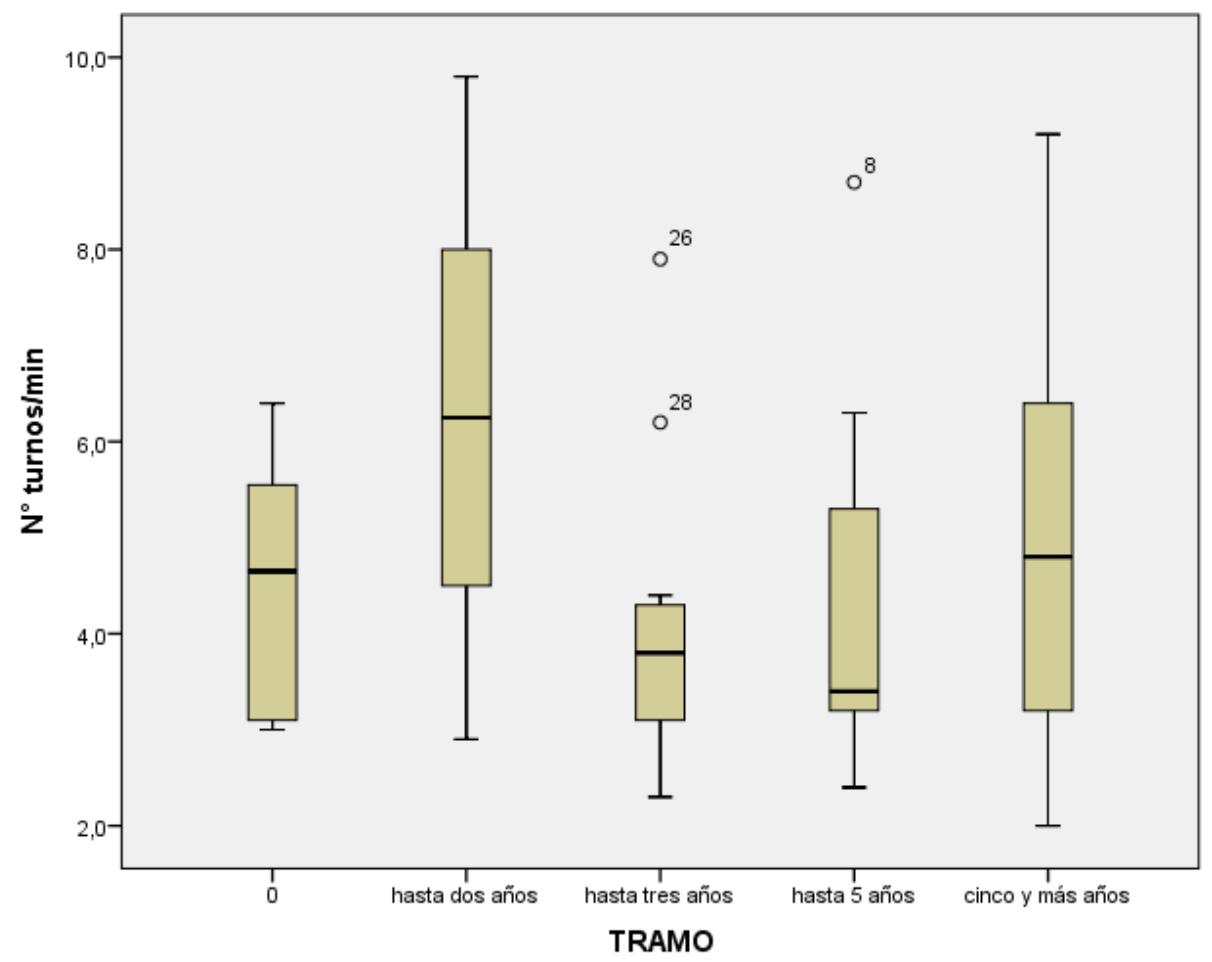

4.3.2.4. Agilidad del turno y subtipo de la enfermedad

Con respecto al análisis de las medias correspondientes a las palabras diferentes según el factor sexo de los sujetos, a continuación se muestran los resultados del análisis paramétrico ANOVA, según el cual la media para los controles es de 4,442; 
para los paranoide de 4,724; para los indiferenciada, 5,222 y para los de esquizofrenia desorganizada, de 5,838. Los resultados no son significativos estadísticamente.

Tabla de contingencia 104:turnos por minuto y subtipo de la enfermedad.

\begin{tabular}{||l|c|r|r|r|r|r||}
\hline \multicolumn{7}{||c||}{ Pruebas de los efectos inter-sujetos } \\
\hline Variable dependiente: Turnos por minuto \\
\hline Origen & $\begin{array}{c}\text { Suma de } \\
\text { cuadrados } \\
\text { tipo III }\end{array}$ & gl & $\begin{array}{c}\text { Media } \\
\text { cuadrática }\end{array}$ & F & Sig. & $\begin{array}{c}\text { Eta al } \\
\text { cuadrado } \\
\text { parcial }\end{array}$ \\
\hline $\begin{array}{l}\text { Modelo } \\
\text { corregido }\end{array}$ & $11,493^{\text {a }}$ & 3 & 3,831 & 1,018 &, 391 &, 050 \\
\hline
\end{tabular}

Gráfico 83. Porcentaje de frecuencia de las variables: número de turnos por minuto y subtipo de la enfermedad

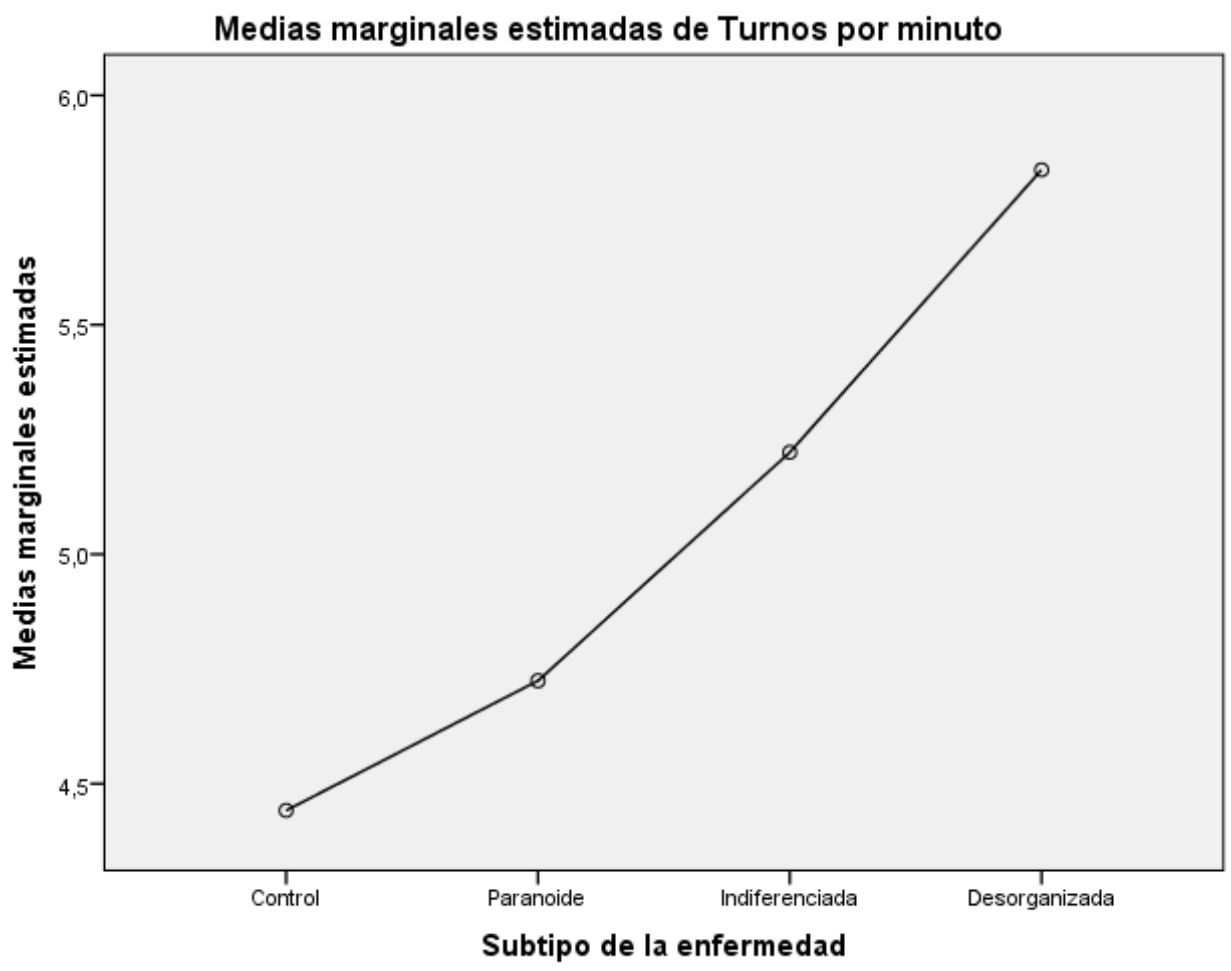

Con el fin de verificar si la dispersión de los datos presentaba alguna anomalía, se incluye el diagrama de caja y bigotes correspondiente. 
84. Diagrama de caja y bigotes 40. Porcentaje de la variable: número de turnos por minuto y subtipo de la enfermedad

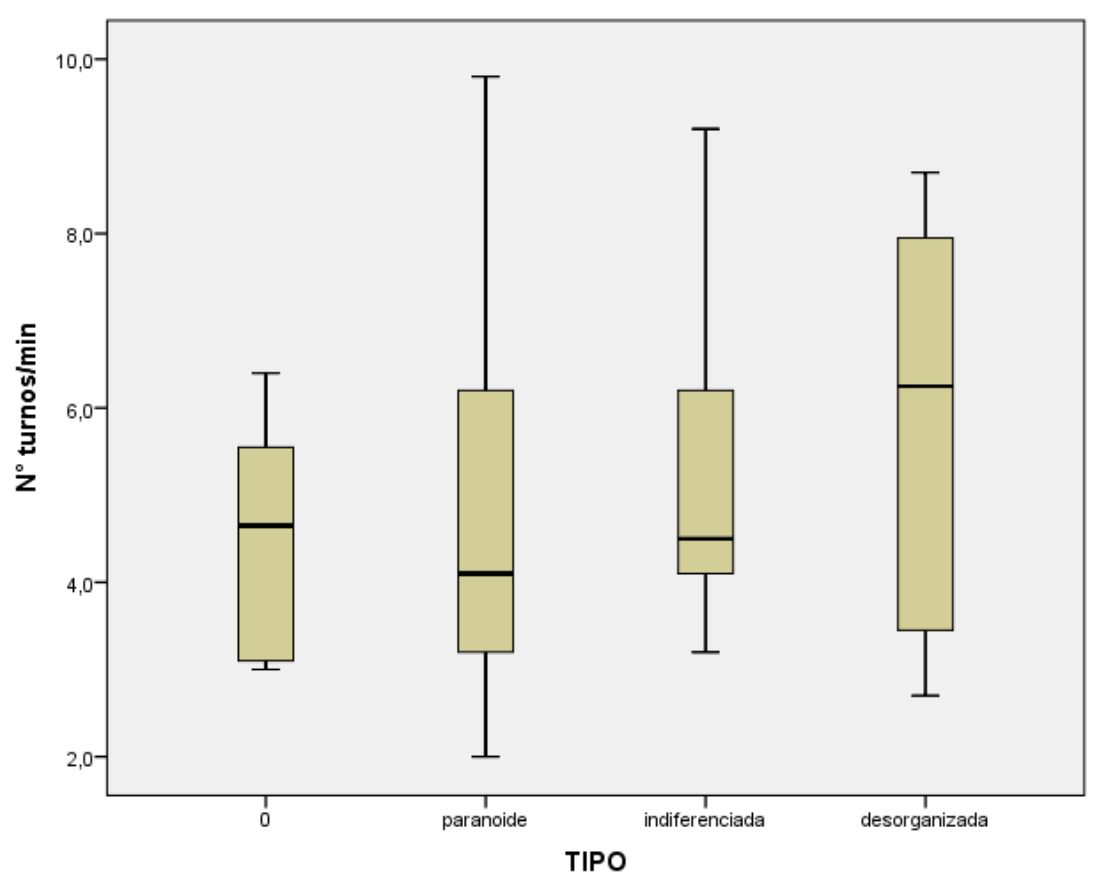




\subsubsection{Conclusiones cluster de Índice de Participación Conversacional}

En este cluster no encontramos medidas estadísticas que sean significativas, se presentaron pocas diferencias respecto de los indicadores cantidad de palabras. En lo que respecta a la agilidad del turno, el indicador número de turnos por minuto, tampoco mostró diferencias sustantivas. Ambos indicadores son parte de los criterios utilizados en afasiología (Gallardo y Hernández Sacristán, 2013), área en la que son marcadores muy robustos de déficit comunicativo.

En este estudio, el grupo de los controles promedió 2712 palabras, los crónicos 2583 palabras y los de primer episodio, 1791. No observamos diferencias de género, ni tampoco fue relevante ni el tramo de la enfermedad o el subtipo.

En lo tocante al número de turnos por minuto, las medidas ofrecen una gran homogeneidad, con 4,4 turnos por minuto en los controles; 4,6 turnos por minuto en los crónicos y 5,3 en los del grupo de primer episodio.

Ahora bien, independientemente de que estas medidas resultantes sean similares para los tres grupos, esta es una impresión superficial, ya que al observar la estructura de las intervenciones de los grupos 1 y 2, nos damos cuenta de que existe en buena medida una interacción guiada y modelada por el entrevistador, por lo tanto la agilidad del turno se ha realizado en un gran porcentaje con apoyo de este. Entre los controles solo registramos un caso en el que un entrevistado recibió ayuda para tomar el turno, en cambio, en los crónicos y en los de primer episodio se realizaron con frecuencia dichas intervenciones. Por otra parte, la toma de turnos con ayuda no siempre cubrió las necesidades informativas del entrevistador, de manera que la toma de turnos que sirvió desde el punto de vista comunicativo, no fue la totalidad de la cifra informada aquí. En suma, la toma de turnos solo es equivalente en la cantidad, no en las mismas condiciones o finalidad que tuvo en la entrevista. 
De manera similar, frente al conteo de la cantidad de palabras empleadas por los participantes, es necesario aclarar una posible falsa impresión. También aquí las cifras son similares, pero es necesario recordar que una porción no menor de las palabras utilizadas por los crónicos y el grupo de primer episodio, se repiten en forma constante, lo que redunda en una actuación discursiva con menos recursos léxicos, por lo tanto, mucho más pobre. 


\subsection{Coherencia temática}

Como ya señalamos en el capítulo anterior, en este núcleo de análisis encontramos elementos discursivos que apuntan, tanto a la evaluación de la estructura profunda o macroestructura, como también a la organización microestructural de los discursos de los sujetos estudiados. Se analizarán fenómenos que afectan la coherencia semántica, en ambos niveles.

En la macroestructura, encontramos una probable reconstrucción teórica de aspectos como el tema o el asunto general del que trata el discurso (Van Dijk, 1997) que evaluaremos incluyendo aspectos que involucran la unidad temática nuclear, (UTN) y la presencia de proposiciones con vínculos explícitos/implícitos respecto del tema central, (PVE-PVI). Como ya hemos señalado, trabajamos desde el enfoque de la eficacia comunicativa que se requiere para hacer más comprensible el discurso. Valoraremos el desempeño de los participantes en tres niveles de significación, es a saber, si es que el sujeto lo realiza adecuadamente (3), si es que requiere ayuda del entrevistador para esclarecer el significado (2), o bien si es deficiente a pesar de contar con el modelamiento del entrevistador (1)

A través de la microestructura, damos cuenta de las propiedades del discurso a partir de las relaciones entre oraciones secuenciadas y discontinuas. Las relaciones importantes entre las oraciones están dadas por su naturaleza semántica, que se evidencian en fenómenos como la pronominalización, secuencias de tiempos verbales, tema, rema, conectores, etc. En este nivel, basándonos en fenómenos como los anteriormente mencionados, evaluaremos el desempeño de los participantes en el desarrollo de tópicos con referentes identificables, saltos topicales y la relación que se observa entre referentes y vínculos referenciales. 


\subsubsection{Unidad temática nuclear}

En este punto nos interesó analizar si en el discurso de los participantes se efectuaba una gestión temática adecuada, es decir, que permitiera establecer un asunto general al que se hará referencia. A continuación presentamos algunos ejemplos del manejo temático en el grupo de crónicos, de inico y controles:

\subsubsection{Ejemplos de unidad temática:}

\section{1) Ejemplo del grupo de crónicos}

23. E: oiga don $\mathrm{D} /$ ¿y por qué está usted acá en el hospital?

24. S: por una confusión enorme

25. E: ¿qué le pasó?

26. S: casi fallezco

27. E: ¿casi<pausa>?/

28. S: casi fallezco

29. E: ¿casi fallece?

30. S: hace un mes

31. E: ¿qué le pasó?

32. S: nada<pausa $>/$ que fui a la posta ${ }^{46} /[\langle$ del hospital BL $>]$ necesitaba una atención/ me volví/ capté una cosa/ un pensamiento y pp <pausa>/ <superpuesto> llegué acá y usted vio/ no estaría conversando con usted.

33. E: ¿y que pens<interrupción>?

34. S: <superp>/ no todo lo malo empieza/ <pausa>/ al margen de la psiquiatría.

35. E: vamos a dejar al margen la psiquiatría.

36. S: yo soy humilde y lo acepto.

37. E: ah/ ya/ $\mathrm{y}<$ pausa $>$ don $\mathrm{D}$ ¿y qué pensamiento captó?/ ¿que gracias a eso/ a ese pensamiento está vivo?

38. S: me di cuenta no más/ que no me sucedió

39. E: ¿qué cosa no le sucedió?

40. S: fallecer

41. E: ya/ eh<pausa>

42. S: las personas se dan cuenta cuando van a fallecer/ o sea $<$ pausa $>/$

43. E:ya<pausa>

44. S: están agonizando/ saben que van a fallecer.

45. E: pero<pausa> ¿usted lo sabía?

46. $\mathrm{S}$ : : <superp>/nons <inint por volumen débil> la verdad de las cosas/ es que le voy a decir yo que/ casi me va a suceder eso/ puedo conversar tranquilamente/ me pongo un poco nervioso/ me gustaría irme para mi casa.

47. E: ¿está nervioso ahora?

${ }^{46}$ Posta=servicio de atención primaria de urgencia 
48. S: por decisión/ noo <alargamiento>/ encantado de estar aquí/ pero me gustaría irme de alta/ podría estar un mes más aquí/ pero en buen estado/ ya tranquilo.

(CRE-H02)

Ejemplificamos con dos temas informados por el entrevistado:

\begin{tabular}{lll}
\hline Turnos & Tema & Observaciones \\
\hline 24 & T 1 (tiene una) confusión enorme & $\begin{array}{l}\text { No presenta continuidad a lo largo del } \\
\text { fragmento }\end{array}$ \\
\hline 26 & T 2 casi fallece (fallecer) & Se repite la referencia al tema en los \\
& turnos $28,30,32,40,42,44$. No se \\
& desarrolla de manera completa, el \\
& entrevistador debe modelar la \\
& referencia al T2 durante varios turnos \\
& para optimizar la comprensión. En \\
& este caso, este ejemplo se valoró con \\
& un 2, es decir, con ayuda del \\
& entrevistador. \\
\hline
\end{tabular}

En este fragmento no se aprecia continuidad ni desarrollo de un tema sino más bien, se presentan varios temas fragmentados, algunos sin conexión entre sí. El entrevistador plantea como tema el motivo de la hospitalización y CRE-H02, plantea un tema T1 (sentir-una gran confusión), que no desarrolla, e inmediatamente agrega T2 (fallecer), que se reitera, pero que tampoco se desarrolla. Podemos desprender del ejemplo anterior, que se incorporan subtópicos no inferibles a partir de los temas planteados, lo que redunda, en primer lugar en la imposibilidad de desarrollar un tema principal, además, de incluir elementos desligados semánticamente, que impiden o dificultan la comprensión del fragmento.

En un trabajo de Soto (2011) se plantea que un recurso típico de la coherencia lineal discursiva es la derivación de un subtópico desde un tópico vigente, con el fin de tener un control sobre la gestión de expectativas que contribuye a la interacción. Estas estructuras subtopicales pueden inferirse a partir de un tópico o tema que se haya explicitado (Dik, 1997) en virtud de nuestro conocimiento de mundo: 


\begin{tabular}{|c|c|c|}
\hline Turnos & Tema/Proposiciones & Observaciones \\
\hline 24 & S: casi fallezco $\langle\mathrm{T} 2\rangle$ & Se introducen los subtópicos que \\
\hline 31 & E: ¿qué le pasó? & nuestro conocimiento de mundo \\
\hline \multirow[t]{5}{*}{32} & S: nada<pausa>/ que fui a la posta $^{47} /$ & nos permite asociar: \\
\hline & {$[<$ del hospital BL $>]$} & la posta" у “necesitaba \\
\hline & atención/ me volví/ capté una cosa/ un & una atención", ya que inferimos \\
\hline & pensamiento $\quad \mathrm{y} \quad \mathrm{pp}$ & que asiste a este centro \\
\hline & $\begin{array}{l}\text { <superpuesto> llegué acá y usted vio/ no } \\
\text { estaría conversando con usted. }\end{array}$ & $\begin{array}{l}\text { asistencial por necesitar atención } \\
\text { médica, debido a que, señala } \\
\text { "casi fallezco" }\end{array}$ \\
\hline
\end{tabular}

Sin embargo, en este caso, ambos subtópicos mencionados en la tabla, pese a que podemos inferir una relación semántica con el tema planteado <casi fallezco>, no aportan ni amplían la información acerca de la causa de su problema de salud que lo tiene hospitalizado, quedando el tema enunciado. El informante CRE-H02 agrega subtópicos como: "me volví/ capté una cosa/ un pensamiento [...] llegué acá y usted vio/ no estaría conversando con usted" que no pueden vincularse ni al tema, ni a los subtópicos implícitos planteados en el mismo turno. Como señalan Gallardo y Hernández Sacristán (2013) en estas proposiciones se combinan tanto aspectos semánticos referenciales, como aspectos informativos de dimensión pragmática. Resulta difícil determinar si en este caso se trata de un nuevo tema o de una ampliación del tema anterior.

2) Presentamos otro ejemplo del grupo de pacientes crónicos:

19. E: ¿Por qué está acá?

20. S: ¿уо? / pausa $>/$ a ver ¿qué podría decir? <pausa $>/$ el amor <ríe> no/ la verdad<pausa $>/$ estoy pasando por mi capacidad/ estoy mucho mejor/ porque la clozapina me faltaba y me desbalanceaba en todo lo que hacía/ y es perjudicial no tomarla/ es parte de la vida $\langle$ pausa $>/$ hay que hacer cosas a veces

yo miro la gente/ yo sé que estoy haciendo lo bueno/ en mi corazón/ en ese <pausa>/ abre la puerta al corazón/ el amor se está definiendo porque viene antes del amor $\langle$ pausa $>$ la bendición/ antes del amor/ la bendición porque un hijo comete errores $\langle$ pausa $>/$ eso no tiene

${ }^{47}$ Posta $=$ servicio de atención primaria de urgencia 
importancia<pausa>/ y como les decía/ que el amor era de $\mathrm{ram}^{48}$ / el corazón es como memoria $\mathrm{ram} /$ y el amor es el disco ${ }^{49}<$ pausa $>$ ¿si o no?/ ya llevan la a y la o poh' $<$ pausa $>/$ y llevan la a y la o/ porque cuando hablo de sinopsis es dar conocimiento de algo <pausa $>$ como un compendio de uno/de acciones de vida/ de un tema/ como te digo<pausa $>$ / fundamental para que entiendan la función del<pausa ext $>/$ para que entiendan la función<pausa $>/$ así está claro/ la función/ porque si se pone lo que dice ahí<pausa $>/$ y ver<pausa $>/$ que es factible<pausa ext $>/$ el justo juicio<pausa ext $>/$ como un<pausa ext $>/$ sentir humano/ como un sentir humano/ porque si le pones los nombres ahí/ de atención/ que dice ahí es muy importante la función// Es un sistema de cosas para que ha pasado en mi vida/ un ritmo de cosas.

21. E: oiga/ don $\mathrm{O} /$ ¿hace cuánto tiempo qué está acá?

22. S: hace dos años.

23. E: ¿y qué le pasa que está hace dos años acá?

24. S: por falta de <pausa ext>/ me faltó un remedio y eso me produjo lo otro/ es que me sentí un poco equivocado de mi vida.

25. E: ¿la clozapina?

26. S. no me sirvió<pausa>/

27. E: ¿y por qué le están dando esos remedios?

28. S: me los están controlando con exámenes de sangre por calidad de vida/ y por eso les decía sinopsis tiene la o y sinapsis tiene la a

29. E: Don $\mathrm{O}<$ pausa $>/$ don $\mathrm{O}<$ pausa $>/$ <entrevistador trata de interrumpir al informante, sin ningún éxito>

30. S: El juicio es una sinopsis de algo para ver cómo está la idea de comportar el respeto $<$ pausa $>$ entonces/ ¿qué significa eso? <pausa>/ significa lo más bonito amor tiene la a y la o $<$ ríe> los juntó<pausa>l

31. <Risas de todos>

\begin{tabular}{|c|c|c|}
\hline Turnos & Tema /Proposiciones & Observaciones \\
\hline 20 & T1 está hospitalizado por el amor & $\begin{array}{l}\text { No presenta continuidad a lo largo del } \\
\text { fragmento, sin subtópicos }\end{array}$ \\
\hline 20 & $\begin{array}{l}\text { T2 está pasando por su capacidad (¿de } \\
\text { mejorar?) }\end{array}$ & $\begin{array}{l}\text { No presenta continuidad a lo largo del } \\
\text { fragmento }\end{array}$ \\
\hline 20 & T3 la falta de clozapina & $\begin{array}{l}\text { No presenta continuidad a lo largo del } \\
\text { fragmento, pero podemos identificar } \\
\text { los subtópicos: desbalance vital } \\
\text { perjuicio de no tomar et } \\
\text { antipsicótico/tomarla es parte de la } \\
\text { vida }\end{array}$ \\
\hline \multirow[t]{2}{*}{20} & T4 hacer el bien & $\begin{array}{l}\text { No presenta continuidad a lo largo del } \\
\text { fragmento, pero podemos identificar }\end{array}$ \\
\hline & & $\begin{array}{l}\text { el subtópico: al mirar a la gente sabe } \\
\text { que está haciendo lo bueno }\end{array}$ \\
\hline 20 & T5 El amor está en el corazón & No presenta continuidad a lo largo del \\
\hline
\end{tabular}

${ }^{48}$ Este participante cuenta con estudios universitarios en Ingeniería en informática, las referencias informáticas son frecuentes en su discurso.

${ }^{49}$ Por disco duro, hardware. 


\begin{tabular}{cl}
\hline & fragmento, pero podemos identificar \\
& los subtópicos: Subtópicos: abrir la \\
& puerta al corazón (amor)/definiendo \\
& al amor/comparación del amor con \\
& memoria ram y disco duro/el amor (la \\
& palabra) tiene una a yna o/ \\
\hline 20 & No presenta continuidad a lo largo del \\
& fragmento, pero podemos identificar \\
& los subtópicos: Subtópicos: \\
& Definición de sinopsis/comparación \\
& de sinopsis con un compendio de \\
& acciones/la sinopsis permite entender \\
& la función (¿de qué?) \\
\hline 20 & No presenta continuidad a lo largo del \\
& T7agmento, sin subtópicos
\end{tabular}

Los intentos del informante CRE-H04 por explicar las razones de su hospitalización resultan vanas. La constante introducción de temas nuevos, desvinculados entre sí y que a menudo ni siquiera presentan desarrollo subtopical, provocan en el interlocutor una imposibilidad de seguir el hilo de la intervención. Por esto fue evaluado con un 1 o falla completa.

En el caso de los sujetos del grupo de primer episodio, la mayoría consigue establecer tanto un tema como su desarrollo parcial o completo, un buen porcentaje de ello, con ayuda del entrevistador, un $68 \%$, mientras que sólo el $20 \%$ lo realizó adecuadamente. A continuación presentamos dos ejemplos:

1) Ejemplo del grupo de primer episodio:

46. E: ¿y qué pasa con esos pensamientos cuando usted dice que son obsesivos?

47. S: me vienen a la mente a cada rato.

48. E: ya ¿en qué circunstancias?/ por ejemplo/ a ver/ ¿qué está haciendo usted?

49. S: eh<pausa $>/$ eh<pausa $>/$ yo eh $<$ pausa $>/$ mmmm<pausa oralizada $>/$ cuando pienso en $<$ pausa $>/$ cuando pienso en las alturas/ cuando pienso en el físico ${ }^{50}\langle$ pausa $>/$ y además que otra cosa que me ha tenido así más o menos mal/ es una obsesión por una eh<pausa $>$ por una cabra $^{51}$ que va en el liceo ${ }^{52}$.

50. E: ya/ ¿una compañera?

\footnotetext{
${ }^{50}$ Se refiere a su estatura.

${ }^{51} \mathrm{Cabra}=$ chilenismo, mujer muy joven.

${ }^{52}$ Liceo $=$ Escuela para nivel de Enseñanza Media.
} 
51. S: no/ no es compañera/ es de otro curso.

52. E: ya

53. S: eh<pausa>/ en el cual/ me obsesioné tanto por ella/ que terminé poniéndome a tomar remedios/o sea/ eh<pausa>/ estuve más o menos mal con mi mamá/ por como esa obsesión me había llevado a una situación amarga/ eh<pausa>/ terminé desquitándome con mi mamá y ahí<pausa>/ eso no es y eso no es algo correcto.

54. E: ¿Usted qué está haciendo ahora?

55. S: estoy<pausa $>/$ estoy dando una entrevista con ustedes.

56. E: ya/ pero<pausa>/ ¿está viviendo en su casa?/ ¿trabajando?/ ¿estudiando<pausa>/?

57. S: si/ estaba estudiando antes de entrar acá al hospital de día.

58. E: ya/¿y en qué curso?

59. S: en tercero ${ }^{53}$.

60. E: ¿estaba en tercero?

61. S:si.

62. E: ¿cómo le iba?

63. S: eh<pausa $>$ / más o me<pausa $>/$ me iba muy $<$ pausa $>$ / me iba bien mal.

64. E: ¿siempre le fue mal?

65. S: hasta<pausa $>/$ o no<pausa $>/$ me iba<pausa $>$ / primero<pausa $>/$ primero/ yo repetí el segundo/ yo repetí el segundo medio por desmotivación a mis compañeros/ de que no estaba/ de que no estaba en un muy buen ambiente/y el otro/ tercero medio lo repetí porque/ la situación negativa de mi <pausa>/ por la cuestión <pausa>/ de que había estado junto con la <pausa>/con la <pausa>/ que va al liceo/ que se llama Carolina/ eh<pausa > eh<pausa / me había llegado tanto la situación/ que tenía amarga/ que terminé descuidando los estudios/ tenía ramos pendientes $<$ pausa $>$ / eh $<$ pausa oralizada $>$

66. E: ¿le afectó mucho?

67. S: exacto me afectó mucho.

68. E: ya/ y antes de que pasara eso en segundo/ ¿cómo le iba?/ en octavo<pausa>

69. S:si me ib<pausa>/ si/ me iba bien/ siempre pasaba con un promedio regular/ pero así regular/ bueno.

70. E:¿cómo cuál?

71. S:no sé<pausa $>/$ como/ no sé/ como cinco $^{54}<$ pausa $>/$ cinco cinco $<$ pausa $>/$ cinco seis $<$ pausa $>/$ cinco ocho/ una onda así.

72. E:B/y usted me comentó algo de la relación con su mamá

73. S:si

74. E:¿cómo empezó<pausa>/ estos problemas con ella?

75. S: no/ que como yo vi que a veces/ no se lavaba las manos al atender a mi abuela/ es por eso que yo le tuve teniendo asco/ o sea/ no me gustaba que mi mamá ni me tocara/ ni mi hermano/ como que también toca a ella/ y toca las paredes $<$ pausa $>/$ incluso caminaba como cangrejo para no tocar las paredes que había tocado mi abuela.

76. E: ¿ella todavía está en su casa?

77. S: si/ todavía está en mi casa.

78. E: y usted/ ¿cuál es la relación con su abuela?

79. S: mala/ siempre ha sido mala.

80. E: ya

81. S: es que como ella tiene una enfermedad que se llama esquizofrenia $y<$ pausa $>/ y<$ pausa $>/$ como y eso<pausa>/ como tiene una enfermedad que se llama esquizofrenia siempre armó problemas/ siempre hizo problemas.

${ }^{53}$ Tercero de Educación Media.

${ }^{54} \mathrm{La}$ escala de calificación en el sistema escolar y universitario chileno es de 1.0 a 7 
82. E: y usted ¿evitaba tocarla también?

83. S: si/ la evitaba mucho tocar.

\begin{tabular}{lll}
\hline Turnos & Tema /Proposiciones & Observaciones \\
\hline $47-49$ & T1: pensamientos obsesivos & El informante introduce una serie de \\
& ejemplos para ilustrara porqué \\
& considera obsesivos sus \\
& pensamientos, presenta subtópicos \\
& como: pensar en la altura (estatura), \\
& en el fisico (aspecto), pensar en una \\
& compañera del liceo \\
\hline
\end{tabular}

T2 obsesión por la compañera del liceo

2) Ejemplo del grupo de primer episodio:

2. $\mathrm{E}: \mathrm{Ya} / \mathrm{R} /$ usted nos contaba recién que había llegado hace dos semanas/ ¿cierto?/ y me había contado también que el motivo era porque había empezado a escuchar voces/ cuéntenos un poquito cómo era eso/ desde cuándo empezó con eso//

3. S: Hace como tres meses/ cuatro meses/ cinco meses/ seis meses.

4. E: ¿Y cómo empezó esto?

5. S: Eh<pausa $>/$ me levantaron estas partes de aquí<pausa $>/<$ se toca las cejas con una mano $>/$

6. E: ¿Cómo?

7. S: Me levantaron estas partes de aquí que tengo en las cejas/ adentro/ me levantaron <se toca las cejas $>1$

8. E: ¿Le levantaron <pausa $>$ ?/

9. $\mathrm{S}: \mathrm{Si} / \mathrm{me}$ las sacaron para arriba.

10. E: ¿Quién le hizo eso?

11. S: Una persona conocida aquí de cerca de mi casa/ a donde yo vivía antes/ se llamaba Tito y él me habla/ me hablaba.

12. E: ¿Y cómo fue esto que le hizo que le levantó las cejas?/ ¿a qué se refiere?

13. S: Es una cuestión que<pausa>/ yo tengo una cuestión aquí ¿cierto<al entrevistador>?

14. E: ¿Qué tiene ahí?

15. S: Eh/ como unos pómulos.

16. E: Ya.

17. S: Que están adentro de las cejas/ que están fijas y a mí me las levantaron/ porque ahora no las tengo.

18. E: ¿Y eso quien lo hizo?/ ¿su amigo?

19. S: Ahora no las tengo.

20. E: Ya.

21. S: ahora no las tengo/ me las levantaron para arriba.

22. E: ¿Y se las sacaron?

23. $\mathrm{S}: \mathrm{Si} / \mathrm{me}$ las tiraron pa' arriba y no las tengo.

24. E: ¿Quién hizo eso? 
25. S: Eh<pausa $>/$ un $<$ pausa $>/$ un vecino un conocido que siempre pasa en la calle// Otra persona.

26. E: Ya.

27. S: Con la hermana y la hermana es universitaria y estudia $<$ pausa $>/$ ¿Qué estudia? Eh<pausa $>/$ veterinaria/ en la universidad Alonso de Ercilla y entre los dos me levantaron una cada uno/ una pa' allá y una pa' acá.

28. E: ¿Y cómo le hicieron le tuvieron que hacer una operación o/ cómo le hicieron eso?

29. S: Es que ellos son eleotósticos

30. E: ¿Cómo?

31. S: Ellos son eleotósticos

32. E: Disculpe/ no le entiendo.

33. S: Ellos son eleotósticos <repite pronunciando mejor>

34. E: ¿Eleotósticos?/ ¿Y qué significa eso?

35. S: son los que hablan mentalmente con las personas/ ¿me entiende?

36. E: Ya.

37. S: hay un libro sobre eso.

38. E: Ya

39. S: Y después<pausa>/ antes de eso yo había visto una pecosa en La Florida/ en el 14 de Vicuña Mackenna/ en Cabildo/ en el Lider/ y yo la vi como cuatro veces/ ya después pasó ese tiempo y pasó lo que dije hace poquito y me hablan hartas personas $<$ pausa $>$ I

40. : Eso fue<pausa>/ ¿hace tres meses empezó con esto?

41. S: Cuatro meses.

42. E: Cuatro meses.

43. S: Y empezó hace<pausa>/ harto tiempo ya que me hablan hartas personas que yo conozco me hablan hartas personas que yo conozco.

44. E: Ya pero antes que eso eh<pausa>/ me gustaría que nos aclarara esto de los amigos que le hicieron eso/ eso se lo hicieron físicamente/ le hicieron alguna operación para eso o cómo se lo hicieron<pausa $>$ / eso que le hayan levantado las cejas $\mathrm{y}<$ pausa $>$ /

45. S: ¿Cómo?

46. E: ¿Cómo le hicieron eso/ que le levantaron las cejas?/ ¿cómo se lo hicieron<pausa >

47. S: Con radioactividad/ ellos piensan y obtienen la radioactividad.

48. E: ¿Lo hicieron con el pensamiento?

49. S: Si con el pensa<pausa>/ con el pensamiento/ claro.

Turnos

3

$7-17$
Tema /Proposiciones

Inicio del problema/ Hace como tres meses/ Hace como tres meses/ cuatro meses/ cinco meses/ seis meses cuatro meses/ cinco meses/ seis meses

Le realizaron una intervención (¿quirúrgica?) a la altura de las cejas/ me levantaron estas partes de aquí<pausa > <se toca las cejas con una mano $>$ /

Que están adentro de las cejas/ que están fijas y a mí me las levantaron/ porque ahora no las tengo

\section{Observaciones}

La alusión temporal sobre el inicio de las molestias, es impresisa.

La explicación de la causa de sus problemas, resulta poco clara. Inferimos que lo que desea transmitirnos es que 'le realizaron (vecinos) una operación, y le sacaron algo de la frente. Posterior a este hecho, escucha voces' 


\section{1) Ejemplo del grupo de controles:}

15. E: ahora te voy a hacer unah preguntah / sobre ek[x]perienciah personaleh

16. I: aham

17. E: yap / eeh <alargamiento/> cuéntame alguna ek[x]periencia divertía que te haya pasa[d]o en el in[s]tituto o en la $\mathrm{U}^{55}$

18. I: ¿divertía? <simultáneo> mmm <alargamiento/>

19. E: o que / no sé poh </simultáneo> que te hayan mechonea[d] $\mathrm{o}^{56}$ en la $\mathrm{U}<$ alargamiento/>

20. <simultáneo> o algo pare <palabra_cortada/>

21. I: no / no me mechonearon $</$ simultáneo $>$ porque me ehcapé

22. E: ya / <risas >

23. I: eeh / divertía me acuerdo de una veh que <alargamiento/> tenía / en veterinaria teniamoh prueba de / anatomía / y el laboratorio ehtaba cerrado y en anatomía te <vacilación/> te ponían el <vacilación/> el perro <vacilación/> el cadáver y dehpuéh te lo marcaban y tú teniai que adivinar <vacilación/> en la prueba que $<$ alargamiento/> que parte era del cuerpo // y <alargamiento/><risas = "I"/> anteh / un día anteh en la tarde / un compañero que era bien alto tomó a otra compañera $<$ vacilación/> al apa ${ }^{57}$

24. E: ya

25. I: para que viera máh o menoh que muehtra iban a poner y <alargamiento/> sacarnos buena nota / ¿cachai? ${ }^{58}$

26. E: $\mathrm{mjm}$

27. I: y <alargamiento/> vimos que venía el profe[sor] / y noh asuhtamoh tanto que salimos corriendo / pero mi compañero salió corriendo <énfasis> con mi amiga arriba </énfasis>

28. E: <entre_risas> ya <alargamiento/></entre_risas >

29. I: sí <alargamiento/> fue muy <simultáneo> chistoso

30. E: y ¿no pasó nada </simultáneo > no se cayó / nada?

31. I: no <simultáneo> fue así wee <alargamiento/>

32. E: aah ya $</$ simultáneo $><$ risas $=" E " />$

33. I: pero ehtabamoh tan urgíoh que <alargamiento/> fue chistoso

34. E: ya // eem <alargamiento/> ¿cuál ha si[d]o la vergüenza <vacilación/> máh grande $<$ alargamiento/> que hayai pasa[d]o?

35. I: ¿vergüenza? Mm <vacilación/> no me acuerdo a ver / ¿qué puede ser? // aah una veh que ehtaba bail <palabra_cortada/> pero no fue tanto // pero <alargamiento/> igual me dió<alargamiento/> me dió vergüenza / eh que fui a una dihco / y <alargamiento/> el piso ehtaba refaloso / y andaba <vacilación/> bailaba con unoh <vacilación/> bluyines ${ }^{59}$ que me quedaban como largoh /

36. E: ya

37. I: < vacilación/> y ehtaba bailando con un $\operatorname{mino}^{60}$ equih $^{61}$ poh // y en <énfasis> una vuelta </énfasis> como que me soltó / y yo ¡yuup! Me dehlicé así me caí <risas = "todos"/> y me paré en un doh por treh / y yo roja ¡bup! <risas = "E"/>

${ }^{55} \mathrm{U}=$ en la jerga juvenil de Chile alude a Universidad.

${ }^{56}$ Mechoneo= novatada universitaria chilena.

${ }^{57} \mathrm{Al}$ apa $=$ cargar a alguien en la espalda.

${ }^{58} \mathrm{Cachar}=$ en jerga juvenil se utiliza cuando se quiere preguntar si lo que se ha dicho se ha entendido.

${ }^{59}$ Bluyines $=$ pantalones de mezclilla (bluejeans)

${ }^{60}$ Mino $=$ del lunfardo, hombre joven atractivo 


\begin{tabular}{|c|c|c|}
\hline Turnos & Tema /Proposiciones & Observaciones \\
\hline 23 & $\begin{array}{l}\text { Tenía prueba de anatomía en veterinaria/ } \\
\text { divertía me acuerdo de una veh que } \\
\text { <alargamiento/> tenía / en veterinaria } \\
\text { teniamoh prueba de / anatomía / y el } \\
\text { laboratorio ehtaba cerrado y en anatomía te } \\
\text { <vacilación/> te ponían el <vacilación/> el } \\
\text { perro <vacilación/> el cadáver y dehpuéh te } \\
\text { lo marcaban y tú teniai que adivinar } \\
\text { <vacilación/> en la prueba }\end{array}$ & $\begin{array}{l}\text { Hay una referencia a un hecho pasado } \\
\text { (Prueba de anatomía en veterinaria, } \\
\text { que es la carrera que estudia el } \\
\text { participante). Se desarrollan remas } \\
\text { derivados del tema : prueba de } \\
\text { anatomía. }\end{array}$ \\
\hline
\end{tabular}

2) Ejemplo del grupo de controles:

61. E: ¡qué mal! / y cuando te pasó esa cuehtión en el metro ¿cómo fue? cuando te pegaron.

62. I: ¡ah! pero esa no fue<alargamiento/> no me dio tanto miedo esa we[v]a[da] fue <vacilación/> de hecho me <vacilación/> me sentí máh <vacilación/> como que ehtaba haciendo lo correcto dehpuéh de to[d]o / porque<alargamiento/> loh we[v]oneh / que <vacilación/> ¿qué queríh que te cuente qué pasó <simultáneo> o<alargamiento/> $<$ vacilación/></simultáneo>

63. E: 〈simultáneo> sí </simultáneo>

64. I: o cómo me sentí?

65. E: lah doh cosah

66. I: ehtaba para[d]o / ehtaba apoya[d]o en la <vacilación/> en la <vacilación/> en una puerta del metro y vi que onda en el otro vagón ehtaban dihcutiendo un cabro de terno con doh we[v]oneh que eran como de la con[s]trucción / ¿cachai? doh viejoh / y en eso el loco de terno se arrancó se arrancó / hahta que llegó al la[d]o mío / y se quedó para[d]o ahí / y<alargamiento/> yo le pregunté<alargamiento/> que qué le <vacilación/> qué le pasaba / y me dijo <cita> no eh que me vienen we[ve]ando por no sé qué </cita> y en eso loh galloh siguieron caminando hahta donde ehtabamoh nosotroh / y cuando llegamoh a la ehtación se abrieron lah puertah / y en eso se abrió la puerta / y el gallo venía tomando cerveza / y<alargamiento/> con el tarro de cerveza ;fa! tira <vacilación/> noh tira cerveza a loh doh / y el gua<palabra_cortada/> gallo como andaba de terno / se enojó poh / le tiró una pata[da] ¿cachai? Y lo <vacilación/> lo tiró pa fuera de la <vacilación/> del metro / y cuando venía entrando ¡pa! Le aforro un combo yo / y ahí quedó tira[d]o en el suelo / y el we[v]ón como iba con el amigo / el amigo / puta era máh chico pero igual<alargamiento/> venía mejor parece y se <vacilación/> se fue contra mí / y ahí noh pusimoh a agarrarnoh a comboh / la gente grita[b]a <cita> ¡llamen a loh guardiah! / ¡llamen a loh guardiah! $</$ cita> eeh <cita> ¡ehto no puede ehtar pasando! </cita> y we[v]a[da]h así $\mathrm{y}<$ alargamiento/>m ah y en eso me dehcuidé / le pasé mih lenteh a una mina / menoh mal / le pasé mih cosah / y me dehcuidé y ahí el we[v]ón se acercó y me pegó el combo <vacilación/> en el ojo/ y me rompió la ceja y sentí ijjj! cuando se rajó la ceja / y empezó a caer <énfasis> sangre </énfasis> y ahí llegaron loh guardiah / y dejaron a loh we[v]oneh

${ }^{61}$ Mino ' $\mathrm{X}$ ' = equis en la jerga juvenil se refiere a que no tiene importancia quien era. 
ahí / noh llevaron al <vacilación/> al baño a <vacilación/> a curarme <vacilación/> pa[ra] que me parara la sangre <vacilación/> porque me corría caleta [d]e sangre / ahí llamé a mi [p]apá / mi viejo llamó a mi hermano que eh de invehtigacioneh ¿cachai? y ahí mandó una patrulla para<alargamiento/> <vacilación/> se llevaron deteni[d]oh a loh we[v]oneh poh / noh llevaron a con[s]tatar lesioneh // $\mathrm{y}<$ alargamiento/ $>\mathrm{m}$ ehtuvimoh hahta como lah cuatro de la mañana<alargamiento/> haciendo la <énfasis> declaración </énfasis> así ultra $<$ vacilación/> ultra penca / al final loh we[v]oneh cambiaron toda la declaración a mi favor $<$ simultáneo $>$ y<alargamiento/ $></$ simultáneo $>$

67. E: <simultáneo> ah ya </simultáneo>

68. I: y a los we[v]oneh loh dejaron en cana to[d]o el fin de semana

69. E: ah bakan / menoh mal / por lo menoh / ya / eeh<alargamiento/>m ¿cuál ha si[d]o la vergüenza<alargamiento/> o plancha máh grande que te ha toca[d]o pasar?

70. I: <silencio/> eh que tú <vacilación/> tú me conocíh <entre_risas><sic> yo como que no me dan vergüenza mucho lah cosah $</$ sic $></$ entre_risas $>$

71. E: no

\begin{tabular}{ll}
\hline Turnos & Tema/Proposiciones \\
\hline 66 & Pelea en el metro/ ehtaba para[d]o / ehtaba \\
& apoya[d]o en la <vacilación/> en la \\
& <vacilación/> en una puerta del metro y vi \\
& que onda en el otro vagón ehtaban \\
& dihcutiendo un cabro de terno con doh \\
& we[v]oneh que eran como de la \\
& con[s]trucción /[...] se enojó poh / le tiró \\
& una pata[da] ¿cachai? Y lo <vacilación/> lo \\
& tiró pa fuera de la < vacilación/> del metro / \\
& y cuando venía entrando ipa! Le aforro un \\
& combo yo / y ahí quedó tira $[d]$ do en el suelo / \\
& y el we[v]ón como iba con el amigo / el \\
& amigo / puta era máh chico pero \\
& igual<alargamiento/> venía mejor parece y \\
& se <vacilación/> se fue contra mí / y ahí noh \\
& pusimoh a agarrarnoh a comboh /
\end{tabular}

Observaciones

Narración de un hecho violento: una pelea callejera, en la que participa el entrevistado.

\subsubsection{Unidad temática nuclear y estadio de la enfermedad}

Cabe destacar que este es un indicador que nos parece informativo. Como se muestra en la tabla, los controles no requieren ayuda del entrevistador, cumplen en un 
$100 \%$ de los casos con este aspecto de la estructura discursiva esencial para la comprensión del propósito conversacional entre los hablantes. En el primer episodio, encontramos una elevada ocurrencia de 17 casos en los que, para llegar a plantear o completar la unidad temática nuclear, se requiere ayuda del entrevistador y, además, los casos en los que este objetivo se consigue, son seis, un 18,8\% de la muestra total, nos resulta interesante que los hablantes de este grupo requieran de más intervención del entrevistador que los del grupo de crónicos. Sin embargo, una explicación plausible es que en este grupo hay un mayor monitoreo cognitvo, mecanismos de regulación y control cognitivo que mantendrían en alerta a los hablantes de este grupo. Se percibe esta actividad de autocontrol en la conducta reticente y poco colaboradora de algunos de ellos, de manera que la suma de estos factores, puede ofrecer una explicación acerca de porqué son más frecuentes los casos de realización con ayuda del entrevistador. En el grupo de los crónicos, registramos una mayor cantidad de hallazgos de realización adecuada, lo que contraviene algunos supuestos sostenidos en la literatura sobre la pérdida de la meta discursiva.

Tabla de contingencia 105: unidad temática nuclear y estadio de la enfermedad.

\begin{tabular}{||l|l|l|l|l||}
\hline \hline \multirow{2}{*}{$\begin{array}{l}\text { Estadio de la } \\
\text { enfermedad }\end{array}$} & \multicolumn{2}{|l||}{ Unidad temática nuclear } & \multirow{2}{*}{ Total } \\
\cline { 2 - 5 } & Falla completa & $\begin{array}{l}\text { Con ayuda del } \\
\text { entrevistador }\end{array}$ & $\begin{array}{l}\text { Realizado } \\
\text { adecuadamente }\end{array}$ & \\
\hline \multirow{3}{*}{ Controles } & 0 & 0 & 12 & 12 \\
\hline \multirow{3}{*}{ Primer episodio } & $0,0 \%$ & $0,0 \%$ & $37,5 \%$ & $19,4 \%$ \\
\hline \multirow{3}{*}{ Crónicos } & 2 & 17 & 6 & 25 \\
\hline \multirow{3}{*}{ Total } & $50,0 \%$ & $65,4 \%$ & $18,8 \%$ & $40,3 \%$ \\
\hline & 2 & 9 & 14 & 25 \\
\cline { 2 - 5 } & $50,0 \%$ & $34,6 \%$ & $43,8 \%$ & $40,3 \%$ \\
\hline
\end{tabular}

El valor de chi cuadrado es de 19,482, dio como resultado (>p, 001>), significativo estadísticamente. 
Tabla valor de chi cuadrado 106: unidad temática nuclear y estadio de la enfermedad.

\begin{tabular}{||l|c|c|c||}
\hline \multicolumn{4}{|c||}{ Pruebas de chi-cuadrado } \\
\hline & Valor & $\mathrm{gl}$ & $\begin{array}{c}\text { Sig. asintótica } \\
\text { (bilateral) }\end{array}$ \\
\hline Chi-cuadrado de Pearson & $19,482^{\mathrm{a}}$ & 4 &, 001 \\
\hline
\end{tabular}

Gráfico 85. Porcentaje de frecuencia de las variables: unidad temática nuclear y estadio de la enfermedad.

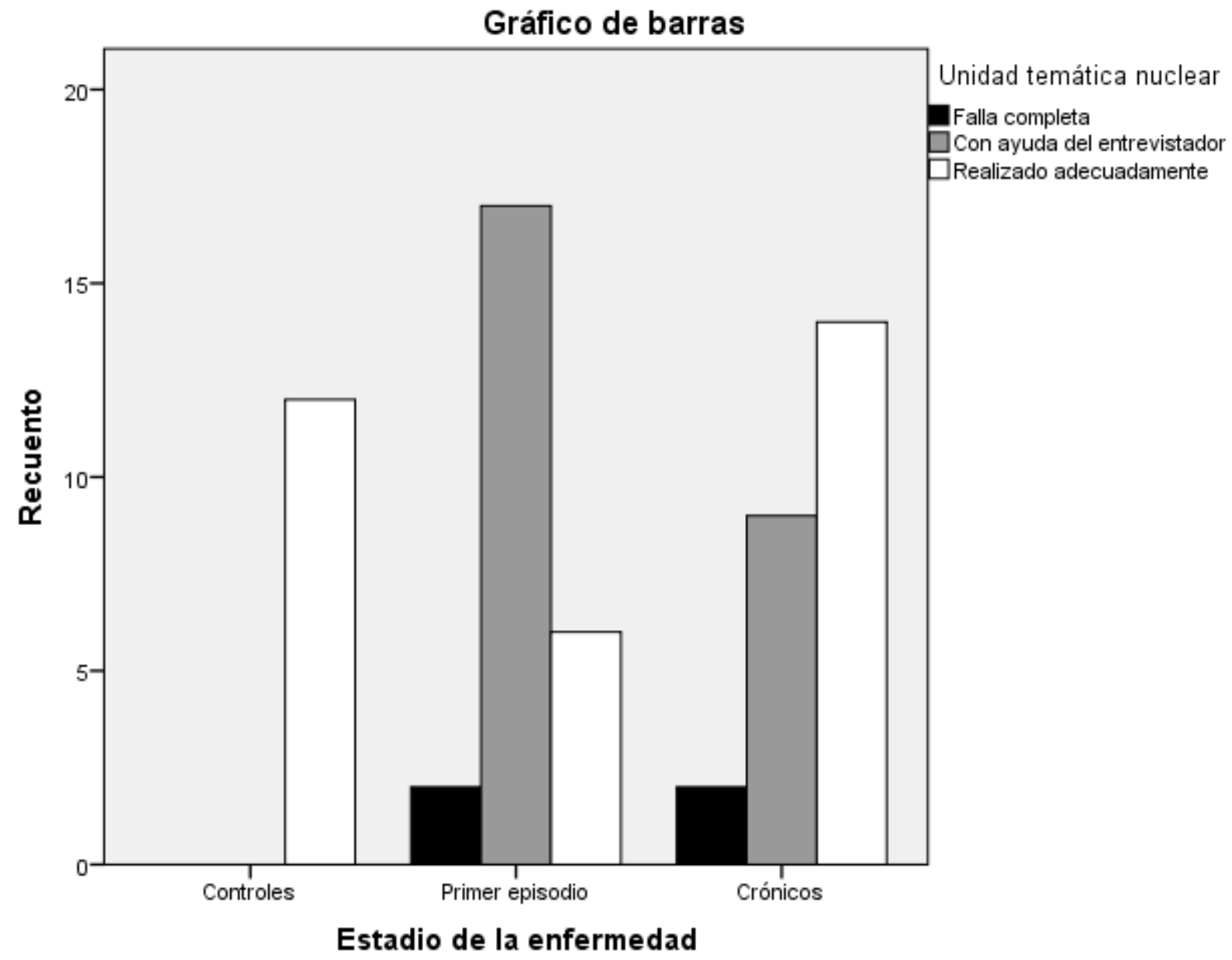




\subsubsection{Unidad temática nuclear y sexo}

Los porcentajes encontrados señalan que no existen diferencias significativas entre hombres y mujeres.

Tabla de contingencia 107:unidad temática nuclear y sexo.

\begin{tabular}{||l|l|l|l|l||}
\hline \multirow{2}{*}{$\begin{array}{c}\text { Sexo de los } \\
\text { sujetos }\end{array}$} & \multicolumn{2}{|l|}{ Unidad temática nuclear } & \multirow{2}{*}{ Total } \\
\cline { 2 - 5 } & Falla completa & $\begin{array}{l}\text { Con ayuda del } \\
\text { entrevistador }\end{array}$ & $\begin{array}{l}\text { Realizado } \\
\text { adecuadamente }\end{array}$ & \\
\hline \multirow{2}{*}{ Mujer } & 2 & 11 & 16 & 29 \\
\cline { 2 - 5 } & $50,0 \%$ & $42,3 \%$ & $50,0 \%$ & $46,8 \%$ \\
\hline \multirow{2}{*}{ Hombre } & 2 & 15 & 16 & 33 \\
\cline { 2 - 5 } & $50,0 \%$ & $57,7 \%$ & $50,0 \%$ & $63,2 \%$ \\
\hline Total & 4 & 26 & 32 & $100,0 \%$ \\
\cline { 2 - 5 } & $100,0 \%$ & $100,0 \%$ & $100,0 \%$ & \\
\hline
\end{tabular}

El valor de chi cuadrado es de ,359 y dio como resultado, (>p, 836>), no significativo estadísticamente.

Tabla valor de chi cuadrado 108: unidad temática nuclear y sexo.

\begin{tabular}{||l|c|c|c||}
\hline \hline \multicolumn{4}{|c|}{ Pruebas de chi-cuadrado } \\
\hline & Valor & $\mathrm{gl}$ & $\begin{array}{c}\text { Sig. asintótica } \\
\text { (bilateral) }\end{array}$ \\
\hline Chi-cuadrado de Pearson &, $359^{\mathrm{a}}$ & 2 &, 836 \\
\hline
\end{tabular}


Gráfico 86. Porcentaje de frecuencia de las variables: unidad temática nuclear y sexo

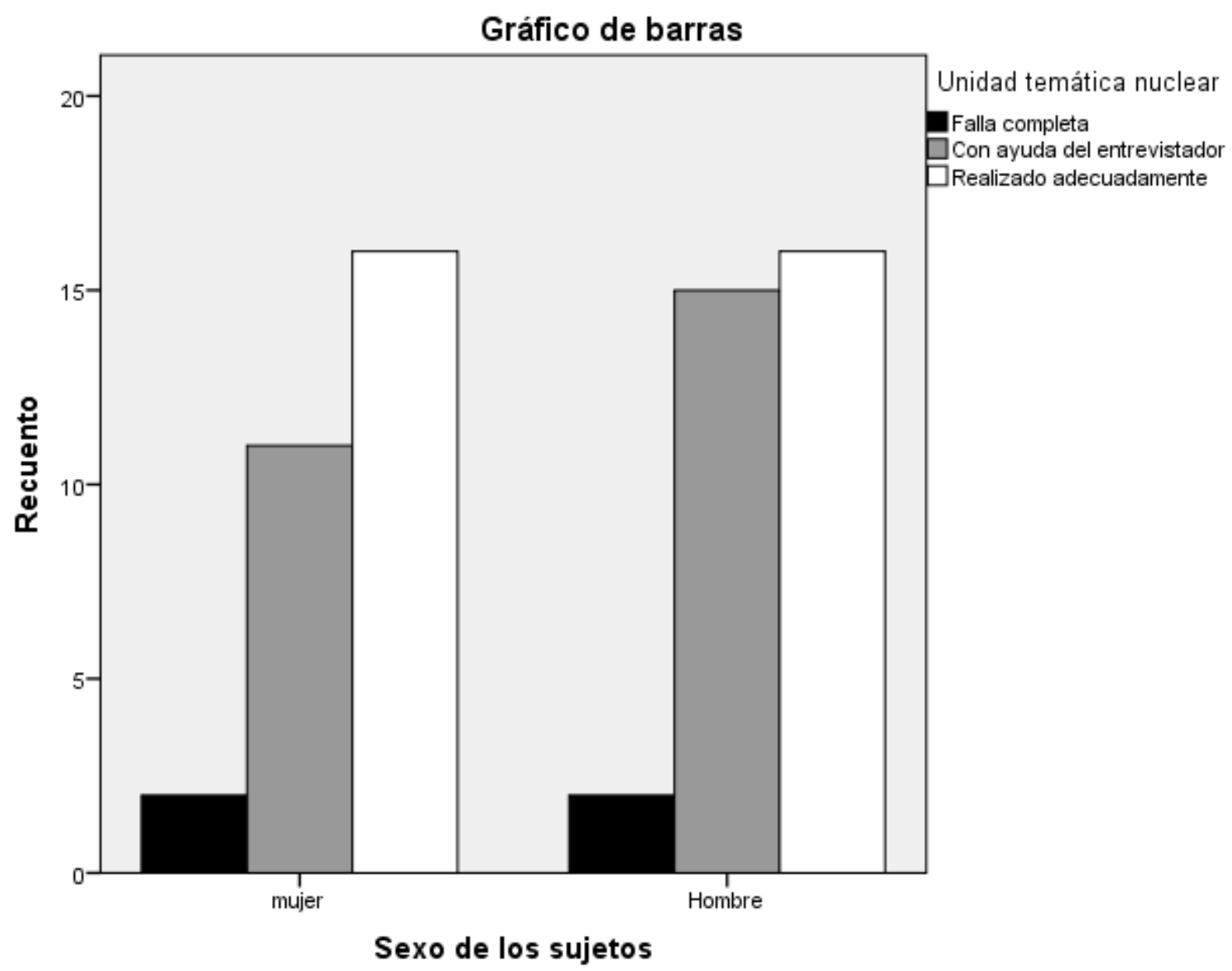

4.4.1.4. Unidad temática nuclear y tramo de la enfermedad

En la comparación con el indicador estadio, podemos observar cuáles son los tramos específicos de la enfermedad en los cuales se observa el fenómeno discursivo. En el contraste entre controles y pacientes nos damos cuenta de que es evidente que la enfermedad provoca un deterioro en el mantenimiento del tema central en una conversación, únicamente entre los grupos de esquizofrénicos. También resulta 
interesante visualizar que tras la fase inicial de $>0-<2$ años, se produce una estabilización discursiva que disminuye las ocurrencias entre los grupos de primer episodio de entre $>2$ y $<3$ años y los crónicos de hasta 5 años. Los hallazgos revelan que se da con mayor prevalencia entre los crónicos de más de 5 años y los del grupo de primer episodio de $>0-<2$ años. Nos preguntamos si es posible pensar en que, a pesar de atravesar por diferentes etapas del proceso mórbido, se generan algunos fenómenos discursivos similares, en los extremos de nuestro corpus.

Tabla de contingencia 109:unidad temática nuclear y tramo de la enfermedad.

\begin{tabular}{|c|c|c|c|c|}
\hline \multirow[t]{2}{*}{ Tramo de la enfermedad } & \multicolumn{3}{|c|}{ Unidad temática nuclear } & \multirow[t]{2}{*}{ Total } \\
\hline & Falla completa & $\begin{array}{l}\text { Con ayuda del } \\
\text { entrevistador }\end{array}$ & $\begin{array}{l}\text { Realizado } \\
\text { adecuadamente }\end{array}$ & \\
\hline \multirow[t]{2}{*}{ Controles } & 0 & 0 & 12 & 12 \\
\hline & $0,0 \%$ & $0,0 \%$ & $37,5 \%$ & $19,4 \%$ \\
\hline \multirow[t]{2}{*}{ Primer episodio de 0 a 2 años } & 2 & 9 & 3 & 14 \\
\hline & $50,0 \%$ & $34,6 \%$ & $9,4 \%$ & $22,6 \%$ \\
\hline \multirow[t]{2}{*}{ Primer episodio de 2 a 3 años } & 0 & 8 & 3 & 11 \\
\hline & $0,0 \%$ & $30,8 \%$ & $9,4 \%$ & $17,7 \%$ \\
\hline \multirow[t]{2}{*}{ Crónicos hasta 5 años } & 0 & 4 & 6 & 10 \\
\hline & $0,0 \%$ & $15,4 \%$ & $18,8 \%$ & $16,1 \%$ \\
\hline \multirow[t]{2}{*}{ Crónicos 5 años y más } & 2 & 5 & 8 & 15 \\
\hline & $50,0 \%$ & $19,2 \%$ & $25,0 \%$ & $24,2 \%$ \\
\hline \multirow[t]{2}{*}{ Total } & 4 & 26 & 32 & 62 \\
\hline & $100,0 \%$ & $100,0 \%$ & $100,0 \%$ & $100,0 \%$ \\
\hline
\end{tabular}

El valor de chi cuadrado es de $23,345^{\mathrm{a}}$ y dio como resultado, (>p, 003>), significativo estadísticamente.

Tabla valor de chi cuadrado 110: unidad temática nuclear y tramo de la enfermedad.

\begin{tabular}{||l|c|r|c||}
\hline \multicolumn{4}{|c||}{ Pruebas de chi-cuadrado } \\
\hline & Valor & $\mathrm{gl}$ & $\begin{array}{c}\text { Sig. asintótica } \\
\text { (bilateral) }\end{array}$ \\
\hline Chi-cuadrado de Pearson & $23,345^{\mathrm{a}}$ & 8 &, 003 \\
\hline \hline
\end{tabular}


Gráfico 87. Porcentaje de frecuencia de las variables: unidad temática nuclear y tramo de la Enfermedad

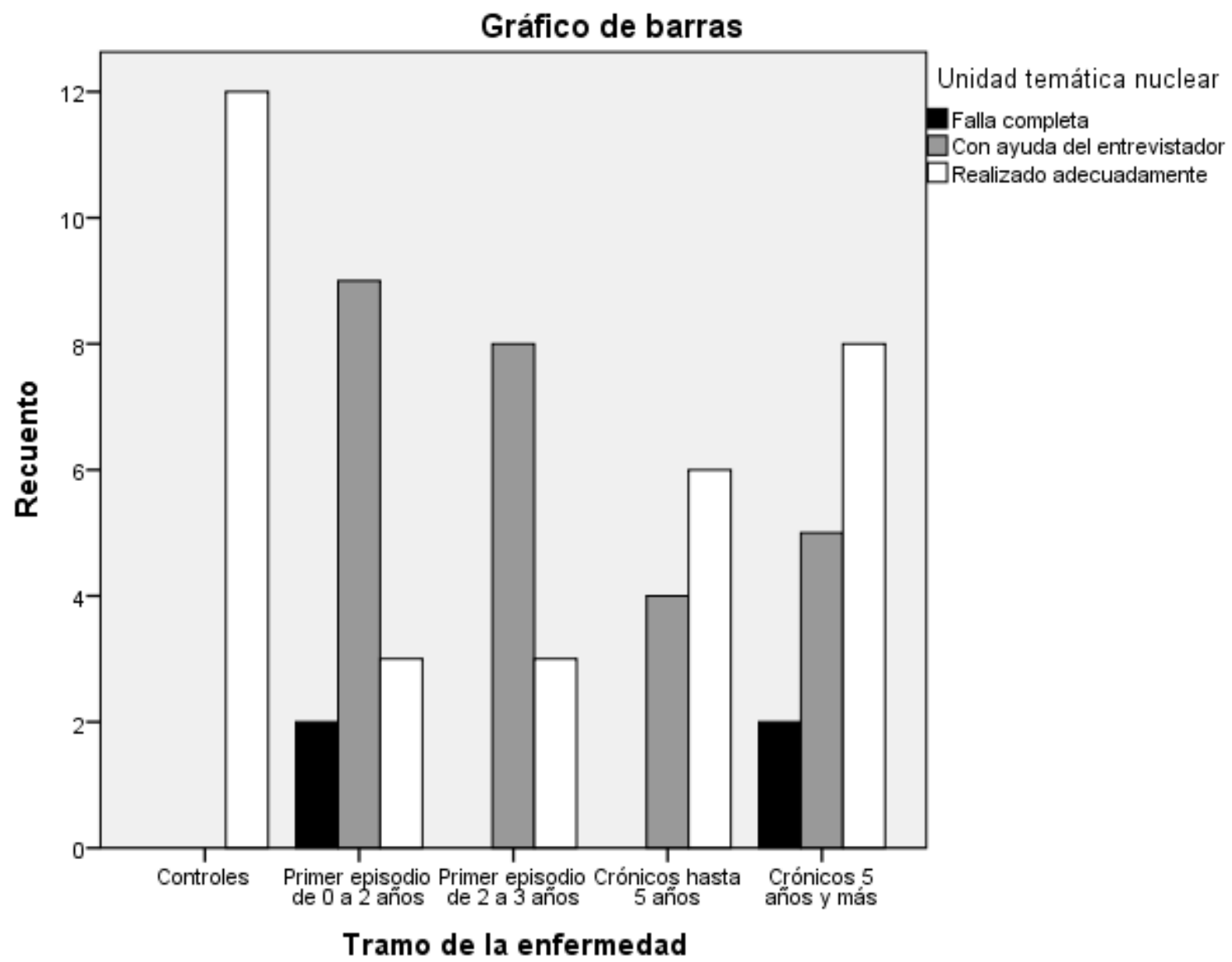

\subsubsection{Unidad temática nuclear y subtipo de la enfermedad}

En la tabla de contingencia correspondiente a este indicador, nos encontramos con la información que señala que la mayor parte de las ocurrencias de mantenimiento del tema nuclear con ayuda del entrevistador, están registradas entre los paranoides, 
quienes suman un total de 33 hablantes, con 19 ocurrencias, que corresponden a un $73 \%$ de este grupo y sólo una ocurrencia de falla completa, también en este grupo encontramos la mayor cantidad de ocurrencias de mantenimiento del tema central, con 13 casos, que equivalen al $40 \%$ del grupo. Las ocurrencias del fenómeno para los del grupo de esquizofrenia indiferenciada, está compuesto por 9 hablantes, que representan un $14 \%$ del grupo total de hablantes con la patología; son 4 casos realizados con ayuda del entrevistador, 2 casos de falla completa, y 3 casos realizados adecuadamente.

Tabla de contingencia 111:unidad temática nuclear y subtipo de la enfermedad.

\begin{tabular}{|c|c|c|c|c|}
\hline \multirow{2}{*}{$\begin{array}{l}\text { Subtipo de la } \\
\text { enfermedad }\end{array}$} & \multicolumn{3}{|c|}{ Unidad temática nuclear } & \multirow[t]{2}{*}{ Total } \\
\hline & Falla completa & $\begin{array}{l}\text { Con ayuda } \\
\text { del } \\
\text { entrevistador }\end{array}$ & $\begin{array}{l}\text { Realizado } \\
\text { adecuadamente }\end{array}$ & \\
\hline \multirow[t]{2}{*}{ Controles } & 0 & 0 & 12 & 12 \\
\hline & $0,0 \%$ & $0,0 \%$ & $37,5 \%$ & $19,4 \%$ \\
\hline \multirow[t]{2}{*}{ Paranoide } & 1 & 19 & 13 & 33 \\
\hline & $25,0 \%$ & $73,1 \%$ & $40,6 \%$ & $53,2 \%$ \\
\hline \multirow[t]{2}{*}{ Indiferenciada } & 2 & 4 & 3 & 9 \\
\hline & $50,0 \%$ & $15,4 \%$ & $9,4 \%$ & $14,5 \%$ \\
\hline \multirow[t]{2}{*}{ Desorganizada } & 1 & 3 & 4 & 8 \\
\hline & $25,0 \%$ & $11,5 \%$ & $12,5 \%$ & $12,9 \%$ \\
\hline \multirow[t]{2}{*}{ Total } & 4 & 26 & 32 & 62 \\
\hline & $100,0 \%$ & $100,0 \%$ & $100,0 \%$ & $100,0 \%$ \\
\hline
\end{tabular}

El valor de chi cuadrado es de 19,289 , que dio como resultado (>p, 004>) no significativo estadísticamente.

Tabla valor de chi cuadrado 112: unidad temática nuclear y subtipo de la enfermedad.

\begin{tabular}{||c|c|c|c||}
\hline \multicolumn{4}{|c|}{ Pruebas de chi-cuadrado } \\
\hline & Valor & $\mathrm{gl}$ & $\begin{array}{c}\text { Sig. asintótica } \\
\text { (bilateral) }\end{array}$ \\
\hline Chi-cuadrado de Pearson & $19,289^{\mathrm{a}}$ & 6 &, 004 \\
\hline
\end{tabular}


Gráfico 88. Porcentaje de frecuencia de las variables: unidad temática nuclear y subtipo de la

enfermedad

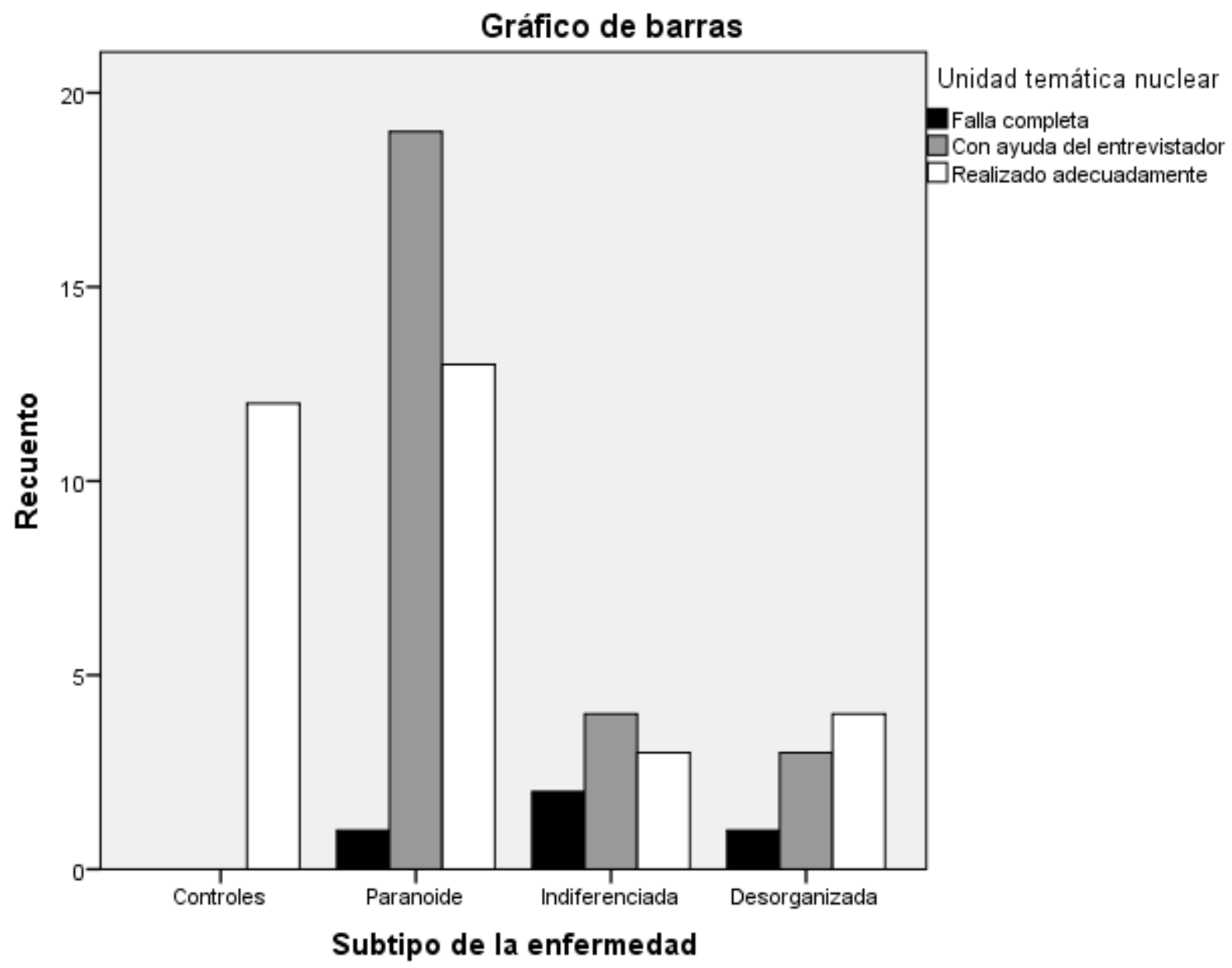

4.4.2. Proposiciones con vínculos explícitos respecto al tema central

Las proposiciones que están expresamente vinculadas con el tema central facilitan la identificación de este, del inicio de los subtemas, o de detalles relevantes 
que contribuyen a la comprensión del discurso, de las intenciones comunicativas del hablante y del contexto en que estas se dan. Pudimos observar que en el grupo de crónicos existe una tendencia a producir menos proposiciones vinculadas explícitamente con el tema central. Esta sería una razón importante de la dificultad semántica que representan los fragmentos de los crónicos en comparación con los controles y los pacientes de primer episodio.

4.4.2.1. Proposiciones con vínculos explícitos respecto al tema central y estadio de la enfermedad

En este indicador no se aprecian diferencias significativas entre los grupos de hablantes con la patología. Los de primer episodio presentan 14 casos realizados con ayuda del entrevistador y 11 casos realizados adecuadamente. Los crónicos presentan mayor cantidad de ocurrencias de realización adecuada, con 15 casos, 9 casos de realización con ayuda del entrevistador y son los únicos que presentan falla conpleta, con una ocurrencia.

Tabla de contingencia 113: Proposiciones con vínculos explícitos y estadio de la enfermedad.

\begin{tabular}{||l|l|l|l|l||}
\hline \multirow{2}{*}{$\begin{array}{l}\text { Estadio de la } \\
\text { enfermedad }\end{array}$} & \multicolumn{2}{|l||}{ Proposiciones con vínculos explícitos } & \multirow{2}{*}{ Total } \\
\cline { 2 - 5 } & Falla completa & $\begin{array}{l}\text { Con ayuda del } \\
\text { entrevistador }\end{array}$ & $\begin{array}{l}\text { Realizado } \\
\text { adecuadamente }\end{array}$ & \\
\hline \multirow{3}{*}{ Controles } & 0 & 0 & 12 & 12 \\
\cline { 2 - 5 } & $0,0 \%$ & $0,0 \%$ & $31,6 \%$ & $19,4 \%$ \\
\hline \multirow{2}{*}{ Primer episodio } & 0 & 14 & 11 & 25 \\
\cline { 2 - 5 } & $0,0 \%$ & $60,9 \%$ & $28,9 \%$ & $40,3 \%$ \\
\hline \multirow{2}{*}{ Crónicos } & 1 & 9 & 15 & 25 \\
\cline { 2 - 5 } & $100,0 \%$ & $39,1 \%$ & $39,5 \%$ & $40,3 \%$ \\
\hline \multirow{2}{*}{ Total } & 1 & 23 & 38 & 62 \\
\cline { 2 - 5 } & $100,0 \%$ & $100,0 \%$ & $100,0 \%$ & $100,0 \%$ \\
\hline
\end{tabular}

El valor de chi cuadrado es de $12,508^{\mathrm{a}}$, que dio como resultado (>p, 014>), no significativo estadísticamente. 
Tabla valor de chi cuadrado 114: proposiciones con vínculos explícitos y estadio de la enfermedad.

\begin{tabular}{||c|c|c|c||}
\hline \multicolumn{4}{|c||}{ Pruebas de chi-cuadrado } \\
\hline & Valor & $\mathrm{gl}$ & $\begin{array}{c}\text { Sig. asintótica } \\
\text { (bilateral) }\end{array}$ \\
\hline Chi-cuadrado de Pearson & $12,508^{\mathrm{a}}$ & 4 &, 014 \\
\hline
\end{tabular}

Gráfico 89. Porcentaje de frecuencia de las variables: proposiciones con vínculos explícitos y estadio de la enfermedad

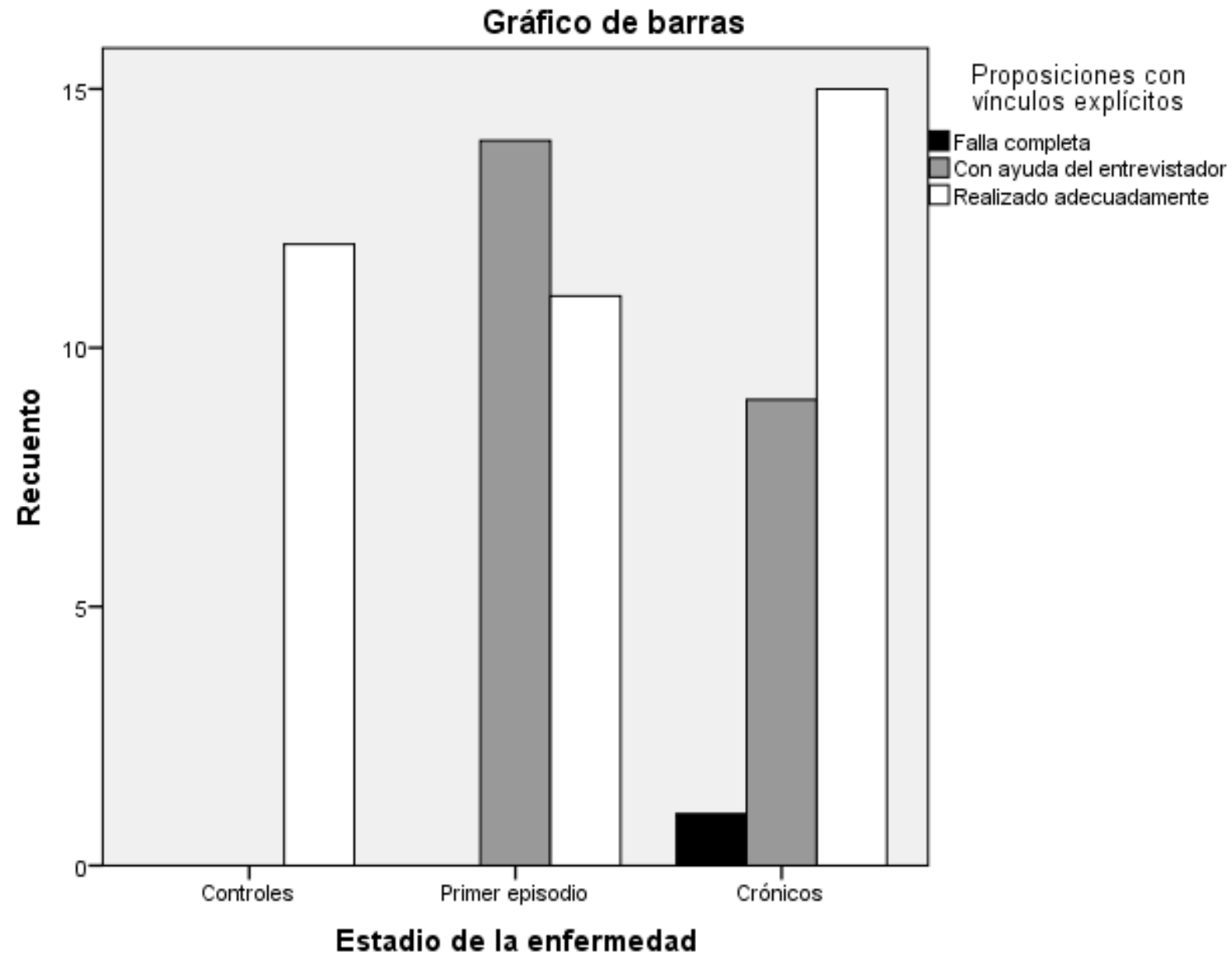


4.4.2.2. Proposiciones con vínculos explícitos respecto al tema central y sexo

El indicador sexo y proposiciones explícitas, no nos ofrece resultados significativos, las diferencias que se observan en el contraste de sexo de los participantes del estudio, no es relevante como indicador de déficit. En lo puntual, más mujeres que hombres realizaron la vinculación de proposiciones de forma explícita y adecuadamente, con 21 casos de 29 mujeres totales, en comparación con el grupo de hombres, compuesto de 33 hablantes, de los que pesquisamos 17 realizaciones sin ayuda. Más hombres que mujeres realizaron la vinculación con ayuda del entrevistador, 16 casos; en cambio, las mujeres, solo requirieron de ayuda en 7 casos. La falla completa, correspondiente a 1 ocurrencia, solo se da entre el grupo de mujeres. En la síntesis global de este indicador podemos señalar que las mujeres tienen un desempeño ligeramente más eficiente que los hombres.

Tabla de contingencia 115: Proposiciones con vínculos explícitos y sexo.

\begin{tabular}{|c|c|c|c|c|}
\hline \multirow{2}{*}{$\begin{array}{l}\text { Sexo de los } \\
\text { sujetos }\end{array}$} & \multicolumn{3}{|c|}{ Proposiciones con vínculos explícitos } & \multirow[t]{2}{*}{ Total } \\
\hline & Falla completa & $\begin{array}{l}\text { Con ayuda del } \\
\text { entrevistador }\end{array}$ & $\begin{array}{c}\text { Realizado } \\
\text { adecuadamente }\end{array}$ & \\
\hline \multirow[t]{2}{*}{ Mujer } & 1 & 7 & 21 & 29 \\
\hline & $100,0 \%$ & $30,4 \%$ & $55,3 \%$ & $46,8 \%$ \\
\hline \multirow[t]{2}{*}{ Hombre } & 0 & 16 & 17 & 33 \\
\hline & $0,0 \%$ & $69,6 \%$ & $44,7 \%$ & $53,2 \%$ \\
\hline \multirow[t]{2}{*}{ Total } & 1 & 23 & 38 & 62 \\
\hline & $100,0 \%$ & $100,0 \%$ & $100,0 \%$ & $100,0 \%$ \\
\hline
\end{tabular}


El valor de chi cuadrado es de 4,704 ${ }^{\mathrm{a}}$, y dio como resultado (>p, 095>), que no es significativo como ya señalamos.

Tabla valor de chi cuadrado 116: proposiciones con vínculos explícitos y sexo.

\begin{tabular}{||l|c|c|c||}
\hline \multicolumn{5}{|c||}{ Pruebas de chi-cuadrado } \\
\hline & Valor & $\mathrm{gl}$ & $\begin{array}{c}\text { Sig. asintótica } \\
\text { (bilateral) }\end{array}$ \\
\hline Chi-cuadrado de Pearson & $4,704^{\mathrm{a}}$ & 2 &, 095 \\
\hline
\end{tabular}

Gráfico 90. Porcentaje de frecuencia de las variables: proposiciones con vínculos explícitos y sexo de los individuos

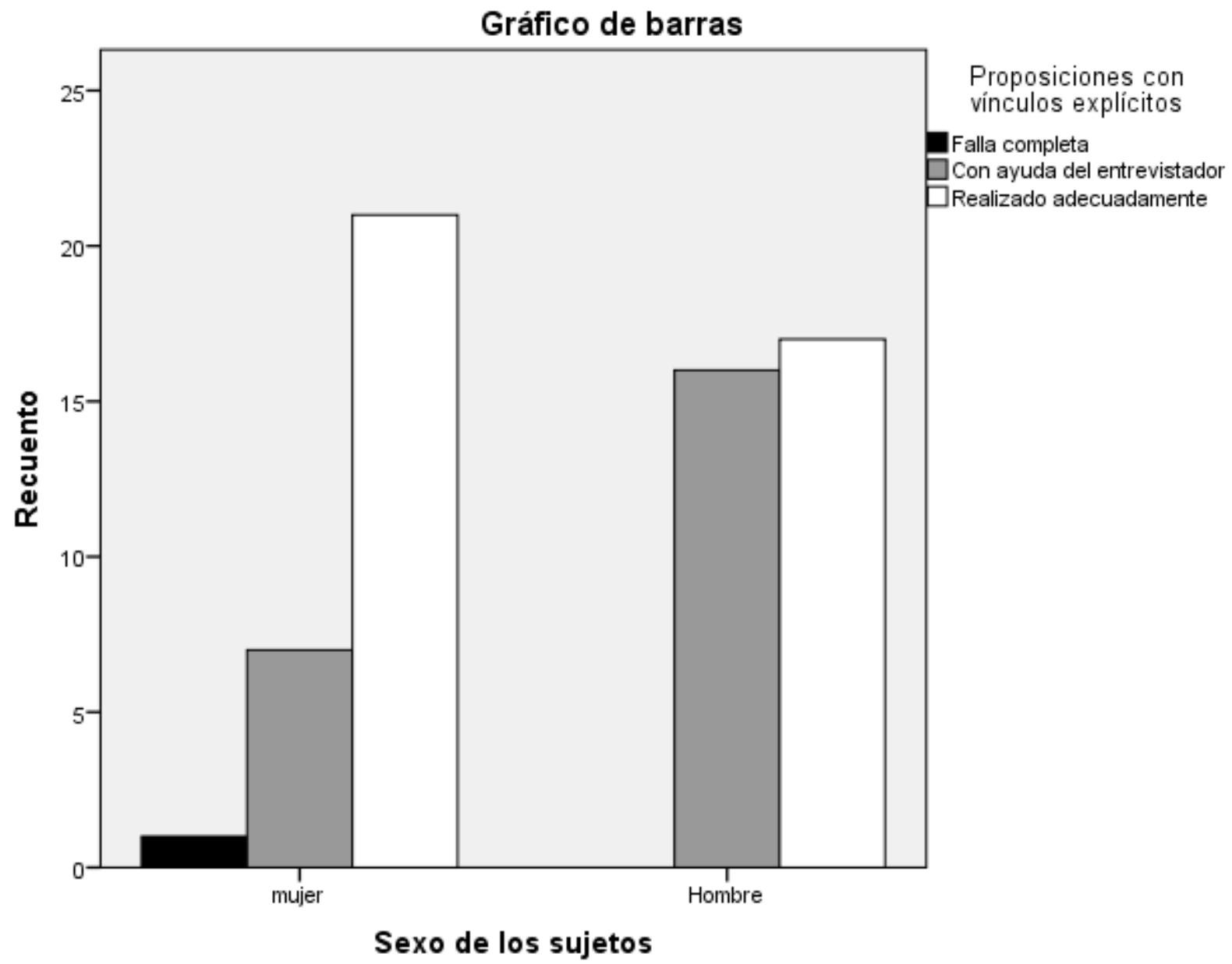


4.4.2.3. Proposiciones con vínculos explícitos respecto al tema central y tramo de la enfermedad

Este indicador no resultó significativo, puesto que las ocurrencias entre los subgrupos son similares, y los controles presentaron adecuación en un 100\%; en el primer episodio de $>0$ a $>2$ años, encontramos, 8 ocurrencias realizadas adecuadamente, $21 \%, 6$ con ayuda del entrevistador, 26,1\% y ninguna falla, $0 \%$. En el grupo de primer episodio de $<2$ a $>3$ años, encontramos 3 ocurrencias de realización adecuada, 7,9\% y 8 casos de realización con ayuda del entrevistador, 34,8\%, ninguna ocurrencia de falla completa. Los crónicos de hasta 5 años, presentaron 7 ocurrencias de realización adecuada, 18,4\%; 3 casos de realización con ayuda del entrevistador, $13 \%$ y ninguna ocurrencia de falla completa. Los crónicos de 5 años y más, presentaron 8 ocurrencias de realización adecuada, 21,1\%; 6 casos de realización con ayuda del entrevistador, $26,1 \%$ y 1 ocurrencia de falla completa. Este punto del análisis de los datos no resulta informativo en forma significativa.

Tabla de contingencia 117: Proposiciones con vínculos explícitos y tramode la enfermedad.

\begin{tabular}{|c|c|c|c|c|}
\hline \multirow[t]{2}{*}{ Tramo de la enfermedad } & \multicolumn{3}{|c|}{ Proposiciones con vínculos explícitos } & \multirow[t]{2}{*}{ Total } \\
\hline & Falla completa & $\begin{array}{l}\text { Con ayuda del } \\
\text { entrevistador }\end{array}$ & $\begin{array}{l}\text { Realizado } \\
\text { adecuadamente }\end{array}$ & \\
\hline \multirow[t]{2}{*}{ Controles } & 0 & 0 & 12 & 12 \\
\hline & $0,0 \%$ & $0,0 \%$ & $31,6 \%$ & $19,4 \%$ \\
\hline \multirow{2}{*}{$\begin{array}{l}\text { Primer episodio de } 0 \text { a } 2 \\
\text { años }\end{array}$} & 0 & 6 & 8 & 14 \\
\hline & $0,0 \%$ & $26,1 \%$ & $21,1 \%$ & $22,6 \%$ \\
\hline \multirow{2}{*}{$\begin{array}{l}\text { Primer episodio de } 2 \text { a } 3 \\
\text { años }\end{array}$} & 0 & 8 & 3 & 11 \\
\hline & $0,0 \%$ & $34,8 \%$ & $7,9 \%$ & $17,7 \%$ \\
\hline \multirow[t]{2}{*}{ Crónicos hasta 5 años } & 0 & 3 & 7 & 10 \\
\hline & $0,0 \%$ & $13,0 \%$ & $18,4 \%$ & $16,1 \%$ \\
\hline \multirow[t]{2}{*}{ Crónicos 5 años y más } & 1 & 6 & 8 & 15 \\
\hline & $100,0 \%$ & $26,1 \%$ & $21,1 \%$ & $24,2 \%$ \\
\hline \multirow[t]{2}{*}{ Total } & 1 & 23 & 38 & 62 \\
\hline & $100,0 \%$ & $100,0 \%$ & $100,0 \%$ & $100,0 \%$ \\
\hline
\end{tabular}


El valor de chi cuadrado es de $16,973^{\mathrm{a}}$, y el resultado que obtuvimos es de (>p, 030>), no significativo como ya señalamos arriba.

Tabla valor de chi cuadrado 118: proposiciones con vínculos explícitos y tramo de la enfermedad.

\begin{tabular}{||c|c|c|c||}
\hline \multicolumn{4}{|c||}{ Pruebas de chi-cuadrado } \\
\hline & Valor & $\mathrm{gl}$ & $\begin{array}{c}\text { Sig. asintótica } \\
\text { (bilateral) }\end{array}$ \\
\hline Chi-cuadrado de Pearson & $16,973^{\mathrm{a}}$ & 8 &, 030 \\
\hline
\end{tabular}

Gráfico 91. Porcentaje de frecuencia de las variables: proposiciones con vínculos explícitos y tramo de la enfermedad

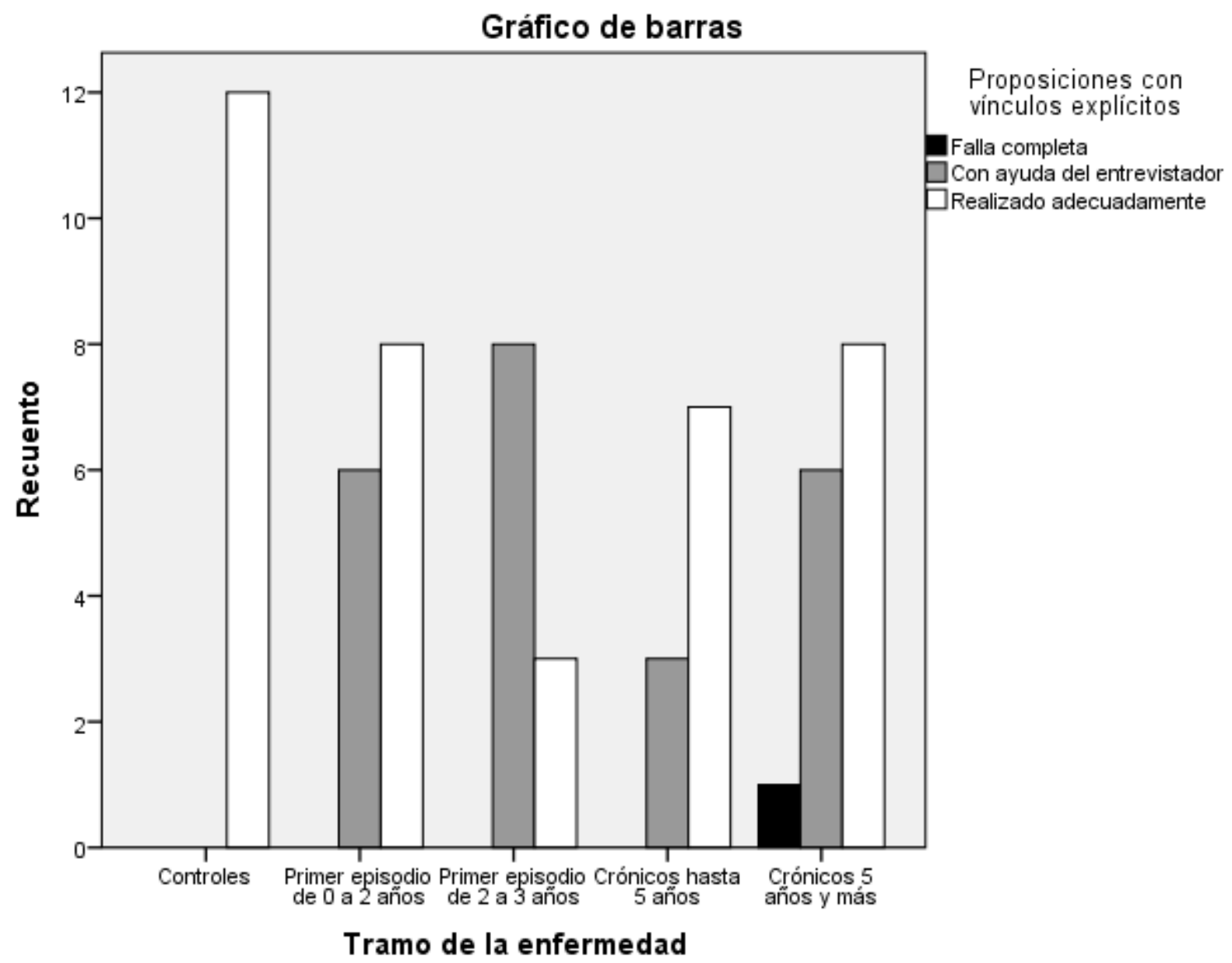


4.4.2.4. Proposiciones con vínculos explícitos respecto al tema central y subtipo de la enfermedad

En la tabla de contigencia podemos apreciar que hay una marcada diferencia entre los subtipos de esquizofrenia y el hallazgo de este indicador. El $42 \%$ de la realización adecuada se contó entre los paranoide, con 16 ocurrencias; el 73,9\% de las realizaciones con ayuda, también se contó en este grupo, con 17 casos. No presentaron ocurrencias de falla completa. Entre los hablantes del grupo de esquizofrenia indiferenciada hay un 15,8\% realizado adecuadamente, con 6 casos; $13 \%$ realizado con ayuda del entrevistador, con 3 ocurrencias y ninguna falla completa. Entre los hablantes del grupo de esquizofrenia desorganizada, el indicador realizado adecuadamente alcanza un $10,5 \%$, con 4 casos; realizado con ayuda del entrevistador un $13 \%$ con 3 casos y 1 ocurrencia de falla completa.

Entre los hablantes de este estudio hay una predominancia del subtipo paranoide, con 33 sujetos, que alcanzan un $66 \%$ de los informantes afectados por la enfermedad, el 34\% restante está dividido entre los del grupo de esquizofrenia indiferenciada y desorganizada; esta proporción, como ya señalamos en la metodología, es equivalente a la frecuencia clínica en que se presentan estos subtipos.

Tabla de contingencia 119: Proposiciones con vínculos explícitos y subtipo de la enfermedad.

\begin{tabular}{||l|l|l|l|l||}
\hline \hline \multirow{2}{*}{$\begin{array}{l}\text { Subtipo de la } \\
\text { enfermedad }\end{array}$} & \multicolumn{2}{|c|}{ Proposiciones con vínculos explícitos } & \multirow{2}{*}{ Total } \\
\cline { 2 - 5 } & Falla completa & $\begin{array}{l}\text { Con ayuda del } \\
\text { entrevistador }\end{array}$ & $\begin{array}{l}\text { Realizado } \\
\text { adecuadamente }\end{array}$ & \\
\hline \multirow{2}{*}{ Controles } & 0 & 0 & 12 & 12 \\
\cline { 2 - 5 } & $0,0 \%$ & $0,0 \%$ & $31,6 \%$ & $19,4 \%$ \\
\hline \multirow{2}{*}{ Paranoide } & 0 & 17 & 16 & 33 \\
\cline { 2 - 5 } & $0,0 \%$ & $73,9 \%$ & $42,1 \%$ & $53,2 \%$ \\
\hline \multirow{2}{*}{ Indiferenciada } & 0 & 3 & 6 & 9 \\
\cline { 2 - 5 } & $0,0 \%$ & $13,0 \%$ & $15,8 \%$ & $14,5 \%$ \\
\hline \multirow{2}{*}{ Desorganizada } & 1 & 3 & 4 & 8 \\
\cline { 2 - 5 } & $100,0 \%$ & $13,0 \%$ & $10,5 \%$ & $12,9 \%$ \\
\hline \multirow{2}{*}{ Total } & 1 & 23 & 38 & 62 \\
\cline { 2 - 5 } & $100,0 \%$ & $100,0 \%$ & $100,0 \%$ & $100,0 \%$ \\
\hline
\end{tabular}


El valor de chi cuadrado es de $17.111^{\mathrm{a}}$, y dio como resultado ( $\left.\langle\mathrm{p}, 009\rangle\right)$, no significativo estadísticamente.

Tabla valor de chi cuadrado 120: proposiciones con vínculos explícitos y subtipo de la enfermedad.

\begin{tabular}{||l|c|r|c||}
\hline \multicolumn{4}{|c||}{ Pruebas de chi-cuadrado } \\
\hline & Valor & $\mathrm{gl}$ & $\begin{array}{c}\text { Sig. asintótica } \\
\text { (bilateral) }\end{array}$ \\
\hline Chi-cuadrado de Pearson & $17,111^{\mathrm{a}}$ & 6 &, 009 \\
\hline
\end{tabular}

Gráfico 92. Porcentaje de frecuencia de las variables: proposiciones con vínculos explícitos y subtipo de la enfermedad

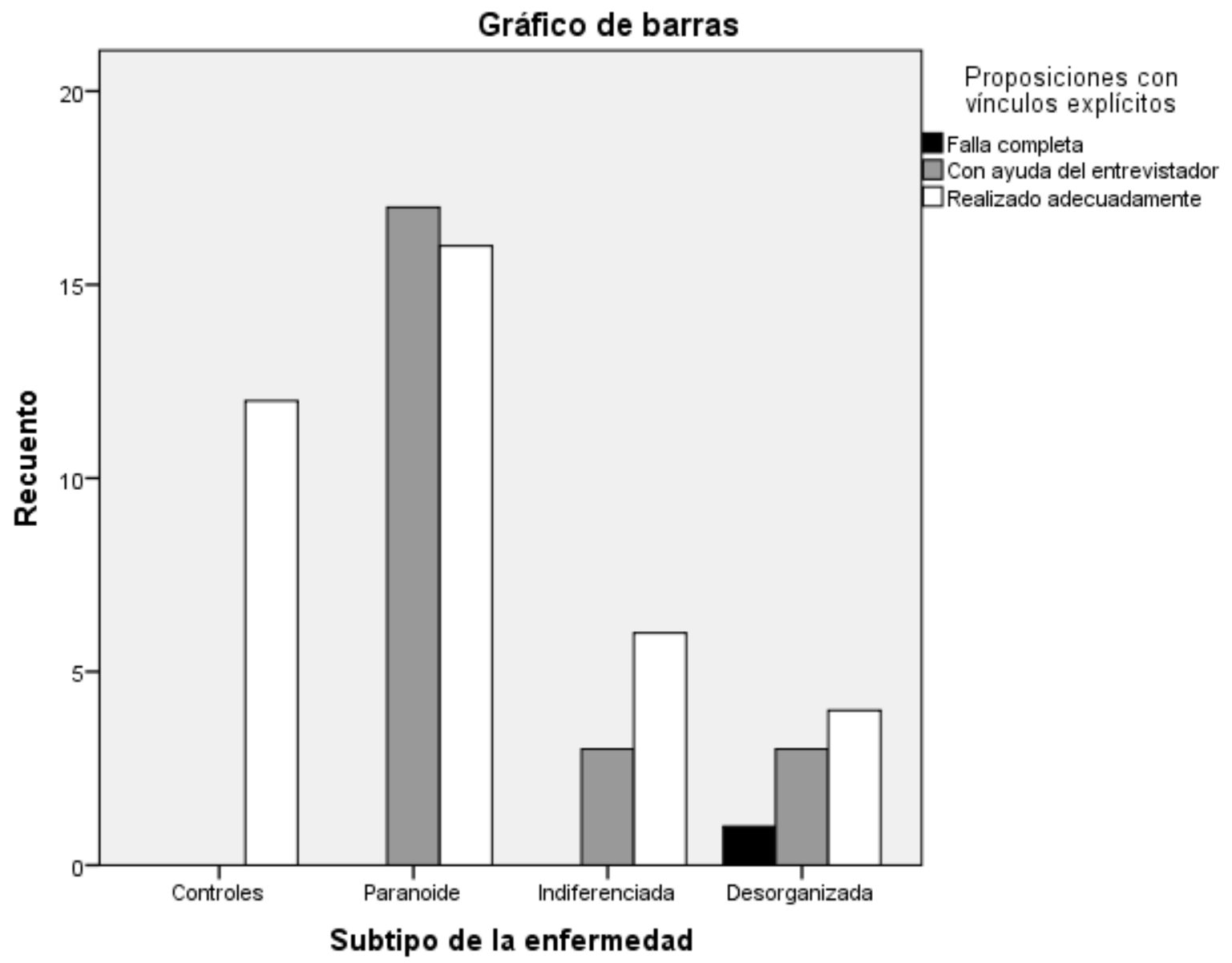




\subsubsection{Proposiciones con vínculos implícitos respecto al tema central}

Las proposiciones que indirectamente se relacionan con el tema central también contribuyen a la comprensión del discurso, ya que emplean elementos cohesivos que pueden ayudar a inferir ideas no visibles en la superficie del discurso. Utilizando el contexto, puede reconstruirse una dimensión semántica que puede facilitar la integración de contenidos explícitos e implícitos, además de contribuir a realizar predicciones sobre la intención del hablante. En este indicador, no encontramos resultados significativos en ninguna de las variables independientes. Revisaremos los porcentajes de ocurrencias de las construcciones con vínculos implícitos respecto al tema central.

4.4.3.1. Proposiciones con vínculos implícitos respecto al tema central y estadio de la enfermedad El estadio de la enfermedad, sugiere que no existan diferencias relevantes en el desempeño entre esquizofrénicos crónicos o de primer episodio, incluso, registramos una mayor ocurrencia de realizaciones con ayuda entre los informantes de primer episodio que entre los crónicos, como se aprecia en la tabla de contingencia. Los controles presentaron 3 casos de realización con ayuda del entrevistador, que representan un $12 \%$ del total en este indicador. El resto de los controles, 9 informantes, realizaron adecuadamente esta vinculación con elementos semánticopragmáticos. Por otro lado, más del 50\% del grupo de crónicos, realizó adecuadamente esta clase de construcciones, un $24 \%$ lo hizo con ayuda del entrevistador y observamos una ocurrencia de falla completa. 
Tabla de contingencia 121: Proposiciones con vínculos implícitos y estadio de la enfermedad.

\begin{tabular}{|c|c|c|c|c|}
\hline \multirow{2}{*}{$\begin{array}{l}\text { Estadio de la } \\
\text { enfermedad }\end{array}$} & \multicolumn{3}{|c|}{ Proposiciones con vínculos implícitos } & \multirow[t]{2}{*}{ Total } \\
\hline & Falla completa & $\begin{array}{l}\text { Con ayuda del } \\
\text { entrevistador }\end{array}$ & $\begin{array}{c}\text { Realizado } \\
\text { adecuadamente }\end{array}$ & \\
\hline \multirow[t]{2}{*}{ Controles } & 0 & 3 & 9 & 12 \\
\hline & $0,0 \%$ & $12,0 \%$ & $25,7 \%$ & $19,4 \%$ \\
\hline \multirow[t]{2}{*}{ Primer episodio } & 1 & 16 & 8 & 25 \\
\hline & $50,0 \%$ & $64,0 \%$ & $22,9 \%$ & $40,3 \%$ \\
\hline \multirow[t]{2}{*}{ Crónicos } & 1 & 6 & 18 & 25 \\
\hline & $50,0 \%$ & $24,0 \%$ & $51,4 \%$ & $40,3 \%$ \\
\hline \multirow[t]{2}{*}{ Total } & 2 & 25 & 35 & 62 \\
\hline & $100,0 \%$ & $100,0 \%$ & $100,0 \%$ & $100,0 \%$ \\
\hline
\end{tabular}

El valor de chi cuadrado es de 10,756 a que dio como resultado (>p, 0,29>), que, como ya señalamos en el comienzo de la sección, no es significativo estadísticamente.

Tabla valor de chi cuadrado 122: Proposiciones con vínculos implícitos y estadio de la enfermedad.

\begin{tabular}{||l|c|r|c||}
\hline \multicolumn{4}{|c|}{ Pruebas de chi-cuadrado } \\
\hline & Valor & $\mathrm{gl}$ & $\begin{array}{c}\text { Sig. asintótica } \\
\text { (bilateral) }\end{array}$ \\
\hline Chi-cuadrado de Pearson & $10,756^{\mathrm{a}}$ & 4 &, 029 \\
\hline
\end{tabular}


Gráfico 93. Porcentaje de frecuencia de las variables: proposiciones con vínculos implícitos y estadio de la enfermedad

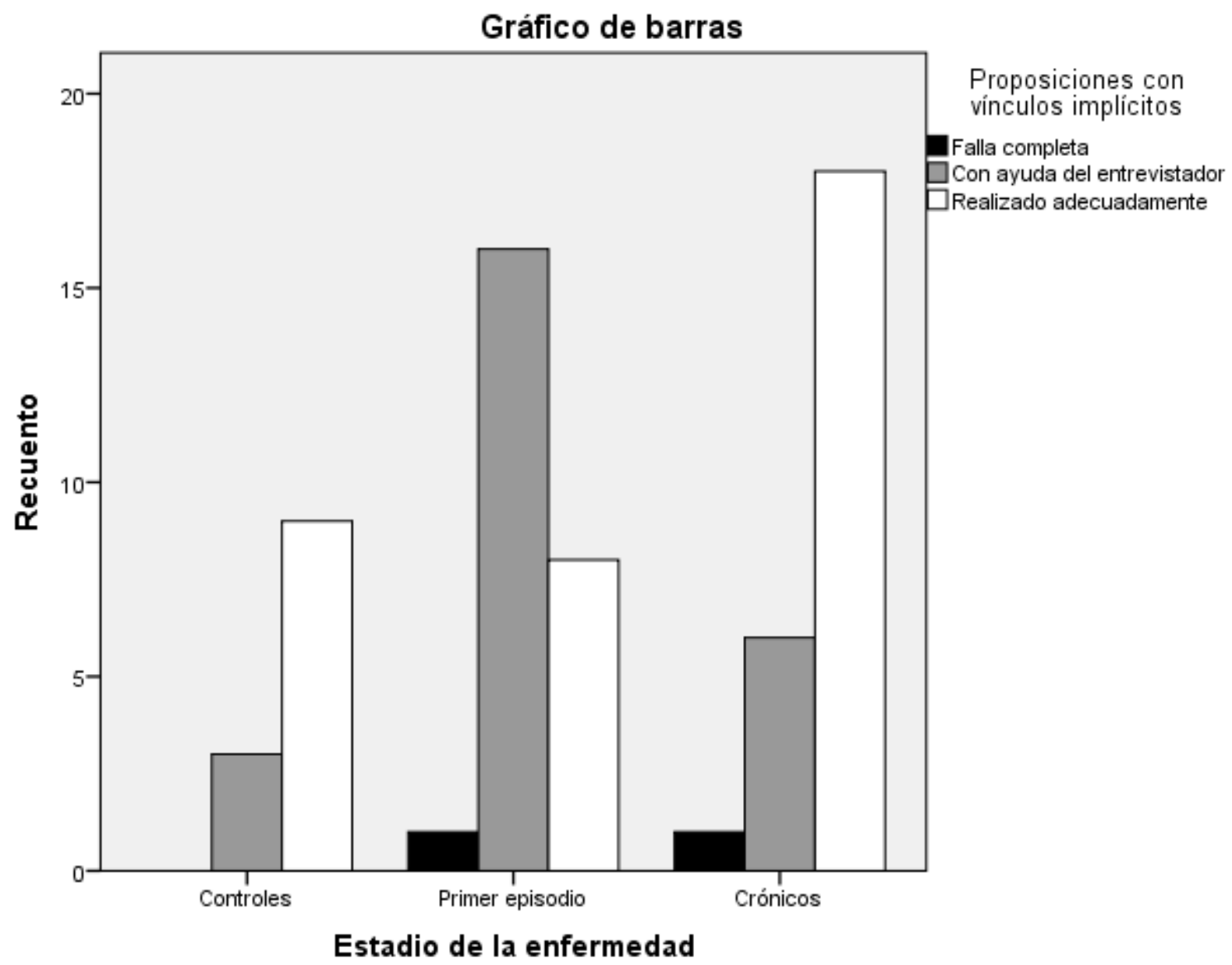

4.4.3.2. Proposiciones con vínculos implícitos respecto al tema central y sexo

Nuevamente probamos que las diferencias de género no son relevantes para explicar la mayor ocurrencia de los fenómenos lingüísitcos estudiados en este trabajo. Entre las mujeres, se observan 19 casos de realización adecuada, 9 ocurrencias realizadas con ayuda del entrevistador y 1 caso de falla completa. En cambio, los 
hombres presentaron 16 casos de realización adecuada; igual número de realización con ayuda del entrevistador y también 1 caso de falla completa:

Tabla de contingencia 123: Proposiciones con vínculos implícitos y sexo.

\begin{tabular}{||l|l|l|l|l||}
\hline \hline \multirow{3}{*}{ Sexo de los sujetos } & \multicolumn{2}{|l||}{ Proposiciones con vínculos implícitos } & \multirow{2}{*}{ Total } \\
\cline { 2 - 5 } & $\begin{array}{l}\text { Falla } \\
\text { completa }\end{array}$ & $\begin{array}{l}\text { Con ayuda del } \\
\text { entrevistador }\end{array}$ & $\begin{array}{l}\text { Realizado } \\
\text { adecuadamente }\end{array}$ & \\
\hline \multirow{2}{*}{ Mujer } & 1 & 9 & 19 & 29 \\
\cline { 2 - 5 } & $50,0 \%$ & $36,0 \%$ & $54,3 \%$ & $46,8 \%$ \\
\hline \multirow{2}{*}{ Hombre } & 1 & 16 & 16 & 33 \\
\cline { 2 - 5 } & $50,0 \%$ & $64,0 \%$ & $45,7 \%$ & $53,2 \%$ \\
\hline \multirow{2}{*}{ Total } & 2 & 25 & 35 & 62 \\
\cline { 2 - 5 } & $100,0 \%$ & $100,0 \%$ & $100,0 \%$ & $100,0 \%$ \\
\hline
\end{tabular}

El valor de chi cuadrado es de $1,967^{\mathrm{a}}$, y dio como resultado (>P, 374>), no significativo

Tabla valor de chi cuadrado 124: Proposiciones con vínculos implícitos y sexo.

\begin{tabular}{||c|c|r|c||}
\hline \multicolumn{4}{|c||}{ Pruebas de chi-cuadrado } \\
\hline & Valor & $\mathrm{gl}$ & $\begin{array}{c}\text { Sig. asintótica } \\
\text { (bilateral) }\end{array}$ \\
\hline Chi-cuadrado de Pearson & $1,967^{\mathrm{a}}$ & 2 &, 374 \\
\hline
\end{tabular}


Gráfico 94. Porcentaje de frecuencia de las variables: proposiciones con vínculos implícitos y sexo de los individuos

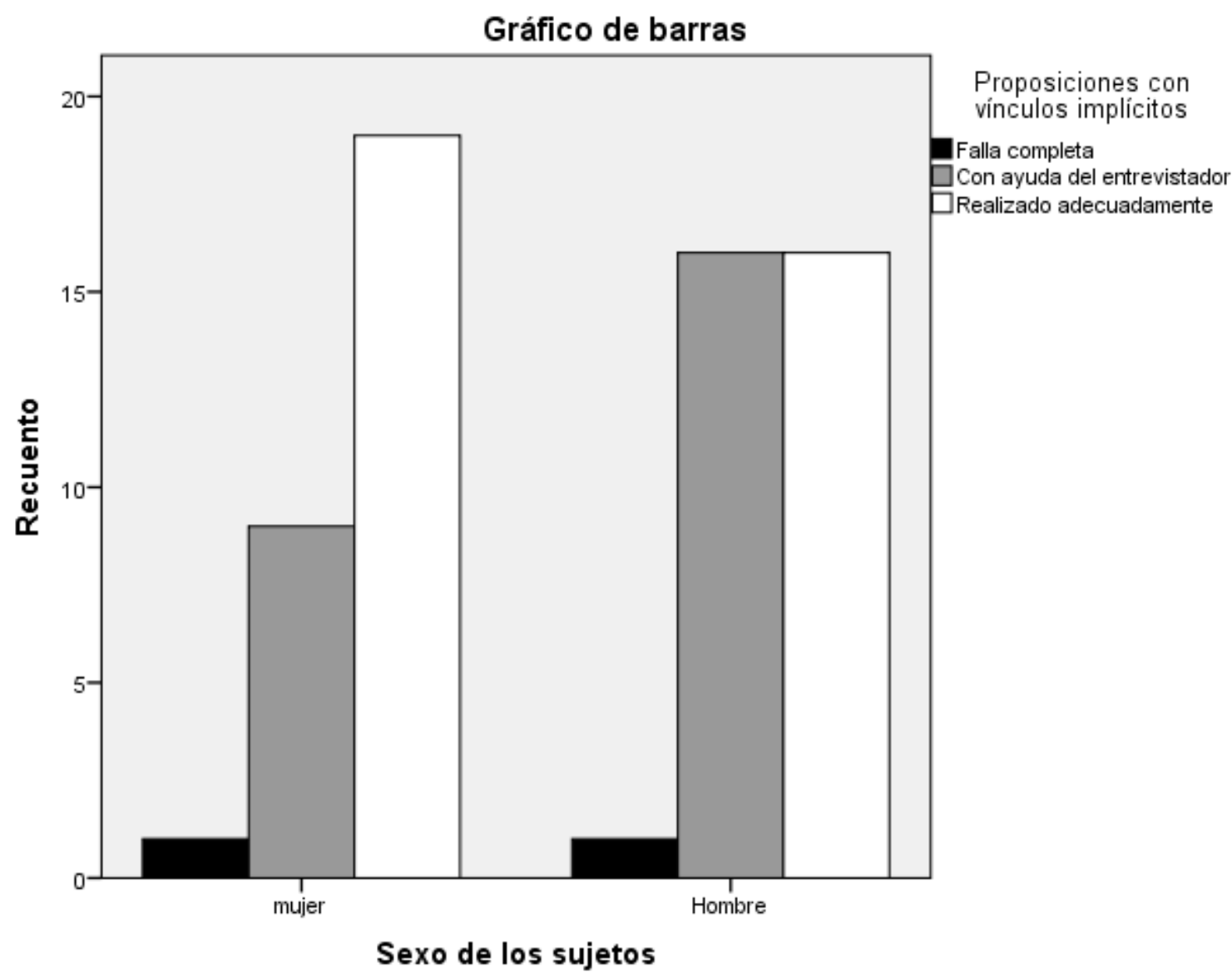

4.4.3.3. Proposiciones con vínculos implícitos respecto al tema central y tramo de la enfermedad

La variable tramo de la enfermedad no ofrece diferencias significativas. Encontramos en los del grupo de primer episodio de $>0$ a $<2$ años, 6 casos de 
realización adecuada; 8 casos de realización con ayuda del entrevistador, no muy diferente es el caso de los de primer episodio de $>2$ a $<3$ años, entre quienes registramos 2 casos de realización adecuada y 8 de realización con ayuda del entrevistador. Entre los crónicos de hasta 5 años, encontramos 7 casos de realización adecuada y 3 casos de realización con ayuda del entrevistador. Finalmente entre los crónicos de más de 5 años, encontramos 11 casos realizados en forma adecuada; 3 realizados con ayuda y 1 caso de falla completa.

Tabla de contingencia 125: Proposiciones con vínculos implícitos y tramo de la enfermedad.

\begin{tabular}{||l|l|l|l|l||}
\hline \hline \multirow{3}{*}{$\begin{array}{l}\text { Tramo de la } \\
\text { enfermedad }\end{array}$} & \multicolumn{2}{|l|}{ Proposiciones con vínculos implícitos } & \multirow{2}{*}{ Total } \\
\cline { 2 - 5 } & Falla completa & $\begin{array}{l}\text { Con ayuda del } \\
\text { entrevistador }\end{array}$ & $\begin{array}{l}\text { Realizado } \\
\text { adecuadamente }\end{array}$ & \\
\hline \multirow{2}{*}{ Controles } & 0 & 3 & 9 & 12 \\
\cline { 2 - 5 } & $0,0 \%$ & $12,0 \%$ & $25,7 \%$ & $19,4 \%$ \\
\hline \multirow{2}{*}{$\begin{array}{l}\text { Primer episodio de 0 a } \\
2 \text { años }\end{array}$} & 0 & 8 & 6 & 14 \\
\hline \multirow{2}{*}{\begin{tabular}{l} 
Primer episodio de 2 a 3 años \\
\cline { 2 - 5 }
\end{tabular}} & $0,0 \%$ & $32,0 \%$ & 2 & $22,6 \%$ \\
\cline { 2 - 5 } & $50,0 \%$ & 8 & $5,7 \%$ & 11 \\
\hline \multirow{2}{*}{ Crónicos hasta 5 años } & 0 & $32,0 \%$ & 7 & $17,7 \%$ \\
\cline { 2 - 5 } & $0,0 \%$ & 3 & $20,0 \%$ & 10 \\
\hline \multirow{2}{*}{ Total } & 1 & $12,0 \%$ & 11 & $16,1 \%$ \\
\cline { 2 - 5 } & $50,0 \%$ & 3 & $31,4 \%$ & $24,2 \%$ \\
\hline
\end{tabular}

El valor de chi cuadrado es de $14,357^{\mathrm{a}}$, y dio como resultado no significativo estadísticamente, $(>\mathrm{P}, 073>)$

Tabla valor de chi cuadrado 126: Proposiciones con vínculos implícitos y tramo de la enfermedad.

\begin{tabular}{||c|c|c|c||}
\hline \multicolumn{4}{|c||}{ Pruebas de chi-cuadrado } \\
\hline & Valor & $\mathrm{gl}$ & $\begin{array}{c}\text { Sig. asintótica } \\
\text { (bilateral) }\end{array}$ \\
\hline
\end{tabular}




\begin{tabular}{||l|r|r|r|}
\hline \hline Chi-cuadrado de Pearson & $14,357^{\mathrm{a}}$ & 8 &, 073 \\
\hline \hline
\end{tabular}

Gráfico 95. Porcentaje de frecuencia de las variables: proposiciones con vínculos implícitos y

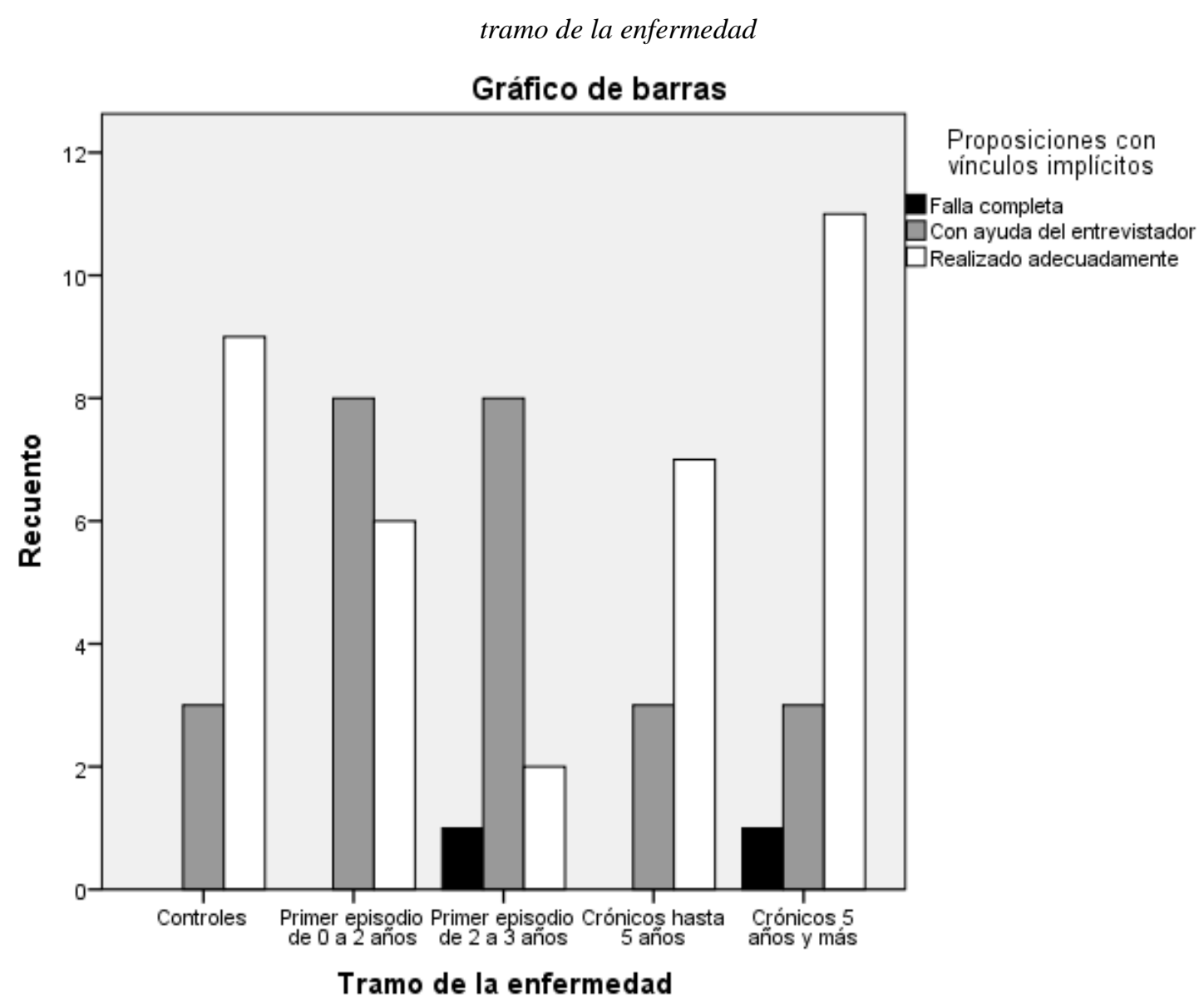

4.4.3.4. Proposiciones con vínculos implícitos respecto al tema central y subtipo de la enfermedad

Los hallazgos en esta variable no dieron resultados significativos. Entre los controles, se contaron 9 casos del indicador realizado adecuadamente y 3 casos de realización con ayuda del entrevistador. Entre los paranoide, las cifras están equilibradas entre los indicadores realizado adecuadamente y realizado con ayuda, con 
17 y 16 casos respectivamente. Entre los del grupo de esquizofrenia desorganizada, encontramos 3 casos realizados adecuadamente, 3 casos realizados con ayuda del entrevistador y 2 casos de falla completa.

Tabla de contingencia 127: Proposiciones con vínculos implícitos y subtipo de la enfermedad.

\begin{tabular}{||l|l|l|l|l||}
\hline \hline \multirow{2}{*}{$\begin{array}{l}\text { Subtipo de la } \\
\text { enfermedad }\end{array}$} & \multicolumn{2}{|c|}{ Proposiciones con vínculos implícitos } & \multirow{2}{*}{ Total } \\
\cline { 2 - 5 } & Falla completa & $\begin{array}{l}\text { Con ayuda del } \\
\text { entrevistador }\end{array}$ & $\begin{array}{l}\text { Realizado } \\
\text { adecuadamente }\end{array}$ & \\
\hline \multirow{2}{*}{ Controles } & 0 & 3 & 9 & 12 \\
\cline { 2 - 5 } & $0,0 \%$ & $12,0 \%$ & $25,7 \%$ & $19,4 \%$ \\
\hline \multirow{2}{*}{ Paranoide } & 0 & 16 & 17 & 33 \\
\cline { 2 - 5 } & $0,0 \%$ & $64,0 \%$ & $48,6 \%$ & $53,2 \%$ \\
\hline \multirow{2}{*}{ Indiferenciada } & 0 & 3 & 6 & 9 \\
\cline { 2 - 5 } & $0,0 \%$ & $12,0 \%$ & $17,1 \%$ & $14,5 \%$ \\
\hline \multirow{2}{*}{ Desorganizada } & 2 & 3 & 3 & $8,6 \%$ \\
\cline { 2 - 5 } & $100,0 \%$ & $12,0 \%$ & 35 & 62 \\
\hline \multirow{2}{*}{ Total } & 2 & 25 & $100,0 \%$ & $100,0 \%$ \\
\cline { 2 - 5 } & $100,0 \%$ & $100,0 \%$ & & \\
\hline
\end{tabular}

El valor de chi cuadrado, es de $16,418^{a}$ y dio como resultado no significativo $(>\mathrm{P}, 012>)$

Tabla valor de chi cuadrado 128: Proposiciones con vínculos implícitos y subtipo de la enfermedad.

\begin{tabular}{||c|c|c|c||}
\hline \multicolumn{4}{|c||}{ Pruebas de chi-cuadrado } \\
\hline & Valor & $\mathrm{gl}$ & $\begin{array}{c}\text { Sig. asintótica } \\
\text { (bilateral) }\end{array}$ \\
\hline Chi-cuadrado de Pearson & $16,418^{\mathrm{a}}$ & 6 &, 012 \\
\hline
\end{tabular}


Gráfico 96. Porcentaje de frecuencia de las variables: proposiciones con vínculos implícitos y subtipo de la enfermedad

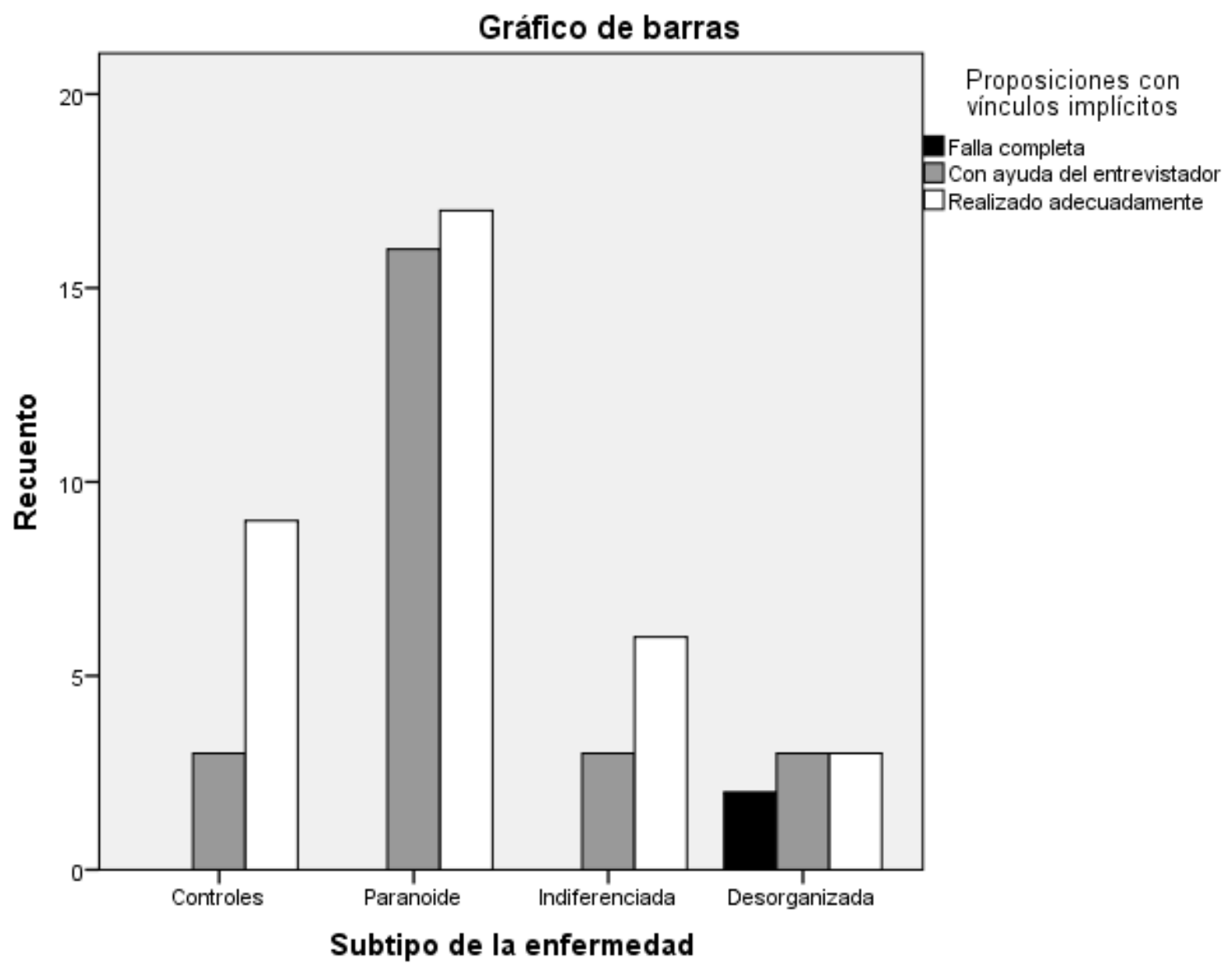

\subsubsection{Tópico con desarrollo topical}

El tópico es una proposición que introduce información nueva en el discurso, lo que denominamos el 'tema del discurso'. Un tópico se denomina también a la información que se intercambia en una situación comunicativa, es decir, la cuestión de 
la que se habla. Para efectos de este estudio, consideramos todas estas alternativas considerando que es una noción fundamental para la interpretación del discurso. A partir del tópico se imponen reglas de coherencia que de ser mantenidas por medio de recursos cohesivos, garantizarán el intercambio eficaz. Una de las reglas asociadas a la introducción de tópicos discursivos, tiene que ver, por ejemplo, con los conectores elegidos para ligarlo al contexto, o bien, procedimientos de carácter semántico como sustituciones léxicas, etc. En los resultados, encontramos mayormente en el grupo de crónicos una tendencia marcada a enunciar tópicos que no cumplían con estas características mencionadas. En forma constante, inventariamos proposiciones que no formaban parte de los contenidos temáticos del entrevistado, una especie de pensamiento en voz alta, que no se relacionaba con los contenidos anteriores o posteriores emitidos. En el caso de los controles se observan diversos estilos discursivos para introducir un tópico, pero, en ninguno de ellos quedaron planteados sin desarrollo. En el caso de los informantes del grupo de primer episodio la mayor parte de la producción discursiva no tuvo este inconveniente, en otros casos, con la intervención del entrevistador, los informantes presentaron tópicos con desarrollo.

\subsubsection{Ejemplos:}

1) Ejemplo del grupo crónico, realizado adecuadamente:

14. E: ¿hasta qué curso llegó<pausa>/ hasta IV?

15. S: $\mathrm{si}<$ pausa $>/ \mathrm{IV}$.

16. E: ya/ ¿después no tuvo más estudios?

17. S: es que estudié/ pero me retire.

18. E: ¿Qué estudió?

19. S: estudié un año de Ingeniera Comercial/ un semestre.

20. E: ya

21. S: pero/ me retire.

22. E: se retiró/ ¿y por qué se retiró?

23. S: porque quería hacer otras cosas/ tenía otros planes.

24. E: ya/ eh/<pausa oralizada $>/ \mathrm{M} \mathrm{A} /$ ¿y por qué está acá?

25. S: porque $<$ pausa $>/$ porque $<$ pausa $>/$ lo que pasa/ es que yo $<$ pausa $>/$ vengo de un/ una historia de<pausa $>$ / de hartos problemas.

26. E: ¿ya?

27. S: entonces $<$ pausa $>/$ últimamente $<$ pausa $>/$ tenía la sensación de que quería estar enferma.

28. E: ¿le da una sensación de querer estar enferma? 
29. S: si.

30. E: ¿Cómo es eso?

31. S: es que/ una parte de mi<pausa $>/$ quiere estar enferma.

32. E: ya

33. S: entonces $<$ pausa $>/$ hago cosas para estar enferma.

34. E: ¿cómo que cosas?

35. S: como querer<pausa $>/$ empiezo a inventar como estoy enferma $<$ pausa $>/$ como quiero estar enferma que cosas puedo hacer para que $<$ pausa $>/$ para comportarme como enferma<pausa $>$ / entonces empiezo ah<pausa oralizada $>/$ a romper cosas $<$ pausa $>/$ tratar de matar a la gente.

36. E: ¿Cómo<pausa>/ perdón?

37. S: <enfática, repite $>/$ romper cosas $<$ pausa $>/$ no lo he hecho<pausa $>/$ pero matar a la gente<pausa $>/$ pero no lo he hecho<pausa $>/$ pero podría ser.

38. E: ¿tiene deseos de matar gente o ideas de matar gente?

39. S: ideas de matar gente.

40. E: ya.

41. S: es que solo<pausa>/ solo lo hago por cómo<pausa>/ como elemento de $<$ pausa $>/$ de $<$ pausa $>/$ de querer estar enferma.

42. E: ya.

43. S: entonces es eso en el fondo<pausa $>/$ querer estar enferma $<$ pausa $>/$ en el fondo yo no quiero estar enferma<pausa $>$ pero/ una pura parte de mi quiere estar enferma// y se<pausa $>/$ se inventa síntomas<pausa $>/$ como que hay que romper cosas $<$ pausa $>/$ hacer tira cosas $<$ pausa $>/$ solo para eso.

44. E: y se lo imagina porque/ ¿esta otra parte de usted quisiera estar enferma?

45. S: no.

46. E: ya.

47. S: no.

48. E: ¿pero es usted misma la que quiere estar enferma?

49. S: una parte de mi.

50. E: ¿Cómo usted diferencia una parte de usted?/ y<pausa $>/$ ¿ la otra parte?

51. S: no sé<pausa $>/ /$ son diferentes.

52. E: ¿y en qué sentido son diferentes?

53. S: no sé.

\section{Ejemplo del grupo crónico, realizado con ayuda del entrevistador:}

4. S: Es que como denante estábamos buscando el horario, para saber qué tratamiento me tocaba ahora <pausa $>/ y$ <pausa oralizada $>$ y la reté por el celular, cuando me pasaron el celular/ $/$ pausa $>/$ no fue capaz de decirme que va a tocarme en taller de computación o <pausa >/ y eso/ no sé.

5. E: ya.

6. S: de hecho, estaba desesperado, la secretaria que estaba ahí, me dijo que no le gritara.

7. E: a ver/ ¿qué quieres decirme con todo eso?

8. S. $<$ pausa $>$ / "Dios santo/ayúdame con todos estos problemas $<$ pausa $>$ " $<$ musita para sí, inaudible>

9. E: más fuerte/ por favor/ no te escucho.

10.S: no/ nada

11.E2: ¿estás rezando <pausa $>/$ ?

12.S: si

13.E2: ¿si? 
14. S: bueno no/ no estaba rezando/ estaba pidiéndole al Señor un súplica.

15.E2:¿una oración?

16.S:si

17. E: ¿y cuál es la súplica?

18. S: la súplica <pausa ext>/

19. E: a ver/ me estabas contando que habías discutido con la abuelita/¿por qué?/ ¿qué sucedió?

20. S: porque me anotó en un taller que no correspondía y no sé cuál era.

21. E: ya

22. S: ese fue mi <pausa>/ problema.

23.E2: ¿y el horario que le pasó la Camila ayer?

24. S: es que me enojé y me desesperé y cosas así <2:00>

25. E: ya/ cuéntame qué más ha pasado estos días/¿cómo te has sentido?

26. S: infeliz, porque todas las cosas que espero bien, salen al revés <pausa ext $>/$ pero/ lo he pasado bien en mi cumpleaños//lo pasé bien en mi cumpleaños, solo que consumí demasiado <pausa ext>/

27. E: ya <alargamiento> consumiste demasiado <pausa>/ ¿qué cosa?

28. S: helado <alargamiento>

29. E2: ¿cuándo fue el cumpleaños?

30. S. un día después de que comí un helado del Bravíssimo ${ }^{62}$ uno que se llama 'crocante' parece, estaba indeciso de los helados que tienen más ingredientes y son más deliciosos por dentro.

31. E: ¿y con quién fuiste a tomar helado?

32. S: fui con mi abuelita y mi mamál fuimos al cine ese día<pausa $>$ y $<$ musita para sí ininteligible>/ <pausa ext>

33. E: ya/¿qué más ha pasado?

34. S: <pausa ext>/ en mi cumpleaños me dieron una galletas grandes/ me dolió un poco el estómago después pero/<pausa $>/$ fue por comer mucho <pausa ext $>/$ el pastel que me dieron era de chocolate, con trozos de piña<pausa ext $>/$ estaba rico<pausa ext $>1$

35. E2: ¿cuántos años cumpliste?

36. S: $26<$ alargamiento>

37.E: $i 26$ ?

38. S: <asiente>

39.E: ¿y ahora estabas en arte terapia?

40. S: ¿qué?

41. E: ¿estabas en arte terapia?

42.S:si

43.E: ¿y qué tal? <superpuesto>/¿te gustó o no?

44. S: es que <pausa ext>/no sé si es el taller que tenía que hacer

\section{Ejemplo del grupo crónico, falla completa:}

12. E: ¿Pero más menos en que época nació?

13. S: Hace poco.

14. E: ¿Hace poco nació?

15. S: la Eliana

16. E: ¿cuál Eliana?

${ }^{62}$ Conocida gelatería de Santiago 
17. S: y me le hacen tiritas<pausa>/ ¡mamacita mía!

18. E: ¿Qué le hacen tiritas?

19. S: Y se escondió para que no cortaran de militar a mí, ni de paco.

20. E: ¿quién, Eliana?

21. S: hasta allá era.

22. $\mathrm{E}: \mathrm{mmm} /\langle$ pausa $>/$ ¿Oiga y dónde está ahora usted ahora?

23. S: Allá, estoy allá abajo<pausa extendida $>/$ adonde <pausa extendida $>/$ a cualquiera puede pasar esto/<pausa $>/$ ¿cierto?

24. E: ¿Qué le puede pasar a cualquiera?

25. S: Me da tanta pena <pausa extendida>/

26. E: ¿qué cosa le da pena?

27. S: ¿fueron?

28. E: ¿quiénes?/ ¿le da pena?/ ¿la tratan mal?

29. S: <como ocurrente>/ porque me tratan muy mal

30. E: ¿Dónde la tratan mal?

31. S: hay que comprarlo <pausa>/

32. E: ¿Dónde?

33. S: Allá abajo<pausa >/

34. E: ¿Allá abajo, dónde?

35. S: No poquito<pausa>/

36. E: ¿Sabe dónde está ahora?

37. S: Aquí 'ta < palabra cortada $>$ / gubatorio/ en el gutaporio

38. E: ¿En el gutaporio?

39. S: En el/ en el gu<pausa $>$ / gu<pausa/ gu<pausa $>$ / $\mathrm{y}<$ pausa $>/$ ustedes tienen una/ una mediagüita y un autito/ aunque sea usadito/ y una niñita que me<pausa $>/$ que me viene a dormir ahí<pausa $>/$ y me gustaría irme de aquí a mí<pausa $>$ se sufre mucho/ me vuelvo loca aquí/<hace ademán de barrido con mano izquierda $>$ / aquí afuera/ <reitera ademán de barrido con la mano izquierda>/ soy feliz <ríe>

\section{1) Ejemplo del grupo de primer episodio, realizado adecuadamente:}

1. E: ¿cuál es tu nombre?

2. S: H.

3. E: ¿H?

4. S: H.

5. E: ¿y el apellido?

6. S: G.

7. E: ¿Qué edad tiene?

8. S: diecisiete años.

9. E: diecisiete... don $\mathrm{H}$ yo soy la doctora $\mathrm{L}$ y todos los que están aquí son doctores y psicólogos y queremos conversar un ratito contigo ¿ya?

10. S: ya.

11. E: ¿cuéntame porque estás aquí hoy?

12. S: por una posible esquizofrenia

13. E: ya, ¿eso te dijeron?

14. S: si

15. E: ya... ¿por qué cree que está usted aquí? Eso es un...un diagnóstico médico, ¿cierto?

16. S: por lo mismo

17. E: usted cree que esta aquí por eso, 
18. S: si

19. E: ¿qué significa tener eso?

20. S: eh

21. E: ¿cómo lo ha vivido?

22. S: eh, no sé, yo encuentro que o he vivido diferente a otras personas que han tenido esquizofrenia.

23. E: ya

24. S: de eso puedo estar seguro un poco

25. E: ya

26. S: de eso puedo estar seguro

27. E: ya ¿Cómo lo ha vivido?

28. S: mmm es difícil en..., explicar, como lo he vivido, he sentido muchas cosas pero no...no... no es como muy explicable.

29. E: nosotros vamos a hacer un esfuerzo en entenderlo.

30. S: ya.

31.E: ya, con sus palabras si me puede relatar que es lo que ha pasado en este último tiempo.

32. S: mmm....¿̨a ver? El frío que sentía...eso es lo más..., que sentía en los pulmones y en el estómago

33. E: ¿frío?

34. S: si

35. E: en los pulmones y en el estómago

36. S: si.

2) Ejemplo del grupo de primer episodio, realizado con ayuda del entrevistador:

80. E: $R$ quería que nos contara esto que empezó a escuchar voces ¿cómo lo vivía/ le parecía extraño/ que sentía?

81. S: Claro/ claro/ o sea lo sentía muy extraño porque<pausa ext $>/$ porque me sentía como que había<pausa>/ como que habían entrado en mi autoridad/ / ¿me entiende?// como que habían entrado/ entrado en mi fuerte por así decirlo/ habían burlado mi seguridad/ eh como que me sentía menos/ de repente me sentía sensible/ ¿me entiende?/ <pausa>/ porque es como que a uno le hablan/ uno se siente: "joh me están hablando!"/ <pausa>/ ¿quizás qué será o qué es lo que es? ¿me están penando?/ <pausa>/ uno se pasa mucho/ mucho rollo /como se dice vulgarmente.

82. E: ¿Qué explicaciones le daba en ese tiempo usted?

83. S: No nada/ yo/ yo la explicación que tenía de que eran ciertos/<pausa $>/$ de que era cierto/ porque no comprendía que en estas cosas de la vida/<pausa $>/$ uno nunca tiene como la certeza y la verdad total/ ¿me entiende?/ bueno yo por lo que entiendo es que nunca debo ser sabio en mi propia opinión/ ¿me entiende?/ o sea nunca debo afirmar correctamente o asertivamente que esto es así/ o que esto es así/ ¿me entiende?/ <pausa>/ si no que las cosas son muy diferentes a veces a lo que uno piensa/ $\langle$ pausa $>/$ o lo que uno tiene como plan o como meta o como algo que es cierto/ ¿me entiende?/ <pausa>/ o que algo que afirme que esto sea correcto/ siendo de que lo otro es contrario/ ¿me entiende?/ <pausa>/ siendo de que lo que yo pienso es contrario a lo que yo pienso/ entonces bueno 
yo<pausa>/ me sentía mal/ me sentía poco/ poco triste/ <pausa>/ le contaba a mi mamá/ le contaba a mi papá y ellos me decían "no hijo/ si eso está en tu mente/ en tu mente/ en tu cerebro/ es tu cerebro es tu mente"// <pausa >/ y yo claro/ yo les entendía/ yo/ yo les escuchaba/ yo tomaba siempre su atención de que nunca los dejaba/ ¿me entiende?/ <pausa>/ siempre rescataba lo que ellos querían decirme/<pausa $>$ pero/ pero/ pero/ siempre tenía yo $\mathrm{mi} / \mathrm{mi} / \mathrm{mi} / \mathrm{mi}$ opinión claro/¿me entiende?// $\langle$ pausa $>/$ mi perspectiva acerca de lo que yo sentía/ acerca de quizás mi patología/ <pausa>/ porque quizás eso es una patología/ ¿me entiende?// <pausa>/ yo también puedo creer que una patología/ ¿me entiende?/ yo creo que un $50 \%$ de eso es una patología y un $50 \%$ de que sea verdad/ ¿me entiende?/ pero/<pausa $>/$ ¿no cree usted que como extraño que venga un ejemplo una voz ajena?/ <pausa>/ ¿me entiende?/ ¿o su hija o su señora a hablarle a la conciencia?/ ¿me entiende?/ eso no corresponde/ no/ no/ no/ no es cierto/ no es cierto/ no es cierto/ eso es patología/¿me entiende?/ pero hay cosas peores/ ¿me entiende?/ hay cosas peores/ que puede haber sido peor haber perdido el juicio eh<pausa $>/$ haberme autoinflingido/ eh haber llegado a la cárcel por algún delito o crimen//

84. E: R había dicho usted/ <pausa>/ que se sentía como perseguido/ explíquenos un poquito más como es eso de sentirse perseguido.

85. S: Bueno o sea/ cuando uno se siente como<pausa>/ como que ha fallado en su autoridad/ en su defensa/<pausa>/ como que/ uno como que se siente<pausa>/ más bien $\langle$ pausa $>/$ como que ha fallado uno mismo / ¿me entiende?// entonces yo sentía como que<pausa>/ como inseguridad / ¿me entiende?//, como inseguridad hasta para hablar/ hasta para hablar/ hasta para expresarme/ sentía inseguridad/ me sentía muy inseguro eh quería estar solo<pausa>/ quería estar libre<pausa>/ quería como le dijera/ estar sin gente/ sin gente que me hablara $<$ pausa $>$ / porque yo pasaba escuchando esa voz<pausa $>$ / entonces como que no quería que me hablaran/ quería estar solo/ quería estar en un lugar espacioso/ porque yo soy igual dotado de la tranquilidad<pausa >/ de la soledad/ me gusta la soledad/ la tranquilidad/ de repente cuando compongo/ cuando escribo/ cuando a veces hago alguna/ alguna escritura/ alguna/ en fin.

\section{3) Ejemplo del grupo control, realizado adecuadamente:}

5. I: <énfasis> seguro seguro </énfasis> donde vivo yo sí poh / porque hace poco pusieron portón

6. E: ah ya

7. I: ¿cachai? / cerraron la calle allá / con permiso de la municipalida[d]

8. E: ya

9. I: pero siempre ha si[d]o tranquilo / onda <alargamiento/>/ pocah veceh pasan cosah / y cuando pasan cosah / pasan we[v]a[da]h bakaneh / <entre_risas> como que </entre_risas> <vacilación/> que<vacilación/> que<alargamiento/> son pa[ra] contar

10. E: ya / cuéntame una / no sé

11. I: ¡uf! ¿cuál te pudo contar? hay una hihtoria de una bolsa / de<alargamiento/> una bolsa que botaron en un auto

12. E: ya

13. I: hay otra hihtoria de un choque<alargamiento/>

14. E: ya<alargamiento/>

15. I: hay una hihtoria de / a [v]er son hartah hihtoriah / mira 
16. E: [es]pera / [es]pera / [es]pera / <énfasis> la bolsa </énfasis> <simultáneo> me intriga la bolsa $</$ simultáneo $>$

17. I: <simultáneo> la hihtoria [d]e <vacilación/> la hihtoria [d]e la bolsa </simultáneo> / yo [es]taba un día en Internet / chateando onda a lah treh de la mañana / y paró un auto afuera [d]e mi casa y se ehcucha que botaron una we[v]a[da] / y cayó fuerte ¿ya? / y miré por la ventana / yo vivo juhto en la ehquina / o sea duermo<vacilación/> mi pieza ehtá en la ehquina / miré pa[ra] fuera y había un bolsa tira[da] en la mita[d] de la calle / y se fue el auto / yo dije <cita> ¡oh! ya filo </cita> y le dije ami amigo por <extranjero> messenger </extranjero> <cita> oye sabíh que botaron una bolsa $</$ cita $>$ <ita y ¿qué es? </cita $>/<$ cita $>$ no sé </cita $>$ y en eso llega el auto / la recogen / y se la lle[v]an de nue[v]o / y yo<alargamiento/> <cita $>$ oye we[v]ón se la llevaron $</$ cita $>\langle$ risas = "I"/> / $\mathrm{y}<$ alargamiento/> veo que el auto llega al final de la calle / y la botan de nuevo / [en]tonceh dij <palabra_cortada/> le dije a mi amigo <cita> ya/ sa[b]íh que la voy a ir a buhcar </cita> me dijo <cita> we[v]ón a lo mejor eh droga </cita> no sé / yo le dije <cita> ah! no sé ni ahí </cita> / partí raja[d]o corriendo a buhcarla / y cuando llegué habían <énfasis> tantah </énfasis> bolsah / y había gente [en]tonceh fue como ya no la voy a buhcar mejor me voy pa[ra] la casa / y cuando iba volviendo la casa / llego el auto a la ehquina / y yo ¡uh! / así como <vacilación/> / y loh galloh<vacilación/> miraron / y se fueron por otro la[d]o / no fueron a buhcar la bolsa / y miré ha<palabra_cortada/ $>$ hacia la dirección donde venía el auto / y habían bota[d]o unoh basureroh al sue<alargamiento/>lo ¿cachai? / ya filo me metí a la casa / y ehperé a ver qué pasa[b]a y le dije a mi amigo <cita> oy que raro que hayan bota[d]o la bolsa y la hayan recogi[d]o $</$ cita $>/$ y me dice $<$ cita $>$ we[v]ón/ recién paró un auto fuera [d]e mi casa y botaron una bolsa </cita> yo ¡oy! ya así / le dije <cita> sale a buhcarla al tiro </cita> porque él vive cerca [d]e mi casa poh

18. E: uhum

19. I: le dije <cita> sale a buhcarla al tiro </cita> y me dijo <cita $>$ ¡no! capah que sea droga/ mi vecino eh medio <énfasis> turbio </énfasis> y <vacilación/> y no no me quiero meter en problemah </cita > y le dije <cita $>$ ¡ah! we[v]ón soy <énfasis $>$ fleto </énfasis> $</$ cita $><$ risas = "todos"/> y salí corriendo [d]e mi casa como cuatro cuadrah / y veo una bolsa en la mita[d] [d]e la calle / la pehco / y me voy pa[ra] la casa / así raja[d]o / llego a la casa / la dejé en el jardín / y entré/ y mi vieja / eran lah cuatro [d]e la mañana / me dijo <cita> ¡we[v]ón! ¿qué andai haciendo? </cita> / y ahí le conté to[d]a la hihtoria $<$ silencio/> y me dijo <cita> ya / ¿sa[b]íh que? revisa lo que tiene la bolsa y si no tiene na[da] anda a botarla afuera / y te vai a acohtar / porque<vacilación/> [es]tai <énfasis> puro we[ve]ando </énfasis> </cita> <risas $=$ "todos"/> / y<alargamiento/> fui / me puse uno guanteh /corté la bolsa/ y revisé<alargamiento/> lo que tenía

20. E: ¿y qué era?

21. I: y ahí se cagaron to[d]oh d la risa porque tenía porotoh verdeh ${ }^{63}$

22. E: yaa<alargamiento/> <risas = "I"/>

${ }^{63}$ Porotos verdes=judías 
4.4.4.2. Tópico con desarrollo y estadio de la enfermedad

Esta variable mostró diferencias interesantes entre los grupos. Los controles presentaron un $100 \%$ de tópicos con desarrollo en la entrevista. En el caso de los de primer episodio alcanzan un 64\% de realización adecuada y un 36\% de realización con ayuda del entrevistador y no presentan ocurrencias de falla completa en este indicador. Entre los crónicos se presentan un 32\% de ocurrencias realizadas adecuadamente, un $44 \%$ realizado con ayuda del entrevistador y un $24 \%$ falla en este indicador.

Tabla de contingencia 129: Tópicos con referentes y estadio de la enfermedad.

\begin{tabular}{|c|c|c|c|c|}
\hline \multirow[t]{2}{*}{ Estadio de la enfermedad } & \multicolumn{3}{|c|}{ Tópicos con referentes } & \multirow[t]{2}{*}{ Total } \\
\hline & Falla completa & $\begin{array}{l}\text { Con ayuda del } \\
\text { entrevistador }\end{array}$ & $\begin{array}{l}\text { Realizado } \\
\text { adecuadamente }\end{array}$ & \\
\hline \multirow[t]{2}{*}{ Controles } & 0 & 0 & 12 & 12 \\
\hline & $0,0 \%$ & $0,0 \%$ & $33,3 \%$ & $19,4 \%$ \\
\hline \multirow[t]{2}{*}{ Primer episodio } & 0 & 9 & 16 & 25 \\
\hline & $0,0 \%$ & $45,0 \%$ & $44,4 \%$ & $40,3 \%$ \\
\hline \multirow[t]{2}{*}{ Crónicos } & 6 & 11 & 8 & 25 \\
\hline & $100,0 \%$ & $55,0 \%$ & $22,2 \%$ & $40,3 \%$ \\
\hline \multirow[t]{2}{*}{ Total } & 6 & 20 & 36 & 62 \\
\hline & $100,0 \%$ & $100,0 \%$ & $100,0 \%$ & $100,0 \%$ \\
\hline
\end{tabular}

El valor de chi cuadrado es de $20,639^{a}$ y dio como resultado un significativo $(>\mathrm{p}, 000>)$

Tabla valor de chi cuadrado 130: Tópicos con referentes y estadio de la enfermedad.

\begin{tabular}{||l|c|r|c||}
\hline \multicolumn{4}{|c||}{ Pruebas de chi-cuadrado } \\
\hline & Valor & $\mathrm{gl}$ & $\begin{array}{c}\text { Sig. asintótica } \\
\text { (bilateral) }\end{array}$ \\
\hline Chi-cuadrado de Pearson & $20,639^{\mathrm{a}}$ & &, 000 \\
\hline \hline
\end{tabular}


Gráfico 97. Porcentaje de frecuencia de las variables: tópico con desarrollo y estadio de la enfermedad

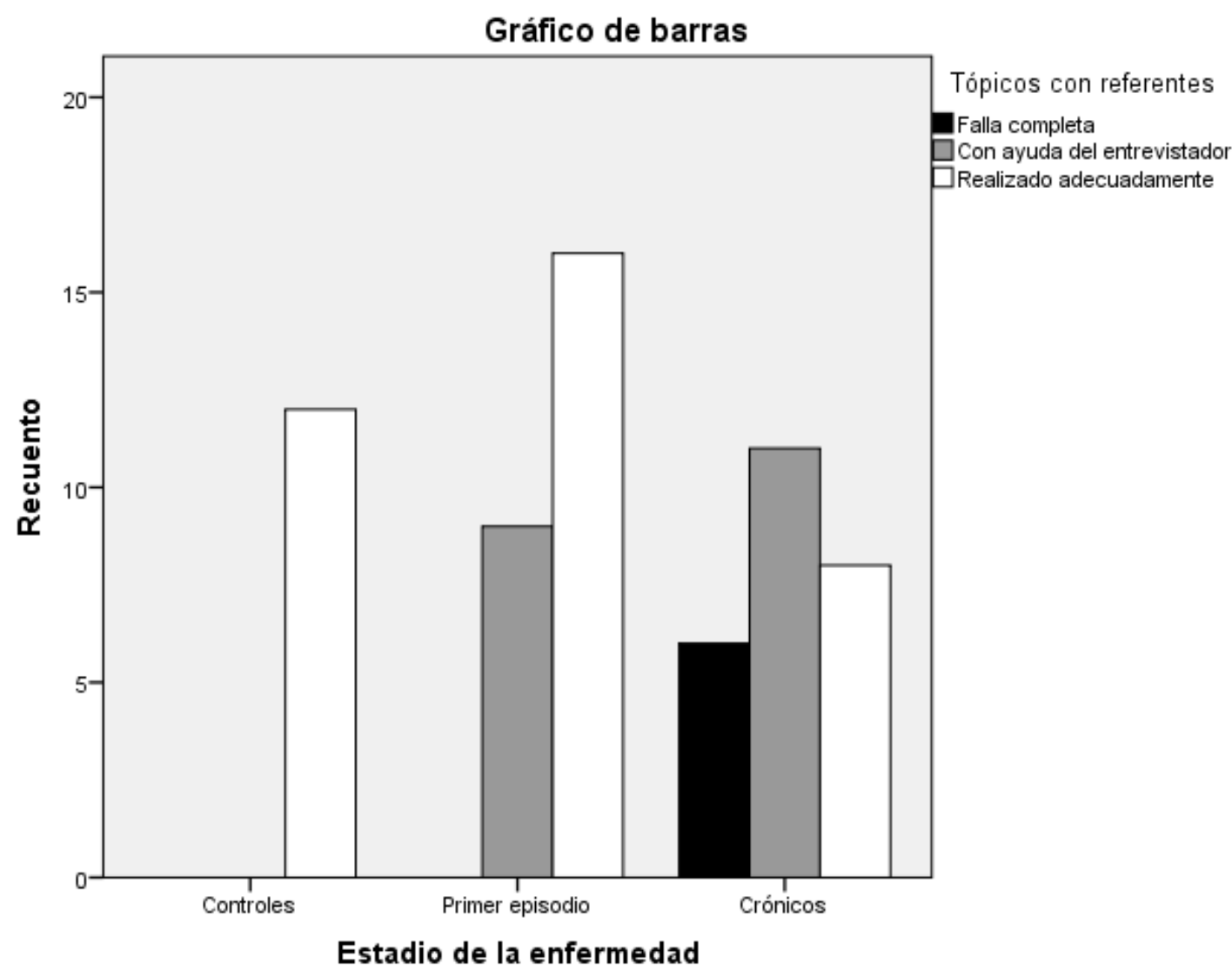

4.4.4.3. Tópico con desarrollo y sexo

Este indicador no es significativo. Se presentan algunos casos más de realización adecuada entre el grupo de mujeres, 19 ocurrencias, que representan el 52\%; de la realización con ayuda del entrevistador, registramos 9 casos que representan el 45\% y 1 caso de falla completa que representa el 16,7\%. Entre los hombres encontramos 17 casos de realización adecuada, representados por un 47,2\%; 11 casos de realizaciones 
con ayuda del entrevistador, representados por el $55 \%$ y finalmente 5 casos de falla completa, representados por el $83,3 \%$.

Tabla de contingencia 131: Tópicos con referentes y sexo.

\begin{tabular}{||l|l|l|l|l||}
\hline \multirow{2}{*}{$\begin{array}{c}\text { Sexo de los } \\
\text { sujetos }\end{array}$} & \multicolumn{3}{|c||}{ Tópicos con referentes } & \multirow{2}{*}{ Total } \\
\cline { 2 - 5 } & Falla completa & $\begin{array}{l}\text { Con ayuda del } \\
\text { entrevistador }\end{array}$ & $\begin{array}{l}\text { Realizado } \\
\text { adecuadamente }\end{array}$ & \\
\hline \multirow{2}{*}{ Mujer } & 1 & 9 & 19 & 29 \\
\cline { 2 - 5 } & $16,7 \%$ & $45,0 \%$ & $52,8 \%$ & $46,8 \%$ \\
\hline \multirow{2}{*}{ Hombre } & 5 & 11 & 17 & 33 \\
\cline { 2 - 5 } & $83,3 \%$ & $55,0 \%$ & $47,2 \%$ & $63,2 \%$ \\
\hline \multirow{2}{*}{ Total } & 6 & 20 & 36 & 62 \\
\cline { 2 - 5 } & $100,0 \%$ & $100,0 \%$ & $100,0 \%$ & $100,0 \%$ \\
\hline
\end{tabular}

El valor de chi cuadrado es de $2,731^{\mathrm{a}}$ y dio como resultado no significativo ( $>\mathrm{p}$, $255>)$.

Tabla valor de chi cuadrado 132: Tópicos con referentes y sexo.

\begin{tabular}{||l|c|c|c||}
\hline \multicolumn{4}{|c|}{ Pruebas de chi-cuadrado } \\
\hline & Valor & $\mathrm{gl}$ & $\begin{array}{c}\text { Sig. asintótica } \\
\text { (bilateral) }\end{array}$ \\
\hline Chi-cuadrado de Pearson & $2,731^{\mathrm{a}}$ & 2 &, 255 \\
\hline
\end{tabular}


Gráfico 98. Porcentaje de frecuencia de las variables: tópico con desarrollo y sexo de los individuos

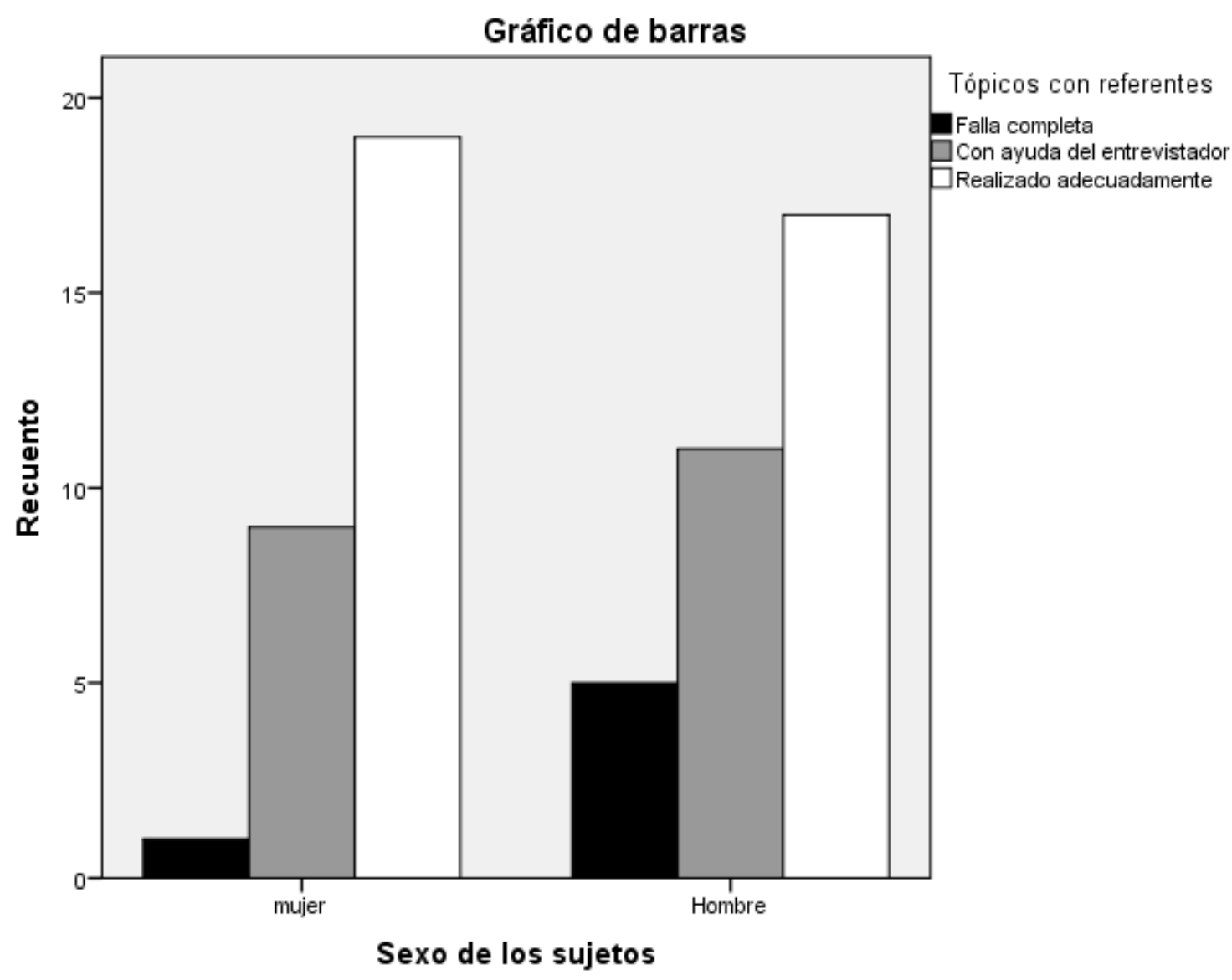

4.4.4.4. Tópico con desarrollo y tramo de la enfermedad

Este indicador resultó significativo en esta variable, los hablantes de primer episodio de $>0$ a $<2$ años presentaron 9 casos, con el 25\% de las realizaciones adecuadas; 5 casos realizados con ayuda del entrevistador, que representan el $25 \%$ y no registramos casos de falla completa. El grupo de primer episodio de $>2$ a $<3$ años, presentó 7 casos de realización adecuada, correspondiente al 19,4\%; 4 casos realizados 
con ayuda del entrevistador, que representan el $20 \%$ y ninguna falla completa. El grupo de crónicos de hasta 5 años presentó 5 casos de realización adecuada, representados por el 13,9\%; 3 casos realizados con ayuda del entrevistador, representados por un 155 y 2 casos de falla completa, representados por un 33,3\%. Finalmente, los crónicos de 5 años y más, presentaron 3 caos de realización adecuada, representados por el 8,3\%; 8 casos de realización con ayuda del entrevistador, representados por el $40 \%$ y 4 casos de falla completa, representados por el $66,7 \%$ del criterio evaluado.

Tabla de contingencia 133: Tópicos con referentes y tramo de la enfermedad.

\begin{tabular}{|c|c|c|c|c|}
\hline \multirow{2}{*}{$\begin{array}{l}\text { Tramo de la } \\
\text { enfermedad }\end{array}$} & \multicolumn{3}{|c|}{ Tópicos con referentes } & \multirow[t]{2}{*}{ Total } \\
\hline & $\begin{array}{l}\text { Falla } \\
\text { completa }\end{array}$ & $\begin{array}{l}\text { Con ayuda del } \\
\text { entrevistador }\end{array}$ & $\begin{array}{l}\text { Realizado } \\
\text { adecuadamente }\end{array}$ & \\
\hline \multirow[b]{2}{*}{ Controles } & 0 & 0 & 12 & 12 \\
\hline & $0,0 \%$ & $0,0 \%$ & $33,3 \%$ & $19,4 \%$ \\
\hline \multirow{2}{*}{$\begin{array}{l}\text { Primer episodio } \\
\text { de } 0 \text { a } 2 \text { años }\end{array}$} & 0 & 5 & 9 & 14 \\
\hline & $0,0 \%$ & $25,0 \%$ & $25,0 \%$ & $22,6 \%$ \\
\hline \multirow{2}{*}{$\begin{array}{l}\text { Primer episodio } \\
\text { de } 2 \text { a } 3 \text { años }\end{array}$} & 0 & 4 & 7 & 11 \\
\hline & $0,0 \%$ & $20,0 \%$ & $19,4 \%$ & $17,7 \%$ \\
\hline \multirow{2}{*}{$\begin{array}{l}\text { Crónicos hasta } 5 \\
\text { años }\end{array}$} & 2 & 3 & 5 & 10 \\
\hline & $33,3 \%$ & $15,0 \%$ & $13,9 \%$ & $16,1 \%$ \\
\hline \multirow{2}{*}{$\begin{array}{l}\text { Crónicos } 5 \text { años y } \\
\text { más }\end{array}$} & 4 & 8 & 3 & 15 \\
\hline & $66,7 \%$ & $40,0 \%$ & $8,3 \%$ & $24,2 \%$ \\
\hline \multirow[t]{2}{*}{ Total } & 6 & 20 & 36 & 62 \\
\hline & $100,0 \%$ & $100,0 \%$ & $100,0 \%$ & $100,0 \%$ \\
\hline
\end{tabular}

El valor de chi cuadrado es de $22,859^{\mathrm{a}}$ y dio como resultado significativo estadísticamente (>p, 004>). 
Tabla valor de chi cuadrado 134: Tópicos con referentes y tramo de la enfermedad.

\begin{tabular}{||c|c|c|c||}
\hline \multicolumn{4}{|c||}{ Pruebas de chi-cuadrado } \\
\hline & Valor & gl & $\begin{array}{c}\text { Sig. asintótica } \\
\text { (bilateral) }\end{array}$ \\
\hline Chi-cuadrado de Pearson & $22,859^{\text {a }}$ & 8 &, 004 \\
\hline
\end{tabular}

Gráfico 99. Porcentaje de frecuencia de las variables: tópico con desarrollo y tramo de la enfermedad

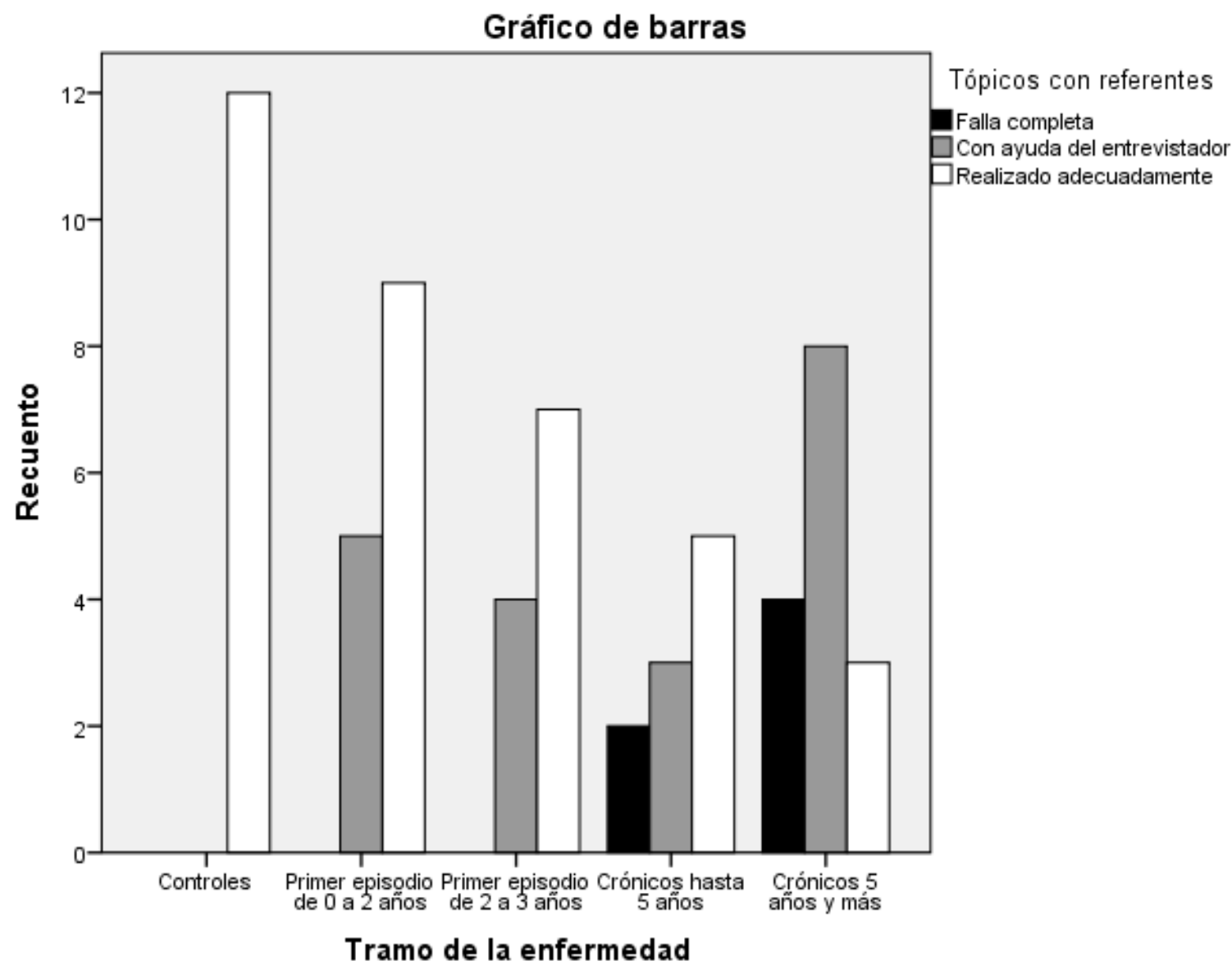

4.4.4.5. Tópico con desarrollo y subtipo de la enfermedad: 
El grupo paranoide presentó 17 ocurrencias, esto es un 47,2\% del indicador tópico desarrollado, realizado adecuadamente; 13 casos con ayuda del entrevistador, con un $65 \%$ y 3 casos de falla completa, con un 50\%. El grupo de esquizofrenia indiferenciada, presentó 5 casos realizado adecuadamente, con un 13,9\%; 2 casos realizados con ayuda del entrevistador, con un $10 \%$ y 2 casos de falla completa, con un $33,3 \%$. Los del grupo de esquizofrenia desorganizada presentaron 2 casos de realización adecuada, con un 5,6\%; 5 casos realizados con ayuda del entrevistador y 1 caso de falla completa, con un $16,7 \%$.

Tabla de contingencia 135: Tópicos con referentes y subtipo de la enfermedad.

\begin{tabular}{|c|c|c|c|c|}
\hline \multirow{2}{*}{$\begin{array}{l}\text { Subtipo de la } \\
\text { enfermedad }\end{array}$} & \multicolumn{3}{|c|}{ Tópicos con referentes } & \multirow[t]{2}{*}{ Total } \\
\hline & Falla completa & $\begin{array}{l}\text { Con ayuda del } \\
\text { entrevistador }\end{array}$ & $\begin{array}{c}\text { Realizado } \\
\text { adecuadamente }\end{array}$ & \\
\hline \multirow[t]{2}{*}{ Controles } & 0 & 0 & 12 & 12 \\
\hline & $0,0 \%$ & $0,0 \%$ & $33,3 \%$ & $19,4 \%$ \\
\hline \multirow[t]{2}{*}{ Paranoide } & 3 & 13 & 17 & 33 \\
\hline & $50,0 \%$ & $65,0 \%$ & $47,2 \%$ & $53,2 \%$ \\
\hline \multirow[t]{2}{*}{ Indiferenciada } & 2 & 2 & 5 & 9 \\
\hline & $33,3 \%$ & $10,0 \%$ & $13,9 \%$ & $14,5 \%$ \\
\hline \multirow[t]{2}{*}{ Desorganizada } & 1 & 5 & 2 & 8 \\
\hline & $16,7 \%$ & $25,0 \%$ & $5,6 \%$ & $12,9 \%$ \\
\hline \multirow[t]{2}{*}{ Total } & 6 & 20 & 36 & 62 \\
\hline & $100,0 \%$ & $100,0 \%$ & $100,0 \%$ & $100,0 \%$ \\
\hline
\end{tabular}

El valor de chi cuadrado es de $15,038^{\mathrm{a}}$, y dio como resultado no significativo $(>\mathrm{p}, 0,20>)$ 
Tabla valor de chi cuadrado 136: Tópicos con referentes y subtipo de la enfermedad.

\begin{tabular}{||l|c|r|c||}
\hline \multicolumn{4}{|c||}{ Pruebas de chi-cuadrado } \\
\hline & Valor & Gl & $\begin{array}{c}\text { Sig. asintótica } \\
\text { (bilateral) }\end{array}$ \\
\hline Chi-cuadrado de Pearson & $15,038^{\mathrm{a}}$ & 6 &, 020 \\
\hline
\end{tabular}

Gráfico 100 Porcentaje de frecuencia de las variables: tópico con desarrollo y subtipo de la enfermedad

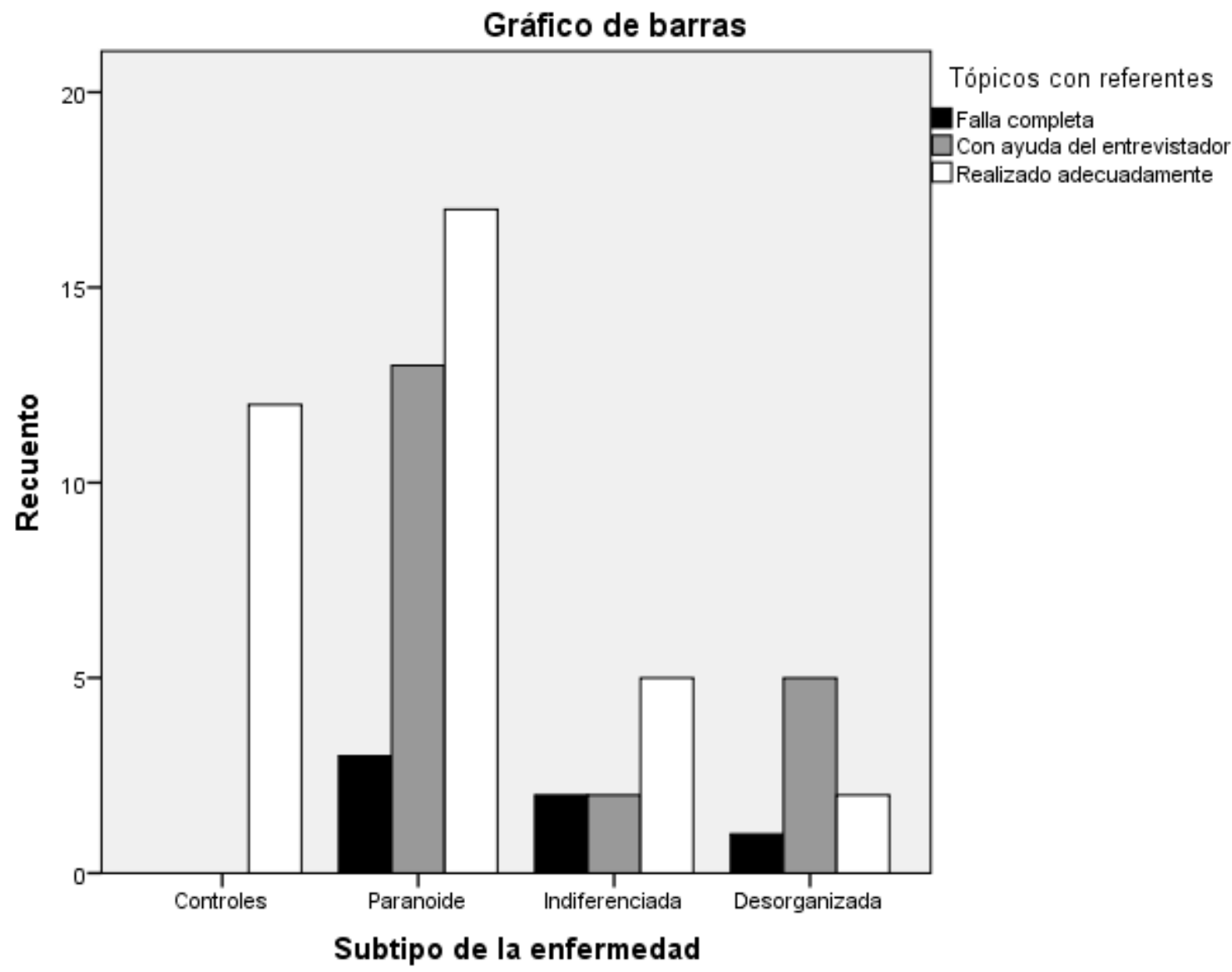




\subsubsection{Salto topical}

Ya referimos arriba la noción de tópico y cuáles son sus características para ser enunciado con un desarrollo que permita la inclusión de información nueva en la conversación de forma eficiente. Existen algunos recursos que permiten realizar adecuados cambios de tópicos en el discurso, tales como, los marcadores discursivos que cumplen funciones introductorias o de alternancia o de digresión, etc. En general, recurrimos a ellos cuando nos interesa hacer notar algún tópico diferente al tratado, ya sea por falta de interés, o por desconocimiento, o por necesidades informativas o porque nos parece un tema incómodo, etc. Se toca aquí un punto fundamental en la eficacia comunicativa, puesto que los saltos topicales o temáticos atentarían contra la progresión temática, que estaría entendida como la vinculación entre los temas de las proposiciones, como el elemento que asegura la continuidad, la estabilidad discursiva, base de la coherencia, requerida para una interacción eficiente. Tanto Halliday como Van Dijk, declaran como un proceso semántico-léxico el rol que cumple la progresión temática, además, ambos autores consideran que la progresión proporciona una red de jerarquizaciones, que develan las prioridades semántico-pragmáticas desplegadas por el hablante.

En el estudio de este indicador, comprobamos que también presenta menoscabo en los crónicos, que son los que presentan mayor menoscabo en este grupo. La presencia de este fenómeno, no fue masiva en los crónicos, pero si presentó en este grupo el mayor índice de errores.

\subsubsection{Ejemplos}

1) Ejemplo del grupo de crónicos, realizado adecuadamente:

5. E: ¿usted está hospitalizado acá? 
6. S: si

7. E: $¿$ Y antes de eso?/ de estar hospitalizado/<pausa>/ ¿no estaba en nada?

8. S: hacía pesas

9. $\quad$ E: ¿de manera profesional o<pausa $>$ ?/

10. S: claro <enfático>

11. E: ¿por qué está acá hospitalizado?

12. S: por una obsesión/<pausa $>/$ obse/<pausa $>/$ obse/<pausa $>/$ obsesión con mis bíceps

13. E: ¿con sus bíceps?

14. S: si

15. E: ¿me podría hablar de esta obsesión?

16. S:Lo que pasa es que/<pausa $>/$ eeh $/\langle$ pausa oralizada $>/$ me obsesioné tanto con los bíceps que $/\langle$ pausa $>/$ veía que trabajaba mucho $/ /\langle$ pausa $>/$ y no tenía nada de $/\langle$ pausa $>/$ eh/<pausa $>/$ de resultado/ así es que/ le dije a mi mamá si me podía hospitalizar/ para ver si podía seguir una rutina de ejercicios/ dentro del recinto/ pero estoy viendo que no tienen pesas $/<$ pausa $>/$ no hay nada de eso/ por lo tanto se/<pausa $>/$ fue algo como/ un impulso medio infantil lo que pensé $/\langle$ pausa $>/$ pero/ $/$ pausa $>/$ eeh $/\langle$ pausa oralizada $>/$ ahora estoy más consciente y más claro.

17. E: ¿de qué estás más consciente y más claro?

18. S: de que voy a tener que seguir la rutina de ejercicios como corresponde en mi caso.

19. E: ¿qué es lo que esperaba usted de sus bíceps que no logró?

20. S: tenerlos más inflados/ más hinchados/<pausa $>/$ con anabólicos o con esteroides

21. E: ¿usted usaba eso?

22. $\mathrm{S}: \mathrm{eh} /<$ pausa $>/ \mathrm{si} /$ pero no los inyectables.

23. E: ¿qué tomaba?

24. S: No me acuerdo el nombre de las pastillas// pero eran anabólicos

25. E: $\mathrm{Y} /\langle$ pausa $>/$ ¿para qué tenía que tener más grande los bíceps?

26. S: Por satisfacción mía.

\section{2) Ejemplo del grupo de crónicos, con ayuda del entrevistador:}

5. E: ¿qué te pasó J?

6. S: <entonación de pregunta> ¿pasó algo malo?

7. E: $\mathrm{no} / \mathrm{no} / \mathrm{no} /$, ¿qué por qué estás aquí en RENOVAL?

8. S: nada/ lo que pasó es que soy incapaz de ser <pausa>/ responsable <alargamiento> de terminar las cosas que hago/y <alargamiento $>/$ me cuesta ser responsable y me cuesta <alargamiento>/ llevar a cabo lo q <palabra cortada>/ de concentrarme también/ lo que sea/ lo hago

9. E: la pregunta es/<pausa $>/$ ¿cuál?

10. S: ¿cuál?

11. E: ¿qué te pregunté?

12. S: usted preguntó por qué estaba infeliz

13. E: no/ no/ no te pregunté por qué estás infeliz/ te pregunté ¿por qué estás en RENOVAL/ por qué?

14. S: si/ eso dije

15. E: es que no te entendí

16. S:lo que dije<pausa $>/$ es necesario que la gente escuche bien $<$ pausa $>/$ ehm $<$ pausa $>/$ vengo aquí porque no soy capaz de trabajar <pausa $>/$ no soy $\mathrm{mmm} / \mathrm{me}$ cuesta llevar las cosas <alargamiento>/ terminadas o a cabo <pausa>/ y bien/ y no soy tan responsable <pausa ext $>/$ me cuesta mucho por ejemplo cocinar/ aunque encuentre divertido eso/ o lavar los 
platos/ o en el trabajo/ aunque sea ficticio/ que es lo que más me gusta/ no lo termino/ no lo hago por completo/ me cuesta mucho eso.

\section{3) Ejemplo del grupo de crónicos, falla completa:}

16. E: cuéntenos un poco acerca de la milicia/ ¿en qué consiste eso de la milicia?

17. S: consiste en ir pa' allá y hacerse el soberbonante y hacerse la chiconaniquetante/ consihte mi vida en ser insistentene/ porque yo no veo televisión y nunca he vihto la televisión/ <pausa>/ ahora ehtoy viendo programah regrabadohy el cable no se desgrava/ no se desgravaba/<pausa $>$ / ni se se desgrobosoba/ se pasteliban/<pausa $>$ y mi robo[t] la aplastó pa' que se haga la luh y la electricidad// tengo doh roboh ahora $\langle$ pausa $>/$ que tengo que alimentar<pausa $>/$ entonceh vinieron unah familiah del cementerio<pausa $>/ /$ primero/ vinieron unoh a pedir préstamoh $\langle$ pausa $>/$ préstamoh que querían $\langle$ pausa $>/$ despuéh vinieron otroh del cementerio/ a vender floreh ahí/ y anteriormente ahí/ vendían cadina/ un neoprén que yo<pausa>/ me<pausa>/ sin molestar a nadien// máh allá en San Bernardo/ había una ferretería de gie-espet/ y aquí en bonanza/ había una ferretería milpren/ y de allá de otro lugar me llegó otro neoprén/ y con ese neoprén estuve averiguando unah cosah que son loh detalleh pa' salir//<pausa $>$ / no exihte la ehpa[d]a del augurio/ esoh son perroh loh tengo que alimentar// lo que dije significa: <cita>/ "tengo que solventarme"/ ya que nadie me solventa/ y tengo que solventar a mih mascotah/ mih mascotah no me van a protegerme nunca/ entonceh aca[b]o de alimentar a mih mascotah/y ahora tengo que congelarlah a to[d]ah.

\section{1) Ejemplo del grupo de Primer episodio, realizado adecuadamente:}

1. E: ¿cuál es tu nombre?

2. $\mathrm{S}: \mathrm{H}$

3. $\mathrm{E}: \iota \mathrm{H}$ ?

4. S: H.

5. E: ¿y el apellido?

6. S: G.

7. E: ¿Qué edad tienes?

8. S: diecisiete añoh.

9. E: diecisiete<pausa>/ don $\mathrm{H}$ yo soy la doctora $\mathrm{L}$ y los que estamos aquí/ queremos conversar un ratito contigo/¿ya?

10. S: ya

11. E: ¿cuéntame porque estás aquí hoy?

12. S: por una posible esquizofrenia

13. E: ya/ ¿eso te dijeron?

14. S: si

15. E: ya <pausa $>/$ ¿por qué crees que estás aquí? Eso es un<pausa $>/$ un diagnóstico médico<pausa $>/$ ¿cierto?

16. S:por lo mismo

17. E: ¿tú crees que estás aquí por eso?

18. S: si

19. E: ¿qué significa tener eso?

20. S:eh

21. E: ¿cómo lo ha vivido?

22. S: eh, no sé, yo encuentro que lo he vivido diferente a otras personas que han tenido 
esquizofrenia.

23. E: ya

24. S: de eso puedo estar seguro un poco.

25. E: ya

26. S: de eso puedo estar seguro.

27. E: ya ¿Cómo lo ha vivido?

28. S: $\mathrm{mmm}<$ pausa oralizada / es difícil en<pausa $>$ / explicar/ como lo he vivido/ he sentido muchas cosas pero no $<$ pausa $>/$ no $<$ pausa $>/$ no es como muy explicable.

29. E: nosotros vamos a hacer un esfuerzo en entenderlo.

30. S: ya.

31. E: ya<pausa $>/$ con sus palabras si me puede relatar que es lo que ha pasado en este último tiempo.

32. S: $\mathrm{mmm}<$ pausa oralizada $>$ ¿¿a ver? < pausa > El frío que sentía <pausa>/ eso es lo más $<$ pausa $>/$ que sentía en los pulmones y en el estómago.

33. E: ¿frío?

34. S: si

35. E: en los pulmones y en el estómago

36. S: si.

37. E: ya ¿así empezó?

38. S: $\mathrm{mmm}<$ pausa oralizada $>/$ no/ así no empezó es que <pausa $>/$ ¿a ver? dicen que se le llama esquizofrenia/ pero yo no estoy seguro de eso.

39. E: ya/ olvidémonos del nombre/ ¿qué es lo que ha sentido usted?

40. S: es el nombre de la enfermedad, yo creo pero no estoy seguro de que sea así.

41. E: ya

\section{2) Ejemplo del grupo de Primer episodio, realizado con ayuda del entrevistador:}

81. E: $\mathrm{R} /<$ pausa $>/$ ¿nos da un ejemplo de cuando se sintió perseguido por algo?

82. S: Eh yo más bien, cuando fui $<$ pausa $>/$ no perdón $<$ pausa $>/$ haber hace como tres años atrás más o menos<pausa $>/$ tres años atráh como que empezó todo esto<pausa $>/$ ¿me entiende?/<pausa $>/$ como que empezó todo este proceso<pausa $>/$ toda esta patología / ¿me entiende?/ toda esta, esta forma de, este paradigma $<$ pausa $>/$ porque eso es un paradigma/ ¿me entiende?/como un modelo de, si no porque uno comienza a ver la vida dehde ehte punto de vista/ ¿me entiende?// dehde esta forma/ ¿me entiende?/ uno empieza a<pausa $>$ / a ver las cosah desde otra perspectiva/ ¿me entiende?/ a tomar como ejemplo otras cosah, se vuelve máh sensible/ máh del corazón/ ¿me entiende?/<pausa>/

83. E: ¿Que sintió en ese momento cuando salió a la calle?/ ¿qué era lo distinto que usted veía?

84. S: Eh lo distinto era que la gente de repente no me miraba/ como que la gente de repente me despreciaba/ como que la gente de repente me hacía vacío/ como que la gente se apartó de mí/ en cierta forma como que la gente ahora ya no estaba conmigo/ ya no me valoraba por lo que era si no que más bien veía lo que soy<pausa>/ como yo me presentaba frente al mundo/ eh como/ como yo tengo entendido que vivimos/ siento decirlo pero vivimos en una sociedad donde todos somos carnales<pausa $>$ ¿ ¿me entiende?/máh que espirituales $<$ pausa $>$ / entonceh/ por ejemplo que quiere decir que seamoh carnaleh $\langle$ pausa $>$ / primeramente yo donde voy miramoh el aspecto/ miramos la vehtimenta/ vemoh nuestro ahpecto físico/ vemos todo/ ¿me entiende?/ todo lo que/ y así vamos entrando/ así vamos compenetrando en esta sociedad/ ¿me entiende?/ vamoh ehcalando/ ehcalando<pausa>/ ehcalando/ hasta tener un nivel jerárquico en esta sociedad// ¿me entiende?/<pausa $>/$ y así un 
ejemplo/ yo me sentía mal/ ¿me entiende?/ me sentía mal porque yo trataba de ser espiritual/ ¿me entiende?/<pausa>/ yo trataba de ser máh/ máh de espíritu/ máh/ máh de adentro/ de sentimiento/ de la pasión/ no de lah emocioneh porque las emocioneh duran poco y son cortah en el tiempo<pausa>/ pero si un ejemplo del sentimiento<pausa>/ del amor/ de/ de las pasioneh/ de todas esah cosah que son desde el corazón / ¿me entiende?/ de lo interno / ¿me entiende?/<pausa $>/$ de lo que no eh tangible/ ¿me entiende?/de lo que no se ve<pausa $>/$ de aquello que no es permisible.

\section{1) Ejemplo del grupo de controles, realizado adecuadamente:}

45.E: perfecto // bueno / tú me contabas al inicio de esta entrevista que / que trabajas en un consultorio público // eh <alargamiento/> ¿cuál es tu opinión respecto al plan auge? / cómo lo ves tú en tu área/ o en general de la salud pública

46. I: o sea en general creo que es una buena / es una buena idea / pero más en el papel que en la realidad / por lo menos en el sistema público / desconozco como funcionará en el sistema priva[d]o // eh <alargamiento/> / ahora siento que también / en la medida que funcione como se escribió / eh <alargamiento/> es / es bueno pero / pero no funciona tan así poh / porque tiene hartas restricciones / o sea en el fondo el plan auge es / es que las personas tienen ciertas garantías pero / esas garantías se dan / cuando se cumplen una serie de criterios / entonces al final / igual se excluye ene ${ }^{64}$ gente / entonces eh / y los plazos no se cumplen / y en el fondo la gente igual tiene que esperar / es un poco disfrazar / un poco lo mismo que había antes siento yo / si/ en la práctica siento yo

47.E. y en lo particular / en tu consultorio/ tú / tú ves que la salud en general de <alargamiento/>del país digamos / pública // eh <alargamiento/> ha ido mejorando con los años que tu llevas trabajando / o tú sientes que es lo mismo / que es pésima / o que es una salud entre comillas de buena calidad

48. I: <silencio/> o sea yo creo que ha ido mejorando / si/ <ruido = "de silla"/> por ejemplo si yo lo veo en mi área / en el área de salud mental / yo siento que ha ido mejorando y ha mejorado mucho // en el / así como en lo general yo creo que también ha mejorado / no podría decir así específicamente en qué / pero yo creo que también ha mejorado / pero es que las condiciones son tan <alargamiento/>/ penca porque no sé / o sea cómo uno no entiende que un médico atienda siete pacientes por hora <ruido_fondo > de silla </ruido_fondo $>/$ o sea / no hay una buena atención / no puede haber una atención / y no es porque el médico sea malo sino que como atendís a alguien en tan poco rato / o solamente podíh atenderlos porque le duele la uña / pero si le duele la uña y el pelo / no el pelo tiene que volver a pedir otra hora / porque al médico no le alcanza el tiempo en el fondo

49. E: c[1]aro

50. I: entonces / y ahí es donde se va produciendo el atochamiento de gente / y la gente siente/ siente que <ruido = "de silla"/> no le resuelven sus problemas cuando lo necesitan / entonceh yo creo que es un tema de recursos y del sistema

51.E: más que nada de recursoh

52. I: si / porque yo creo que en términos profesionaleh / hay buenos profesionaleh /sí

64 ene $=$ mucha 


\subsubsection{Salto topical y estadio de la enfermedad}

Este resultó ser un indicador muy significativo ya que muestra en la elaboración de aspectos más complejos y estratégicos de la estructura discursiva, la que demanda un manejo conciente de las asociaciones semántico-pragmáticas. Los controles presentaron 10 casos de realización adecuada, con un 27,8\% y 2 casos realizados con ayuda del entrevistador, con un 11,8\%. Los de primer episodio presentaron 15 casos de realización adecuada, con un 41,7\% y 10 casos realizados con ayuda del entrevistador. Los crónicos presentaron 11 caos realizados adecuamente, un 30,6\%; 5 caos drealizados con ayuda del entrevistador, con un $29,4 \%$ y 9 caos de falla completa, con un $100 \%$.

Tabla de contingencia 137: salto topical y estadio de la enfermedad.

\begin{tabular}{||l|r|r|r|r|}
\hline \hline \multirow{2}{*}{$\begin{array}{l}\text { Estadio de la } \\
\text { enfermedad }\end{array}$} & \multicolumn{3}{|c|}{ Salto topical } & \multirow{2}{*}{ Total } \\
\cline { 2 - 5 } & \multicolumn{1}{|c|}{$\begin{array}{c}\text { Falla } \\
\text { completa }\end{array}$} & $\begin{array}{c}\text { Con ayuda del } \\
\text { entrevistador }\end{array}$ & $\begin{array}{c}\text { Realizado } \\
\text { adecuadamente }\end{array}$ & 12 \\
\hline \multirow{2}{*}{ Controles } & 0 & 2 & 10 & $19,4 \%$ \\
\cline { 2 - 5 } & $0,0 \%$ & $11,8 \%$ & $27,8 \%$ & 25 \\
\hline Primer episodio & $0,0 \%$ & 10 & 15 & $40,3 \%$ \\
\cline { 2 - 5 } & $100,0 \%$ & $58,8 \%$ & $11,7 \%$ & 25 \\
\cline { 2 - 5 } Crónicos & 9 & $29,4 \%$ & $30,6 \%$ & $60,3 \%$ \\
\hline Total & $100,0 \%$ & 17 & 36 & $100,0 \%$ \\
\cline { 2 - 5 } & & $100,0 \%$ & $100,0 \%$ & \\
\hline
\end{tabular}

El valor de chi cuadrado es de $17,958^{\mathrm{a}}$ y dio como resultado, (>p, 001>), significativo estadísticamente. 
Tabla valor de chi cuadrado 138: salto topical y estadio de la enfermedad.

\begin{tabular}{||l|c|r|c||}
\hline \multicolumn{4}{|c|}{ Pruebas de chi-cuadrado } \\
\hline & Valor & $\mathrm{gl}$ & $\begin{array}{c}\text { Sig. asintótica } \\
\text { (bilateral) }\end{array}$ \\
\hline Chi-cuadrado de Pearson & $17,958^{\mathrm{a}}$ & 4 &, 001 \\
\hline
\end{tabular}

Gráfico 101 Porcentaje de frecuencia de las variables: salto topical y estadio de la enfermedad

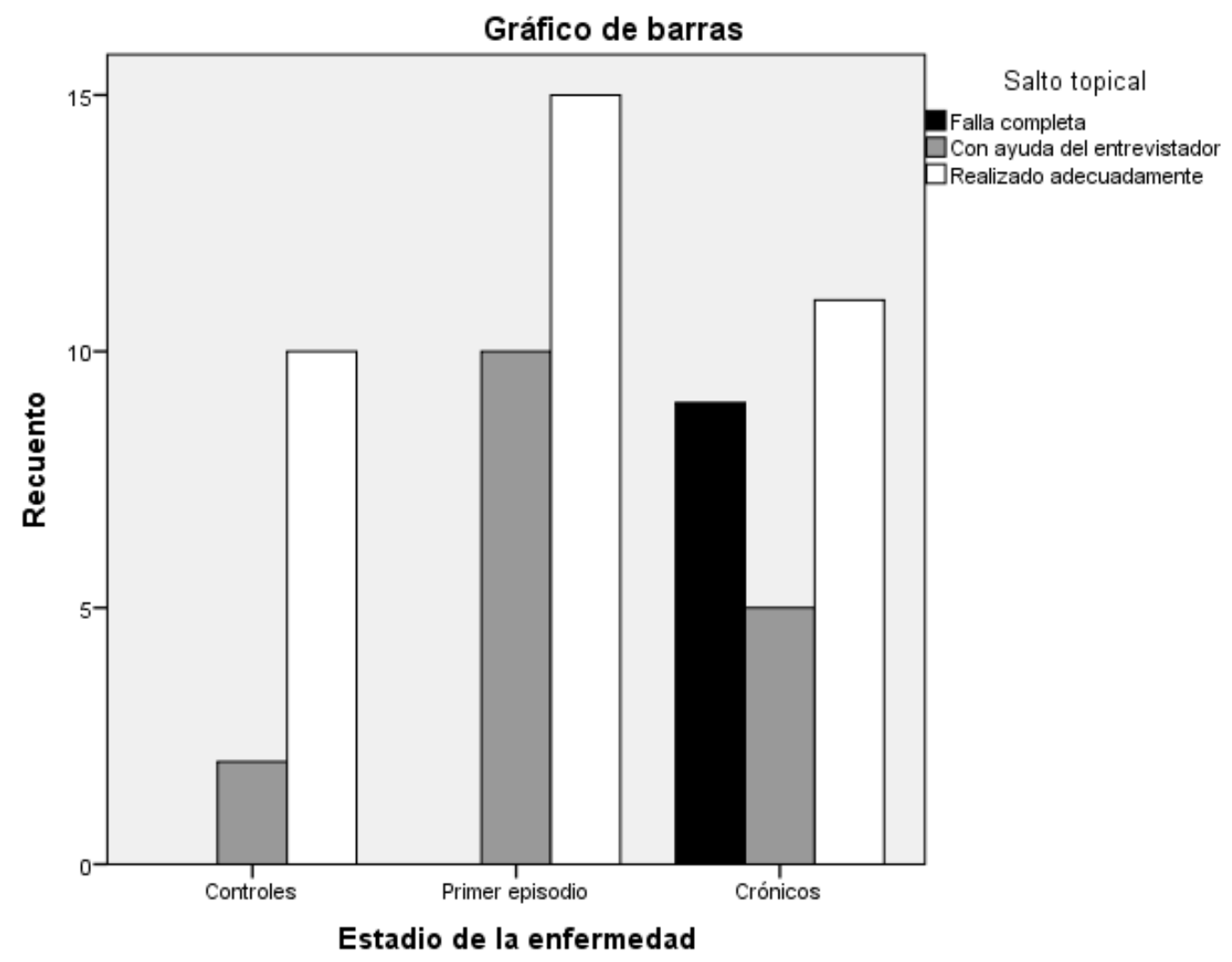




\subsubsection{Salto topical y sexo}

Entre las mujeres encontramos 20 casos de realización adecuada, con un 55,6\% ; 7 casos realizados con ayuda del entrevistador, con un $41,2 \%$ y 2 casos de falla completa, con un 22,2\%. Los hombres presentaron 16 casos realizados adecuadamente, con un 44,4\%; 10 casos realizados con ayuda del entrevistador con un $58,8 \%$ y 7 casos de falla completa, con un $77,8 \%$.

Tabla de contingencia 139: salto topical y sexo.

\begin{tabular}{|c|c|c|c|c|}
\hline \multirow[t]{2}{*}{ Sexo de los sujetos } & \multicolumn{3}{|c|}{ Salto topical } & \multirow[t]{2}{*}{ Total } \\
\hline & Falla completa & $\begin{array}{l}\text { Con ayuda del } \\
\text { entrevistador }\end{array}$ & $\begin{array}{c}\text { Realizado } \\
\text { adecuadamente }\end{array}$ & \\
\hline \multirow{2}{*}{ Mujer } & 2 & 7 & 20 & 29 \\
\hline & $22,2 \%$ & $41,2 \%$ & $55,6 \%$ & $46,8 \%$ \\
\hline \multirow[t]{2}{*}{ Hombre } & 7 & 10 & 16 & 33 \\
\hline & $77,8 \%$ & $58,8 \%$ & $44,4 \%$ & $53,2 \%$ \\
\hline \multirow[t]{2}{*}{ Total } & 9 & 17 & 36 & 62 \\
\hline & $100,0 \%$ & $100,0 \%$ & $100,0 \%$ & $100,0 \%$ \\
\hline
\end{tabular}

El valor de chi cuadrado es de 3,508 y dio como resultado ( $>$ p, 173>), no significativo estadísticamente.

Tabla valor de chi cuadrado 140: salto topical y sexo.

\begin{tabular}{||c|c|c|c||}
\hline \multicolumn{4}{|c||}{ Pruebas de chi-cuadrado } \\
\hline & Valor & $\mathrm{gl}$ & $\begin{array}{c}\text { Sig. asintótica } \\
\text { (bilateral) }\end{array}$ \\
\hline Chi-cuadrado de Pearson & $3,508^{\mathrm{a}}$ & 2 &, 173 \\
\hline
\end{tabular}


Gráfico 102. Porcentaje de frecuencia de las variables: salto topical y sexo

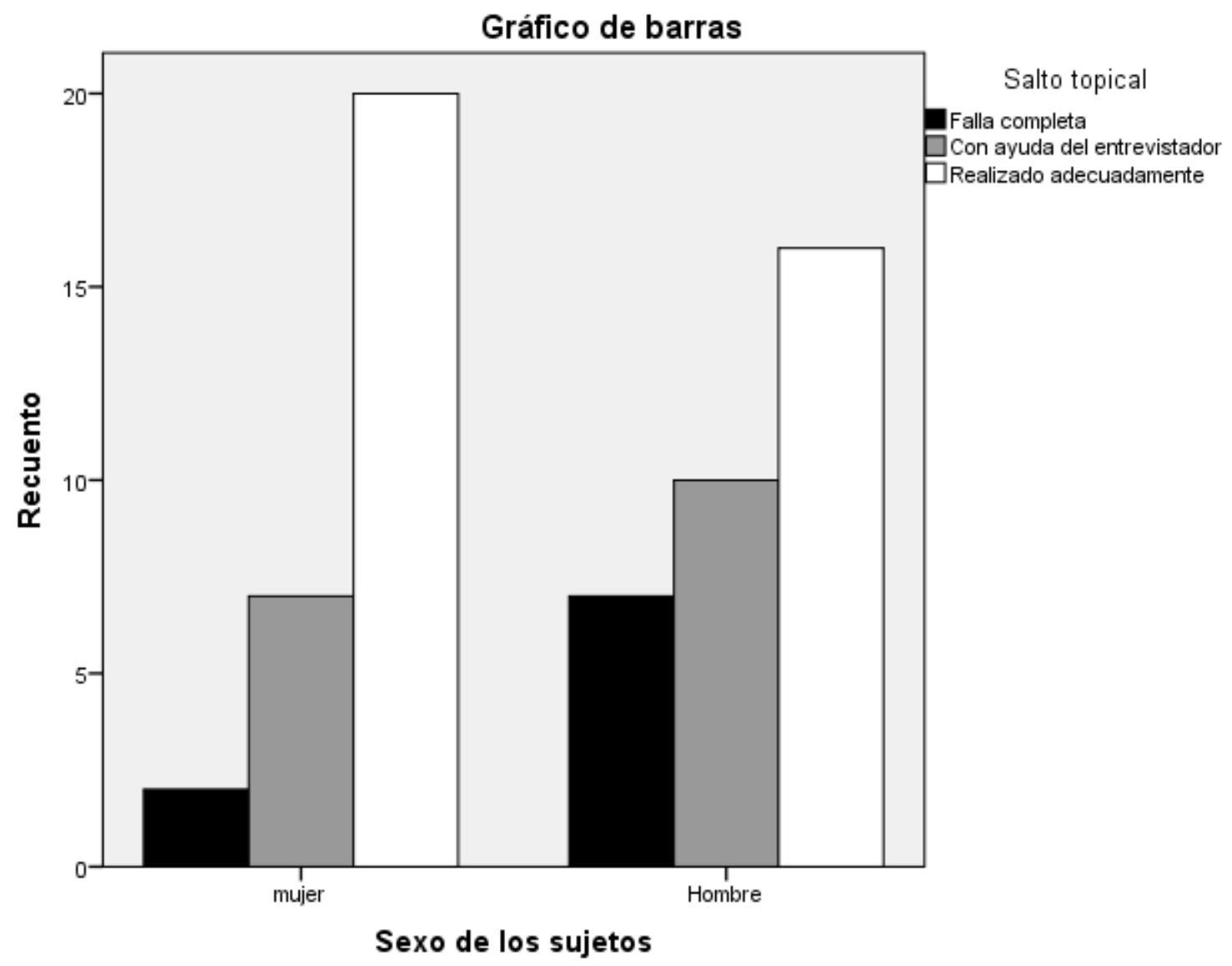

4.4.5.4. Salto topical y tramo de la enfermedad

Este indicador resultó significativo. Podemos observar que los controles presentaron 10 casos de realización adecuada con un 27,8\% del indicador, y 2 casos realizados con ayuda del entrevistador, con un 11,8\%, medidas similares encontramos en los de primer episodio de $>0$ a $<2$ años, presentaron 10 casos de realización adecuada, que corresponden a un 27,8\%; 4 casos de realización con ayuda del entrevistador, que corresponden a un $23,5 \%$ y no presentaron casos de falla completa. 
En el grupo de primer episodio de $>2$ a $>3$ años, encontramos 5 casos realizados adecuadamente, con un 13,9\%; 6 casos realizados con ayuda del entrevistador, que corresponden a un 35,3\%; y no encontramos casos de falla completa. En el grupo de crónicos de hasta 5 años, observamos 5 casos de realización adecuada, con un 13,9\%; 3 casos realizados con ayuda del entrevistador, que corresponden a un 17,6\% y 2 casos de falla completa, que corresponden a un 22,2\%. Finalmente los crónicos de 5 años y más presentaron 6 casos de realización adecuada, con un 16,7\%; 2 caos realizados con ayuda del entrevistador, que correponden a un $11,8 \%$ y 7 casos de falla completa, correspondientes a un $77,8 \%$.

Este indicador muestra con bastante claridad que pueden diferenciarse este tipo de estructuras entre los grupos estudiados, pues la complejidad que implica la mantención de un tópico y el desarrollo de éste requiere el despliegue de mecanismos de planificación discursiva específicos, tales como la selección de los elementos de cohesión, las reglas de progresión para añadir información nueva o reforzar alguna idea que se haya planteado de forma superficial, por mencionar algunos de ellos. Por otra parte, la complejidad misma del desarrollo topical, que no fue estudiada aquí, no llama la atención sobre las capacidades de abstracción de los sujetos participantes. Incluso entre los más jóvenes encontramos algunas diferencias interesantes. Un ejemplo de esto es la complejidad de las narraciones referidas por unos y otros hablantes de este estudio. Entre los controles encontramos narración de historias que cumplen con la totalidad de la estructura canónica propuesta por Lyon (1997) o Labov y Waletzky (1967), en cambio entre los hablantes con esquizofrenia, la narración de historias evidentemente contiene menos recursos narrativos canónicos. 
Tabla de contingencia 141. salto topical y tramo de la enfermedad.

\begin{tabular}{|c|c|c|c|c|}
\hline \multirow[t]{2}{*}{ Tramo de la enfermedad } & \multicolumn{3}{|c|}{ Salto topical } & \multirow[t]{2}{*}{ Total } \\
\hline & $\begin{array}{c}\text { Falla } \\
\text { completa }\end{array}$ & $\begin{array}{l}\text { Con ayuda del } \\
\text { entrevistador }\end{array}$ & $\begin{array}{c}\text { Realizado } \\
\text { adecuadamente }\end{array}$ & \\
\hline \multirow[t]{2}{*}{ Controles } & 0 & 2 & 10 & 12 \\
\hline & $0,0 \%$ & $11,8 \%$ & $27,8 \%$ & $19,4 \%$ \\
\hline \multirow[t]{2}{*}{ Primer episodio de 0 a 2 años } & 0 & 4 & 10 & 14 \\
\hline & $0,0 \%$ & $23,5 \%$ & $27,8 \%$ & $22,6 \%$ \\
\hline \multirow[t]{2}{*}{ Primer episodio de 2 a 3 años } & 0 & 6 & 5 & 11 \\
\hline & $0,0 \%$ & $35,3 \%$ & $13,9 \%$ & $17,7 \%$ \\
\hline \multirow[t]{2}{*}{ Crónicos hasta 5 años } & 2 & 3 & 5 & 10 \\
\hline & $22,2 \%$ & $17,6 \%$ & $13,9 \%$ & $16,1 \%$ \\
\hline \multirow[t]{2}{*}{ Crónicos 5 años y más } & 7 & 2 & 6 & 15 \\
\hline & $77,8 \%$ & $11,8 \%$ & $16,7 \%$ & $24,2 \%$ \\
\hline \multirow[t]{2}{*}{ Total } & 9 & 17 & 36 & 62 \\
\hline & $100,0 \%$ & $100,0 \%$ & $100,0 \%$ & $100,0 \%$ \\
\hline
\end{tabular}

El valor de chi cuadrado es de $23,840^{\mathrm{a}}$ y dio como resultado $\left.(<\mathrm{p}, 00,2\rangle\right)$, significativo estadísticamente.

Tabla valor de chi cuadrado 142: salto topical y tramo de la enfermedad.

\begin{tabular}{||c|c|c|c||}
\hline \multicolumn{4}{|c||}{ Pruebas de chi-cuadrado } \\
\hline & Valor & Gl & $\begin{array}{c}\text { Sig. asintótica } \\
\text { (bilateral) }\end{array}$ \\
\hline Chi-cuadrado de Pearson & $23,840^{\mathrm{a}}$ & 8 &, 002 \\
\hline
\end{tabular}


Gráfico 103. Porcentaje de frecuencia de las variables: salto topical y tramo de la enfermedad

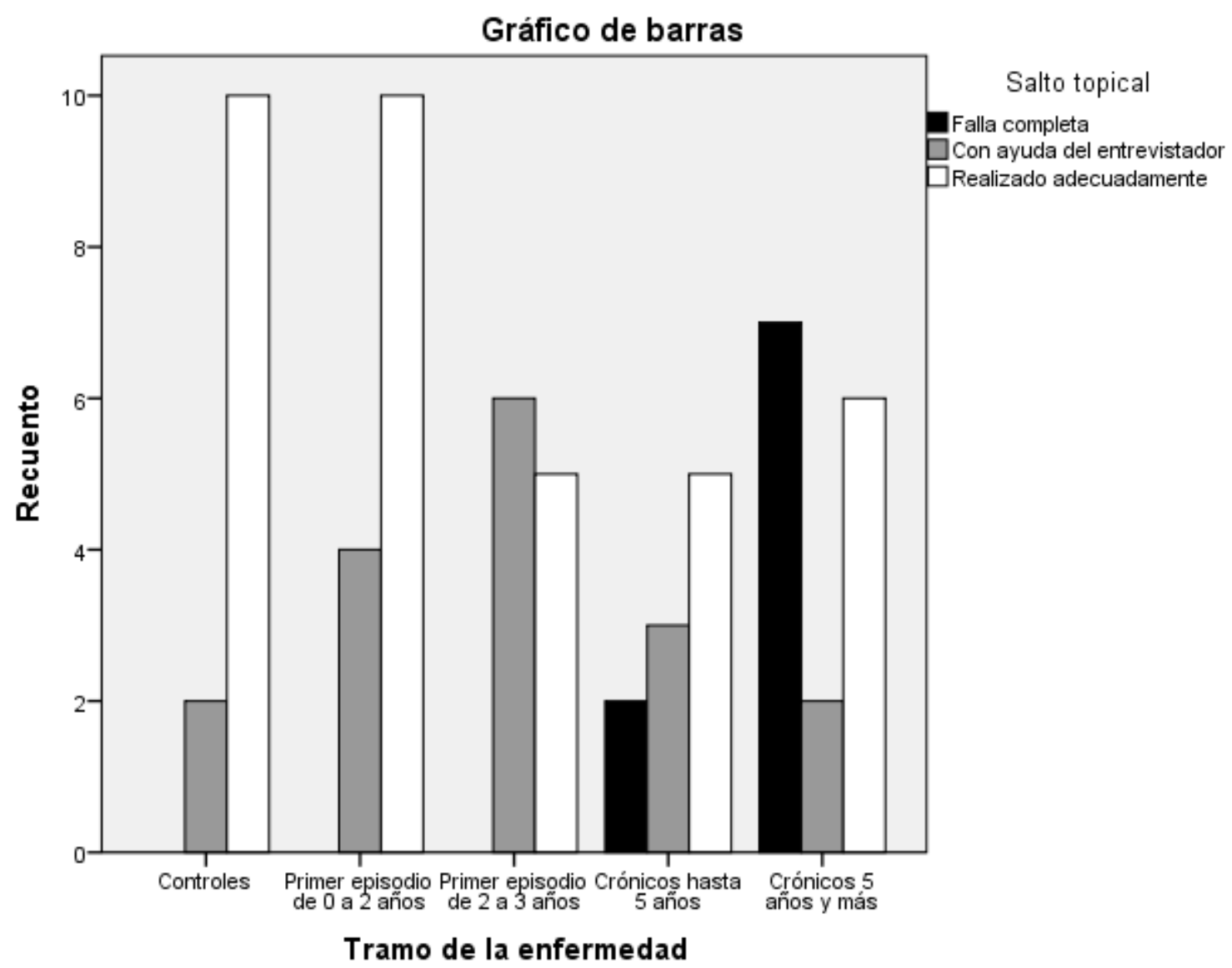

\subsubsection{Salto topical y subtipo de la enfermedad}

En este indicador no encontramos resultados significativos, podemos observar que los controles presentaron 10 casos de realización adecuada con un $27,8 \%$ del indicador, y 2 casos realizados con ayuda del entrevistador, con un 11,8\%. A su vez, encontramos 15 casos de realización adecuada entre los paranoides, que corresponden a un 41, 7\%; 13 casos de realización con ayuda del entrevistador, que representan un 
$76,5 \%$ del indicador y 5 casos de falla completa, que representan un 55,6\%. En el grupo de la esquizofrenia indiferenciada, tenemos 7 casos de realización adecuada, que representan un 19,4\%; 1 caso de realización con ayuda del entrevistador, que representa un 5,9\% y 1 caso de falla completa, que representa un $11,1 \%$. Por último el grupo de esquizofrenia desorganizada presentó 4 casos del criterio realizado adecuadamente, que representan un 11,1\%; 1 caso realizado con ayuda del entrevistador, que representa un 5,9\% y 3 casos de falla completa, que representan un $33,3 \%$.

Tabla de contingencia 143: salto topical y subtipo de la enfermedad.

\begin{tabular}{|c|c|c|c|c|}
\hline \multirow{2}{*}{$\begin{array}{l}\text { Subtipo de la } \\
\text { enfermedad }\end{array}$} & \multicolumn{3}{|l|}{ Salto topical } & \multirow[t]{2}{*}{ Total } \\
\hline & Falla completa & $\begin{array}{l}\text { Con ayuda del } \\
\text { entrevistador }\end{array}$ & $\begin{array}{l}\text { Realizado } \\
\text { adecuadamente }\end{array}$ & \\
\hline \multirow{2}{*}{ Controles } & 0 & 2 & 10 & 12 \\
\hline & $0,0 \%$ & $11,8 \%$ & $27,8 \%$ & $19,4 \%$ \\
\hline \multirow[t]{2}{*}{ Paranoide } & 5 & 13 & 15 & 33 \\
\hline & $55,6 \%$ & $76,5 \%$ & $41,7 \%$ & $53,2 \%$ \\
\hline \multirow[t]{2}{*}{ Indiferenciada } & 1 & 1 & 7 & 9 \\
\hline & $11,1 \%$ & $5,9 \%$ & $19,4 \%$ & $14,5 \%$ \\
\hline \multirow[t]{2}{*}{ Desorganizada } & 3 & 1 & 4 & 8 \\
\hline & $33,3 \%$ & $5,9 \%$ & $11,1 \%$ & $12,9 \%$ \\
\hline \multirow[t]{2}{*}{ Total } & 9 & 17 & 36 & 62 \\
\hline & $100,0 \%$ & $100,0 \%$ & $100,0 \%$ & $100,0 \%$ \\
\hline
\end{tabular}

El valor de chi cuadrado es de $11,404^{\mathrm{a}}$ que da como resultado $(\mathrm{p}<0,77>)$ 
Tabla valor de chi cuadrado 144: salto topical y subtipo de la enfermedad.

\begin{tabular}{||l|c|r|r||}
\hline \multicolumn{5}{|c||}{ Pruebas de chi-cuadrado } \\
\hline & Valor & $\mathrm{gl}$ & $\begin{array}{c}\text { Sig. asintótica } \\
\text { (bilateral) }\end{array}$ \\
\hline Chi-cuadrado de Pearson & $11,404^{\mathrm{a}}$ & 6 &, 077 \\
\hline
\end{tabular}

Gráfico 104. Porcentaje de frecuencia de las variables: salto topical y subtipo de la enfermedad

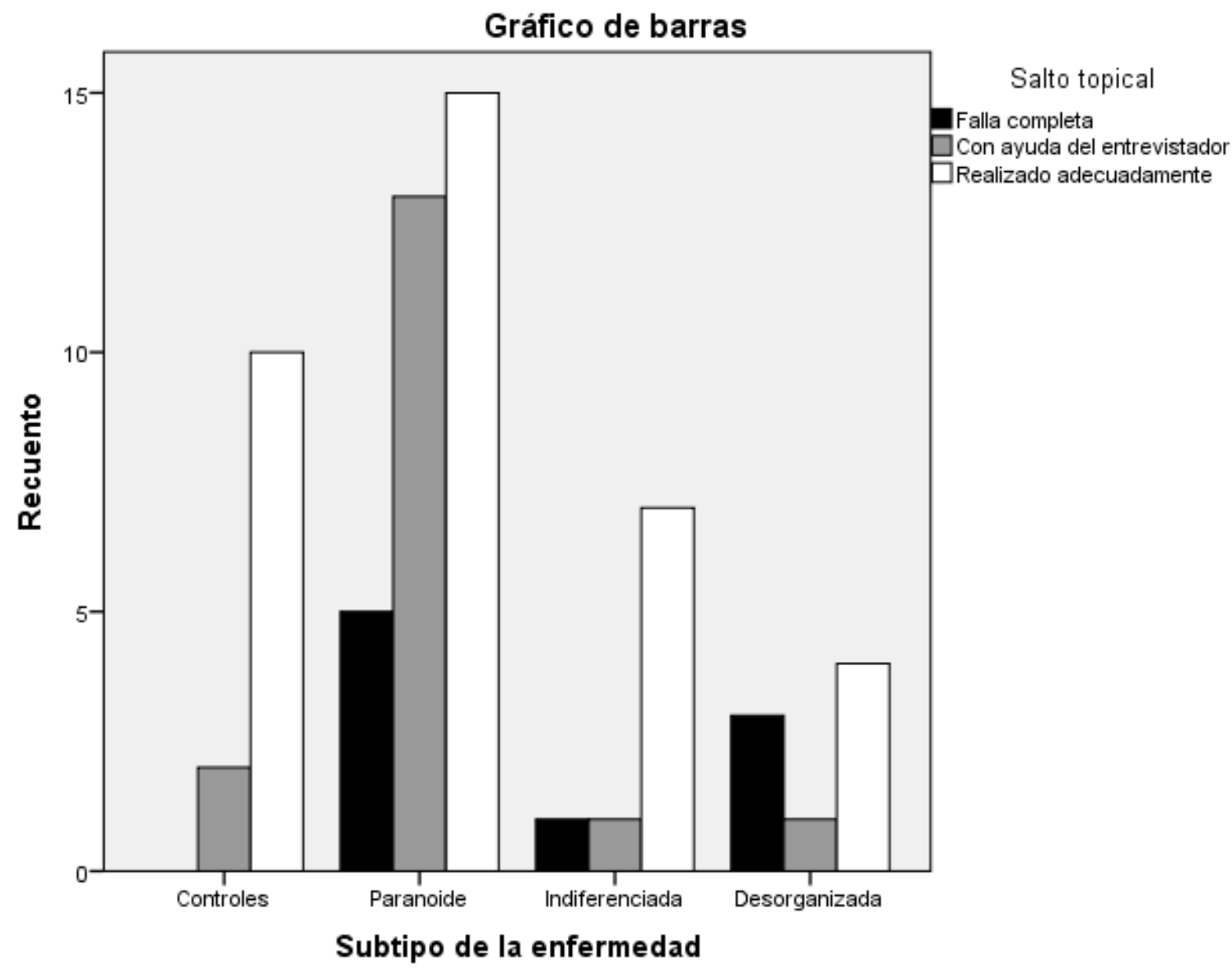




\subsubsection{Interacción entre referentes y vínculos referenciales}

La interacción es de carácter semántico, léxico y gramatical; consiste en efectuar una constante actualización del referente a través de los vínculos referenciales. Los mecanismos empleados son diversos dependiendo, entre otras cosas, de la capacidad del hablante para mantener la atención del interlocutor en función de sus objetivos discursivos.

Si la distancia que se da entre los vínculos referenciales es muy extensa, el interlocutor debe realizar un mayor esfuerzo para relacionarlos. Ya que en el cluster de Fluidez, evaluamos el promedio de vínculos que ostentan los participantes, nos interesa ahora comprobar si la relación entre estas estructuras es adecuada o no lo es, o bien, se realiza con ayuda del entrevistador:

\subsubsection{Ejemplos:}

1) Ejemplos del grupo de crónicos, realizado adecuadamente:

61. E: otra pregunta/<pausa>/ ¿usted en el colegio qué notas tenia más o menos?

62. S: <pausa $>/$ cincos.

63. E: $i \mathrm{y} /<$ pausa $>/$ estudiaba poco?/ o le costaba estudiar? <pausa $>/$ ¿, por eso tenía ' cincos'?

64. S: no/<pausa $>/$ estudiaba poco/<pausa $>/$ o sea $/\langle$ pausa $>/$ no es que antes $/\langle$ pausa $>/$ en la básica me iba bien en el colegio/<pausa $>$ en,/ en,/ en la básica,/ <pausa $>/$ antes de llegar a octavo básico/<pausa $>$.

65. E: ya./ <pausa>/

66. S: eh,/ <pausa $>/$ he $/<$ pausa $>/$ ahí me iba bien en el colegio/<pausa $>$ y después en $/\langle$ pausa $>/$ en/ $<$ pausa $>/$ en la enseñanza media no $/\langle$ pausa $>/$ no quise estudiar mucho,/ <pausa $>$ entonces baje las notas/<pausa $>/$ pero no era porque me costaba /si no porque no quería.

67. E: <pausa>/ ¿y amigas tenía antes?

68. S: no/ no / tenia amigas.

69. E: ¿desde chica que no tenía amigas?/ <pausa>/ o ¿en algún momento dejó de tener amigas?/ <pausa>/ ¿ en la básica?

70. S: es que siempre me costó tener amigas.

71. E: ¿Por qué?

72. S: no seé/<pausa>/ parece que era tímida,/no sé. 
73. E: ¿no le gustaba a usted la gente?

74. S: no/ a la gente no le gustaba yo/ después/ en la enseñanza media,/ enseñanza media tampoco tenía amigos.

75. E: ya/<pausa>/ entiendo.

(CRE-M08)

2) Ejemplos del grupo de crónicos, realizado con ayuda del entrevistador:

17. S: Si, pero no me acuerdo de <pausa $>/$ me acuerdo de pocas cosas que no<pausa ext $>/$ caí como una pantalla <pausa>/ vi gente muerta y <pausa>/ me asustaba/ y de ahí/ no me acuerdo qué pasó/ en un hospital al que iba yo/ hace 8 años.

18. E: Hace tiempo// ¿No le ha vuelto a pasar algo similar?/ ¿cómo es esto de la pantalla?

19. S: qué es como una luz así/ <señala con ambas manos $>/$ que me $<$ pausa $>/$ se ve una $<$ pausa $>$ / se ve una foto $\mathrm{y} /<$ pausa $>$ / eh $<$ pausa $>$ / uno ve lo que está ocurriendo// no quiero acordarme de eso porque me da mala onda/ me da cosa acordarme de lo que me pasó hace 8 años.

20. E: ¿qué le produce?

21. S: insatisfacción y <pausa $>$ miedo.

(CRE-H08)

39. E: ¿Qué/ qué síntomas?/ ¿qué molestias tuviste que estás aquí ahora?

40. S: ah/ ya yo te cuento/ voy hacerte como un resumen rápido/ bueno resulta que<pausa>/ eh<pausa>/ ia ver?// haciendo un resumen de todo lo que pasó en la casa// no es que yo sentía como voces/ como que habla/ no cacho mucho/ pero digamos<pausa $>/ /$ un día de repente me puse a ver televisión y vi que la televisión me saluda/ "ihola televisión!”/ y como que me conversaba con la televisión/ gesticulaba con la televisión/ con las personas de la televisión/y dije/ "me pareció bien" una forma de/ de cómo de ver el mundo/ porque yo te digo/ la televisión a todos nos sirve/ ¿cierto?/ yo dije/ "quizás la televisión sea como una ventana para/ para ver el mundo"/ por la televisión.

41. E: ¿O sea tú dices que la gente de la televisión te estaba hablando a ti?

42. S: Me hablaban/ y se habla todos los días cuando estaba en mi casa y <pausa > y eso (CRE-H03)

\section{3) Ejemplo del grupo de crónico, falla completa:}

47. E: ¿Y cómo fue que usted llegó acá al hospital de día? / <pausa>/ ¿por qué esta acá ahora?

48. S: No sé poh.

49. E: Más o menos/ <pausa $>/$ ¿tiene alguna idea?.

50. S: / <pausa>/ la doctora del consultorio de San Joaquín me mandó para acá / <pausa>/que me mejorara mejor aquí.

51. E: Ya. ¿Y a usted que le estaba pasando que estaba haciendo antes de estar acá?

52. S: Hay no me acuerdo.

53. E: Trate de recordarse, para tener alguna idea. 
54. S: a ver/ <pausa >/ no hallo por donde empezar /<risas de la paciente>/ él rompe cabezas/ <pausa>/ no se coman las uñitas // <pausa>/yo me las comía/ <pausa>/ ahora tengo que limarlas por falta de money/ <pausa $>$ / no me las puedo arreglar/ <pausa $>$ / pero me gustan bien escobilláh.

55. E: Pero señora $\mathrm{P} /<$ pausa $>/$ trate de acordarse por qué llegó acá.

56. S: No sé/ <pausa $>/ /<$ risas de la paciente $>/$

57. E: ¿Qué es lo que usted le habrá contado a la doctora del consultorio / que la mandó para acá?

58. S: No sé/<risas de la paciente $>/$ mi hermana se dio cuenta.

59. E: ¿de qué? / <pausa / ¿Y le habrá contado a usted?

60. S: A la doctora/ <pausa >/ y la doctora se dio cuenta que me estaban dando crisis

61. E: ¿le estaba dando una crisis?

62. S: mi hermana.

(CRE-M04)

1. Ejemplo del grupo de primer episodio, realizado adecuadamente:

121. E:ya, / <pausa $>$ ¿cuándo fue esto que lo hospitalizaron?, / <pausa $>$ ¿ ihace cuánto tiempo? / <pausa>/

122. S: del viernes que me tienen aquí.

123. E:ya / <pausa> ¿ ¿esta es la primera vez que usted está hospitalizado?

124. S:si

125. E:¿ha tomado medicamentos por/ <pausa>/

126. S:si

127. E: ¿y por qué motivo ha tomado medicamentos?\}

128. S: por la misma depresión

129. E: ya / <pausa>/ ¿de cuándo?

130. S:el 2010 estaba tomando/ <pausa > los dejé/ <pausa > y ahora me los dio la psiquiatra.

131. E: durante ese período en que usted estaba tomando medicamentos/ <pausa $>/$ ¿escuchaba alguna cosa que no escucharan los demás?

132. S:si

133. E:¿qué escuchaba? / <pausa>/ ¿una voz?

134. S:una voz pequeñita

135. E: ¿y / <pausa>/ la escuchaba dentro o fuera de su cabeza?

136. S: dentro de su cabeza.

137. E: dentro de su cabeza.

138. S:si.

139. E: ¿y/ <pausa>/ de quién podría ser esta voz por ejemplo?

140. S: eco

141. E: ¿era una voz? ¿o eran varias voces al mismo tiempo?

142. S: era un eco, / <pausa $>$ / pero de varias voces

143. E: un eco, / <pausa >/ con varias voces

144. S:si

145. E:pero / <pausa>/ era de ¿hombre,/mujer/ de niño/ <pausa>/ ?

146. S: de todo tipo.

(PEE-H14) 
64. S: yo no quiero algo así,/ yo quiero algo como / <pausa > .yo no quiero enseñar lenguaje/ quiero enseñar literatura,/ de hecho / <pausa $>/$ al principio yo quería trabajar en un lugar como RENOVAL

65. E: ya

66. S: para enseñarle a los niños/ a la gente/ a desahogarse mediante la literatura

67. E: ya

68. S: cómo esto nos puede ayudar en la vida/ porque lo otro de escribir o leer / es fantástico

69. E: $\mathrm{mmm}$

70. S: y eso/ en un café literario también/ ahora estoy buscando pega/ para hacer algo por mi vida/ porque el próximo año quiero irme a Inglaterra a estudiar inglés/ trabajar y cosas así

71. E: ¿y te irías sola a Inglaterra?

72. S: si

73. E: ya

74. S:pero me iría como por un mes/ porque igual soy súper casera/ me gusta estar en la casa/ cerca de mi familia

75. E:mmm / <pausa > ya / como $i$ para ir a recorrer? qué se yo / <pausa >

76. S:claro/ para hablar inglés con gente que es nativa del idioma

77. $\mathrm{E}: \mathrm{mmm}$

78. S: y recorrer también/ y pasarlo bien/ una buena experiencia para mi

79. E:muy buena,/ claro que sí/ es la única manera de aprender en muchos sentidos

80. S: $\mathrm{mmm}$

(PEE-M11)

2. Ejemplo del grupo de primer episodio, realizado con ayuda del entrevistador:

38 E: pero/ cuénteme/ ¿usted ha sentido algo extraño?/ ¿diferente?/¿qué le llame la atención?

39 S: no me llama/<pausa $>/$

40 E: no/<pausa $>/$ si hay algo que le pase a usted/ que sea fuera de lo común.

41 S: no quiero escuchar

42 E: ¿qué no quiere escuchar?

43 S: me llama

44 E: ¿quién?

45 S: recuerdo a veces

46 E: pero $/<$ pausa $>/$ ¿hay algo que le ocurra fuera de lo normal?

47 S: no

48 E: ¿y qué es lo que no quiere escuchar?/¿quién lo llama?

49 S: hombres y mujeres

$50 \quad$ E: $¿$ a usted lo llaman?

51 S: $\mathrm{mmm}$

52 E: ¿cómo?/ ¿usted escucha que lo llaman?

53 S: los escucho

$54 \quad$ E: ¿son voces de personas?/¿de hombres y mujeres?

55 S: si

$56 \quad$ E: ¿usted oye voces de personas?

57 S: si, los escucho 
58 E: cuénteme/ <pausa>/ ¿cómo es eso?/¿cuándo fue la primera vez que escuchó esas voces?

59 S: eh $/<$ pausa extensa $>/$

$60 \quad$ E: ¿Fue en su pieza/ en el living/ en el patio?

$61 \mathrm{~S}: \mathrm{Si}$, recuerdo en la calle me acuerdo, es que no me recuerdo el primer día doctor.

62 E: Ya pero usted escuchó voces

63 S. si/ si escuché/ escucho desde tiempo atrás.

64 E. ¿y cómo fueron las primeras veces que le pasó?

65 S: En la calle/ en la calle.

66 E: $¿$ En la calle?

67 S: Si/ en la calle.

68 E: ¿Qué le paso ahí en la calle?

69 S: Nada/ empecé a escuchar/ decía: "te vamos a matar" $/<$ pausa $>/$ una cosa así.

70 E: ¿escuchó voces que le decían a usted?

71 S: si

72 E: ¿Y dónde estaba usted? / $<$ pausa $>/$ ¿iba andando/ estaba parado/estaba solo/ con amigos?

73 S: Estaba parado solo/ no si/ cuando estoy solo/ es cuando más me/<pausa exensa>/

74 E: ¿Estaba solo y que pasó ahí?

$75 \mathrm{~S}:$ Eh $/\langle$ pausa $>/$ nada yo nada me preocupe $/\langle$ pausa $>/$ me descoloque/ $/$ pausa $>/$ ¿me entiende? $/<$ pausa $>/$ me descoloqué.

$76 \quad$ E: $i \mathrm{Y} /<$ pausa $>/$ de donde venían esas voces?

77 S: No sé vienen de afuera/ $/$ pausa $>/$ un ejemplo del ambiente/ $/$ pausa $\rangle /$ digo yo/<pausa $>/$ el ambiente.

78 E: pero $/$ ¿son de alguien real esas voces?

79 S. ambiente.

80 E: ¿son del ambiente que lo rodea?

$81 \quad$ S: no/<pausa $>/$

82 E: ¿a qué se refiere con ambiente?

83 S: las voces/<pausa $>$ me imagino como del ambiente.

84 E: pero/<pausa $>/$ ¿son reales o las imagina?

85 S: no/ si las oí/<pausa $>/$

86 E: $\mathrm{Y}$ cuando le pasó eso/<pausa $>/$ i usted miro para alrededor?

87 S: Claro/ y no era nadie/<pausa >/ no era nadie.

88 E: ¿De dónde se suponía que venían esas voces?

89 S: No sabría decirle de donde venían.

$90 \quad$ E: ¿Y eran voces/<pausa $>/$ que voces eran?

91 S: Voces de mujer y de hombre.

92 E: ¿De mujer y de hombre?

93 S: Claro.

\section{Ejemplo del grupo de primer episodio, falla completa:}

E: ya, cuéntame una cosa $\mid\langle$ pausa $>/$ ¿qué dificultades has tenido? $/\langle$ pausa $>/$ ¿tú estabas en tratamiento con un médico? / pausa $>/$ ¿cierto?

122 S:si

123 E: ¿por qué? $/<$ pausa $>/$ ¿qué te pasaba?

124 S: eeeeso/<pausa $>/$

125 E: ¿qué te pasaba? / $/$ pausa $>/$ ¿eso qué?

126 S: del dr. Rodríguez 
127

128

129

130.

E: ¿qué médico es?//<pausa>/¿por qué causa te atendía?

S: psiquiatra

E: ya/<pausa $>/$ pero antes habías estado con la dra/<pausa $>/$

$\mathrm{S}:$ ¡ah! / pausa $>/$ eso/<pausa $>/$ no/ pero eso era para verme/<pausa $>/$ para verme $/\langle$ pausa $>/$ cómo estaba $/\langle$ pausa $>/$ to $/\langle$ pausa esxtensa $\rangle /$ cada tres meses $/\langle$ pausa $>/$ porque $\mathrm{yo} /\langle$ pausa $>/$ la primera vez que fui con la Muriel $/\langle$ pausa $\rangle /$ porque estaba como flaco $/\langle$ pausa $\rangle /$ porque no quería comer/ $<$ pausa $>/$ porque me decían al comienzo que estaba como gordo y no quería comer/ pausa $>/$ estaba un poquito pasado/<pausa $>/$ entonces yo adelgacé harto/<pausa $>/$ y quedé como de la parte flaca/ $/$ pausa $>/$ entonces $/<$ pausa $>/$ quería comer poco $/\langle$ pausa $>/$ entonces fui con la nutricionista $/\langle$ pausa $>/$ y entonces empecé $/\langle$ pausa $>/$ yyyymmm//<pausa $>/$ me dijo que fuera con la psicóloga $/<$ pausa $>$ /yyyyy la/<pausa $>/$ la Muriel/<pausa $>/$ ahí hablamos/<pausa $>/$ y me dijo que comiera más/<pausa $>/$ y todo eso/<pausa $>/$ yyyy comí $\mathrm{mmmm} /<$ pausa $>/$ más y ahora estoy como normal $/<$ pausa $>/$.

131. E: pero/<pausa $>/$ ¿quién es la Muriel? /<pausa $/ /$ la nutricionista? / pausa $\rangle /$

132. S: no/ me dijo que comiera más.

133. E: ¿quién?

134. S: la Muriel

135. E: ¿Qué es/<pausa>/?

136. S: porque estaba como flaco.

137. E: pero/<pausa>/¿quién es la Muriel?

138. S: hace tiempo.

139. $\mathrm{E}: /<$ pausa $>/ \mathrm{mmm} /<$ pausa $>/$ ¿pero hace cuánto fue eso?

130. S:hace como/ $<$ pausa $>/$ fue hace tiempo

131. E: ¿cuánto tiempo?/<pausa $>/$ un año/ dos años?

132. S: hace como dos años/<pausa $>/$ y desde ahí $v /<$ pausa $>/$ toca cada tres meses $/\langle$ pausa $\rangle /$ va/ voy/<pausa $>/$ como para ver cualquier problema que tenga/ $<$ pausa $>/$ para ver/<pausa $>$ /para solucionarlo/<pausa $>/$ no sé// Pero la primera vez que fui con la Muriel/<pausa $>/$ fue por eso.

133. E: ya

4.4.6.2. Interacción entre referentes y vínculos referenciales y estadio de la enfermedad

$\mathrm{n}$

El indicador Interacción entre referentes y vínculos referenciales, arrojó resultados significativos ofreciendo los siguientes datos; todos los controles presentaron una realización adecuada, que corresponde al $40 \%$ del total. Los de primer episodio presentaron 13 casos de realización adecuada, que representan un 43,3\%; 6 casos de realizació con ayuda del entrevistador, que representan un 42,9\% y 6 casos de 
falla completa, que representan un 33,3\%. Los crónicos en cambio, presentaron 5 caos realizados adecuadamente, con un 16,7\% del indicador; 8 casos de realización con ayuda del entrevistador, que representan un $57,1 \%$ y 12 casos de falla completa, con un $66,7 \%$ del indicador.

Tabla de contingencia 145: interacción entre referentes y vínculos y estadio de la enfermedad.

\begin{tabular}{||l|l|l|l|l||}
\hline \hline \multirow{2}{*}{$\begin{array}{l}\text { Estadio de la } \\
\text { enfermedad }\end{array}$} & \multicolumn{2}{|c|}{ Interacción entre referentes y vínculos } & \multirow{2}{*}{ Total } \\
\cline { 2 - 5 } & Falla completa & $\begin{array}{l}\text { Con ayuda del } \\
\text { entrevistador }\end{array}$ & $\begin{array}{l}\text { Realizado } \\
\text { adecuadamente }\end{array}$ & \multirow{2}{*}{} \\
\hline \multirow{2}{*}{ Controles } & 0 & 0 & 12 & 12 \\
\hline \multirow{2}{*}{ Primer episodio } & $0,0 \%$ & $0,0 \%$ & $40,0 \%$ & $19,4 \%$ \\
\hline \multirow{2}{*}{ Crónicos } & 6 & 6 & 13 & 25 \\
\cline { 2 - 5 } & $33,3 \%$ & $42,9 \%$ & $43,3 \%$ & $40,3 \%$ \\
\hline \multirow{2}{*}{ Total } & 12 & 8 & 5 & 25 \\
\cline { 2 - 5 } & $66,7 \%$ & $57,1 \%$ & $16,7 \%$ & $40,3 \%$ \\
\hline \hline
\end{tabular}

El valor de chi cuadrado es de 21,352a , que da como resultado $(<\mathrm{p}, 000>)$, significativo estadísticamente.

Tabla valor de chi cuadrado146: interacción entre referentes y vínculos y estadio de la enfermedad.

\begin{tabular}{||l|c|r|c||}
\hline \multicolumn{4}{|c||}{ Pruebas de chi-cuadrado } \\
\hline & Valor & $\mathrm{gl}$ & $\begin{array}{c}\text { Sig. asintótica } \\
\text { (bilateral) }\end{array}$ \\
\hline Chi-cuadrado de Pearson & $21,352^{\mathrm{a}}$ & 4 &, 000 \\
\hline
\end{tabular}


Gráfico 105. Porcentaje de frecuencia de las variables: interacción entre referentes y vínculos referenciales y estadio de la enfermedad

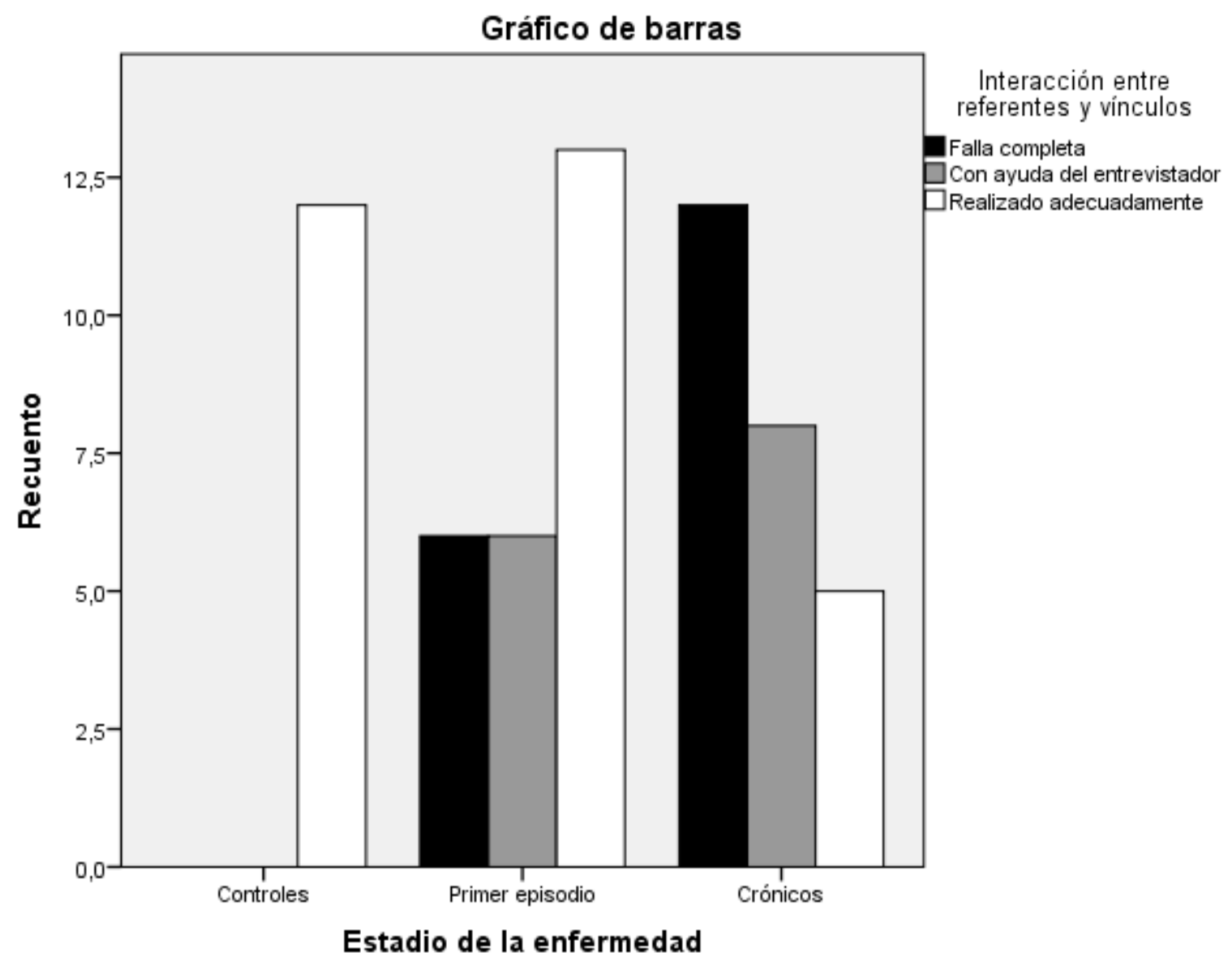

4.4.6.3. Interacción entre referentes y vínculos referenciales y sexo

Las diferencias entre hombres y mujeres, no son significativas en este indicador; entre las mujeres encontramos 14 casos de realización adecuada, que representan un 46,7\%; 8 casos de realización con ayuda del entrevistador, con un 57,1\% y 7 casos de falla completa, con un 38,9\%. Entre los hombres, tenemos 16 casos de realización 
adecuada, con un 53,3\%; 6 casos de realización con ayuda del entrevistador, con $42,9 \%$ y 11 casos de falla completa con un $61,1 \%$ del indicador.

Tabla de contingencia 147: interacción entre referentes y vínculos y sexo.

\begin{tabular}{||l|l|l|l|l||}
\hline \multirow{2}{*}{ Sexo de los sujetos } & \multicolumn{2}{|l||}{ Interacción entre referentes y vínculos } & \multirow{2}{*}{ Total } \\
\cline { 2 - 5 } & Falla completa & $\begin{array}{l}\text { Con ayuda del } \\
\text { entrevistador }\end{array}$ & $\begin{array}{l}\text { Realizado } \\
\text { adecuadamente }\end{array}$ & \\
\hline \multirow{2}{*}{ Mujer } & 7 & 8 & 14 & 29 \\
\cline { 2 - 5 } & $38,9 \%$ & $57,1 \%$ & $46,7 \%$ & $46,8 \%$ \\
\hline \multirow{2}{*}{ Hombre } & 11 & 6 & 16 & 33 \\
\cline { 2 - 5 } & $61,1 \%$ & $42,9 \%$ & $53,3 \%$ & $53,2 \%$ \\
\hline \multirow{2}{*}{ Total } & 18 & 14 & 30 & 62 \\
\cline { 2 - 5 } & $100,0 \%$ & $100,0 \%$ & $100,0 \%$ & $100,0 \%$ \\
\hline
\end{tabular}

El valor de chi cuadrado es de $1,054^{\mathrm{a}}$, que dio como resultado no significativo estadísticamente $(<\mathrm{p}, 590>)$

Tabla valor de chi cuadrado 148: interacción entre referentes y vínculos y sexo.

\begin{tabular}{||l|c|r|r||}
\hline \multicolumn{4}{|c||}{ Pruebas de chi-cuadrado } \\
\hline & Valor & $\mathrm{gl}$ & $\begin{array}{c}\text { Sig. asintótica } \\
\text { (bilateral) }\end{array}$ \\
\hline Chi-cuadrado de Pearson & $1,054^{\mathrm{a}}$ & 2 &, 590 \\
\hline
\end{tabular}


Gráfico 106. Porcentaje de frecuencia de las variables: interacción entre referentes y vínculos referenciales y sexo

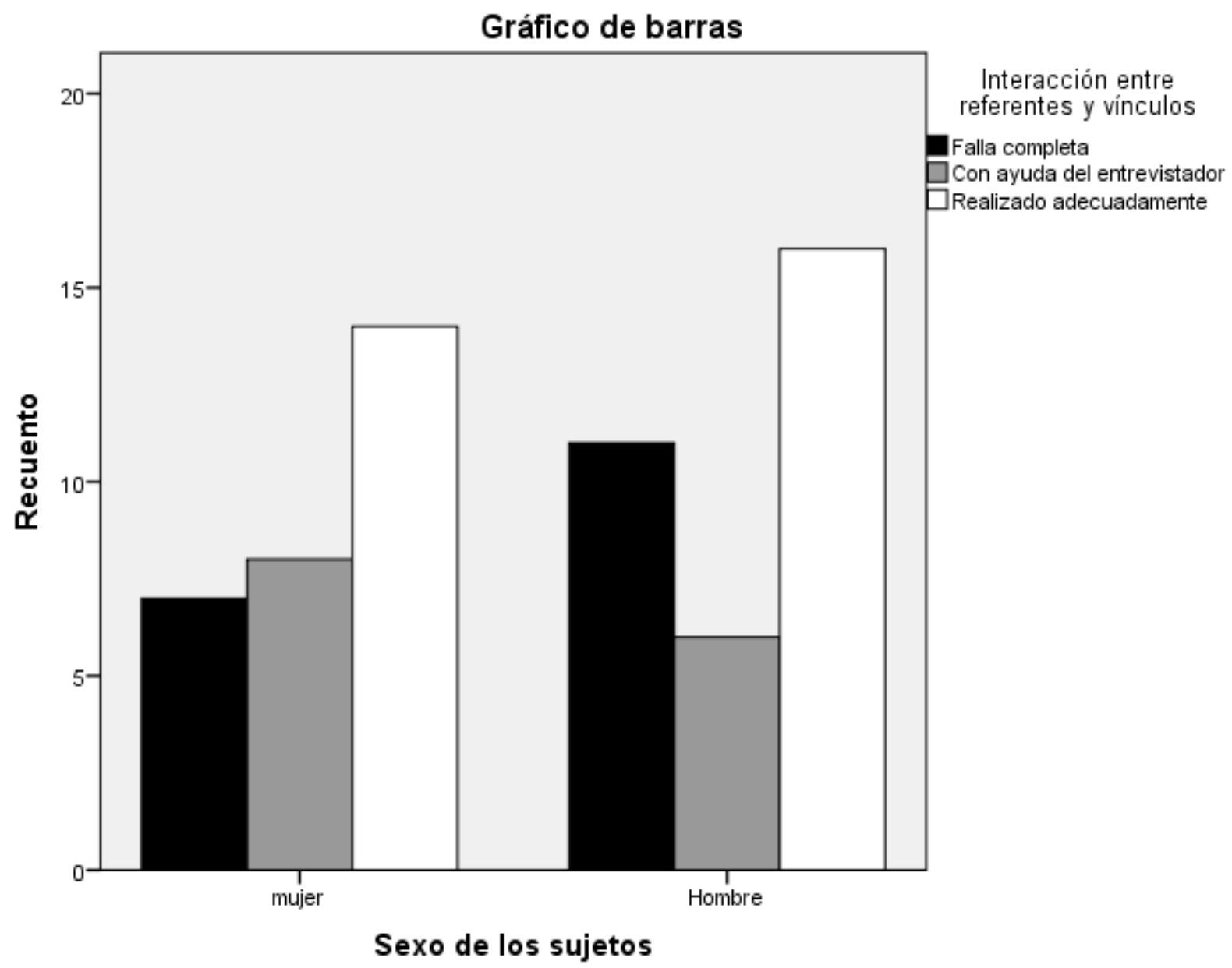

4.4.6.4. Interacción entre referentes y vínculos referenciales y tramo de la enfermedad

Al igual que el estadio de la enfermedad, el indicador tramo de la enfermedad, también resultó significativo. Entre los controles solo se registran casos de realización adecuada, que representan un $40 \%$ del indicador. En el grupo de primer episodio de $>0$ a $<2$ años presenta 9 casos de realizado adecuadamente, con un 30\%; 3 casos de 
realización con ayuda del entrevistador, con un $21,4 \%$ y 2 casos de falla completa, con un $11,1 \%$. En el grupo de primer episodio de $>2$ a $<3$ años, encontramos 4 casos de realización adecuada, con 13,3\%; realizado con ayuda del entrevistador, tenemos 3 casos, que corresponden a un $21,4 \%$ y 4 casos de falla completa, con un $22,2 \%$. En el grupo de los crónicos de hasta 5 años encontramos 2 casos de realización adecuada, con un $6,7 \% ; 4$ casos de realización con ayuda, con un 28,6\% y 4 casos de falla completa, con un 22,2\%. Finalmente el grupo de crónicos de 5 años y más, encontramos 3 casos realizados adecuadamente, con un 10\%; 4 casos realizados con ayuda del entrevistador, que representan un $28,6 \%$ y 8 casos de falla completa que representan un $44,4 \%$.

Tabla de contingencia 149: interacción entre referentes y vínculos y tramo de la enfermedad.

\begin{tabular}{|c|c|c|c|c|}
\hline \multirow[t]{2}{*}{ Tramo de la enfermedad } & \multicolumn{3}{|c|}{ Interacción entre referentes y vínculos } & \multirow[t]{2}{*}{ Total } \\
\hline & $\begin{array}{c}\text { Falla } \\
\text { completa }\end{array}$ & $\begin{array}{c}\text { Con ayuda } \\
\text { del } \\
\text { entrevistador }\end{array}$ & $\begin{array}{c}\text { Realizado } \\
\text { adecuadamente }\end{array}$ & \\
\hline \multirow[t]{2}{*}{ Controles } & 0 & 0 & 12 & 12 \\
\hline & $0,0 \%$ & $0,0 \%$ & $40,0 \%$ & $19,4 \%$ \\
\hline \multirow[t]{2}{*}{ Primer episodio de 0 a 2 años } & 2 & 3 & 9 & 14 \\
\hline & $11,1 \%$ & $21,4 \%$ & $30,0 \%$ & $22,6 \%$ \\
\hline \multirow[t]{2}{*}{ Primer episodio de 2 a 3 años } & 4 & 3 & 4 & 11 \\
\hline & $22,2 \%$ & $21,4 \%$ & $13,3 \%$ & $17,7 \%$ \\
\hline \multirow[t]{2}{*}{ Crónicos hasta 5 años } & 4 & 4 & 2 & 10 \\
\hline & $22,2 \%$ & $28,6 \%$ & $6,7 \%$ & $16,1 \%$ \\
\hline \multirow[t]{2}{*}{ Crónicos 5 años y más } & 8 & 4 & 3 & 15 \\
\hline & $44,4 \%$ & $28,6 \%$ & $10,0 \%$ & $24,2 \%$ \\
\hline \multirow[t]{2}{*}{ Total } & 18 & 14 & 30 & 62 \\
\hline & $100,0 \%$ & $100,0 \%$ & $100,0 \%$ & $100,0 \%$ \\
\hline
\end{tabular}

El valor de chi cuadrado es de $24,311^{\mathrm{a}}$, que dio como resultado $(<\mathrm{p}, 002>)$, estadísticamente significativo. 
Tabla valor de chi cuadrado150: interacción entre referentes y vínculos y tramo de la enfermedad.

\begin{tabular}{||l|c|r|c||}
\hline \multicolumn{4}{|c||}{ Pruebas de chi-cuadrado } \\
\hline & Valor & $\mathrm{gl}$ & $\begin{array}{c}\text { Sig. asintótica } \\
\text { (bilateral) }\end{array}$ \\
\hline Chi-cuadrado de Pearson & $24,311^{\mathrm{a}}$ & 8 &, 002 \\
\hline
\end{tabular}

Gráfico 107. Porcentaje de frecuencia de las variables: interacción entre referentes y vínculos referenciales y tramo de la enfermedad

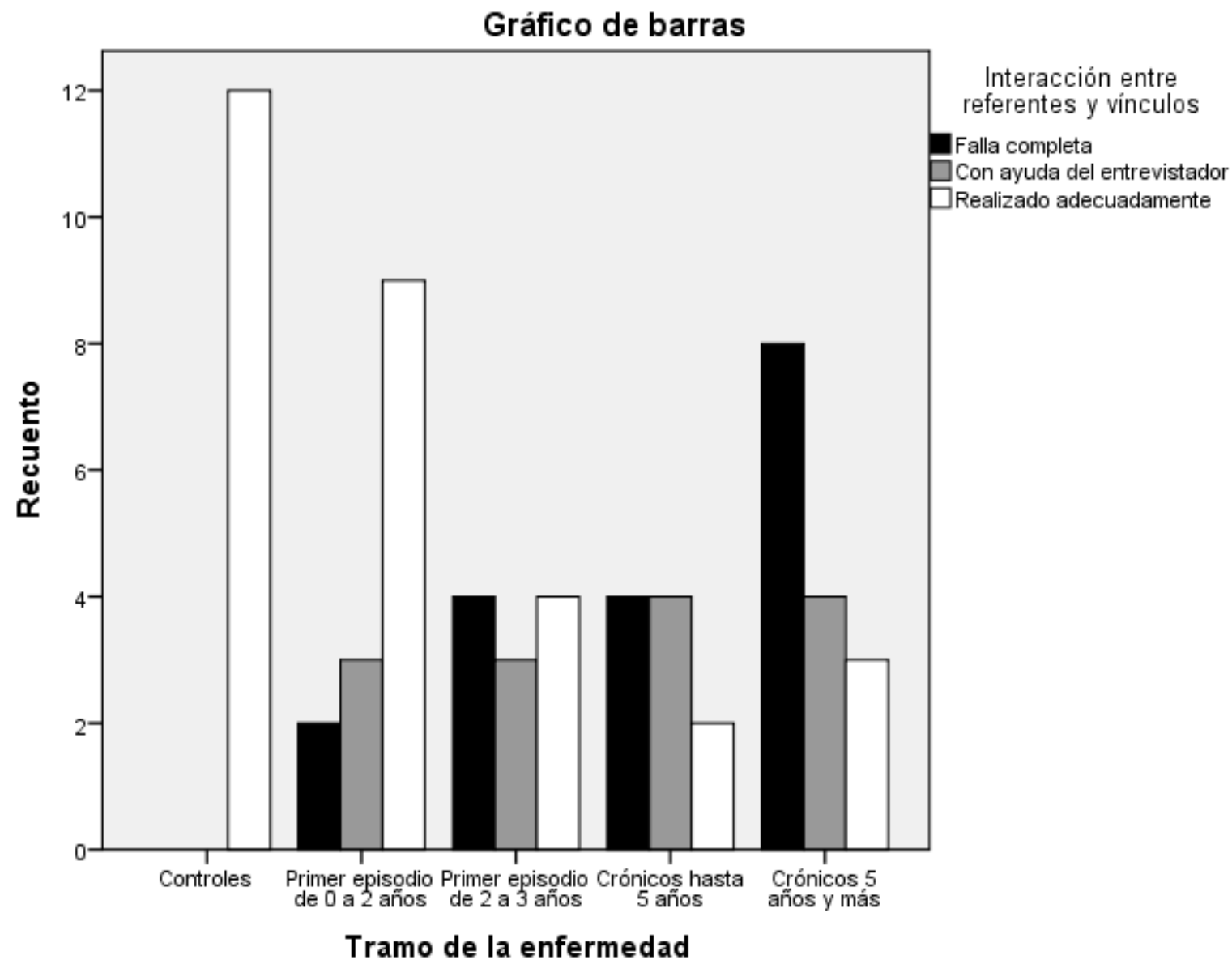


4.4.6.5. Interacción entre referentes y vínculos referenciales y subtipo de la enfermedad

También el subtipo de la enfermedad resultó ser relevante en lo estadístico, pesquisamos que la totalidad de los controles lo realizaron adecuadamente, representando un $40 \%$ del indicador, en el grupo paranoide, encontramos 10 casos realizados adecuadamente, correspondientes al 33,3\%; 10 casos realizados con ayuda del entrevistador, que corresponden al $71,4 \%$ y 13 casos de falla completa, que corresponden al 72,2\%. En el grupo de los de esquizofrenia indiferenciada, encontramos 5 casos realizados adecuadamente, que representan un16,7\%, 1 caso realizado con ayuda del entrevistador, con un 7,1\% y 3 casos de falla completa con un 16,7\%. Finalmente el grupo de esquizofrenia desorganizada presentó 3 casos realizados adecuadamente, con un 10\%; 3 casos realizados con ayuda del entrevistador, con un $21,4 \%$ y 2 casos de falla completa con un $11,1 \%$.

Tabla de contingencia 151: interacción entre referentes y vínculos y subtipo de la enfermedad.

\begin{tabular}{|c|c|c|c|c|}
\hline \multirow{2}{*}{$\begin{array}{l}\text { Subtipo de la } \\
\text { enfermedad }\end{array}$} & \multicolumn{3}{|c|}{ Interacción entre referentes y vínculos } & \multirow[t]{2}{*}{ Total } \\
\hline & Falla completa & $\begin{array}{l}\text { Con ayuda del } \\
\text { entrevistador }\end{array}$ & $\begin{array}{c}\text { Realizado } \\
\text { adecuadamente }\end{array}$ & \\
\hline \multirow[t]{2}{*}{ Controles } & 0 & 0 & 12 & 12 \\
\hline & $0,0 \%$ & $0,0 \%$ & $40,0 \%$ & $19,4 \%$ \\
\hline \multirow[t]{2}{*}{ Paranoide } & 13 & 10 & 10 & 33 \\
\hline & $72,2 \%$ & $71,4 \%$ & $33,3 \%$ & $53,2 \%$ \\
\hline \multirow[t]{2}{*}{ Indiferenciada } & 3 & 1 & 5 & 9 \\
\hline & $16,7 \%$ & $7,1 \%$ & $16,7 \%$ & $14,5 \%$ \\
\hline \multirow[t]{2}{*}{ Desorganizada } & 2 & 3 & 3 & 8 \\
\hline & $11,1 \%$ & $21,4 \%$ & $10,0 \%$ & $12,9 \%$ \\
\hline \multirow[t]{2}{*}{ Total } & 18 & 14 & 30 & 62 \\
\hline & $100,0 \%$ & $100,0 \%$ & $100,0 \%$ & $100,0 \%$ \\
\hline
\end{tabular}

El valor de chi cuadrado es de 18,829a , y dio como resultado ( $<\mathrm{p}, 004>)$, significativo estadísticamente. 
Tabla valor de chi cuadrado 152: interacción entre referentes y vínculos y subtipo de la enfermedad.

\begin{tabular}{||c|c|c|c||}
\hline \multicolumn{4}{|c||}{ Pruebas de chi-cuadrado } \\
\hline & Valor & $\mathrm{gl}$ & $\begin{array}{c}\text { Sig. asintótica } \\
\text { (bilateral) }\end{array}$ \\
\hline Chi-cuadrado de Pearson & $18,829^{\mathrm{a}}$ & 6 &, 004 \\
\hline
\end{tabular}

Gráfico 108. Porcentaje de frecuencia de las variables: interacción entre referentes y vínculos referenciales y subtipo de la enfermedad

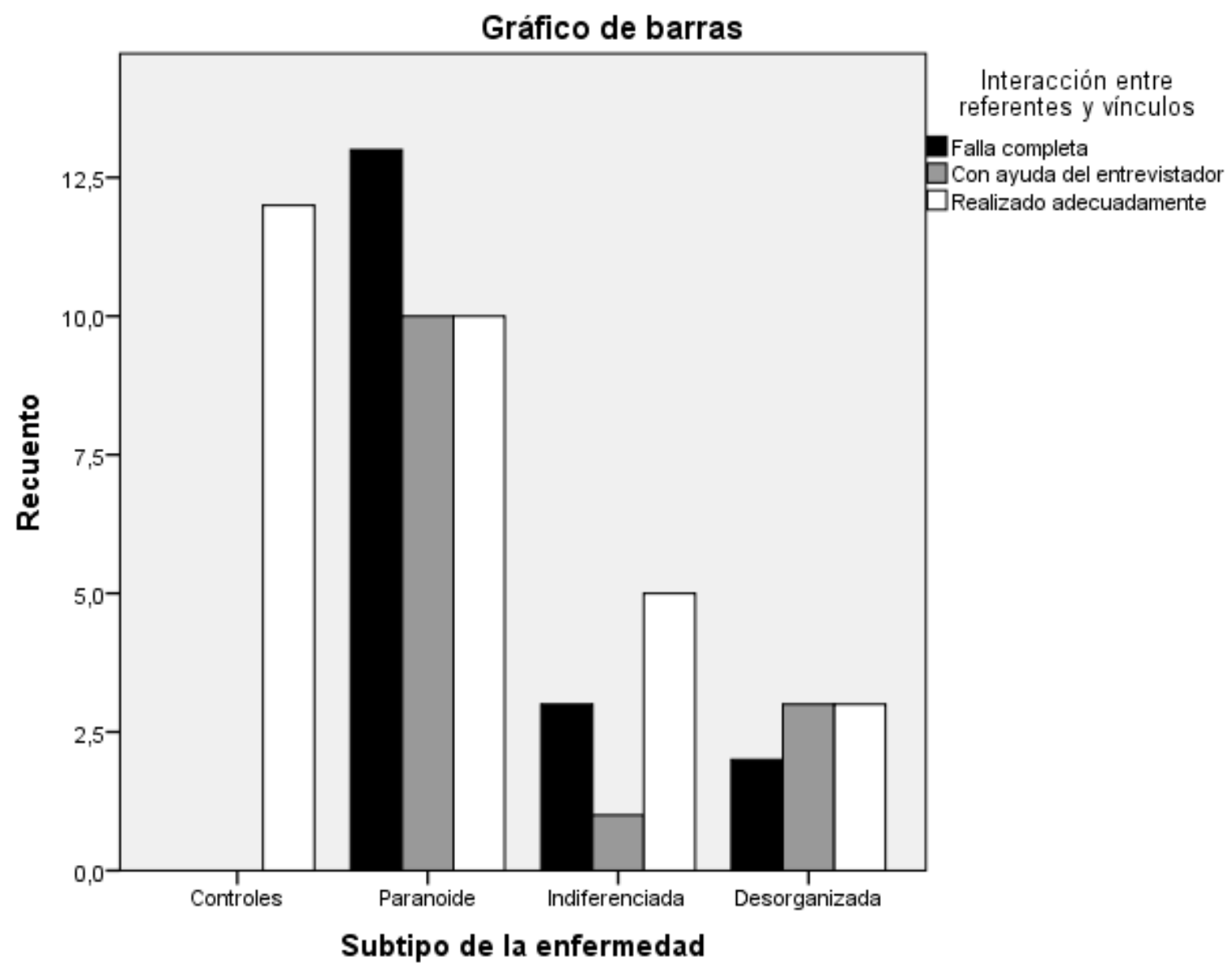




\subsubsection{Conclusiones cluster de coherencia temática}

Es importante relevar aquellos aspectos más sensibles frente a la consideración de coherencia en diferentes planos. Este cluster en particular es sensible a dicho análisis. La coherencia como núcleo de la eficacia en un discurso, posee requisitos fundamentales, algunos de ellos son la estabilidad y consistencia temática, como lo señalan Beaugrande y Dressler (2003).

Como ya especificamos anteriormente, este análisis ha distinguido entre dos niveles de profundidad semántica; en el primero, los indicadores de la macroestructura discursiva: Unidad temática nuclear, Proposiciones con vínculos explícitos y Proposiciones con vínculos implícitos respecto del tema central.

Tomando en cuenta el tema, el contenido proposicional, la función ilocutiva y la orientación de la interacción, evaluamos las intervenciones de los participantes para determinar si presentaban coherencia en estos aspectos temáticos del discurso. Pensamos que entre los indicadores de este cluster es donde encontramos mayores diferencias respecto del denominado discurso normal, por tanto, serían indicadores de deterioro comunicativo por excelencia.

En la literatura, algunas de las características diferenciales del discurso en personas con esquizofrenia lo señalan como perseverante y redundante. Sin embargo, aún se discute en torno a cuáles son las evidencias de estos rasgos, y se han desestimado muchos tipos de análisis por considerarlos sesgados en la tarea de levantar un perfil lingüístico que detalle estos rasgos. Pensamos que uno de los factores que ha impedido respaldar esta impresión recogida por los psicopatólogos, es el hecho de que no se cuenta con estudios contrastivos y sistemáticos para hacer más rigurosa la observación, mediante un análisis linguiístico del contenido proposicional del discurso entre grupos de pacientes que estén cursando diferentes estadios de la enfermedad. En cuanto a los hallazgos de este estudio, podemos decir que esta 
impresión de que es un discurso perseverativo y redundante nos resultó más evidente en este cluster, ya que pudimos comprobar, en parte, que registramos algunos recursos lingüísticos deteriorados, como la construcción de tópicos en torno a un tema o referente, o bien, los saltos topicales, entre otros.

Encontramos diversos ejemplos que ilustran la pérdida de unidad temática nuclear en la intervenciones de los grupos 1 y 2 asimismo, encontramos algunas dificultades específicas que pueden explicar el déficit en estos tres indicadores de la macroestructura discursiva.

Dentro de las dificultades principales, recogimos en primer término la omisión de información esencial para comprender el tema central planteado, como por ejemplo iniciar un narración desde el principio; por el contrario, el inicio se realiza desde un episodio, o bien, partiendo desde un subtema, o más aún, un comentario a un subtema. También la presencia frecuente de proposiciones implícitas y/o tangenciales respecto del supuesto tema central, lo que para el oyente significa acceder solo a algunos fragmentos discontinuos del tema, lo que impide una comprensión completa, inclusive con la ayuda del entrevistador.

Ahora bien, las proposiciones emitidas por los pacientes a menudo se elicitan con naturalidad, como si su lugar dentro del contexto comunicativo fuese lógico, no pocas veces son correctas gramaticalmente, no obstante, su contenido es altamente críptico para el oyente, se pierde el equilibrio informativo, previo a la interpretación del discurso, que sostiene que, a un menor grado de contextualización, se requiere de más indicadores lingüísticos que sustenten la coherencia. En parte, este resultado difícil de entender se da asimismo, por el uso inapropiado de marcadores y/o partículas del discurso que pueden, por ejemplo, perder su carácter fórico y resultar disfuncionales o, tal vez, sufrir un desplazamiento semántico y resultar descontextualizadas. Por otro lado, cuando son gramaticalmente adecuadas, pueden presentarse como proposiciones encifradas semánticamente, con un significado propio, claro solo para el paciente. 
Se suma en la exposición temática dificultades tales como la repetición de estructuras como recurso lingüístico. La repetición se utiliza con el fin de actualizar la información planteada con anterioridad, es decir, permite mantener a la vista el asunto del que se está hablando. No obstante, la repetición de tipo calco, es decir, las mismas palabras o frases, aplicadas en vez del desarrollo de algún subtema, no funciona como estrategia de actualización. Es con frecuencia una conducta perseverativa, poco informativa y que no ayuda a hacer más eficaz lo dicho.

La hipótesis de Belinchón (1988) acerca del carácter egocéntrico de las emisiones de estos pacientes es comprobable al observar que no tienen en cuenta las necesidades informativas del interlocutor, por lo tanto, tampoco están interesados (¿pero si capacitados?) en entregar claves lingüísticas para que el oyente pueda interpretarlas. Aún cuando algunas de esas claves son cohesivas, nos damos cuenta de que participan en forma directa en la composición de la macroestructura de la que solo tenemos algunos atisbos. En el llamado discurso normal, se recurre, por ejemplo, a los procedimientos endofóricos con el fin de mantener la unidad temática. En cambio, encontramos construcciones en donde se presentan referentes aislados, sin elementos asociados, o con proposiciones vinculadas en forma tangencial a dichos referentes, convirtiéndolos en disfóricos.

Los indicadores estudiados en la microestructura son: tópico con desarrollo, salto topical e interacción entre referentes y vínculos referenciales. Según Van Dijk (1983) la microestructura estaría conformada por una serie de microproposiciones jerarquizadas, coincidiendo la más importante de ellas con la macroestructura. Las estructuras microestructurales, también se encuentran afectadas en los grupos 1 y 2 .

Principalmente, encontramos fenómenos como tópicos enunciados, pero sin desarrollo, presencia de constantes saltos topicales, algunos abruptos, dentro de una 
oración o de una oración a otra, otros un poco más distanciados, tras un turno de habla, por ejemplo.

También observamos cambios temporales frecuentes y sin justificación. Se suma a estos hallazgos la referencia a subtemas para explicar algún aspecto vivenciado. Es decir, relatos que pueden progresar temporalmente, pero que están compuestos por hechos circunstanciales, que en función de la insistencia del entrevistador, terminan por ser aclarados, casi siempre en forma parcial. Queda entonces la duda de si se interpreta un significado diferente al que el paciente pretende aportar.

Con respecto a la interacción entre vínculos referenciales, podemos señalar que con frecuencia se observaron estructuras de puenteo, es decir, que presentan una relación verbal indirecta con el referente. También una relación aditiva entre los vínculos, por asociación incluso consonántica, generalmente injustificada. Esta preferencia, a nuestro juicio, debilita la relación entre referentes y sus vínculos referenciales, lo que se traduce en una fragmentación topical, por tanto, discursiva. 


\subsection{Semántica de la coherencia}

Por semántica de la coherencia comprendemos aquellos fenómenos relacionados con el juicio de realidad que establece el entrevistado respecto de su entorno y de su vida. Este tema brinda un amplio campo de investigación desde la psicopatología clásica. El concepto ha sido discutido desde las diferentes escuelas de psiquiatría contemporáneas, y no existe consenso absoluto respecto a los alcances de este concepto. Con el fin de dar cuenta de aquellos rasgos que suponen una visión universal entre los psiquiatras chilenos, usamos las tres etapas propuestas por Gomberoff (1999). De ellas únicamente consideramos la segunda etapa: mantenimiento de criterios sociales, ya que por su perfil como fenómeno, nos parece que es factible hacer un análisis lingüístico para verificar presencia o ausencia del rasgo. Las etapas de las que habla Gomberoff (1999:78) son:

iv. Presencia / ausencia de alucinaciones o ideas delirantes: circunstancia en que se alude a si el paciente percibe o no el significado de estas manifestaciones, ya sea las tenga en el momento de la entrevista, o las haya tenido en otra ocasión. Se considera perdido el juicio de realidad si es que no le causan extrañeza. Sobre este punto en particular, no propusimos una evaluación lingüística, ya que nos parece muy complejo de sistematizar un haz de indicadores para etiquetar presencia o ausencia de alucinaciones o ideas delirantes.

v. Mantenimiento de criterios sociales: se confronta al paciente con algún aspecto bizarro que ha llamado la atención del clínico, en especial si el paciente nunca ha tenido alucinaciones ni ideas delirantes, con preguntas del tipo: "veo que usted estaba cree/hace/piensa esto o reacciona de tal forma y esto me pareció raro ¿usted entiende que a mí me haya parecido extraño o es un problema mío?" el juicio de realidad conservado se daría si el paciente en dicha confrontación explica la situación 
mejorando el entendimiento de esta, o relativizando su planteamiento como posible o imaginado. Por el contrario, el juicio de realidad se denota perdido si el paciente no puede ver por qué a otra persona le resulte extraño cierto comportamiento.

vi. Identificar en la interacción mecanismos de defensa primitivos e interpretarlos: Se debe tener una visión global del paciente, tomar en cuenta su comportamiento y cómo responde a las preguntas del entrevistador. Las reacciones defensivas primitivas comienzan a aparecer en las estructuras limítrofes y psicóticas al pedirle al paciente que se describa y continúan apareciendo en el transcurso de la entrevista estructural. Ante las defensas del paciente, hay que interpretar en el presente y ver la reacción de este. Los pacientes limítrofes mejoran con esta intervención, los psicóticos empeoran (Kernberg, 1987; Gomberoff, 1999).

Como ya señalamos, nos interesa dar cuenta de la segunda dimensión. En ella consideramos como evidencia la elaboración de proposiciones con verbos estativos que se definen como un estado, es decir, un evento que se da en forma homogénea en cada momento de la fase a través de la que se extiende. No expresaría progreso, ni avance, no puede alcanzar un límite o dirigirse a una meta, es un continuo, mientras se mantengan las condiciones de existencia que lo propiciaron. Este sería el caso de construcciones como "Yo soy la Virgen María". El contraste a estas construcciones las tomamos de verbos de percepción, definidos por Enghels y Rogiest (2004) como un tipo específico de proceso cognitivo, por la que un individuo (humano generalmente) experimenta un estímulo exterior, obteniendo mediante este estímulo, información sobre el mundo exterior. Tal es el caso de construcciones como "me imagino que soy X", "siento que soy X", etc.

Dado que los verbos y los esquemas sintácticos representan escenas del mundo real o imaginado, nos parece bastante claro que si el paciente es capaz de establecer diferencias entre este tipo de construcciones oracionales, es porque está conceptualizando una situación a nivel cognitivo que interpreta como real o 
imaginada. Como lo plantea García-Miguel (2005) el significado verbal evocaría una estructura conceptual compleja, que integraría el conocimiento enciclopédico y pragmático del mundo, traducido en el uso de expresiones verbales específicas.

Van Dijk, (1995) señala que las relaciones al interior de lo que él llama; semántica de la coherencia, existen entre frases o partes de proposiciones y entre las estructuras modélicas implicadas, razón por la cual se deben asignar valores a dichas partes (operadores, cuantificadores, predicados, argumentos, etc). De esta forma los individuos pueden relacionar el sentido de cada frase en relación con su dominio real del mundo. Entonces, "El mundo posible en el que una frase se interpreta está determinado por la interpretación de las frases previas en los modelos anteriores del modelo discursivo" (van Dijk, 1995:152) por tanto, también se modificarán los valores de las propiedades o relaciones y los cuantificadores, según el mundo posible dónde se sitúen para el individuo. La concepción de mundo posible, también ha sido respaldada por la lógica, en Stalnaker (1976).

Por ello, estamos plenamente conscientes de que esta propuesta de análisis es una aproximación a un problema mucho más complejo, cuya cobertura estamos lejos de abordar en este trabajo. A pesar de estas limitaciones, los hallazgos fueron interesantes ya que al menos nos permitieron contar con un aspecto lingüístico visible acerca del juicio de realidad. En efecto, en el grupo de controles no se reportó ninguna incidencia de una falsa interpretación del mundo, si bien hubo referencias a mundos posibles, siempre se los abordó con estructuras oracionales de deseo o percepción, etc. En los grupos 1 y 2 , encontramos ejemplos de interpretaciones anómalas de la realidad, a pesar de la confrontación del entrevistador para que el paciente reevaluara su planteamiento, algunas de estas proposiciones no se rectificaron como situadas en un mundo posible, sino como parte del mundo real. 


\subsubsection{Confusión de los mundos posibles (Juicio de realidad)}

Como señalamos, van Dijk (1995) es quien propone matices para las relaciones que se dan en el marco de lo que él llama; semántica de la coherencia. De esta forma, el mundo posible, en el que se encuadra una frase u oración, se interpretaría en base a las propuestas previas planteadas como modelos discursivos anteriores.

Por lo tanto, lo que pretendemos verificar en esta sección, es el perfil discursivo de las construcciones que representan los juicios de realidad de los hablantes de este estudio. En virtud de los relatos de sus experiencias relacionadas con el hecho de estar enfermos, nos encontramos con diversos tipos de construcciones que subvierten el principio básico de lo que puede ser considerado un mundo posible. Los relatos de los controles, en ningún momento transgreden el modelo discursivo propuesto, no incluyen elementos divergentes, ni se refieren a sí mismos como sujetos de una forma que interfiera en la comprensión de las experiencias compartidas en la entrevista; por ejemplo, que incorporen revelaciones acerca de estar dotados de alguna investidura o poder excepcional, como es el caso del paciente CRE-H06, quien señala que está hospitalizado por pertenecer a la inteligencia naval, y ser lo que él denomina un Under 8. En este caso, esta declaración del paciente afectaría a la lógica de una explicación correcta del modo en como representa las causas de su estadía en el hospital.

En suma, tomamos el contenido de frases sobre las razones o causas o explicaciones que los hablantes les atribuyeron a la condición de estar padeciendo una enfermedad psiquiátrica como la esquizofrenia o al hecho de estar hospitalizados.

\subsubsection{Ejemplos}

Ejemplos del grupo de crónicos:

1)

E: Sra. C/ me puede explicar ¿cómo es eso de la virgen María/ y lo de la reencarnación? 
S: es que <pausa $>$ la reencarna<pausa $>/$ reencarnación, porque que he resucitado varias veces y soy<pausa $>/$ y $<$ pausa $>/$ yo soy María $<$ pausa $>/$ yo para mi es mejor ser C B que la virgen María/ porque es menos la responsabilidad.

E: ya

CRE-M03

2)

E: pero <pausa>/ cuénteme un poco más/ ¿cómo se ha sentido durante la hospitalización?// ¿encuentra que la ha ayudado?/ ¿se ha sentido cómoda acá?

S: pero obviamente que me he sentido cómoda/ po' chico/ si ustedes me conocen cuando yo no entraba y no entraba <pausa >/ a la cocina <pausa>/ a lo que sea/ al patio/ a lo que sea a trotar/ subir escalera/ subir cerro/ lo que sea//<pausa $>$ Eso/ mira<pausa $>$ t te voy a decirte una cosa// yo soy médico cirujano/ especialista en dientes/ opero/ traigo hijos al mundo/ yo al bebé/ lo preparo/ me olvidé pero ya<pausa $>$ / eeh<pausa oralizada $>$ mmm<pausa oralizada $>$ nnn<pausa oralizada $>$ / quien encuentre ahí para recibir a mi nieto/ a su nieto/ qqq/ que así/ <mímica de tamaño, altura de alguien>/ mide un metro ochenta y nueve/ ehh <pausa oralizada>/ va a pesar uno $38<$ pausa $/$ etcétera/ etcétera/ etcétera/ eso todo está bien/ su corazón está todo bien/ lo que pasa es que quiere nacer/ yo le digo: "ino!”// que se espere hasta la pascua/ ahí va a nacer con esos villancicos/ que Cristo Jesús <pausa>/ "no/ mami/ no"/ yo sé que él quiere/ pero tiene que luchar/ salir a combatir/ como su papá y su tía/ le digo: “¡no!”.

CRE-M07

3)

E: ¿Y cuál es su relación con INTERPOL?

S: Soy informante de la Interpol.

E: ¿y cuál es su función como informante?

S: Digamos/los que viven por ahí más o menos<pausa $>$ q que encuentro que tiene gruesos modos con lo que $<$ pausa $>$ / porque carabineros ya me dijeron que iba pa' la población a informar//No yo iba pa' allá con un coche y cosas no/ no/ no/ no/ no llevaba información pero yo le decía que era pa' la población, me llevaron a un lado, eso es lo que yo entiendo/la prefectura, no la comisaría entonces ahí eh<pausa>/ me llevaron a la INTERPOL.

CRE-H02

\section{Ejemplos del grupo de primer episodio}

\section{1)}

E: ¿por qué no puede ser en otro supermercado?

S: en el Santa Isabel/ en el Monserrat/ no puedo comprar porque<pausa>

E: ¿qué pasa?

S: porque ehhh<pausa oralizada $>$

E: ¿por?

S: Porque el Monserrat/ está la Monserrat Bustamante ${ }^{65} /$ del Rojo $^{66} /$ y no la encuentro bonita yo a ella/ la encuentro fea $y<$ pausa $>$ t tengo miedo que si compro algo de ahí/ me voy a convertir en ella.

${ }^{65}$ Monserrat Bustamante $=$ cantante que concursaba en el programa Rojo de televisión Nacional de Chile.

${ }^{66}$ Rojo=Popular programa de la televisión chilena que consistía en una competencia entre 12 bailarines y 12 cantantes, los cuales, día a día se presentaban en el programa, para posteriormente ser evaluados por el jurado, y semanalmente ir siendo eliminados, hasta llegar a una gran final, con los 5 mejores de 
2)

E: usted me dijo que/ era el único que existía en el planeta.

S: Si.

E: ¿Por qué cómo fue eso?/ ¿A qué se refería con: “el único que existía en el planeta”?

$\mathrm{S}:$ ¿Cómo?

E: ¿A qué se refería cuando decía que era el único que existía en el planeta?

$\mathrm{S}$ : ¿qué me pareció? ¿Ah<pausa>/? extraño/ porque me dice que para la radioactividad/ se necesitan juntarse conmigo/ porque soy el único que existe en el planeta/ necesitan hacer un reencuentro conmigo// eh<pausa $>$ / que: "no es tan así de pasarte la radioactividad a ti/ $\mathrm{R} /$ porque tú veis a la gente y la gente tiene la radioactividad" y eso es la radioactividad/ y esa gente sabe qué es la radioactividad y no te va hacer/ caso porque no puede/ porque no quiere/ porque a lo mejor son nazis/ son racistas<pausa>/ o no pueden darte la radioactividad/ yo creo que no pueden porque no saben porque no pueden/ porque no quieren a lo mejor.

\subsubsection{Juicio de realidad y estadio de la enfermedad}

El recuento esperado para los controles es de 3,9 que corresponde al $0.0 \%$ dentro de Juicio de realidad. En el primer episodio, la presencia del rasgo, fue pesquisada en 7 hablantes, con un $35 \%$ dentro de juicio de realidad. En el caso de los crónicos, la presencia del rasgo, fue pesquisada en 13 hablantes, con un 65\% dentro de juicio de realidad.

Tabla de contingencia 153: juicio de realidad y estadio de la enfermedad.

\begin{tabular}{|c|c|c|c|c|}
\hline \multicolumn{2}{|c|}{ Estadio de la enfermedad } & \multicolumn{2}{|c|}{ Juicio de realidad } & \multirow{3}{*}{$\begin{array}{l}\text { Total } \\
12 \\
\end{array}$} \\
\hline & & \multirow{2}{*}{$\begin{array}{r}\text { Ausencia } \\
12\end{array}$} & \multirow{2}{*}{$\begin{array}{r}\text { Presencia } \\
0\end{array}$} & \\
\hline Control & Recuento & & & \\
\hline & Recuento esperado & 8.1 & 3.9 & 12.0 \\
\hline & $\%$ dentro de Juicio de realidad & $28.6 \%$ & $0.0 \%$ & $19.4 \%$ \\
\hline \multirow[t]{3}{*}{ Primer episodio } & Recuento & 18 & 7 & 25 \\
\hline & Recuento esperado & 16.9 & 8.1 & 25.0 \\
\hline & $\%$ dentro de Juicio de realidad & $42.9 \%$ & $35.0 \%$ & $40.3 \%$ \\
\hline \multirow[t]{2}{*}{ Crónico } & Recuento & 12 & 13 & 25 \\
\hline & Recuento esperado & 16.9 & 8.1 & 25.0 \\
\hline
\end{tabular}

cada especialidad, los cuales definían su lugar en una noche, conocido como "La gala" de la generación correspondiente. Muy popular entre 2004 y 2008. 
ANÁLISIS PRAGMALINGÜÍSTICO DE LOS MARCADORES DE COHERENCIA EN EL DISCURSO DE SUJETOS CON ESQUIZOFRENIA CRÓNICA Y DE PRIMER EPISODIO

\begin{tabular}{|c|c|c|c|c|}
\hline & $\%$ dentro de Juicio de realidad & $28.6 \%$ & $65.0 \%$ & $40.3 \%$ \\
\hline \multirow[t]{3}{*}{ Total } & Recuento & 42 & 20 & 62 \\
\hline & Recuento esperado & 42.0 & 20.0 & 62.0 \\
\hline & $\%$ dentro de Juicio de realidad & $100.0 \%$ & $100.0 \%$ & $100.0 \%$ \\
\hline
\end{tabular}

El valor de chi cuadrado es de $10.381^{\mathrm{a}}$, que dio como resultado $(<\mathrm{p}, 006>)$, no significativo estadísticamente.

Tabla valor de chi cuadrado 154 juicio de realidad y estadio de la enfermedad.

\begin{tabular}{||l|l|l|r||}
\hline \multicolumn{1}{|c||}{ Pruebas de chi-cuadrado } & \multicolumn{2}{|c||}{} \\
\cline { 1 - 1 } & Valor & gl & Sig. asintótica (2 caras) \\
\hline Chi-cuadrado de Pearson & $10.381^{\mathrm{a}}$ & 2 & .006 \\
\hline
\end{tabular}


Gráfico 109. Porcentaje de frecuencia de las variables: juicio de realidad y estadio de la enfermedad.

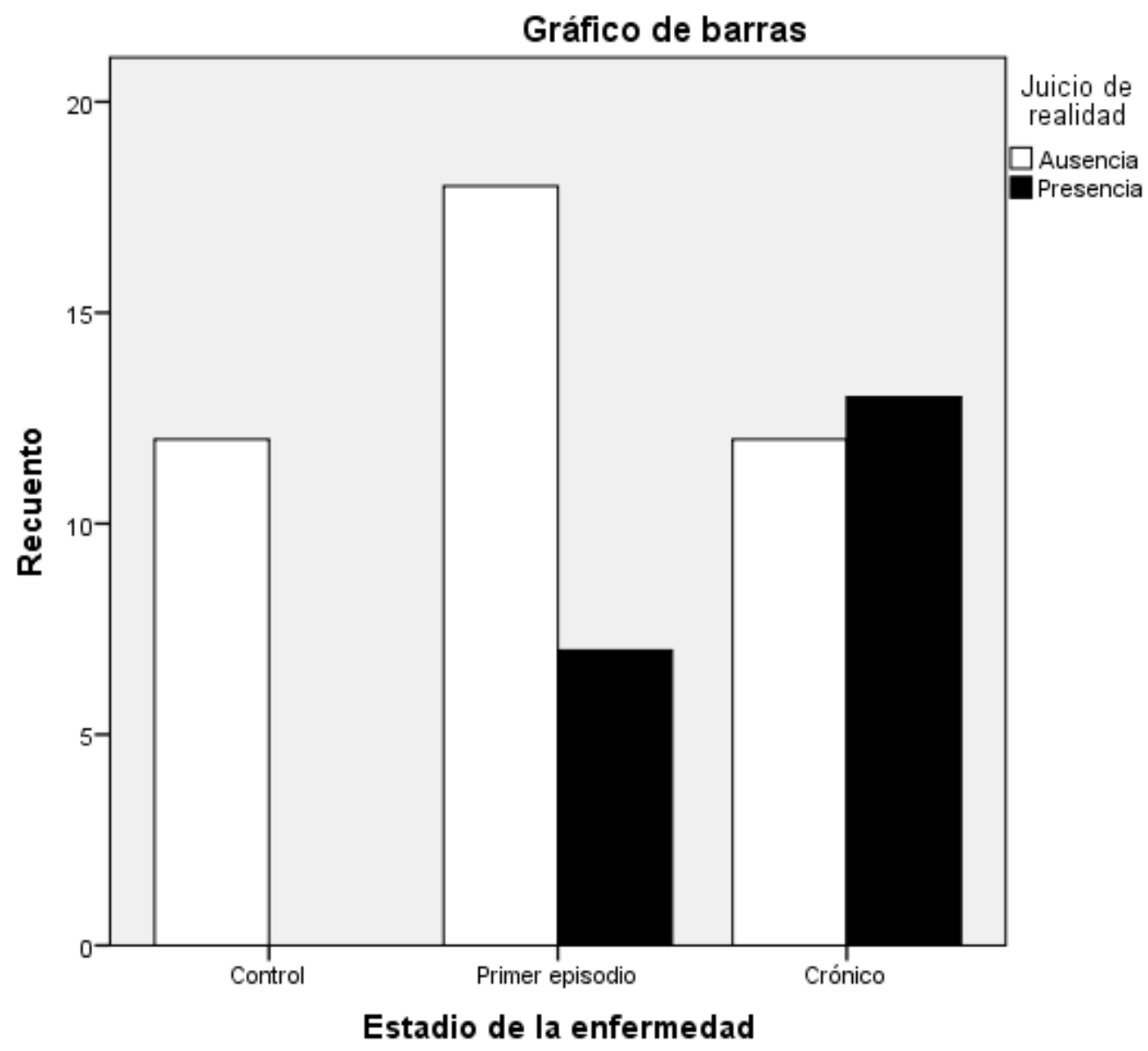

4.5.1.3. Juicio de realidad y sexo

En este indicador no encontramos resultados significativos, entre las mujeres encontramos presencia del rasgo solo en 7 hablantes femeninos, correspondientes al 
$35 \%$ dentro de juicio de realidad. Entre los hombres del estudio, hay una Presencia del rasgo en 13 de ellos, con un 65\% dentro de juicio de realidad.

Tabla de contingencia 155: juicio de realidad y sexo.

\begin{tabular}{|c|c|c|c|c|}
\hline \multicolumn{5}{|c|}{ Sexo del sujeto*Juicio de realidad tabulación cruzada } \\
\hline & & \multicolumn{2}{|c|}{ Juicio de realidad } & \multirow[t]{2}{*}{ Total } \\
\hline & & Ausencia & Presencia & \\
\hline \multirow[t]{3}{*}{ Mujer } & Recuento & 22 & 7 & 29 \\
\hline & Recuento esperado & 19.6 & 9.4 & 29.0 \\
\hline & $\%$ dentro de Juicio de realidad & $52.4 \%$ & $35.0 \%$ & $46.8 \%$ \\
\hline \multirow[t]{3}{*}{ Hombre } & Recuento & 20 & 13 & 33 \\
\hline & Recuento esperado & 22.4 & 10.6 & 33.0 \\
\hline & $\%$ dentro de Juicio de realidad & $47.6 \%$ & $65.0 \%$ & $53.2 \%$ \\
\hline \multirow[t]{3}{*}{ Total } & Recuento & 42 & 20 & 62 \\
\hline & Recuento esperado & 42.0 & 20.0 & 62.0 \\
\hline & $\%$ dentro de Juicio de realidad & $100.0 \%$ & $100.0 \%$ & $100.0 \%$ \\
\hline
\end{tabular}

El valor de chi cuadrado es de $1.644^{\mathrm{a}}$, que dio como resultado $(<\mathrm{p}, 200>)$, no significativo estadísticamente.

Tabla valor de chi cuadrado 156: juicio de realidad y sexo.

\begin{tabular}{||l|c|c|c|c|c||}
\hline \multicolumn{7}{|c||}{ Pruebas de chi-cuadrado } \\
\hline & Valor & gl & $\begin{array}{c}\text { Sig. asintótica } \\
\text { (2 caras) }\end{array}$ & $\begin{array}{c}\text { Significación } \\
\text { exacta (2 caras) }\end{array}$ & $\begin{array}{c}\text { Significación } \\
\text { exacta (1 cara) }\end{array}$ \\
\hline $\begin{array}{l}\text { Chi-cuadrado de } \\
\text { Pearson }\end{array}$ & $1.644^{\mathrm{a}}$ & 1 & .200 & & \\
\hline
\end{tabular}


Gráfico 110. Porcentaje de frecuencia de las variables: juicio de realidad y sexo de los individuos.

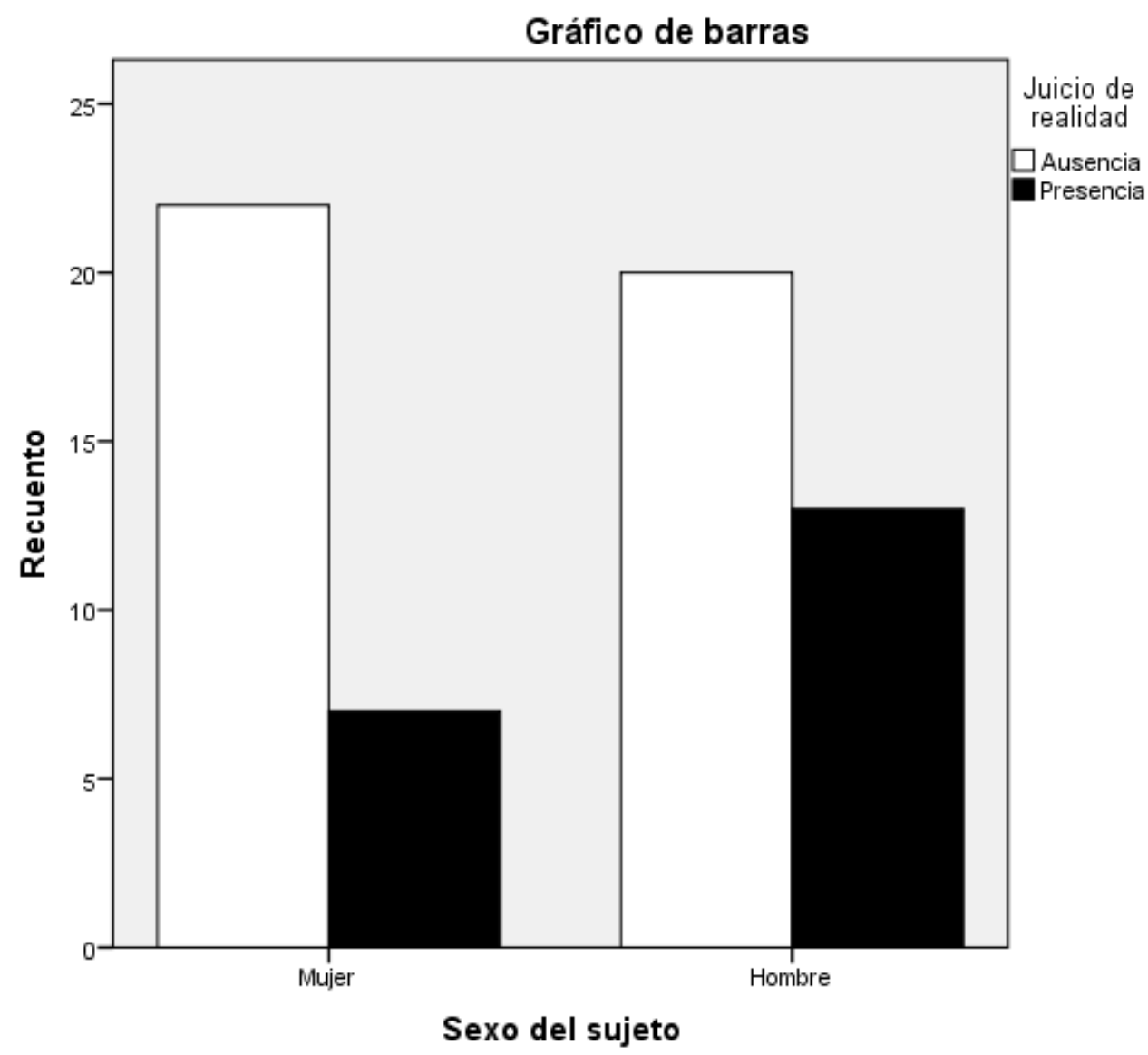

4.5.1.4. Juicio de realidad y tramo de la enfermedad

Este indicador no resultó significativo estadísticamente. El recuento esperado para los controles es de 3,9 que corresponde al $0.0 \%$ dentro de Juicio de realidad. En cambio en el grupo de primer episodio de $>0$ a $<2$ años fue de presencia del rasgo, con 
un $20 \%$ dentro de juicio de realidad. En el grupo de primer episodio de $>2$ a $<3$ años encontramos 3 casos de presencia del rasgo, con un $15 \%$ dentro de juicio de realidad. En el grupo de crónicos de hasta 5 años encontramos 5 presencias, que representan un $25 \%$ dentro de juicio de realidad. Finalmente los crónicos de 5 años y más, presentaron 8 casos de presencia del rasgo, que corresponden a $40 \%$ dentro de juicio de realidad.

Tabla de contingencia 157: juicio de realidad y tramo de la enfermedad.

\begin{tabular}{|c|c|c|c|c|}
\hline \multicolumn{2}{|c|}{ Tramo de la enfermedad } & \multicolumn{2}{|c|}{ Juicio de realidad } & \multirow{3}{*}{$\begin{array}{l}\text { Total } \\
12\end{array}$} \\
\hline & & \multirow{2}{*}{$\begin{array}{l}\text { Ausencia } \\
12\end{array}$} & \multirow{2}{*}{$\begin{array}{l}\text { Presencia } \\
0\end{array}$} & \\
\hline Control & Recuento & & & \\
\hline & Recuento esperado & 8.1 & 3.9 & 12.0 \\
\hline & $\%$ dentro de Juicio de realidad & $28.6 \%$ & $0.0 \%$ & $19.4 \%$ \\
\hline \multirow{3}{*}{$\begin{array}{l}\text { Primer episodio } 0 \text { a } 2 \\
\text { años }\end{array}$} & Recuento & 10 & 4 & 14 \\
\hline & Recuento esperado & 9.5 & 4.5 & 14.0 \\
\hline & $\%$ dentro de Juicio de realidad & $23.8 \%$ & $20.0 \%$ & $22.6 \%$ \\
\hline \multirow{3}{*}{$\begin{array}{l}\text { Primer episodio } 2 \text { a } 3 \\
\text { años }\end{array}$} & Recuento & 8 & 3 & 11 \\
\hline & Recuento esperado & 7.5 & 3.5 & 11.0 \\
\hline & $\%$ dentro de Juicio de realidad & $19.0 \%$ & $15.0 \%$ & $17.7 \%$ \\
\hline \multirow[t]{3}{*}{ Crónico hasta 5 años } & Recuento & 5 & 5 & 10 \\
\hline & Recuento esperado & 6.8 & 3.2 & 10.0 \\
\hline & $\%$ dentro de Juicio de realidad & $11.9 \%$ & $25.0 \%$ & $16.1 \%$ \\
\hline \multirow[t]{3}{*}{ Crónico 5 y más años } & Recuento & 7 & 8 & 15 \\
\hline & Recuento esperado & 10.2 & 4.8 & 15.0 \\
\hline & $\%$ dentro de Juicio de realidad & $16.7 \%$ & $40.0 \%$ & $24.2 \%$ \\
\hline \multirow[t]{3}{*}{ Total } & Recuento & 42 & 20 & 62 \\
\hline & Recuento esperado & 42.0 & 20.0 & 62.0 \\
\hline & $\%$ dentro de Juicio de realidad & $100.0 \%$ & $100.0 \%$ & $100.0 \%$ \\
\hline
\end{tabular}

El valor de chi cuadrado es de $10.416^{\mathrm{a}}$, y dio como resultado ( $\left.<\mathrm{p}, 034>\right)$, no significativo estadísticamente. 
Tabla valor de chi cuadrado 158: juicio de realidad y tramo de la enfermedad.

\begin{tabular}{||c|c|c|c||}
\hline \multicolumn{5}{|c||}{ Pruebas de chi-cuadrado } \\
\hline & Valor & $\mathrm{gl}$ & $\begin{array}{c}\text { Sig. asintótica } \\
(2 \text { caras })\end{array}$ \\
\hline Chi-cuadrado de Pearson & $10.416^{\mathrm{a}}$ & 4 & .034 \\
\hline
\end{tabular}

Gráfico 111. Porcentaje de frecuencia de las variables: juicio de realidad y tramo de la enfermedad.

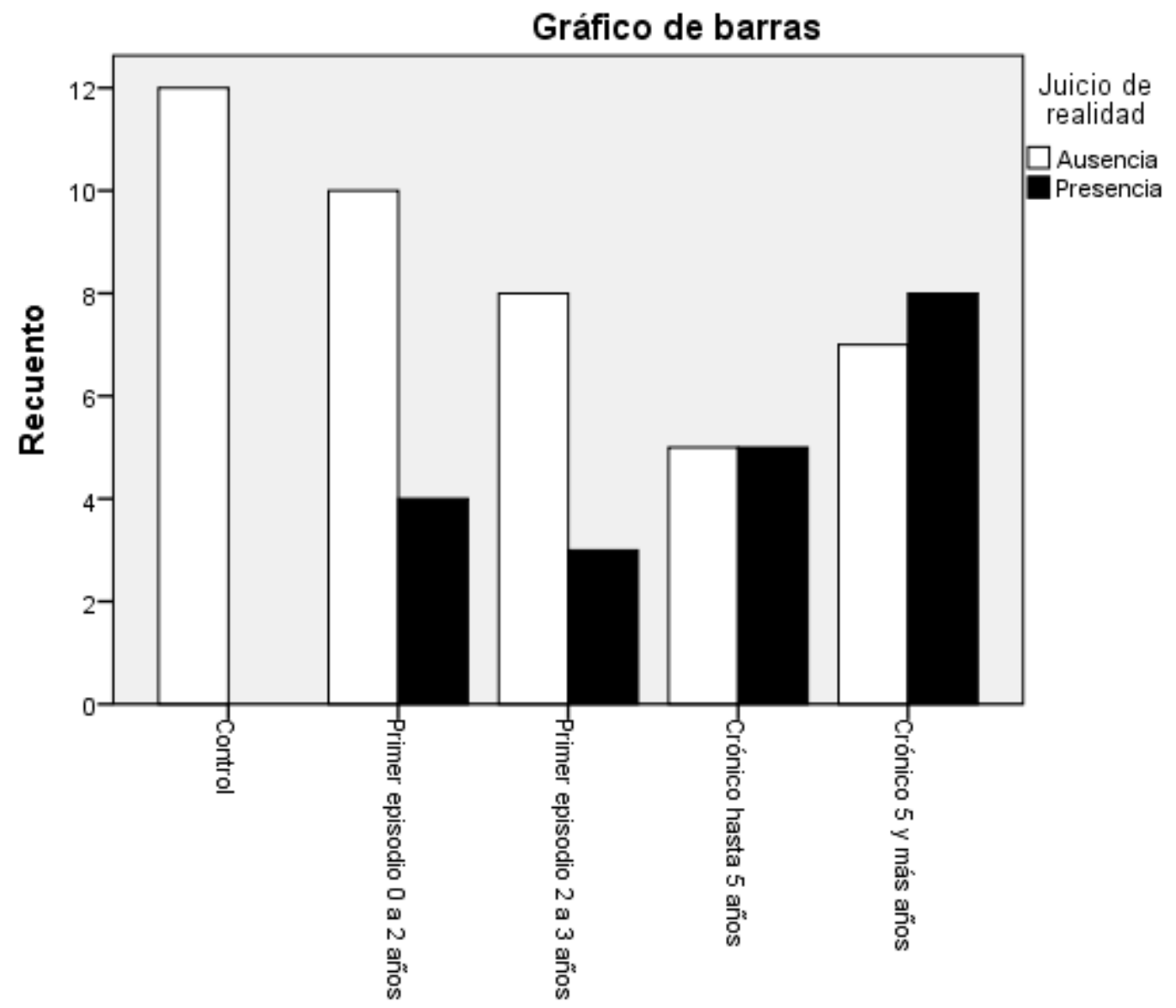

Tramo de la enfernedad 
4.5.1.5. Juicio de realidad y subtipo de la enfermedad

Este indicador no resultó significativo estadísticamente. El recuento esperado para los controles es de 3,9 que corresponde al $0.0 \%$ dentro de juicio de realidad. En el grupo de esquizofrenia paranoide encontramos 14 casos de presencia del rasgo, equivalentes al $70 \%$ dentro de juicio de realidad. En el grupo de esquizofrenia indiferenciada encontramos 2 casos, que equivale al $10 \%$ dentro de juicio de realidad. Por último, en el grupo de esquizofrenia desorganizada encontramos 4 casos de presencia del rasgo, que equivalen al $20 \%$ dentro de juicio de realidad.

Tabla de contingencia 159: juicio de realidad y subtipo de la enfermedad.

\begin{tabular}{|c|c|c|c|c|}
\hline \multirow{2}{*}{\multicolumn{2}{|c|}{ Subtipo de la esquizofrenia }} & \multicolumn{2}{|c|}{ Juicio de realidad } & \multirow{3}{*}{$\begin{array}{l}\text { Total } \\
12\end{array}$} \\
\hline & & \multirow{2}{*}{$\begin{array}{r}\text { Ausencia } \\
12\end{array}$} & \multirow{2}{*}{$\begin{array}{ll}\text { Presencia } & \\
& 0\end{array}$} & \\
\hline Control & Recuento & & & \\
\hline & Recuento esperado & 8.1 & 3.9 & 12.0 \\
\hline & $\%$ dentro de Juicio de realidad & $28.6 \%$ & $0.0 \%$ & $19.4 \%$ \\
\hline \multirow[t]{3}{*}{ Paranoide } & Recuento & 19 & 14 & 33 \\
\hline & Recuento esperado & 22.4 & 10.6 & 33.0 \\
\hline & $\%$ dentro de Juicio de realidad & $45.2 \%$ & $70.0 \%$ & $53.2 \%$ \\
\hline \multirow[t]{3}{*}{ Indiferenciada } & Recuento & 7 & 2 & 9 \\
\hline & Recuento esperado & 6.1 & 2.9 & 9.0 \\
\hline & $\%$ dentro de Juicio de realidad & $16.7 \%$ & $10.0 \%$ & $14.5 \%$ \\
\hline \multirow[t]{3}{*}{ Desorganizada } & Recuento & 4 & 4 & 8 \\
\hline & Recuento esperado & 5.4 & 2.6 & 8.0 \\
\hline & $\%$ dentro de Juicio de realidad & $9.5 \%$ & $20.0 \%$ & $12.9 \%$ \\
\hline \multirow[t]{3}{*}{ Total } & Recuento & 42 & 20 & 62 \\
\hline & Recuento esperado & 42.0 & 20.0 & 62.0 \\
\hline & $\%$ dentro de Juicio de realidad & $100.0 \%$ & $100.0 \%$ & $100.0 \%$ \\
\hline
\end{tabular}

El valor de chi cuadrado es de $8.842^{\mathrm{a}}$, que dio como resultado $(<\mathrm{p}, 031>)$, no significativo estadísticamente. 
Tabla valor de chi cuadrado 160: juicio de realidad y subtipo de la enfermedad.

\begin{tabular}{||l|c|c|c||}
\hline \multicolumn{4}{|c||}{ Pruebas de chi-cuadrado } \\
\hline & Valor & $\mathrm{gl}$ & $\begin{array}{c}\text { Sig. asintótica } \\
(2 \text { caras })\end{array}$ \\
\hline Chi-cuadrado de Pearson & $8.842^{\mathrm{a}}$ & 3 & .031 \\
\hline
\end{tabular}

Gráfico 112. Porcentaje de frecuencia de las variables: juicio de realidad y subtipo de la enfermedad

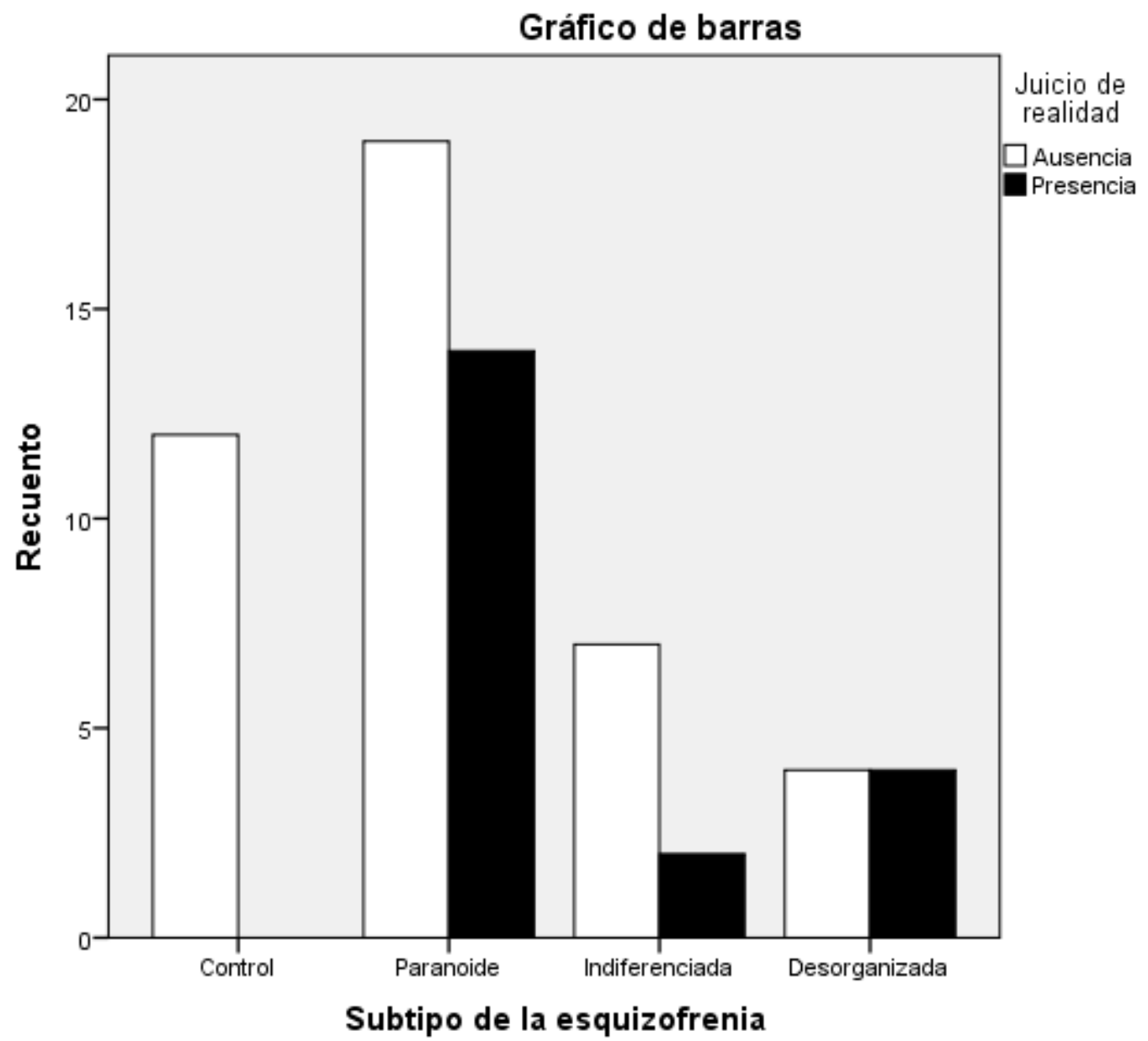




\subsubsection{Conclusiones de semántica de la coherencia}

Los resultados de este cluster en general, no nos ofrecieron un perfil lingüísitco relevante de los participantes con esquizofrenia. Es probable que con otro tipo de instrumento o tarea discursiva, en la que puedan ser incluidas las dos dimensiones del juicio de realidad que no abordamos, se logre realizar una aproximación más precisa al problema. Somos concientes de que la complejidad de este concepto del análisis psiquiátrico impide una una evaluación de presencia/ausencia sin generar un sesgo. Sin embargo, lo expuesto aquí podría considerarse como un punto de partida inicial en el análisis, ya que ofrece algunas evidencias en el discurso en torno a la conceptualización que los hablantes del estudio se atribuyen como sujetos. No podemos ignorar declaraciones como: "yo soy la virgen María", o "soy un informante de la Interpol", etc. En ambos ejemplos, resulta evidente una discordancia con el modelo discursivo que los mismos hablantes proponen en el transcurso de la entrevista. 


\subsection{Coherencia interaccional}

Con el fin de indagar la naturaleza de la interacción, se valorará el desempeño de los informantes en función de dos índices: los turnos de habla y los pares adyacentes. Ambos índices aportan información sobre la participación comunicativa de los informantes. Se valorarán en términos de desempeño adecuado, o no, o si se realizó con ayuda del entrevistador.

\subsubsection{Pares adyacentes}

Los pares adyacentes están construidos por dos turnos de habla sucesivos, y responden a necesidades informativas específicas, tales como pregunta-respuesta; saludo-despedida; ofrecimiento-aceptación o rechazo; agradecimiento-minimización, etc. Para este trabajo, hemos evaluado el desempeño general en este tipo de turnos de habla, sin clasificarlos de forma detallada o específica, sin embargo, observamos que en los crónicos, aquellos pares que se sitúan al inicio de la entrevista, como los saludos, o preguntas directas, tienen mejor desarrollo que otros que requieran mayor elaboración.

\subsubsection{Ejemplos :}

1) Ejemplo del grupo de crónicos, realizado adecuadamente:

1. E: ¿Cuál es su nombre?

2. S: M. A.

3. E: ¿M. A. cuál es su apellido?

4. S: A.

5. E: <pausa>/¿perdón?

6. S: A.

7. $\mathrm{E}: \mathrm{A} /$ ¿su edah?

8. S: 26.

9. E: $26 /$ ¿a qué se dedica M. A?

10. S: no/<pausa>/ en estos momentos no estoy haciendo nada/ no<pausa extendida $>/$

11. E: ya/ ¿y estudió/ terminó el colegio? 
12. S: si.

13. E: ¿hasta qué curso llegó/? ?pausa>/ ¿hasta cuarto?

14. S: si/ cuarto.

15. E: ya/ ¿después no tuvo más estudios?

16. $\mathrm{S}:$ : pausa $>/$ es que estudié/ pero me retiré.

17. E: ¿Qué estudió?

18. S: estudié un año ingeniera comercial/ <pausa $>/$ un semestre.

19. E: ya.

20. S: pero/ me retiré.

21. E: se retiró/<pausa $>/$ ¿y por qué se retiró?

22. S: porque quería hacer otras cosas $/<$ pausa $\rangle /$ tenía otros planes. CRE-M08

2) Ejemplo del grupo de crónicos, realizado con ayuda del entrevistador:

1. E: ¿qué te pasó $\mathrm{J}$ ?

2. S: <entonación de pregunta> ¿pasó algo malo?

3. E: $\mathrm{no} / \mathrm{no} / \mathrm{no} /$, ¿qué por qué estás aquí en RENOVAL?

4. S: nada/ lo que pasó es que soy incapaz de ser <pausa $>/$ responsable $<$ alargamiento > de terminar las cosas que hago/y <alargamiento $>/$ me cuesta ser responsable y me cuesta <alargamiento $>/$ llevar a cabo lo q <palabra cortada $>/$ de concentrarme también/ lo que sea/ lo hago

5. E: la pregunta es $/<$ pausa $>/$ ¿cuál?

6. S: ¿cuál?

7. E: ¿qué te pregunté?

8. S: usted preguntó por qué estaba infeliz

9. E: no/ no/ no te pregunté por qué estás feliz, te pregunté por qué estás en RENOVAL/ por qué

10. S: si/ eso dije

11. E: es que no te entendí

12. S:lo que dije<pausa $>/$ es necesario que la gente escuche bien<pausa $>/$ ehm<pausa $>$ /vengo aquí porque no soy capaz de trabajar $\langle$ pausa $>/$ no soy $\mathrm{mmm} /$ me cuesta llevar las cosas <alargamiento $>/$ terminadas o a cabo <pausa $>/$ y bien/ y no soy tan responsable <pausa ext>/ me cuesta mucho por ejemplo cocinar/ aunque encuentre divertido eso/ o lavar los platos/ o en el trabajo/ aunque sea ficticio/ que es lo que más me gusta/ no lo termino/ no lo hago por completo/ me cuesta mucho eso.

CRE-H13

\section{3) Ejemplo del grupo de crónicos, falla completa:}

76. E: y esas máquinas/ usted las fabrica/ las repara/ ¿qué hace con ellas?

77. S: lah fábricas las reparo.

78. E: ya.

79. S: de mentira/ porque no las he reparado siempre/ de hecho pelo/<pausa $>/$ las dejo más protectible.

80. E: $i<$ pausa $>/$ pelo?

81. S: si. 
82. E: ya.

83. S: arreglo la antenas y limpio/<pausa>/ ya limpié unos vehículos/ me deben dinero.

84. E: ¿quién le debe ese dinero?

85. S:el estadio chimbinbalan/ <pausa $>/$ traigmola/ chimbimbon/ chimbinbona/ chimbombina/ chimbo/ chimboni/ <pausa extensa $>$

86. E: ya <pausa $>/$ pero <alargamiento $>/$ ile encargaron un trabajo?

87. S: lo que quiero es una pura luca ${ }^{67} /$ no máh $/ /<$ pasua $>/$ para ir a comprarme un coso que tengo que comprarme.

88. E: ¿y para que le sirve ese dinero?

89. S: voy a ir escuchando radio en el auto/<pausa $>/$ donde mi tío Carrera/ que es Vivado/ esa es mi papá/ Vivado es mi papá/<pausa $>$ y yo le digo Carrera y Vivado.

90. E: ya. CRE-H10

1) Ejemplo del grupo de primer episodio, realizado adecuadamente:

1. E: a ver/ ¿por qué has venido? <pausa>/ ¿cuál es la dificultad que estás pasando?

2. S: lo que me acompleja es lo que le decía anteriormente<pausa>/ lo que me acompleja es lo de los estudios<pausa $>/$ el año pasado tuve muchos problemas de estudios// Casi repito<pausa $>$ / eh<pausa $>/$ pasé<pausa $>/$ en verdad/ no sé cómo pasé.

3. E: explícame/ ¿en qué consiste la dificultad?

4. S: no me puedo concentrar $<$ pausa $>/$ en los estudios $<$ pausa $>/$ leo $<$ pausa $>/$ leo $<$ pausa oralizada $>$ pero no $<$ pausa $>$ / como que no $<$ pausa $>/$ logro captarlo

5. E: dame un ejemplo.

6. S: recuerdo una prueba de historia $<$ pausa $>/$ trataba de estudiar sobre la Edad Media<pausa $>/$ recogía palabras $<$ pausa $>/$ pero<pausa $>/$ una idea bastante general<pausa $>$ / no podía $<$ pausa $>/$ eh $<$ pausa oralizada $>/$ aprenderme todo $<$ pausa $>/$ todo $<$ pausa $>/$ solo podía aprenderme partes $<$ pausa $>/$ partes pequeñas.

7. E: ya $<$ pausa $>/$ ¿y qué pasaba en sus pensamientos?

8. S: ehm<pausa oralizada $>/$ pienso mucho<pausa $>/$ pienso mucho todo el día $<$ pausa $>/$ pienso mucho todo el día<pausa $>/$ todos los días//Pero más que nada porque estaba muy ensimismado<pausa $>/$ muy decaído.

9. E: ¿y cómo es la forma de pensar?

10. S: o son recuerdos $\langle$ pausa $>/ o$ son pensamientos que yo creo<pausa $>/ /$ De recuerdos/ puede ser/ a veces/ estoy en un lugar aparece y ocupar hartos minutos $<$ pausa $>/ /$ Cuando yo quiero pensar/ me tomo $<$ pausa $>/$ mi tiempo $<$ pausa $>/$ media hora $<$ pausa $>/$ entre pensar e imaginar.

11. E: ya.

PEE-H10

2) Ejemplo del grupo de primer episodio, realizado con ayuda:

74. E: y en segundo año/ ¿qué pasó?

75. S: me dio depresión/ y<pausa>/ no quería estudiar máh

${ }^{67}$ Luca=billete de mil pesos, referencia a dinero en general 
76. E: pero/ <pausa $>/$ ¿inició el año normalmente/ en marzo ${ }^{68}$ ?

77. S: si/ normalmente/<pausa $>/$ ah! $\langle$ pausa $>/$ eehh $<$ pausa extensa oralizada $>/$ no.

78. E:¿cómo?

79. S: <pausa extensa $>/ ; a h ! /$ no/ no/ no/<pausa $>/$ no comencé en marzo

80. E:¿cuándo empezó?

81. S:bueno/ $2010 /$ por el terremoto

82. E:ya

83. S:no me acuerdo bien

84. E:ya <pausa>/

85. S: la verdad/ no me acuerdo bien

86. E: pero/ trate de hacer un poquito de memoria <pausa extensa>/ el 2010/ usted estuvo en primero medio.

87. S:si

88. E: ¿para el terremoto?

89. $\mathrm{S}: \mathrm{si} /<$ pausa $>/$ dejémoslo en que entré bien

90. E:¿dejémoslo en que entró bien?

91. S:si

92. E: ¿no en marzo?

93. S:si

94. E:¿no entiendo?

95. S:si

E:ya/ pero ¿qué relación tiene el terremoto con no entrar en marzo?

96. $\mathrm{S}: \mathrm{ah} /<$ pausa $>$ / bueno/ ninguna PEE-H14

4.6.1.2. Pares adyacentes y estadio de la enfermedad

Entre los controles registramos 10 casos de realización adecuada, correspondientes al $83,3 \%$ del indicador y 2 casos realizados con ayuda del entrevisador, que representan un 16,7\%. En el grupo de primer episodio encontramos 14 casos realizados adecuadamente, con un 56\%, además de 11 casos realizados con ayuda del entrevistador, con un 44\%. En el grupo de crónicos sólo encontramos 5 caos realizados adecuadamente, que corresponderían al 20\%, la mayor ocurrencia de casos fueron realizados con ayuda del entrevistador, con 17 ocurrencias que representan un $68 \%$ del indicador; finalmente registramos también 3 caos de falla completa, que representan un $12 \%$.

${ }^{68}$ Año académico en Chile y cono sur, se inicia en marzo, finaliza en diciembre. 
Tabla de contingencia 161: pares adyacentes y estadio de la enfermedad.

\begin{tabular}{|c|c|c|c|c|}
\hline \multirow{2}{*}{$\begin{array}{l}\text { Estadio de la } \\
\text { enfermedad }\end{array}$} & \multicolumn{3}{|c|}{ Pares adyacentes } & \multirow[t]{2}{*}{ Total } \\
\hline & Falla & $\begin{array}{c}\text { Realizado con } \\
\text { ayuda }\end{array}$ & $\begin{array}{c}\text { Realizado } \\
\text { adecuadamente }\end{array}$ & \\
\hline \multirow[t]{3}{*}{ Control } & 0 & 2 & 10 & 12 \\
\hline & .6 & 5.8 & 5.6 & 12.0 \\
\hline & $0.0 \%$ & $16.7 \%$ & $83.3 \%$ & $100.0 \%$ \\
\hline \multirow[t]{3}{*}{ Primer episodio } & 0 & 11 & 14 & 25 \\
\hline & 1.2 & 12.1 & 11.7 & 25.0 \\
\hline & $0.0 \%$ & $44.0 \%$ & $56.0 \%$ & $100.0 \%$ \\
\hline \multirow[t]{3}{*}{ Crónico } & 3 & 17 & 5 & 25 \\
\hline & 1.2 & 12.1 & 11.7 & 25.0 \\
\hline & $12.0 \%$ & $68.0 \%$ & $20.0 \%$ & $100.0 \%$ \\
\hline \multirow[t]{3}{*}{ Total } & 3 & 30 & 29 & 62 \\
\hline & 3.0 & 30.0 & 29.0 & 62.0 \\
\hline & $4.8 \%$ & $48.4 \%$ & $46.8 \%$ & $100.0 \%$ \\
\hline
\end{tabular}

El valor de chi cuadrado es de $16.738^{\mathrm{a}}$, y dio como resultado (<p, 002〉), significativo estadísticamente.

Tabla valor de chi cuadrado 162: pares adyacentes y estadio de la enfermedad.

\begin{tabular}{||l|c|c|c||}
\hline \multicolumn{4}{|c||}{ Pruebas de chi-cuadrado } \\
\hline & Valor & $\mathrm{gl}$ & $\begin{array}{c}\text { Sig. asintótica } \\
(2 \text { caras })\end{array}$ \\
\hline Chi-cuadrado de Pearson & $16.738^{\mathrm{a}}$ & 4 & .002 \\
\hline
\end{tabular}


Gráfico 113. Porcentaje de frecuencia de las variables: pares adyacentes y estadio de la enfermedad.

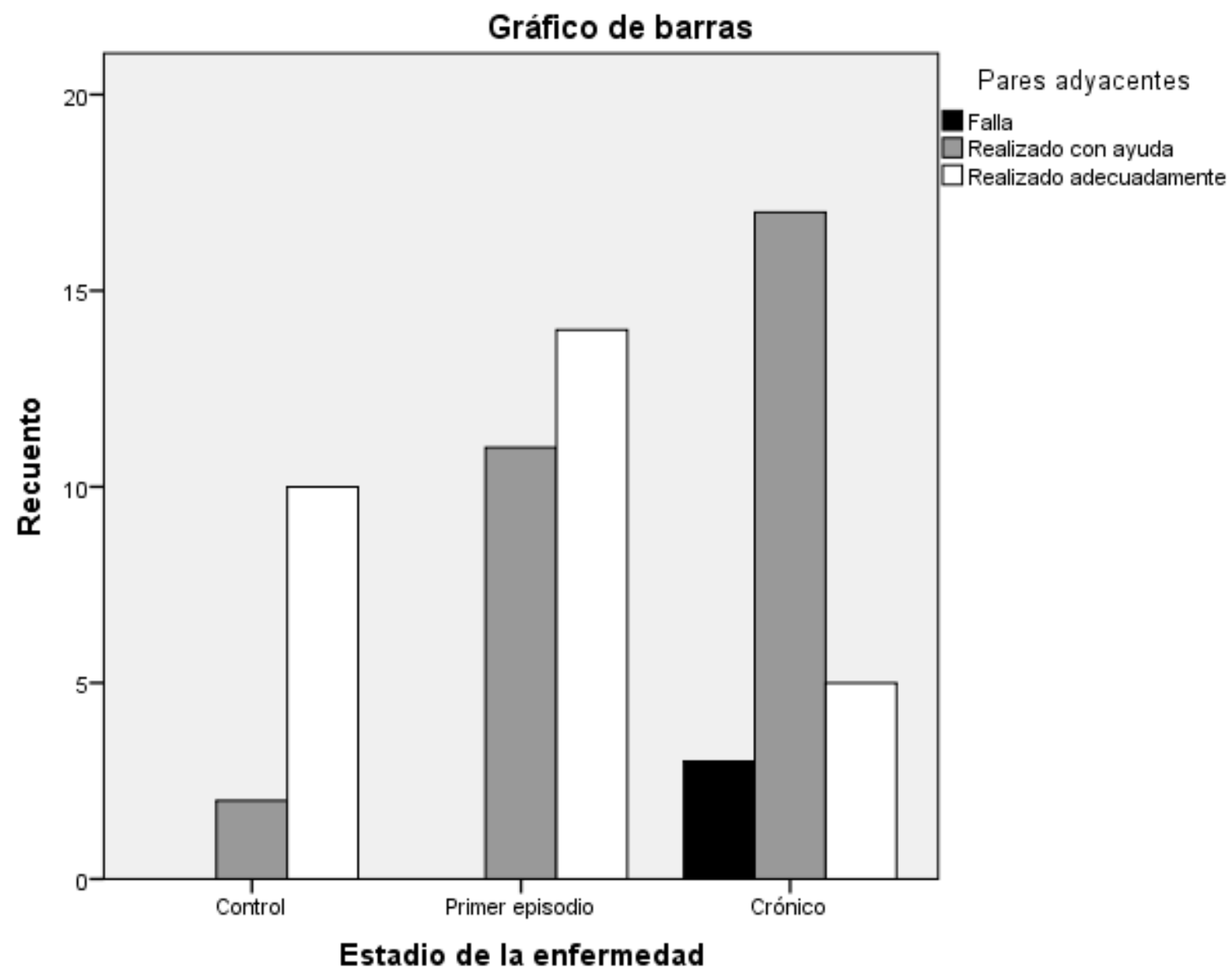

\subsubsection{Pares adyacentes y sexo}

Este indicador no fue significativo, como podemos ver en la tabla, las mujeres presentaron 15 casos realizados adecuadamente, con un 51,7\%; 13 casos de realización con ayuda del entrevistador, con un $44,8 \%$ y 1 solo caos de falla completa, que corresponde a un 3,4\%. Entre los hombres, encontramos medidas similares; 14 caos 
realizados adecuadamente, con un 42,4\%; 17 casos realizados con ayuda del entrevistador, con un 51,5\% y 2 casos de falla completa, con un 6,1\%. Como ya lo hemos señalado a lo largo del análisis, en general los hombres presentan una tendencia levemente ascendente en la ocurrencia de errores discursivos, a pesar de ello, no podemos decir que exista una diferencia que estadísticamente sea significativa.

Tabla de contingencia 163: pares adyacentes y sexo.

\begin{tabular}{|c|c|c|c|c|}
\hline \multirow[t]{2}{*}{ Sexo del sujeto } & \multicolumn{3}{|c|}{ Pares adyacentes } & \multirow[t]{2}{*}{ Total } \\
\hline & Falla & Realizado con ayuda & $\begin{array}{c}\text { Realizado } \\
\text { adecuadamente }\end{array}$ & \\
\hline \multirow[t]{3}{*}{ Mujer } & 1 & 13 & 15 & 29 \\
\hline & 1.4 & 14.0 & 13.6 & 29.0 \\
\hline & $3.4 \%$ & $44.8 \%$ & $51.7 \%$ & $100.0 \%$ \\
\hline \multirow[t]{3}{*}{ Hombre } & 2 & 17 & 14 & 33 \\
\hline & 1.6 & 16.0 & 15.4 & 33.0 \\
\hline & $6.1 \%$ & $51.5 \%$ & $42.4 \%$ & $100.0 \%$ \\
\hline \multirow[t]{3}{*}{ Total } & 3 & 30 & 29 & 62 \\
\hline & 3.0 & 30.0 & 29.0 & 62.0 \\
\hline & $4.8 \%$ & $48.4 \%$ & $46.8 \%$ & $100.0 \%$ \\
\hline
\end{tabular}

El valor de chi cuadrado es $.646^{\mathrm{a}}$, que dio como resultado no significativo $(<\mathrm{p}, 724>)$

Tabla valor de chi cuadrado 164: pares adyacentes y sexo.

\begin{tabular}{||l|c|c|c||}
\hline \multicolumn{4}{|c||}{ Pruebas de chi-cuadrado } \\
\hline & Valor & gl & $\begin{array}{c}\text { Sig. asintótica } \\
(2 \text { caras })\end{array}$ \\
\hline Chi-cuadrado de Pearson & $.646^{\mathrm{a}}$ & 2 & .724 \\
\hline
\end{tabular}


Gráfico 114 Porcentaje de frecuencia de las variables: pares adyacentes y sexo.

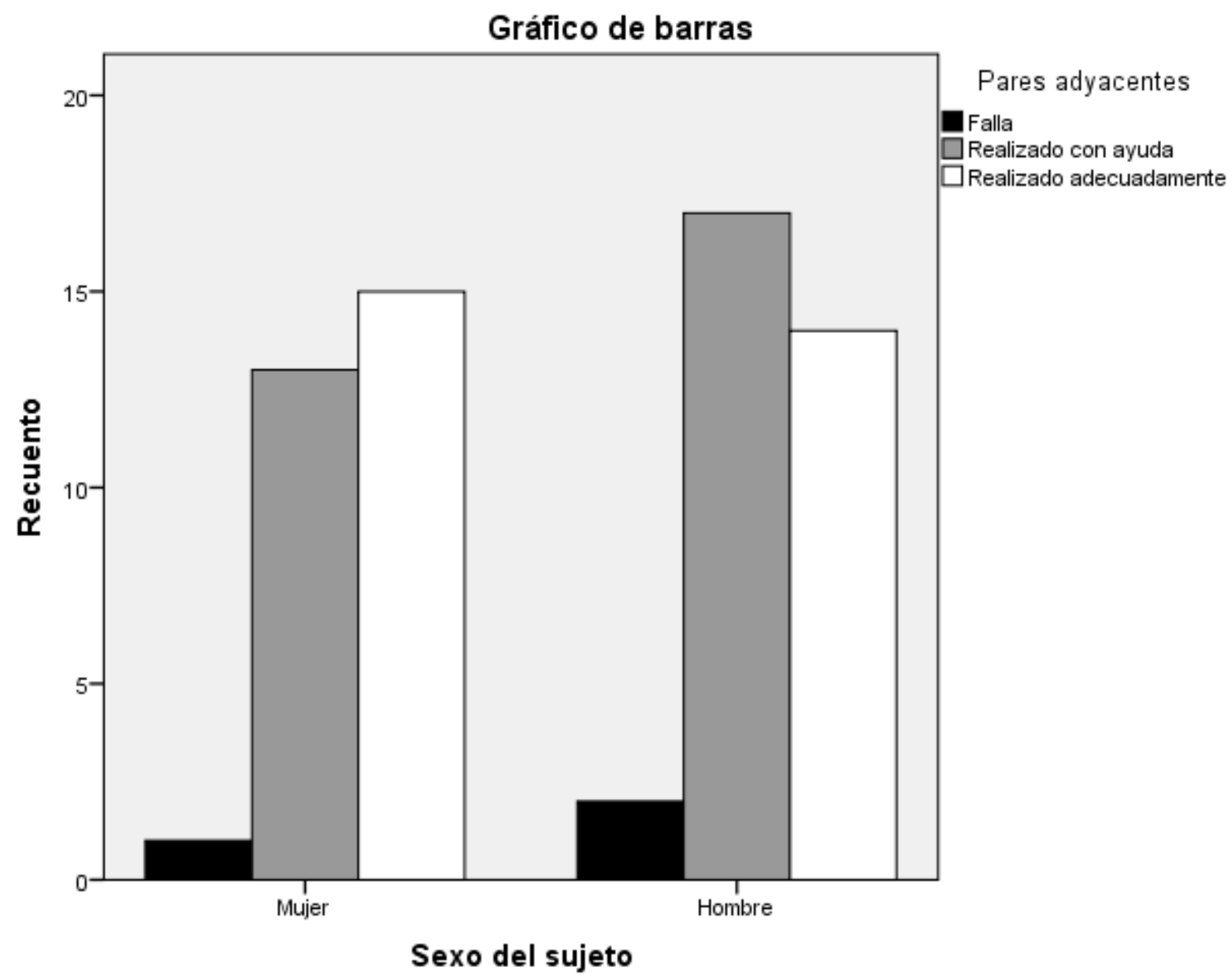

4.6.1.4. Pares adyacentes y tramo de la enfermedad

Este indicador no resultó significativo, observamos entre los controles, 10 casos de realización adecuada, equivalentes al 83,3\% y 2 casos de realizado con ayuda del entrevistador, con un 16,7\%. En el grupo de primer episodio de $>0$ a $<2$ años encontramos 8 casos de realización adecuada, con un 57,1\% y 6 casos de realización con ayuda del entrevistador, con 42,9\%. Luego, en el grupo de primer episodio de $>2$ a >3 años, encontramos 6 casos de realización adecuada, con un 54,5\% y 5 casos realizados con ayuda del entrevistador, que corresponden a un 45,5\%. En el grupo de 
crónicos de hasta 5 años, encontramos solo 2 casos de realización adecuada, con un 20\%; 7 casos de realización con ayuda del entrevistador, con un 70\% y 1 caso de falla completa, con un 10\%. En el grupo de los crónicos de 5 años y más, encontramos 3 casos de realización adecuada, con un 20\%; 10 casos de realización con ayuda del entrevistador, con un $66,7 \%$ y 2 casos de falla completa, con un $13,3 \%$.

Tabla de contingencia 165: pares adyacentes y tramo de la enfermedad.

\begin{tabular}{|c|c|c|c|c|}
\hline \multirow{2}{*}{$\begin{array}{l}\text { Tramo de la } \\
\text { enfermedad }\end{array}$} & \multicolumn{3}{|c|}{ Pares adyacentes } & \multirow[t]{2}{*}{ Total } \\
\hline & Falla & $\begin{array}{l}\text { Realizado con } \\
\text { ayuda }\end{array}$ & $\begin{array}{c}\text { Realizado } \\
\text { adecuadamente }\end{array}$ & \\
\hline \multirow[t]{3}{*}{ Control } & 0 & 2 & 10 & 12 \\
\hline & .6 & 5.8 & 5.6 & 12.0 \\
\hline & $0.0 \%$ & $16.7 \%$ & $83.3 \%$ & $100.0 \%$ \\
\hline \multirow{3}{*}{$\begin{array}{l}\text { Primer episodio } 0 \text { a } 2 \\
\text { años }\end{array}$} & 0 & 6 & 8 & 14 \\
\hline & .7 & 6.8 & 6.5 & 14.0 \\
\hline & $0.0 \%$ & $42.9 \%$ & $57.1 \%$ & $100.0 \%$ \\
\hline \multirow{3}{*}{$\begin{array}{l}\text { Primer episodio } 2 \text { a } 3 \\
\text { años }\end{array}$} & 0 & 5 & 6 & 11 \\
\hline & .5 & 5.3 & 5.1 & 11.0 \\
\hline & $0.0 \%$ & $45.5 \%$ & $54.5 \%$ & $100.0 \%$ \\
\hline \multirow[t]{3}{*}{ Crónico hasta 5 años } & 1 & 7 & 2 & 10 \\
\hline & .5 & 4.8 & 4.7 & 10.0 \\
\hline & $10.0 \%$ & $70.0 \%$ & $20.0 \%$ & $100.0 \%$ \\
\hline \multirow[t]{3}{*}{ Crónico 5 y más años } & 2 & 10 & 3 & 15 \\
\hline & .7 & 7.3 & 7.0 & 15.0 \\
\hline & $13.3 \%$ & $66.7 \%$ & $20.0 \%$ & $100.0 \%$ \\
\hline \multirow[t]{3}{*}{ Total } & 3 & 30 & 29 & 62 \\
\hline & 3.0 & 30.0 & 29.0 & 62.0 \\
\hline & $4.8 \%$ & $48.4 \%$ & $46.8 \%$ & $100.0 \%$ \\
\hline
\end{tabular}

El valor de chi cuadrado es de $16.907^{\mathrm{a}}$, y dio como resultado (<p, 031>), no significativo estadísticamente. 
Tabla valor de chi cuadrado 166: pares adyacentes y tramo de la enfermedad.

\begin{tabular}{||c|c|c|c||}
\hline \multicolumn{4}{|c||}{ Pruebas de chi-cuadrado } \\
\hline & Valor & $\mathrm{gl}$ & $\begin{array}{c}\text { Sig. asintótica } \\
(2 \text { caras })\end{array}$ \\
\hline Chi-cuadrado de Pearson & $16.907^{\mathrm{a}}$ & 8 & .031 \\
\hline
\end{tabular}

Gráfico 115 Porcentaje de frecuencia de las variables: pares adyacentes y tramo de la enfermedad.

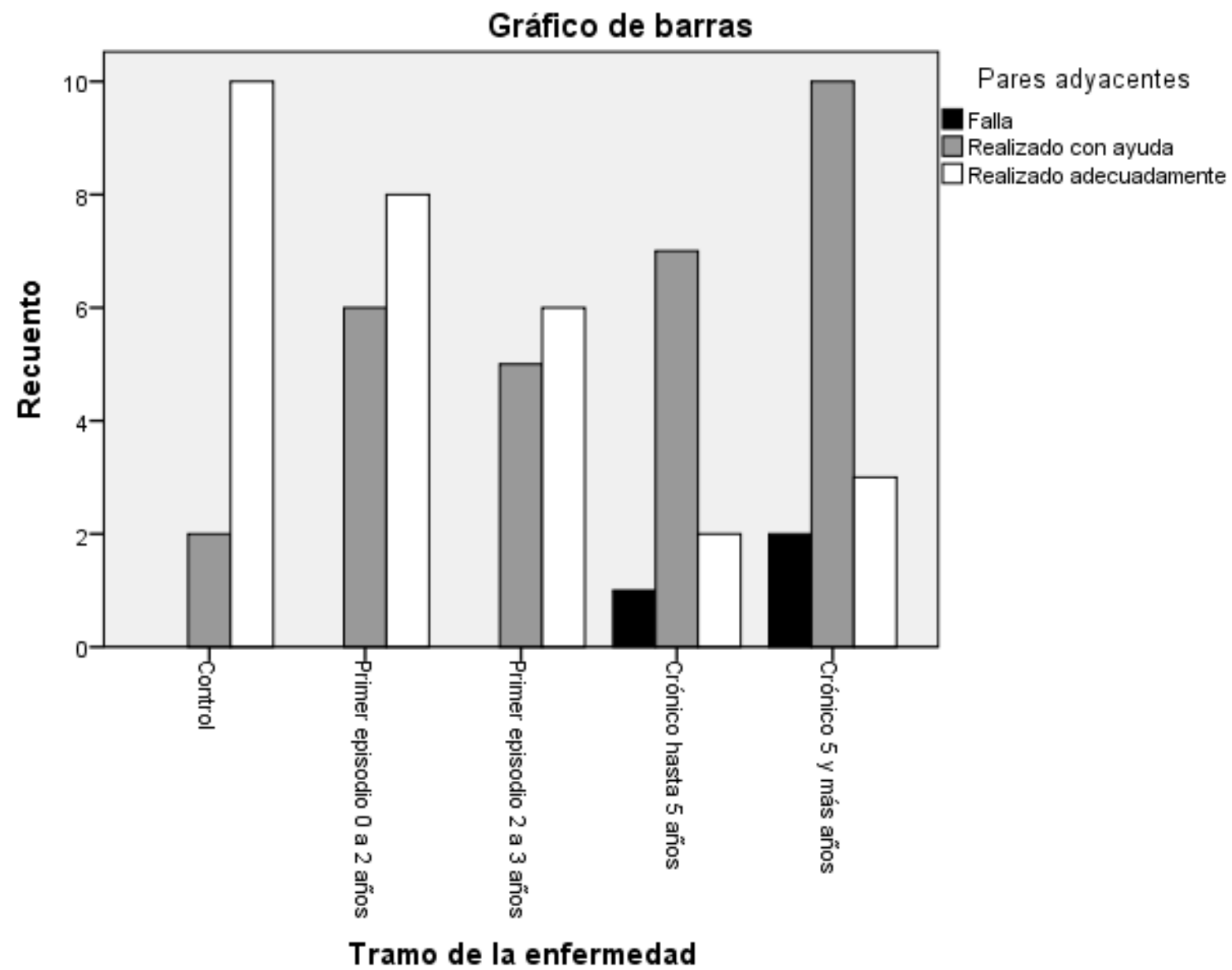




\subsubsection{Pares adyacentes y subtipo de la enfermedad}

Este indicador no resultó significativo. Observamos, entre los controles, 10 casos de realización adecuada, equivalentes al 83,3\% y 2 casos de realizado con ayuda del entrevistador, con un $16,7 \%$. Entre el grupo de esquizofrenia paranoide, observamos 12 casos de realización adecuada, con un 36\%; 20 casos de realización con ayuda del entrevistador, con un 60,6\% y 1 caso de falla completa, que corresponde al 11,1\%. En el grupo de esquizofrenia desorganizada encontramos 3 casos de realizado adecuadamente, con un 37,5\%; 4 casos realizados con ayuda del entrevistador, con un $50 \%$ y 1 caso de falla completa, con un $12,5 \%$.

Tabla de contingencia 167: pares adyacentes y subtipo de la enfermedad.

\begin{tabular}{|c|c|c|c|c|}
\hline \multirow{2}{*}{$\begin{array}{l}\text { Subtipo de la } \\
\text { esquizofrenia }\end{array}$} & \multicolumn{3}{|c|}{ Pares adyacentes } & \multirow[t]{2}{*}{ Total } \\
\hline & Falla & $\begin{array}{c}\text { Realizado con } \\
\text { ayuda }\end{array}$ & $\begin{array}{c}\text { Realizado } \\
\text { adecuadamente }\end{array}$ & \\
\hline \multirow{3}{*}{ Control } & 0 & 2 & 10 & 12 \\
\hline & .6 & 5.8 & 5.6 & 12.0 \\
\hline & $0.0 \%$ & $16.7 \%$ & $83.3 \%$ & $100.0 \%$ \\
\hline \multirow[t]{3}{*}{ Paranoide } & 1 & 20 & 12 & 33 \\
\hline & 1.6 & 16.0 & 15.4 & 33.0 \\
\hline & $3.0 \%$ & $60.6 \%$ & $36.4 \%$ & $100.0 \%$ \\
\hline \multirow[t]{3}{*}{ Indiferenciada } & 1 & 4 & 4 & 9 \\
\hline & .4 & 4.4 & 4.2 & 9.0 \\
\hline & $11.1 \%$ & $44.4 \%$ & $44.4 \%$ & $100.0 \%$ \\
\hline \multirow[t]{3}{*}{ Desorganizada } & 1 & 4 & 3 & 8 \\
\hline & .4 & 3.9 & 3.7 & 8.0 \\
\hline & $12.5 \%$ & $50.0 \%$ & $37.5 \%$ & $100.0 \%$ \\
\hline \multirow[t]{3}{*}{ Total } & 3 & 30 & 29 & 62 \\
\hline & 3.0 & 30.0 & 29.0 & 62.0 \\
\hline & $4.8 \%$ & $48.4 \%$ & $46.8 \%$ & $100.0 \%$ \\
\hline
\end{tabular}


El valor de chi cuadrado es de $10.404^{\mathrm{a}}$, y dio como resultado $\left.(<\mathrm{p}, 109\rangle\right)$ no significativo estadísticamente.

Tabla valor de chi cuadrado 168: pares adyacentes y subtipo de la enfermedad.

\begin{tabular}{||l|c|r|c||}
\hline \multicolumn{4}{|c||}{ Pruebas de chi-cuadrado } \\
\hline & Valor & $\mathrm{gl}$ & $\begin{array}{c}\text { Sig. asintótica } \\
(2 \text { caras })\end{array}$ \\
\hline Chi-cuadrado de Pearson & $10.404^{\mathrm{a}}$ & 6 & .109 \\
\hline
\end{tabular}

Gráfico 116 Porcentaje de frecuencia de las variables: pares adyacentes y subtipo de la enfermedad.

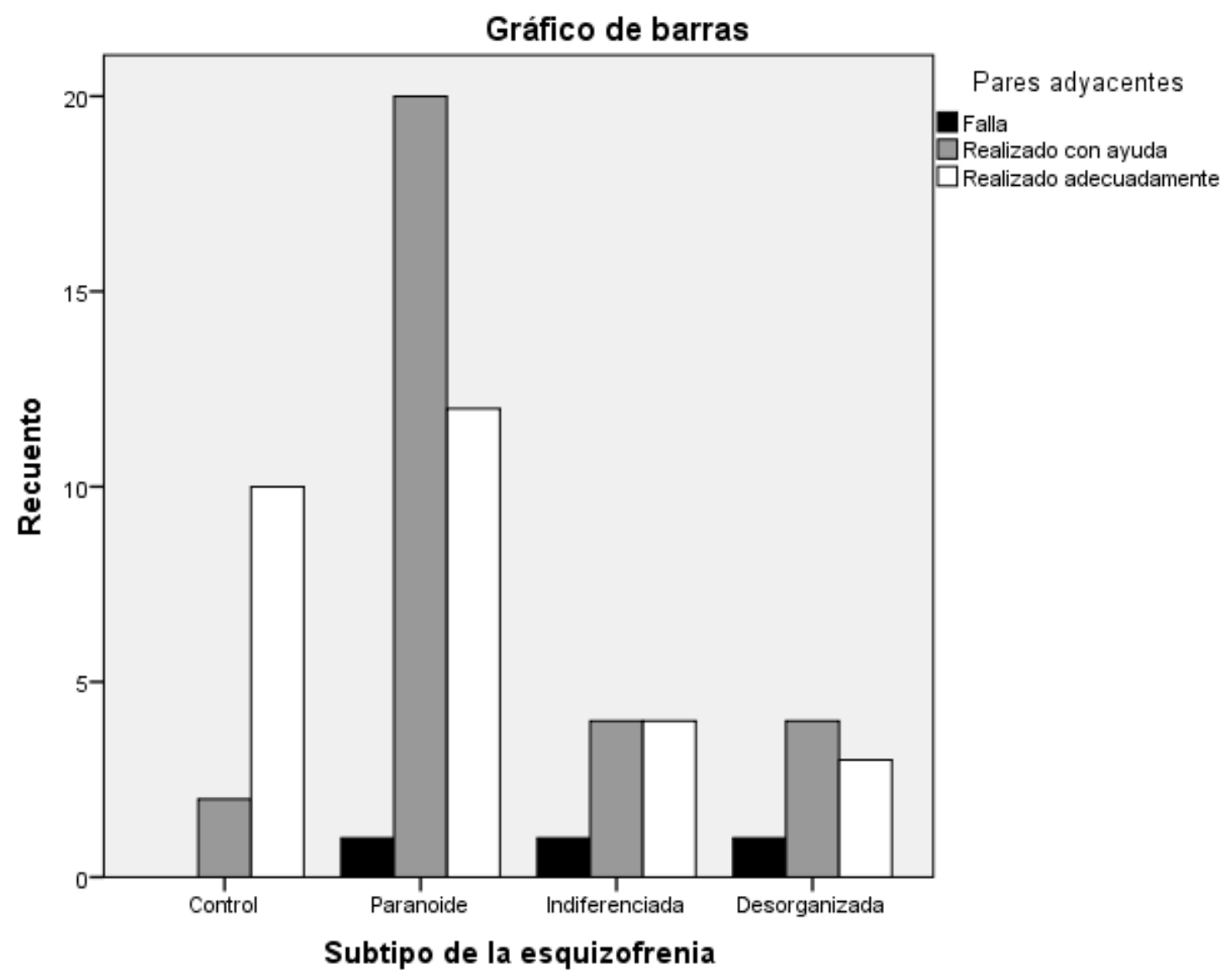




\subsubsection{Toma de turnos}

Para la transición de un turno a otro, es necesario comprender las claves pragmáticas de la situación comunicativa. En Condon y Ogston (1967) señalaron que existe lo que ellos denominaron, una "sincronía interactiva", entre todos los elementos que componen el discurso, incluyendo los no verbales como los kinésicos. Esto haría posible no solo el intercambio de información, sino también la comprensión de esta. Poyatos (1994) concibe la conversación como una serie de intercambios verbales y no verbales, distingue diferentes claves para hablante y oyente en diferentes instancias de la conversación, como las conductas de inicio, de cambio de turno o conductas secundarias. En estas instancias encontramos claves como petición de turno, cesión de turno, ofrecimiento de turno, retención de turno, abandono de turno, entre otras. Para el presente estudio tomamos en cuenta el desempeño global de los informantes y consideramos la evaluación de este desempeño a partir de las diferentes conductas comunicativas observadas. Según eso, valoramos si la toma de turnos se realizó sin ayuda del entrevistador, es decir, adecuadamente, requirió intervención de éste, o bien, falló en la tarea.

\subsubsection{Ejemplos:}

Ejemplos del grupo de crónicos realizado adecuadamente:

1. E: A ver/ A

2. S: $\quad$ <murmulla>

3. E: ¿qué/ fue lo que le pasó?/ cuénteme

4. S: ya le dije

5. E: qué

6. S: quería cambiar los remedios químicos/ por remedios vitaminas/ minerales/ cosa asíii $<$ pausa oralizada $>$ y... $<$ pausa oralizada $>$ lo hice y no resultó/ y ya sé que tengo que tomar <murmulla $>$

7. $\quad$ E: $\mathrm{y} /<$ pausa $>/$ ¿por qué te acontece todo esto?/ ¿por qué te pasa todo esto?

8. S: por querer probar $\mathrm{po} / \mathrm{a} / \mathrm{ver}$ si puedooo $\langle$ pausa oralizada $>$

9. $\quad$ E: ¿controlar que?/ que es lo que <pausa $>$ /

10. S: probar/ no controlar

11. E: ah/ya/ y ¿qué quieres probar?

12. S: si puedooo<pausa oralizada> con la vitaminas y los minerales 
13. E: ya/ si/¿ si tu puedes con?/ vitaminas y minerales/ ¿qué cosa puedes?

14. S: mantener mi cerebro bien/ mi mente/<pausa $/$ y no puedo/ ya lo tengo claro

15. E: ¿y qué pasó con tu mente?

16. S: se descontroló <ríe>

17. E: ¿de qué manera?

18. $\mathrm{S}$ : aaaay<pausa oralizada $>$ / seee $<$ pausa oralizada $>$ desequilibró/ se puso rara/ ahí me bajo la cosa que tengo <ríe>

19. E: ¿Qué tiene?

20. S: la esquizofrenia que tengo

21. E: ¿ en qué consiste?/ ¿qué es para ti eso?

22. S: $/<$ pausa $>/$ ¿para miiii?<pausa oralizada> es/ ¿qué puede ser?/ como desconfianzaaa<pausa oralizada $>$ paranoicaaa<pausa oralizada $>/$ pero no escucho ni veo nada/ es co<palabra cortada> mi cabeza como enrolla no más

23. E: de acuerdo/ pero/ ¿qué significa paranoica?/ ¿que es para ti eso?

24. S: eso/ para mí es/ perseguí<da>a, que/ todos me quieren hacer algo 〈ríe> desconfianza de la gente

25. E: ¿Qué percibes tú de la gente?

26. S: percibooo<pausa oralizada> que es mala la gente <ríe>

27. E: ya

28. S: enserio/ algo uno nota/ pero son cosas mías pero ya a lo mejor es

29. E: que bueno/ me alegro mucho que ya te vas a mejorar

30. S: si

Ejemplo del grupo de crónicos realizado con ayuda:

75. E: ¿cómo le va?

76. S: bien dr.

77. E: ¿qué me cuenta esta semana?

78. S: <pausa extensa>

79. E: ¿cómo ha estado esta semana?

80. S: bien

81. E: ¿le ha ocurrido alguna cosa en especial?

82. S: no, nada.

83. E: y/ ¿qué es lo que ha hecho?

84. S.mmm

85.E: ¿ha salido?/ ¿ha ido de compras?/

86.S: $/<$ pausa $>/$ fui al super

87. E: ya

Ejemplos del grupo de crónicos, falla completa:

\section{1) Por retención de turno:}

E: buen $<$ palabra cortada $>/<$ superposición $>/<$ el entrevistador ofrece asiento con la mano, el entrevistado se sienta mientras toma el turno de habla inicial $>$

S: Buenos días a todos los presentes/<saluda a los entrevistadores $>/<$ pausa $>$ /eh $<$ pausa $>/$ mi nombre es J. D. D. O. <pausa $>/$ yo soy de Iquique<pausa $>/$ llevo dos años y medio hospitalizado acá en El Peral $<$ pausa $>/ /$ bueno/ eh $<$ pausa $>/$ como les puedo contarles/ eh/ $<$ pausa $>$ yo tengo una enfermedad/ eh $<$ pausa>/ un cuadro obsesivo <pausa>/ a mi me afecta todo lo que es callo/ durezas/ heridas/marcas/ 
manchas/ cicatrices<pausa $>/ /$ Estoy más que obsesionado con mi cuerpo <pausa $>$ / es una preocupación exagerada como dice mi doctora $\mathrm{P}$ <pausa extensa>///Estoy tan obsesionado de mi piel/ de mi mente/ quizáh de mi cabeza también/ totalmente obsesionado<pausa>/ yo ya no sé qué hacer/ esto me<pausa>/ me tiene consumido por dentro/<pausa $>/$ me duele el alma $<$ pausa $>/$ el corazón<pausa $>/$ me da pena $<$ pausa $>/$ me da tristeza $<$ pausa $>/ / A$ veces no me dan ganas de seguir viviendo más $<$ pausa $>/$ y entonces<pausa $>/$ a lo que quiero llegar yo/ es que yo/ cuando niño también vi cosas que no<pausa $>/$ tenía que haber visto un niño/ de cinco años/ yo cuando era niño/<pausa $>$ vi cosas terribles <pausa $>$ / a los cinco años yo <pausa>/ no había armonía en mi casa ni felicidad <pausa $>/ / / \mathrm{Vi}$ jarana/ vi droga/ vi adicción/ vi orgía/ vi<pausa $>/$ cuanto se llama<pausa $>/$ eh $<$ pausa $>/$ hombres con mujeres teniendo sexo/ dándose besos con lengua eh<pausa $>$ / jarana todos los días a cada rato/ sexo arriba en la pieza de mi mamá/de mi padre<pausa $>$ y todas esas cosas<pausa $>/$ las golpizas que le daba mi papá a mi mamá<pausa $>$ eh<pausa>/ ¿Qué más? <pausa $>/ /$ Eh<pausa>/ cuando le pegaba/ cuando la arrastraba del pelo/ y esas cosas me quedaron marcadas $<$ pausa $>$ esas cosas a mi me quedaron marcadas $<$ pausa $>/ /$ Eso lo de mi papá con mi mamá/ las peleas que tuvieron ellos<pausa $>/$ esas cosas me quedaron marcadas <pausa>/ y yo no sé poh<pausa>/ yo no sé<pausa>/ si yo no soy psicólogo/ ni tampoco soy adivino<pausa $>$ /ni tampoco soy psiquiatra <pausa>/en el sentido de que/ yo tampoco no tenía idea/ o nunca iba a pensar que yo iba a caer en un hospital psiquiátrico<pausa $>/ /$ Yo a los catorce/ quince años no tenía nada en mi piel<pausa $>/$ no tenía callos<pausa $>/$ no tenía durezas $<$ pausa $>/$ no tenía heridas $<$ pausa $>/$ no tenía marcas $<$ pausa $>/$ manchas nada $<$ pausa $>/ /$ Yo me miraba mih pieh $<$ pausa $>/$ y no tenía nada<pausa $>$ si lo mío es la pura piel<pausa $>$ /yo sé que está en la mente<pausa $>/$ todo<pausa>/porque todo se conecta con la mente/ la mente ordena el cuerpo completo<pausa>/ y eso es lógico yo se lo aclare<pausa > y esa es la verdad<pausa $>$ yo admito que es una enfermedad<pausa $>$ / pero posiblemente se haya formado un trastorno<pausa $>$ /por lo que viví y posiblemente $<$ pausa $>/$ a lo mejor hay un corto circuito <pausa>/entre una neurona y otra/ puede ser la otra posibilidad/ porque siento un palpitar acá $/<$ se toca la cabeza $>/$ pausa $>/$ y como que me apreta la sien<pausa $>/$ las dos $<$ pausa $>/$ las dos partes de acá de la sien $/<$ se toca la cabeza $>/<$ pausa $>/ y$ eso a mí me tiene muy preocupado $/\langle$ pausa $\rangle /$ demasiadamente preocupado/ $/$ se toca la cabeza $>/$ también $/\langle$ pausa $\rangle /$ por eso muchas veces he pedido que me hicieran un scanner/ o una resonancia magnética/ o descubrir por dentro de mi cerebro/ lo que puede estar sucediendo<pausa>/ que también quiero saber /qué puede ser<pausa $>$ y eso a mí me/<se toca la cabeza $>/$ da susto/ me da miedo también<pausa $>$ que puede suceder/ y bueno y<pausa > yo qué no daría/ por ver mi mente sana/ y mi piel sana/ nada más le pido al Señor<pausa $>$ nada más le pido<pausa $>/ /$ A veces me da mucha pena <pausa $>/$ me da mucha tristeza $<$ pausa $>$ yo veo una cicatriz / por no querer tenerla/ me la saco/ me la saco/ me la escarbo/ y se transforma en herida<pausa>/ y que a mí me descompone<pausa>/ ya no sé qué hacer<pausa>/ se transforma en herida/ veo un granito/ un porotito/ una verruga/ un $<$ pausa $>/$ cualquier cosa $<$ pausa $>$ / me la saco <pausa>/se transforma en herida <pausa>/y ahí me desespero <pausa>/queda una cicatriz/ me angustio/ me da pena/ no sé qué hacer<pausa>/ si no es por vanidad/ lo mío no es por vanidad/ no es porque me digan: $<\operatorname{cita}>$ : “oh J. tenís las manos bonitas/ qué lindas tus manos/ qué lindo tu $<$ pausa $>$ "/ no $<$ pausa $>$ /realmente me afecta esa parte psicológica $<$ pausa $>/ y$ yo ya no sé qué hacer<pausa>//A lo mejor hay tantas personas que tienen esto heridas/ cicatrices o callos y son felices/ hacen su vida normal/ porque su mente no está centrada en eso<pausa>/ lo mío si está centrado en esto<pausa>/ y como está centrado en esto/ está en la memoria/ y está en la mente/ está pegado el dedo entero con esta herida/<señala un dedo $>/$ está pegado dentro de mi sien/ de mi mente/ se/ me refleja/ así dentro<pausa $>/ /$ Pegado/ pegado total la herida de la rodilla/ la herid/ la cicatriz que tengo acá en mi frente $<$ pausa $><$ se toca la frente $>/$ también está pegado en mi mente<pausa $>/$ en la memoria está pegado<pausa>/ pero pegado/ está muy/ muy pegado/ muy/ muy pegado/ está demasiadamente 
pegado mi<pausa $>$ /mi piel/ solamente es mi piel nada más<pausa $>/ /$ Yo no he estado por drogas/ ni por alcohol/ ni por marihuana/ ni por pasta base/ ni por digamos/ ni por un<pausa>/gracias a Dios no se transformó en una esquizofrenia esto<pausa>/ pero mi mente mis neuronas deben estar buenas $<$ pausa $>$ pero hay algo que debe estar batallando en la mente<pausa $>/$ que porque se manifestó de ese punto<pausa>/ en la piel/ poh mira poh/ en la piel/ me da risa/ <ríe>/ pero es la piel<pausa $>/ /$ Ésta herida/ ya estoy preocupado ya/ ya me estoy asustando/ porque va a quedar para siempre/ me asusta/ me agarra el temor/ el temor de que pueda quedar así<pausa>/ si yo no pido la perfección tampoco/ porque nadie/somos perfectos/ nadie en este mundo es perfecto/ pero pido ser sanado en lo que a mi realmente a mí me afecta/ nada más/ no es mucho pedir/ es eso no más<pausa>/ de corazón se los pido/ yo sería el hombre más feliz del mundo/ al ver sanado lo que a mí me afecta y nada más<pausa $>$ / eso.

E: ¿Jean es su nombre?

S: J.

\section{2) Falla por superposición de turnos:}

S: mire/ hablemos de lógica un poco/ a ver<pausa extensa $>$

E: ¿sobre?

S: bueno/ los Gun's Roses que según los tipoh/ $<$ pausa extensa $>/$

E: ¿quié /<palabra cortada por interrupción>

S: logra acostarse en una camilla/médica/ camilla como yo<pausa>/ el baterista/ el guitarrista y el artista que es cantante/ logra eso/ acostarse en una camilla/ después lo sacan/ y le ponen mujeres esculturales no más// El baterista/ es más correcto y yo soy más correcto que él.

E: ya/ pero

S: <superpuesto>/ que le quede claro todo

E. ya...

S: <superpuesto $>/ ¿$ alguna pregunta?

E: si <superposición>

S: el sistema muscular/ yo vine aquí a dar una entrevista completa estoy lleno de ideas/tengo 42 años/ <superpuesto>

E: si/ claro

S: ¿usted es psiquiatra? es dra?

E. si.

\section{3) Falla por pausas extensas, respuestas monosilábicas o ecos:}

S: <pausa $>$ lila <pausa $>/$ esos dos colores encuentro y amarillo

E: ¿rojo/ lila $\mathrm{y}<$ pausa $>/$ amarillo?

S: amarillo <confirmatorio>/

E: ya/ ¿y ese color / depende de qué? <pausa>/ ¿qué usted los vea así? <pausa>/ ¿cambian de repente?

$\mathrm{S}:$ <pausa>/ no/ yo no tengo nada que ver con eso.

E: ya <alargamiento>/ ya/ ¿y usted los ve todo el tiempo? 
S: <pausa>/ si.

E:¿sí?

S: si

E: <superpuesto>/ ahor <palabra cortada>/ ahora mismo/ me decía usted que los veía

S: si

E: ya

S: si

$\mathrm{E}:$ ya $<$ pausa $>/$ ¿y por qué rojo significa que uno se va a morir?

S: porque así es.

E:¿porque así es?

S: si

E: ya<pausa $>/$ ¿estas líneas también le hablan a usted?

S: si

E: pero <pausa>/

\subsubsection{Toma de turnos y estadio de la enfermedad}

Este indicador resultó significativo estadísticamente. Observamos entre los controles 11 casos realizados adecuadamente, con un $91,7 \%$ y 1 caso realizado con ayuda del entrevistador, que corresponde a un 8,3\%. Entre los de primer episodio, encontramos 14 casos realizados adecuadamente, con un $56 \%$ y 11 casos realizados con ayuda del entrevistador, con un 44\%. En el grupo de crónicos, encontramos 5 casos realizados adecuadamente, con un 20\%; 14 casos realizados con ayuda del entrevistador, con un $56 \%$ y 6 casos de falla completa, con un $24 \%$.

Tabla de contingencia 169: toma de turnos y estadio de la enfermedad.

\begin{tabular}{|c|c|c|c|c|}
\hline \multirow{2}{*}{$\begin{array}{l}\text { Estadio de la } \\
\text { enfermeddad }\end{array}$} & \multicolumn{2}{|c|}{ Toma de turnos } & \multicolumn{2}{|c|}{ Total } \\
\hline & Falla & $\begin{array}{l}\text { Realizado con } \\
\text { ayuda }\end{array}$ & $\begin{array}{l}\text { Realizado } \\
\text { adecuadamente }\end{array}$ & \\
\hline \multirow[t]{3}{*}{ Control } & 0 & 1 & 11 & 12 \\
\hline & 1.2 & 5.0 & 5.8 & 12.0 \\
\hline & $0.0 \%$ & $8.3 \%$ & $91.7 \%$ & $100.0 \%$ \\
\hline \multirow{3}{*}{$\begin{array}{l}\text { Primer } \\
\text { episodio }\end{array}$} & 0 & 11 & 14 & 25 \\
\hline & 2.4 & 10.5 & 12.1 & 25.0 \\
\hline & $0.0 \%$ & $44.0 \%$ & $56.0 \%$ & $100.0 \%$ \\
\hline \multirow[t]{2}{*}{ Crónico } & 6 & 14 & 5 & 25 \\
\hline & 2.4 & 10.5 & 12.1 & 25.0 \\
\hline
\end{tabular}




\begin{tabular}{||l|l|l|l|l||}
\hline \multirow{3}{*}{ Total } & $24.0 \%$ & $56.0 \%$ & $20.0 \%$ & $100.0 \%$ \\
\cline { 2 - 5 } & 6 & 26 & 30 & 62 \\
\cline { 2 - 5 } & 6.0 & 26.0 & 30.0 & 62.0 \\
\cline { 2 - 5 } & $9.7 \%$ & $41.9 \%$ & $48.4 \%$ & $100.0 \%$ \\
\hline
\end{tabular}

El valor de chi cuadrado es de $22.424^{\mathrm{a}}$, y dio como resultado, $\left.(<\mathrm{p}, 000\rangle\right)$ significativo estadísticamente.

Tabla valor de chi cuadrado 170: toma de turnos y estadio de la enfermedad.

\begin{tabular}{||l|c|r|r||}
\hline \multicolumn{4}{|c|}{ Pruebas de chi-cuadrado } \\
\hline & Valor & $\mathrm{gl}$ & Sig. asintótica (2 caras) \\
\hline Chi-cuadrado de Pearson & $22.424^{\mathrm{a}}$ & 4 & .000 \\
\hline
\end{tabular}

Gráfico 117. Porcentaje de frecuencia de las variables: toma de turnos y estadio de la

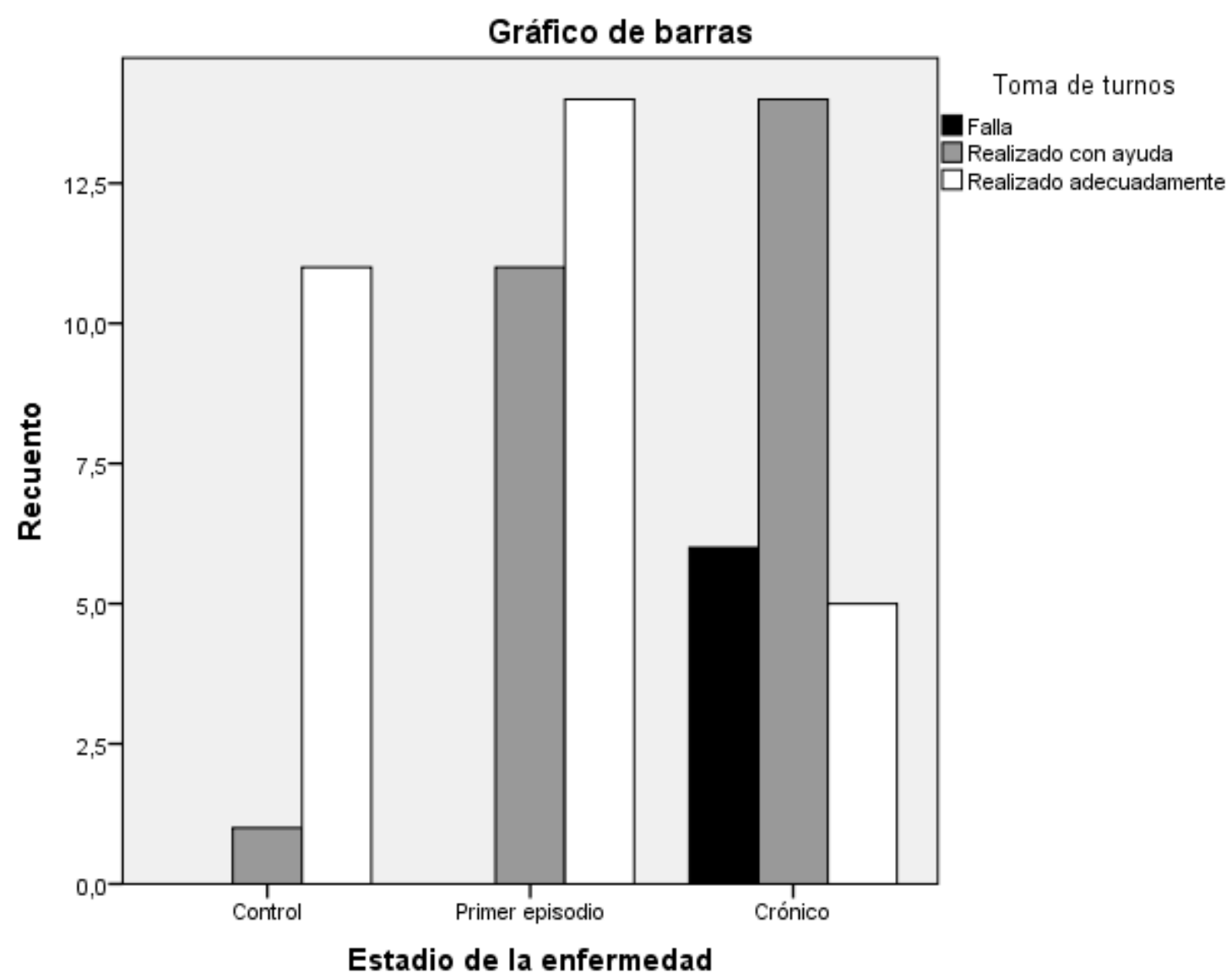




\subsubsection{Toma de turnos y sexo}

En la variable toma de turnos y sexo, no se registran contrastes relevantes entre los grupos. Las mujeres presentaron 16 casos realizados adecuadamente, con un 55,2\%; 12 casos realizados con ayuda del entrevistador, con un 41,4\% y 1 caso de falla completa, con un 3,4\%. Entre los hombre observamos, 14 casos realizados adecuadamente, con un 42,4\%; 14 casos realizados con ayuda del entrevistador, con un $42,4 \%$ y 5 casos de falla completa, con un $15,2 \%$.

Tabla de contingencia 171:toma de turnos y sexo.

\begin{tabular}{||l|l|l|l|l||}
\hline \multirow{3}{*}{ Sexo del sujeto } & \multicolumn{2}{|l|}{ Toma de turnos } & \multirow{2}{*}{ Total } \\
\cline { 2 - 5 } & Falla & $\begin{array}{l}\text { Realizado con } \\
\text { ayuda }\end{array}$ & $\begin{array}{l}\text { Realizado } \\
\text { adecuadamente }\end{array}$ & \\
\hline \multirow{3}{*}{ Mujer } & 1 & 12 & 16 & 29 \\
\cline { 2 - 5 } & 2.8 & 12.2 & 14.0 & 29.0 \\
\cline { 2 - 5 } & $3.4 \%$ & $41.4 \%$ & $55.2 \%$ & $100.0 \%$ \\
\hline \multirow{3}{*}{ Hombre } & 5 & 14 & 14 & 33 \\
\cline { 2 - 5 } & 3.2 & 13.8 & 16.0 & 33.0 \\
\cline { 2 - 5 } & $15.2 \%$ & $42.4 \%$ & $42.4 \%$ & $100.0 \%$ \\
\hline \multirow{3}{*}{ Total } & 6 & 26 & 30 & 62 \\
\cline { 2 - 5 } & 6.0 & 26.0 & 30.0 & 62.0 \\
\cline { 2 - 5 } & $9.7 \%$ & $41.9 \%$ & $48.4 \%$ & $100.0 \%$ \\
\hline
\end{tabular}

El valor de chi cuadrado es de $2.707^{\mathrm{a}}$, y dio como resultado (>p, 258>), no significativo estadísticamente.

Tabla valor de chi cuadrado 172: toma de turnos y sexo.

\begin{tabular}{||c|c|c|c||}
\hline \multicolumn{4}{|c||}{ Pruebas de chi-cuadrado } \\
\hline & Valor & $\mathrm{gl}$ & $\begin{array}{c}\text { Sig. asintótica } \\
(2 \text { caras })\end{array}$ \\
\hline Chi-cuadrado de Pearson & $2.707^{\mathrm{a}}$ & 2 & .258 \\
\hline
\end{tabular}


Gráfico 118. Porcentaje de frecuencia de las variables: toma de turnos y sexo.

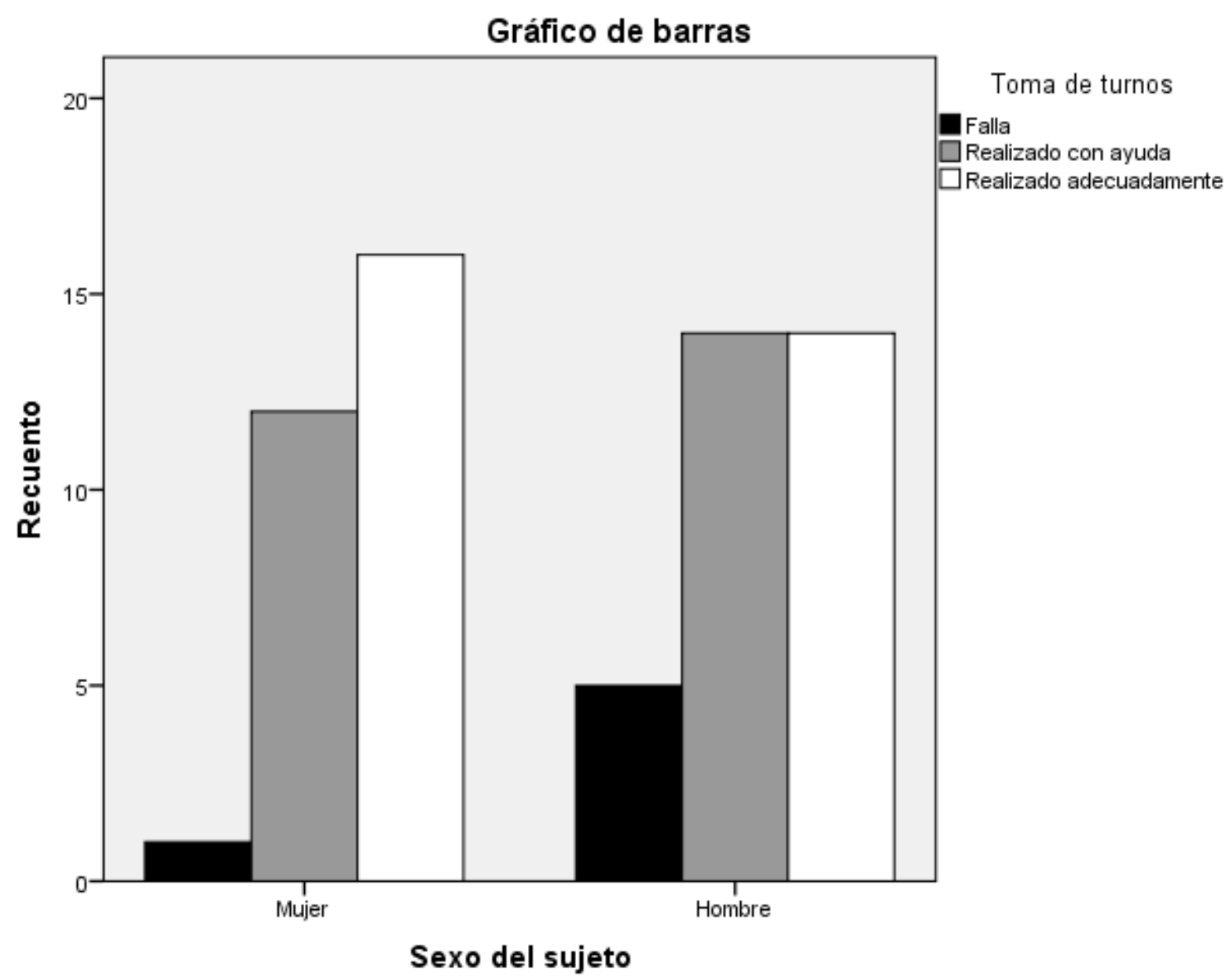

4.6.2.4. Toma de turnos y tramo de la enfermedad

Entre el grupo de controles encontramos 11 casos realizados adecuadamente, con un $91,8 \%$ y 1 caso realizado con ayuda del entrevistador, con un $8,3 \%$. En el grupo de primer episodio de $>0$ a $>2$ años, encontramos 8 casos realizados adecuadamente, con un $57,1 \%$ y 6 casos realizados con ayuda del entrevistador, con un $42,9 \%$. En el grupo 
de primer episodio de $>2$ a $>3$ años, encontramos 6 casos realizados adecuadamente, con un $54,5 \%$ y 5 casos realizados con ayuda del entrevistador, con un 45,5\%. En el grupo de crónicos de hasta 5 años encontramos, 2 casos realizados adecuadamente, con un 20\%; 5 casos realizados con ayuda del entrevistador, con un $50 \%$ y 3 casos de falla completa, que representan un 30\%. En el grupo de crónicos de 5 años y más encontramos, 3 casos realizados adecuadamente, con un 20\%; 9 casos realizados con ayuda del entrevistador, con un $60 \%$ y 3 casos de falla completa, que representan un $20 \%$.

Tabla de contingencia 173: toma de turnos y tramo de la enfermedad.

\begin{tabular}{|c|c|c|c|c|}
\hline \multirow[t]{2}{*}{ Tramo de la enfermedad } & \multicolumn{3}{|c|}{ Toma de turnos } & \multirow[t]{2}{*}{ Total } \\
\hline & Falla & $\begin{array}{l}\text { Realizado con } \\
\text { ayuda }\end{array}$ & $\begin{array}{l}\text { Realizado } \\
\text { adecuadamente }\end{array}$ & \\
\hline \multirow[t]{3}{*}{ Control } & 0 & 1 & 11 & 12 \\
\hline & 1.2 & 5.0 & 5.8 & 12.0 \\
\hline & $0.0 \%$ & $8.3 \%$ & $91.7 \%$ & $100.0 \%$ \\
\hline \multirow[t]{3}{*}{ Primer episodio 0 a 2 años } & 0 & 6 & 8 & 14 \\
\hline & 1.4 & 5.9 & 6.8 & 14.0 \\
\hline & $0.0 \%$ & $42.9 \%$ & $57.1 \%$ & $100.0 \%$ \\
\hline \multirow[t]{3}{*}{ Primer episodio 2 a 3 años } & 0 & 5 & 6 & 11 \\
\hline & 1.1 & 4.6 & 5.3 & 11.0 \\
\hline & $0.0 \%$ & $45.5 \%$ & $54.5 \%$ & $100.0 \%$ \\
\hline \multirow[t]{3}{*}{ Crónico hasta 5 años } & 3 & 5 & 2 & 10 \\
\hline & 1.0 & 4.2 & 4.8 & 10.0 \\
\hline & $30.0 \%$ & $50.0 \%$ & $20.0 \%$ & $100.0 \%$ \\
\hline \multirow[t]{3}{*}{ Crónico 5 y más años } & 3 & 9 & 3 & 15 \\
\hline & 1.5 & 6.3 & 7.3 & 15.0 \\
\hline & $20.0 \%$ & $60.0 \%$ & $20.0 \%$ & $100.0 \%$ \\
\hline \multirow[t]{3}{*}{ Total } & 6 & 26 & 30 & 62 \\
\hline & 6.0 & 26.0 & 30.0 & 62.0 \\
\hline & $9.7 \%$ & $41.9 \%$ & $48.4 \%$ & $100.0 \%$ \\
\hline
\end{tabular}

El valor de chi cuadrado es de $23.205^{\mathrm{a}}$, y dio como resultado ( $\left.\left.<\mathrm{p}, 003\right\rangle\right)$, significativo estadísticamente. 
Tabla valor de chi cuadrado 174: toma de turnos y tramo de la enfermedad.

\begin{tabular}{||l|c|c|c||}
\hline \multicolumn{4}{|c|}{ Pruebas de chi-cuadrado } \\
\hline & Valor & gl & $\begin{array}{c}\text { Sig. asintótica } \\
(2 \text { caras })\end{array}$ \\
\hline Chi-cuadrado de Pearson & $23.205^{\text {a }}$ & 8 & .003 \\
\hline
\end{tabular}

Gráfico 119 Porcentaje de frecuencia de las variables: toma de turnos y tramo de la enfermedad.

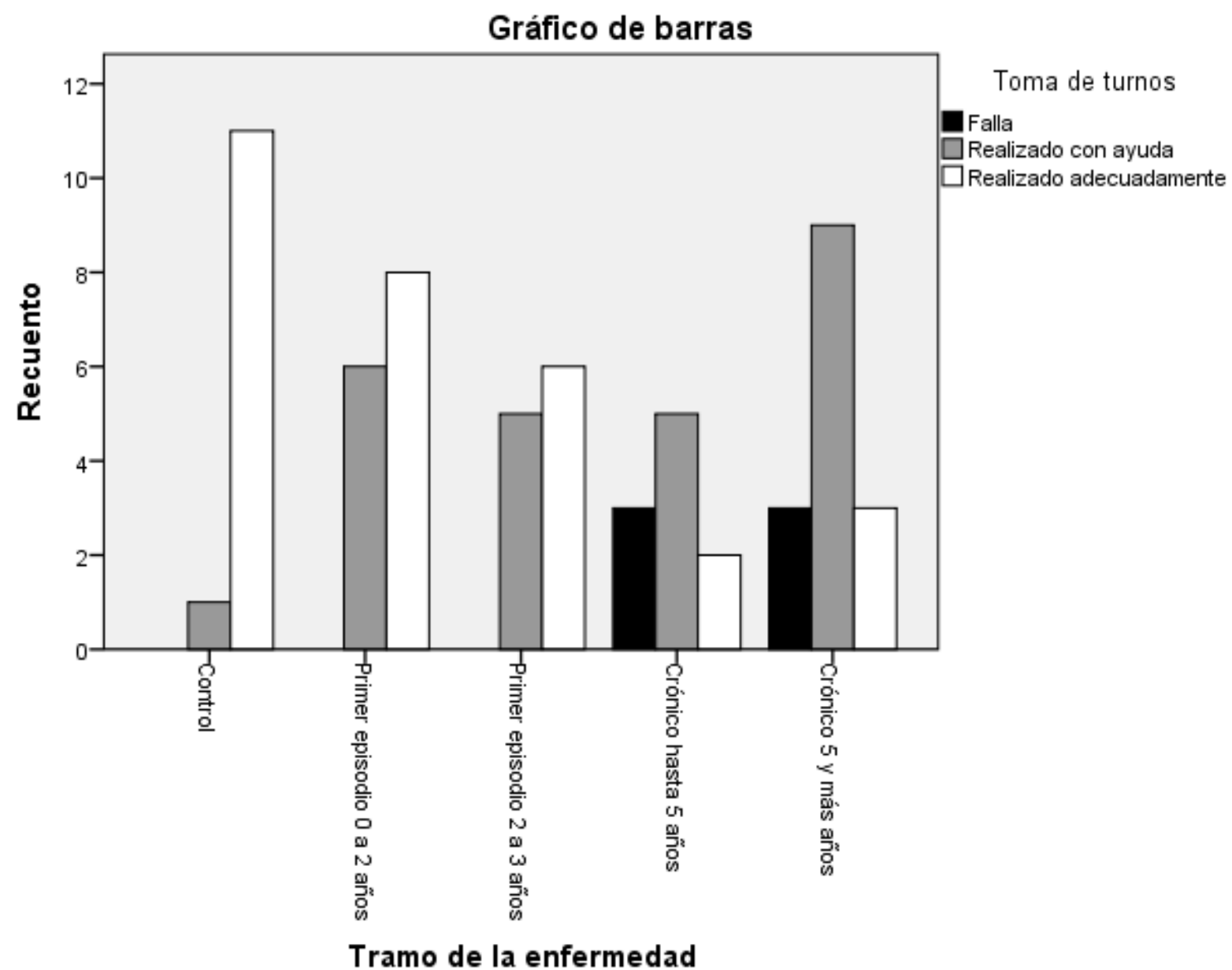




\subsubsection{Toma de turnos y subtipo de la enfermedad:}

Finalmente, la variable toma de turnos y subtipo de la enfermedad no resultó relevante como indicador. Como ya señalamos, entre el grupo de controles encontramos 11 casos realizados adecuadamente, con un $91,8 \%$ y 1 caso realizado con ayuda del entrevistador, con un $8,3 \%$. Entre el grupo de esquizofrenia paranoide, encontramos 12 casos realizados adecuadamente, con un 36,4\%; 19 casos realizados con ayuda, con un $57,6 \%$ y 2 casos de falla completa, con un $6,1 \%$. En el grupo de esquizofrenia indiferenciada, encontramos 4 casos, con un 44,4\%; 3 casos realizados con ayuda del entrevistador, con $33,3 \%$ y 2 casos de falla completa, con un $22,2 \%$. En el grupo de esquizofrenia desorganizada, encontramos 3 casos realizado adecuadamente; 3 casos realizados con ayuda del entrevistador, con un 37,5\% y 2 casos de falla completa, con un 9,7\%.

Tabla de contingencia 175: toma de turnos y subtipo de la enfermedad.

\begin{tabular}{|c|c|c|c|c|}
\hline \multirow[t]{2}{*}{ Subtipo de la esquizofrenia } & \multicolumn{3}{|c|}{ Toma de turnos } & \multirow[t]{2}{*}{ Total } \\
\hline & Falla & $\begin{array}{l}\text { Realizado con } \\
\text { ayuda }\end{array}$ & $\begin{array}{l}\text { Realizado } \\
\text { adecuadamente }\end{array}$ & \\
\hline \multirow[t]{3}{*}{ Control } & 0 & 1 & 11 & 12 \\
\hline & 1.2 & 5.0 & 5.8 & 12.0 \\
\hline & $0.0 \%$ & $8.3 \%$ & $91.7 \%$ & $100.0 \%$ \\
\hline \multirow[t]{3}{*}{ Paranoide } & 2 & 19 & 12 & 33 \\
\hline & 3.2 & 13.8 & 16.0 & 33.0 \\
\hline & $6.1 \%$ & $57.6 \%$ & $36.4 \%$ & $100.0 \%$ \\
\hline \multirow[t]{3}{*}{ Indiferenciada } & 2 & 3 & 4 & 9 \\
\hline & .9 & 3.8 & 4.4 & 9.0 \\
\hline & $22.2 \%$ & $33.3 \%$ & $44.4 \%$ & $100.0 \%$ \\
\hline \multirow[t]{3}{*}{ Desorganizada } & 2 & 3 & 3 & 8 \\
\hline & .8 & 3.4 & 3.9 & 8.0 \\
\hline & $25.0 \%$ & $37.5 \%$ & $37.5 \%$ & $100.0 \%$ \\
\hline \multirow[t]{3}{*}{ Total } & 6 & 26 & 30 & 62 \\
\hline & 6.0 & 26.0 & 30.0 & 62.0 \\
\hline & $9.7 \%$ & $41.9 \%$ & $48.4 \%$ & $100.0 \%$ \\
\hline
\end{tabular}


El valor de chi cuadrado es de $16.220^{\mathrm{a}}$, y dio como resultado $(\langle\mathrm{p}, 013\rangle)$ no significativo estadísticamente.

Tabla valor de chi cuadrado 176: toma de turnos y subtipo de la enfermedad.

\begin{tabular}{||c|c|c|c||}
\hline \multicolumn{4}{|c||}{ Pruebas de chi-cuadrado } \\
\hline & Valor & $\mathrm{gl}$ & $\begin{array}{c}\text { Sig. asintótica (2 } \\
\text { caras) }\end{array}$ \\
\hline Chi-cuadrado de Pearson & $16.220^{\mathrm{a}}$ & 6 & .013 \\
\hline
\end{tabular}

Gráfico 120. Porcentaje de frecuencia de las variables: toma de turnos y subtipo de la enfermedad.

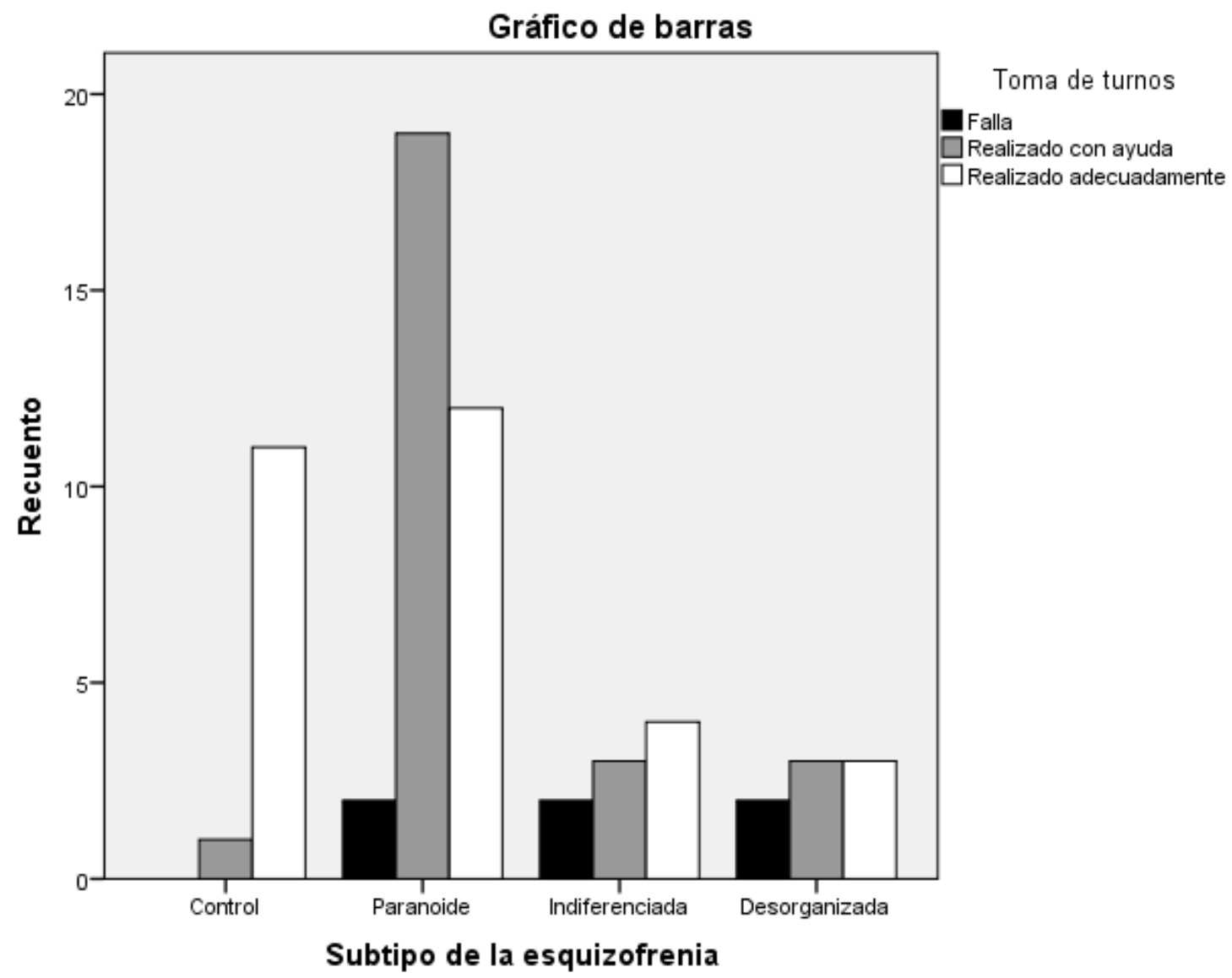




\subsubsection{Conclusiones cluster Coherencia Interaccional}

La coherencia interaccional complementa la dimensión de la participación conversacional de los informantes de este estudio. Los principales fenómenos interactivos que estudiamos fueron los pares adyacentes y la toma de turnos. Sobre los primeros, en el grupo de los controles no se presentó ninguna situación de falla completa, sólo en una ocasión el entrevistador intervino apenas para colaborar en el inicio de la participación del entrevistado. La casi totalidad de los controles registraron estructuras de pares adyacentes sin ningún impedimento. En el caso de los crónicos, la falla completa solo se aprecia en una porcentaje inferior, un 15\%. La gran mayoría de los informantes de este grupo, 68\%, realiza esta interacción con ayuda del entrevistador, solo un $17 \%$ interactúa sin dificultades. En el caso del grupo de primer episodio, percibimos que esta clase de interacciones no constituye un obstáculo para la participación comunicativa, pues ninguno de ellos presenta falla completa, un $40 \%$ requiere de apoyo del entrevistador en algún momento y el $60 \%$ de los informantes lo realiza de forma autónoma.

Con respecto a la toma de turnos, las medidas son similares. Encontramos que ninguno de los controles, ni los informantes de primer episodio, presentan falla completa en la toma de turnos; en cambio, los crónicos, alcanzan un $15 \%$. La toma de turnos con ayuda del entrevistador se registró en un procentaje del 56\% en los crónicos y $40 \%$ en los del grupo de primer episodio, en el grupo de los controles no se registró la necesidad de ayuda por parte del entrevistador.

Estas cifras nos permiten realizar un análisis complementario de este aspecto de la interacción discursiva. En el contraste entre los tres grupos, nos damos cuenta de que hay habilidades interaccionales disminuidas o inhibidas en $\operatorname{los}$ grupos 1 y 2 . Las causas del requerimiento de ayuda por parte del entrevistador nos parecen 
diferenciables entre ambos grupos. En el caso de los crónicos, es evidente la desinhibición, por tanto la ayuda más bien puede obedecer a dificultades de planificación, debido al deterioro cognitivo. El apoyo requerido por el grupo de primer episodio, nos hace pensar en estrategias de autocontención que manifiesta el paciente al ser entrevistado. Hay una reticencia a responder de manera fluida, o sin reflexionar. Esto nos induce a suponer que existen mecanismos de monitoreo cognitivo de suficiente robustez como para no ceder al impulso de responder de forma automática. 


\section{Capítulo 5}

\section{Conclusiones}

"La esquizofrenia es el precio que el hombre pagó por el lenguaje" (Timothy Crow) 
Conclusiones

Tras analizar los resultados obtenidos, podemos sintetizar las siguientes conclusiones generales:

1. Disponemos de evidencia suficiente para afirmar que existe un perfil lingüístico que puede ser denominado como "lenguaje esquizofrénico". Sus características diferenciales otorgan un marco de referencia que se aparta de otras manifestaciones comunicativas de pacientes psicóticos, estas van más allá de la consideración idiolectal de las personas diagnosticadas como esquizofrénicos.

2. En su globalidad, el lenguaje esquizofrénico constituye un síntoma codificable y operacionalizable. Las alteraciones del lenguaje que se presentan en las personas con esquizofrenia son pesquisables y susceptibles de evaluación lingüística.

3. El lenguaje esquizofrénico es un rasgo permanente y prevalente durante todo el curso de la enfermedad.

4. Las alteraciones del lenguaje se encuentran presentes desde el primer episodio de esquizofrenia.

5. A pesar de la diversidad de las alteraciones lingüístico-comunicativas, es posible diferenciar algunas que pueden servir como indicadores de déficit.

6. Algunos de esos indicadores de déficits fueron pesquisados en los pacientes de primer episodio y, por tanto, pueden constituir indicadores tempranos. 
7. Las personas con esquizofrenia crónica y de primer episodio presentan alteraciones comunicativas variadas, tanto en intensidad como respcto del tipo de fenómeno que puede observarse.

8. Las áreas más afectadas en el lenguaje esquizofrénico, en ambos estadios de la enfermedad, son las del nivel pragmático y las del semántico.

9. La dificultad que presentan, en el nivel pragmático se traduce en alteraciones que afectan los aspectos cooperativos del intercambio, tales como:

Dificultades en aspectos inferenciales de la conversación, entre ellas, encontramos la incomprensión de las intenciones del interlocutor. De aquí se desprende que la detección de este componente intersubjetivo falla probablemente debido a un juicio erróneo sobre el contexto en el que se inserta la situación comunicativa general, y una inadecuación a la situación de entrevista. Derivado de este problema, encontramos una dificultad para tomar en cuenta los requerimientos informativos de los entrevistadores, sumado a una atribución emocional deficiente, que se manifiesta, particularmente, como alteraciones de los procedimientos de cortesía verbal, ya sea por su exageración y/o por su amaneramiento o, también, por su total ausencia. De un modo paradójico, empobrecen la imagen que el paciente presupone que está transmitiendo de sí mismo. También observamos dificultades para inhibir la información irrelevante, ya que como la lectura contextual es deficiente, los pacientes no perciben las transgresiones constantes hacia las máximas conversacionales; en especial la de cantidad y de relación. Todas estas circunstancias van minando la coherencia discursiva que sostiene un intercambio eficiente, ya sea por exceso de elementos accesorios, como por los circunloquios que abordan lejanamente el foco de información que se pretende comunicar.

Otro aspecto que presenta dificultades pragmáticas fue identificado a partir de la toma y ejecución efectiva de los turnos de habla y de los pares adyacentes. En ambos fenómenos comprobamos que buena parte de la participación interactiva 
eficiente era alcanzada con el modelado del entrevistador, ya que alteraciones como las pausas extensas, el volumen de voz inaudible, los falsos inicios y conforman fenómenos que contribuyen a una discontinuidad discursiva, que afecta la calidad y comprensión de todo el discurso. Entre los pacientes crónicos, se aprecia una mayor duración de las pausas extensas, que en los de primer episodio. No obstante, entre los de primer episodio se percibieron más titubeos, vacilaciones, falsos inicios y respuestas monosilábicas que en el grupo de los pacientes crónicos.

En lo tocante a los aspectos paraverbales, la kinésica y la proxémica también denotan desconexión o falta de comprensión de la situación comunicativa. En particular hay una pérdida del contacto visual en ambos grupos. Aunque es un indicador que no incorporamos, formalmente, por no contar con grabaciones audiovisuales de todos los pacientes, podemos agregarlo como un rasgo que asume ribetes autísticos.

Toda esta suma de elementos se observaron en forma parcial, en la mayoría de los casos, y entre algunos crónicos, de forma completa.

La dificultad que presentan, en el nivel semántico, se traduce en alteraciones que afectan el sentido completo del discurso, así como algunas estructuras específicas:

En este nivel, encontramos dificultades para elaborar cadenas oracionales con referentes identificables observamos que, en ocasiones, se enunciaron referentes sin que estuviesen vinculados al desarrollo de un tópico dentro del discurso. Una cuestión que nos llamó la atención es que, a veces, esos referentes inconexos se daban por una motivación personal del entrevistado una especie de relación semántica clara para él, pero no para quien lo entrevistaba. También observamos laxitud entre los vínculos que unían los referentes, distanciándolos entre sí, lo que indica una dificultad para utilizar recursos de correferencialidad, como la anáfora. En algunos casos, aparentemente, los pacientes se hacían conscientes del problema, pero como solución comunicativa, repetían fragmentos completos, que no agregaban más información o claridad. De aquí 
desprendemos uno de los rasgos descritos en muchos trabajos, acerca de lo redundante del discurso esquizofrénico esta alteración devela dificultades en la planificación de la ordenación de los materiales sintácticos y semánticos, que se presentan discontinuos o desordenados, generando incoherencia.

Un aspecto que se relaciona con los referentes es el manejo de los tópicos discursivos, puesto que en ambos corpus de pacientes encontramos dificultades en esta tarea. La escasa eficacia en la elaboración de frases cohesivas genera, como consecuencia, problemas en la gestión temática del discurso. Los saltos topicales obedecen a la probable necesidad de incorporar mayor información, pero la forma en que se agregan, muchas veces no es canónica, confundiendo al interlocutor, que a menudo pierde el hilo y tiene que pedir precisiones al entrevistado.

La elaboración de proposiciones, gramaticalmente, adecuadas resultó ser un indicador deficiente, en ambos grupos. Las dificultades para visualizar la relación explícita e implícita del tema central con los eventuales subtemas fue una tarea compleja. Es importante destacar que, en la mayoría de los casos, la sintaxis básica está conservada y a pesar de ser elemental es eficaz.

Otra cuestión vinculada al plano semántico es la utilización del léxico. Si bien en este estudio no registramos una presencia significativa de neologismos, podemos afirmar que la utilización peculiar de palabras de baja frecuencia, en español, se dio con regularidad entre los pacientes crónicos. En un primer momento, nos dio la falsa impresión de ser evidencia de un acervo léxico indemne al deterioro cognitivo que provoca la enfermedad sin embargo; esa impresión se desvaneció cuando confrontamos los volúmenes de palabras diferentes empleadas por los tres grupos de estudio. Esta operación reveló que hay una disminución del volumen léxico como una tendencia general, lo que coincide con las dificultades en el control inhibitorio de interferencias que no permiten un acceso al léxico de forma fluida. Eso sí, la disminución del volumen, está teñida de la peculiaridad léxica, como ya mencionamos. También sobre esto encontramos afirmaciones en la literatura que 
relacionan este rasgo con un procesamiento léxico inusual, provocado por redes semánticas ineficientes. Otro aspecto derivado del léxico es el uso del sentido literal de las expresiones que se da en forma independiente del contexto semántico en que se presentan. Este fenómeno solo fue observado entre los crónicos y en un grupo que alcanza al $30 \%$ del corpus.

A continuación presentamos algunas conclusiones por cluster:

Entre los indicadores de FLUIDEZ, podemos concluir que fenómenos discursivos como: los titubeos, los falsos inicios y los tartamudeos se encuentran presentes en todos los entrevistados, incluyendo a los controles; no obstante, la frecuencia y, las características que presentan, en los tres grupos analizados, genera claras diferencias en la calidad de la eficacia comunicativa. En el grupo de los controles, los titubeos, falsos inicios y tartamudeos, en primer lugar, se presentan en una baja frecuencia, y a pesar de que se interrumpe la continuidad inmediata de la información, no se ve afectada la comprensión, puesto que se mantiene el contacto con el entrevistador, dada su predictibilidad, se asumen como una reformulación estratégica, o bien como rellenos mientras operan los sistemas de memoria. Además, coinciden con aspectos sintácticos: entre los pacientes crónicos se dan al inicio e interturnos; la discontinuidad resultante afecta la comprensión de lo dicho, evidencia que se aprecia en la constante vuelta atrás de los entrevistadores, pidiendo precisiones o realizando una y otra vez preguntas para esclarecer el asunto que ha planteado el entrevistado, en este sentido, aparentan ser estrategias reparatorias, pero no coinciden con los momentos en que se deberían utilizar, ya que son forma, no función.

Una situación similar se observó en el grupo de primer episodio. Las preguntas directas que indagan información sobre tiempo, lugar, entre otras, no se responden de manera específica o directa, lo que apuntaría a diversas dificultades en la planificación de los mensajes, al igual que en el grupo de crónicos. 
Ahora bien, los turnos de habla con volumen débil y las pausas extendidas no fueron registrados en los controles. De los fenómenos estudiados en este cluster, estos últimos generan mayor interferencia en la comprensión de las emisiones de los grupos de pacientes, por lo tanto, podemos considerarlos como indicadores de déficit en la fluidez.

II. Entre los indicadores de PRODUCTIVIDAD VERBAL, se encontraron diversos elementos que hacen creer que las demandas discursivas en cuanto a volumen de la producción son un perfil que se ve disminuido, de forma consistente, en ambos grupos. En primer lugar, en el indicador total de oraciones, el grupo de los controles presenta una diferencia considerable en el volumen de oraciones producidas; asimismo, observamos que en el indicador promedio de palabras por oración, también es más elevado que en los grupos de pacientes. Si solo se toma en cuenta el dato sobre la cantidad de oraciones o promedio de palabras por oración, este no resulta muy informativo, sin embargo, sí lo es si se considera que, en los controles, la casi totalidad de esas oraciones son adecuadas y productivas en términos semántico-sintácticos, en contraste con muchas frases sueltas de los crónicos y también entre algunos pacientes de primer episodio, que no alcanzan a configurar una relación gramatical con el resto del discurso; de igual modo, que las oraciones efectivas son extremadamente simplificadas en dichos pacientes. Por tanto, la configuración oracional, la sintaxis empobrecida y la extensión de las oraciones denotan rasgos que reflejan un déficit desde el primer episodio. Ahora bien, las causas de una sintaxis empobrecida pueden deberse a diferentes fenómenos cognitivos. Las evaluaciones neuropsicológicas que se realizan en adolescentes, apuntan a que existe una estructura cognitiva de alto rendimiento en la mayoría de los casos. Por lo tanto, se infiere que rasgos como el humor paranoide y los síntomas negativos son las causas más probables de una sintaxis pobre, en lugar de un deterioro cognitivo.

Respecto del empleo de palabras diferentes, observamos que se da la utilización de un acervo reducido, en el caso de los pacientes de primer episodio, 
incluso comparados con los hablantes del grupo control, que tenían las mismas características etarias. Hay un volumen importante de palabras repetidas (sustantivos) y de palabras vacías (conectores); este grupo es el que presenta la mayor disminución en el volumen léxico. En el caso del grupo de crónicos, muestran un volumen más elevado que el de primer brote, pero muy disminuido en relación con los controles que correspondían a este grupo etario; también se observaron repeticiones constantes de palabras de nominación, al igual que entre los de primer episodio. Lo que nos pareció llamativo es el uso más frecuente de palabras inusuales entre los crónicos que entre los otros grupos.

Con respecto a los indicadores: neologismos parciales y neologismos totales, no se reportaron en el caso de los controles, y su ocurrencia en los grupos 1 y $2^{69}$ fue muy baja. Este fenómeno se presenta como un síntoma insidioso y es claramente señal de un deterioro cognitivo importante.

Finalmente, los indicadores: Total de referentes, Total de vínculos referenciales y Promedio de vínculos referenciales ofrecen un interesante perfil de las emisiones de los entrevistados, que si analizamos, en términos de promedio, delinean diferencias significativas. Los controles presentaron un promedio general de 120 referentes utilizados en el transcurso de la entrevista; en cambio, los crónicos sólo alcanzaron 85 referentes en promedio y los sujetos de primer episodio, solo 62. Como es lógico, en el caso de los controles, los referentes tenían un propósito directamente desarrollado en la conversación, relacionándose de forma pertinente con los demás elementos temáticos. Estas estrategias fueron alcanzadas por los controles mediante la explicitación de diferentes relaciones semánticas, y comprendidas por el entrevistador, quien casi nunca inquirió una segunda vez lo preguntado al participante. Entre los crónicos, hay mayor frecuencia de referentes que entre los de primer episodio, pero esto no significa que les den un tratamiento semántico que facilite la comprensión de su lugar dentro de la producción discursiva. Los del grupo de primer episodio, ciertamente

${ }^{69}$ Grupo 1: Crónicos, (CRE) Grupo 2: Primer episodio (PEE) 
emiten menos referentes, pero casi la totalidad ofrece un contexto que seguir o, a través del cual es posible seguir una ruta semántica.

Por lo que se refiere a la cantidad de vínculos referenciales, los promedios son similares, aunque dejan claro que entre los crónicos existe una mayor distancia entre ellos; este rasgo también está presente en el grupo de primer episodio, a nuestro juicio, constituye un indicador interesante a la hora de evaluar el deterioro comunicativo.

\section{Indicadores del ÍNDICE DE PARTICIPACIÓN CONVERSACIONAL:}

En este cluster no encontramos medidas estadísticas que sean significativas, puesto que se presentaron pocas diferencias respecto de los indicadores cantidad de palabras y, en lo que respecta a la agilidad del turno, el indicador número de turnos por minuto, tampoco mostró diferencias sustantivas. En cuanto al género, no se observó ninguna diferencia significativa en los tres grupos. Ambos indicadores son parte de los criterios utilizados en afasiología, área en la que son marcadores muy robustos de déficit comunicativo.

Nuevamente nos llama la atención el hecho de que si la intervención no hubiese sido guiada en forma constante, por el entrevistador, es posible que las realizaciones de estas unidades no se dieran con las mismas características. En suma, la toma de turnos solo es equivalente en la cantidad, no en las mismas condiciones o con la finalidad que tuvo en la entrevista.

De manera similar, frente al conteo de la cantidad de palabras empleadas por los participantes, es necesario aclarar una posible falsa impresión. También aquí las cifras son similares, pero, es necesario recordar que una porción no menor de las palabras utilizadas por los crónicos y el grupo de primer episodio se repiten en forma constante, lo que redunda en una actuación discursiva con menos recursos léxicos y, por lo tanto, mucho más pobre.

IV. Indicadores de COHERENCIA TEMÁTICA: 
La coherencia como núcleo de la eficacia en un discurso posee requisitos fundamentales; algunos de ellos son la estabilidad y consistencia temática. Las intervenciones de los participantes fueron, evaluadas, según la gestión del tema, el contenido proposicional, la función ilocutiva y la orientación de la interacción. Entre los indicadores de este cluster es donde encontramos mayores diferencias relativos al denominado discurso normal, por tanto, serían indicadores de deterioro comunicativo por excelencia.

Como ya especificamos, anteriormente, este análisis ha distinguido entre dos niveles de profundidad semántica. En el primero, los indicadores de la macroestructura discursiva fueron: unidad temática nuclear, proposiciones con vínculos explícitos y proposiciones con vínculos implícitos respecto del tema central. La construcción deficiente de tópicos en torno a un tema o referente, esto es, los saltos topicales, dieron como resultado medidas estadísticas significativas, con lo que podemos confirmar lo que plantea la literatura acerca del carácter redundante y deficiente en la gestión temática que presentan los pacientes.

Dentro de las dificultades principales, recogimos, en primer término, la omisión de información esencial para comprender el tema central planteado, como por ejemplo iniciar un narración desde el principio; por el contrario, el inicio se realiza desde un episodio, o bien, partiendo desde un subtema o, más aún, un comentario a un subtema. También fue identificada la presencia frecuente de proposiciones implícitas y/o tangenciales relativa al supuesto tema central, lo que para el oyente significa acceder solo a algunos fragmentos discontinuos del tema lo anterior impide una comprensión completa, inclusive con la ayuda del entrevistador.

Ahora bien, las proposiciones emitidas por los pacientes a menudo se elicitan con naturalidad, como si su lugar dentro del contexto comunicativo fuese lógico, incluso no pocas veces son correctas gramaticalmente. No obstante, su contenido es altamente críptico para el oyente, por consiguiente; se pierde el equilibrio informativo, 
previo a la interpretación del discurso, que sostiene que a un menor grado de contextualización se requiere de más indicadores linguiísticos que sustenten la coherencia. En parte, este resultado difícil de entender se da, asimismo, por el uso inapropiado de marcadores y/o partículas del discurso, que pueden, por ejemplo, perder su carácter fórico y resultar disfuncionales o, tal vez, sufrir un desplazamiento semántico y resultar descontextualizadas. Por otro lado, cuando son gramaticalmente adecuadas, pueden presentarse como proposiciones encifradas semánticamente, con un significado propio, claro que solo para el paciente.

A lo anterior, podemos agregar dificultades tales como la repetición de estructuras como recurso lingüístico. La repetición se utiliza con el fin de actualizar la información planteada con anterioridad, es decir, permite mantener a la vista el asunto del que se está hablando. No obstante, la repetición del tipo calco, es decir, las mismas palabras o frases aplicadas en vez del desarrollo de algún subtema no funciona como estrategia de actualización. Es, con frecuencia, una conducta perseverativa, poco informativa y que no ayuda a hacer más eficaz lo dicho.

La hipótesis de Belinchón (1988), acerca del carácter egocéntrico de las emisiones de estos pacientes es comprobable al observar que no tienen en cuenta las necesidades informativas del interlocutor, por lo tanto, tampoco están interesados en entregar claves lingüísticas para que el oyente pueda interpretarlas. Aún cuando algunas de esas claves son cohesivas, nos damos cuenta de que participan en forma directa en la composición de la macroestructura de la que sólo tenemos algunos atisbos. En el llamado discurso normal, se recurre por ejemplo, a los procedimientos endofóricos, con el fin de mantener la unidad temática. En cambio, en pacientes de la muestra encontramos construcciones en donde se presentan referentes aislados, sin elementos asociados, o con proposiciones vinculadas en forma tangencial a dichos referentes, convirtiéndolos en disfóricos. 
Los indicadores estudiados en la microestructura son tópico con desarrollo, salto topical e interacción entre referentes y vínculos referenciales. Según van Dijk (1980) la microestructura estaría conformada por una serie de microproposiciones jerarquizadas, coincidiendo la más importante de ellas con la macroestructura. Las estructuras microestructurales, también se encuentran afectadas en los grupos 1 y 2.

Principalmente, encontramos fenómenos como tópicos enunciados, pero sin desarrollo, presencia de constantes saltos topicales, algunos abruptos, dentro de una oración o de una oración a otra, otros un poco más distanciados, tras un turno de habla, por ejemplo. También observamos cambios temporales frecuentes y sin justificación. Se suma a estos hallazgos, la referencia a subtemas para explicar algún aspecto vivenciado. Es decir, relatos que pueden progresar, temporalmente, pero que están compuestos por hechos circunstanciales, que en función de la insistencia del entrevistador terminan por ser aclarados, casi siempre en forma parcial. Queda, entonces, la duda de si se interpreta un significado diferente al que el paciente pretende aportar.

Con respecto a la interacción entre vínculos referenciales, podemos señalar que, con frecuencia, se observaron estructuras de "puenteo", es decir, que presentan una relación verbal indirecta con el referente. También una relación aditiva entre los vínculos, por asociación incluso consonántica, generalmente injustificada. Esta preferencia, a nuestro juicio, debilita la relación entre referentes y sus vínculos referenciales, lo que se traduce en una fragmentación topical, por tanto, discursiva.

\section{Indicadores de SEMÁNTICA DE LA COHERENCIA:}

Los resultados de este cluster, en general, no nos ofrecieron un perfil lingüísitco relevante de los participantes con esquizofrenia. Es probable que con otro tipo de instrumento o tarea discursiva, en la que puedan ser incluidas las dos dimensiones del juicio de realidad que no abordamos, se logre realizar una 
aproximación más precisa al problema. Estamos concientes de que la complejidad de este concepto del análisis psiquiátrico impide una evaluación de presencia/ausencia sin generar un sesgo. Sin embargo, lo expuesto aquí podría considerarse como un punto de partida inicial en el análisis, ya que ofrece algunas evidencias en el discurso, en torno a la conceptualización que los hablantes del estudio se atribuyen como sujetos. No podemos ignorar declaraciones como: "yo soy la virgen María" o "soy un informante de la Interpol”, etc. En ambos ejemplos, resulta evidente una discordancia con el modelo discursivo que los mismos hablantes proponen en el transcurso de la entrevista.

\section{Indicadores de COHERENCIA INTERACCIONAL:}

La coherencia interaccional complementa la dimensión de la participación conversacional de los informantes de este estudio. Los principales fenómenos interactivos que estudiamos fueron los pares adyacentes y la toma de turnos. Sobre los primeros, en el grupo de los controles, no se presentó ninguna situación de falla completa, solo en una ocasión el entrevistador intervino apenas para colaborar en el inicio de la participación del entrevistado. La casi totalidad de los controles registró estructuras de pares adyacentes sin ningún impedimento. En el caso de los crónicos, la falla completa solo se aprecia en una porcentaje inferior, un 15\%; la gran mayoría de los informantes de este grupo el $68 \%$, realiza esta interacción con ayuda del entrevistador, solo un $17 \%$ interactúa sin dificultades. En el caso del grupo de primer episodio, percibimos que esta clase de interacciones no constituye un obstáculo para la participación comunicativa, ninguno de ellos presenta falla completa un $40 \%$ requiere de apoyo del entrevistador en algún momento y el $60 \%$ de los informantes lo realiza de forma autónoma.

Con respecto a la toma de turnos, las medidas son similares, puesto que encontramos que ninguno de los controles, ni los informantes de primer episodio presentan falla completa en la toma de turnos, en cambio, en los crónicos alcanza a un $15 \%$. La toma de turnos con ayuda del entrevistador, se registró en un procentaje del 
$56 \%$, en los crónicos y, un 40\%, en los del grupo de primer episodio; en el grupo de los controles, por su parte, no se registró la necesidad de ayuda por parte del entrevistador.

Estas cifras nos permiten realizar un análisis complementario de este aspecto de la interacción discursiva. En el contraste entre los tres grupos, nos damos cuenta de que hay habilidades interaccionales disminuidas o inhibidas en los grupos 1 y 2 . Las causas del requerimiento de ayuda por parte del entrevistador nos parecen diferenciables entre ambos grupos. En el caso de los crónicos, es evidente la desinhibición, por tanto, la ayuda más bien puede obedecer a dificultades de planificación, debido al deterioro cognitivo. El apoyo requerido por el grupo de primer episodio nos hace pensar en estrategias de autocontención que manifiesta el paciente al ser entrevistado. Hay una reticencia a responder de manera fluida o sin reflexionar. Esto nos induce a suponer que existen mecanismos de monitoreo cognitivo de suficiente robustez como para no ceder al impulso de responder, de forma automática.

Los principales hallazgos estadíhsticos de nuestro estudio pueden ser sintetizados del siguiente modo:

Se probó un modelo de regresión lineal que estuvo compuesto por los siguientes grupos de variables: tipo, sexo, tramo, fluidez, productividad verbal, índice de participación conversacional, coherencia temática, semántica de la coherencia y coherencia interaccional. El modelo final que explica el estadio fue compuesto por las variables: neologismos totales, promedio de vínculos, neologismos parciales, palabras diferentes, promedio palabras oración, total vínculos, total oraciones. Las únicas variables dentro del modelo que se asocian de manera significativa y, positivamente, con el estadio de la enfermedad es el tramo de la enfermedad, el subtipo, que explican el $78 \%$ y $11 \%$, respetivamente. Además, el total de oraciones se relaciona de manera significativa e indirecta, explicando el $23 \%$ de la varianza del estadio. 
Se aplicó la prueba no paramétrica Kruskal-Wallis, dado que las muestras de crónicos, controles y primer episodio eran pequeñas (menores a 30 casos), esto se realizó, para poner a prueba la hipótesis nula de que los promedios poblacionales son iguales. En los anexos incluimos dichas tablas.

Finalmente, nos interesa relevar que pudimos confirmar nuestra hipótesis general sobre la existencia entre los déficits del discurso de la población de CRE y $\mathrm{PEE}^{70}$, ya que en ambos grupos se encuentran diferenciadas las alteraciones comunicativas, asimismo podemos deducir que aquellos déficits compartidos representan indicadores transversales, por lo tanto tempranos y que pueden configurar una base de análisis del comportamiento comunicativo de los pacientes.

De los 24 fenómenos estudiados, creemos que idependiente de sus números finales, aquellos que impactan la competencia comunicativa desde el primer episodio son:

1. Titubeos

2. Falsos inicios

3. Pausas extensas

4. Tartamudeos

5. Turnos de habla con volumen muy débil

Sí

6. Total de oraciones/frases por tarea

7. Promedio de palabras por oración

Sí

8. Total de palabras diferentes (no repetidas)

Sí

9. Neologismos parciales

10. Neologismos totales

11. Referentes

Sí

12. Total vínculos referenciales

Sí

13. Promedio de vínculos referenciales

Sí

14. Índice de participación conversacional

15. Promedio de turnos de habla por minuto

16. Unidad temática nuclear reconocible

Sí

17. Proposiciones con vínculos explícitos alusivos al tema centra

Sí

18. Proposiciones con vínculos implícitos alusivos al tema central Sí

${ }^{70} \mathrm{CRE}$ : crónicos esquizofrenia, PEE: primer episodio de esquizofrenia 
19. Tópico con referente Sí

20. Salto topical Sí

21. Interacción entre referentes y vínculos referenciales Sí

22. Confusión en el juicio de realidad (mundos posibles)

23. Pares adyacentes Sí

24. Toma de turnos Sí

Proyecciones futuras del trabajo:

Esperamos ampliar el corpus de pacientes de primer episodio y añadir pruebas y/o tareas que revelen con más claridad si presentan aspectos deficientes en los mismos indicadores que aquí expusimos.

Uno de nuestros propósitos centrales es la elaboración de un modelo de screening discursivo que pueda ser factible como una evaluación dentro de la entrevista clínica, ya que en muchas ocasiones se cuenta con poco tiempo y en los servicios de salud pública de Chile, a menudo los pacientes no regresan hasta presentar un cuadro agudo, con el consecuente deterioro cognitivo. Este screening, contendría los indicadores de mayor sensibilidad encontrados en este estudio. También pretendemos iniciar un programa de entrenamiento sobre aspectos lingüístico-comunicativos de los pacientes psicóticos para los médicos que cursan la especialidad de psiquiatría en el Campus Sur de la Facultad de Medicina de la Universidad de Chile.

Con los datos obtenidos de un estudio de mayores dimensiones, en el mediano plazo, pretendemos proponer algún tipo de evaluación comunicativa para la población juvenil chilena en edad escolar, que correspondan al grupo etario de 12 a 14 años. Dicha evaluación debería ser incorporada en las escuelas y aplicadas por agentes preparados. No en vano, a menudo, son los docentes los que inician las pesquisas en torno al comportamiento singular de sus alumnos, incluso antes que los padres lo reporten.

Para finalizar, quisiéramos insistir en el carácter necesariamente limitado de los resultados de nuestra investigación, así como también en la naturaleza provisional de 
las interpretaciones y explicaciones derivadas de este análisis. En este sentido, a nuestro juicio, resultaría de gran interés llevar a cabo trabajos con corpus de mayores dimensiones, que eventualmente replicaran lo desarrollado en este estudio, de manera de corroborar o relativizar nuestros hallazgos. Igualmente sería pertinente incorporar tareas discursivas narrativas o argumentativas para revelar rasgos asociados a la elaboración de discursos específicos. 
ANÁLISIS PRAGMALINGÜÍSTICO DE LOS MARCADORES DE COHERENCIA EN EL DISCURSO DE SUJETOS CON ESQUIZOFRENIA CRÓNICA Y DE PRIMER EPISODIO

\section{Referencias Bibliográficas}


Aboitiz,F, García R, Bosman C, Brunetti E (2006). Cortical memory mechanisms and language origins. Brain and language, 98:40-56.

Adams, W., Kendell, RE, Hare, EH and Munk, JP (1993) Epidemiological evidence that maternal influenza contributes to the aetiology of schizophrenia: An analysis of Scottish, English and Danish data. British Journal of Psychiatry 163, pp. 522-534.

Addington, J. y Addington, D. (2000) Neurocognitive and social functioning in schizophrenia: a 2-5 years follow-up study. Schizophrenia Research. 44, 47-56.

Adolphs, R. (2001). The neurobiology of social cognition. Current opinion in Neurology, 11, 231-239

Adolphs, R. (2006) How do we know the minds of others? Domain-specificity, simulation, and enactive social cognition. Brain in Research.1079. 25-35

Aitchinson, J. (1988) Words in the Mind: An Introduction to the Mental Lexicon. WhileyBalckwell. UK.

Alvarado R, Erazo C, Poblete C. (2006) ¿Es factible y útil la detección precoz como estrategia de salud pública para el primer episodio de psicosis? Rev Chil Salud Pública; Vol 10 (3): 158-163

Alvarado, R, et al, (2012). Diseño y evaluación de proceso de una intervención comunitaria para la detección precoz del primer episodio de psicosis en Chile. Rev Chil Salud Pública 2012; Vol 16 (2): $123-130$

Alexander, M.P, Benson, D.F., Stuss, D.T. (1989) Frontal lobes and language. Brain and Language, 37, 651-691

American-Psychiatric Association. (1994) Diagnostic and Statistical Manual of Mental Disorders. Four edition, revised.

Anand, A, Wales, R.G., Jackson, H.J. and Copolov, D.L. (1994) 'Longuistic impairment in early psychosis'. Journal of Nervous and Mental Diseases 189, 9, 488-493

Andreasen, N. (1979). Thought, language and communication disorders: I. Clinical assessment, definition of terms and evaluation of their reliability. Archives of general Psychiatry, 36, 13151321.

Andreasen, N. (1979) Thought, language and communication disorders: II. Diagnostic significance. Archives of general Psychiatry, 36, 1325-1330.

Andreasen, N. and Grove, W.M.(1986)Evaluation of positive and negative symptoms in 
schizophrenia. Psychiatrie et Psychobiologie, 1, 108-121.

Addington DE, McKenzie E, Norman R, Wang JL, Bond, GR. (2013)Essential evidence-based components of firstepisode psychosis services, Psychiatric Services in Advance, February 1, doi: 10.1176/appi.ps.201200156).

Allen, H.A, Liddle, P.F. y Frith, C.D.(1993) Negative features, retrieval process and verbal fluency in schizophrenia. British Journal of Psychiatry, 163, 769-775

Aro, S., Aro, H. and Keskimaeki, I. (1995) Socio-economic mobility among patients with schizophrenia or major affective disorder: A 17-year retrospective follow-up. British Journal of Psychiatry 166, pp. 759-767.

Ayuso, J. L. (1979). Valoración estadísticolingüística de las psicosis esquizofrénicas. Actas Luso España 7, nov.-dic.: 353-362.

Bai, O., Wei, Z., Lu, W., Bowen, R., Keegan, D. and Li, XM (2002) Protective effects of atypical antipsychotic drugs on PC12 cells after serum withdrawal. Journal of Neuroscience Research $69: 2$, pp. 278-283.

Bambini, V. (2010) Neuropragmatics: A foreword. Italian Journal of Linguistics 22.1, pp. 1-20.

Barison, F (1984) L' esistenza schizofrenica e la cronicitá. In psichiatria generales e dell'etá evolutiva, 22, pp11-14

Barison, F. (1949) Dizociazione e incomprensibilitá schizofreniche. Riv.neurol. 19, 1.

Barison F. (1953) Le manierisme schizophrénique, Evol. Psych., 1, 1-5.

Baron Cohen, S. (2001) 'Theory of mind and autism: A review'. International Review of Research in Mental Retardation 23, 169-184.

Binswanger, L. (1972) Tres formas de existencia frustrada. Exaltación, excentricidad y manierismo. Madrid. Amorrortu.

Binswanger, L: (1981) Antropología, psicología, psicopatología. Barcelona. Labor.

Baskak B, Ozel ET, Atbasoglu EC, Baskak SC. Peculiar word use as a possible trait marker in schizophrenia. Schiz Res. 2008; 103:311-317.

Beaugrande, R. y Dressler, W. (2003) Introducción a la Lingüística del Texto. Ariel. España.

Belinchón M. (1991). Aspectos cognitivos en la esquizofrenia. Trotta. Madrid.

Belinchón M. (1988) Esquizofrenia y lenguaje: una aproximación psicolingüística. Estudios de Psicología, 33-34, 105-144

Bernárdez, E. (1982). Introducción a la lingüística del texto. Madrid: Espasa Calpe. 
Bechdolf, A., Ruhrman, S., Wagner, M., Kuhn, KU, Janssen, B. and Bottlender, R. (2005) Interventions in the initial prodromal states of psychosis in Germany: Concept and recruitment. British Journal of Psychiatry 187: suppl. 48, pp. s45-48.

Bechdolf, A., Veith, V., Schwarzer, D., Schormann, M., Stamm, E. and Janssen, B. (2005) Cognitive-behavioural therapy in the pre-psychotic phase: An exploratory study. Psychiatry Research 136, pp. 251-255.

Benson D.F. (1982) The treatable dementias. In: DF Blumer D. eds Psychiatris aspects of neurologic disease, vol 2 New York: Grune \& Stratton, 1982:123.

Benson, D.F. (1967). Fluency in aphasia: correlation with radioactive scan localization. Cortes, 3, 373-393.

Benton AL, Hamsher K. (1989) Multilingual aphasia examination manual. Iowa City, IA: University of Iowa.

Berger, GE, Wood, S. and McGorry, PD (2003) Incipient neurovulnerability and neuroprotection in early psychosis. Psychopharmacology Bulletin 37, pp. 79-101.

Bertolote J, McGorry P. (2005). Early intervention and recovery for young people with early psychosis: Consensus statement. British Journal of Psychiatry, 187 (suppl. 48):s116 - s119.

Bicknell and Levy (2012). The utility of modelling Word identification from visual input within models of eye movements in reading. VISUAL COGNITION, 20: 422-456.

Birchwood, M., Todd, P. and Jackson, C. (1998) Early intervention in psychosis. The critical period hypothesis. British Journal of Psychiatry 172: suppl. 33, pp. s53-s59.

Binswanger, Ludwig (1972). Tres formas de la existencia frustrada. Exaltación, excentricidad, manierismo. Madrid. Editorial: Amorrortu Editores.

Bleuler, E. (1911) Dementia praecox; or the group of schizophrenias. Nueva York: International Universities Press. [Traducción al castellano: Demencia precoz; el grupo de las esquizofrenias (1993), Buenos Aires; Home-Paidós]

Bottlender, R. and Moller, HJ (2003) The impact of the duration of untreated psychosis on shortand long-term outcome in schizophrenia. Current Opinion in Psychiatry 16 :Suppl. 2, pp. S39S43

Boudewyn, M.A., Swaab, T.Y. \& Carter, C.S. (2012). Context, control and comprehension in schizophrenia: getting the global message depends on local semantic priming. Slide presentation presented at the annual meeting of the Cognitive Neuroscience Society, Chicago, Illinois March 31- April 3.

Bowie, C. y Harvey, P. (2008) Administration and interpretation of the Trail Making Test. Nature Protocols1, 2277 - 2281 (2006) Published online: 21 
Bowie, C; Gupta, M; Holshausen, K; Jokic, R; Best, M; Milev, R (2013) Journal of Nervous \& Mental Disease: Volume 201 - Issue 8 - p 680-685

Briz, Antonio. 2001. El español coloquial en la conversación. Esbozo de pragmagramática. Barcelona: Ariel.

Brown, Gillian y George Yule. 1993. Análisis del discurso. Madrid: Visor.

Brunetti E. (2013) Schizophrenia and language: New vistas for an old couple. Frontiers in Psychiatry. Submitted, Feb.

Burgess PW, Alderman N, Evans J, Emslie H, Wilson BA (1998) The ecological validity of test of executive function. J Int Neuropsychol Soc. Nov:4(6):547-58.

Burin D, Drake M. (2008) Evaluación Neuropsicológica en adultos. Paidós. España.

Byrne, M.E., Crowe, T.A. and P.S. Griffin (1998): 'Pragmatic language behaviours of adults diagnosed with chronic schizophrenia’. Psychological Reports 83: 835-46.

Cabello Rangel, H., Díaz Castro, L., y Arredondo, A. (2011). Costo-efectividad de intervenciones para esquizofrenia en México. Salud mental, 34(2), 95-102.

Calsamiglia, H y Tusón A. (2002). Las cosas del decir. Manual de análisis del discurso. Ariel. Barcelona.

Cameron, N. (1968)“Análisis experimental del pensamiento esquizofrénico” en Kasanin, J. S: Lenguaje y pensamiento en la esquizofrenia. En Kasanin, J.A. Lenguaje y pensamiento en la esquizofrenia. Hormé. Buenos Aires.

Cameron, N. (1944) Experimental analysis of schizophrenic thinking. In: Kasanin, J.A. (1968) Lenguaje y pensamiento en la esquizofrenia. Hormé. Buenos Aires.

Castilla del Pino, C. 1974. Hermenéutica del lenguaje. Madrid: Cátedra.

Chaika, E. 1974. A linguist looks at 'schizophrenic' language. Brain and Language, 1, 257-276.

Chaika, E. Lambe, R. The Locus of Dysfunction in Schizophrenic Speech. Schizophrenia bulletin. Vol. 11, No. 1, 1985.

Chaika, E. Accounting for linguistic data in schizophrenic research. Behavioral and Brain Sciences, 5:594 595, 1982a.

Chaika, E. Thought disorder or speech disorder in schizophrenia. Schizophrenia Bulletin, 8:588591

Chapman, LJ and Chapman, JP (1987) The search for symptoms predictive of schizophrenia. Schizophrenia Bulletin 13: 3 , pp. 497-503.

Chapman LJ, Chapman JP. (1973) Disordered Thought in Schizophrenia. Apple-Century-Crofts; New York. 
Chapman LJ, Chapman JP, Miller GA. (1964) A theory of verbal behavior in schizophrenia. In: Maher BA, editor. Progress in Experimental Personality Research. Vol. 1. Academic press; New York, pp. 49-77.

CIE-10 Clasificación internacional de enfermedades, décima versión online http://deis.minsal.cl/deis/codigo/capacitacion/indicecap.asp

Cohen, P. and Cohen, J. D. (1984) The clinician's illusion. Archives of General Psychiatry $41: 12$ , pp. 1178-1182.

Cohen J.D. and Servan-Schreiber, D. (1992) Context, cortex, and dopamine: A connectionist approach to behavior and biology in schizophrenia. Psychological Review, Vol 99(1), Jan 1992, 45-77

Compton MT \& Broussard B. (2011). Conceptualizing determinants of DUP. Current Psychiatry Reviews, 7(1):1

Condon, W.S., Ogston, W.D. (1966) Sound film analysis of normal and pathological behavior patterns. J. nerv. ment. Dis. 1966; 143:338.

Corcoran, R. (2001) Theory of Mind in schizophrenia. In Corrigan, Patrick W. (Ed); Penn, David L. (Ed), (2001). Social cognition and schizophrenia. , (pp. 149-174). Washington, DC, US: American Psychological Association, xvii, 353 pp.

Cornblatt, B., Lencz, T. and Obuchowski, M. (2002) The schizophrenia prodrome: Treatment and high-risk perspectives. Schizophrenia Research 54, pp. 177-186.

Covington, M.A., He, C., Brown, C., Naci, L., McClain, J.T., Fjordbak, B.S., Semple, J. and J. Brown (2005): 'Schizophrenia and the structure of language: the linguist's view'. Schizophrenia Research 77(1): 85-98.

Chattopadhyay, S: Cognitive déficits in schizophrenia. J Sci Soc, 2012; 39:57-62).

Clifton and Staub (2011) Syntactic influences on eye movements during reading. In The Oxford Handbook of Eye Movements. Liversedge SP., Gilchrist ID., and Everling S. Eds. Oxford University Press Inc. New York.

Clifton, Staub and Rayner (2007) Eye Movements in Reading Words and Sentences. In Eye Movements: A Window on Mind and Brain. van Gompel RPG., Fischer MH., Murray WS. and Hill RL., Eds. Elsevier, Oxford UK.

Coloma, C, Peñaloza, Fernández, C. (2007) Producción de Oraciones complejas en niños de 8 y 10 años. RLA, Revista de Lingüística Teórica y Aplicada, 45 (1), I Sem. 2007, pp. 33-44

Collins, A. y Loftus, E. (1975) A spreading-activation theory of semantic processing. Psychological Review, Vol 82(6), Nov 1975, 407-428

Crawford, H. and Henry, J.(2004) The Positive and Negative Affect Schedule (PANAS): Construct validity, measurement properties and normative data in a large non-clinical sample. British Journal of Clinical Psychology. Volumen 43, Número 3 ,páginas 245-265, septiembre 
Crockford C., and Lesser, R. (1994)"Assesing functional communication in aphasia: Clinical utility and time demands of three methodos" European Journal of Disorders of Communicaton, 29, pp. 165-182.

Crow, T. (1997) Is schizophrenia the price homo sapiens pay for language? Schiz Res. 28:127141.[

Crystal, D. (1981) Clinical Linguistics. Londres: Edward Arnold

Crystal, D. (2001). "Clinical linguistics", en M. Aronoff \& J. Rees-Miller (Eds.): The Handbook of Linguistics, Oxford: Blackwell, pp. 673-682.

Condray, R., Stenhauer, S. and Goldstein, G. (1992) Language Comprehension in Schizoprenics and they brothers. Biol Psychiatry, 32, 790-802.

Couture,S.; Penn, D.; Roberts, D. (2006).The Functional Significance of Social Cognition in Schizophrenia: A Review. Schizophrenia Bulletin vol. 32 no. S1 pp. S44-S63

Cuetos, F. (2012) Neurociencia del lenguaje. Bases neurológicas e implicaciones clínicas. Panamericana. Madrid.

Dascal, M. (1983) Language use in jokes and dreams: Sociopragmatics vs psychopragmatics. Language \& Communication. Volume 5, Issue 2, Pages 95-106

Damasio, A.R. y Damasio, H. (1992). Brain and language. Scientific American, 267, 63-71.

Davidson, M., Reichenberg, A., Rabinowitz, J., Weiser, M., Kaplan, Z. and Mark, M. (1999) Behavioral and intellectual markers for schizophrenia in apparently healthy male adolescents. American Journal of Psychiatry 156, pp. 1328-1335.

DeLisi LE. (2001)Speech disorder in schizophrenia: Review of the literature and exploration of its relation to the uniquely human capacity for language. Schizophr Bull. 2001;27(3):481-496

Docherty, JP, Van Kammen, DP, Siris, SG and Marder, SR (1978) Stages of onset of schizophrenic psychosis. American Journal of Psychiatry 135: 4, pp. 420-426.

Done, DJ, Sacker, A. and Crow, TJ (1994) Childhood antecedents of schizophrenia and affective illness: Intellectual performance at ages 7 and 11. Schizophrenia Research 11, p. 96.

Done, DJ, Crow, TJ, Johnstone, EC and Sacker, A. (1994) Childhood antecedents of schizophrenia and affective illness: Social adjustment at ages 7 and 11. British Medical Journal 309, pp. 699-703.

Dik, S.C. (1978). Gramática Funcional. SGEL. Madrid. 
Ditman, T. y Kuperberg, G (2010) Building coherence: A framework for exploring the breakdown of links across clause boundaries in schizophrenia. J Neurolinguistics. $201001 \mathrm{de}$ may; 23 (3): 254-269.

Dahan, Tanenhaus and Salverda, (2007). The Influence of Visual Processing on Phonetically Driven Saccades in the "Visual World" Paradigm. In Eye Movements: A Window on Mind and Brain. van Gompel RPG., Fischer MH.,Murray WS. and Hill RL., Eds. Elsevier, Oxford UK.

Dubois B, Slachevsky A et al. (2000) The FAB: a Frontal Assessment Battery at bedside. Neurology. Dec 12: 55(11):1621-6.

Durán E. y Figueroa A. (2009). Análisis del nivel pragmalingüístico del discurso de un sujeto esquizofrénico. Gaceta de Psiquiatría Universitaria. Año 5, v. 2.

Durán, E y Figueroa, A. (2009). Sobre el déficit pragmático en la utilización de pares adyacentes, por pacientes esquizofrénicos crónicos y de primer brote. Revista Chilena de Neuropsiquiatría. v.47 n.4

Donlon, PT and Blacker, KH (1973) Stages of schizophrenic decompensation and reintegration. Journal of Nervous and Mental Disease 157, pp. 200-209.

Eaton, W. and Harrison, G. (2001) Life chances, life planning, and schizophrenia: A review and interpretation of research on social deprivation. International Journal of Mental Health 30, pp. 58-81.

Edwards, J., Jackson,H.J. and Pattison, P. (2002). Emotion recognition via facial expression and affective prosody in schizophrenia: a methodological review. Clin Psychol Rev. 2002 Nov; 22(8):1267-85.

Ellis, W. and Young, A. (1988). Human Cognitive Neuropsychology.Londres: LEA.

Engbert R. and Kliegl, R. (2011). Parallel graded attention models of reading. In The Oxford Handbook of Eye Movements. Liversedge SP., Gilchrist ID., and Everling S. Eds. Oxford University Press Inc. New York.

Enghels, R. y Roegiest, E. (2004): "Percepción visual y percepción auditiva: La naturaleza del objeto". En Serra, E. y G. Wotjak (eds), págs. 47-59.

Epstein, S. (1953) Overinclusive thinking in a schizophrenic and control group. Journ. Consult. Psychol. 17.

Escandell, V. (1996) Introducción a la Pragmática. Ariel. Barcelona.

Escribano, J.L. (1991) Una teoría de la oración. Universidad de Oviedo, Servicio de publicaciones.

Feldman, M., J.; Drasgow, J. (1951). A visual-verbal test for schizophrenia. Psychiatric Quarterly Supplement, Vol 25, 55-64. 
Ferreres, A., Abusamra, V., Martínez-Cuitiño, M., Ska, B., Côté H., e Y. Joanette. (2007). Protocolo para la Evaluación de la Comunicación de Montréal (MEC). Buenos Aires: Neuropsi.

Figueroa, A. (2009). Aproximación al discurso esquizofrénico. Aplicación del modelo de Sergio Piro. Tesis para optar al Diploma de Estudios Avanzados. Universidad de Valladolid, España.

Figueroa, A. y Durán, E. (ed) (2011) Psicolingüística aplicada a las enfermedades mentales. Cores. Santiago, Chile.

Figueroa, G., (2008) La psicología fenomenológica de Husserl y la psicología. REV CHIL NEURO-PSIQUIAT 2008; 46 (3): 224-237

Fioravanti M, Carlone O, Vitale B, Cinti ME, Clare L.(2005) A meta-analysis of cognitive déficit in adults with a diagnosis of schizophrenia. Neuropsychol Rev. Jun; 15(2); 73-95.

Flekkoy, K. (1975). Semantic meaning and associative responding. Scandinavian Journal of Psychology. Volume 16, Issue 1, pages 149-151, September 197

Frith, C.D. (1987) Consciousness, information processing and schizophrenia. British Journal of Psychiatry, n. 134, p. 225-235, 1979.

Frith C. D. (2007) Making up the mind; how the brain creates our mental world. Oxford, UK: Blackwell.

Gallardo-Paúls, B. (2005) Categorías inferenciales en pragmática clínica. Rev. Neurol; 40

Gallardo, Páuls B. (2009) Valoración del componente pragmático a partir de datos orales. Rev Neurol 2009; 48 (supl 2): s57-s61

Gallardo, Páuls B. y Hernández Sacristán C. (2013) Lingüística Clínica. Un enfoque funcional sobre las alteraciones del lenguaje. Arco. Madrid.

Gallardo Paúls B. y Valles B. (2008) Lingüística en contextos clínicos: la lingüística clínica. Lengua y Habla (Revista del Centro de Investigación y Atención Lingüística C.I.A.L.) 32-50

Garayzábal (ed) (2006) Lingüística clínica y logopedia, Madrid, A. Machado Libros.

García-Miguel J.M. (2005) Aproximación empírica a la interacción de verbos y esquemas construccionales, ejemplificada con los verbos de percepción. ELUA, 19.

Gaskell, M. y Marslen-Wilson, W. (1997) integrating from and meaning: A distributed model of speech perception. Language and cognition processes, 12, 613.656.

Gernsbacher, M.A, Tallent, K.A. y Bolliger, C.M. (1999) Disordered discourse in schizophrenia described by structure building framework. Discourse Studies, 1(3), 355-372 
Green A., Canuso C., Brenner M., Wojcik J. (2003) Detection and management of comorbidity in patients with schizophrenia. Psychiat. Clin. N Am 26, $115-139$.

Geschwind, N. (1975) The apraxias: neural mechanisms of disorders of learned movement. Am Sci, 63:188

Green MF, Nuechterlein KH, Gold JM, Barch DM, Cohen J, Essock S, Fenton WS, Frese F, Greenfield, S., Strakowski, S., Tohen, M., Batson, S. and Kolbrener, M. (1994) Child abuse in first episode psychosis. British Journal of Psychiatry 64, pp. 831-834.

Gray, J. A., Feldon, J., Rawlins, J. N. P., Hemsley, D. R., and Smith, A. D. (1991). The neuropsychology of shizophrenia. Behav. Brain Sci. 14, 1-84.

Gruber, J., and Kring, A. (2008). Emotion narratives in schizophrenia. Journal of Abnormal Psychology. Vol 117, n|3, 520-533.

Goffman, E. (1959) La presentación de la persona en la vida cotidiana. Amorrortu editores Buenos Aires

Goldberg TE, Heaton RK, Keefe RS, Kern RS, Kraemer H, Stover E, Weinberger DR,Zalcman S, Marder SR. (2004) Approaching a consensus cognitive battery for clinical trials in schizophrenia: the NIMH-MATRICS conference to select cognitive domains and test criteria. Biol Psychiatry Sep 1; 56 (5); 301-7.

Goldstein, K. (1974). Enfoque metodológico para el estudio del desorden del pensamiento esquizofrénico. En: Kasanin, J.S. Lenguaje y pensamiento en la esquizofrenia. Buenos Aires: Paidós

Goldstein, K. (1943) The significance of psychological research in schizophrenia. Journ. Nerv. Ment. Dis.., 97, 3.

Goldman-Eisler, F. (1964). Disurther cussion and further comments. In E.H. Lenneberg (ed), New directions in the study of language. Cambridge: MITPress.

Goodglass y Kaplan, (1983). The Assesment of Aphasia and Related Disorders (2ed) (Philadephia: Lea\&Febiger).

Grice, H. P. 1975. Logic and conversation. Cole y J. Morgan (eds). (1975). Speech and semantics, 3: Speech acts, pp. 41- 58. Nueva York: Academic Press.

Godefroy O. (2003) Frontal syndrome and disorders of executive functions. J Neurol Jan; 250(1):1-6.

Gomberoff, L. (1999). Difusión de identidad, Bordeline y su medida. Tesis para optar al grado de licenciado en Psicología. Escuela de Psicología. Universidad Diego Portales, Santiago, Chile.

Gross G. The 'basic' symptoms of schizophrenia. Br J Psychiatry Suppl 1989:21-5; discussion $37-40$.

Gutiérrez Ordóñez, S. (1997). Temas, remas, focos, tópicos y comentarios. Arco Libros. Cuadernos de Lengua Española. 
Habermas, J. (1971). Technik und Wissenschaft als Ideologie. Frankfurt: Suhrkamp.

Halliday, M.A.K. (1979). El lenguaje como semiótica social. Fondo de cultura económica. México.

Halliday, M.A.K. (1976). Cohesion in English.London: Longman

Happé, F.; Frith, U. (1994). Language and Communication in Autistic Disorders. Phil. Trans. R. Soc. Lond. 346:97-104

Harrison, G et al. (1986) Recovery from psychotic illness: a 15- and 25- year international follow-up study. Br J Psychiatry 2001; 178: 506 - 517). (KUA J et al. A 20-year follow-up study on schizophrenia in Singapore. Acta Psychiatr Scand 2003; 108: 118 - 125

Harrow, M and Marengo, J. (1986) Trastorno esquizofrénico pensamiento en el seguimiento: Su persistencia y significado pronóstico. Schizophrenia Bulletin, Vol 12 (3), 1986, 373-393.

Harrow, M. and Quinlan, D.M. (1985) disorders thinking and schizophrenic pathology. Nueva York. Gardner Press, Inc.

Haas, G. and Sweeney JA. (1992) Premorbid and onset features of first-episode schizophrenia. Schizophrenia Bulletin;18: 373-386.

Hernández Sacristán, C. (2006) La unidad palabra y su significado: una perspectiva logopédica sobre la capacidad léxica. En E. Garayzábal (ed), Lingüística clínica y logopedia, Madrid, A. Machado Libros.

Heydebrand G, Weiser M, Rabinowitz J, Hoff AL, DeLisi LE, Csernansky JG. (2004) Correlates of cognitive deficit in first episode schizophrenia. Schizophr Res 68:1-9.

Himelhoch,S., Taylor, S., Goldman, R., and Tandom, R. (1996). Frontal lobe tasks, antipsychotic medication, and schizophrenia syndromes. Biological Psychiatry. Volume 39, Issue 3, 1 February 1996, Pages 227-229.

Ho B, Andreasen NC, Flaum M, Nopoulos P, Miller D. (2000) Untreated initial psychosis: Its relation to quality of life and symptom remission in first-episode schizophrenia. American Journal of Psychiatry;157: 808-815.

Hoffman, R., and Slegde, W. (1982) "A micogenetic model of paragrammarims produced by a schizophrenic speaker'Brain \&Language, 21, 147-173,

Holm-Hadulla, R. 1986. Sobre las relaciones entre lenguaje, delirio e intencionalidad en la esquizofrenia. Revista chilena de neuro-psiquiatría, no 1: 9-15.

Huber G, Gross G. Basic symptom concept - historical aspects in view of early detection of schizoprenia. Neurol Psychiatr Br Res 1998; 5:183-90.

Huber G, Gross G. The concept of basic symptoms in schizophrenic and schizoaffective psychoses. Recenti Prog Med 1989; 80:646-52. 
Huff, F.J. (1990). Language in normal aging and related neurological diseases. En F. Boller y J. Grafman (Eds.): Handbook of Neuropsychology (pp. 252-265). Amsterdam: Elsevier.

Husserl E.(1962). Ideen zu einer reinen Phanomenologie und phanomenologischen Philosophie. Husserliana III. Den Haag: Martinus Nijhoff. En Figueroa, G., (2008) La psicología fenomenológica de Husserl y la psicología. REV CHIL NEURO-PSIQUIAT 2008; 46 (3): 224237

Hymes, D. (1974) "Hacia etnografías de la comunicación" en: Antología de estudios de etnolingüística y sociolingüística. México: UNAM.

Hymes, D. (1996) “Acerca de la competencia comunicativa”, Forma y Función (9), Santafé de Bogotá, junio de p.p. 13 - 37.

Insúa, P y Belinchón M (2004). Alteraciones del relato. Arbor CLXVII, 697 (Enero 2004), 157 $187 \mathrm{pp}$.

Jakobson, R. (1985) Ensayos de Lingüística General. Madrid. Planeta de Agostini.

Jaspers, K. 1993. Psicopatología general. México: Fondo de Cultura Económica.

Joanette, I. y P. Goulet (1993). "Verbal Communication Deficits after Right- Hemisphere Damage" en Blanken, G., J. Dittmann, H. Grimm, J. Marshall y C. Wallesch (1993). Linguistic Disorders and Pathologies. Berlin-New York: Walter de Gruyter, 383-388.

Joanette, Y., Ska, B. \& Côté, H. (2004). Protocole Montréal d'Évaluation de la Communication. Isbergues, France: Ortho Édition.

Jiménez García-Bóveda y Vázquez Morejón:2006. Esquizofrenia y género. Apuntes de Psicología, 2006, Vol. 24, número 1-3, págs. 157-183.

Jimeno, N. (2002). Diagnóstico sindrómico de la esquizofrenia. Informaciones Psiquiátricas Tercer trimestre. Número 169

Jimeno N, Jimeno Valdés A, Vargas ML. El síndrome psicótico y el Inventario de Frankfurt. Conceptos y resultados. Barcelona: Springer-Verlag Ibérica, 1996.

Juhasz and Pollatsek (2011) Lexical influences on eye movements in reading. In The Oxford Handbook of Eye Movements. Liversedge SP., Gilchrist ID., and Everling S. Eds. Oxford University Press Inc. New York.

Kasanin, J.A. (1968) Lenguaje y pensamiento en la esquizofrenia. Hormé. Buenos Aires.

Kreysa and Pickering (2011) Eye movements in dialogue. In The Oxford Handbook of Eye Movements. Liversedge SP., Gilchrist ID., and Everling S. Eds. Oxford University Press Inc. New York.

Kernberg, O.F. (1987). Ego relaciones psicología a objetos enfoque de la teoría a la transferencia. Psychoanal. P., 56: 197-221.

Killackey, E. and Yung, AR (2007) Effectiveness of early intervention in psychosis. Current 
Opinion in Psychiatry 20, pp. 121-125.

Killackey, EJ, Jackson, HJ, Gleeson, J., Hickie, IB and McGorry, PD (2006) Exciting career opportunity beacons! Early intervention and vocational rehabilitation in first-episode psychosis: Employing cautious optimism. Australian and New Zealand Journal of Psychiatry 40, pp. 951962.

Klösterkotter, J., Ebel, H., Schultze-lutter, F. and Steinmeyer, EM (1996) Diagnostic validity of basic symptoms. European Archives of Psychiatry and Clinical Neurosciences 246, pp. 147-154.

Klösterkotter, J., Ruhrmann, S., Schultze-Lutter, F., Salokangas, RK, Linszen, D. and Birchwood, M. (2005) The European Prediction of Psychosis Study (EPOS): Integrating early recognition and intervention in Europe. World Psychiatry 3, pp. 1-7.

Klösterkotter, J., Gross, G., Huber, G., Wieneke, A., Steinmeyer, EM and Schultze-lutter, F. (1997) Evaluation of the 'Bonn Scale for the Assessment of Basic Symptoms-BSABS' as an instrument for the assessment of schizophrenia proneness: A review of recent findings. Neurology, Psychiatry and Brain Research 5, pp. 137-150.

Klösterkotter, J., Hellmich, MI, Steinmeyer, EM and Schultze-Lutter, F. (2001) Diagnosing schizophrenia in the initial prodromal phase. Archives of General Psychiatry 58, pp. 158-164

Kaplan, HI, Sadock, BJ and Grebb, JA (1994) Kaplan and Sadock's synopsis of psychiatry Williams \& Wilkins, Baltimore

Kessler RC, Berglund, P., Demler, O., Jin, R., Merikangas, KR and Walters, EE (2005) Lifetime prevalence and age-of-onset distributions of DSM-IV disorders in the National Comorbidity Survey Replication. Archives of General Psychiatry 62, pp. 593-602.

Kiang, M.(2010) Schizotypy and language: A review. Journal of Neurolinguistics 23, 193-203

Kraepelin, E. (1909) L' introduction á la Psychiatrie clinique. Paris. Vigot Fréres. [Traducción al castellano: Introducción a la clínica psiquiátrica (1988), Madrid; Nieva]

Kraepelin, E. (1919) Dementia Praecox and Paraphrenia. Krieger, Huntington, NY E. [Traducción al español (2008) La demencia precoz. Madrid. Polemos]

Kuperberg GR, McGuire PK, David AS. (1998) Reduced sensitivity to linguistic context in schizophrenic thought disorder: evidence from on-line monitoring for words in linguistically anomalous sentences. J Abnorm Psychol, 107:423-434.

Kuperberg, G. (2000) Schizophrenia and cognitive function. Current Opinion in Neurobiology, 10:205-210. 
Kuperberg, G. (2010) Language in Schizophrenia Part 1: An Introduction Language and Linguistics Compass 576-589, Journal Compilation Blackwell Publishing.

Kuperberg, G, Sitnikova, T, Caplan, D, Holcomb, P. (2003) Electrophysiological distinctions in processing conceptual relationships within simple sentences. Cognitive Brain Research 17:117129.

Labov, W. and Waletzky J. (1967) Narrative Analysis: Oral Versions of Personal Experience, en: Macneish, J. H. (ed.) (1967): Essays on the Verbal and Visual Arts. Proceedings of the 1966 Annual Spring Meeting, Seattle, pp. 12-44.

Laguna, E. y Turull, N. (2000) Aplicaciones del análisis del discurso en rehabilitación psicosocial con pacientes esquizofrénicos. Rev Psiquiatría, Fac. Med. Barna; 27(4):193-200

Lahera G, Herrera S, Reinares M, Benito A, Rullas M, Gonz alez-Cases J, Vieta E. Hostile attributions in bipolar disorder and schizophrenia contribute to poor social functioning. Acta Psychiatr Scand 2015: 131: 472-482.

Lahera G., Herrera S., Fernandez C., Bardon M, Angeles V., Fernandez-Liria A. Familiarity and face emotion recognition in patients with schizophrenia. Comprehensive Psychiatry 2013

Larsen, TK, Melle, I., Auestad, B., Friis, S., Haahr, U. and Johannessen, JO (2006) Early detection of first-episode psychosis: The effect on 1-year outcome. Schizophrenia Bulletin 32 , pp. 758-764.

Lévy et al (1998) Linguistically anomalous sentences. J Abnorm Psychol, 107:423-434.

Leroy, F., Penard, L., nandrino, .J.L. and Beaune, D (2008). Langage et schizophrénie: L' intention en question. Anales Médico Psycholoques, 166 (8), 612-619.

Lezak, M.D. (1995). Neuropsychologycal Assessment. New York: Oxford University Press (orig. 1975).

Loprete en Asociación Argentina de tartamudez. DEFINICIÓN CONCEPTUAL DE LAS VARIABLES https://www.aat.org.ar/definicionconceptualdelasvar/html

Lyon, J. (1997) Semántica Lingüística. Una Introducción. Paidós, Buenos Aires

Marengo JT, Harrow M, et al. (1983) A manual for assessing aspects of bizarre-idiosyncratic thinking. In: Harrow M, Quinlan D, eds. Disordered thinking and schizophrenic psychopathology. New York: Gardner Press, 394-411.

Marengo J. and Harrow M.(1983) Thought Disorder: A Function of Schizophrenia, Mania, or Psychosis?. Journal of Nervous \& Mental Disease:Vol 173. N1.

Marshall, M., Lewis, S., Lockwood, A., et al.,( 2005) Association between duration of untreated psychosis and outcome in cohorts first-episode patients.Archives of Generals Psychiatry.62, 975983

Martínez, A., Oyarzún, S., Vargas C. (2014) El rol del proceso atencional en la atribución emocional de personas con diagnóstico de esquizofrenia de primer episodo. Tesis para optar al 
grado de Magister en Psicología clínica Universidad del Desarrollo.

McGlashan T. Melle I, Larsen TK, Haahr U, et al. (2004). Reducing the duration of untreated first-episode psychosis: effects on clinical presentation. Archives of General Psychiatry, 61:143150.

McGrath, J., Saha, S., Welham, J., et al. (2004). A systematic review of the incidence of schizophrenia. B.M.C.Med. 2, 13.

McGorry, P., A. Yung, et al. (2002). "Closing in": what features predict the onset of first episode psychosis within a high risk group? The Early Stages of Schizophrenia. R. Zipursky. Washington, DC, American Psychiatric Press: 2-31.

McGorry, PD and Yung, AR (2003) Early intervention in psychosis: An overdue reform. Australian and New Zealand Journal of Psychiatry 37:4, pp. 393-398.

McGorry, PD, Yung, AR and Phillips, LJ (2003) The 'close-in' or ultra high risk model: A safe and effective strategy for research and clinical intervention in prepsychotic mental disorder. Schizophrenia Bulletin 29: 4 , pp. 771-790.

McGorry Patrick D, Killackey Eóin, Yung Alison R. (2007) Early intervention in psychotic disorders: detection and treatment of the first episode and the critical early stages MJA Volume 187 Number 7 .

Mc Gurk, S. R:1999) The effects of clozapine on cognitive functioning in schizophrenia. Journal of Clinical Psychiatry, 60, 24-29.)

McClelland, J.L. y Elman, J.L. (1986) the TRACE Model of speech perception. Cognitive psychology, 18, 1-86.

Mc Kenna, P. y Oh, T. 2005. Schizophrenic speech. Cambridge University Press. United Kingdom.

Marshall M, Lewis S, Lockwood A, Drake R, Jones P, Croudace T. (2005). Association between duration of untreated psychosis and outcome in cohorts of first-episode patients: A systematic review. Archives of General Psychiatry, 62:975-983.

Marslen-Wilson, W. y Tyler, L.K.(1980)The temporal structure of spoken language understanding. Cognition, 8, 1-71.

Meilijson, S.R, Kasher, A. and A. Elizur (2004): 'Language performance in chronic schizophrenia: a pragmatic approach'. Journal of Speech, Language, and Hearing Research 47(3): 695-713.

Mendizábal de la Cruz, N. (2004). Los errores espontáneos en la producción lingüística. Artifara: Revista de lenguas y literaturas ibéricas y latinoamericanas, ISSN-e 1594-378X, №. 4.

Menjura, P. (2007). La fluidez discursive oral una propuesta de evaluación. Ogigia. Revista electrónica de estudios hispánicos, n. ${ }^{\circ}$ 1, enero 2007, pp. 7 a 16. 
Miller, TJ, McGlashan, TH, Rosen, JL, Somjee, L., Markovich, PJ and Stein, K. (2002) Prospective diagnosis of the initial prodrome for schizophrenia based on the Structured Interview for Prodromal Syndromes: Preliminary evidence of interrater reliability and predictive validity. American Journal of Psychiatry 159 :5 , pp. 863-865.

Milner B (1963) "Effects on different brain regions on card sorting." Archives of Neurology 9: $100-110$.

Minkowsky, E. (2000) La esquizoprenia: Psicopatología de los esquizoides y de los esquizoprénicos. México. Fondo de Cultura Económica.

Mohamed S, Paulsen JS, O’Leary D, Arndt S, Andreasen NC. (1999) Generalized cognitive deficits in schizophrenia: a study of first episode patients. Arch Gen Psychiatry, 56:749-754)

Moreno Fernández, F. (2010). Principios de sociolingüística y sociología del lenguaje. Barcelona. Ariel.

Morice R, Ingram JCL. (1983) Language analysis in schizophrenia: Diagnostic implications. Australian and New Zealand J Psychiatry. 1982; 16:11-21.

Morice, R. (1986) Beyond language_speculations on the prefrontal cortex and schizophrenia. Aust NZ J Psychiatry 20:7-10.

Mueser, KT and McGurk, SR (2004) Schizophrenia. The Lancet 363, pp. 2063-2072.

Newcombe,F.(1969). Missle Wounds of the Brain. A Study of Psychological Deficits. London: Oxford UniversityPress.

Nippold, M., Heskett, L., Duthie J. and Mansfield, T. (2005) Conversational Versus Expository Discourse: A Study of Syntactic Development in Children, Adolescents, and Adults. Journal of Speech, Language, and Hearing Research Vol. 48 _ 1048-1064.

Nippold, M. (1993) Clinical forum: adolescent language developmental markers in adolescent language: syntax, semantics, and pragmatics. Language, Speech and Hearing Services in Schools, 24, 21-28.

Nordentoft, M., Jeppesen, P., Abel, MB, Kassow, P., Petersen, L. and Thorup, A. (2002) OPUS study: Suicidal behaviour, suicidal ideation and hopelessness among patients with first-episode psychosis. One-year follow-up of a randomised controlled trial. British Journal of Psychiatry 43 (Suppl.), pp. s98-s106.

Nuecherterlein, K.H.y Dawson, ME (1984) A heuristic vulnerability/stress model of schizophrenic episodes. Schizophr Bull, 10(2), 300-312 
Ninullain, M., O’Hare, A. y Walsh, D. (1987). Incidence of schizophrenia in Ireland. Psychological Medicine, 17, 943-948.

Nuthmann and Henderson (2012) Using CRISP to model global characteristics of fixation durations in scene viewing and reading with a common mechanism. VISUAL COGNITION, 20: 457-494.

Ochs, E. (1998). Narrative. In T. van Dijk (Ed.), Discourse as Structure and Process (pp. 185207). London: Sage Publications.

Oh TM, McCarthy RA, McKenna PJ. (2008) Is there a schizophasia? A study applying the single case study approach to formal thought disorder in schizophrenia. Neurocase. ; 8: 233-244.

Orellana, G. (2009). Conductas disejecutivas en primer episodio de esquizofrenia: rol de la atención ejecutiva y de la autorregulación estratégica. Título para optar al grado de Doctora en Ciencias Biomédicas. www.cybertesis.uchile.cl/tesis/uchile/2009/meorellana_g/pdfAmont/me-orellana_g.pdf

Orellana G., Peña M, Slachevsky A. (2012) "First episode of Schizophrenia: specific impairment in executive attention". BMC Psychiatric 22; 12:154.

Orellana G., Salachevsky A. (2013) "Executive functioning in schizophrenia" Front Psychiatry. In press.

Orellana G., Slachevsky A. (2006) "Trastornos neurocognitivos en la Esquizofrenia". Rev. Chilena de Neuropsicología.vol 1, $\mathrm{N}^{\circ}$ 1, 41-49.

Pavéz, M. M.; Coloma, C. y González, P. (2001). Discurso narrativo y desempeño gramatical en niños con Trastorno Específico del Lenguaje. Revista de Logopedia, Foniatría y Audiología, XXI, pp. 224-230

Payne, R.W., Matussek, P., G, (1961) E.I. Experimental study of schizophrenic thought disorder. Brit J Psychiat.;108:362-367

Penn D, Waldheter E, Perkins D, Mueser K, Lieberman J. (2005). Psychosocial treatment for first-episode psychosis: A research update. American Journal of Psychiatry,162: 2220-2232.

Pantelis, C., Yucel, M., Wood, SJ, McGorry, PD and Velakoulis, D. (2003) Early and late neurodevelopmental disturbances in schizophrenia and their functional consequences. Australian and New Zealand Journal of Psychiatry 37, pp. 339-406.

Perkins, DO, Gu, H., Boteva, K. and Lieberman, JA (2005) Relationship between duration of untreated psychosis and outcome in first-episode schizophrenia: A critical review and metaanalysis. American Journal of Psychiatry 162, pp. 1785-1804.

Petofi, J. (1978) Structure and Function of the Grammatical Component of the Text-Structure 
World-Structure Theory. In Formal Semantics and Pragmatics for Natural Languages. Synthese Language Library Volume 4, 1978, pp 303-338

Pfersdorff, C. (1935) Les catégories du langage aphasique et la dissociation schizophrénique. Annales médico-psychologiques, II, 1, p. 1-11.

Pinker, S. (1992). Review of Bickerton (1990). Language 68, 375-382.

Piro, S. (1987) El lenguaje esquizofrénico. Fondo de Cultura Económica. México.

Poyatos, F (1994) la comunicación no verbal. Madrid. Itsmo.

Premack, D., \& Woodruff, G. (1978b). Cognition and Consciousness in Nonhuman Species Reply. Behavioral and Brain Sciences, 1(4), 616-628.

Premack D, Woodruff G. (1978) Does chimpanzee have a theory of mind? Behav Brain Sci 1978; 4: 9-30.

Prutting C. y Kirchner D. 1987. A clinical appraisal of the pragmatic aspects of language Journal of Speech and Hearing Disorders 52, 105-119.

Racenstein JM, Penn D, Harrow M, Schleser R. (1999) Thought disorder and psychosocial functioning in schizophrenia: The concurrent and predictive relationships. J Nerv Ment Dis. 1999; 187:281-289.

Radach R., Reilly R. and Inhoff A (2007). Models of Oculomotor Control in Reading: Toward a Theoretical Foundation of Current Debates. In Eye Movements: A Window on Mind and Brain. van Gompel RPG., Fischer MH., Murray WS. and Hill RL., Eds. Elsevier, Oxford UK.

Rapaport, D., Gill M. y R. Schafer (1987) Test para diagnóstico psicológico. Cit. por Piro, Sergio. 1987. El lenguaje esquizofrénico. México: Fondo de Cultura Económica.

Rapaport, D., Gill M. y R. Schafer (1945) Diagnostic psychological testing. Year book Publisher, Chicago.

Rayner K. and Liversedge, S.P. (2011). Linguistic and cognitive influences on eye movements during reading. In The Oxford Handbook of Eye Movements. Liversedge SP., Gilchrist ID., and Everling S. Eds. Oxford University Press Inc. New York.

Reichle, C.D. (2011) Serial-attention models of reading. In The Oxford Handbook of Eye Movements. Liversedge SP., Gilchrist ID., and Everling S. Eds. Oxford University Press Inc. New York.

Reichle, C.D. Pollatsek, A. and Rayner K. (2007) Modeling the Effects of Lexical Ambiguity on Eye Movements During Reading. In Eye Movements: A Window on Mind and Brain. van Gompel RPG., Fischer MH., Murray WS. and Hill RL., Eds. Elsevier, Oxford UK.

Reichle, C.D., Rayner K. and Pollatsek, A. (2003) The E-Z Reader model of eye-movement control in reading: Comparisons to other models. BEHAVIORAL AND BRAIN SCIENCE 26, 
$445-526$

Reichle, C. D. Rayner, K. and Pollatsek, A. (2012) Eye movements in Reading versus nonreading tasks: Using E-Z Reader to understand the role of word/stimulus familiarity. VISUAL COGNITION 20, 360:90.

Renkena, J. (1999) Introducción a los estudios del discurso. Barcelona. Gedisa.

Reyes, G (1990) La pragmática lingüística. Editorial Montesinos. Barcelona.

Rivière, A. y J. Castellanos. (2003). Autismo y teoría de la mente. En M. Belinchón, A. Rosa, M. Sotillo, I. Marichalar y A. Rivière (Eds.), Obras Escogidas. Vol. II. Lenguaje, simbolización y alteraciones del desarrollo. Madrid: Panamericana.

Rizzolatti, G y Sinigaglia, C (1996) Mirrors in the Brain: How Our Minds Share Actions and Emotions. Oxford University Press. New York

Rochester, S and Martin, J. (1979). Crazy talk: A study of the discourse of schizophrenic speakers. Plenum. New York.

Roder, (2010) Cognition and Schizophrenia. In Clinical Manual, for Treatment of Schizophrenia. Lauriello, J and Pallanti, S (ed) British Library Cataloguing in Publication data. UK

Román et al (2012) ToM en pacientes con diversas patologías psiquiátricas, entre ellas, la esquizofrenia.

Roulet, E (1987) 'L' intégration des movements discursifs et le róle des conecteurs interactifs dans une approche dynamique de la construction du discourse monologique". Modéles Lingusitiques 9/I, 19-31

Sacks, H., Schegloff, E. y G. Jefferson. (1974). A simplest systematics for the organization of turn-taking for conversation. Language 50 (4): 696-735.

Saettele (1977) hacia una crítica de la Sociolingüística. Arte, Sociedad, Ideología, núm.2 agostoseptiembre. México.27-33

Saussure, F. (1968). Curso de lingüística general. Losada. Buenos Aires.

Saville-Troike, M. (2006). Etnografía de la comunicación. Prometeo. Buenos Aires.

Salavera, C. and Puyuelo, M. Aspectos semánticos y pragmáticos en personas con esquizofrenia. (2010) Revista de Logopedia, Foniatría y Audiología. Vol. 30, Issue 2, April-June, Pages 84-93

Searle, John. 1969. Speech acts: An Essay in the Philosophy of Language. Cambridge: Cambridge University Press (trad. esp. 1980. Actos de Habla. Madrid: Cátedra).

Séglas, J. (1892) Des troubles du langage chez les aliénés. Paris: J. Rueff et C ${ }^{\text {ie }}$ Editeurs.

Sereno, S.C. , O’Donnell , P.J. , and Rayner , K. ( 2006 ). Eye movements and lexical ambiguity 
resolution: Investigating the subordinate-bias effect. Journal of Experimental Psychology: Human Perception and Performance 32, 335 - 350 .

Serra M, Serrat E, Solé R, Bel A, Aparici M. (2000) La adquisición del lenguaje. Barcelona: Ariel.

Sperber, D. y Wison, D. (1991) "sobre la definición de relevancia" en La búsqueda del significado". En Luis Valdés (ed) La búsqueda del significado. Madrid. Tecnos. p. 583-598.

Shallice T \& Burgess P (1991) Déficit in strategy application following frontal lobe damage in man. Brain, 114: 727-741.

Shibatani, M (1990) The languages of Japan. Cambridge University Press, UK.

Slachevsky A, Pérez C, Silva J, Orellana G, Preñafeta M, Alegria P, Peña M (2005) Córtex prefrontal y trastornos del comportamiento: Modelos explicativos y métodos de evaluación. Rev. Chilena de Neuropsiquiatría 43:2:77- 170.

Slachevsky A, Villalpando JM, Sarazin M, Hahn-Barma V, Pillon B, Dubois B (2004) Frontal assessment battery and differential diagnosis of frontotemporal dementia and Alzheimer disease.Arch Neurol Jul;61(7):1104-7.

Slattery, T.J. ( 2009 ). Word misperception, the neighbor frequency effect, and the role of sentence context: Evidence form eye movements. Journal of Experimental Psychology: Human Perception and Performance , 35, $1969-1975$

Spauwen, J., Krabbendam, L., Lieb, R., Wittchen, HU and Van Os, J. (2006) Evidence that the outcome of developmental expression of psychosis is worse for adolescents growing up in an urban environment. Psychological Medicine $36: 3$, pp. 407-415.

Solovay, M.R., Shenton, M.E., Gasparetti, C., et al. (1986) Scoring manual for the thought disorder index. Schizophr Bull;12: 483-496.

Soto, G., Hasler F., García R. (2011). Lenguaje, cognición e interacción. El dominio de la gestión de expectativas. Psicolingüística Clínica aplicada a las enfermedades mentales. Lingüa\&Psyché Lugar: Santiago; Año: p. 151 - 170

Sperber, Dan y Deidre Wilson. (1994). La relevancia. Comunicación y procesos cognitivos. Madrid: Visor.

Staub , A. , White , S.J. , Drieghe , D. , Hollway , E.C. and Rayner , K. ( 2010 ). Distributional effects of word frequency on eye fixation durations . Journal of Experimental Psychology: Human Perception and Performance, 36: 1280 - 1293.

Stalnaker, R (1976) Mundos Posibles". Nous, 10 (1976), 65-75. (Reproducido en MJ Loux (ed),. lo posible y lo real, Ithaca y Londres:. Cornell U. Press, 1979, y en Ted Honderich y Myles Burnyeat (eds), La filosofía tal como es. Pingüino traducción polaca en Tadeusza. Szubki (ed.), Metafizyka W filozofii Aanalitycznej . Lublin, 1995) 
Stubbs, Michael 1987. Análisis del discurso. Análisis sociolingüístico del lenguaje natural. Madrid: Alianza Editorial.

Stuss D T, Levine B, Alexander MP, Hong J, Palumbo C, Hamer L, Murphy KJ and Izukawa D.(2000) "Wisconsin Card Sorting Test performance in patients with focal frontal and posterior brain damage: effects of lesion location and test structure on separable cognitive processes." Neuropsychologia 38(4): 388-402.

Tannen, Deborah. 1993. Framing in discourse. Oxford: Oxford University Press.

Tanenhaus (2007). Eye Movements and Spoken Language Processing. In Eye Movements: A Window on Mind and Brain. van Gompel RPG., Fischer MH., Murray WS. and Hill RL., Eds. Elsevier, Oxford UK.

Tanzi E.( 1889-1890) I neologismi degli alienati in rapporto col delirio cronico. Rivista Sperimentale di Freniatria e di Medicina Legale delle Alienazioni Mentali, v. 15, p. 352-393.

Tavano, A., Sponda, S., Fabbro, F., Perlini, C., Rambaldelli, G., Gero, A., y cols. 2008

Tenyi, T., Herold, R., Szili, I. y M. Trixler. Schizophrenics show a failure in the decoding of violations of conversational implicatures. Psychopathology; Jan/Feb 2002; 35, 1; ProQuest Medical Library pg. 25

Tirapu-Ustárroz, J, Pérez-Sayes, G, Erekatxo-Bilbao, M, Pelegrín-Valero, C (2007) ¿Qué es la teoría de la mente? REV NEUROL 2; 44 (8): 479-489

Titone, D. (2010) Language, communication, \& schizophrenia. Journal of Neurolinguistics 23, $173-175$.

Titone, D, Levy, D and Holzman, P (1994) Contextual Insensitivity in Schizophrenic Language Processing: Evidence From Lexical Ambiguity. Journal of Abnormal Psychology Vol. 109, No. $4,761-767$

Tomasello, M. (2010) ¿Porqué cooperamos? Buenos Aires. Katz.

Tusón, A. (1997). Análisis de la conversación. Barcelona: Ariel

Truscott, P. (1970) contextual constraint and schizophrenic language. Journal of Consulting and Clinical Psychology 35 189-194.

Valdés, L.(1991) (ed). La búsqueda del significado. Madrid. Tecnos.

van Dijk, T. (1983). La ciencia del texto. Un enfoque interdisciplinario. Barcelona: Paidós.

van Dijk, T. (1996) Estructuras y funciones del discurso. México. Siglo XXI

van Dijk, T. (1988). Texto y contexto. Madrid: Editorial Cátedra.

van Dijk, T. A. (2006). "Discourse, context and cognition". Discourse Studies, 8(1), Discourse Studies Copyright $($ C 2006 SAGE Publications. (London, Thousand Oaks, CA and New Delhi) pp. 159- 177. 
van Gompel, Fischer, Murray, Hill (2007). Eye Movements: A Window on Mind and Brain. van Gompel RPG., Fischer MH., Murray WS. and Hill RL., Eds. Elsevier, Oxford UK.

van Gompel , R.P.G. , Pickering, M. , Pearson , J., and Liversedge , S.P(2005). Evidence against competition during syntactic ambiguity resolution. Journal of Memory and Language, $52,284-307$

Vargas, M.L.; Jimeno-Bulnes, N.; Jimeno-Valdés, A. (1995): Los síntomas básicos como indicadores cognitivos de vulnerabilidad a la esquizofrenia. Psiquiatría Biológica, 2:63-70.

Vega de, M. y Cuetos, F. (1999). Psicolingüística del español. Trotta. Madrid.

Vigotsky, L.S. (1978). Lenguaje y comportamiento. Madrid: Visor

Vitu, A. (2011). On the role of visual and oculomotor processes in reading. In The Oxford Handbook of Eye Movements. Liversedge SP., Gilchrist ID., and Everling S. Eds. Oxford University Press Inc. New York.

von Domarus, E. (1974). "Las leyes específicas de la lógica en la esquizofrenia”. En Kasanin, J. S. Lenguaje y pensamiento en la esquizofrenia. Buenos Aires: Paidós.

Walker, D., and Grosz, J., B., (1978) Understanding Spoken Language: Elsevier Science Inc. de Nueva York, Nueva York, EE.UU.

Warren (2011) The influence of implausibility and anomaly on eye movements during reading. In The Oxford Handbook of Eye Movements. Liversedge SP., Gilchrist ID., and Everling S. Eds. Oxford University Press Inc. New York.

Warren, T. and Gibson, E. (2002). The influence of referential processing on sentence complexity . Cognition , 85: 79-112.

Waters, G.S. and Caplan, D. ( 1996 ). The capacity theory of sentence comprehension: Critique of Just and Carpenter .Psychological Review, 103, $761-772$.

Walder, D. Seidman, L. Cullen, N. Su, J. Tsuang, S. Goldstein, J. Sex Differences in Language Dysfunction in Schizophrenia. Am J Psychiatry 2006; 163:470-477.

Weinberger, D.R. (1987) Implications of normal brain development for the pathogenesis of schizophrenia. Arch Gen Psychiatry. 1987 Jul;44(7):660-9.

Wimmer H, Perner J.(1983) Beliefs about beliefs: representation and constraining function of wrong beliefs in young children's understanding of deception. Cognition. 13: 103-28.

Wheeldon, Meyer and Femke (2007) Speech-to-Gaze Alignment in Anticipation Errors. In Eye Movements: A Window on Mind and Brain. van Gompel RPG., Fischer MH., Murray WS. and Hill RL., Eds. Elsevier, Oxford UK.

White, M. J. (1965) "Un estudio del lenguaje esquizofrénico". Cit. por Arieti, Silvano: .Interpretación de la esquizofrenia. Barcelona: .Labor. 
Wilson B et al. (1997) Behavioural assessment of disexecutive syndrome. En: PATRICK RABBITT. Methodology of frontal and executive function. 239-250.

Wozniak, T. Narrative discourse in schizophrenia. (2006) Psychology of Language and Communication, Vol. 10, No. 2

Woodruff, G., Premack, D., \& Kennel, K. (1978). Conservation of liquid and solid quantity by the chimpanzee. Science, 202(4371), 991-994.

WHO (2001) World health report 2001: Mental health, new understanding, new hope World Health Organisation, Geneva.

Wright, A., McGorry, PD, Harris, MG, Jorm, AF and Pennell, K. (2006) Development and evaluation of a youth mental health community awareness campaign-The Compass Strategy. BMC Public Health 6, p. 215.

Yung, AR and McGorry, PD (1996) The prodromal phase of first-episode psychosis: Past and current conceptualizations. Schizophrenia Bulletin 22:2, pp. 353-370.

Yung, AR, McGorry, PD, McFarlane, CA, Jackson, HJ, Patton, GC and Rakkar, A. (1996) Monitoring and care of young people at incipient risk of psychosis. Schizophrenia Bulletin 22:2, pp. 283-303.

Yung, AR and McGorry, PD (1997) Is pre-psychotic intervention realistic in schizophrenia and related disorders?. Australian \& New Zealand Journal of Psychiatry 31, pp. 799-805.

Yung, AR, Phillips, LJ, McGorry, PD, McFarlane, CA, Francey, S. and Harrigan, SM (1998) Prediction of psychosis: A step towards indicated prevention of schizophrenia. British Journal of Psychiatry 172:Suppl. 33, pp. s14-s20.

Yung, AR, Phillips, LJ, Yuen, HP, Francey, SM, McFarlane, CA and Hallgren, M. (2003) Psychosis prediction: 12-month follow up of a high-risk ('prodromal') group. Schizophrenia Research $60: 1$, pp. 21-32.

Yung, AR, Phillips, LJ, Yuen, HP and McGorry, PD (2004) Risk factors for psychosis in an ultra high-risk group: Psychopathology and clinical features. Schizophrenia Research 67 :2-3 , pp. 131-142.

Yung, AR, McGorry PD, McFarlane CA, Jacson HJ, Patton GC, Rakkar A.(1996) Monitoring and care of young people at incipient risk of psychosis. Schizophrenia Bull; 22 (2):283-303.

Yung, AR, McGorry PD. (1996). The initial prodrome in psychosis: descriptive and qualitative aspects. Aust n Z J Psychiatry. 1996; 30,587-599.

Yung, AR, McGorry PD. (1996) The prodromal phase of first episode psychosis: past and 
current conceptualizations. Schizophrenia Bull; 22,353-370.

Zubin J. y Spring, B. (1977) Vulnerability, a new view in schizophrenia. Journal of abnormal psychology. Vol 86; n2; 103-126 
ANÁLISIS PRAGMALINGÜÍSTICO DE LOS MARCADORES DE COHERENCIA EN EL DISCURSO DE SUJETOS CON ESQUIZOFRENIA CRÓNICA Y DE PRIMER EPISODIO

\section{ANEXOS}




\section{CONSENTIMIENTO INFORMADO:}

1. PARA GRABACIÓN DE ENTREVISTA EN AUDIO Y/O VIDEO.

2. PARA UTILIZACIÓN DEL CONTENIDO AUDIOVISUAL PARA INVESTIGACIÓN Y DOCENCIA.

3. PARA UTILIZACIÓN DE DATOS CLÍNICOS EN INVESTIGACIÓN Y DOCENCIA.

Este documento de consentimiento informado se dirige a hombres y mujeres, menores de 18 años, atendidos en el Departamento de Psiquiatría y Salud Mental Campus Sur de la Facultad de Medicina de la Universidad de Chile en el curso de Psicopatología clínica para becados de Psiquiatría de la Universidad mencionada.

Se les invita a participar en el proyecto de Investigación: "Análisis pragmalingüístico de los indicadores de coherencia en el discurso de sujetos esquizofrénicos crónicos y de primer episodio", para lo cual se requiere de la utilización de sus datos clínicos, grabaciones de entrevistas en audio y/o videos, que serán transcritos para efectos de docencia e investigación.

Nombre del Investigador Principal: Alicia Figueroa Barra (doctoranda en Lingüística por la Universidad de Valladolid, España)

Este Documento de Consentimiento Informado tiene dos partes:

- Información (proporciona información sobre el estudio)

- Formulario de Consentimiento (para firmar si está o no de acuerdo en participar)

Se le dará una copia del Documento completo de Consentimiento Informado

\section{PARTE I: Información}

Mi nombre es Alicia Figueroa Barra, soy lingüista e investigo el lenguaje en patologías psiquiátricas, especialmente en esquizofrenia, bajo la supervisión de Eduardo Durán Lara, Médico Psiquiatra y académico del Clínica del Departamento de Psiquiatría Sur.

Para cumplir con nuestros objetivos, requerimos sistematizar datos clínicos de personas que estén en tratamiento por este tipo de patologías, y por otro lado nos es de gran ayuda el poder contar con registros, ya sea en video o en la grabación de las entrevistas clínicas realizadas por el equipo tratante.

Le invitamos a otorgar su autorización para que usted o su representado pueda participar de este proyecto. No tiene que decidir hoy si participar o no.

Antes de decidirse, puede hablar con alguien con quien que se sienta cómodo, sobre esta propuesta. 
Puede que haya algunas palabras que no entienda. Por favor, me avisa según le informo para darme tiempo a explicarle. Si tiene preguntas más tarde, puede preguntarme a mí, o al resto del equipo.

\section{Propósito}

Los objetivos del equipo de Psicolingüística son:

-Recopilar la mayor cantidad de antecedentes y datos clínicos posibles, que permitan sistematizar la información con fines de investigación en esquizofrenia.

-Contar con registros de audio de las entrevistas clínicas realizadas, a fin de investigar aspectos del lenguaje de las personas entrevistadas.

-Contar con registros de video de las entrevistas, a fin de poder tener una visión más completa de cómo se da la comunicación entre el entrevistado y el entrevistador.

\section{Tipo de Intervención}

La participación en este proyecto, puede incluir:

-Otorgar antecedentes clínicos personales, para ser incluidos en una base de datos que servirá de apoyo a nuevas investigaciones y autorizar que estos sean utilizados de manera anónima en docencia en investigación.

-Otorgar autorización para registrar en audio (grabaciones de voz), las entrevistas clínicas realizadas por participantes del equipo, y autorizar que éstas o su transcripción, sean utilizadas de manera anónima en docencia e investigación.

-Otorgar autorización para registrar en video (grabación de imagen y voz), las entrevistas clínicas realizadas por participantes del equipo, y autorizar que éstas o su transcripción, sean utilizadas en docencia e investigación, procurando omitir datos de identificación de la persona entrevistada.

\section{Selección de participantes}

Estamos invitando a personas con diagnóstico de esquizofrenia para que sean entrevistadas por el equipo de investigación.

\section{Participación Voluntaria}

$\mathrm{Su}$ participación o la de su representado en este proyecto es totalmente voluntaria. Usted puede elegir si él/ella participará o no. Tanto si elige o no dar su autorización, continuarán todos los servicios que reciba en este Hospital.

Usted puede cambiar de idea más tarde y decidir si participa, aún cuando haya aceptado antes.

\section{Riesgos}

Participar en este proyecto, no implicará ningún riesgo para usted o su representado

\section{Beneficios}

Puede que no haya beneficio para usted o su representado, pero es probable que su participación nos ayude a encontrar alguna respuesta que pueda beneficiar a generaciones futuras. 


\section{Incentivos}

No se proporcionará incentivos a las personas por participar. No se otorgará dinero ni regalos por tomar parte en esta investigación.

\section{Confidencialidad}

No compartiremos la identidad de aquellos que participen en la investigación.

La información que recojamos por este proyecto de investigación se mantendrá en estricta confidencialidad.

La información que se recogerá durante las entrevistas, será puesta fuera de alcance de terceros y nadie sino los integrantes del equipo tendrán acceso a ella.

Cualquier información acerca de usted tendrá un número en vez de su nombre, o su nombre será cambiado.

Solo los investigadores sabrán cual es su número o el nombre alternativo.

Toda esta información no será compartida ni entregada a nadie, excepto a su médico tratante de ser necesario para fines de su tratamiento.

\section{Difusión de Resultados}

El conocimiento que obtengamos por realizar esta investigación podrá compartirse para efectos de docencia o podrá ser eventualmente publicado, para que otras personas interesadas puedan aprender de nuestra investigación.

\section{Derecho a negarse o retirarse}

Usted no tiene por qué participar en esta investigación si no desea hacerlo, y el negarse a participar no le afectara en ninguna forma.

Puede dejar de participar en cualquier momento que desee sin perder sus derechos como paciente de ninguna forma.

\section{A quién contactar}

Si tiene cualquier pregunta puede hacerlas ahora o más tarde, incluso después de que se inicie el estudio.

Si así lo desea, puede contactar al Dr. Eduardo Durán Lara, Departamento de Psiquiatría Sur, Facultad de Medicina Universidad de Chile.

\section{PARTE II: Formulario de Consentimiento}

He sido invitado a otorgar mi autorización o mi representado participe en el proyecto de investigación de esta tesis doctoral en el marco de la cátedra de Psicopatología clínica del Departamento de Psiquiatría y Salud Mental Campus Sur, de la Universidad de Chile.

He sido informado de que no existen riesgos asociados a su participación.

Sé que no habrá beneficios para él/ella ni para mi persona y que no se me recompensará económicamente.

Se me ha proporcionado el nombre del investigador responsable, que puede ser fácilmente contactado en el Departamento de Psiquiatría y Salud Mental, Campus Sur. 
He leído la información proporcionada o me ha sido leída. He tenido la oportunidad de preguntar sobre ella y se me ha contestado satisfactoriamente las preguntas que he realizado.

Acepto voluntariamente y sin presiones, o mi representado participe en este proyecto y entiendo que tengo el derecho de retirarme en cualquier momento sin que me afecte en ninguna manera mi cuidado médico.

Acepto que mis entrevistas realizadas por los investigadores, sean grabadas (audio), luego transcritas y luego puedan ser utilizadas para fines de docencia e investigación, de manera anónima.

Acepto que sus entrevistas realizadas por los investigadores, sean grabadas (video), y que luego puedan ser utilizadas para fines de docencia e investigación, siempre que se me garantice que mis datos de identificación serán resguardados de manera confidencial.

Nombre y firma del Participante

Nombre del Padre/Madre

O Representante Legal

RUT

Nombre y Firma del representante

Del equipo de Investigación

Fecha 
Resumen estadístico:

Se probó un modelo de regresión lineal que estuvo compuesto por los siguientes grupos de variables: tipo, sexo, tramo, fluidez, productividad verbal, indice de participación conversacional, coherencia temática, semántica de la coherencia y coherencia interaccional.

\begin{tabular}{|c|c|c|c|}
\hline \multicolumn{2}{|c|}{ REGRESIÓN } & & \\
\hline \multicolumn{4}{|c|}{ Variables introducidas/eliminadas ${ }^{\mathrm{a}}$} \\
\hline Modelo & $\begin{array}{c}\text { Variables } \\
\text { introducidas }\end{array}$ & $\begin{array}{l}\text { Variables } \\
\text { eliminadas }\end{array}$ & Método \\
\hline 1 & $\begin{array}{l}\text { TIPO, SEXO, } \\
\text { TRAMO }\end{array}$ & & Introducir \\
\hline 2 & $\begin{array}{l}\text { TITUBEOS, T.H. } \\
\text { VOLUMEN DÉBIL, } \\
\text { FALSOS INICIOS, } \\
\text { TARTAMUDEOS, } \\
\text { PAUSAS } \\
\text { EXTENDIDAS }\end{array}$ & & Introducir \\
\hline 3 & $\begin{array}{l}\text { NEOL TOT, } \\
\text { PROMEDIO DE } \\
\text { VÍNCULOS, NEOL } \\
\text { PARC, PALABRAS } \\
\text { DIFERENTES, } \\
\text { PROMEDIO PAL } \\
\text { ORACIÓN, TOTAL } \\
\text { VÍNCULOS, TOTAL } \\
\text { OR., } \\
\text { REFERENTES }\end{array}$ & & Introducir \\
\hline 4 & $\begin{array}{l}\text { No turnos/min, } \\
\left.\mathrm{N}^{\circ} \mathrm{Pa}\right|^{\mathrm{b}}\end{array}$ & & Introducir \\
\hline \multicolumn{4}{|c|}{ a. Variable dependiente: ESTADIO } \\
\hline b. Toda & las introducidas. & & \\
\hline
\end{tabular}




\begin{tabular}{|c|c|c|c|c|c|c|c|c|c|c|}
\hline \multicolumn{11}{|c|}{ RESUMEN DEL MODELO ${ }^{E}$} \\
\hline \multirow[t]{2}{*}{ Modelo } & \multirow[t]{2}{*}{$\mathrm{R}$} & \multirow{2}{*}{$\begin{array}{l}\mathrm{R} \\
\text { cuadrado }\end{array}$} & \multirow{2}{*}{$\begin{array}{c}\text { R } \\
\text { cuadrado } \\
\text { corregida }\end{array}$} & \multirow{2}{*}{$\begin{array}{l}\text { Error típ. } \\
\text { de la } \\
\text { estimación }\end{array}$} & \multicolumn{5}{|c|}{ Estadísticos de cambio } & \multirow{2}{*}{$\begin{array}{c}\text { Durbin- } \\
\text { Watso } \\
n\end{array}$} \\
\hline & & & & & $\begin{array}{c}\text { Cambio } \\
\text { en R } \\
\text { cuadrado }\end{array}$ & $\begin{array}{l}\text { Cambio } \\
\text { en } \mathrm{F}\end{array}$ & gl1 & gl2 & $\begin{array}{c}\text { Sig. } \\
\text { Cambio } \\
\text { en F }\end{array}$ & \\
\hline 1 &, $954^{\mathrm{a}}$ & ,910 & ,905 & ,231 & ,910 & 194,659 & 3 & 58 &, 000 & \\
\hline 2 &, $959^{b}$ & ,920 & ,908 & ,227 & 010 & 1,387 & 5 & 53 & ,244 & \\
\hline 3 &, $971^{\mathrm{c}}$ & ,943 & ,923 & ,208 & ,023 & 2,288 & 8 & 45 & ,038 & \\
\hline 4 &, $974^{d}$ & ,949 & ,928 & ,202 &, 006 & 2,407 & 2 & 43 & ,102 & 1,809 \\
\hline \multicolumn{11}{|c|}{ a. Variables predictoras: (Constante), TIPO, SEXO, TRAMO } \\
\hline \multicolumn{11}{|c|}{$\begin{array}{l}\text { b. Variables predictoras: (Constante), TIPO, SEXO, TRAMO, TITUBEOS, T.H. VOLUMEN DÉBIL, FALSOS INICIOS, } \\
\text { TARTAMUDEOS, PAUSAS EXTENDIDAS }\end{array}$} \\
\hline \multicolumn{11}{|c|}{$\begin{array}{l}\text { c. Variables predictoras: (Constante), TIPO, SEXO, TRAMO, TITUBEOS, T.H. VOLUMEN DÉBIL, FALSOS INICIOS, } \\
\text { TARTAMUDEOS, PAUSAS EXTENDIDAS, NEOL TOT, PROMEDIO DE VÍNCULOS, NEOL PARC, PALABRAS DIFERENTES, } \\
\text { PROMEDIO PAL ORACIÓN, TOTAL VÍNCULOS, TOTAL OR., REFERENTES }\end{array}$} \\
\hline \multicolumn{11}{|c|}{$\begin{array}{l}\text { d. Variables predictoras: (Constante), TIPO, SEXO, TRAMO, TITUBEOS, T.H. VOLUMEN DÉBIL, FALSOS INICIOS, } \\
\text { TARTAMUDEOS, PAUSAS EXTENDIDAS, NEOL TOT, PROMEDIO DE VÍNCULOS, NEOL PARC, PALABRAS DIFERENTES, } \\
\text { PROMEDIO PAL ORACIÓN, TOTAL VÍNCULOS, TOTAL OR., REFERENTES, Nº turnos/min, NPal }\end{array}$} \\
\hline \multicolumn{11}{|c|}{ e. Variable dependiente: ESTADIO } \\
\hline
\end{tabular}

El modelo final que explica el estadio está compuesto por las variables neol tot, promedio de vínculos, neol parc, palabras diferentes, promedio pal oración, total vínculos, total oraciones.

\begin{tabular}{|c|c|c|c|c|c|c|}
\hline \multicolumn{7}{|c|}{ ANOVA $^{\mathrm{A}}$} \\
\hline \multicolumn{2}{|c|}{ Modelo } & Suma de & gl & Media & $F$ & Sig. \\
\hline \multirow[t]{3}{*}{1} & Regresión & 31,178 & 3 & 10,393 & 194,659 &, $000^{\mathrm{b}}$ \\
\hline & Residual & 3,097 & 58 & ,053 & & \\
\hline & Total & 34,274 & 61 & & & \\
\hline \multirow[t]{3}{*}{2} & Regresión & 31,536 & 8 & 3,942 & 76,300 &, $000^{c}$ \\
\hline & Residual & 2,738 & 53 & ,052 & & \\
\hline & Total & 34,274 & 61 & & & \\
\hline 3 & Regresión & 32,328 & 16 & 2,020 & 46,713 &, $000^{d}$ \\
\hline
\end{tabular}


ANÁLISIS PRAGMALINGÜÍSTICO DE LOS MARCADORES DE COHERENCIA EN EL DISCURSO DE SUJETOS CON ESQUIZOFRENIA CRÓNICA Y DE PRIMER EPISODIO

\begin{tabular}{|c|c|c|c|c|c|c|}
\hline & Residual & 1,946 & 45 & ,043 & & \\
\hline & Total & 34,274 & 61 & & & \\
\hline \multirow[t]{3}{*}{4} & Regresión & 32,524 & 18 & 1,807 & 44,387 &, $000^{\mathrm{e}}$ \\
\hline & Residual & 1,750 & 43 &, 041 & & \\
\hline & Total & 34,274 & 61 & & & \\
\hline \multicolumn{7}{|c|}{ a. Variable dependiente: ESTADIO } \\
\hline \multicolumn{7}{|c|}{ b. Variables predictoras: (Constante), TIPO, SEXO, TRAMO } \\
\hline \multicolumn{7}{|c|}{$\begin{array}{l}\text { c. Variables predictoras: (Constante), TIPO, SEXO, TRAMO, TITUBEOS, T.H. VOLUMEN DÉBIL, FALSOS } \\
\text { INICIOS, TARTAMUDEOS, PAUSAS EXTENDIDAS }\end{array}$} \\
\hline \multicolumn{7}{|c|}{$\begin{array}{l}\text { d. Variables predictoras: (Constante), TIPO, SEXO, TRAMO, TITUBEOS, T.H. VOLUMEN DÉBIL, FALSOS } \\
\text { INICIOS, TARTAMUDEOS, PAUSAS EXTENDIDAS, NEOL TOT, PROMEDIO DE VÍNCULOS, NEOL PARC, } \\
\text { PALABRAS DIFERENTES, PROMEDIO PAL ORACIÓN, TOTAL VÍNCULOS, TOTAL OR., REFERENTES }\end{array}$} \\
\hline \multicolumn{7}{|c|}{$\begin{array}{l}\text { e. Variables predictoras: (Constante), TIPO, SEXO, TRAMO, TITUBEOS, T.H. VOLUMEN DÉBIL, FALSOS } \\
\text { INICIOS, TARTAMUDEOS, PAUSAS EXTENDIDAS, NEOL TOT, PROMEDIO DE VÍNCULOS, NEOL PARC, } \\
\text { PALABRAS DIFERENTES, PROMEDIO PAL ORACIÓN, TOTAL VÍNCULOS, TOTAL OR., REFERENTES, № } \\
\text { turnos/min, NPal }\end{array}$} \\
\hline
\end{tabular}


ANÁLISIS PRAGMALINGÜÍSTICO DE LOS MARCADORES DE COHERENCIA EN EL DISCURSO DE SUJETOS CON ESQUIZOFRENIA CRÓNICA Y DE PRIMER EPISODIO

ESCALA DE SINTOMAS POSITIVOS Y NEGATIVOS DE ESQUIZOFRENIA

(PANSS)

INSTRUCCIONES: Encierre en un círculo el rango apropiado para cada ítem siguiendo la entrevista clínica.

Tome como referencia las definiciones del manual de clasificación.

1= Ausente 2= Mínimo 3= Leve 4= Moderado 5= Moderadamente severo 6= Severo 7= Extremo.

\section{1.- SUBESCALA POSITIVA}

P1 Delirios.

1234567

P2 Desorganización conceptual.

1234567

P3 Comportamiento alucinatorio

1234567

P4 Excitación.

1234567

P5 Grandiosidad.

1234567

P6 Suspicacia / persecución

1234567

P7 Hostilidad.

1234567 
ANÁLISIS PRAGMALINGÜÍSTICO DE LOS MARCADORES DE COHERENCIA EN EL DISCURSO DE SUJETOS CON ESQUIZOFRENIA CRÓNICA Y DE PRIMER EPISODIO

\section{2.- SUBESCALA NEGATIVA}

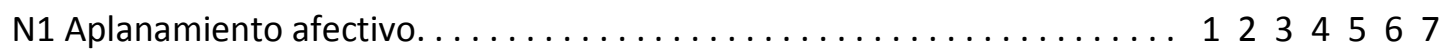

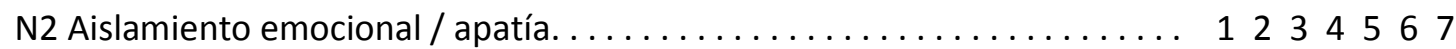

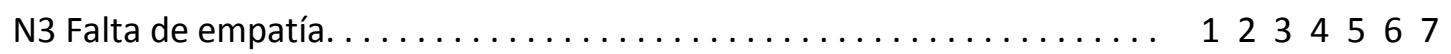

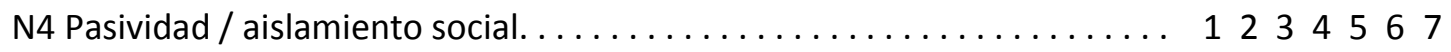

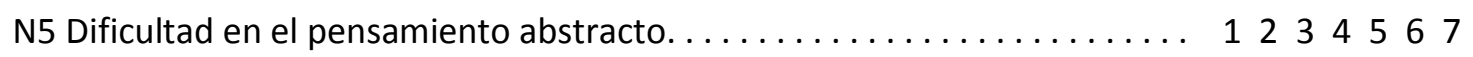

N6 Falta de espontaneidad y fluidez en la conversación. ........... 1234567

N7 Pensamiento estereotipado......................... 1234567

\section{SUBESCALA PSICOPATOLOGICA GENERAL}

G1 Preocupaciones somáticas

1234567

G2 Ansiedad. . .

1234567

G3 Sentimientos de culpa.

1234567

G4 Tensión.

1234567

G5 Manierismos y estereotipos.

1234567

G6 Depresión.

1234567

G7 Retardo motor.

1234567

G8 Falta de cooperación.

1234567

G9 Contenido de pensamiento peculiar o extraño.

1234567

G10 Desorientación

1234567

G11 Distractibilidad

1234567 
ANÁLISIS PRAGMALINGÜÍSTICO DE LOS MARCADORES DE COHERENCIA EN EL DISCURSO DE SUJETOS CON ESQUIZOFRENIA CRÓNICA Y DE PRIMER EPISODIO

G12 Alteración de juicio de realidad. ..................... 1234567

G13 Abulia ..................................... 1234567

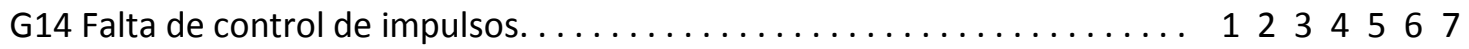

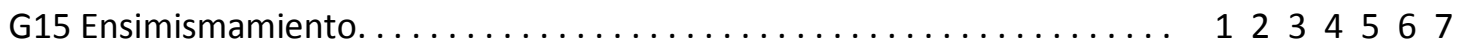

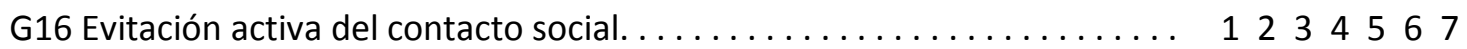

Firma del profesional Fecha 
ANÁLISIS PRAGMALINGÜÍSTICO DE LOS MARCADORES DE COHERENCIA EN EL DISCURSO DE SUJETOS CON ESQUIZOFRENIA CRÓNICA Y DE PRIMER EPISODIO 